San Jose State University

SJSU ScholarWorks

Master's Theses

Master's Theses and Graduate Research

1991

\title{
Prehistoric native American adaptations along the central California coast of San Mateo and Santa Cruz counties
}

Mark Gerald Hylkema

San Jose State University

Follow this and additional works at: https://scholarworks.sjsu.edu/etd_theses

\section{Recommended Citation}

Hylkema, Mark Gerald, "Prehistoric native American adaptations along the central California coast of San Mateo and Santa Cruz counties" (1991). Master's Theses. 131.

DOI: https://doi.org/10.31979/etd.qke6-ss3e

https://scholarworks.sjsu.edu/etd_theses/131

This Thesis is brought to you for free and open access by the Master's Theses and Graduate Research at SJSU ScholarWorks. It has been accepted for inclusion in Master's Theses by an authorized administrator of SJSU ScholarWorks. For more information, please contact scholarworks@sjsu.edu. 


\section{INFORMATION TO USERS}

This manuscript has been reproduced from the microfilm master. UMI films the text directly from the original or copy submitted. Thus, some thesis and dissertation copies are in typewriter face, while others may be from any type of computer printer.

The quality of this reproduction is dependent upom the quality of the copy submitted. Broken or indistinct print, colored or poor quality illustrations and photographs, print bleedthrough, substandard margins, and improper aligniment can adversely affect reproduction.

In the unlikely event that the author did not send UMI a complete manuscript and there are missing pages, these will be noted. Also, if unauthorized copyright material had to be removed, a note will indicate the deletion.

Oversize materials (e.g., maps, drawings, charts) are reproduced by sectioning the original, beginning at the upper left-hand corner and continuing from left to right in equal sections with small overlaps. Each original is also photographed in one exposure and is included in reduced form at the back of the book.

Photographs included in the original manuscript have been reproduced xerographically in this copy. Higher quality 6" $\times$ 9" black and white photographic prints are available for any photographs or illustrations appearing in this copy for an additional charge. Contact UMI directly to order.

\section{$\mathrm{U} \cdot \mathrm{M} \cdot \mathrm{I}$}

University Microfilms International

A Bell \& Howell Information Company

300 North Zeeb Road. Ann Arbor. Ml 48106-1346 USA

$313 / 761-4700 \quad 800 / 521-0600$ 

Prehistoric Native American adaptations along the central California coast of San Mateo and Santa Cruz counties

Hylkema, Mark Gerald, M.A.

San Jose State University, 1991

Copyright (C1991 by Hylkema, Mark Gerald. All rights reserved.

\author{
$\mathrm{U} \cdot \mathrm{M} \cdot \mathrm{I}$ \\ 300 N. Zeeb Rd. \\ Ann Arbor, MII 48106
}


PREHISTORIC NATIVE AMERICAN ADAPTATIONS

ALONG THE CENTRAL CALIFORNIA COAST OF

SAN MATEO AND SANTA CRUZ COUNTIES.

\author{
A Thesis \\ Presented to \\ The Faculty of the Department of Social Science \\ San Jose State University
}

\author{
In Partial Fulfillment \\ of the Requirements for the Degree \\ Master of Arts
}

by

Mark Gerald Hylkema

May 1991 


\section{APPROVED FOR THE DEPARTMENT OF SOCIAL SCIENCES}
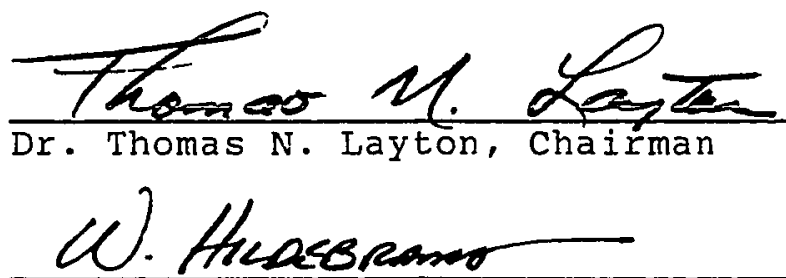

Dr. William R. Hildebranat

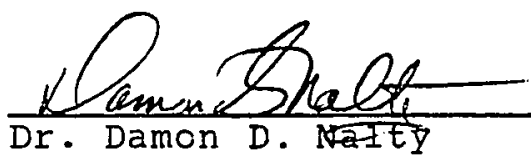

APPROVED FOR THE UNIVERSITY

Serena Mt Etaxfore 


\section{ABSTRACT \\ PREHISTORIC NATIVE AMERICAN ADAPTATIONS \\ ALONG THE CENTRAL CALIFORNIA COAST OF \\ SAN MATEO AND SANTA CRUZ COUNTIES}

by Mark G. Hylkema

This study reviews prehistoric adaptive strategies reflected by archaeological and ethnohistoric data for the San Mateo and Santa Cruz coastal area. The model of forager and collector adaptive modes proposed by Dietz and Jackson (1981) for the Monterey Bay Area is tested. They proposed that early foraging populations maintained a generalized economic focus with frequent residential shifts during various seasons of the year. The storage of food resources was not a component of this strategy. Later populations characterized by a collector economy replaced the forager strategy sometime after 2000 years ago. Collectors maintained a narrow economic focus, relying on stored resources in centralized villages occupied for most of the seasonal year. Basically, foragers moved consumers to goods while collectors moved goods to consumers.

This stuay found that both strategies co-existed. While a collector strategy developed around the Monterey and San Francisco Bay Areas at an early time, a forager economy continued within the study area to after 1000 A.D. 


\section{ACKNOWLEDGMENTS}

The author would like to express his sincere gratitude to the many people and institutions that contributed to this study. My parents, John and Mieke Hylkema, provided the primary source of support throughout the lengthy duration of my research. My wife, Linda Hylkema, and her priceless ability to salvage documents that became lost to the computer as a result of user error prevented the total abandonment of the project. Special thanks must also be given to Mara Melandry for correcting punctuation errors and for providing sufficient time off from my employment with the California Department of Transportation during the critical thesis completion season.

Further recognition is due to Gary Parsons who bears the distinction of having initiated many aspects of this project, and also was the liaison with many of the local collectors and land owners. Thanks are due to the McCrary family and Big Creek Lumber Company, the Hudson family of Coastways Ranch, and Dr. Richard Hencke. Terry Kvenild and Joe Ward also provided access to their collections, and hopefully they will stop looking for additional specimens. Members of the ohlone Indian community provided a great deal of support for this project and also participated as field crew. Rosemary Cambra of the Muwekma Ohlone was 
largely responsible for organizing her extensive clan of relations. She viewed the field work as a classroom which provided them with exposure to archaeological excavation. The California Department of Parks and Recreation as well as the California Department of Forestry and Fire Protection provided access to many of the sites. Thanks to Lee Motz, Michael Sampson, Bob Orlins, Gary Reinoehl, and Dan Foster.

The crew members participating in this project are too numerous to name; however, they consisted of volunteers and students from San Jose State University, the University of California at Santa Cruz, the Santa Cruz Archaeological Society, and the Santa Clara Archaeological Society.

Many professional analysts also contributed their time to this research. The obsidian sourcing and hydration studies were conducted by Dr. Thomas Jackson, Thomas origer, and John Holson. The faunal analysts include Blandy Merrill, Glen Wilson, and Jeff Hall. They spent a considerable amount of time at the Museum of Vertebrate Zoology at San Jose State University. Terry Jones, Dr. Robert Jurmain, Rob Edwards, Alan Leventhal and Dr. Gary Breschini also provide a great deal of technical support.

Several individuals contributed funds for the radiocarbon dating analysis and include Dr. Bert Gerow, Jim 
Rutherford, Glen Wilson, and others. Also, a research grant from the Sourisseau Academy at San Jose State University provided funding for both radiocarbon dating and obsidian studies.

To everyone involved, thank you. 
TABLE OF CONTENTS

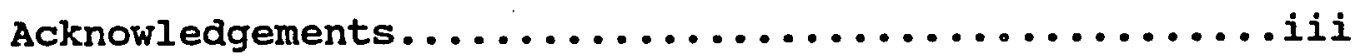

I. INTRODUCTION. ........................

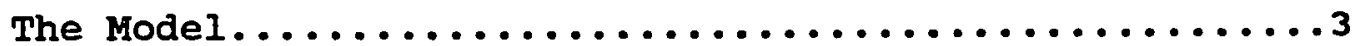

Development of the Model.....................

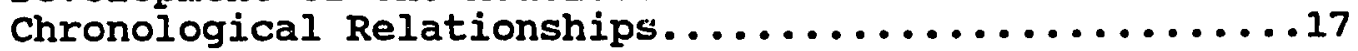

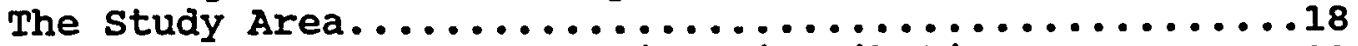

San Mateo and Santa Cruz Site Distributions.........21

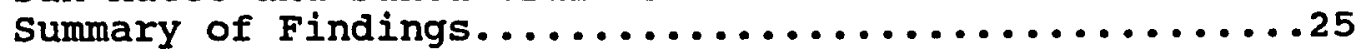

II. REGIONAL ENVIRONMENTAL CONTEXT..............27

Topography and Geology ....................27

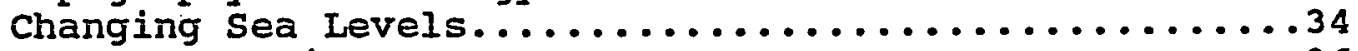

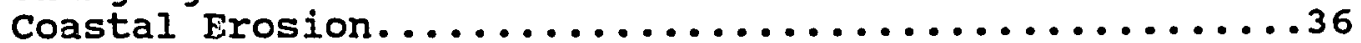

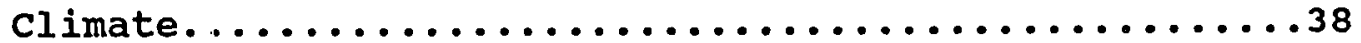

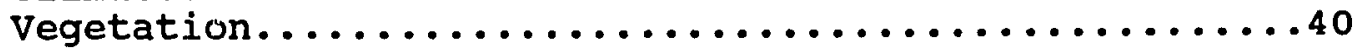

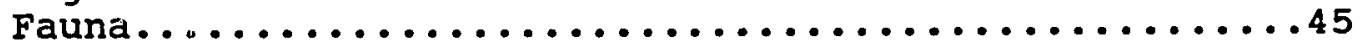

III. ETHNOGRAPHIC CONTEXT..................50

Social organization...................... 52

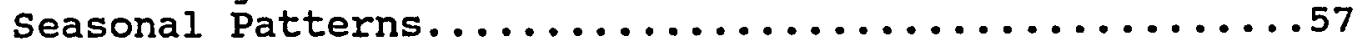

Archaeological Implications..................61

IV. EXCAVATION AND ANALYTICAI METHODS............63

Field Methods.............................64

Analytical Methods and Artifact Types...........66

Faunal Remains-Bone....................67

Faunal Remains-shell...................68

Beads and other ornaments..................69

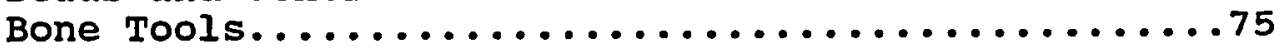

Chipped Stone Tool and Debitage Materials........77

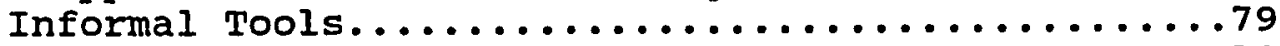

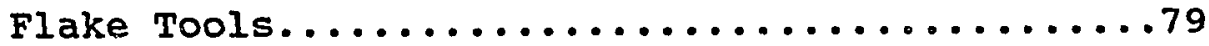

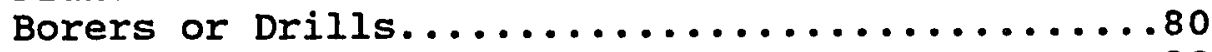

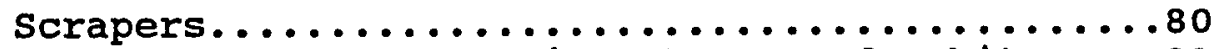

Chipped Stone Tool Reduction Stages and Debitage.. 81

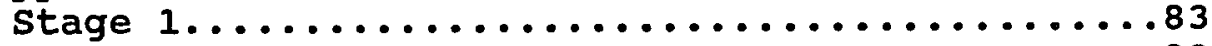

stage $2 \ldots \ldots \ldots \ldots \ldots \ldots \ldots \ldots \ldots \ldots \ldots \ldots \ldots . \ldots \ldots . \ldots \ldots$

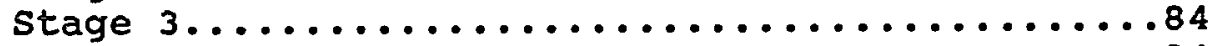

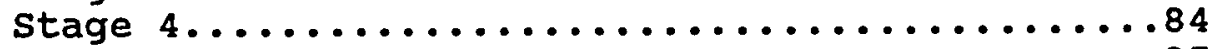

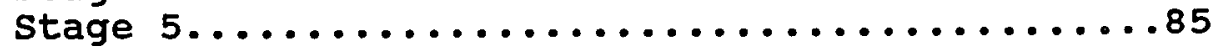


TABLE OF CONTENTS, CON'T

Projectile Point Types and Forms............87

Desert side-notched....................90

stockton serrated......................90

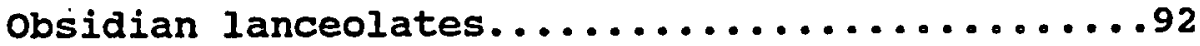

Ano Nuevo long-stemmed...................93

Rossi square-stemmed.....................94

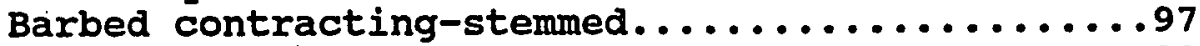

Notched points........................99

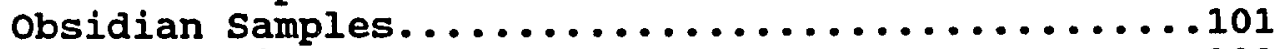

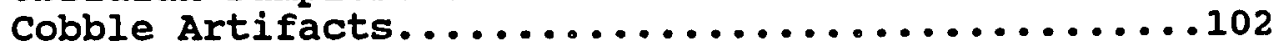

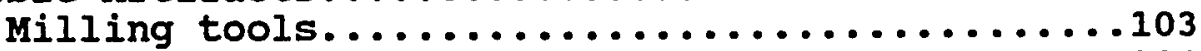

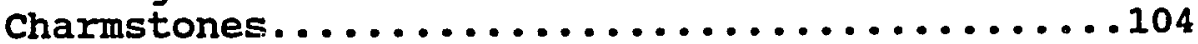

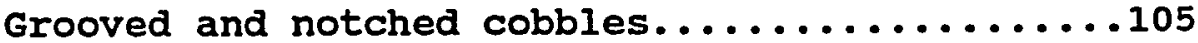

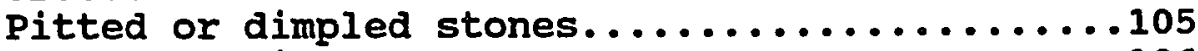

Awl sharpening stones...................106

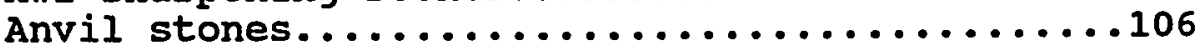

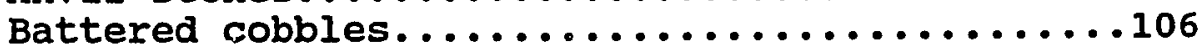

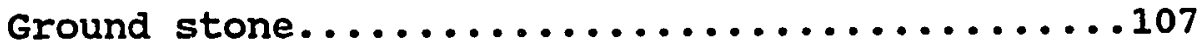

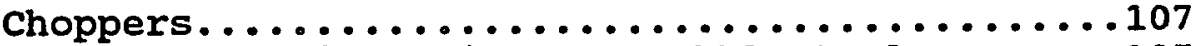

Temporal considerations of cobble tools.......107

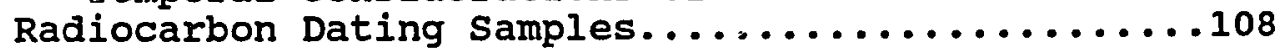

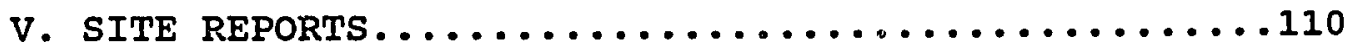

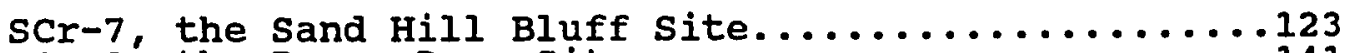

SCr-9, the Bonny Doon site......................141

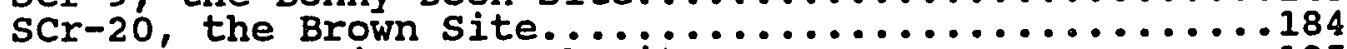

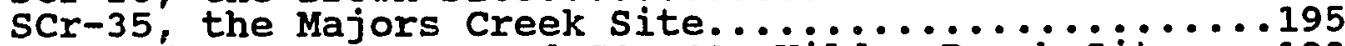
SCr-38/123, SCr-39, and SCr-40, wilder Ranch sites...198 sCr-93 the sunflower House site...............213

SCr-132, the scott Creek site...................220

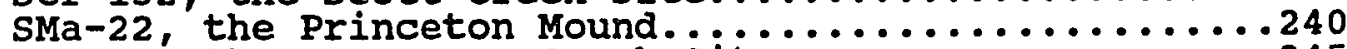

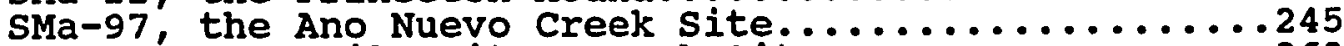

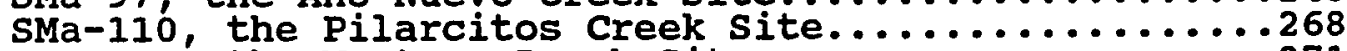

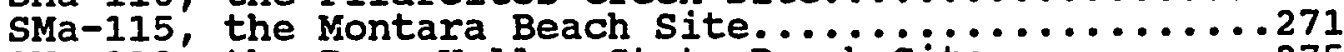

SMa-118, the Bean Hollow state Beach Site..........275

SMa-139, the Frenchmans creek site..............281

SMa-140, the Denniston Creek site...............284

SMa-218, the Ano Nuevo state Reserve site..........287

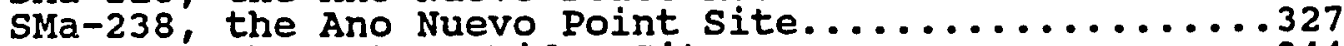

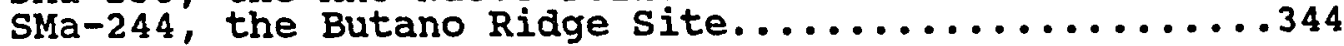

VI. RESULTS AND CONCLUSIONS.......................... 360

Summary of Radiocarbon Dating Results..............361 Summary of obsidian Sourcing and Hydration Results...365 chronological sequencing of selected coastal sites...373

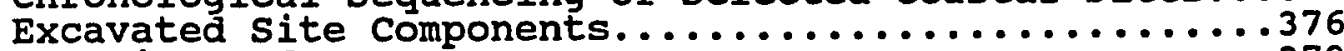

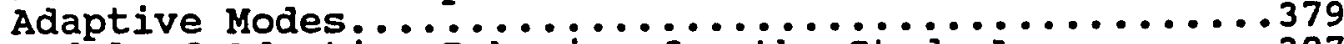
Model of Adaptive Behavior for the study Area.......387

vii 
TABLE OF CONTENTS, CON'T

REFERENCES... . . . . . . . . . . . . . . . . . . . . . . 392

APPENDICES............................... 407

Appendix A Faunal Inventories.................408

Appendix B Shell Artifact Inventories.............423

Appendix $C$ Bone Tool Inventories................433

Appendix D Chipped Stone Tool Inventories..........442

Appendix E Cobble Artifact Inventories............488 


\section{LIST OF TABLES}

TABLE

PAGE

1) Chronological sequences.....................19

2) Site Distribution Summary...................23

3) Percentage of Vegetation Coverage in Study Area.....45

4) Fauna Present in the Study Area..............47

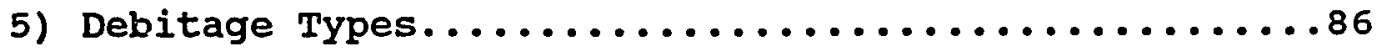

6) Notched Point Measurements from Selected sites.....101

7) Radiocarbon Dates for $\mathrm{scr}-7 \ldots \ldots \ldots \ldots \ldots \ldots \ldots \ldots \ldots \ldots . \ldots \ldots 25$

8) Chipped Stone Artifact Materials from SCr-7.......127

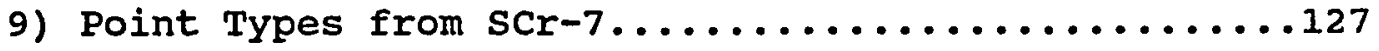

10) Unit Dimensions and Volumes from scr-9...........142

11) Radiocarbon Dates for $s c r-9 . \ldots \ldots \ldots \ldots \ldots \ldots \ldots \ldots 143$

12) Column sample from $s c r-9 . \ldots \ldots \ldots \ldots \ldots \ldots \ldots \ldots \ldots . . \ldots 144$

13) Taxa Frequencies from $\mathrm{scr}-9 . \ldots \ldots \ldots \ldots \ldots \ldots \ldots . \ldots \ldots$

14) Bone Tool Types from scr-9......................

15) Debitage Volume from scr-9....................147

16) Chipped stone summary, Unit 2 from sCr-9.........148

17) Chipped stone Tool Material from scr-9...........150

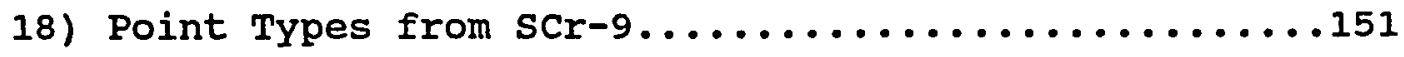

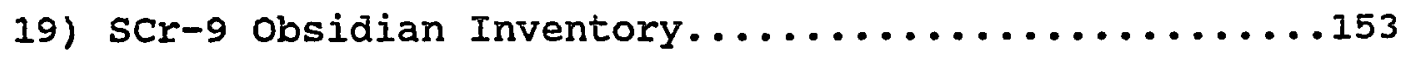

20) Obsidian Sourcing and Hydration Results, scr-9.... 154

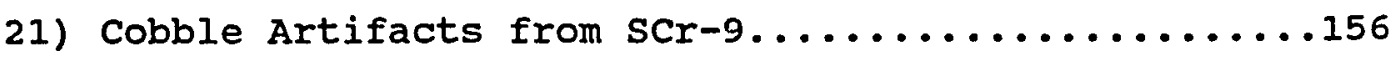

22) Component summary from $\operatorname{scr}-9 . \ldots \ldots \ldots \ldots \ldots \ldots \ldots . \ldots . \ldots 160$ 
LIST OF TABIES, CON'T.

23) scr-20 Point Types..........................

24) Obsidian Inventory from $s c r-20 \ldots \ldots \ldots \ldots \ldots . . \ldots . . . .189$

25) Component summary from $\operatorname{scr}-20 \ldots \ldots \ldots \ldots \ldots \ldots \ldots . \ldots . \ldots 192$

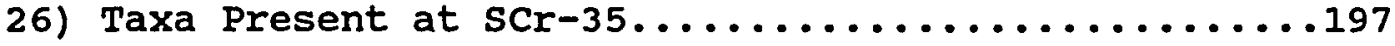

27) SCr-38/123 Excavation Unit Dimensions and Volumes..199

28) Column sample from sCr-38/123................200

29) SCr-38/123 Chipped stone summary from Unit 5......201

30) Point Types from wilder Ranch sites.............203

31) Radiocarbon Dates for $s c r-38 / 123 \ldots \ldots \ldots \ldots \ldots \ldots \ldots . \ldots 204$

32) Obsidian Inventory from $\mathrm{scr}-38 / 123 \ldots \ldots \ldots \ldots \ldots \ldots$......205

33) Component summary from scr-38/123..............207

34) Taxa Frequencies for $\operatorname{scr}-93 \ldots \ldots \ldots \ldots \ldots \ldots \ldots \ldots \ldots . \ldots . \ldots 215$

35) Obsidian Summary from $\mathrm{scr}-93 \ldots \ldots \ldots \ldots \ldots \ldots \ldots \ldots \ldots . \ldots 216$

36) Radiocarbon Dates for scr-93.................218

37) Component summary from scr-93................219

38) SCr-132 Excavation Unit Dimensions and Volumes....220

39) Obsidian Inventory from scr-132...............223

40) Column sample from scr-132..................224

41) Taxa Frequencies for $\operatorname{scr}-132 \ldots \ldots \ldots \ldots \ldots \ldots \ldots \ldots \ldots . \ldots \ldots 25$

42) Chipped Stone Summary from Unit 1, scr-132.......227

43) Chipped Stone Summary from Unit C.U. 1, SCr-132...228

44) Debitage Volumes from scr-132................226

45) Cobble Artifacts from scr-132..................229 
LIST OF TABLES, CON'T.

46) Osteological Summary for Burial 1, SCr-132........231

47) Component summary from scr-132...............232

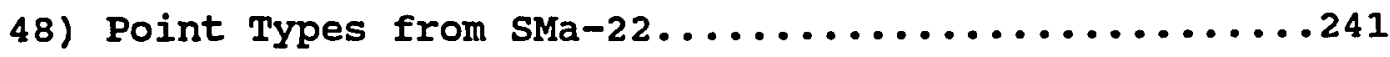

49) Taxa Represented at sMa-22...................242

50) Component summary from sMa-22................243

51) SMa-97 Excavation Unit Dimensions and Volumes.....246

52) Radiocarbon Date from SMa-97...........................

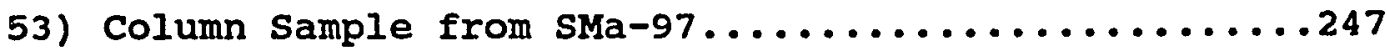

54) Taxa Frequencies for SMa-97..................249

55) Chipped stone Summary for Unit 1, SMa-97.........251

56) Debitage Volumes from sMa-97..................250

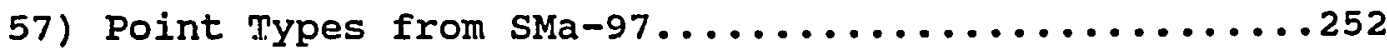

58) Obsidian Inventory from sMa-97...............254

59) Cobble Artifacts from SMa-97..................255

60) Component summary from sMa-97..................256

61) Cobble Artifacts from sMa-110.................269

62) Component summary from sMa-110....................

63) Radiocarbon Date for SMa-115..................272

64) Taxa Frequencies from SMa-115...............273

65) Component summary from sMa-115................274

66) Radiocarbon Dates for SMa-118................276

67) Debitage Materials from sMa-118....................

68) Cobble Artifacts from sMa-118................. 277

69) Taxa Frequencies from SMa-118...............278 


\section{LIST OF TABLES, CON'T}

70) Component summary from sMa-118...............280

71) Radiocarbon Dates for sMa-139................281

72) Obsidian Inventory for sia-139................282

73) SMa-218 Excavation Unit Dimensions and Volumes.....289

74) Radiocarbon Date for sMa-218.................290

75) Taxa Frequencies from SMa-218...................... 292

76) Debitage Volumes from SMa-218..................293

77) Chipped Stone Summary from Unit 7, SMa-218.......294

78) Point Reduction stages from SMa-218............295

79) Stage 5 Point Types from sMa-218............... 297

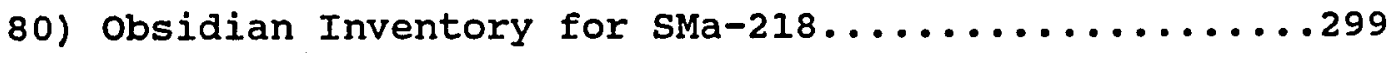

81) Component summary from SMa-218....................

82) SMa-238 Excavation Unit Dimensions and Volumes.....328

83) Radiocarbon Date for $\mathrm{SMa}-238 \ldots \ldots \ldots \ldots \ldots . \ldots \ldots 39$

84) Chipped Stone Summary from Unit 1, SMa-238.......331

85) Cobble Artifacts from sMa-238...................... 30

86) Osteological Summary for Burial 1, SMa-238........333

87) Component summary from sMa-238................... 334

88) SMa-244 Excavation Unit Dimensions and Volumes.....345

89) Column sample from sMa-244.................. 346

90) Taxa Frequencies from $\mathrm{SMa}-244 \ldots \ldots \ldots \ldots \ldots . \ldots . \ldots 34$

91) Obsidian Inventory from SMa-244.................. 349

92) Debitage volumes from SMa-244.................... 350

93) Chipped stone Summary from Unit 1, SMa-244.......351 xii 
IIST OF TABLES, CON'T

94) Cobble Artifacts from sMa-244..................... 352

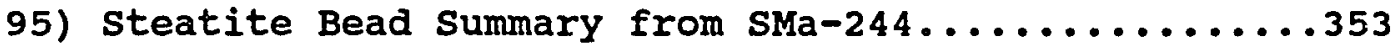

96) Component summary from SMa-244......................

97) Radiocarbon Dating Summary.........................

98) Obsidian Sourcing and Hydration Sample Summary.....366

99) Obsidian Hydration Readings Summary............. 367

100) Chronologicai Sequences for the Study Area........374

101) Taxa Frequencies from Selected sites..............384

102) Relative Frequencies of site Constituents.........388 


\section{LIST OF FIGURES}

FIGURE

PAGE

1) Point Types within the study Area.............91

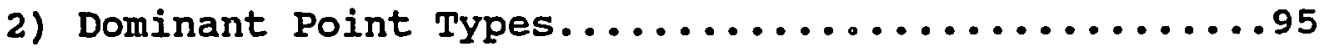

3) Reduction stages from SMa-218...............98

4-13) scr-7 Point Types..................... 129-140

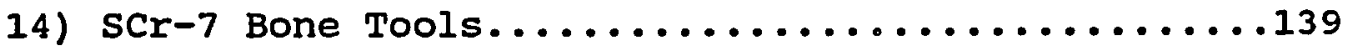

15) scr-7 Cobble Tools...............................

16) SCr-9 Stratigraphic Profile from Units 2 to 5...162

17) Shell Artifacts from scr-9................163

18-20) scr-9 Bone Tools........................164-166

21-29) scr-9 Points and Drills..................... 167-175

30-36) scr-9 Cobble Tools........................... 176-182

37) $\operatorname{scr}-9$, Feature $1 \ldots \ldots \ldots \ldots \ldots \ldots \ldots \ldots . \ldots \ldots \ldots$

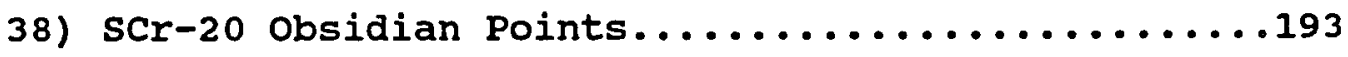

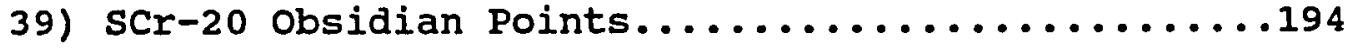

40) $\mathrm{sCr}-38$ point Types.......................208

41) sCr-38 Point Types.......................209

41-44) SCr-39 and scr-40 Point Types............210-212

45) SCr-132 Stratigraphic Profile from Unit 1......234

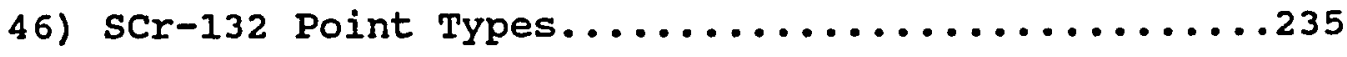

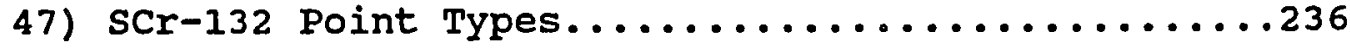

48) $\mathrm{sCr}-132$ Cobble Tools......................237

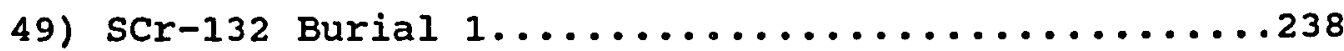


LIST OF FIGURES, CON'T

50) $\operatorname{scr}-132$ Feature $1 \ldots \ldots \ldots \ldots \ldots \ldots \ldots \ldots \ldots \ldots . \ldots \ldots$

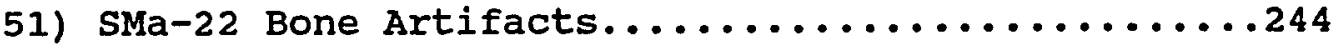

52) SMa-97 Stratigraphic Profile from Unit 4.......258

53) SMa-97 Bone Tools........................259

54-58) sMa-97 Point Types.....................260-264

59-61) SMa-97 Cobble Tools.................... 265-267

62) SMa-218 Stratigraphic Profile from Unit 2......303

63) SMa-218 Bone Tools............................. 304

64-89) SMa-218 Chipped stone Tools................. 305-325

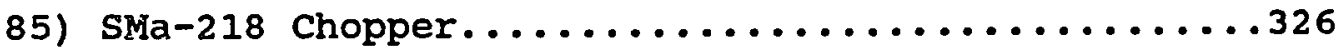

86) SMa-238 Haliotis Pendant from Burial 1.........336

87) SMa-238 Bone Tools....................................

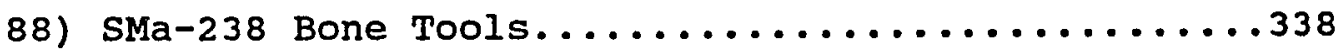

89) SMa-238 Cobble Tools..................................

90) SMa-238 Cobble Tools..............................

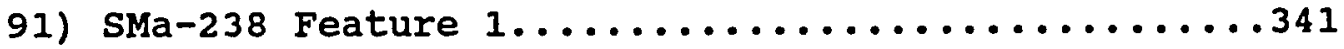

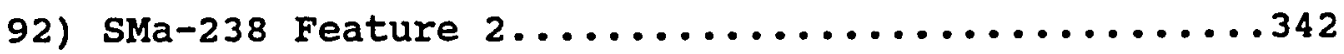

93) SMa-238 Feature 3, Burial 1...................... 343

94) SMa-244 Stratigraphic Profile from Unit 1.......357

95) SMa-244 Bone Tools........................... 358

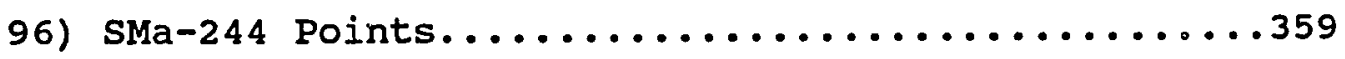




\section{LIST OF MAPS}

MAP

PAGE

1) Selected Archaeological Sites.................6

2) The study Area...........................20

3) Vegetation (after Kuchler 1977)...............41

4) Tribelet Locations (after Milliken 1983).........56

5) SCr-7 and SCr-35, U.S.G.S. Topographic............112

6) SCr-9 and SCr-20, U.S.G.S. Topographic............113

7) Scr-38, scr-39, and SCr-40, U.S.G.S. Topographic....114

8) SCr-93, U.S.G.S. Topographic................... 115

9) SMa-22 and SMa-110, U.S.G.S. Topographic.........116

10) SMa-110 and SMa-139, U.S.G.S. Topographic.........117

11) SMa-115, U.S.G.S. Topographic.................118

12) SMa-118, U.S.G.S. Topographic..................119

13) SCr-132, U.S.G.S. Topographic.................120

14) SMa-97, SMa-218, and SMa-238, U.S.G.S. Topographic..121

15) SMa-244, U.S.G.S. Topographic.................122

16) scr-9 Excavation Unit Locations.....................

17) $\mathrm{sCr}-132$ Excavation Unit Locations...............233

18) SMa-97 Excavation Unit Locations............... 257

19) SMa-218 Excavation Unit Locations...................

20) SMa-238 Excavation Unit Locations........................

21) SMa-244 Excavation Unit Locations................... 356 
CHAPTER I

INTRODUCTION

The cultural prehistory of the San Mateo and Santa Cruz coastal region is relatively unknown. Many of the region's prehistoric cultural resources have been lost to natural erosion, artifact collectors, agriculture, and development. Limited archaeological research conducted along the san Mateo and Santa Cruz coast has not established chronological ranges of occupation for the region nor has it generated adequate data for inter-regional comparisons.

The Monterey and San Francisco Bay Areas have been the focus of a number of theoretical discussions in which hypothetical settlement patterns and subsistence adaptations have been associated with inferred ethnolinguistic group migrations (Breschini 1983; Dietz and Jackson 1981; Dietz, Hildebrandt and Jones 1986; Moratto 1984). However, artifact assemblages documenting local archaeological sequences have not been defined, thus depriving these proposals of supporting facts.

The goal of this study is to address this problem by generating information from archaeological sites within the San Mateo and Santa Cruz coastal area with which to evaluate these proposals. Specifically, the model of foraging and collecting adaptive strategies as proposed by Dietz and Jackson (1981) is tested by using data derived from 
excavated sites, and through a review of artifacts contained in private collections. Excavated sites consist of those tested specifically for this study and those from past investigations conducted by others.

Archaeological sites excavated for this study include: SCr-9, the Bonny Doon site; SCr-38/123, the Wilder Ranch sites; SCr-132, the Scott Creek site; SMa-97, the Ano Nuevo Creek site; SMa-218, the Ano Nuevo Reserve site; SMa-238, the Ano Nuevo Point site, and SMa-244, the Butano Ridge site. Excavations conducted at SMa-115, Montara Beach, and SMa-118, Bean Hollow Beach conducted by this author led to the initiation of this study.

Selected sites tested by others include: SCr-7, the Sand Hill Bluff site; SCr-20, the Brown site; SCr-35, Majors Creek; SCx-93, the Sunflower House site; SMa-22, the Princeton site; SMa-110, Pilarcitos Creek; SMa-139, the Frenchman Creek site, and SMa-140, the Denniston Creek site.

Several large private collections of artifacts were also examined and have been described in this study. These include the Kvenild and the ward collection from SCr-7, the Sand Hill Bluff site; the Engelsman and the Kvenild collections from scr-38, scr-39, and scr-40, the wilder Creek sites; the Hudson collection from SMa-97, the Ano Nuevo Creek site; the Harris collection from SMa-218, Ano Nuevo Reserve, and the steele collection from Ano Nuevo Point. 
The Model

Researchers in the Monterey Bay area have been defining adaptive modes through the modified use of Binford's (1980) discussion of forager and collector strategies. Dietz and Jackson (1981) proposed that early foraging populations who were organizea into small groups made a series of residential moves within a variety of resource locations in the coastal and interior regions, gathering resources on an encounter basis. Due to the mobile nature of this adaptation, the storage of foods was not a necessary aspect of their economy. It was expected that people undertaking such activities would locate themselves in places providing a high diversity of resources. Residential bases were predicted to be adjacent to complex coastlines with terrestrial and marine resources. Because of the productive nature of these places, it was expested that a repetitive use of residential areas would result in a high level of archaeological visibility. Residential sites would contain a wide variety of artifacts, features, exchange items, evidence of tool production, food processing tools and debris, as well as human skeletal remains.

At some time before 2000 years ago it was hypothesized that a second population, characterized as collectors, entered the Monterey Bay area. The collectors' adaptive mode consisted of food storage during part of the year, logistically organized resource procurement stations, and 
residence in villages centrally located among various resources which were occupied for most of the seasonal year. The residential base served as the center from which resource gathering parties originated and where most processing, storage, manufacturing and maintenance activities took place. Collector villages were predicted to be located along interior drainages within the mixed hardwood forest habitat where acorn producing oaks were readily available. The storage of acorns was thought to be the primary motivation for this adaptive strategy. Sites along the coast would typically reveal more task-specific types of pursuits (Dietz and Jackson 1981; Dietz et al. 1986).

Breschini (1981: 4) has mentioned that the main influx of the collectors' adaptive lifeway would have taken hold in the Monterey Bay area at some time but the Santa cruz Mountains probably continued to maintain a forager adaptive pattern for a longer time. He concluded that the replacement of the foragers by the collectors was brought about by a better technology (storage of foods), a larger population and a more integrated social structure. Breschini has proposed that within the Monterey Bay area the replacement of a foraging strategy by collecting was a result of the expansion of Penutian speaking populations entering the region at the expense of resident Hokan speaking populations. Unfortunately, the linguistic model lacks a 
defined range of cultural attributes with which the archaeological record can be compared thus it will not be tested in this study.

Development of the Model

over the years many attempts have been made to interpret changes in the archaeological record represented at a range of Central California sites. A brief review of this process is presented below. Map 1 locates most of the sites for the Monterey Bay Area and the San Francisco Peninsula described here.

Prior to 1900, only a few brief descriptions of large shell mound sites in Central California had been published. Subsequently many of these sites were destroyed by increasing population and urban expansion. Amateur collectors frequently ravaged the more productive sites, causing a considerable loss of information. Fortunately, shortly after the turn of the century, academic institutions began to sponsor archaeological investigations and publish their findings.

The first intensive survey of archaeological sites within Central California was conducted between 1906 and 1908 by Nels c. Nelson, then associated with the University of California at Berkeley. Nelson recognized the San Francisco Bay Area as a discrete archaeological region and recorded over 400 sites. While he understood the possibility of cultural change through time, he viewed the intensive use 


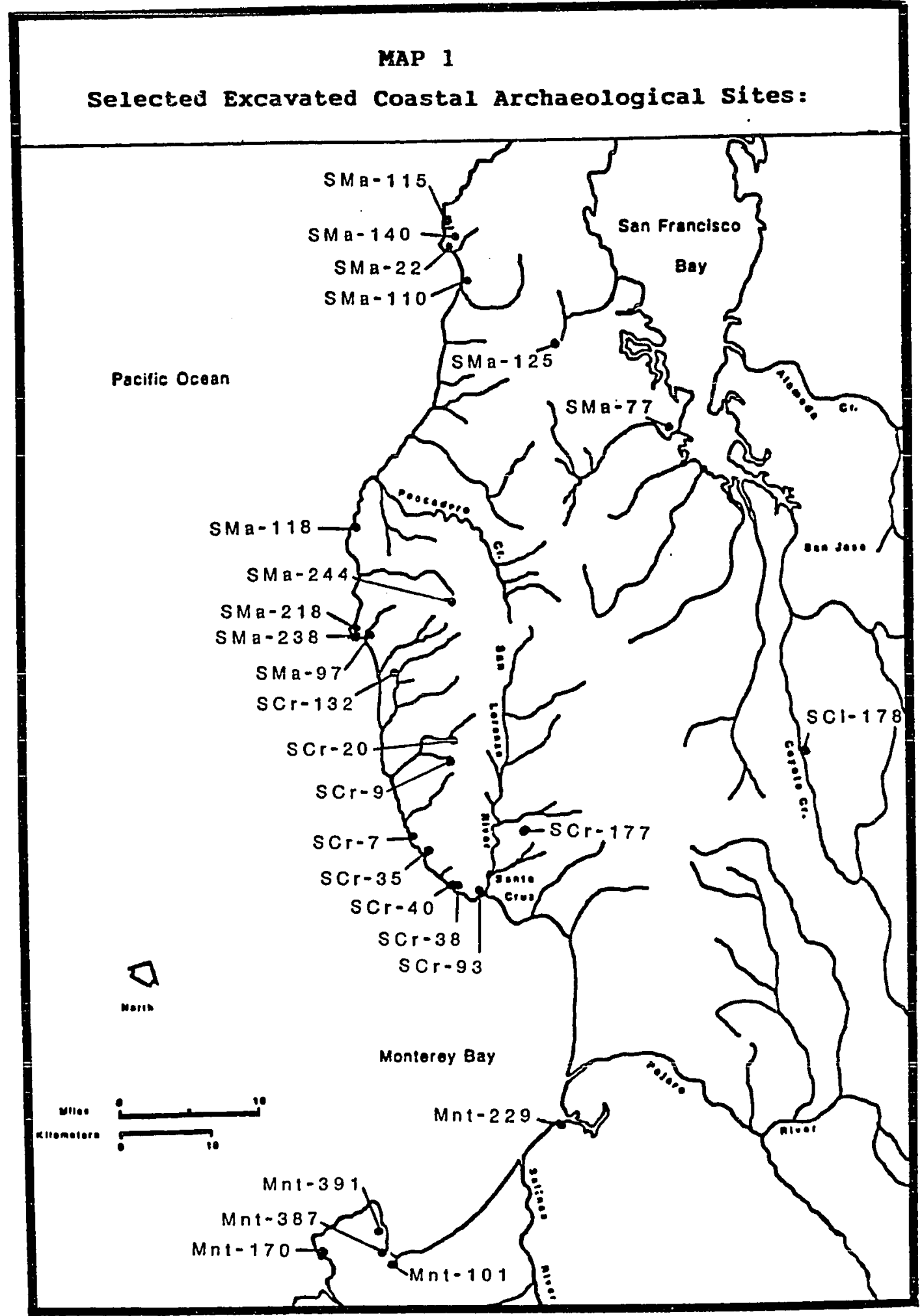


of shellfish at both coastal and bayshore mounds as evidence of a stable adaptive mode throughout the region with little actual variation across space or through time (Nelson 1909). slightly earlier than Nelson's survey, Max Uhle, also associated with the University of California at Berkeley, excavated a large mound $(\mathrm{Ala}-309)$ on the bayshore at Emeryville south of Berkeley (Uhle 1907). Uhle observed diachronic change in the recovered artifact assemblages and segregated the site into two components. The lower component was characterized by flexed burials, red ochre, perforate charmstones, and an emphasis on non-obsidian flaked stone tools. He noted that the upper component contained cremations, polished stone implements, artifacts of flaked obsidian, and he identified a shift in frequency of certain harvested shellfish species. Unfortunately, Uhle's demonstration of culture change, based upon the artifact assemblages, went unnoticed until the 1920s.

In 1910, Nelson excavated another large shell mound near Brooks Island in Richmond. Nelson divided the material remains from the Ellis Landing site (CCo-295) into two components: the lower containing spatulate bone tools, triangular and rectangular Haliotis ornaments, red ochre, cobble mortars, an atlatl spur, grooved stones, large nonstemmed points, and olivella saucer and saddle beads; the upper component contained perforate charmstones, incised bone tubes, olivella saucer beads, stemmed projectile 
points, and mortars with flared sides (Nelson 1910). Nelson did not discuss the significance of the components he had identified.

By 1916, the University of California at Berkeley had tested eleven of Nelson's sites, only one of which was located on the coast (SMa-22). Researchers generally failed to address ideas of cultural development, largely because of the lack of chronological control. These findings brought A.L. Kroeber (1925: 11) to conclude: "relatively little transformation and but slight succession of civilizations occurred in prehistoric California."

During the 1930s, excavations in the sacramento and San Joaquin Delta led to the development of a temporal sequence of cultures in Central California. The sequence, called the Central California Taxonomic System (CCTS), was divided into three cultural horizons based primarily on mortuary patterns and associated artifacts. The sequence included the Early Horizon (2500 to 1500 B.C.), the Middle Horizon (1500 B.C. to 500 A.D.), and the Late Horizon (500 to 1800 A.D.) (Lillard, Heizer, and Fenenga 1939).

Initially the geographic applicability of the CCTS sequence was thought to extend throughout much of California. In Central California, sites of the Early Horizon were restricted to the Delta and Central Valley. It was thought that the economy was dominated by hunting with little use of storable plant foods, acorns in particular. By 
Middle Horizon times, people had spread to the BaY Area, and acorns had become a major element of the native diet. Because the Bay Area was still thought to be lacking evidence of culture change and early occupation, subsequent changes were considered to parallel those changes initiated in the central Valley. Further, it was also believed that the Middle Horizon was established earlier in the Valley than the Bay Area.

Beardsieỹ (1948;1954), Heizer (1949) and others worked to develop this model of Central California prehistory. The University of California Archaeological Survey program applied this sequence as far south as Diablo Canyon on the San Luis obispo county coast where a cultural boundary was thought to exist between the southern and central California cultural regions (Greenwood 1972). Beardsley added regional. and temporal subdivisions to the previously generalized Early, Middle, and Late Horizons. Between 1946 and 1948 Beardsley applied to Central California archaeology the terms "province," "facies," and "component." Breschini (1983: 11) summarizes Beardsley's definitions by noting that the term "horizon" referred to broad temporal and spatial levels, the term "province" to geographic subdivisions within horizons, and the term "facies" to a group of sites which may be distinguished on the basis of recurrent trait assemblages from another group within a province. Finally, the term "component" was used to designate an archaeological 
record of occupation at a single locality during a specific period of time.

In Southern California, archaeological patterns contemporaneous with the Early Horizon of the Valley were known as Early Millingstone cultures (Wallace 1954: 122), and were thought to be a southern variant of the general Windmiller Tradition of the Lower Sacramento Valley. The Windmiller site (Sac-107) was, at that time, the type site for Early Horizon assemblages (Baumhoff and olmsted 1963). During the 1950s ethnolinguistic labels began to be applied to the archaeological record, and it was suggested that prior to 2000 B.C. Northern California was inhabited by people speaking languages within the Hokan stock, and that around 2000 B.C. people speaking languages within the protoPenutian stock entered the Valley and displaced the Hokan.

During the late 1950 s Bert Gerow of Stanford University excavated a site on the western side of San Francisco Bay. The University Village site $(\mathrm{SMa}-77)$ in Palo Alto contained a mortuary complex with grave associations apparently contemporaneous with Early Horizon assemblages in the Central Valley. Extensive comparative studies led Gerow to conclude that the Bay Area was occupied by a different cultural tradition than that of the valley, and that this population and tradition showed a greater similarity to the early cultures of the Southern California coast (Gerow with Force 1968). Gerow noted that the Early Horizon sites of the 
Delta and Valley were generally characterized by extended burials with a westerly orientation, high incidence of drilled shell ornaments and beads, flaked stone points, quartz crystals, and a relatively low incidence of powdered red ochre. The Early Bay sites, including University Village, were much different. Grave lots included flexed burials with no consistent orientation, powdered red ochre, an emphasis on whole olivella shell beads, large chert points, edge-notched stone weights, and a low frequency of obsidian. Anthropometric studies suggested to Gerow that differences between the Bay and Delta/Valley populations were greater, rather than less, at an earlier date (Gerow 1967). Indeed, Gerow argued that Bay and Valley cultures became more similar through time, and he proposed that a model of convergent change in the two areas better explained the data than the general model of parallel change proposed by Heizer and others (Gerow 1974). Gerow concluded that these two distinct cultures co-existed between 1500 and 1000 B.C., and that after this time they gradually converged.

In response to the inadequacies of the vague three horizon chronological sequence, Fredrickson (1974) proposed that the transition from one culture type to another did not occur uniformly throughout the area, but took place at different times in different regions. Fredrickson established a sequence defined on the basis of time as well as general adaptations. He defined a series of temporal 
periods within which a range of cultural patterns occurred. He used the term "pattern" as the archaeological manifestation of a lifeway, shared by a number of different people residing in a particular geographical space. His scheme consisted of five temporal divisions: the PaleoIndian Period $(10,000$ to 6000 B.C.); the Lower Archaic (6000 to 3000 B.C.); the Middle Archaic Period (3000 to 1000 B.C.); the Upper Archaic Period (1000 B.C to 500 A.D.); and the Emergent Period (500 to 1800 A.D.) (Fredrickson 1974: 48)

The Paleo-Indian Period was characterized by large fluted points and chipped stone crescents, with an emphasis upon hunting and lacustrine habitat occupation. The Lower Archaic Period was represented by wide-stem projectile points, a decreased emphasis on hunting, and an expanded reliance on seed plants reflected by the occurrence of handstones and milling slabs.

The Middle Archaic Period assemblages included nonfluted concave base points and large leaf-shaped contracting stem points. Handstones and milling slabs continued to be present, but the mortar and pestle became prevalent as people began to rely heavily on acorns. Hunting became more important once again, and in general, the economy became more diversified. Intensification of acorn, shellfish, sea mammal, and fish procurement was perceived to have occurred during this period. Fredrickson placed the University 
Village site into this period under the title of "Berkeley Pattern." He agreed with Gerow that the Berkeley Pattern was contemporaneous with the windmiller Pattern of the Valley.

The Upper Archaic Period included both contracting stem and lanceolate points, almost exclusive use of mortar and pestle and a continued emphasis on hunting. Culturally, the period was marked by increasing socio-political complexity, a growth of status differentiation based on wealth, and greater complexity of the exchange systems.

Fredrickson identified the Emergent Period as a time when populations modified their environment to increase its productivity. Food storage and exchange systems equalized the distribution of resources, and complex forms of social, religious, and settlement organization emerged.

In an effort to correlate archaeological patterns with the spread and distribution of ethnographic tribal groups, Whistler (1977; 1980) used comparative linguistics, glottochronology, and the archaeological record to develop a model of cultural transitions in California. Whistler associated languages of the Hokan stock with archaic Native Californians of the "Milling stone" horizon dated to approximately 5000 B.C. He postulated that between 3000 and 2500 B.C., the Utian language family of the Penutian stock spread into the state and its speakers settled in the productive estuarine environment of the Central Valley and San Francisco Bay Area. Whistler believed that the Utians of 
the Modoc Plateau and Great Basin brought with them their technology for processing and storing acorns and were represented archaeologically by Fredrickson's Berkeley Pattern. Whistler further hypothesized that another expansion of Penutian speakers crossed the Sierras sometime after 1000 B.C. and settled in the San Joaquin Valley.

Breschini (1983) developed a model of ethnolinglistic shifts within the Monterey Bay Area based upon Whistler's proposed Penutian expansion, which involved a displacement of resident Hokan speaking people sometime between 2000 and 1000 B.C. Of particular interest to this study, Breschini noted:

It is likely that areas of the Santa cruz Mountains and portions of the San Francisco Peninsula remained as population isolates for a period, while the main thrust of the incoming population moved throughout the santa clara valley to Monterey Bay and gradually spread out from that point, eventually reaching their ethnographic distribution (Breschini 1981: 4).

Dietz and Jackson (1981) excavated a series of sites along the Monterey Peninsula and applied Binford's (1980) model of forager and collector adaptive strategies. They hypothesized that the early foraging populations were organized into small groups. These small communities made seasonal residential moves along a series of resource locations in the coastal and interior regions, gathering food and other materials on an encounter basis with a return to a residential base. Because this adaptation required mobility, storage of foods could not be a major apect of 
their economy. It was expected that people undertaking such activities would locate themselves in places providing a high diversity of resources. Residential bases were predicted to be adjacent to complex coastlines with terrestrial and marine resources. Because these places were highly productive, it was expected that their repeated use as residential areas through time would result in a high level of archaeological visibility. Residential sites would contain a wide variety of artifacts, features, structural remains, exchange items, tool production and food processing debris, human burials, etc.

Dietz and Jackson proposed that a second population, characterized as collectors, entered the coastal region. The collectors' adaptive mode consisted of food storage during part of the year, logistically organized resource procurement labor groups, intensive utilization of task specific procurement stations, and residence in villages centrally located among various resources which were occupied for most of the year. The residential base served as the center from which resource gathering parties originated and where most processing, storage, manufacturing and maintenance activities took place.

Dietz and Jackson hypothesized that the collectors displaced the foragers sometime after 2000 years ago. Unlike the forager residential bases which were assumed to be located along complex shorelines, the collector villages 
were predicted to be found along interior drainages within mixed hardwood habitats where acorn producing oaks were readily available. Sites along the outer open coast would typically reveal more temporary, task specific types of activities.

In summary, the forager strategy required that consumers move to the goods, while the collector method moved goods to the consumers.

Based on research conducted at Elkhorn Slough located along the central Monterey Bay shore, Patch and Jones (1984) proposed that while an economic change in the area probably did occur around 2000 years ago, the archaeological data was inadequate to attribute this change to the immigration of new populations. They proposed instead that there was an intensification in the use of specific coastal resources (task specific sites) by a resident population.

During the mid-1980s several major archaeological investigations were completed in the Monterey Bay Area. These include the following excavations: $\mathrm{scr}-177$, the scotts Valley site in the Santa Cruz Mountains (Cartier n.d.); Mnt391, the Cannery Row site and Mnt-387, the Rossi site, on the Monterey Peninsula (Cartier 1984); Mnt-101, the Presidio site on the Monterey Peninsula (Dietz 1987); Mnt-229, the Moss Landing site at Elkhorn Slough (Dietz, Hildebrandt and Jones 1986; Dondero 1984). Along the Santa Cruz and San Mateo coast several sites were tested at this time as well. 
These include: $\operatorname{scr}-93$, the Sunflower House site at Santa Cruz (Bourdeau 1986; Breschini 1981); SCr-38/123, the wilder Ranch site (Hylkema n.d.): SMa-118, the Bean Hollow state Beach site (Hylkema 1989); SMa-115, the Montara State Beach site (Hylkema 1985); and SMa-72, the Mussel Rock site (Clark 1986). All of the above sites, and those excavated for this project, which were also investigated during this period have provided artifact types and radiocarbon dates which form the data base for this thesis. Chronological Relationships

As can be seen from the foregoing discussion, various chronological sequences have been proposed for central California. Studies of bead types from sites with radiocarbon dates in the Monterey Bay Area have led to the development of temporal schemes which employ an Early, Middle and Late range of cultural periods. The use of the term "Period" developed by King (1981) for the Santa Barbara Channel instead of "Horizon" as identified by Lillard, Heizer and Fenenga (1939) resulted from the organization of shell beads and ornaments into a temporal framework which recognized changes in the morphological attributes of these artifact types.

Using Fredrickson's scheme (1974) the term "Horizon" is applied in a temporal sense, with changes in artifact types and adaptive modes marking the variations between Horizons. These temporal designations have been further refined by 
Fredrickson (1974: 48) into the Middle Archaic Period, the Upper Archaic Period and the Emergent Period. Gibson and Fenenga (1978: 102), have constructed a temporal sequence using the Horizon concept with sub-phases ascribed on the basis of changing shell bead types. Concurrently, Bennyhoff and Hughes (1987: 149) presented a synthesis of the Periods and phases within them through the use of dated shell bead assemblages. Table 1 lists chronological sequences that have been applied to sites within Central California.

The data for this thesis encompass a Middle and Late Period developmental sequence. An Early Period may be represented in the study area by radiocarbon dates and some of the artifact types from SCr 7 , the sand Hill Bluff site. The study Area

The area used to evaluate the model of forager vs. collector adaptive strategies consists of the coast of san Mateo and Santa Cruz Counties from Point San Pedro, south to the San Lorenzo River, the western slopes of Montara Mountain and northern Santa Cruz Mountains. This area includes the drainages from the santa cruz Mountains that flow to the open coast (see Map 2). Boundary parameters for the San Mateo and Santa Cruz coastal area were constructed for the purpose of quantifying site distributions within a range of environmental zones.

The southern boundary follows the route of Highway 9, which begins at the mouth of the San Lorenzo River in 
Table 1

Chronological Sequences Used in Central California

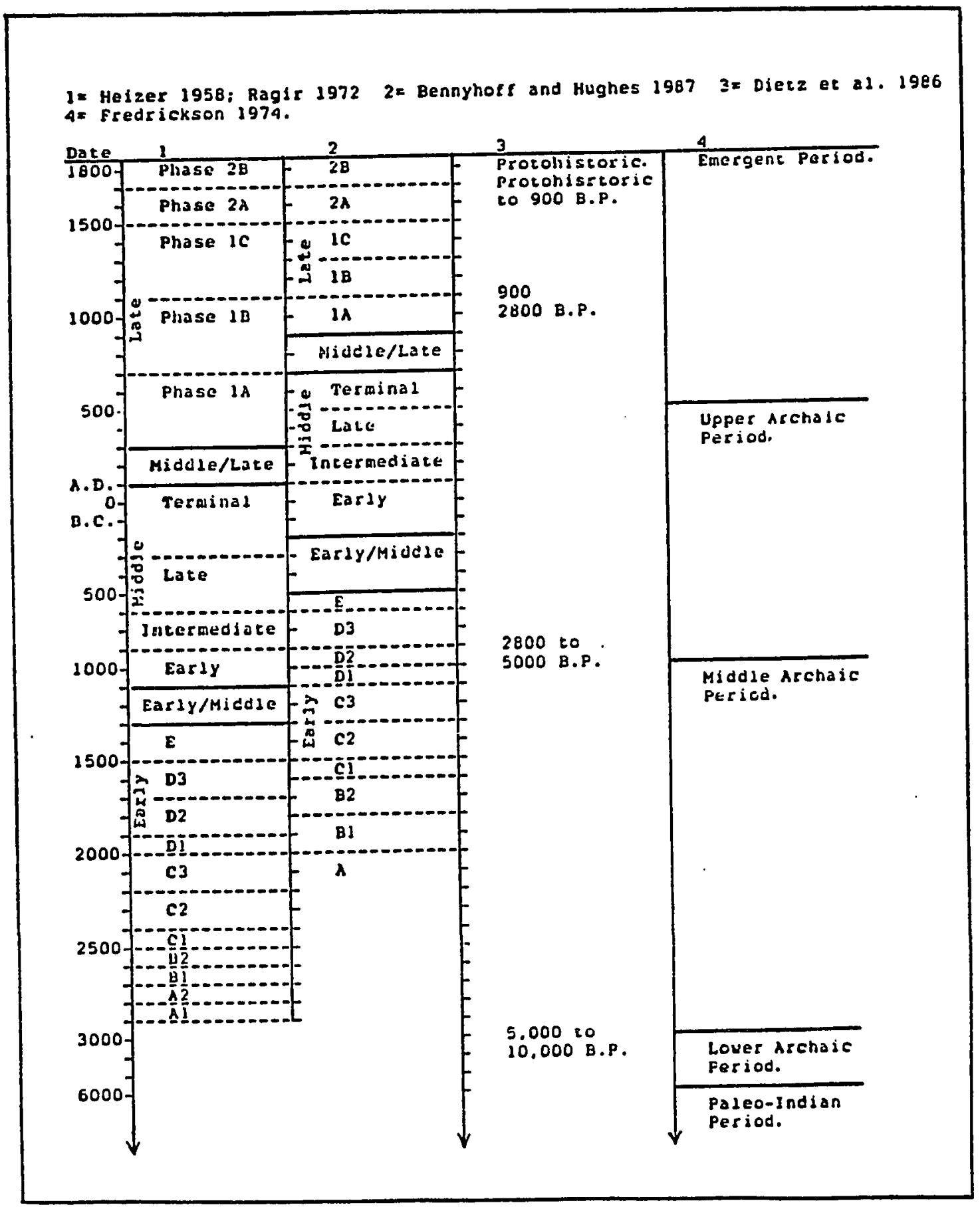




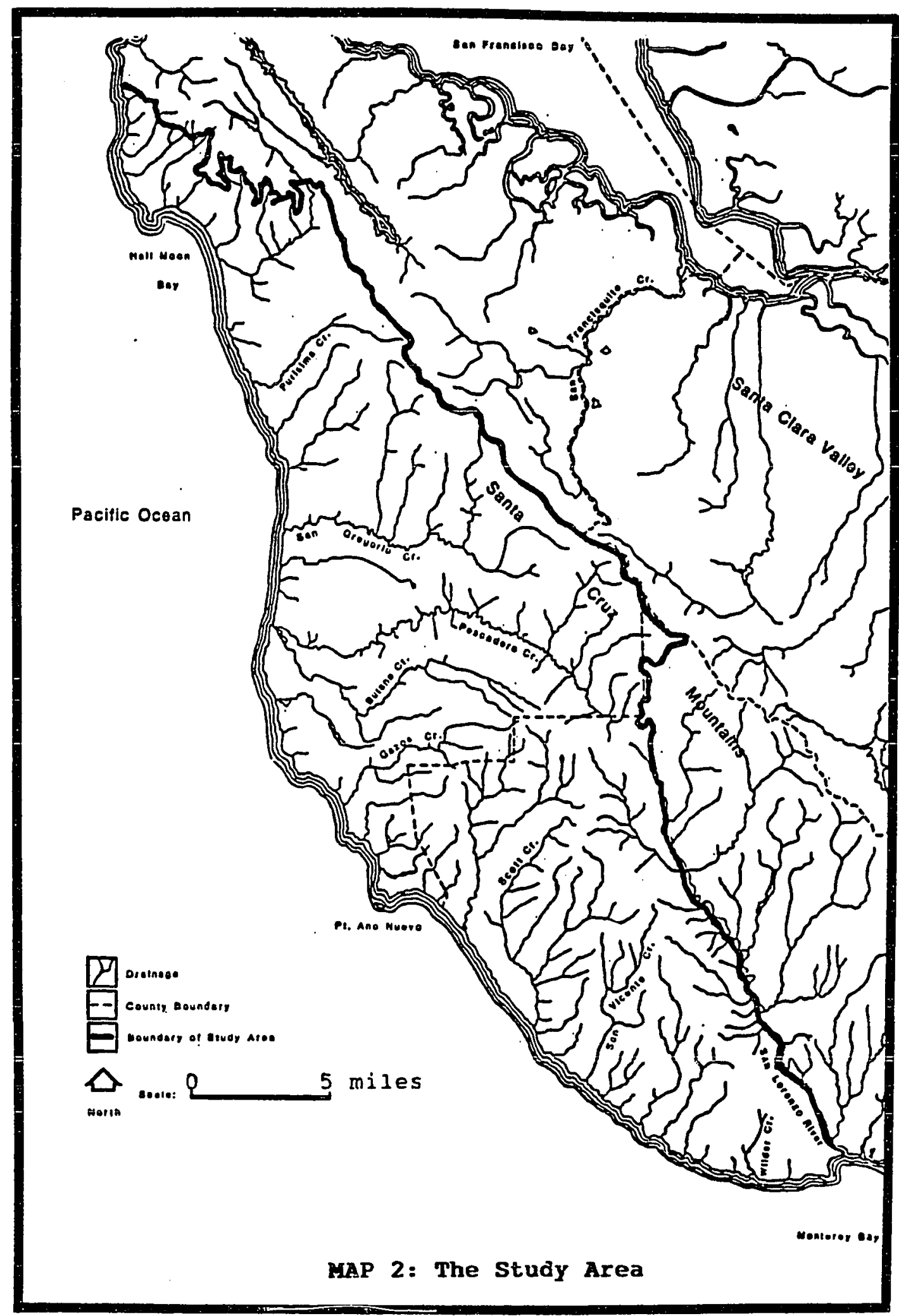


downtown santa cruz and follows the drainage to its headwaters near skyline Boulevard (Highway 35). The boundary then proceeds northwest along the crest of the Santa cruz Mountains following Highway 35 , and continues along the crest of Montara Mountain to the northernmost limit at Point San Pedro.

San Mateo and Santa Cruz site Distributions

In an effort to plot site distributions and attributes within the study area, this author reviewed 182 site survey records for sites within the study area. The survey records for San Mateo and Santa cruz counties are filed at the California Archaeological Inventory Northwest Information Center at Sonoma state University.

The sites were assigned to four ecological zones. These zones comprise a range of habitats and the definitions used here were designed to facilitate the investigation of the relationships between terrestrial and marine economic modes. These ecological zones include the coastal terrace, ridge system, riverine, and upland meadow categories. Given the Dietz and Jackson model of forager and collector adaptive strategies, forager residential bases should be primarily located along the coast, with a high frequency of multi-use sites, while collector sites should reveal a greater number of multi-use sites in the interior along with a greater frequency of task specific sites along the coast. 
The coastal terrace habitat zone encompassed sites situated adjacent to the shoreline, along the coastal plain and up to the lowermost uplifted terraces which appear as low foothills overlooking the ocean. The riverine zone was particularly difficult to apply to this study because many of the coastal terrace sites are clustered along the mouths of drainages. The primary application of this category was to identify site frequencies along streams or river valleys inland from the coastal terraces. These river valleys are typically narrow and surrounded by the steep slopes of the ridge systems. Sites within the ridge system zone are those located on ridges which generally extend from larger mountain systems. Actually, most of the mountains in the study area are larger ridge lines themselves. The upland meadow category was constructed to differentiate the ridge zone from sites situated on open flats along the mountain slopes and crests. At such places open meadows and springs create a concentrated biomass, and the vegetation attracts a variety of fauna.

Table 2 presents a summary of sites in San Mateo and Santa cruz Counties by ecological zone and notes the presence or absence of mortars and pestles, milling slabs and handstones, cobble tools, chipping debris, projectile points, shell, bone, human burials, and other miscellaneous artifacts. 
Table 2

Site Distribution Summary:

Santa cruz (\# of sites and their attributes):

\begin{tabular}{llllllllll} 
& 亘 & MP & SH & CT & CD & $\underline{\text { PT }}$ & $\underline{\text { SL }}$ & $\underline{\text { BN }}$ & BU \\
Coast Terrace & 50 & 21 & 9 & 20 & 41 & 20 & 37 & 13 & 13 \\
Ricge System & 15 & 3 & 0 & 1 & 14 & 1 & 7 & 1 & 0 \\
Riverine & 10 & 4 & 1 & 1 & 4 & 2 & 5 & 1 & 1 \\
Upland Meadov & 23 & 8 & 6 & 4 & 18 & 9 & 10 & 3 & 2 \\
Total: & 98 & 36 & 16 & 26 & 77 & 32 & 59 & 18 & 16 \\
\hline
\end{tabular}

San Mateo (\# of sites ano their attributes):

\begin{tabular}{llllllllll} 
& $\underline{4}$ & $\underline{\mathbf{M P}}$ & $\underline{\mathbf{S H}}$ & $\underline{\mathbf{C T}}$ & $\underline{\mathbf{C D}}$ & $\underline{\text { PT }}$ & $\underline{\text { SL }}$ & $\underline{\text { BN }}$ & $\underline{\text { BD }}$ \\
Coast Terrace & 69 & 9 & 5 & 43 & 61 & 28 & 69 & 46 & 7 \\
Ridge System & 5 & 3 & 3 & 1 & 3 & 2 & 3 & 3 & 1 \\
Riverine & 8 & 1 & 1 & 1 & 5 & 0 & 5 & 4 & 0 \\
Uplana Meadow & 2 & 2 & 0 & 1 & 2 & 1 & 0 & 1 & 0 \\
Total: & 84 & 15 & 10 & 46 & 71 & 31 & 77 & 54 & 8 \\
\hline
\end{tabular}

Santa Cruz and San Mateo (\# of sites and their attributes): \# $\underline{\text { MP }} \underline{\mathrm{SH}} \underline{\mathrm{CT}} \underline{\mathrm{CD}} \underline{\mathrm{PT}} \underline{\mathrm{SL}} \underline{\mathrm{BN}} \underline{\mathrm{BU}}$

$\begin{array}{llllllllll}\text { Coast Terrace } & 119 & 30 & 15 & 63 & 102 & 48 & 106 & 59 & 20\end{array}$

$\begin{array}{llllllllll}\text { Ridige System } & 20 & 6 & 3 & 2 & 17 & 3 & 10 & 4 & 1\end{array}$

$\begin{array}{llllllllll}\text { Upland Meadow } 25 & 10 & 6 & 5 & 20 & 10 & 10 & 4 & 2\end{array}$

\begin{tabular}{llllllllll} 
Total : & 182 & 51 & 26 & 72 & 148 & 63 & 136 & 72 & 24 \\
\hline
\end{tabular}

Frequencies of sites by Habitat: (\%)

\section{Total CosTerr Ridge $\underline{\text { Riverine DplMeadou }}$}

$\begin{array}{llllllllll}\text { Santa Cruz } & 98 & 50 & (51) & 15 & (15.5) & 10 & (10) & 23 & (23.5) \\ \text { San Mateo } & 84 & 69 & (82) & 5 & (6) & 8 & (9.5) & 2 & (2.5) \\ \text { SCr \& SMa } & 182 & 119 & (65.5) & 20 & (11) & 18 & (10) & 25 & (13.5) \\ & \end{array}$


of the 182 sites recorded $65.5 \%$ are located along the coastal terrace, $11 \%$ are on a ridge system, $10 \%$ are riverine and $13.5 \%$ are in the upland meadows. This review has found that San Mateo County sites show an intensive reliance on the coastal terrace zone (84\%) while santa cruz county sites are distributed over a wider range of zones with the coastal terrace still containing just over half of them (51\%).

The upland meadow zone is more extensive in Santa Cruz County and $23.5 \%$ of the sites occur here. In San Mateo county, only $2.5 \%$ of the sites are in the upland meadows. santa Cruz and San Mateo have a fairly similar distribution of riverine sites but santa cruz has three times the number of ridge system sites.

of the sites noted as having human remains the coastal terrace zone dominates in both counties (SCr $=81 \%$ and $\mathrm{SMa}=$ 87.5\%). A greater number of milling tools are associated with the coastal terrace $(S C r=57 \%$ and $S M a=60 \%)$, and many sites report mortar and pestle tools present with milling slab and handstone tools. Shell debris provided a readily identifiable marker of site location and surface extent. Over $75 \%$ of the site records describe the presence of shell which can be found throughout the defined zones. One exception is that neither of the two upland meadow sites for San Mateo county reported any. Projectile points are well represented at the sites (34.5\%) despite the limited discussions of site constituents in the survey records. 
Again the coastal terrace zone maintains the greatest frequencies of projectile point occurrence (87.5\%). Sites within the coastal terrace zone also contained the greatest recorded presence of debitage (70\%).

Summary of Findings

The results of this study have led to the conclusion that a foraging adaptive strategy continued to be the optimal technique for a considerably later span of time than has been postulated by Dietz and Jackson (1981) - Further, while a collector strategy probably developed much earlier in areas such as the San Francisco Bay, Santa Clara Valley and Monterey Bay regions, it did not replace the foraging strategy throughout the San Mateo and Santa cruz coastal area in a uniform manner. Both strategies co-existed, perhaps until the time of European contact in the 1770s. The northern and southern sections of the study area were influenced by the collector method in the late period as evidenced by site morphology at SMa-115 and temporally diagnostic artifact types at SCr-20; however, the coast from approximately scott Creek to San Gregorio creek retained the older foraging strategy until sometime after 1,000 A.D. as evidenced by sites SMa-97, SMa-118 and SMa-244. Storable food resources, acorns in particular, were incorporated into the economy, but did not result in a major shift in adaptive modes. Milling tools recovered from both the Middle and Late 
Periods evidence a mix of hard seed grinding implements along with acorn processing tools.

Breschini's proposition that areas of the santa cruz Mountains and coast were not initially absorbed or displaced by collectors $(1981: 4)$ is supported by the findings of this study. However, the linguistic model which Breschini employed to explain observed shifts in adaptive strategies remains an untested hypothesis.

The methods and techniques leading to the above conclusions are presented in the subsequent sections of this study. 
CHAPTER II

REGIONAL ENVIRONMENTAL CONTEXTS

Topography and Geology

The study area lies within the California coast Ranges which extend north-northwesterly along the Pacific Ocean coast of California. The coast Ranges consist of numerous separate mountains and valleys, formed by the extreme folding and faulting that accompanied the uplift of this terrain which began some five million years ago. The process of uplifting is still occurring and many fault zones are active as the ranges continue to rise.

San Francisco Bay forms the division between the north and south coast ranges. The santa cruz mountains dominate the topography of the study area and are situated in the northwestern end of the south coast Ranges. The Santa cruz mountains extend 120 kilometers from the Golden Gate to the northwest and the Pajaro River to the southeast. These mountains are bounded to the east by San Francisco Bay and Santa clara Valley and to the west by the Pacific Ocean. The topography of the area is rugged with elevations ranging from sea level to over 800 meters along the ridge crest of Ben Lomond Mountain. Major ridges within the study area include Montara Mountain, Kings Mountain, Mindego Hill, Butano Ridge, Castle Rock Ridge, and Ben Lomond Mountain. 
Numerous lesser ridges and mountains diverge from these major ridge systems.

Several fault zones within the study area largely determine the physiography of the region. These include the San Andreas, Pilarcitos, San Gregorio, Zayante, and Ben Lomond faults (Brabb et al. 1977).

The active san Andreas fault and its ancestral branch, the Pilarcitos fault, have juxtaposed two major tectonic blocks with contrasting basement complexes and with differing stratigraphies. The exposure of a series of overlying strata with differing lithic constituents within these two major tectonic blocks provided access to a range of raw lithic materials which were used by the prehistoric inhabitants of the area. The distribution of these materials within the excavated archaeological sites has provided information about the level of exchange between populations within and outside the primary locations of the resources. of particular importance to this study is the frequency of chert debitage and tools from the Franciscan Formation occurring within the coastal sites, as opposed to the distribution of the locally available Monterey cherts. Cherts from the Franciscan Formation were readily available east of the San Andreas fault, which is outside the study area. Cherts from the Monterey Formation were readily available from the outcrops at Point Ano Nuevo. Researchers have argued as to whether or not Ano Nuevo was the prime 
center of distribution for Monterey cherts (Davis 1961; Heizer and Treganza 1944; Roop 1986). This study has shown that the Ano Nuevo area was indeed the primary point of distribution. While the Monterey Formation extends beyond the Ano Nuevo area, siliceous cobbles of the chert do not. The block to the northeast is characterized by heterogeneous rocks of the Franciscan Formation. This assemblage, of Late Jurassic to Late Cretaceous age, is in fault contact with Upper cretaceous clastic sedimentary rocks of the Great Valley sequence, which in turn are overlain by Cenozoic clastic sedimentary rocks (Clark 1981). Southwest of the San Andreas fault and northeast of the San Gregorio fault, crystalline rocks of the salinian block form the basement complex. Cretaceous strata are absent, and Cenozoic clastic sedimentary and volcanic rocks rest upon the crystalline basement (Clark 1981).

Southwest of the San Gregorio fault, crystalline rocks of the Salinian block are not exposed while Upper Cretaceous clastic sedimentary rocks crop up along the coast. Resting unconformably upon these strata are Cenozoic sedimentary and volcanic rocks that differ from those of the northeast (Clark 1981).

The crystalline rocks northeast of the San Gregorio fault are most visible along Montara Mountain and along the center of Ben Lomond Mountain, where an elongate granite complex is in association with several large metasedimentary 
deposits. The exposed plutonic rocks consist of several distinct intrusions that range in composition from granite to gabbro. An intrusive unit consisting primarily of quartz diorite underlies about $3 / 4$ of the surface area of the exposed complex. Other intrusive units consist of course grained leucocratic rock, gneissic granodiorite, and gabbro (Leo $1967: 34$ ).

The southern part of Ben Lomond Mountain is made of metasedimentary rocks which intrude into the granitic rocks of the crystalline complex. The metasedimentary rocks are approximately ninety percent quartzites and peltic schists and ten percent marbles and calcsilicate rocks (Leo 1967). The metasedimentary rocks are the oldest rocks in the area and were originally miogeosynclinal sandstone, shale, and carbonate beds of Paleozoic or Mesozoic age. East of Ben Lomond Mountain, the crystalline basement surface has been warped down beneath the Scotts Valley syncline (Clark 1981).

Southwest of the San Gregorio fault no basement rocks are exposed. However, porphyritic volcanic rocks that crop out south of Pescadero Road may form part of the basement complex. Sedimentary strata southwest of the San Andreas fault and northeast of the San Gregorio fault are of Tertiary and Quaternary age (Clark 1981).

Resting upon the Eocene to Lower Miocene sequence northeast of the San Gregorio Fault are local deposits of a marine sedimentary cycle of Middle Miocene age. This Middle 
Miocene sedimentary sequence consists of a widely transgressive basal sandstone unit, the Lompico sandstone, and an overlying organic mudstone unit, the Monterey Formation. In the northern santa cruz mountains, sandstone beds that are locally found at the base of the Monterey Formation are correlative with the Lompico sandstone, and rest on beds of quartz diorite on the southern slope of Montara Mountain near Half Moon Bay. The Monterey Formation was named by Blake (1856), for exposures of diatomaceous and siliceous shale near the city of Monterey. The siliceous shale from this formation was utilized extensively by Native Americans for chipped stone tools, and will be discussed further in subsequent chapters. This formation crops out on the east slope of Ben Lomond Mountain and underlies the scotts Valley syncline. The Monterey Formation of this area consists of semisiliceous organic mudstone that grades upward into micaceous and carbonaceous sandy siltstone. The westward coarsening of the Monterey Formation and the appearance of numerous arkosic sandstone interbeds on both sides of Ben Lomond Mountain show that the crystalline basement complex there was a topographic high, possibly an island, that supplied clastic detritus to adjacent areas of deposition (Clark 1981).

sedimentary strata exposed southwest of the San Gregorio fault are of Mesozoic and cenozoic age, and differ from the strata northeast of the fault. The Mesozoic section 
consists of marine clastic sedimentery rocks of the Pigeon Point Formation, of late cretaceous age. These strata are visible along the coast. Clastic and volcanic rocks, that range in age from oligocene to Holocene, rest unconformably on the Pigeon Point Formation. The Cenozoic section includes the Vaqueros, Monterey, and Purisima Formations, which are folded and faulted in exposures north and east of Ano Nuevo (Clark 1981).

Strata from the Vaqueros Formation extend north and east of Ano Nuevo. At low tide beds of this formation are exposed. The mudstone beds of the Vaqueros Formation are faulted against the siliceous beds of the Monterey Formation. The Vaqueros Formation exposed east of Ano Nuevo is near the axis of an anticline, the central part of which consists of volcanic breccia. The volcanic breccia is highly altered and cut by dolomitic veins. The groundmass consists largely of plagioclase and clay (Hall, Jones and Brooks 1959).

The sea cliffs north and east of Point Ano Nuevo reveal the Monterey Formation, consisting of thin bedded siliceous mudstone, resting upon the Vaqueros Formation. The contact between the Purisima and Monterey Formations is also visible in the sea cliffs. This contact exhibits a 1 to 1.5 meter thick basal conglomerate bed of the Purisima Formation composed largely of siliceous Monterey Chert cobbles, which rest at a slight angle on the siliceous beds of the Monterey 
Formation (Clark 1981). The erosion of the Purisima Formation at this location provided an abundant supply of Monterey chert nodules for the production of chipped stone tools, and constitutes the most accessible and reliable point of collection by prehistoric stone tool workers. Five distinct emergent marine terraces are documented along the seaward slope of Ben Lomond Mountain. Each terrace consists of remnants of wave cut platforms and sea cliffs, which are carved into the crystalline and Tertiary sedimentary rocks of the mountain. Six terraces can be counted when the shelf currently being formed at sea level is included. These surfaces are overlain by a thin, uneven cover of marine and nonmarine sediments. Terrace deposits typically consist of massive, well sorted sand (Bradley 1965) .

Exposed terrace platform surfaces of the Santa Cruz mudstone or the purisima Formation reveal pitting in the bedrock from molluscan borings. The terraces were likely cut by wave erosion when the sea level was rising, and the marine sediments were laid down as beach deposits when the sea level was falling. These marine sediments were then locally covered by a relatively thin layer of fluvial and colluvial sediments. This sequence of erosion and deposition appears to have been repeated at least five times during the uplift of Ben Lomond Mountain (Bradley). 
Landslide conditions are widespread in the area, primarily where steeper slopes are underlain by one of the mudstone units. The highly fractured rocks of the Monterey Formation and of the Santa cruz mudstone are susceptible to landsliding, and extensive movement of these strata has resulted in unreliable stability of slopes and narrow ridges (Cooper, Clark and Associates 1975).

Alluvial deposits of Holocene age are discontinuously distributed along the bottoms of the larger streams and consist of unconsolidated moderately sorted silt, sand, and gravel, derived from the drainage watersheds of the streams (Clark 1981).

\section{Changing sea Levels}

Sea level has changed dramatically along the California coast over the past 15,000 years. A rise in sea level over thousands of years is a direct result of melting glaciers during the Holocene and Pleistocene epochs. Rapid changes in the sea level had a major effect upon the geography of the coast, and probably greatly influenced human populations that were adapting to the changing coastal habitat (Moratto, King, and wolfenden 1978: 147).

The rise in sea level, at about the time when human populations are thought to have been expanding into western North America, may account for the absence of coastal sites exhibiting greater antiquity. Conversely, older sites may yet be discovered to refute this possibility. 
Bickel (1978) has investigated rates of sea level fluctuation along the California coast. Bickel notes that approximately 15,000 years ago sea level was at a minimum and rose rapidly thereafter until about 6,000 years B.P. as a result of large scale glacial melting. She calculated that $95 \%$ of the frozen water in continental glaciers was released by 7,000 years ago, during a period of melting, then slowed, and sea. level rise occurred at a slower rate reaching the current mean sea level.

Bickel states that variations within regional sea level rises are attributed to differential rates of emergence and submergence of tectonic blocks. Shoreline changes were greater in areas where the continental shelf is broad and slopes to shallow depths, such as the area of the San Mateo and Santa cruz coast. She estimated that a 70 meter rise in sea level between 15,000 and 10,000 B.P. corresponds to an advance of the shoreline of approximately 20 to 25 kilometers eastward toward the present coastline. She further estimated that 400 to 500 meters of land was submerged per century. Bickel comments:

It seems certain that visitors or residents on the california shore, if any, must have observed the changes caused by sea level rise, especially in wide shelf areas. Doubtless they did not simply observe, but necessarily responded to the changes. This would have required shifts of villages and territorial boundaries almost generationally during the period of rapid sea level rise (Bickel 1978: 7-8). 


\section{Coastal Erosion}

The distinctive landforms along the California coast such as sea cliffs, beaches and dunes, and sea stacks (rocks and landforms detached from the mainland) are shaped by wave erosion, littoral drift, and wind transport. Within the study area the northwest, southeast trending rocky coastline consists of nine geomorphically distinct segments that reflect local variations in coastal processes and geologic conditions. Within these segments the erosional power of marine activity and the resistance to the geologic units exposed to wave action along the shoreline cause various localities to erode at differential rates.

Weakly indurated sedimentary rocks with little or no erosional resistance within the Half Moon Bay area are exposed to wave impact along the shoreline. Under natural conditions, the rate of sea cliff erosion is generally very low because a dynamic balance is attained in which sand derived primarily from local erosion forms permanent beaches that protect the erosive cliffs from wave action, except during major storms.

Areas such as Devil's Slide, Montara, Pescadero, and Franklin Points, which consist of indurated rocks which are resistant to erosion, are exposed to wave impact along the shoreline. Geologic factors such as bedding and joint fractures in the rocks control the rates at which they 
disintegrate. Generally, wave patterns have little effect on these areas.

The coastal formations of Point San Pedro, Moss Beach to Pillar Point, Miramontes Point to Pescadero Point, and Point Ano Nuevo are comprised of moderately indurated and highly fractured rocks with moderate resistance to wave impact. These regions are characterized by high vertical sea cliffs with numerous sea caves and arches. Frequently small rocky headlands shelter small beaches. As protective sea stacks and rocky headlands breakdown, sea cliffs collapse from exposure to wave activity until they reach a point of stabilization again.

Locally, natural erosion rates are the highest for the San Mateo county coast. The sedimentary rocks exposed along the Santa cruz county coast erode at variable rates as well, with a statistically calculated erosion rate of $30 \mathrm{~cm}$. of sea cliff per year. Much of this erosion is episodic, and mostly occurs during major storms (Griggs and Johnson 1979). The Santa Cruz mudstone and Purisima Formations (siltstone and sandstone) form the sea cliffs throughout the Santa cruz area. The santa cruz mudstone is fairly resistant to wave patterns, whereas the Purisima Formation is more variable. Where unconsolidated or poorly indurated beds are exposed to wave action, undercutting usually occurs followed by collapse of the overlying material. 
Aeolian erosion along the coast contributes to a slower process of landform change, but is largely responsible for the extensive loss of sand dune fields at Franklin and Ano Nuevo Points, and at sand Hill Bluff. In these locations sand is no longer being deposited at a rate which can sustain or spread the dunes. Archaeological sites within these dune fields are becoming exposed at an increasingly rapid speed as the dunes deflate.

\section{Climate}

The study area maintains a mild Mediterranean climate that varies considerably within the region because of the diverse topography.

Overall, precipitation is lowest along the coastal terraces and greatest at the higher elevation ridge systems. Prevailing westerly winds drive moisture laden clouds over the northerly trending mountains where the western facing slopes receive large amounts of rainfall as the clouds uplift over them. This creates a rain shadow effect, causing vegetation on the eastern slopes to be less luxuriant and dense.

Average annual rainfall along the coastal terraces ranges from 18 inches around Pillar Point south nearly to San Gregorio Creek, to 26 inches near Davenport. The ridge systems receive 30 to 40 inches; however, Ben Lomond Mountain averages 55 inches. The highest elevations of Ben Lomond Mountain at 2,600 feet receive 60 inches of rain 
annually. Severe storms dropped nearly 100 inches of rain on top of Ben Iomond Mountain in 1983 and 1986. Conversely, the severe drought beginning in 1986 through the present date has resulted in record lows.

Most of the rainfall occurs between December and May. summers are hot and dry, although coastal fog is common from May to August when summer patterns of air circulation proluce upwelling of cold water along the coast (Gordon 1977). The fog stays close to the shoreline and drifts into valleys and rifts along drainages, maintaining the redwood forest habitat.

Temperatures are kept moderate by ocean and fog during summer while in winter the ocean acts as a heater, preventing extremely cold weather. Along the coast summer mean temperatures are about 65 degrees (F) while winter temperatures are about 55 degrees. Away from the littoral zone, in the interior, ridges and valleys average 80 degrees in summer, and the winter mean temperature is about 40 degrees. Snow forms at the higher elevations during exceptionally cold winters, sometimes lasting for several days. Extreme temperatures range from lows near 20 degrees, and highs well above 90 degrees.

Numerous streams and tributaries flow from the Santa Cruz mountains into the Pacific ocean. They generally flow westward and follow steep grades from their watersheds along the ridges cutting into the various geologic formations. 
Slope grades greatly influence rates of water flow and the deposition of sediments. Most of the streams originating on the western slopes of ridges are perennial while most of the streams on the eastern slopes are seasonal. Springs and ponds are scattered along the ridges and hills throughout the study area, many of which maintain water flow all year. Major streams include the San Lorenzo River, San Vicente Creek, Scott Creek, Wadell Creek, Gazos Creek, Pescadero Creek, San Gregorio Creek, and Tunitas Creek. In addition to these major streams there exist some 46 named creeks with dependable water flow in the study area. Vegetation

Archaeological sites within the study area are located within four broad ecological zones. These include the coastal terrace, ridge system, riverine/drainage and upland meadow zones. The distribution of vegetation communities within these zones was calculated and the number of sites occurring within them has been presented in Table 2 of Chapter I.

Using Kuchler's (1977) vegetation distribution map for California, five major vegetation communities were found to be within the study area. These communities include the Coastal Prairie-scrub Mosaic, Northern Seashore, Coastal Cypress and Pine Forest, Redwood Forest, and Mixed Hardwood Forest (see Map 3). 


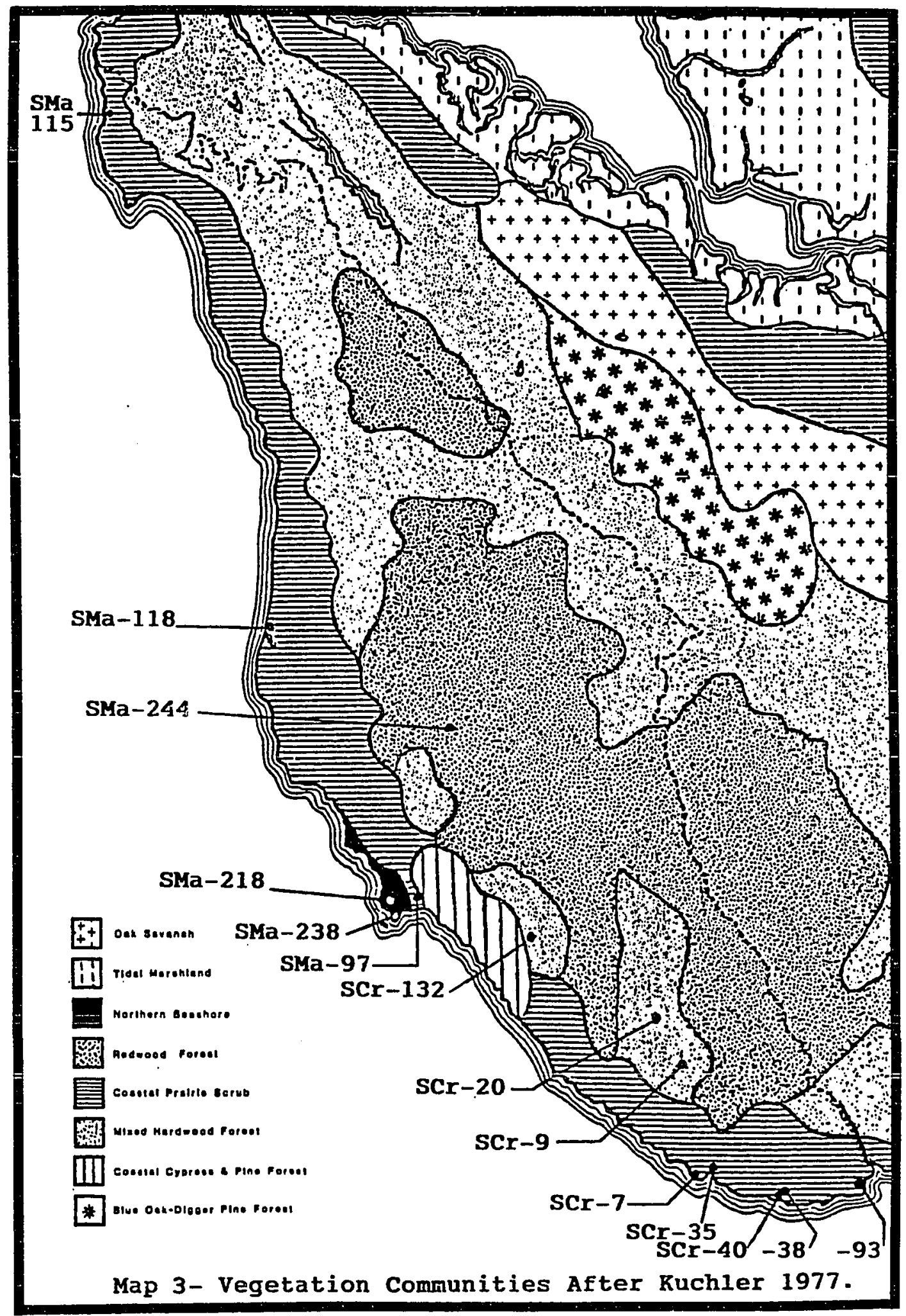


of these five vegetation communities, the most productive in terms of vegetal resources for human use is the Mixed Hardwood Forest and Coastal Prairie-scrub Mosaic. The Mixed Hardwood Forest, typically surrounded by Redwood Forest, dominates the upland meadow and ridge system zones. Small areas of open grassland meadows are interspersed throughout the Mixed Hardwood Forest and many animal species are attracted to them, causing the fauna to be concentrated within clumped rescurce patches. The coastal Prairie-scrub Mosaic is also attractive to game, but the fauna is dispersed over a greater area within it. This vegetation community dominates the coastal terrace zone. The riverine zone contains the greatest diversity of plant species but is primarily composed of Mixed Hardwood and Redwood Forest, with occasional narrow river terraces of grassy meadows. Coastal Prairie-scrub Mosaic: Within this community coastal prairies are differentiated from coastal scrub. Farther inland, the scrub disappears and only the prairie prevails. Oatgrass (Danthonia californica) and red fescue (Festuca rubra), are dominant grasses of the coastal prairie, with a variety of forbs and bulbs like Brodiaea (Brodiaea pulchella), soaproot (Chlorogalum pomeridianum), iris (Iris dougasiana), and squaw potato (Perideridia gairderi). Within the coastal scrub dominant species include coyote brush (Bacharis pilularis ssp. consanquinea), coastal sage (Artemisia californica), and man root (Marah fabaceus). 
This community spreads over the coastal terrace and is broken in places such as Point Ano Nuevo south to near scott creek and then continues south again to beyond Santa Cruz. Northern seashore Community: This community is divided into northern beach and northern dune. The northern beach community includes such dominant species as silver beach weed (Ambrosia chamissonis), rye grass (Elymus mollis), and willow (Salix sp). The northern scrub dominants include coyote brush (Bacharis pilularis ssp consangunea), goldenweed (Haploppapus ericoides), lupines (Lupines arboreus and L. chamissones). This vegetation community is located at Point Ano Nuevo and Franklin Point.

Coastal Cypress and Pine Forest: This community consists of fairly dense needle leaved evergreen forest. The dominant species here include the Monterey pine (pinus radiata). Beneath the pines, shrubs include California lilac (Ceanothus spp.), California holly (Heteromeles arbutifolia), hazelnut (Corylus sp.), and poison oak (Rhus diversiloba). This community has a limited distribution in the Santa cruz mountains and is found east of Point Ano Nuevo south nearly to scott creek.

Redwood Forest: Very tall, dense, needle-leaved evergreen forest define this community. The undergrowth is low and patchy with forbs mainly on alluvial deposits; shrubs and low trees grow within the uplands. Dominant species include the coast redwood (Sequoia sempervirens) and 
Douglas fir (Pseudotsuqa menziesii). This community is widespread in the santa Cruz mountains; however, stands are less extensive in northern San Mateo County.

Mixed Hardwood Forest: Within this community both broad leaved and needle leaved evergreen forest is combined with broad-leaved deciduous vegetation. The forest is somewhat dense, and in high elevations, the height of the foliage may be low and appear shrubby. Occasional chaparral vegetation inclusions can be seen within the mixed hardwood. Dominant species include madrone (Arbutus menziesii), coast live oak (Quercus agrifolia), canyon oak (Quercus chrysolepis), buckeye (Aesculus californica), and California bay (Umbellaria californica). Dominants within the chaparral include chamise (Adenostoma fasciculatum), manzanita (Arctostaphlos sp.), California lilac (Ceanothus spp.), toyon (Photinia arbutifoloia), and poison oak (Rhus diversiloba). The mixed hardwood community is widespread throughout the santa cruz mountains. It can be found surrounding and intruding into the redwood community, and also intruding into the coastal prairie community along drainages.

The relative percentages of the five general vegetation communities within the study area, based on Kuchler's (1977) definitions, were calculated with the use of a planimeter. As can be seen on Table 3, the Mixed Hardwood Forest comprises the largest community. This, combined with the 
Coastal Prairie-scrub Mosaic community, result in $65 \%$ of the study area being covered by very productive vegetation communities.

Table 3: Percentage of Vegetation Communities within the Study Area

Vegetation Community Coverage Eco. Zone*

1) Northern Seashore...............

2) Coastal Cypress/Pine Forest....4.5\% CT RS

3) Coastal Prairie/Scrub Mosaic...28.0\% CT

4) Redwood Forest.............28.0\% RS RV UM

5) Mixed Hardwood Forest...........37.0\% RS RV UM

* CT= Coastal Terrace RS= Ridge system RV= Riverine $\mathrm{UM}=\mathrm{Upl}$ and Meadow

\section{Fauna}

The Santa cruz Mountains and adjacent coast supported a wide range of fauna. This section lists the terrestrial, marine, and avian creatures available to prehistoric hunters. While a wide variety of insects are also present, this study does not include them. A comprehensive list of all the species within the study area is beyond the scope of this project, but the most common ones known to have been exploited by the native inhabitants is presented in Table 4. This information has been garnered from existing archaeological data, historic documents, and other sources. Many of the species described here are seasonal residents of the study area.

The most intensively exploited creatures were the ocean mollusks, marine mammals and terrestrial herbivores. The 
temporal relationship of marine vs. terrestrial economic

pursuits has been examined through the identification and quantification of faunal remains recovered from the

excavated sites within the study area. This data is presented in subsequent sections.

The most common terrestrial mammal remains found at the sites within the study area included elk, deer, and rabbits. Smaller rodent remains were also recovered but these were not tallied in the taxa frequencies described in the site reports, Chapter V (although they were identified when possible and tallied in Appendix A).

The most common marine mammals included sea otter, fur seals, sea lions, and harbor seals. Interestingly, no elephant seal remains were recovered despite their abundant presence at Ano Nuevo Reserve today.

Birds and fish were also commonly recovered at the sites but, like the smaller rodents, were not included in the taxa frequencies. Also, whale bone was not included in the taxa frequency tables because a single element would bias the sample weight in favor of this species despite the fact that these elements were the exception rather than the rule. 
Table 4: Fauna Present in the Study Area

Marine Mammals:

California sea lion
Stellar sea lion
Harbor seal
Northern fur seal
Southern fur seal
Sea otter
California gray whale

Zalophus californicus

Eumetopias jubata

Phoca vitulina

Callorhinus ursinus

Arctocephalus townsendii

Enhydra lutris

Eschrichtius robustus

Terrestrial Mammals:

Tule Elk

Black tailed deer

Grizzly bear

Mountain lion

Bobcat

Antelope

Coyote

skunk

Jack rabbit

Brush rabbit

Gray fox

Raccoon

Woodrat

Squirrel

Gopher

Cervus nannoides

odocoileus hemionus

Ursus arctos

Felis concolor

Lynx rufus

Antilocapra americana

Canis sp.

Mephitis mephitis

Lepus townsendii

Sylvilaqus audubonii

Urocyon cineretoargenteus

Procyon lotor

Neotoma lepida

Scirius griseus

Thomomys bottae

Birds:

Bald eagle

Golden eagle

Rough legged hawk

Red tailed hawk

Sparrow hawk

Turkey vulture

snow goose

Great blue heron

Brown pelican

Cormorant

Common murre

Black scoter

Rhinocerous aucklet

Tufted puffin

Western grebe

Sheerwater

Terns

Ducks and teals

Gulls

Aquila chrysaetos

Haliaeetus leucocephalus

Buteo lagopus

Buteo iamaicensis

Falco sparverius

Chen caerulescens

Chen hyperborea

Ardea herodias

Pelecanus occidentalis

Phalacrocorax penicillatus

Uria aalqae

Melanitta nigra

Cerohinca monocerata

Lunda cirrhata

Aachmorphorus occidentalis

Fulmaris qracialis

Sterna sp.

Aythya Sp. \& Anas Sp.

Gavia sp. 
Table 4 (con't)

\author{
Auks \\ California quail \\ stellars jay \\ Northern flicker \\ Mourning Dove \\ Rock Dove
}

\section{Fish:}

steelhead rainbow trout starry flounder

Surf perches

Pacific herring

Pacific sardine

Bat ray

Leopard shark

Pacific hake

Plain fin midshipmen

White croaker

Pacific mackerel

Yellow tail

Jack mackerel

Perch

California halibut

English sole

Jack smelt

Cabezon

Rockfish

Ling cod

Kelp greenling

sacramento perch

Tule perch

Minnows

\section{Mollusks:}

Black abalone

Red abalone

California mussel

Bay mussel

Black turban snail

Limpet

slipper shell

Bay oyster

California oyster

Pismo clam

Rock cockle

Heart cockle

olive snail

Horseneck clam
Alciáae sp.

Callipepla californica

Cyanocitta stelleri

Colaptes auratus

Zenaida macroura

Columba livia

Salmo gairdnerii

Platichthys stellatus

Amphistichus sp.

Clupea harengus

Sardinops saqax

Myliobatus californica

Triakis semifasciata

Merliccius productus

Porichthys notatus

Genyonemus Iineatus

Scomber japonicus

Seriola lalandi

Trachurus symmetricus

Ebiotaca sp.

Pralichthys californicus

Parophrys vetulus

Atherinopsis californiensis

Scorpaenichthys marmoratus

Sebastes sp.

Ophiodon elongatus

Hexagrommos decagrammus

Archoplites interruptus

Hysterocarpus traskii

Cyprinidae

Haliotis cracherodii

Haliotis rufescens

Mytilus californianus

Mytilus edulis

Tequla funebral is

Acmea sp.

Crepidula sp.

Ostrea lurida

Tivela stultorum

Saxidomus nuttalli

Protothaca staminea

clinocardium nuttali

olivella biplicata

Tresus nuttalli 
Table 4 (con't)

Sand clam

Macoma nasuta

Barnacle

Purple sea urchin

Balanus sp.

Stronaylocentrotus purpuratus

crab

Cancer Sp. 
CHAPTER III

\section{ETHNOGRAPHIC CONTEXT}

The Central California region contains a diversity of terrains and an extensive range of ecological habitats that have supported dynamic and distinctive human societies. over the years native populations became as diverse as the landscape they adapted to.

The first European expeditions exploring the San Francisco and Monterey Bay Areas encountered numexous groups of Indians and referred to them as the costanos, or coastal people. After the establishment of the Hispanic mission system, they were named after the missions to which they were assigned. Those tribes of Santa Cruz were known as the Cruzenos; at Santa clara they were Clarenos; at Monterey they were the Carmelenos. Later writers adopted the term Costanoan to describe the Indians from soledad west to Monterey, north to San Francisco, and east to Livermore. Merriam (1967: 371) interviewed several mission descendants from the Monterey Bay Area during the early 1900 s and referred to their language stock as Ohlonean. Many of the descendants of the Costanoan Mission Indians currentiy prefer to be referred to as the ohlone. Recently, some members of the ohlone community of santa clara county have adopted the name Muwekma, which means "people" in the recorded Clareno dialect (Kroeber 1910: 243). 
Information pertaining to the native lifeway is documented in the diaries and journals of the Spanish explorers and in mission records. These sources have provided insights to the native lifeway with implications regarding aboriginal settlement and subsistence orientations. These implications can be compared with the archaeological record.

The first land expedition to explore the central California coast was led by Gaspar de Portola in 1769. The diaries and journals of this expedition (Stanger and Brown 1969), and a subsequent one in 1774, the Palou-Fages exploration (Bolton 1926; 1930), describe Indians along the coast. With the establishment of Mission San Francisco de Asis in 1776, Mission Santa Clara de Tamien in 1777 and Mission Santa Cruz in 1791, Indians began to face the severe impacts of the mission system. Initially the goal of the spaniards was to develop the missions into agricultural centers where the Indians could be "civilized" and become laborers for the presidio and civilian pueblos. Ultimately it was hoped that the Indians would become citizens and as such, they would be used to colonize the interior. This interaction resulted in the decimation of the native population who were exposed to introduced European diseases and malnutrition while living at the missions (Cook 1976). This process and the effects have been described in great detail by numerous European travelers visiting the missions 
of the San Francisco and Monterey Bay Area (Beechey 1831; Kotzebue 1821; Lansdorff 1814; LaPerouse 1786; Vancouver 1801).

\section{Social organization}

It has been estimated that at the time of European contact the costanoan population consisted of some 10,000 individuals. The people were organized into at least 50 separate and autonomous political groups within eight language families (Levy 1978). Two of these are described within the study area. Linguistic boundaries were likely to have been very interwoven through marriage and exchange relations and any real attempt to draw absolute divisions between them would be difficult. The Ramaytush language has been attributed to the San Francisco Peninsula and the coast south to Ano Nuevo, while Awaswas has been ascribed to the Santa Cruz area (Levy 1978). Milliken (1983) argues that Levy's divisions were speculative, and while very real distinctions can be macie between the languages of the Costanoan cultural sphere, the recorded vocabularies do not provide sufficient territorial boundaries for them.

The term Awaswas was derived from a post mission period informant from Gilroy who told Merriam (1969: 372) that her people called the Indians living collectively at Mission Santa Cruz A-guas-was or A-kwas-was. Evidently, the language spoken at santa cruz was a different dialect from that of other Monterey Bay communities. Palou observed in 1774 that 
the Indians north of Santa Cruz and south of San Gregorio Creek spoke a language different from that of Monterey, while those north of San Gregorio Creek again spoke the Monterey dialect (Bolton 1926). The term Ramaytush is derived from the notes of J.P. Harrington (Levy 1978: 495) who recorded the term from an East Bay informant who said that it was what they calied the people of the peninsula. Milliken (1983: 78) states that the word "Ramay" meant "back of the neck" in the East Bay dialect and was possibly in reference to the north peninsula resembling the head of a body. Why Levy (1978) extended this linguistic category south along the coast to Ano Nuevo is not explained. In light of the early spanish explorers' observations and sketchy vocabularies recorded for the Santa Cruz coast, Ano Nuevo people were speaking a dialect totally distinct from the more northerly peninsula people. Some of the accounts (Crespi, in stanger and Brown 1969) go as far as to claim that the coastal folks were physically different as well. The socio-political unit characteristic of Central California, the tribelet, was defined by kroeber (1962) as being composed of one or more sedentary villages with a central village that functioned as an economic and religious center. They were occupied by extended families and varied in population between 50 and 300 people. People radiated out from the villages during various seasons of the year to scattered locations within the groups territory to hunt, 
fish, gather plants and other resources (Broadbent 1972 ; Heizer 1974; Levy 1978; Milliken 1983).

Mission register data indicate that six tribelet groups occupied the coast in the study area. These include the Chiquan of Half Moon Bay, the Cotegen of Purisima Creek, the oljon of San Gregorio Creek, the Quiroste of Ano Nuevo, the Cotoni of scott Creek and the Uypin of Santa Cruz. In addition to these, a small group or clan appears to have occupied the upper Pescadero Creek area, and they are referred to as the Guemelento, or Wemelente (Brown 1973: Milliken 1983). Map 4 identifies San Francisco Peninsula tribelet locations.

Many villages have been attributed to these tribelets and several of them were encountered by the first European explorers. Kroeber (1925: 465) notes that the ending $-n$ on Costanoan tribelet names means "people of" while -te is the locative term "place of."

Population estimates for the coast and interior valley/bay shore reveal that the valley region was more intensively occupied. Milliken (1983: 120) concluded that the population of the San Francisco Peninsula north of San Gregorio creek was "at least 1.25 to 1.5 persons per square mile, while the bayshore was 4.25 to 5.0 persons." Tribelet populations within coastal groups show considerable variability. Milliken estimates the combined population of the cotegen and Chiquan to be less than 80 persons while 


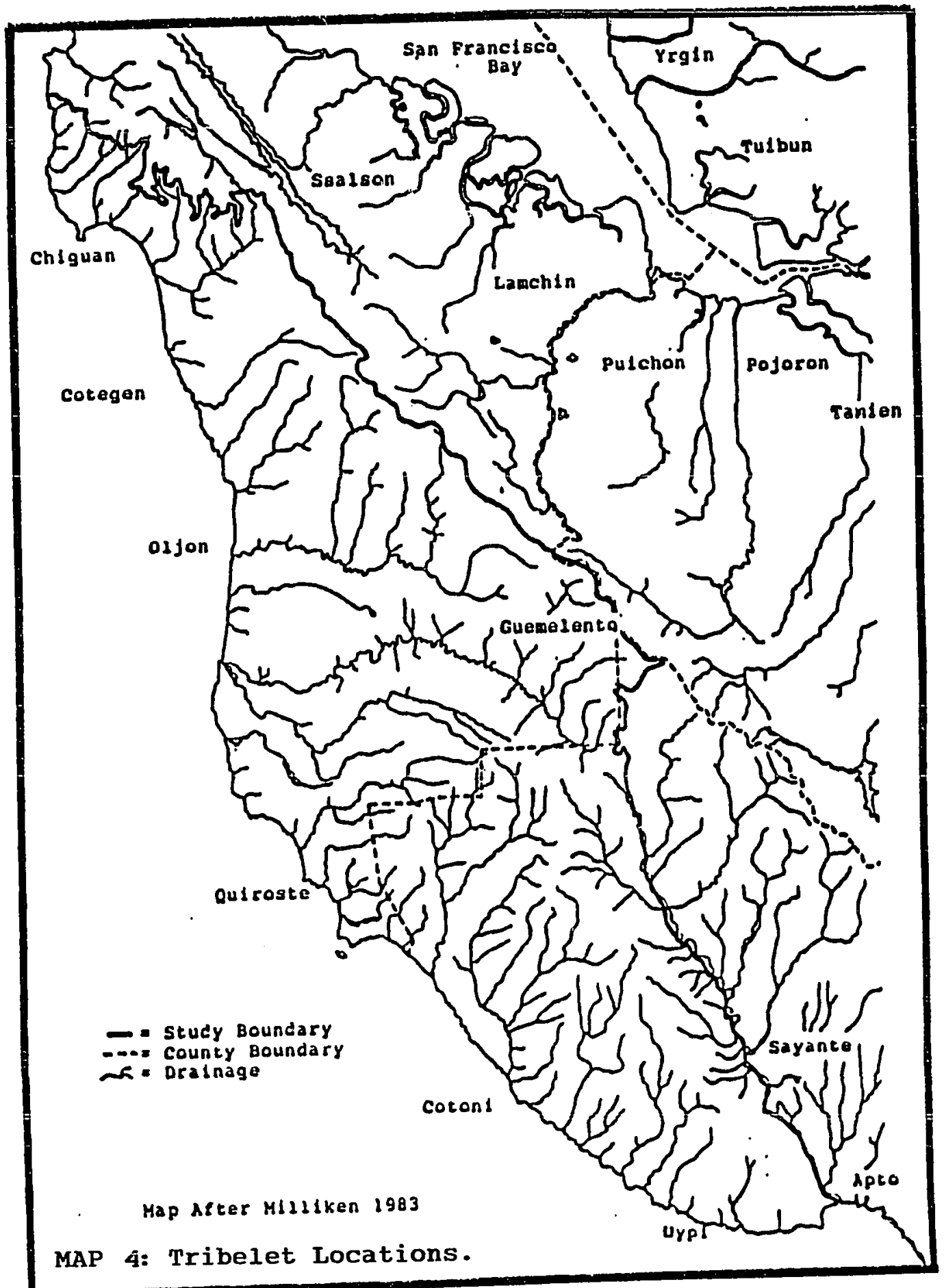


members of the Portola expedition record that they were invited to a village near Ano Nuevo, apparently at Whitehouse creek, which held some 200 people. In regards to this village, Crespi noted in his diary of 1769 that:

Here we stopped close to a large village of very well behaved heathens, who greeted us with loud cheers and rejoiced greatly at our coming. At this village there was a very large grass-roofed house, round like a half -orange, which by what we saw of it inside, could hold everyone in the whole village. Around the big house they had many little houses of split sticks set upright. (Crespi, in Stanger and Brown 1969: 88)

Miguel Costanso who was also with this expedition adas to this description by mentioning that the smaller houses were pyramidal shaped and constructed of pine splints (Costanso, in stanger and Brown, 1969: 87). Milliken (1983: 97) believes that this was the quiroste village called Mitine.

Members of the Rivera expedition of 1774 observed a cemetery near the same village, "in which was planted a high pole, this being the monument used by the heathen for the sepulchers of the chief men of the village" (Bolton 1926: 295) .

During the expedition of 1769 , Crespi described other details about the Indians of this village:

These heathens presented us with a great many large black and white-colored tamales: the white tamales were made of acorns, and they said the black-colored ones were very good too. They brought two or three bags of the wild tobacco they use, and our people took all they wanted of it. One old heathen man came up smoking upon a very large and well-carven Indian pipe made of hard stone. The Indians almost all carry tall red-colored 
staffs, some with many feathers: they presented four of these staffs to Sergeant Don Francisco ortega. (Crespi, in Stanger and Brown 1969: 88)

The ceremonial use of tobacco smoke by certain individuals within the community was also observed by Palou in 1774 near skyline Boulevard at the northern limit of the study area. Palou observed the following:

I again made them a present of beads, and a little tobacco, upon seeing which they named it with the same term as at Monterey, "sauans;" they set to smoking, and I noticed used the same ceremony of blowing the smoke upwards, saying some words with each puff: I could understand only one of them, which was "Esmen," meaning sun. I saw they had the same custom of the headman's smoking first and then giving the pipe to another, when it goes around among all of them. (Palou, in stanger and Brown 1969: 141-142)

Villages had leaders, or captains, who were subordinate to tribelet headmen. These headmen usually inherited the position patrilineally and acted as arbitrators in disputes, organizers of expeditions, and supervisors of the storage and distribution of food and goods (Broadbent 1972 ; Milliken 1983: $54-55)$.

\section{Seasonal Patterns}

The Costanoan organized their settlements in such a way as to optimize the retrieval and storage of resources. Sedentary occupation sites were places where food storage, processing, ceremonial events and procurement organization occurred. Temporary camp sites were places where collecting groups maintained themselves while exploiting specific resources as they became seasonally available. The Spanish accounts frequently described seasonal village abandonment. 
As the Portola expedition crossed scott creek on October 19, 1769, Crespi observed "vestiges of a village which had been deserted shortly before" (Crespi, in Stanger and Brown 1969). While traveling. with the Rivera expedition on December 10, 1774, Palou noted at scott creek that: good villages are not lacking in the neighborhood, although in the days march we have not seen a single heathen. At every step we have come upon paths well beaten by them which descend from the mountains to the shore. (Bolton 1926: 300)

on December 9, 1774, the Rivera party found that the large village described by Crespi near Ano Nuevo was abandoned. This was the case for most of the villages which the first expedition found.

At San Gregorio Creek, October 24, 1769, Crespi stated that there was a village near the shore, "where they have many grass houses at the place this valley opens onto the beach; but are now living in the valley." When Fray Palou traveling with the Rivera expedition arrived there he observed:
Near this arroyo I saw some little houses of the heathen, abandoned, and it was thought that the village which formerly was situated in this arroyo had been moved to the beach, where they also have a village, only about half a league distant. (Bolton 1926: 293) on October 27, 1769, along Purisima Creek the Portola party again observed abandoned houses, but were visited by Indians from Pilar Point where a large village was said to be. In summary, this group found within the vicinity of Half Moon Bay four inhabited villages and two vacant ones. When 
they returned in November, all of the coastal villages were occupied. The Rivera Expedition found all of the coastal villages abandoned during December, 1774, and Palou concluded, "The people of the villages which they found on the first expedition we thought must be in the mountains collecting acorns" (Bolton 1926: 296).

Intense procurement activities occurred during the fall months when vegetal food supplies had to be obtained and stored for the more difficult winter months. Acorns, late maturing grass seeds, buckeye nuts, berries, large and small game, shellfish and anadromous fish were among the staples retrieved.

Controlled burning was also an important fall activity. Burning of the vegetation increased seed production for human consumption and also improved the growth of browse that was eaten by a variety of animals (Lewis 1973). Burned grassland was frequently observed along the coast by the spanish explorers. The process of controlled burning was described as follows in 1774 near Monterey:

The heathen are wont to cause these fires because they have the bad habit, once harvesting their seeds, and not having any other animal to look after except their stomachs, set fire to the brush so that new weeds may grow to produce more seeds, also to catch rabbits that get overcome and confused by the smoke. (Clar 1959: 7)

Spot burning near villages concentrated game which was attracted to the new browse and reduced the hunting search time, whereas burning the upland meadow habitats prevented 
the intrusion of evergreen trees and improved the acorn harvest (Lewis 1973). Grass seeds and acorn foods were often mentioned in the early Spanish accounts. Along the San Mateo coast Palou wrote that the Indians presented them some very large baskets of thick porridge, "which appeared to be of acorns, and some large tamales of black seeds, which have not a bad taste" (Bolton 1926). In 1786 La Perousse noted that the Indians of Monierey roasted the grain before grinding it into flour, and stated that they did so in baskets with small burning coals "turning them with so much skill and rapidity as to make the grain swell and burst, without burning the baskets" (La Perousse 1786). During the winter, villagers congregated at the central villages, although resources away from the residences continued to be exploited.

As Dietz and Jackson (1981: 667) have noted, the end of fall harvests and the beginning of winter were probably marked by ceremony which, through trade and exchange among local tribelets, served to redistribute food goods and wealth items in a system that ensured that no one would go hungry during the winter and early spring months.

Currency was used to facilitate exchange. Kotzebue (1816) noted, "They work with great labour small white shells, which are used by them instead of money." Archaeological investigations have identified the shell as olivella biplicata (Bennyhoff and Hughes 1987). 
The collection of shellfish, hunting of small game, and fishing continued to be sources of food throughout the winter. These activities did rot necessarily require the organization of labor groups because populations subsisted largely on the resources stored at the central villages. costanoan hunters used the bow and arrow, lances, nets, snares and other tools to obtain game. The Rivera expedition observed Indians with throwing spears, or darts, in the san Mateo mountains and Palou reported:

They carried short lances having curved blades made of flint as well worked as if it had been iron, the only difference being these have no grain. (Palou, in stanger and Brown 1969: 141)

During the spring, active procurement of resources was required to supplement the depleted winter supplies. With the return of new vegetal growth, the people organized into task specific labor groups. Emphasis at this time was upon the gathering of bulbs and legumes as well as hunting the game that was attracted to the new shoots and sprouting grasses.

With the coming of summer, labor groups dispersed throughout the tribelet territory, extending procurement, and repeated their seasonal cycle. Archaeological Implications

The ethnohistoric record indicates that frequent residential shifts was a feature of the coastal lifeway and villages were located along the coastal terrace and in the 
uplands. Large and small village aggregates were observed; some of those situated along the coastal terrace exhibited organized cemeteries near the villages. At least seven distinct tribelet groups occupied the study area and individuals with distinctive status were reported.

Vegetal foods presented to the Spanish explorers included both acorn and hard seed products, therefore various types of milling tools can be expected to co-occur. The explorers also observed that the coastal Indians used darts or spears as well as the bow and arrow. This indicates that both small and large projectile points should be present in the same temporal contexts.

While the ethnographic record provides interesting insights into the local economy and adaptive patterns, it does not provide sufficient data with which to address the temporal development of the forager and collector model as proposed in chapter I. 
CHAPTER IV

EXCAVATION AND ANALYTICAL METHODS

This chapter describes the excavation methods and the analytical methods used to recover and describe the cultural elements collected from the sites. The field and lab methods discussed here pertain to sites scr-9, SCr-132, SMa-97, SMa238, SMa-218 and SMa-244. These are the sites tested for this project. Field and $1 \mathrm{ab}$ methods for other excavated sites within the study area have been reported by their respective authors and are described in the site reports. These sites include scr-7, scr-20, scr-35, scr-38, scr-39, SCr-40, SCr-93, SMa-22, SMa-110, SMa-115, SMa-118, SMa-139 and SMa-140. Artifacts reported by others have been described using the nomenclature applied to the sites excavated by this author.

As stated in Chapter I, the goal of this study is to compare archaeological data from other sites within the study area, generate additional comparable data from controlled excavations of sites within selected ecological zones and organize the results into a local chronological order. In this way, regional adaptive trends witinin the san Mateo and Santa cruz counties coast can be viewed within a temporal framework, and the forager/collector model proposed by Dietz and Jackson for the Monterey Bay area can be tested to determine its applicability to the region. To accomplish 
this, six archaeological sites were tested to provide a data base with which finds reported by others could be integrated. These sites were selected because of their locations and access.

Sites SMa-97, the Ano Nuevo Creek site, SMa-238 and SMa-218, the Ano Nuevo Reserve site, are within the coastal terrace zone. SCr-132, the scott creek site, is riverine. SMa-244, the Butano Ridge site, is within the ridge system zone. Finally, scr-9, the Bonny Doon site, is within the upland meadow zone.

The coastal sites examined in this study represent at least two kinds of use: temporary special-use sites and multi-use occupation sites. Archaeological locations identified by this author as being temporary special-use areas are characterized by shell, faunal remains, burned rock, and low tool diversity. These sites can be said to be task specific in nature. Multi-use sites occupied for longer durations contain shell, faunal remains, well defined activity features, wide tool diversity, and frequently human remains. The temporal distribution of task specific and multi-use sites and the economic mode reflected at these sites (terrestrial vs. marine orientations) will be described.

\section{Field Methods}

The following techniques were used at each of the sites excavated for this study: 
1) Establishment of a site datum and magnetic north south grid system.

2) Construction of a surface contour map.

3) Surface collection of selected artifacts.

4) Excavation of a series of units in $10 \mathrm{~cm}$. arbitrary levels, sifting soils through either $1 / 8$ " or $1 / 4$ " mesh screens.

5) Excavation of column units from the sidewalls of selected excavated units for quantifiable samples of shell and other small constituents.

6) Illustration of unit stratigraphic profiles.

7) Backfilling open units and restoring the original surface contour of the sites.

The number of units, their dimensions and ending depths will be presented in the site reports. Excavation volume was kept to a functional minimum to avoid unnecessary damage to the sites.

All midden constituents recovered from screened soils were collected except for unmodified shell. These elements include bone, chipped stone tools, debitage, cobble tools, olivella shell, beads, ornaments and asphaltum. Shell was collected from the column units measuring $25 \times 25 \mathrm{~cm}$, and were excavated in $10 \mathrm{~cm}$. levels. Soil from the column units was wet screened through $1 / 8^{\prime \prime}$ mesh and the remaining materials were bagged in the field for later sorting in the 
lab at San Jose State University. Level records and field notes were compiled for each excavated level. Analytical Methods and Artifact Types

This section describes artifact types represented in the study area and the analytical methods involved in the recording of recovered cultural elements. Upon returning to the lab from the field, artifacts were segregated into categories, cleaned and assigned catalog numbers. These categories include:

1) Faunal remains: bone and shell

2) Beads and other ornaments

3) Bone tools

4) Chipped stone tool and debitage material

5) Informal chipped stone toois

6) Chipped stone tool reduction stages and debitage

7) Projectile point types and forms

8) Obsidian sourcing and hydration

9) Cobble artifacts

10) Radiocarbon dating samples

A simple and very basic cataloging system was employed. Artifacts were given individual numbers corresponding to their lot. Catalog numbers start with a site number, excavation unit number, depth below surface number and an item number for the level. For example, a projectile point from Scr-9, unit 4, 130-140 cm. level, which has been listed in the catalog as the fourth item on the list for that 
level, would read 9-4-14-4. Bone from that level would be lumped together as 9-4-14-2 (all 312 pieces), and the debitage would be listed as 9-4-14-1 (all 127 pieces). The first level of any unit is $0-10 \mathrm{~cm}$. and is designated as level one.

\section{Faunal Remains-Bone}

Bone was separated into identifiable and unidentifiable pieces. Unidentifiable pieces were further separated into burned and unburned fragments, then weighed and counted. Identifiable pieces were segregated into mammal, bird and fish. These categories were further identified by order, genus and species level through the use of the faunal type collection at the Museum of Vertebrate zoology at San Jose State University. Bone elements were counted, weighed and listed in a faunal catalog by site, unit and level. The catalog lists the elements and their anatomical positions (i.e. right tibia, left femur, etc.).

Tables listing the results of the unit bone counts, weights and identified taxa by unit and level have been presented in Appendix A. Also, tables correlating taxa frequencies for sites as a whole have been constructed and they list species present and their percentages. These tables also list the ratio of terrestrial versus marine fauna at a given site, and have been presented in their respective site reports. Intersite comparisons of the amount of bone and frequency of taxa provided a basis for 
conclusions regarding site use and settlement/subsistence trends through time.

Generally, bone preservation at the sites was very good. This was probably due to the alkali rich shell, mixed in with the deposit, neutralizing the typically acidic soils.

\section{Faunal Elements-Shell}

Shell samples were obtained by excavating column units adjacent to selected excavation units. During the field work shell was frequently observed to be evenly distributed within the site boundaries. Moreover, site boundaries were usually delineated by the surface presence of shell. They are good markers of site area; however, the vertical distribution of shell volume varied. Considerable mixing of shell occurred in the soils as a result of rodent burrowing: nevertheless, levels of greatest shell densities usually corresponded to levels of greatest artifact yield.

In order to quantify the volume of shell at the sites without becoming overwhelmed by large samples, columns were uniformly excavated in units measuring $25 \times 25 \mathrm{~cm}$, using 10 cm. levels. These soils were dry screened at the site through 1/8" mesh, and all the remaining constituents were later wet screened at the lab through 1/8" mesh by level, and were then dried. Shell, bone and chipped stone were sorted from the sample and separated for further review. Tables documenting the results were then constructed and the 
total volume of shell per cubic meter presented. These tables have been presented in the site reports.

Shell recovered from the column samples was not segregated into quantifiable samples by species. However, observations were made regarding the general composition of the various shell types. The California mussel (Mytilus californianus) dominated virtually all of the sites. Only the Bean Hollow Beach site (SMa-118) contained a different single species in greater volume than the mussel. At this site the turban snail (Tequla funebralis) ranked higher than the mussel. Other species commonly found at the sites included the purple sea urchin (strongylocentrotus purpuratus), barnacle (Balanus sp.), limpet (스ea sp.), littleneck clam (Protothaca staminea), chiton (stenoplax heathiana), olive snail (Olivella biplicata), red abalone (Haliotis rufescens) and black abalone (Haliotis cracherodii). Interestingly, abalone shell was generally sparse, and the little that was observed was fragmented into small exfoliated pieces. This is unusual given the favorable environmental conditions of the study area. It is likely that abalone shells were exported out of the area to more distant groups of people to be made into pendants. Beads and other ornaments

olivella shell was used by the native people of Central California for the production of beads and ornaments. The snail itself was not a food resource and their presence 
within the sites relates to their value as the raw material for bead production. Because of this, olivella shells have been treated as an artifact class of their own. olivella shells are readily obtainable along this section of the coast, being most frequent in areas with gravel bottoms. This author has examined a great many of them washed up on the shore within the study area and observed that the spire portion was frequently missing, a result of their having been battered by wave action on the beaches. Olivella shells have often been found in large numbers in association with human burials at other central California sites, and these are in the form of cut and shaped beads, or as the whole shell with the spire modified for stringing on a cord or other object such as clothing or basketry.

The degree of spire modification was quantified after a classification system of attributes was developed by this author. This system separated olivella shells recovered from the excavated sites into six categories:

1) Spire Intact- Shells which have not been modified into beads or ornaments. The apex or spire is complete and closed. Their presence at sites is a result of their being collected as the raw material for future bead production or for export.

2) Spire Broken- spire is absent as a result of humans breaking off the end to create an aperture in order to string the shell as a bead or ornament. The missing spire 
can also be attributed to the shell rolling against rocks and gravel in the surf.

3) Spire Ground- The spire of the shell has been ground off through deliberate abrasion. The rim of the aperture appears flat and even, frequently being polished smooth, and the wear is easily seen with a magnification lens.

4) Basal Ground- Shells which have been deliberately ground at the base, leaving a flat edge around the circumference of the base. The spire has also been ground flat to create an aperture. These are often rererred to as barrel beads in the archaeological literature.

5) Modified Bead- This type consists of a variety of styles of beads, all of which have been cut and ground from the raw shell. Bennyhoff and Hughes (1987) have defined 17 categories of olivella beads along with sub-types, many of which have temporally diagnostic attributes. Using the Bennyhoff and Hughes nomenclature, specific bead types found at individual sites within the study area will be described in the site reports.

6) Fragments (detritus)- Pieces of olivella discarded during the process of manufacturing modified beads. These fragments can provide information about the intensity of bead manufacturing at a given site. This category was used in order to assess the potential presence of manufacturing remnants at the tested sites. 
All olivella pieces were weighed by categories and counted. Tables were constructed to describe their frequencies at a given site and are presented in Appendix $B$. The number of these types per cubic meter of soil was calculated for each site. The few modified beads recovered were treated as individual artifacts, while unmodified types were cataloged by level in lots.

This study was able to retrieve some beads and ornaments, although the presence of these artifacts at the tested sites was surprisingly rare. In addition to the olivella beads, Haliotis pendants and stone beads were recovered.

The Haliotis pendants were classed using the types defined by Gifford (1947). No one has yet published classifications for stone beads; however, those recovered during this project were compared to other sites reporting them. Descriptions of the stone beads will be presented in the site report for SMa-244, the Butano Ridge site, which was the only one in the study area which contained them.

All of the modified olivella and steatite beads were individually cataloged, measured in $\mathrm{mm}$. with dial calipers and weighed. All of these were illustrated and are included in the site reports.

Shell artifacts consisting of fish hooks, pendants and beads have been identified at sites within the study area. Pendants made from Haliotis shells were not commonly found 
nor were modified olivella shell beads. On the other hand, unmodified olivella shells were well represented and probably reflected the demand for them as exchange items to the interior regions. The use of olivella shell beads by prehistoric Central california populations and their temporally diagnostic morphological attributes make them useful markers of diachronic changes. Sites containing modified shell beads included scr-9, scr-20, scr-93, sMa-22 and SMa-218.

Using the bead terminology developed by Bennyhoff and Hughes (1987), modified beads from SCr-9 included three olivella saddles (type G6a, G6b and G6c). Although the number of beads recovered from SCr-9 was not great, 3,462 type 66 saddle beads recovered from Mnt-229 appear to be contemporaneous with those from SCr-9. Dietz et al. (1986: 396) noted that: "Class G, olivella saucers, is representative of the Middle Period in both the San Francisco Bay Area and the South Coast." Bennyhoff (1988: 50-51) identified eight of the G6 types at SCr-93 and states that they "probably represent the early phase of the Middle Period (200 B.C. to A.D. 100)." Radiocarbon dates from these three sites corroborate a temporal designation of occurrence for this bead type for the Middle Period. A single G6 bead from SMa-218 indicates that this bead type may be older than currently thought. 
scr-20 produced 219 class $M$ rectangular olivella beads. of these, 199 were found in direct association with burials 2 and 3. The radiocarbon date of $500 \pm 50$ years from burial 3 corresponds in time with a Late Period designation (Phase I) and all 219 beads were recovered in the upper $80 \mathrm{~cm}$. of the midden, as were the desert side-notched points.

33 olivella beads were recovered in association with human burials at SMa-22 (Loud 1915). These included types C2 Split Drilled and $F 2 b$ Round saddle. Bennyhoff and Hughes (1987) place the c2 type in the Transitional Early/Middle Period for the San Francisco Bay Area, and the F2b are noted as Middle Period time markers.

Coastal sites contain numerous unmodified olivella shells. These include shells with intact spires, broken spires, and ground spires. Although ground spires can be considered to be a form of modification, their random distribution with the other unmodified shells and their lack of grinding at the aperture end resulted in their being lumped with the others. The spire broken shells did not sort out by size at any of the sites and consisted of types Ala, $A I b$ and Alc. The spire ground type was of class B.

Late Period sites contained the greatest numbers of these. shells with SMa-244 producing 54 specimen and SMa-97 produced 87 specimens per cubic meter of site. Middle Period site scr-9 produced only 5 and scr-132 just 3 specimen per cubic meter of site. Middle Period sites reflect a greater 
number and variety of obsidian projectile point types and the lack of raw olivella shells at Middle Period coastal sites may be a result of their export to exchange for obsidian tools or because of a lack of demand for them at that time. Perhaps the development of beads as an economic mode developed to greater levels during the Late Period. Sices around the Monterey Bay Area and Santa Clara valley seem to contain greater numbers of modified beads and Haliotis pendants, possibly a reflection of their strategic locations in the direction of intensive exchange networks. Bone Tools

Bone artifacts were recovered at every site and consisted of pieces which had been modified for use as tools. Each artifact was examined for evidence of polishing, abrasion or burning, the latter was a process that strengthened the tool. Bone artifacts were not included in the total bone counts of the faunal inventories. The most common bone tools encountered were awls. Awls for this study were described by the appearance of the working end, which was either pointed, blunt, spatulate or some other descriptive form. Pointed awls were typically sharpened to a needle-like tip and frequently appeared to have been made from a bone splinter. Blunt awls were usually rounded in section view with a rounded tapering blunt tip. Antler tips also reflected this attribute. Spatulate awls had wide rounded tips, and were somewhat flat in cross view. 
These were often made from split bone which had been ground to the desired shape.

None of the dated sites contained any distinctive type of awl and given this studies' findings, nothing can be said about temporal significance within this artifact class.

A single fragment of a serrate tool was recovered from scr-9. These tools are widely distributed throughout central California and have a strong affinity with Middle Period sites (Bickel 1981: 136). Several bone "hair pins" or "knives" as defined by Gifford (1940) recovered from SMa-22 were attributed by Beardsley (1954) as being representative of the Middle Horizon.

other types of bone tools besides awls were recovered and rive been described in the site reports and in Appendix c. Many of these were illustrated and all were weighed. Measurements included maximum length, maximum width, and maximum thickness. To measure these artifacts, specimens were oriented so that the axial length provided the maximum length measurement. Usually these artifacts were incomplete, and sometimes the width readings were greater than the length. Measurements of broken ends were denoted in the tables by the symbol + . In some cases more measurements were taken, such as maximum thickness at base and maximum thickness at the tip instead of just one thickness reading. This was done mostly for specimens which taper and vary in 
dimension significantly from one end to another. Bone tools were individually cataloged.

Chipped stone Tool and Debitage Materials

Projectile points, point preforms and bifacially chipped blades were defined as formal tools. Scrapers, flake tools, choppers, and borers/drills were defined as informal tools.

The raw materials from which the chipped stone tools and debitage were made included Monterey and Franciscan cherts, jasper, quartzite, chalcedony and obsidian. Many projectile point styles have temporal significance and sometimes they can be used to distinguish subsistence techniques through time (Weissner 1983; White et al. 1982).

Along the coast Monterey chert was the most readily available material suitable for formal and informal tools. Because Monterey chert is difficult to chip with any great degree of control, the local native people learned to heat the stone and improve the knapping qualities. Parsons (1987: 28) has tested over 30,000 pieces of Monterey chert from archaeological contexts within San Mateo and Santa Cruz Counties, and he discovered that $83 \%$ exhibited evidence of heat treatment. The amount of work involved in heating chert probably caused exotic materials such as obsidian to be highly esteemed.

Franciscan cherts are common to alluvial terraces and stream beds east of the San Andreas fault line. Native 
people around the San Francisco Bay and Santa clara valley had greater access to this variety of chert. The presence of this chert at coastal sites is a result of either direct procurement or from trade relations. The ratio of Franciscan to Monterey chert debitage and chipped stone tools from sites tested for this study was used in part to define the relationships between coastal and interior peoples.

Jasper and quartzite can be obtained along the coast, usually in the form of rounded cobbles. Jasper artifacts recovered from the excavations were red to tan in color. sometimes it is difficult to distinguish the difference between jasper and Franciscan chert because Franciscan cherts are multi-colored and include colors similar to jasper. Quartzite did not appear to have been used in the production of formal tools but was a favored material for cobble choppers and handstone tools.

Obsidian was brought to the coast through exchange with interior people. Researchers in the Monterey Bay Area have been attempting to correlate obsidian hydration rim readings to calender years and isolate temporal components within stratified sites (Dietz, Hildebrandt and Jones, 1986: 134137). Obsidian specimens of similar age from the same sources at a given site should have readings that are alike. Therefore, stratigraphic relationships within the sites can be monitored. Obsidian pieces from coastal sites are almost always complete or fragmented formal tools, and the only obsidian debitage recovered reflected formal tool edge 
maintenance (i.e. pressure and thinning flakes). Cores ô obsidian have not been observed in eitner private collections or from the archaeological sites. This indicates that formal tools rather than the raw material was imported. obsidian present in the study area originated from both the clear Lake region of Northern California and from east of the Sierra Nevada Ranges. Most of the obsidian artifacts recovered from the sites excavated for this study were sourced and the hydration measured as were specimens from several sites excavated prior to this project. The results of the obsidian studies are presented in the site reports. Informal Tools

Informal tools identified for this project consisted of implements used for a variety of tasks such as cutting, scraping, etching or drilling. The amount of shaping required to make these kinds of tools was minimal.

Edge wear analysis of the chipped stone artifacts was not attempted for this study. The informal tools are described with formal tools in Appendix D. Summaries of these artifacts have been presented in the site reports.

Flake Tools: Flake tools, or utilized flakes, were made from primary or thinning flakes which exhibited one or more edges with visible wear from use. The wear caused the edges to appear crushed, polished or chipped. Sometimes a section of a flake edge was chipped unifacially, or slightly 
bifacially by applied pressure to sharpen and prepare it for use.

Borers or Drills: Borers, used for drilling objects by applying a projected edge to a surface and using a twisting motion, were recovered. These tools were often constructed from primary or thinning flakes. The drill bits on many of the borers were chipped by applied pressure to create a desired dimension. None of the ones recovered appeared to have been hafted, and the bits usually exhibited polish and crushing around the bits circumference. These tools were typically triangular in cross section.

Scrapers: Scrapers were generally formed from chunky polyhedral shaped cores and primary flakes. Many were made from exhausted cores which had been split to create a smooth ventral surface, terminating in edges with steep angles. These were usually dome shaped in cross section (planoconvex) -

Chipped stone Tool Reduction stages and Debitage

Coastal sites normally contained large quantities of debitage, which resulted from the construction and maintenance of stone tools. Sites throughout the study area revealed an intensive reliance on the available Monterey chert source at Point Ano Nuevo. The various stages involved in the construction of formal tools was readily visible at sites located near there, especially at SMa-218. Sites without completed points frequently contained broken bifaces 
and cores which, through the use of the staged reduction scheme defined below, could be compared to other sites containing diagnostic types.

SMa-218 produced the largest assemblage of chipped stone artifacts and debitage, and provided enough material from which a model of chipped stone tool reduction could be constructed.

Cooley (1984) and Parsons (1987) have defined biface reduction and point construction observed at coastal sites in terms of stages. Cooley presented a background of the use of the staged method (1984: 6-8) for his analysis of a coastal site in San Luis obispo County. Cooley described several intuitive attributes which defined the finish of the specimen. These were as follows:

The first criterion was overall biface symmetry, i.e., degree of achievement of a generally elliptical outline, longitudinal section and cross section. The second criterion consisted of the characteristics of flake removal along the lateral margins or edges, i.e., the degree of edge sinuousness, size of flake scars, and type of flaking (percussion or pressure). The third was relative maximum thickness and the fourth was the width/thickness ratio. (Cooley 1984: 8)

Parsons (1987) used a five stage sequence. His stages were applied to this study, but were slightly modified. Before further defining the stages of formal tool manufacturing trajectories, it should be noted that this sequence applied to tools produced from cores which were reduced so that the core eventually became the final 
product. The Ano Nuevo longstemmed points are a good example of this technology. In contrast, some point types were produced from primary flakes and other debitage resulting from core reduction. The use of this latter technology would apply to many of the notched points, particularly the desert side-notched, and the obsidian varieties. The stages proposed here do not apply to them. In the case of small projectile points, which are often the end product of debitage reduction trajectories, they were given the same stage value as the finished products of the core/tool reduction technology in order to distinguish them from point blanks and preforms.

The need to use the staged approach as proposed by Parsons came about during the course of reviewing the private collections and tools recovered from the excavated sites. Certain similar characteristics regarding the degree of completion of these artifacts began to be apparent. The sequence used in this study was based on intuitive classifications, and it should be noted that one stage generally graded into the next, and absolute distinctions between the gradation were not possible. Despite this potential gray area, a relative value was attributed to the tools. These values consist of the following stages:
1) Cores
2) Cores/Bifaces
3) Bifaces 


\section{4) Point Preforms}

5) Finished Points

The five stages used were the result of a replicative experiment conducted on tabular pieces of Monterey chert which were heat treated during controlled experiments (Parsons 1987: 29). Biface and projectile point replicas were made during this experiment which were identical to those recovered from the excavations. Even the failed attempts, where the biface replicas broke during construction, were identical to broken ones from the sites. Further elaboration of the stage definitions and the range of debitage resulting from them follows below.

Stage 1: The first stage consisted of making the raw material into a core. Both cooley and Parsons described this stage as including cores which exhibited one or more large flakes detached as a result of hard hammer percussion, usually unifacially. Many cores retain the weathered cortex, except where flakes have been removed. The size of the cores ranged from very large to small. This stage produced cortical flake debitage and some angular shatter as a byproduct. Cortical flakes were identified by the retention of weathered cortex on the dorsal surfaces.

Stage 2: The second stage was composed of core/bifaces with most of the cortex removed bifacially by hard hammer percussion. A generally elliptical form begins to take shape. The blanks were heavy and thick in cross section. Cortical and primary flakes were produced as debitage. 
Primary flakes frequently retained cortex on the platforms and exhibited flake scars on dorsal surfaces. Shapes and sizes of primary flakes varied a great deal and were either lenticular or wedge shaped in cross section. Large amounts of angular shatter were produced as a result of this stage. stage 3: The third stage is comprised of bifaces which had been further reduced by both hard and soft hammer percussion, and had well defined symmetrical outlines. These tools were often used as cutting implements because the bifacially worked lateral edges were less sinuous than the previous stage and retained useful edge angles. Cortex was usually completely removed at this stage, although some specimens retained small areas of it. Artifacts at this stage were referred to as bifaces. Primary and thinning flakes were produced as debitage during their construction as well as some smaller pieces of angular shatter. Thinning flakes were characterized by thin flakes with multiple flake scars on the dorsal surface, a bulb of percussion from soft hammer impact, and a typically lenticular cross section. Stage three artifacts fell into the formal tool category. Stage 4: Stage four specimens were classed as projectile point preforms. These pieces were produced by the reduction of stage three bifaces through the use of soft hammer percussion and pressure applied directly to lateral edges. At this stage the tool had a clearly defined shape and may function as a projectile or cutting tool (which was 
often the case for leaf shaped points). Sizes varied according to the type of point being formed. Debitage produced at this stage consisted of thinning and pressure flakes. Pressure flakes were very small and were usually lost through $1 / 4$ " mesh screens, but retained in the 1/8" mesh screens. These flakes reflected the process of sharpening the lateral edges. Very few shatter flakes were created at this stage.

stage 5: stage five tools consisted of projectile points. These occurred in several types of styles which served a variety of functions through time. Spear, dart and arrow points were made from the preforms with some additional soft hammer percussion and a lot of pressure flaking. Lateral edges were sharpened and notches, serrations and distinctive basal attributes were completed at this stage. Debitage produced during this process was mostly pressure flakes and very small thinning flakes.

Chipped stone tools reviewed during this project are described in Appendix D, and the stages of production were included as well. Debitage from selected units was tabulated using the definitions described above and a summary of types is presented in Table 5. Debitage was organized into these broad classes so that trends in lithic production and the intensity of site use could be monitored. The results of these quantified debitage samples have been compiled into tables listing the counts and weights of debitage and the 
formal and informal tools from units chosen as being representative of the sites. In this way results were compared ard observations were formulated.

\section{Table 5: Debitage Types}

Primary Reduction

1) Exhausted cores

2) Cortical flakes

3) Primary flakes
Secondary Reduction

4) Thinning flakes

5) Pressure flakes
Debris

6) Shatter

Bipolar reduction forms a distinctive class of cores and debitage which have been noted at other sites around the Monterey Bay Area (Dietz, Hildebrandt and Jones 1986; Leventhal et al. 1989). This reduction process involved the reduction of cores by placing the cobble on an anvil and striking it with a hard hammer, leaving two bulbs of percussion at opposite ends. Crabtree (1972: 42) has noted that the cone of percussion on one end is often shattered and severed, leaving one distinctly visible remnant bulb. This technique was particularly useful at locations where larger cobbles were harder to obtain. The use of this technique was observed at some of the excavated sites in the study area, principally those south of scott Creek, but was not recorded in greater detail.

In summary, five stages of formal tool construction were defined for this study. The frequencies of these stages reflected in the chipped stone tool assemblages from the 
excavated sites were tabulated and provided information about site use. Debitage was also seriated into populations reflecting primary reduction (cores, cortical flakes and primary flakes), and secondary reduction (thinning flakes and pressure flakes). Another category, shatter pieces, occurred throughout the reduction sequences and provided little information of value to this study. However, it should be mentioned that most of the borers (or drills) from the excavated sites were produced from larger shatter pieces which may have been intentionally knapped to serve specific functions. Whether these pieces were intentionally formed or not has little bearing on the immediate goals of this study and were not pursued further.

The frequencies of primary versus secondary debitage elements provided information regarding the intensity of onsite tool construction and curated tools. Also, the comparisons added to interpretations regarding site use. Tables describing the results of these studies are presented in the site reports.

Projectile Point Types and Forms

Projectile points, point preforms and bifaces were measured and weighed, and many were illustrated. This class of artifacts was documented from both the excavation of sites and from private collections.

Points recovered from dated archaeological deposits provided types with which those from private collections 
could be compared. The largest numbers of points in private collections originated from Point Ano Nuevo (sites SMa-218, SMa-97 and others), sand Hill Bluff (SCr-7), and from wilder Ranch (SCr-38, SCr-39 and $\mathrm{SCr}-40)$. Artifacts from these sites were made available for review and are described in Appendix $D$ and in the site reports. Most of them were illustrated and have been included in the site reports. Incomplete measurements taken from broken points were denoted by the symbol + .

Points were measured using Thomas' (1970) key of defined attributes. Points were aligned on a polar coordinate graph so that the tip was oriented at 180 degrees and the bases at 0 degrees. The maximum length was measured along the axis centered through the middle of the specimen. Maximum width was measured from the lateral edges while maximum thickness was measured from the thickest cross section of the specimen. Additional measurements were made based on the morphological attributes of the artifact. These include basal depth, basal width, and neck width (taken from the position where the blade junctions with the stem in the case of contracting stem types or from the narrowest distance between notches on notched points). Weights are in grams.

Point styles were described by their physical appearance and, in the case of better known types, by the names attributed to them from other published sites. Figure 
1 outlines the various styles and terms used to describe points. Points were made from either bifacially reduced cores or from flakes detached from cores which were then further reduced to the final product.

Projectile points recovered from the dated sites included a wide variety of styles and materials, with the locally available Monterey chert accounting for the majority of the material used to produce them. Several factors may account for the wide variety of types discussed here, including the possibility that different point forms were used to hunt the diversity of fauna which was present in a wide range of habitats. Extensive trade relations with interior groups resulted in forms common to other areas arriving in the study area. Also, bow and arrow technology required a different kind of point than atlatl darts and spears.

only two distinctive projectile point types have been adequately defined for the central California coast. These include the Rossi square-stemmed and the Ano Nuevo longstemmed types (Jones and Hylkema 1988). Other point types have been defined outside the coastal region and some have temporal significance. These, and the two defined by Jones and Hylkema, are presented in Figure 2.

While a variety of points have been recorded within the study area, several basic categories are presented here. These include the desert side-notched, stockton serrated, 
leaf shaped lanceolate, Ano Nuevo long-stemmed, Rossi square-stemmed, notched (corner and side notched), and barbed contracting stemmed.

Desert side-notched: The desert side-notched type has been found at sCr-7 and scr-20. This type is a small triangular shaped point with either a flat or concave base. Notches are typically circular in appearance with narrow openings along the blade edges. This type is associated with a bow and arrow technology and is widely distributed throughout central California and the Great Basin. This point type is considered to be a very good Late Period time marker and is thought to occur post 1500 A.D. (Baumhoff and Byrne 1959; Bickel 1981; Cartier 1980; Jones 1984; Olsen and Payen 1968, 1983; Moratto 1971; Pritchard 1970; Roop 1976; Wallace 1970).

All of the desert side-notched points from sCr-20 were found in the upper levels of the site. The single specimen from SCr-7 was collected from the site surface. All of the desert side-notched points from these two sites were made from Monterey chert.

stockton serrated: The stockton serrated type has been found at $\mathrm{SCr}-20$ and SMa-244. These points are lanceolate shaped, have a convex base and several deep notches or serrations along the blade length from the base to nearly the tip. Only obsidian points have been recovered and they do not appear to have been made from any other material. 


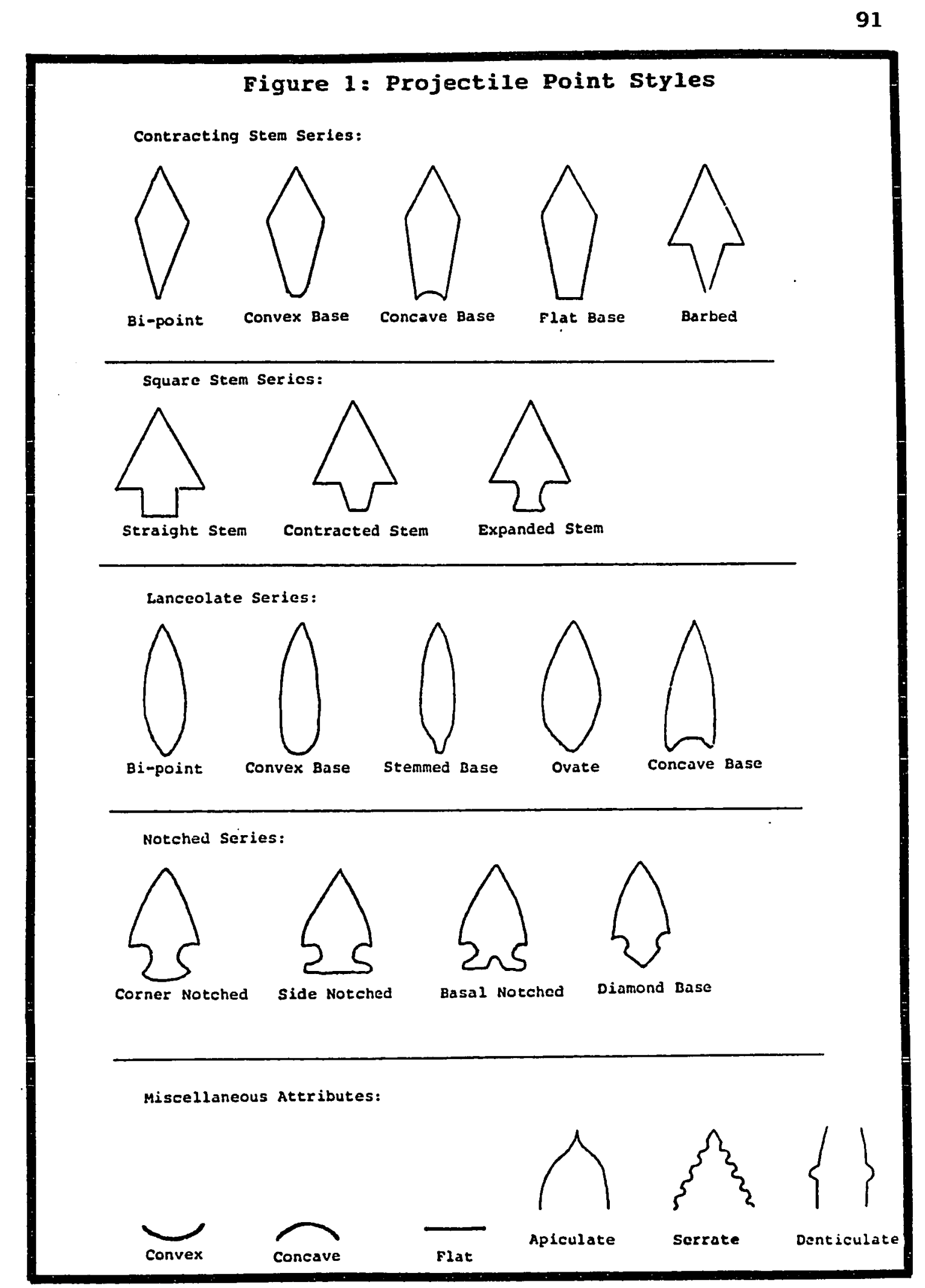


These points are also good Late Period time markers and have been found at numerous sites within Central California (Bickel 1981; Coberly 1973; Fredrickson 1968; Hildebrandt 1983; Lillard, Heizer and Fenenga 1939; Moratto 1971; Olsen and Payen 1968; Roop 1976; Schenk and Dawson 1929).

six stockton serrated points from SCr-20 and SMa-244 provided obsidian hydration rim readings between 1.2 and 1.7 microns and were all from the Napa Valley obsidian source. one additional specimen from sMa-244 yielded variable rim hydration readings but brings the total of this type recovered in the study area to seven. This point type probably related to a bow and arrow technology.

Obsidian lanceolates: Several willow-leaf shaped obsidian lanceolate points were recovered from sites $\mathrm{sCr}-7$, SCr-20 and sMa-97. These points are typically long bladed with the maximum width position close to the base, which is convex shaped and sometimes had a barely perceptible stem. Their temporal distribution is not well established but those recovered from SCr-20 and SMa-97 provided obsidian hydration rim readings for eight specimens which ranged from 1.5 to 2.7 microns, all of which were from the Napa valley obsidian source.

These points are widely distributed throughout the san Francisco Bay Area (Bickel 1981; Coberly 1973; Davis and Treganza 1959; Heizer 1958; Roop 1976; Schenk 1926; WaIlace and Lathrap 1975). These points may mark a transitional 
period between the Middle and Late Horizon. An especially large specimen from SMa-97 may have related more towards wealth and status than having functioned as a hafted point.

Ano Nuevo long-stemmed: The Ano Nuevo Long-stemmed projectile point type is of the contracting stem series and is characterized by a long tapering stem with the maximum width position greater than 45\%. Most extend more than 50 $\mathrm{mm}$. in length and many exhibited an apiculate tip. Bases were either convex or pointed. Some pieces had asphaltum stains along the base which solves the problem of differentiating the tip from the base. This type of projectile point was first identified by Gerow (1968) and several were found in direct association with a human burial at $\mathrm{SMa}-77$ which produced a radiocarbon date of $2950 \pm 350$ B.P. This point type has been identified at numerous sites throughout the Monterey and San Francisco Bay regions and a complete description of them has been presented by Jones and Hylkema (1988). The name is derived from Ano Nuevo state Reserve where sites there have produced hundreds of them, many of which are in the hands of private collectors. SMa218 was identified as having produced the large number presently contained in the Harris collection, and the site was tested in order to provide further resolution to the type. A single c-14 date of $2880 \pm 75$ B.P. matches the one for sMa-77. The stages of long-stem construction evident at SMa-218 have led to the observation of their construction at 
other sites where completed points were lacking. Figure 3 illustrates the five stages of Ano Nuevo long-stemmed point construction present at SMa-218. These points are frequently reworked resulting in considerable variations in length measurements. The degree of reworking visible on many of these points attests to their utility.

Sites in the study area which have the Iong-stemmed type include scr-7, scr-9, scr-20, scr-35, scr-38, scr-39, SCr-40, SCr-93, SCr-132, SMa-22, SMa-97, and SMa-218. Outside the study area they have been reported at sMa-77, scl-1, Scl-178, Mnt-101, Mnt-185, Mnt-229, and Mnt-391, just to name a few (Bourdeau 1986; Cartier 1979, 1984; Dietz 1987; Dietz and Jackson 1981; Dietz et al. 1986; Gerow 1968; Gifford and Marshall 1979; Jones and Hylkema 1988; Moratto 1971; Phebus 1973; Pohorecky 1976; Pritchard 1968; Roop 1976). These points are considered to be good Middle Period time markers persisting over a long period. They are prevalent in coastal sites dating from 2,800 to 1,000 years B.P., and have been noted in sites dating between 2,800 and 4,000 years B.P. Obsidian specimens from sCr-9 and sCr-20 include Napa Valley pieces with rim hydration readings ranging from 3.1 and 5.2, and one from Casa Diablo reading 5.6 microns

Rossi square-stemmed: The Rossi square-stemmed type is typically large, with an excurvate to triangular shaped blade and short stems which are square to slightly 
1 1 留

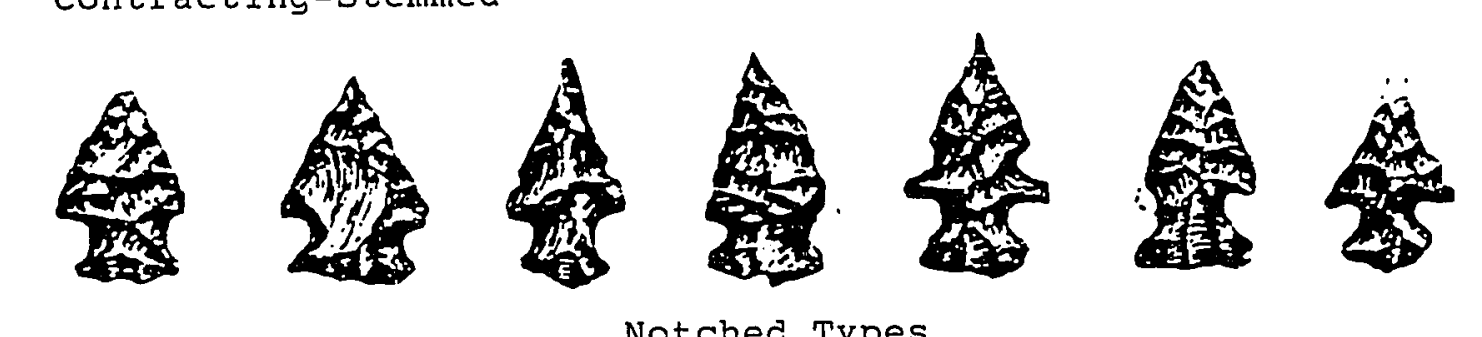
4 
expanding. Bases are usually flat although some have rounded, partly convex shapes. Extensive reworking of the blade is not unusual which creates a range of lengths. This type has been extensively described by Jones and Hylkema (1988) and often occurs at sites with the Ano Nuevo longstemmed type. These points derive their name from the Rossi site, Mnt-387 where several were recovered. Square-stemmed points found with Human burials at Mnt-391 dated at 3,270 \pm 90 and $3,620 \pm 90$ years B.P. compare well with radiocarbon dates from Mnt-387 of $3,200 \pm 130,3,800 \pm 240$ and 4,080 \pm 100 years B.P.

within the study area they have been recorded at sites scr-7, scr-9, scr-20, scr-38, scr-39, scr-40, scr-93 and scr-132. They are widely distributed outside of the study area and have been found at SMa-125, SMa-160, Mnt-101, Mnt116, Mnt-229, Mnt-238, Mnt-254, Mnt-387, Mnt-391, Ala-307, Mer-S94 and SBn-156 (Bourdeau 1986; Cartier 1984; Dietz 1987 ; Dietz and Jackson 1981; Dietz et al. 1986; Gibson et al. 1976; Hylkema 1989; Jones et al. 1987; Jones and Hylkema 1988; Olsen and Payen 1969; Roop 1976; Uhle 1907; Wallace and Lathrap 1975). Like the Ano Nuevo long-stemmed type, the square-stemmed points are found at sites ranging over a long period of time from 4,000 to 1,000 years B.P. These points are good Middle Period time markers. Only one obsidian specimen has been subjected to obsidian hydration analysis 
and is from scr-9. It is from the Bodie Hills source with a rim reading of 3.8 microns.

Barbed contracting-stemmed: Barbed or tanged contracting stemmed points have been recovered from a number of sites in the Monterey Bay Area but are considerably more common at sites within the South Coastal region. This form is distinct from the Ano Nuevo long-stemmed type in that it has tangs, or low distal shoulder angles. Jones (1984) has tabulated a range of measurements for this type which he further sub-divided into types II, IIIA and IIIB. Given the broad areal distribution of this type of point and the lack of adequate seriational data, it is not surprising to find that they have been identified at sites spanning all of the temporal horizons discussed in this thesis.

Some of the sites containing barbed contracting-stemmed points include Mnt-88, Mnt-101, Mnt-185, Mnt-114, Mnt-115, Mnt-116, Mnt-229, Mnt-282, Mnt-323 and Mnt-387. Within the study area they have been identified at sCr-7, sCr-20, scr38, SCr-40, and SMa-97 (Cartier 1979; Dietz and Jackson 1981; Dietz et al. 1986; Howard 1976; Jones 1984; Pohorecky 1976; Pritchard 1984; Roop 1976; Swernoff 1982). Interior sites with this point style span the Central California region from the San Francisco Bay Area, the South Coastal Area and the San Joaquin Valley area (Hoover and Sawyer 1977; Heizer 1949; Hylkema 1989; Olsen and Payen 1969; Schenk 1926; Wallace and Lathrap 1975). 

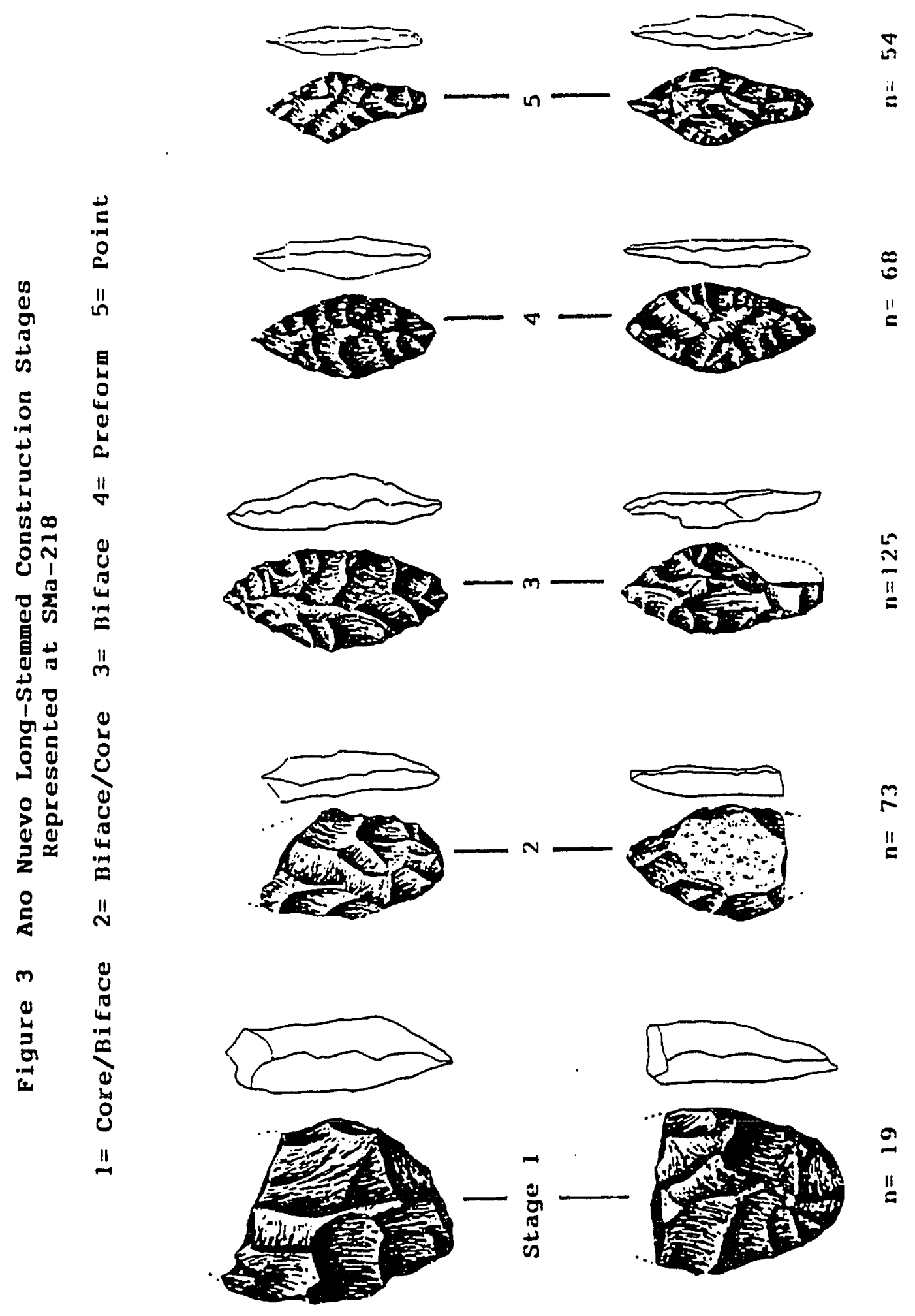
Notched points (side and corner): Notched points, excluding the desert side-notched and stockton serrated types, encompass a wide range of forms which probably seriate into distinctive types but, because of their tendency to grade from one form to another, have been lumped together in this study. Notched points include side and corner notched varieties with bases that range from slightly concave to flat to convex. Jones (Dietz et al. 1986: 141146) has provided a discussion of this point class and noted that a distinction between older wide side-notched types defined for the South Coastal region (Jones 1984) and more recent narrow side-notched forms "does not appear to be valid for the Monterey Bay Area." Also, when neck width measurements used to describe these points were applied to those from the Monterey Bay and Santa Clara Valley area, deceptive results occurred as variations in side-notched points probably represented local variations in forms. The corner-notched points described for this project are included under the general term of notched points and, because of their co-occurrence with side-notched types and the grading of one form into another, the focus for this study was on the use of the notching technology.

Examples of the notched forms are present at Mnt-88, Mnt-101, Mnt-107, Mnt-229, Mnt-391, SCl-178, and SMa-77. within the study area they have been found at scr-7, sCr-9, SCr-20, SCr-38, SCr-93 and SMa-22 (Bourdeau 1986; Cartier 
1984; Dietz and Jackson 1981; Dietz et al. 1986; Gerow with Force 1968; Howard 1974, 1976; Hildebrandt 1983; Jones 1984; Phebus 1973; Pritchard 1984; Roop 1976). Jones (Dietz et al. 1986: 146) observed that the points which he had classed as small side-notched points occur between circa 3,000 and 1,500 years B.P. which places them in the Middle Period. Jones noted that this style of point did not appear to occur in late contexts, which may be related to their postulated use as atlatl dart tips. Only two obsidian corner notched specimens have been sourced and hydrated. Both were from the Casa Diablo obsidian source with the one from scr-9 providing a rim reading of 2.6 microns and the other from SCr-20 with a reading of 1.9 microns.

The Kvenild and Ward collections from SCr-7, the Sand Hill Bluff site, contained many notched points. These, and others from selected sites within the Monterey Bay Area were measured and are presented in Table 6. Proximal and distal shoulder angles were not measured because of their tendency to grade from corner to side notched forms, and this author feels that this morphological attribute would not assist in distinguishing types. 
Table 6: Notched Point Measurements from Selected Monterey Bay Area Sites

$\begin{array}{ll}\text { SCr-7 } & (\mathrm{N}=62) \\ \text { SCr-9 } & (\mathrm{N}=6) \\ \text { SCr-20 } & (\mathrm{N}=6) \\ \text { SCr-38 } & (\mathrm{N}=1) \\ \text { SCr-40 } & (\mathrm{N}=1) \\ \mathrm{Mnt}-229 & (\mathrm{~N}=5)\end{array}$

\begin{tabular}{lrrrr} 
& Range & Average & Stand.Dev. & N \\
ML- $14.1-54.0$ & 34.5 & 4.8 & 52 \\
MW- $13.3-29.0$ & 21.0 & 2.9 & 73 \\
MT- $4.7-11.0$ & 7.5 & 1.4 & 74 \\
NW- $7.5-19.5$ & 13.4 & 1.9 & 75 \\
BW- $11.0-26.0$ & 15.5 & 2.2 & 74 \\
WT- $1.9-14.0$ & 4.8 & 1.6 & 44 \\
\hline
\end{tabular}

Many other point forms have been recovered within the study area which are probably temporally diagnostic but because of their limited occurrences they are not discussed in greater detail here.

\section{Obsidian Samples}

Obsidian present at coastal sites was in the form of formal tools and as debitage derived from tool maintenance. Dietz, Hildebrandt and Jones (1986: 21) have noted that sites within the Monterey Bay Area south of Santa Cruz contained a proportionally greater number of pieces from Sierran sources while sites of the northern coastal area were dominated by coast Range sources. They also state that there is as yet an insufficient sample of temporally discrete collections of artifactual obsidian from any site in the Monterey Bay area with which to ascertain whether 
there were fluctuations in the obsidian distributions over time.

Bennyhoff and Hughes (1987) have proposed that the Monterey Bay Area was one of four major bead source areas and Dietz et al. (1986: 22) have pointed out that this leads "to the reciprocal demonstration that this production capability was translated into a form of wealth by which such exotica as obsidian could be readily obtained." Further, they note that there is a parallel relationship between the scant obsidian appearing on the coast, and the limited number of shell beads found at sites east of the sierra Nevada ranges. The potential to use obsidian pieces to identify exchange systems through time is great; therefore obsidian from this study was sourced and hydrated. The XRF sourcing and visual sourcing as well as the hydration readings have been presented in the obsidian inventory tables in the site reports.

Obsidian results are from sites sCr-9, scr-20, scr-93, SCr-132, SMa-97, SMa-139, SMa-218 and SMa-244. A total of 147 pieces were sourced and 137 were subjected to obsidian hydration analysis.

\section{Cobble Artifacts}

This category of artifacts derive from waterworn cobbles which had been used in their raw form, or had been shaped to perform a specific function. This category of artifacts included the following varieties: 
1) Milling slab

2) Handstone

3) Mortar

4) Pestle

5) Charmstone/Plummet

6) Grooved and notched stone

7) Pitted/Dimpled stone

8) Awl sharpening stone

9) Anvil stone

10) Battered/Hammer stone

11) Ground stone

12) Chopper

All of these types were measured in $\mathrm{mm}$. by maximum length, width, and thickness and were weighed. The resulting descriptions of the tool types and material composition have been compiled in Appendix E. Summaries of cobble artifacts from specific locations have been presented in the site reports.

Milling tools: Milling tools, used for processing vegetal foods, included both milling slabs and handstones, as well as mortars and pestles. Milling slabs were typically flat stone slabs with a surface which had been ground smooth from abrasion with a handstone. Handstones were fist-sized discoidal or ovoid shaped cobbles which exhibited one, or two very ground surfaces. Many of the handstones that were recovered had shoulders which were battered and pecked 
around the circumference to form a desired shape. Many also had battered axial ends which left a beveled appearance. Milling slabs occurred in many sizes; however, complete ones were not found during this project. These artifacts are known to have been used to grind hard seeds into flour for food. This study used the term milling slab and handstone as proposed by Mikkelsen (1985: 9). The mortar and pestle technology was related to the grinding of acorns into flour for food and sometimes for shellfish, fish meats and pine nuts. Mortars consisted of cobbles pecked and ground to shape a circular bowl receptacle within which cylindrical stone pestles were used to pound substances. Very small mortars are known to have been used to grind tobacco leaves and minerals for paint pigments (Harrington 1942) •

Mortars were pecked and ground into bedrock outcrops and were also made into transportable bowls from large cobbles. Sizes, shapes and material used to construct them vary, however, most were made from granite and sandstone. Charmstones: Charmstones or plummets have been hypothesized as having ceremonial affiliations. However, they may also have been used as tools for some as yet unknown utilitarian needs. It is also possible that earlier people had one use for them while later groups ascribed a different attribute to them. Archaeologists do not know their exact role in prehistoric societies, but this artifact 
type does have a wide distribution throughout the world, particularly within very archaic contexts (Nova \#1420 1987). within California, these artifacts occur in a variety of shapes and Beardsley (1954: 10) described fifteen types. of these types, two general distinctive classes can be distinguished by their proximal ends and are either perforated or piled. Perforate plummets have a hole drilled through an end while piled ones have a tapering end which sometimes retains a black stain from asphaltum. One specimen recovered from the excavation at scr-132, the scott creek site, had asphaltum stains on the proximal end with reveal cordage imprints. This implies that it was probably suspended. A distal end portion of a perforate charmstone was identified from scr-93, the sunflower House site. These artifacts were shaped by pecking and abrasion.

Grooved and notched cobbles: Grooved and notched stones were made from fist-sized cobbles which had been grooved or notched for the attachment of cordage. These tools functioned as net weights for snaring birds or fish and as hook and line fishing weights. The grooved types have a pecked line around the equatorial circumference, while the notched type has pecked notches on opposite edges of the widest portion of the cobble.

Pitted or dimpled cobbles: Pitted or dimpled cobbles were made from fist-sized stones with shallow circular depressions pecked into one or more surfaces. Their function 
is not known but they have been frequently iclentified at coastal sites. They may have been used as anvils for cracking open small shells. These tools have also been observed at interior sites where they are typically larger and globular shaped and are thought to be acorn shelling stones. Many are broken at a point perpendicular to the axial length along the depressions. This type of break would result from their being impacted at the point of the depression.

Awl sharpening stones: Several awl sharpening stones were recovered. They consisted of angular to discoidal cobbles with one or more grooves etched into the surfaces. These grooves were $\mathrm{v}$-shaped in cross section, as though pointed objects had been ground into the groove. Because of their appearance at sites with pointed bone tools, it is concluded that they were used to shape and sharpen them.

Anvil stones: Anvil stones were cobbles which exhibited pecked surfaces, concentrated on single areas of the cobble. Pecked areas formed a shallow irregular working depression. These stones were probably used to split hard objects such as cherts or other cobbles and were often in the form of slabs.

Battered cobbles: Battered cobbles were very common and are simply cobbles which exhibit a battered shoulder or end. These tools were used against moderately resistant materials which left impact scars on the cobble. These stones served a 
variety of functions such as hard hammer percussion and pounding as evidenced by the remaining wear scars.

Ground stone: Ground stone, as defined here, is a general term used to describe cobble pieces which exhibited ground surfaces from abrasion. Many of these were probably fragments of milling tools which could not be further identified.

Choppers: Choppers consisted of cobbles that had flakes detached by hard hammer percussion, creating an edge which could be used to chop or split material. Flake detachment was either unifacial or bifacial. These tools were generally wedge shaped in cross section. Prepared edges frequently exhibited polish and crushing from use.

Temporal considerations of cobble tools: Researchers in Central California have postulated that shifts in milling tool types may be indicative of changes in adaptive orientations. A discussion of this concept has been presented by Basgall (1987). Specifically, the focus of the debate has been the increased use of mortar and pestle over handstones and milling slabs prior to or during the Middle Period.

The recovered cobble tools from the sites within the study area show that both milling tool technologies co-occur through the Middle and Late Periods and that one set of tools was not replaced by the other. Late Horizon site sMa244 contained a balanced number of artifacts, reflecting 
both types of milling tool sets and SMa-118 was exclusively handstone and milling slab. Transitional Middle/Late Period site SMa-97 was almost exclusively mortar and pestle. Middle Period sites with both types of milling tool sets included scr-9, scr-20, scr-38, scr-93 and scr-132. The site distribution study in chapter I identified 17 sites reporting the co-occurrence of mortar/pestles and milling slab/handstones.

Other cobble tools which occur throughout the Middle and Late Periods included Pitted/dimpled cobbles (SCr-7, SCr-20, SCr-132, SMa-97, SMa-118 and SMa-218) and Grooved or edge notched cobbles (SCr-20, SCr-38, SCr-93, SCr-132, SMa115 and SMa-118). Both of these cobble tool types were also present in the other sites discussed in Chapter $V$ which were not ascribed to a temporal period, but were probably affiliated with Middle Period times. Most notably site SMa22 was reported to have had many pitted cobbles.

\section{Radiocarbon Dating Samples}

Radiocarbon samples for this project were submitted to the radiocarbon Dating Laboratory at washington state University for analysis. Samples submitted included bone, shell and charcoal.

Berger et al. (1966) has noted a "reservoir effect" in which excessive amounts of ancient carbon accumulates in shellfish species from sheltered estuarine habitats, resulting in inaccurate measurements. Because of this, a 
correction factor of 680 years has been proposed for marine shell dates from the Central California coast (Robinson and Thompson 1981). Patch and Jones (1984: 30) proposed that the correction factor does not apply to open coast species such as Mytilus californianus and Haliotis. Other researchers in the Monterey Bay Area have reported good correspondence between Mytilus californianus and charcoal dates (Breschini et a1. 1985; 1986; Dietz and Jackson 1981). Open coast habitats are prevented from accumulating ancient carbons by tidal and wave action (Dietz, Hildebrandt and Jones 1986: 125).

A total of 36 radiocarbon dates have been generated from 11 sites within the study area, 18 of which were submitted by this author. The sample locations and compositions from the excavations conducted specifically for this study, and the results of others, have been presented in the site reports. 


\section{CHAPTER V}

\section{SITE REPORTS}

This chapter presents information about excavated sites, and several private collections from within the study area. Sites described in this section include many which were excavated by others as well as those tested specifically for this study. Each site report contains a description of location, excavation volumes, field methods and analytical results. The results from these investigations were examined to determine the economic and adaptive modes represented by sites within the four environmental zones, through time. In this way the model of forager and collector adaptations proposed by Dietz and Jackson (1981) could be evaluated.

Santa Cruz and San Mateo County sites that were excavated by this author and others (prior to the initiation of this study), or produced artifacts contained in private collections that were used in this study include: SCr-7, (Map 5) the Sand Hill Bluff site (Jones and Hildebrandt 1990; Morejohn 1976; Breschini et al. 1984; Terry Kvenild Collection 1989; Joe Ward Collection 1989). SCr-20, (Map 6) the Brown site (Roop 1976). SCr-35, (Map 5) the Majors Creek site (Gifford and Marshall 1984). 
SCr-38/123, (Map 7) the wilder Ranch State Park site (Hylkema n.d.; Led Engelsmen Collection 1986; Terry Kvenild Collection 1989).

SCr-39 and SCr-40, (Map 7) Wilder Ranch state Park (Terry Kvenild Collection 1989).

SCr-93, (Map 8) the Sunflower House site (Bourdeau 1986; Breschini 1981).

SMa-22, (Map 9) the Princeton Mound site (Loud 1915; Phebus 1973) .

SMa-110, (Map 10) the Pilarcitos Creek site (Asturias 1971). SMa-115, (Map 11) the Montara state Beach site (Hylkema with Hall 1985).

SMa-118, (Map 12) the Bean Hollow state Beach site (Hylkema 1989).

SMa-139, (Map 10) the Frenchmans Creek site (Orlins n.d.). SMa-140, (Map 9) the Denniston Creek site (Moratto 1971). sites that were tested specifically for this study include the following Santa cruz and San Mateo county sites: SCr-9, (Map 6) the Bonny Doon site. SCr-132, (Map 13) the Scott Creek site. SMa-97, (Map 14) the Ano Nuevo Creek site. SMa-218, (Map 14) the Ano Nuevo Reserve site. SMa-238, (Map 14) the Ano Nuevo Point site. SMa-244, (Map 15) the Butano Ridge site. 


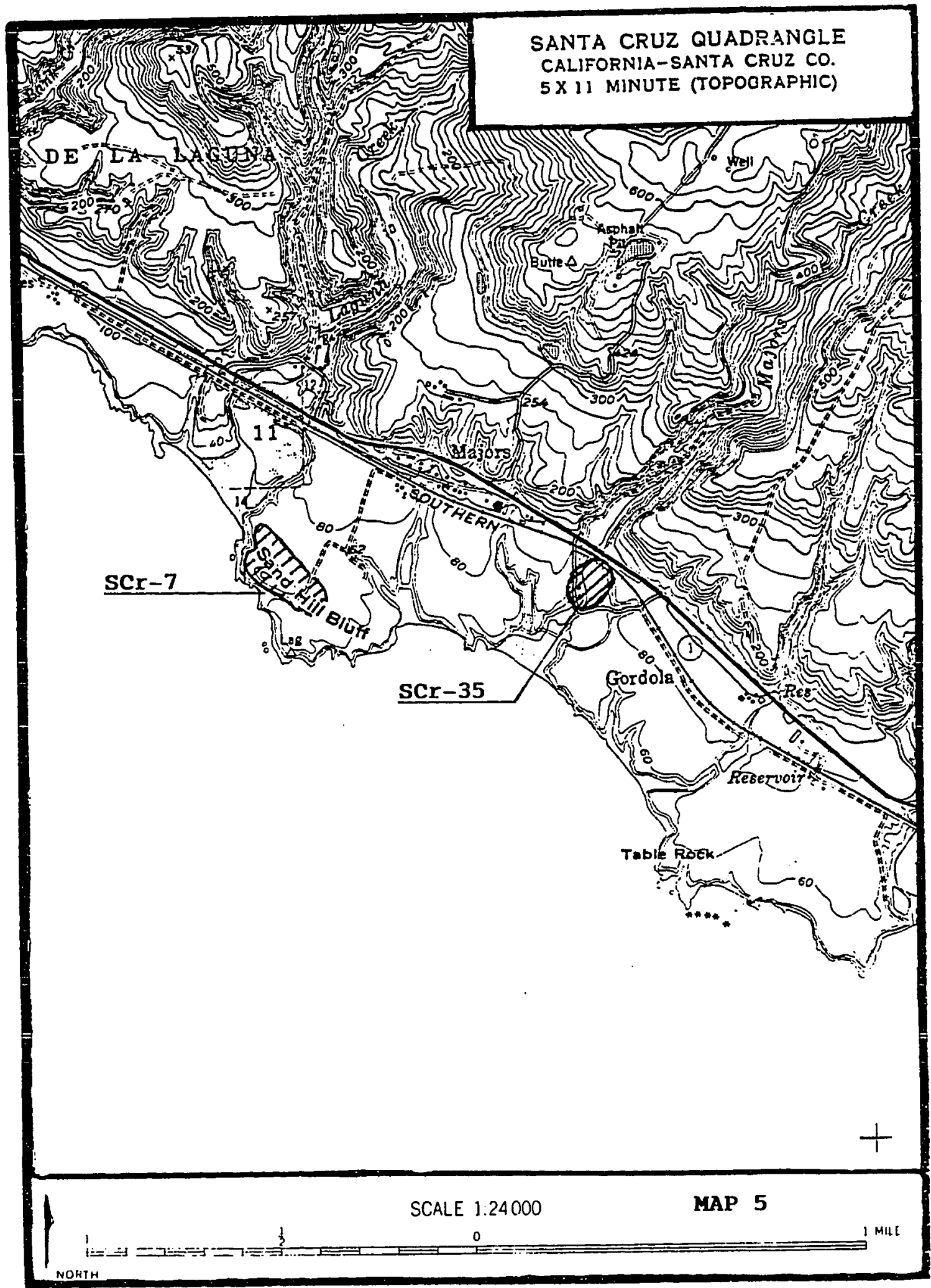




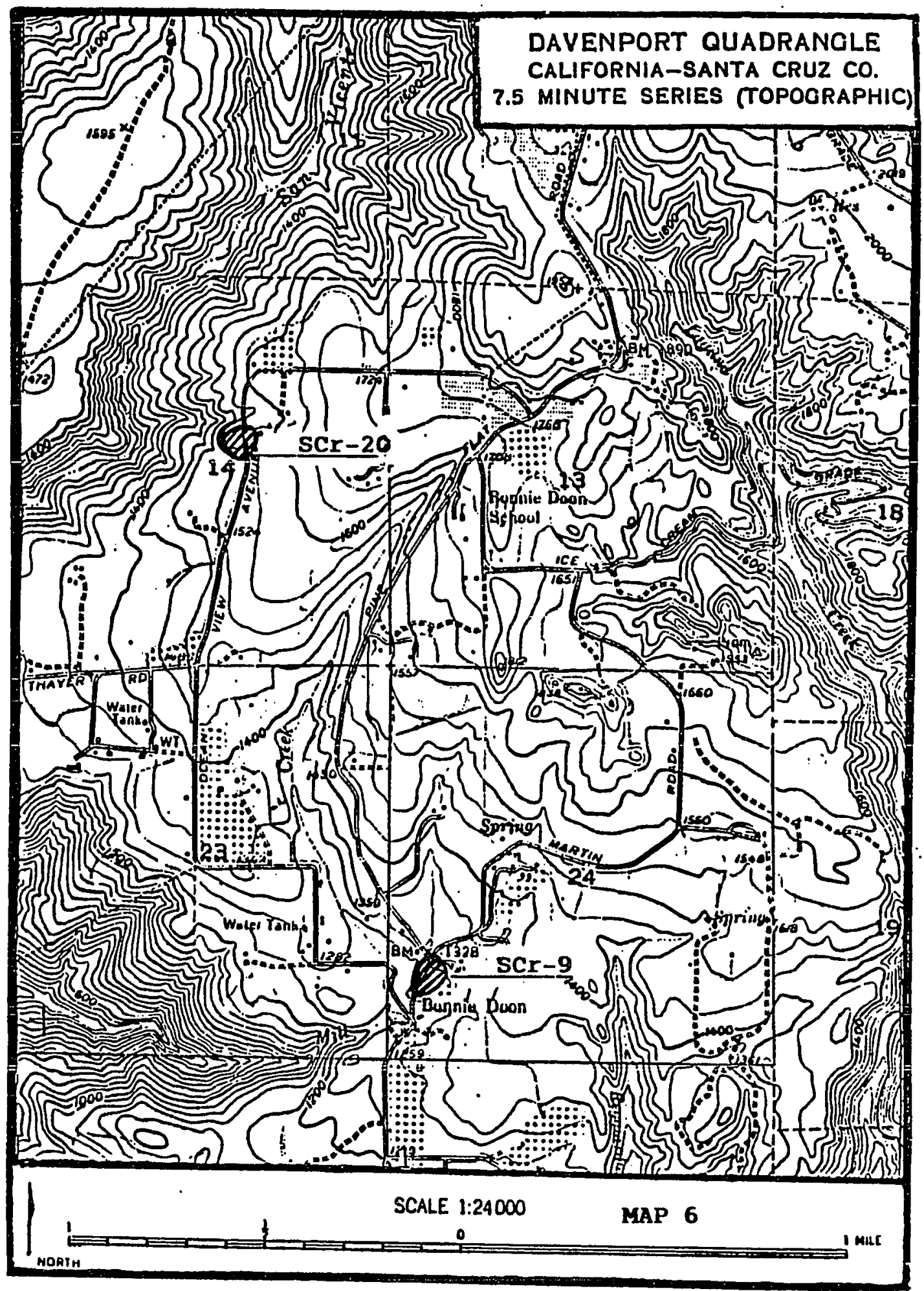




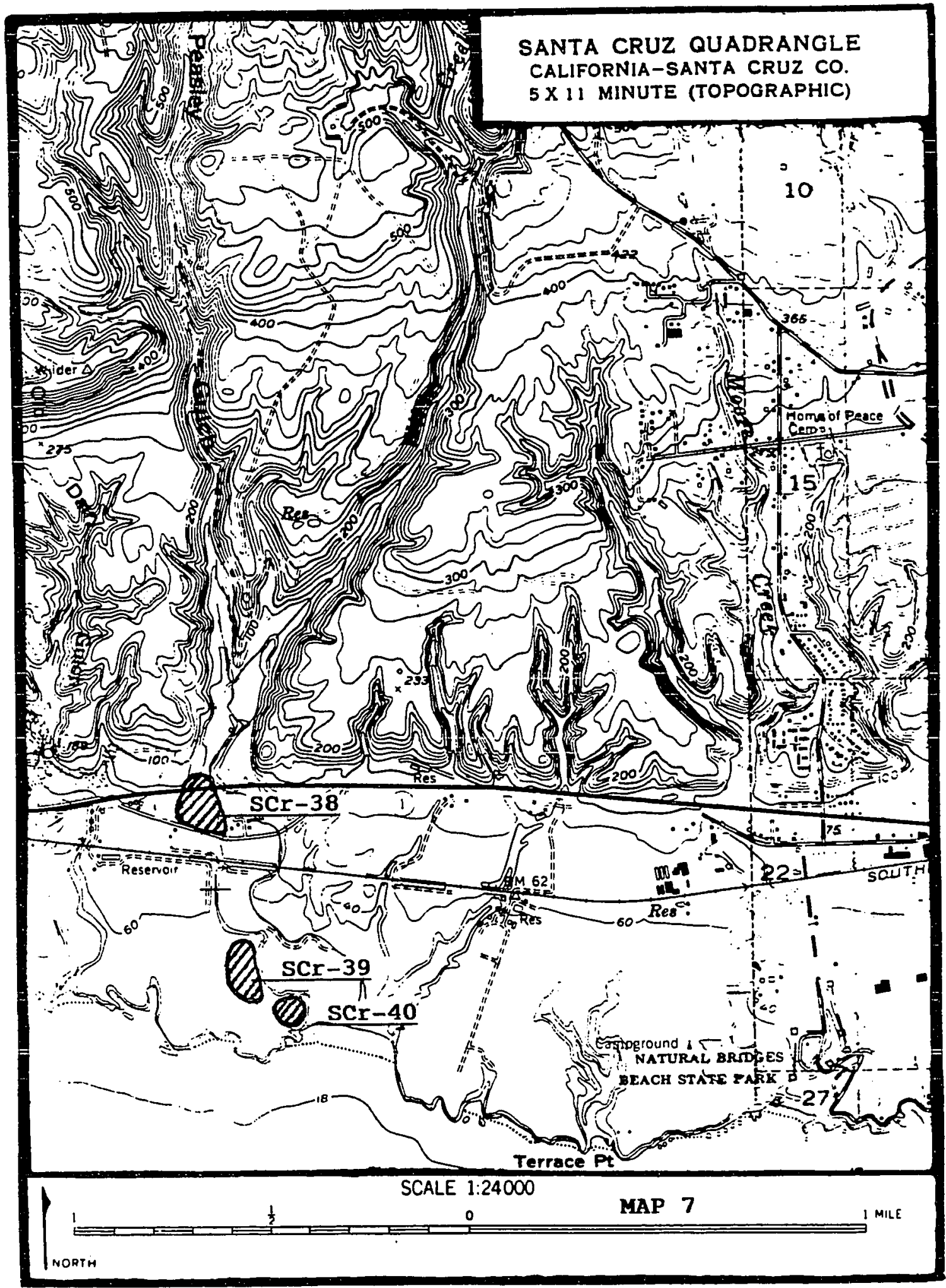




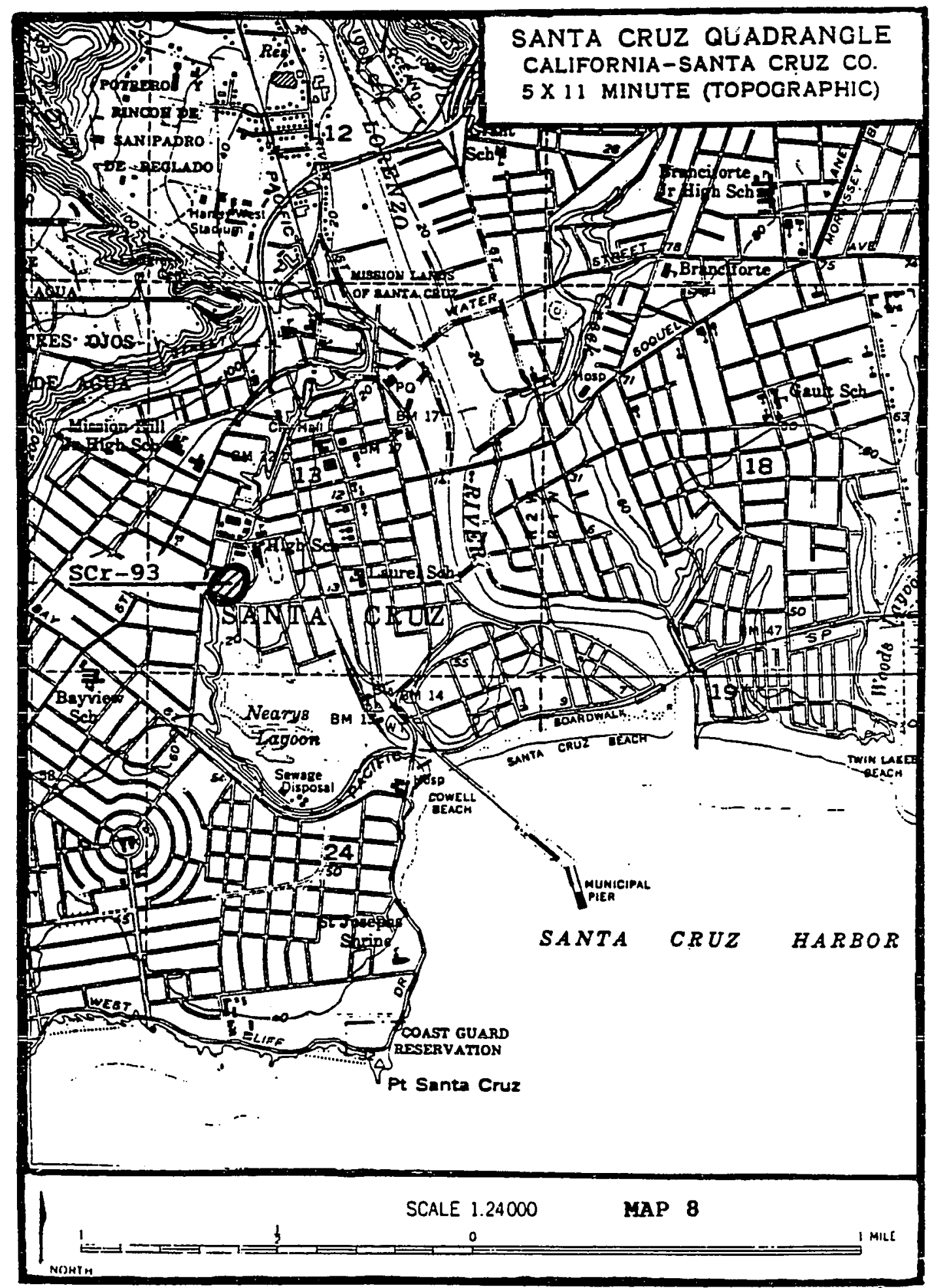




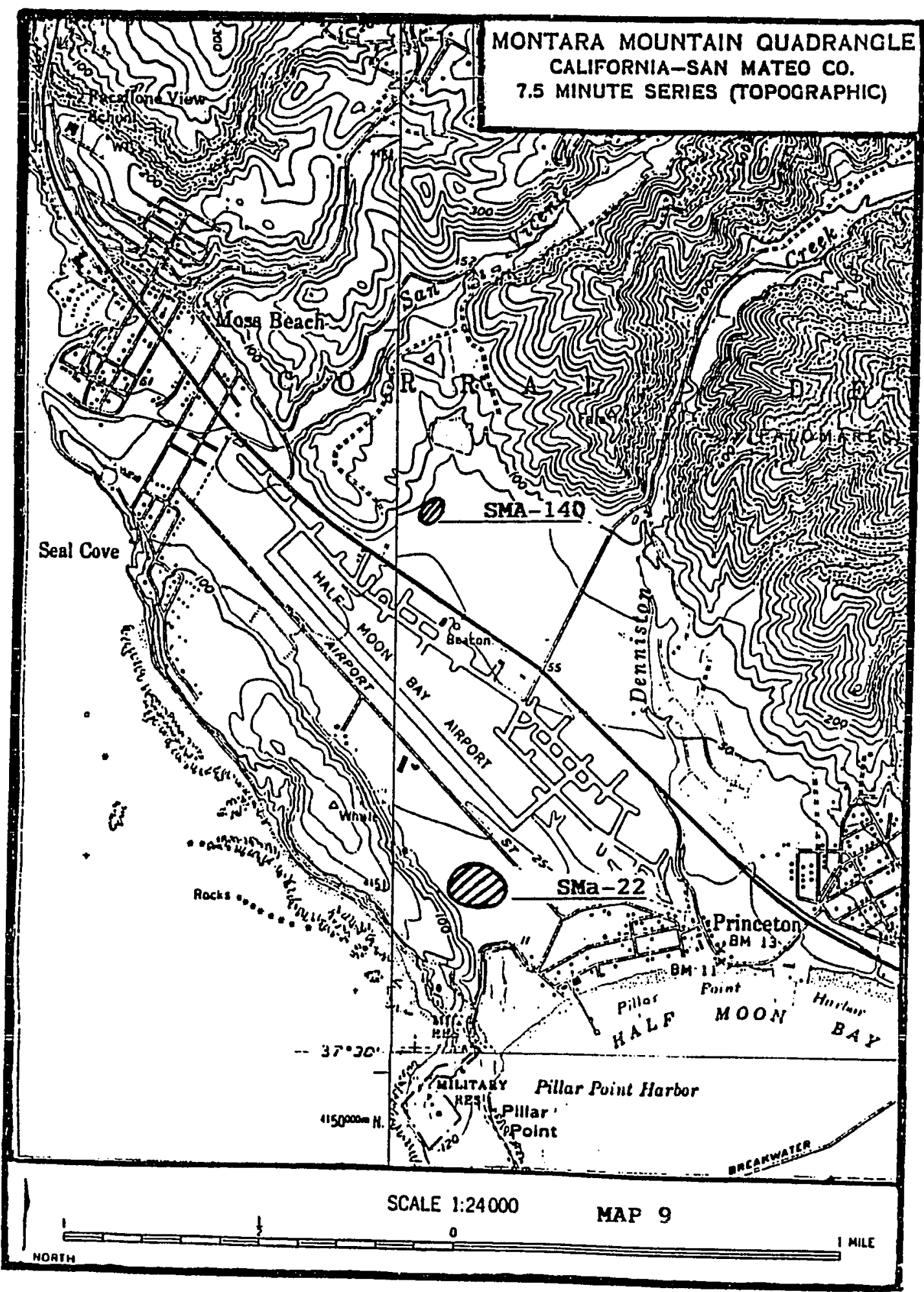




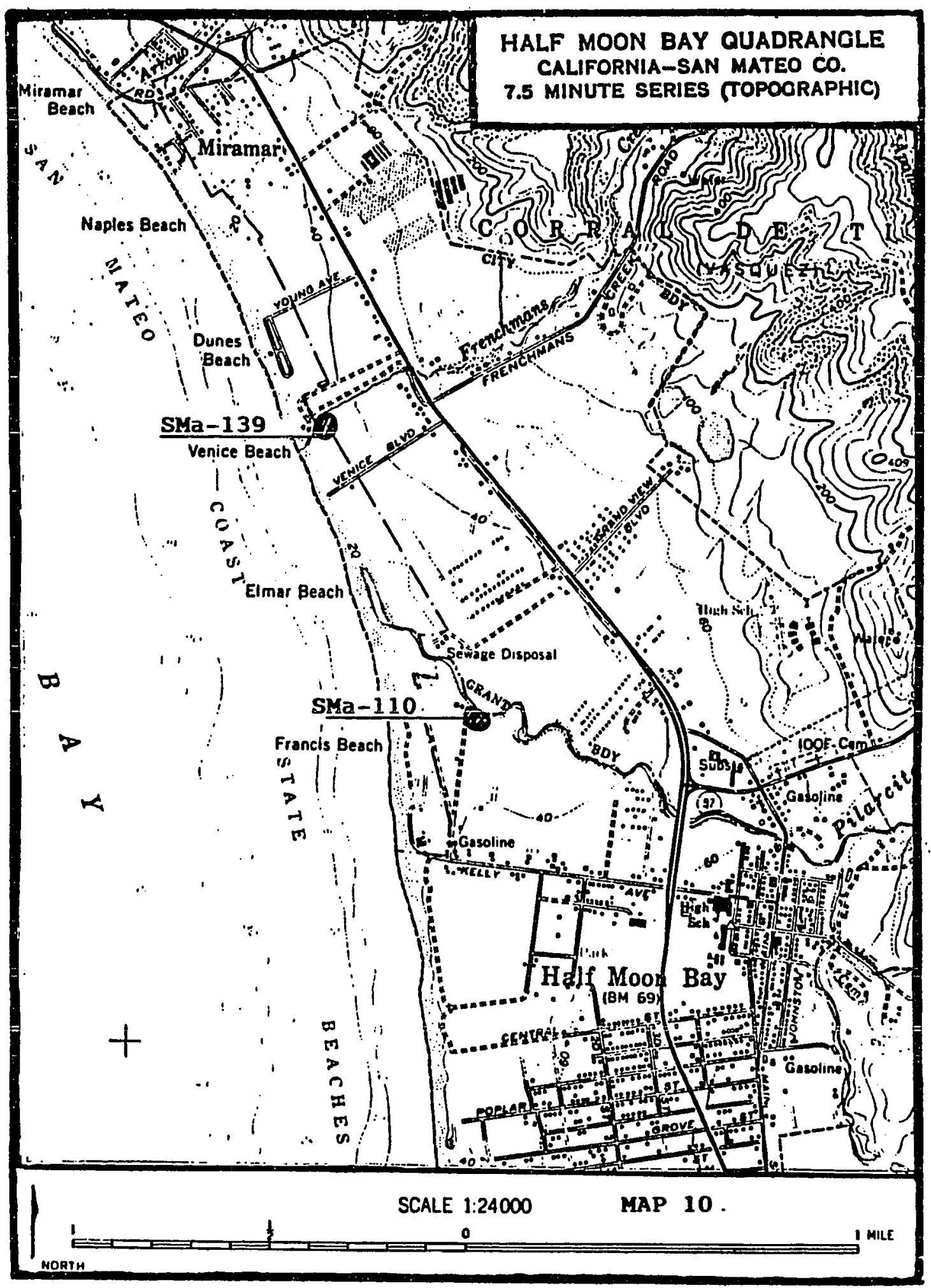




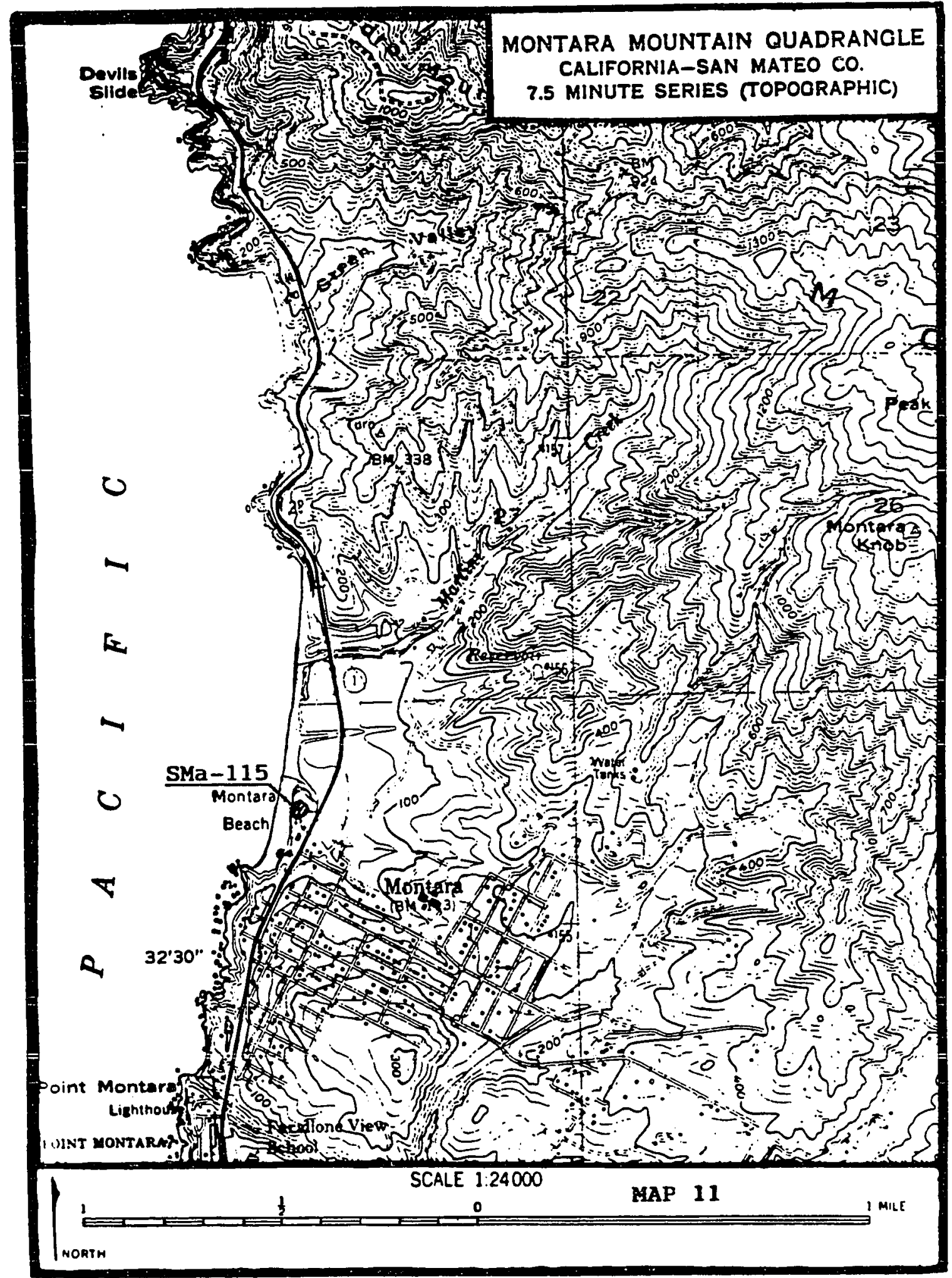




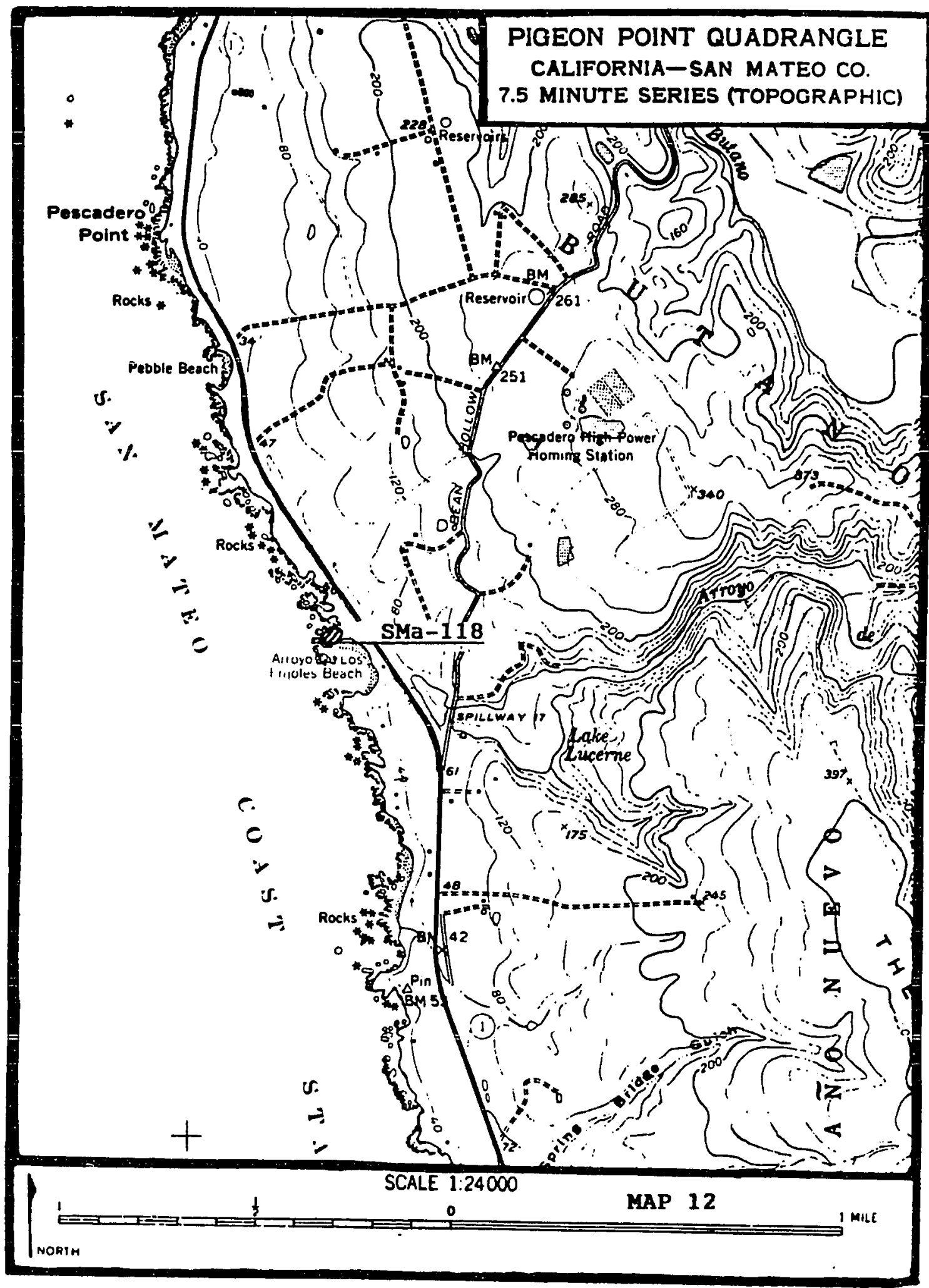




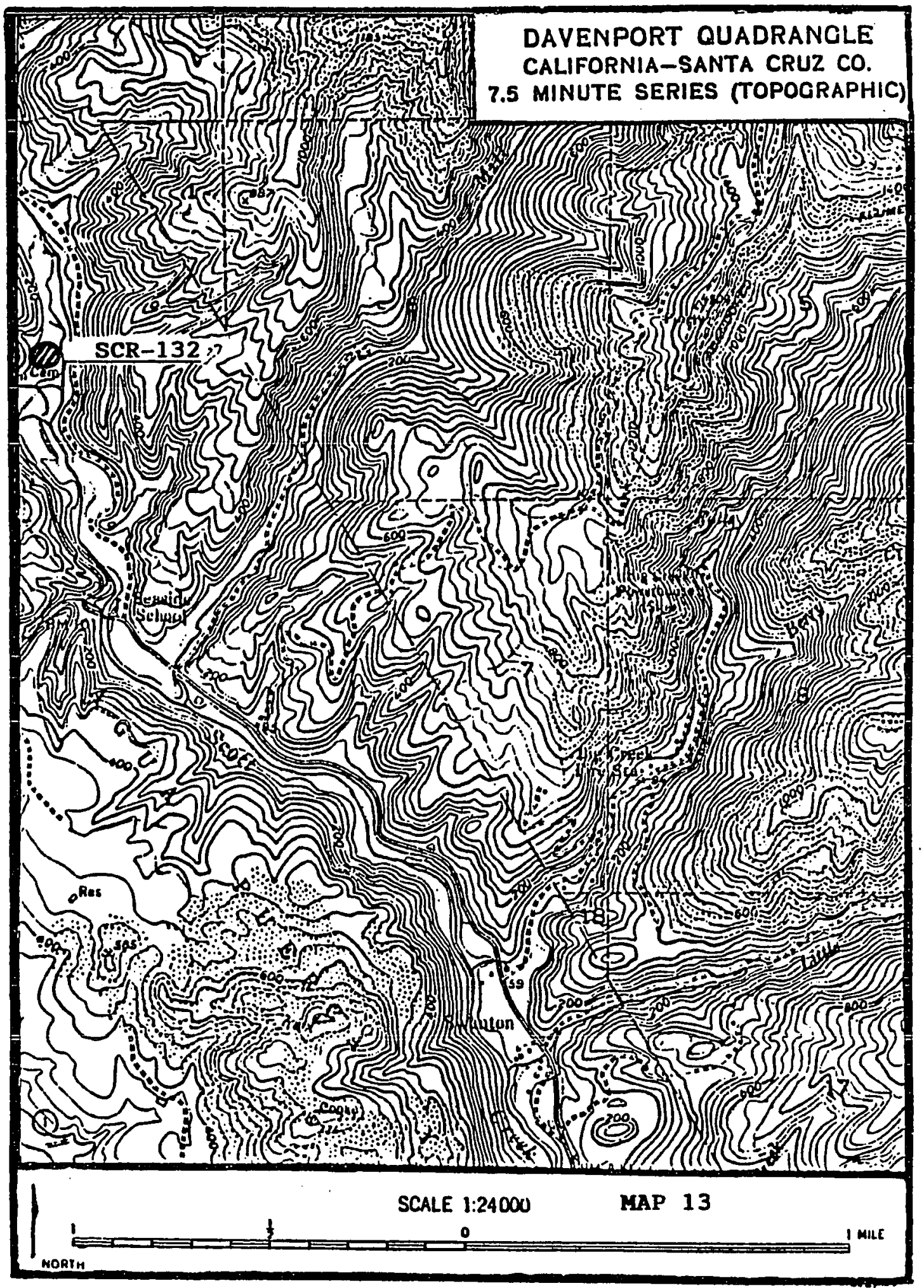




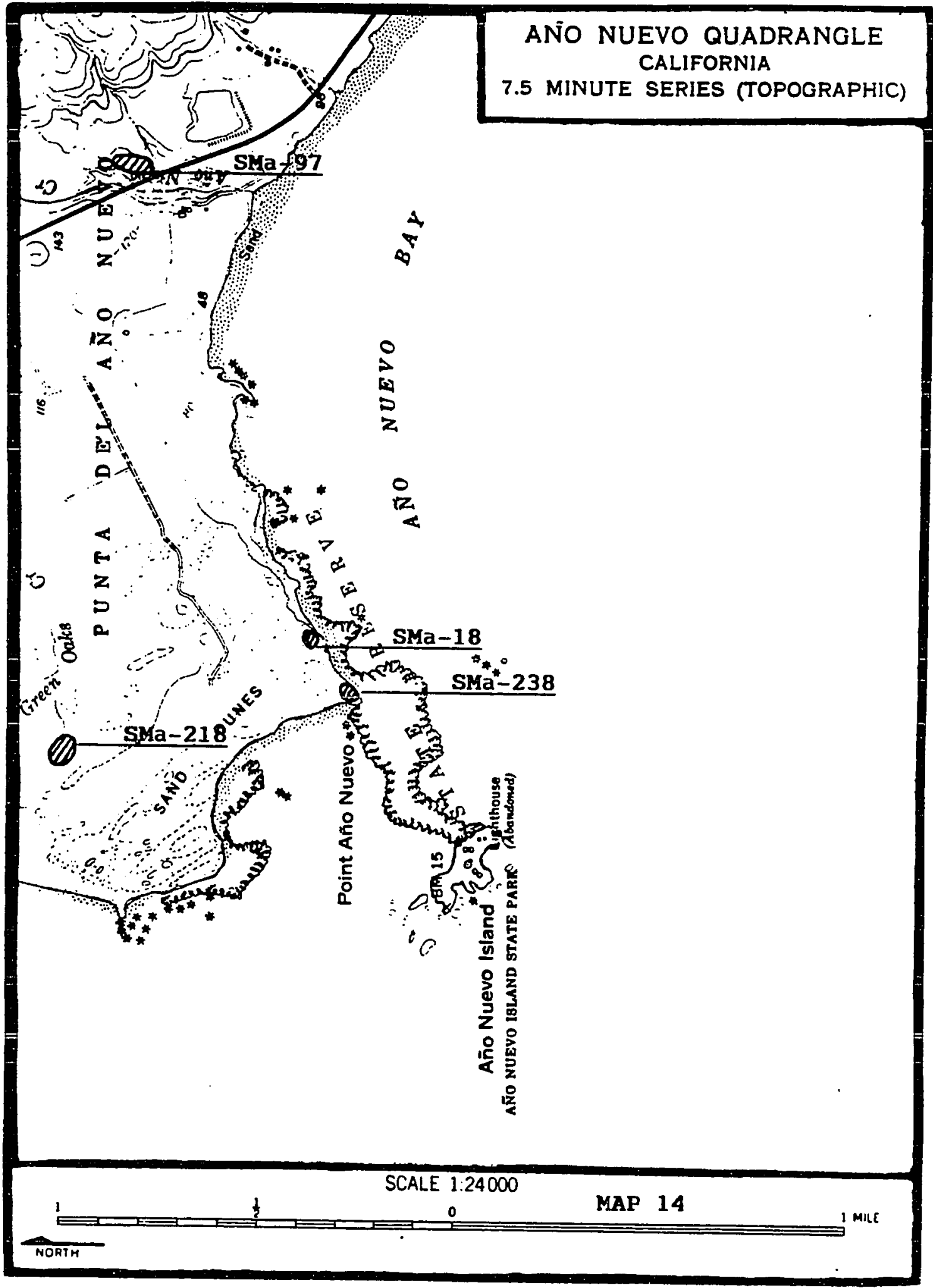




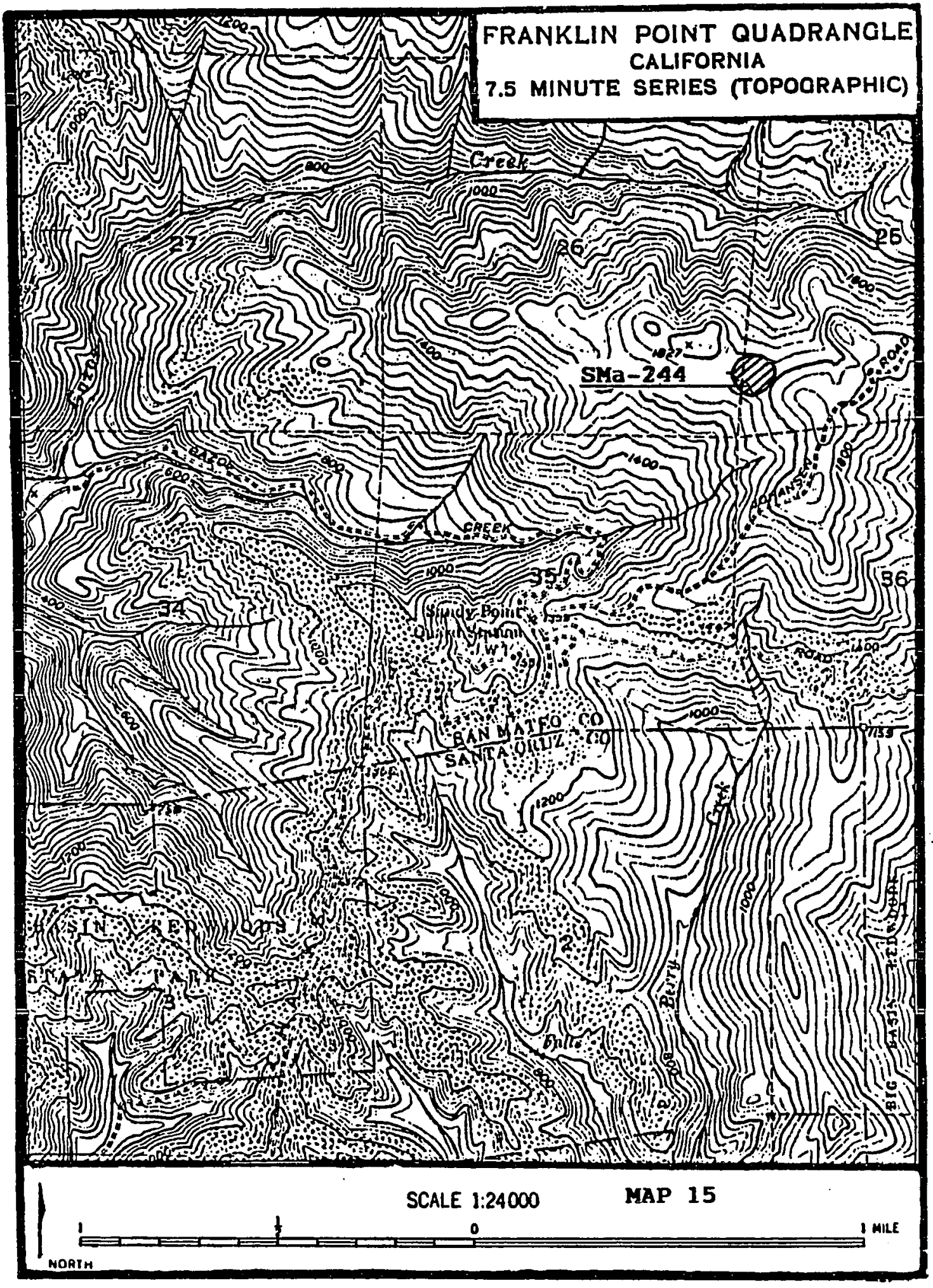


scr-7, the Sand Hill Bluff site

The Sand Hill Bluff site is located on the edge of the coastal bluffs overlooking the mouth of Laguna Creek and is within the coastal terrace zone. The site consists of an extensive midden-covered sand ridge with scattered lesser mounds around the base of the large dune. The western slope of the site is bounded by steep vertical cliffs, which have collapsed in sections and are eroding into the sea. Portions of the dune have been spread throughout the cultivated fields by local farmers, leaving a wide scatter of cultural debris exposed. Large quantities of shell fragments are currently visible throughout the site. A single layer of concentrated mussel shells, over one meter thick, is visible near the top of the dune. This site bears the distinction of having been one of the first excavated in California winich was the subject of a published report (Saxe 1875). This area has also been a favorite spot for collectors, and many artifacts have been removed. Two large surface collections have been examined and are described in this section. Radiocarbon dates and artifacts in private collections indicate that this location has been used throughout the middle and late periods and even as far back as the lower archaic period, using Fredrickson's 1974 chronological nomenclature. This is the oldest dated site in the study area. 
In the early 1970s, Victor Morejohn of the Biology Department at San Jose state University conducted an investigation of the site. His goal was to retrieve faunal specimens for study. Morejohn ultimately recovered the largest collection on the west coast of bones from an extinct bird, Chendytes laiwii, a flightless scoter which is thought to have disappeared some 33,000 years ago (Morejohn 1974). He obtained two radiocarbon dates from the lower and upper levels of the midden, which had a stratigraphically distinct profile exposed on the western face as a result of erosion. The basal date, derived from mussel shell was 5390 \pm 100 B.P., and the upper date also of mussel shell was 3790 \pm 110 B.P. (Moratto 1984).

Smith and Breschini (1986) processed three additional dates that were obtained from the upper and basal layer of the main dune. The upper date derived from mussel shell was $4500 \pm 80$ B.P. The two lower dates, also of mussel, read $4520 \pm 110$ and $4570 \pm 140$ B.P. Recently additional work conducted at this site has provided yet another radiocarbon date. The sample was derived from a sea lion bone from the basal portion of the main dune and resulted in a date of $5970 \pm 120$ B.P. (Jones and Hildebrandt 1990). A summary of the radiocarbon dates is presented in Table 7 . 
Table 7: Radiocarbon Dates for $\mathrm{sCr}-7$

Sample Location, Composition $\quad$ c14 Age (yrs. B.P.)

Upper Mound Levels, Mytilus californianus $3790 \pm 90$

Upper Mound Levels, Mytilus californianus $4500 \pm 80$

Lower Mound Levels, Mytilus Californianus $4520 \pm 110$

Lower Mound Levels, Mytilus californianus $4570 \pm 140$

Lower Mound Levels, Mytilus californianus $5390 \pm 100$

Basal Mound Levels, Faunal Bone $5970 \pm 120$

SCr-7 has often been referred to as the oldest dated coastal site in Central California (Moratto 1984), but writers have failed to mention that the location is composed of at least five smaller dune locations, and these may represent a range of time. This possibility has been further supported after having reviewed projectile point styles from the Kvenild and ward collections.

The Terry Kvenild and Joe ward collections contain chipped stone tools from the cultivated fields and dunes of scr-7. Together these collections contained a total of 107 projectile points that represented a wide variety of types and materials. Most of these were measured and illustrated for this study. Descriptions have been provided in Appendix D. The illustrated specimens are in Figures 4 through 13. These were collected from three generally clustered locations and have been cataloged by denoting the collector and location. The Kvenild collection was numbered SC for surface collection, followed by the area and then an artifact number. The Ward collection was accessioned the 
same way, with a $\mathrm{W}$ added to the artifact number. Artifacts from the main dune have no area number and were, for example, noted as sc-l etc. Area two was the cultivated field adjacent to the northeastern slope of the main dune. Area three was the cultivated field adjacent to the southern tip of the main dune.

Both Terry Kvenild and Joe Ward were granted permission to collect by the farmers managing the land, and have retrieved many tools in a very short time. More have been collected since the time this site report was written. The large number of points attests to the intensity of prehistoric use at this location and the serious problem of axtifact hunting at prehistoric sites in general. Fortunately, both of these collections are available for temporary review upon request. In addition to the points, their collections included several large quartzite handstones with well shaped shoulders. These were not measured and were identical to forms found at other coastal sites. San Jose State University also has several artifacts including cobble and bone tools. These have been described by others (Jones and Hildebrandt 1990). Descriptions of the Ward and Kvenild collections have been provided in Appendices $C$ and $E$. Many of these are illustrated in Figures 4 through 15.

It is interesting to note the unusual number of Franciscan chert and obsidian points that were contained in 
the private collections. Although Monterey chert is the dominant material, as with all of the sites in this study area, sCr-7 contained the highest ratio of other materials. Table 8 presents the material frequencies.

Table 8: Material Frequencies of Chipped Stone Tools from $\mathrm{SCr}-7(\mathrm{~N}=108)$

Monterey Chert.........69 (64\%)

Obsidian...............13 (12\%)

Franciscan Chert........12 (11\%)

Jasper................11 $(10 \%)$

Siltstone/Chalcedony......3 (3\%)

of the points and bifaces, Table 9 presents the styles and the number of specimens from the collections.

Table 9: Point styles from $\mathrm{SCr}^{-7}(\mathrm{~N}=108)$

Contracting stemAno Nuevo Long-stemmed...........8

Barbed contracting stem........... (6.5\%)

Square stemmed-

Rossi square stemmed............. (7.5\%) Lanceolate-

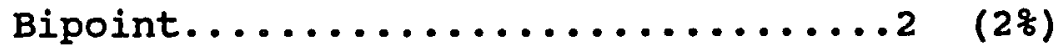

Notched-

Convex Base..................4 (3.58)

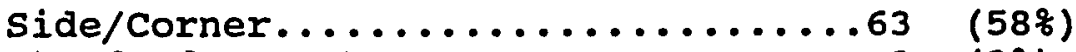

stanford Man II................... (28)

Desert Side-notched................ (18)

Undetermined Types and Bifaces..........13 (12\%)

The collections from SCr-7 site contained the largest number of notched points from any site in the Monterey Bay Area. It was found that side and corner notched points grade in style, and shoulder angle measurements will not sort them. Further, neither the side nor corner notched positions 
retained any distinctive basal forms related to notching positions. Measurements from 54 notched points from SCr-7 and several from other sites have been presented in Chapter IV and were used to describe their morphological attributes. 

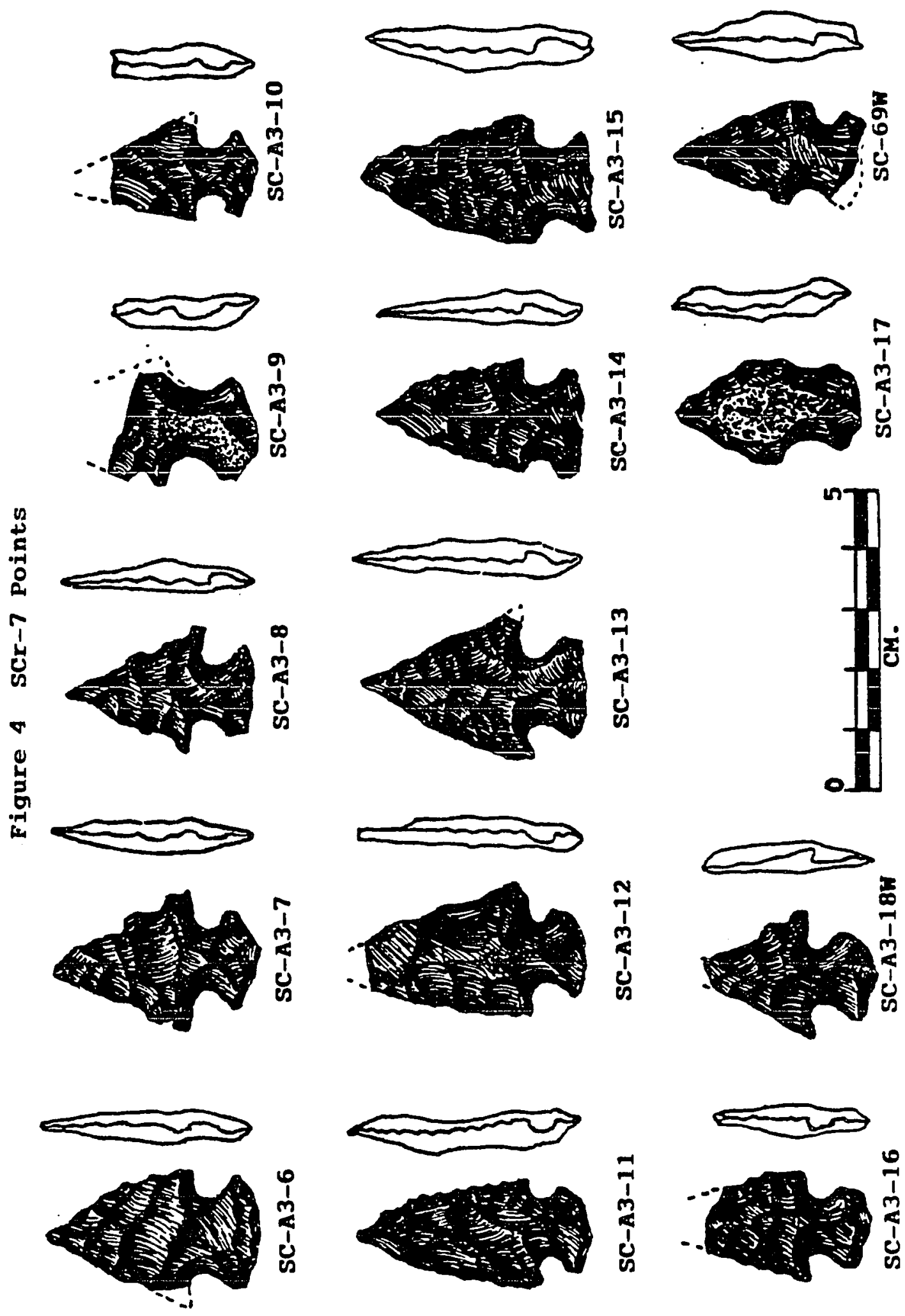

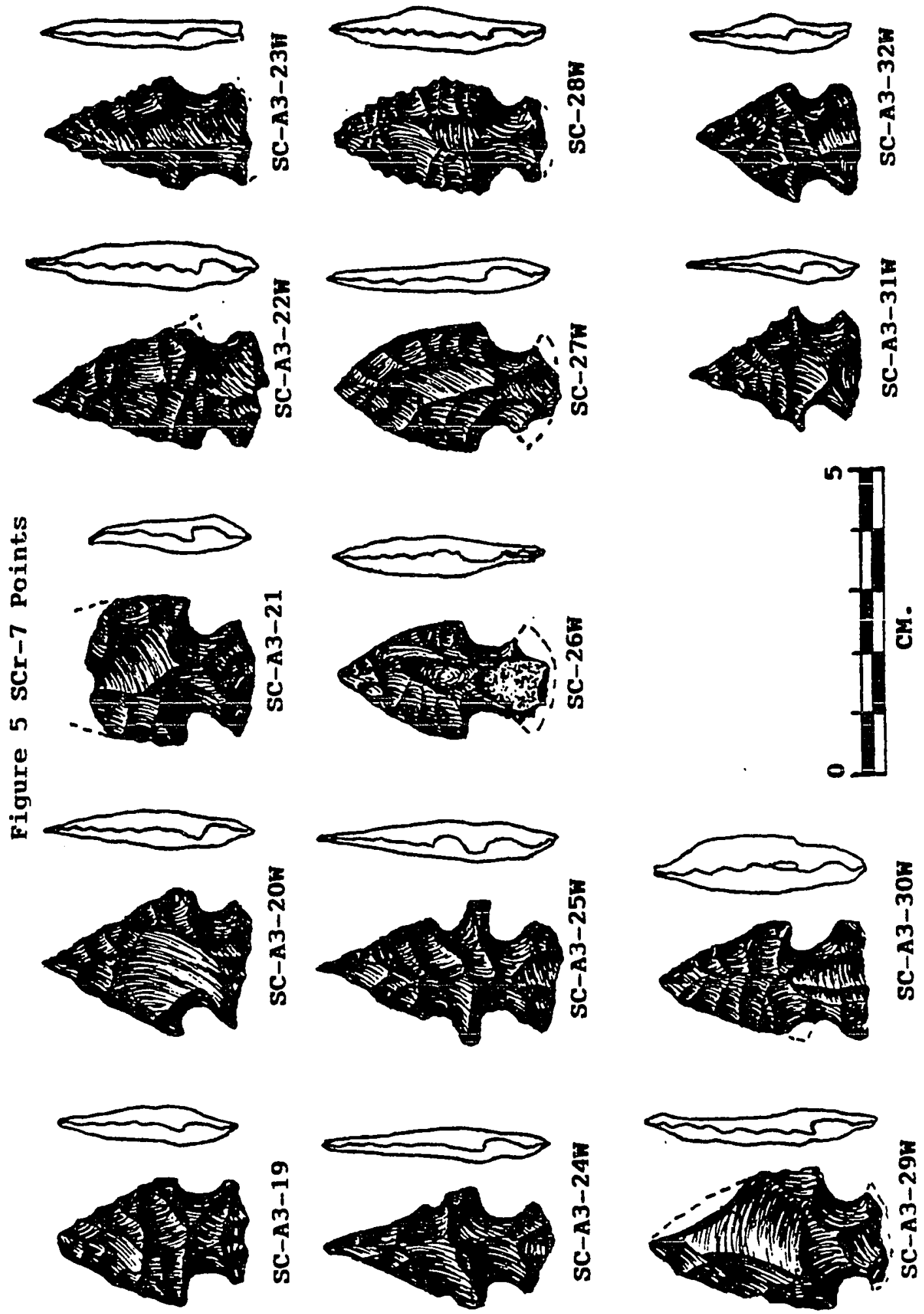

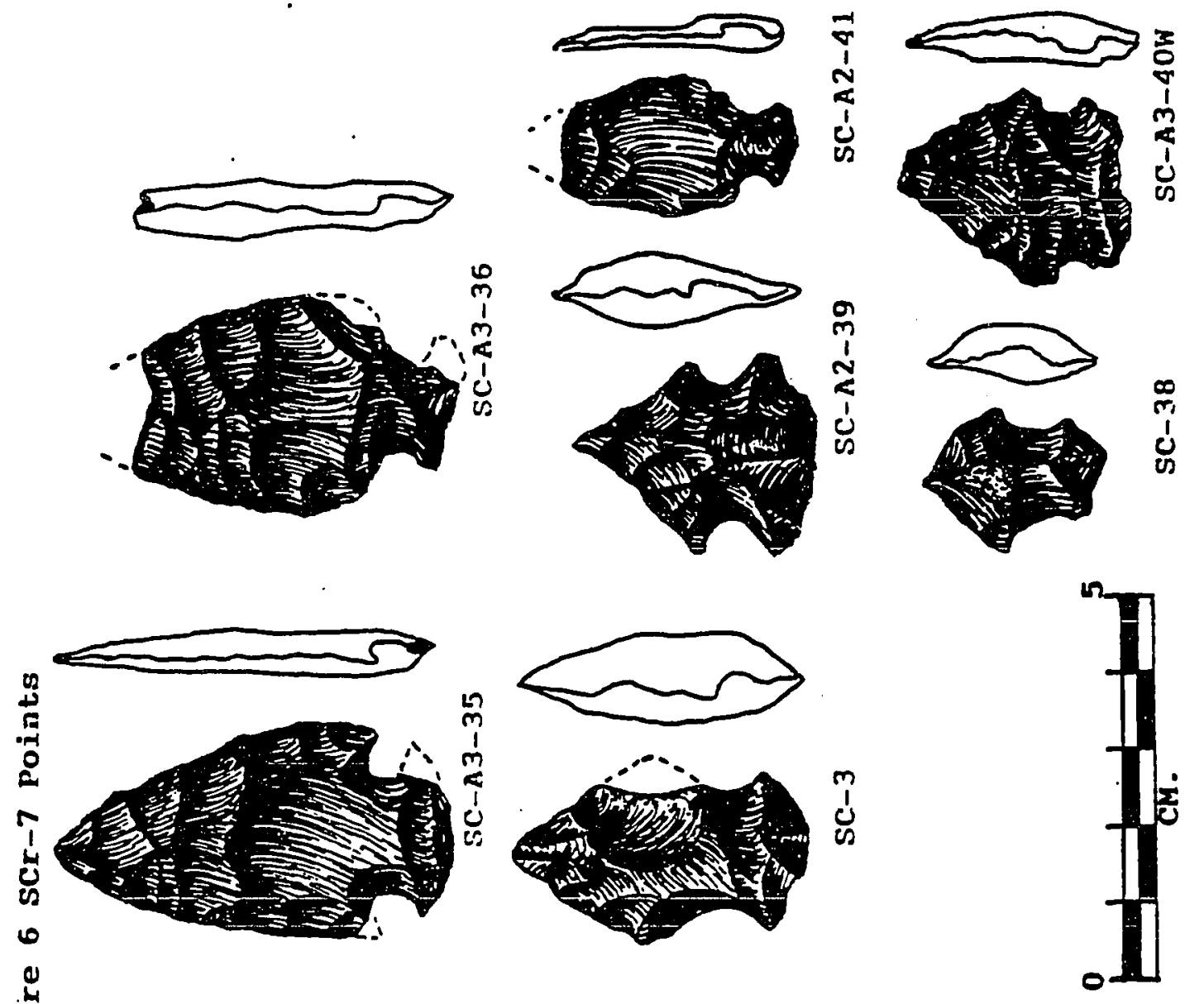

है
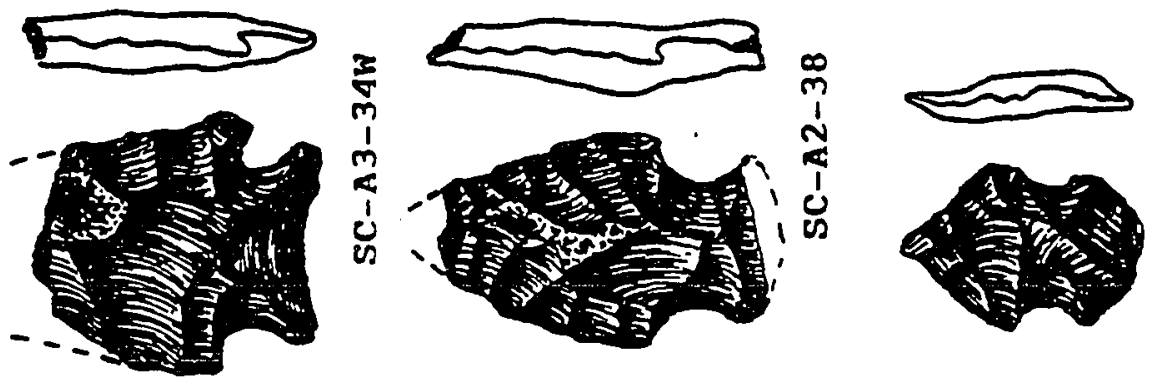

m
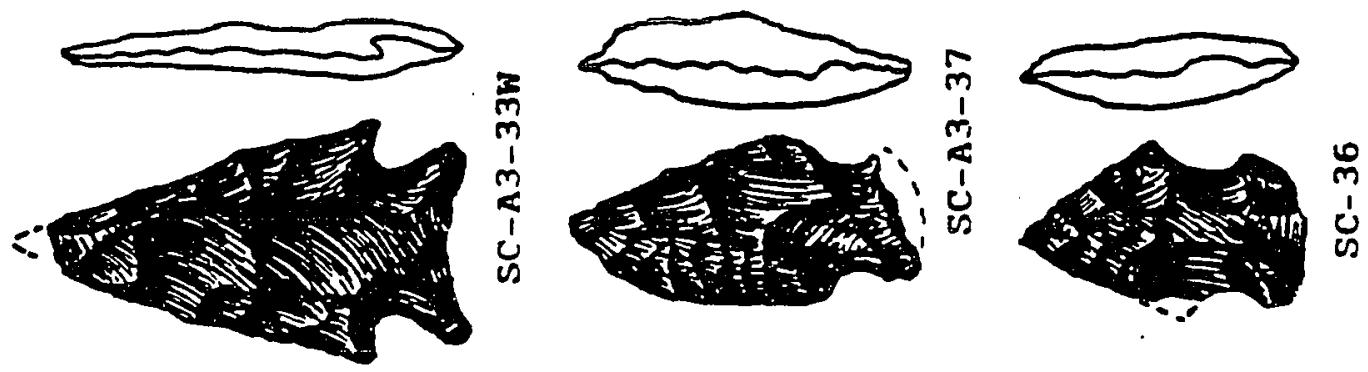


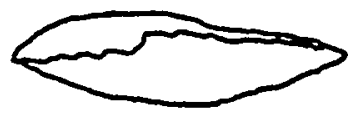

m
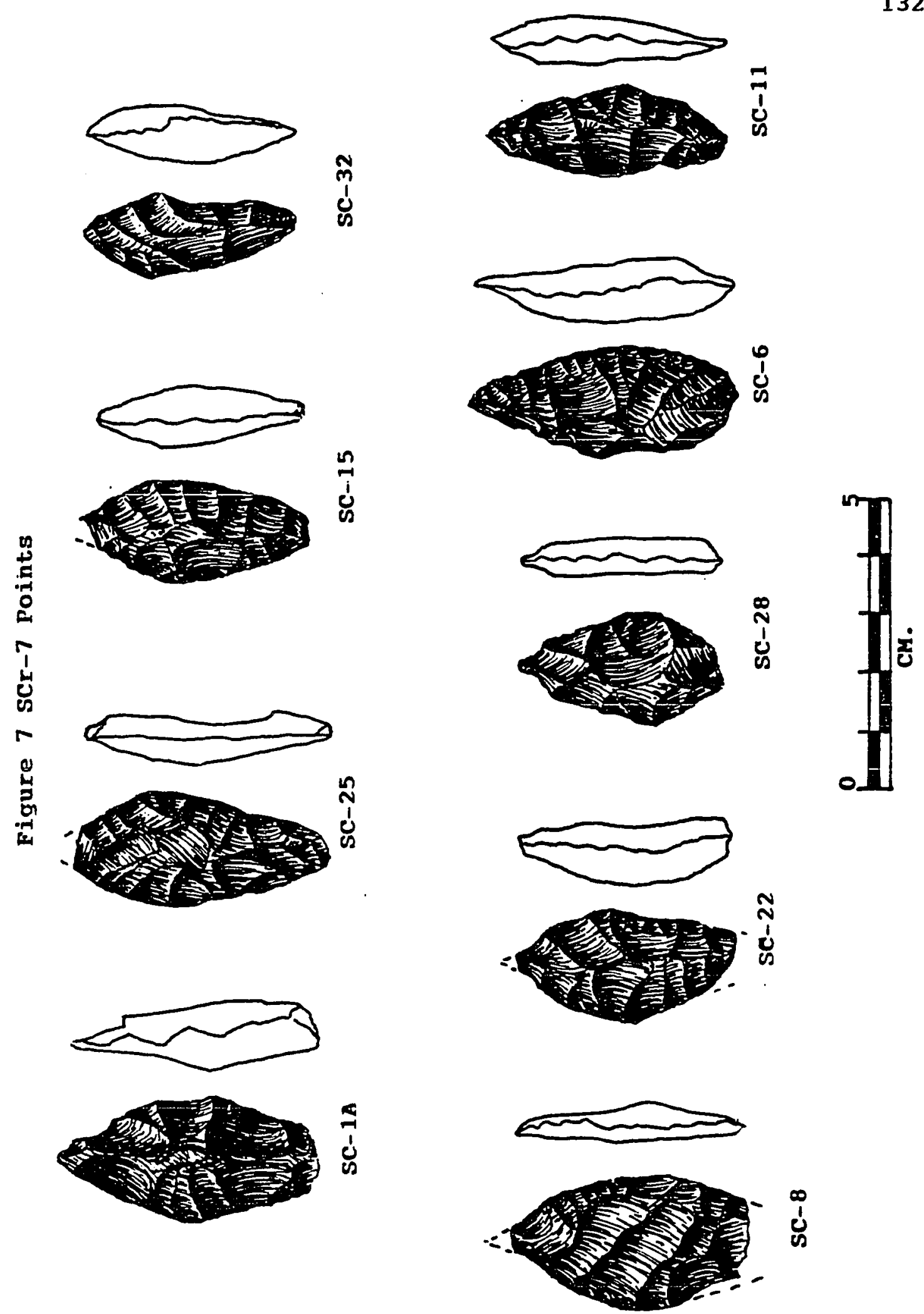

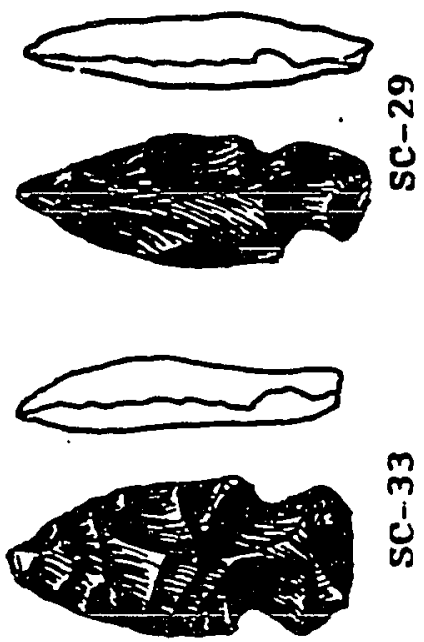

m
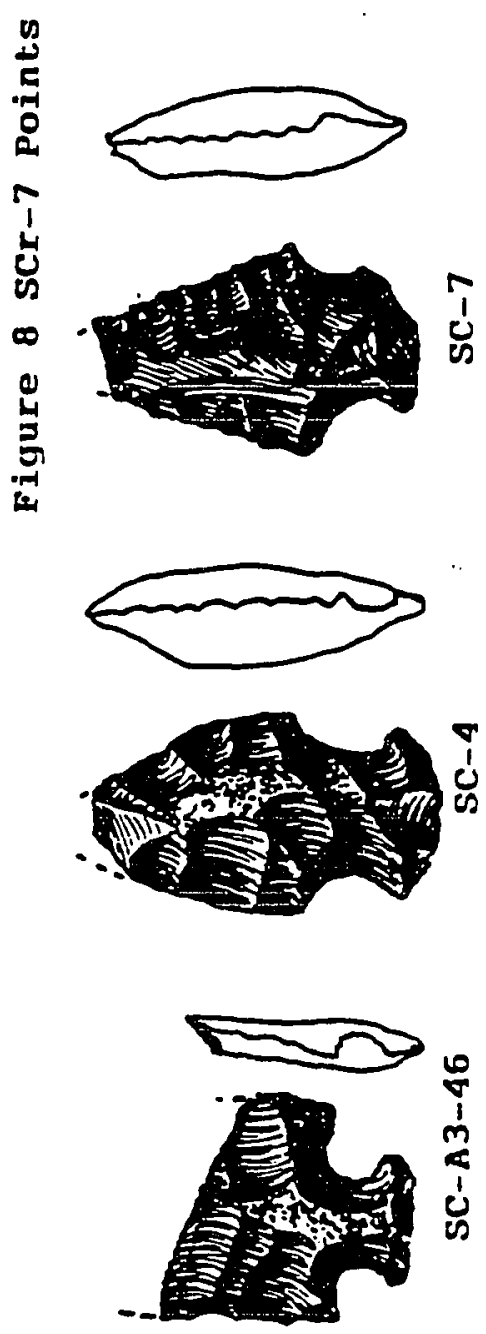
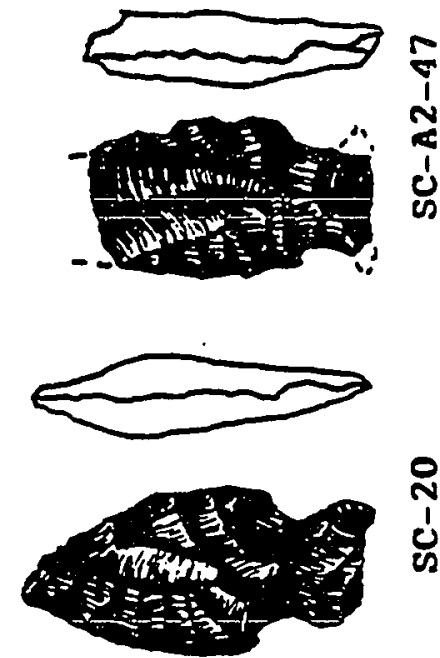

离
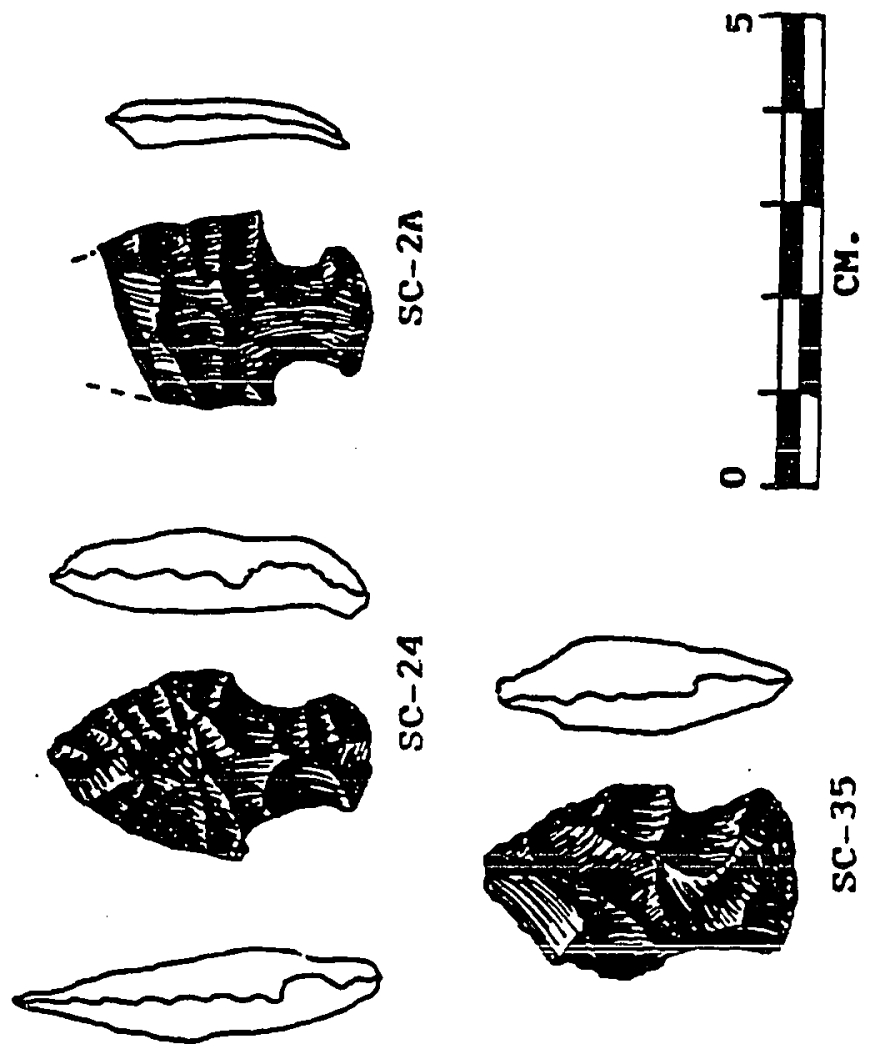

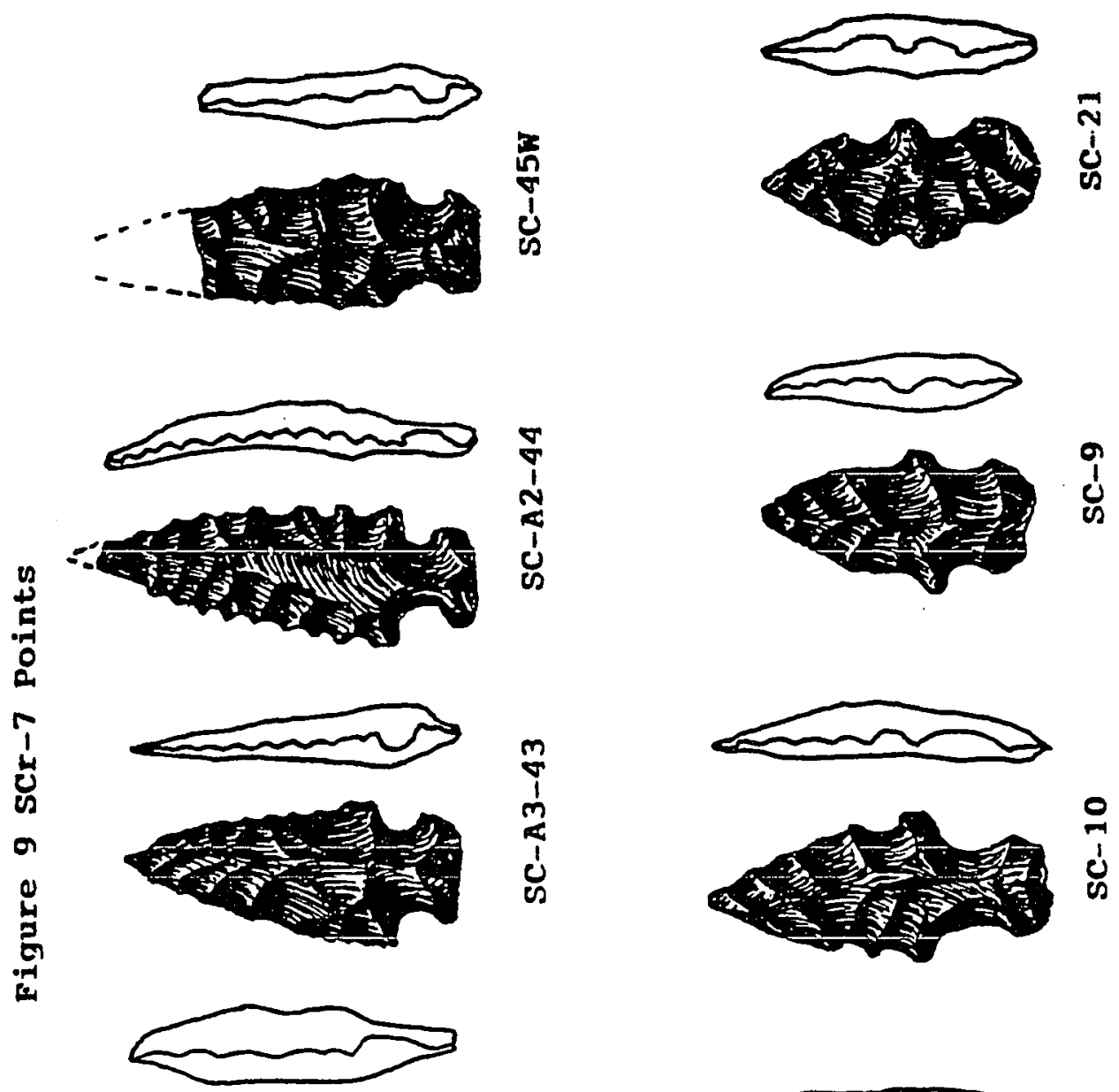

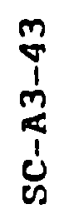

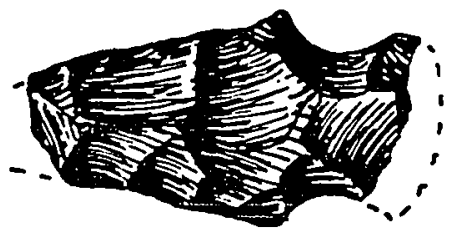

$m$

y
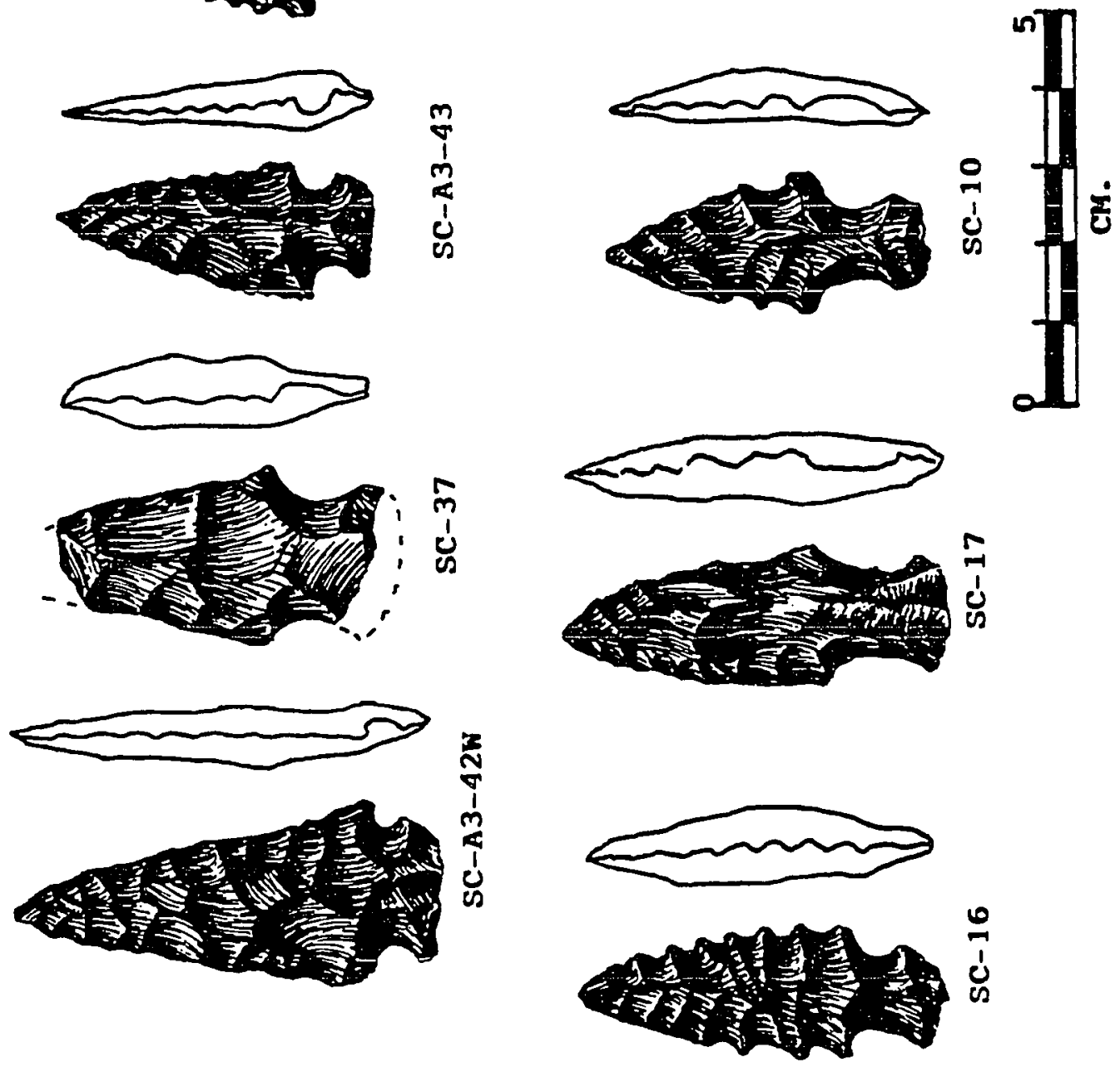


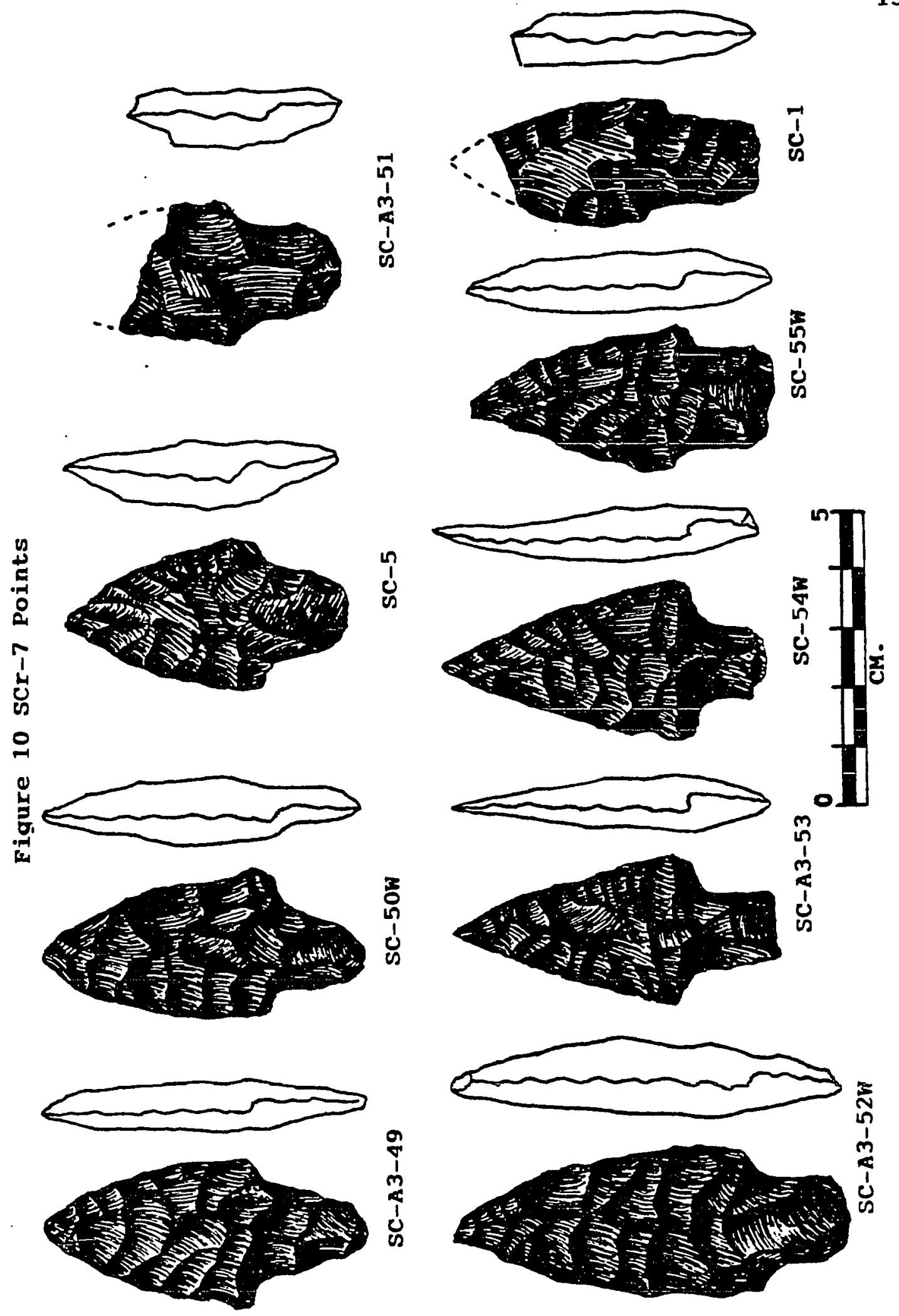




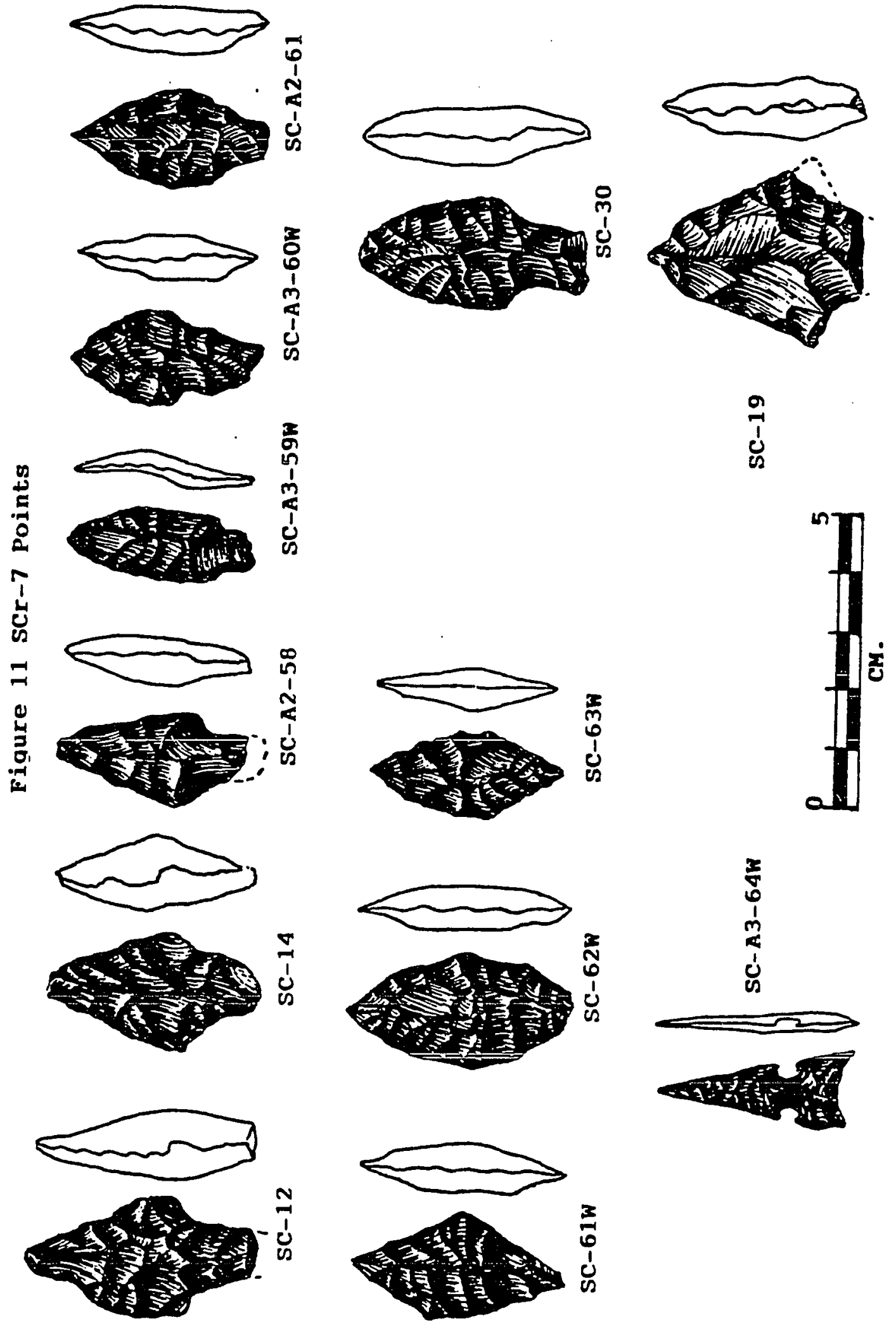



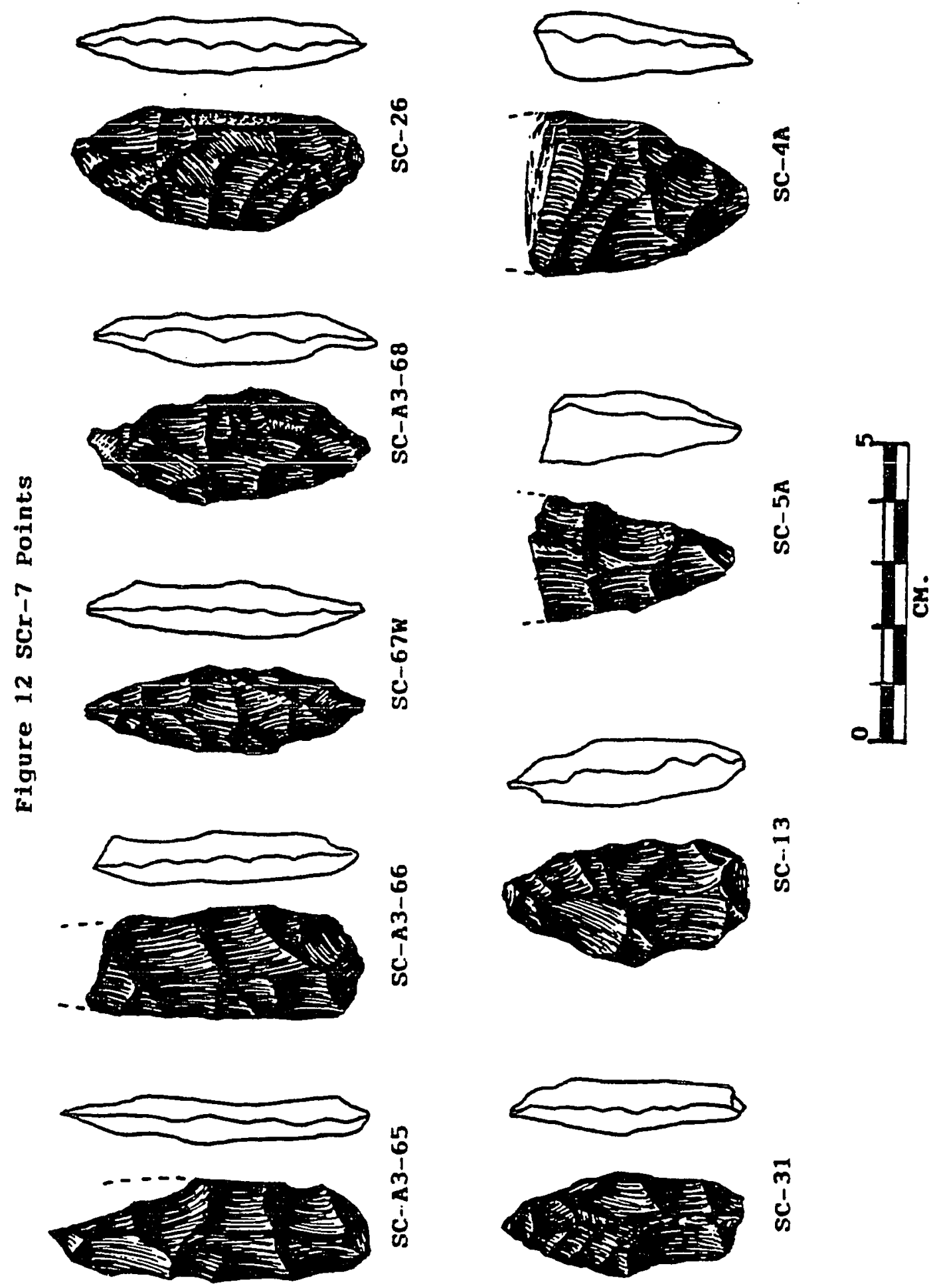

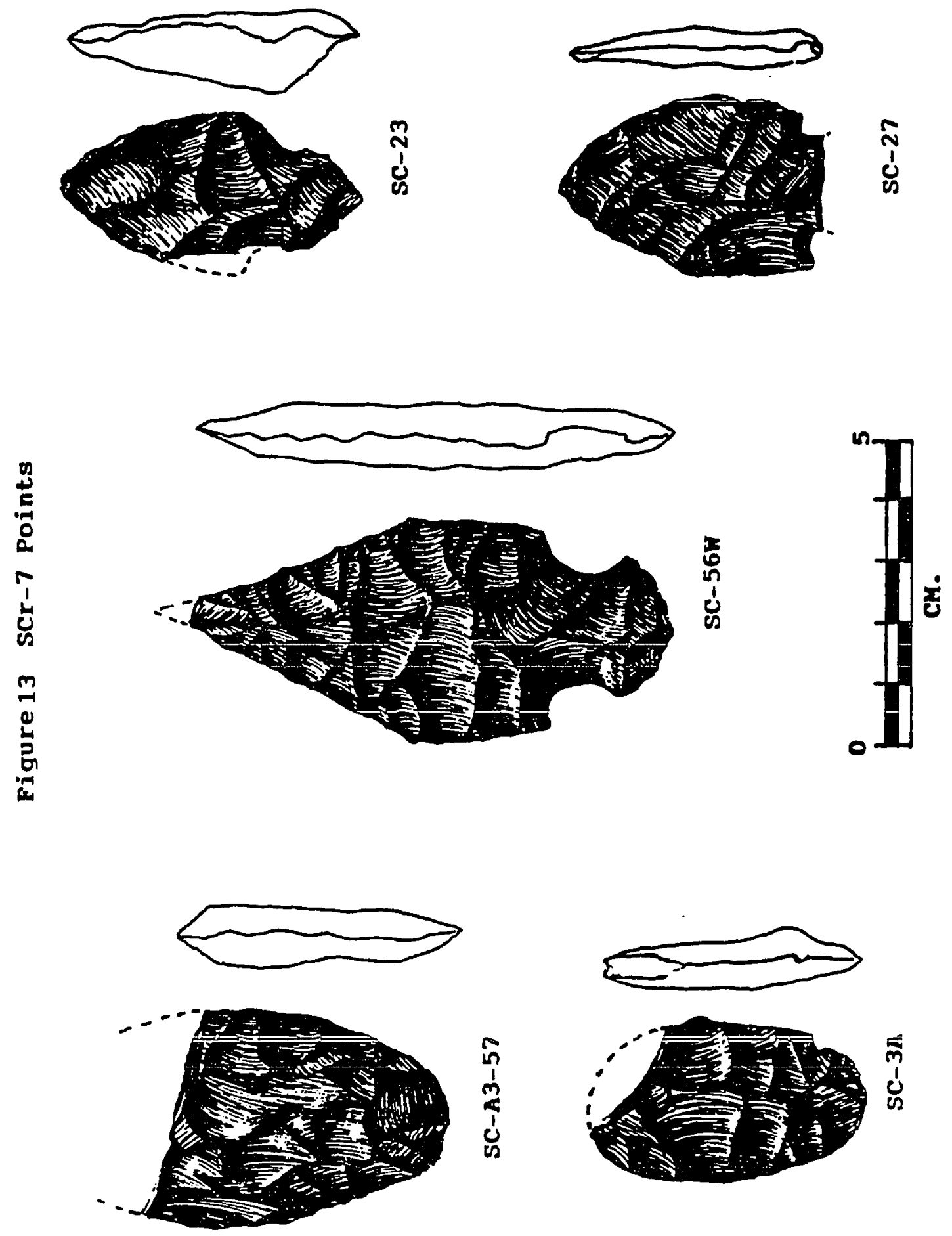


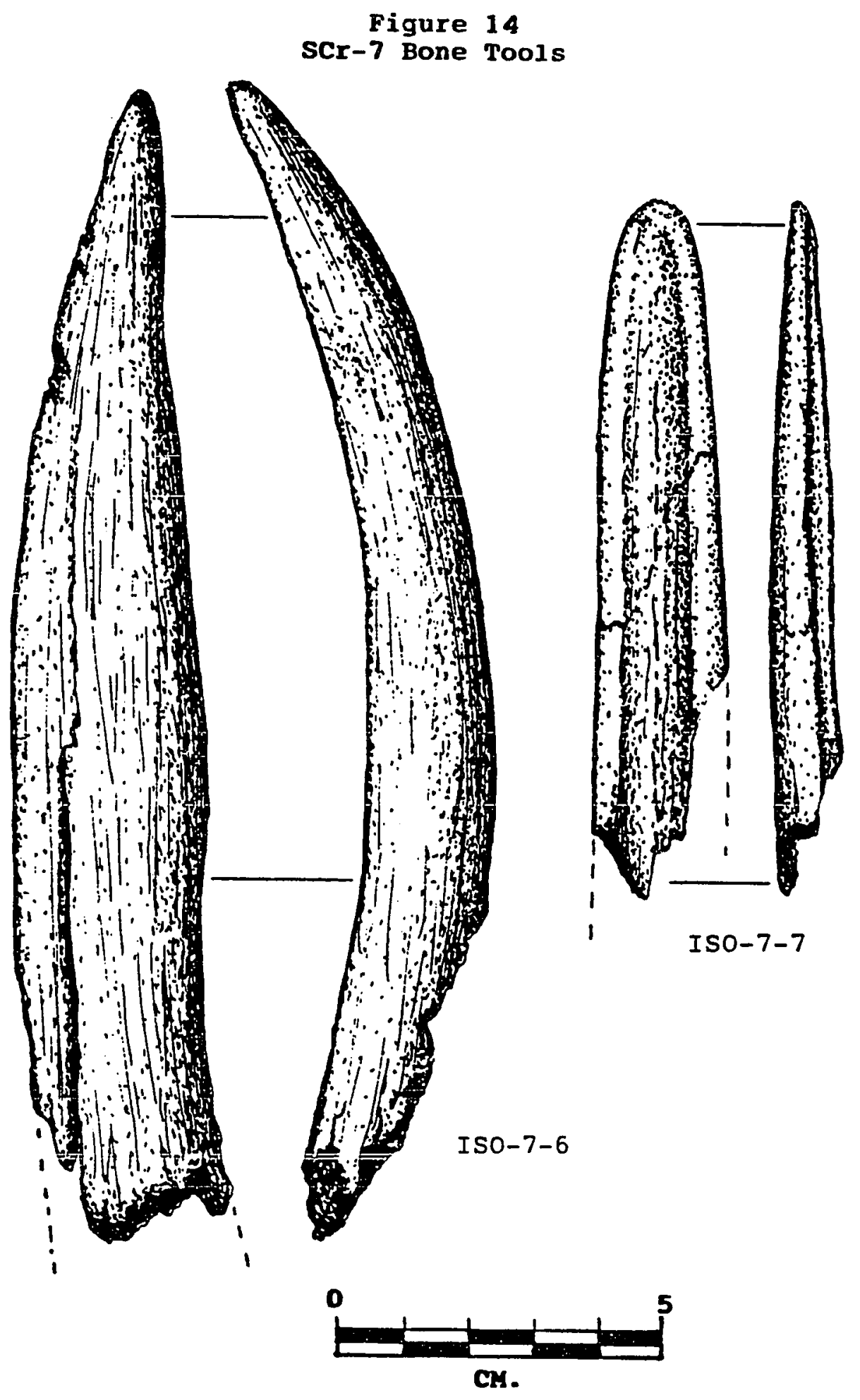




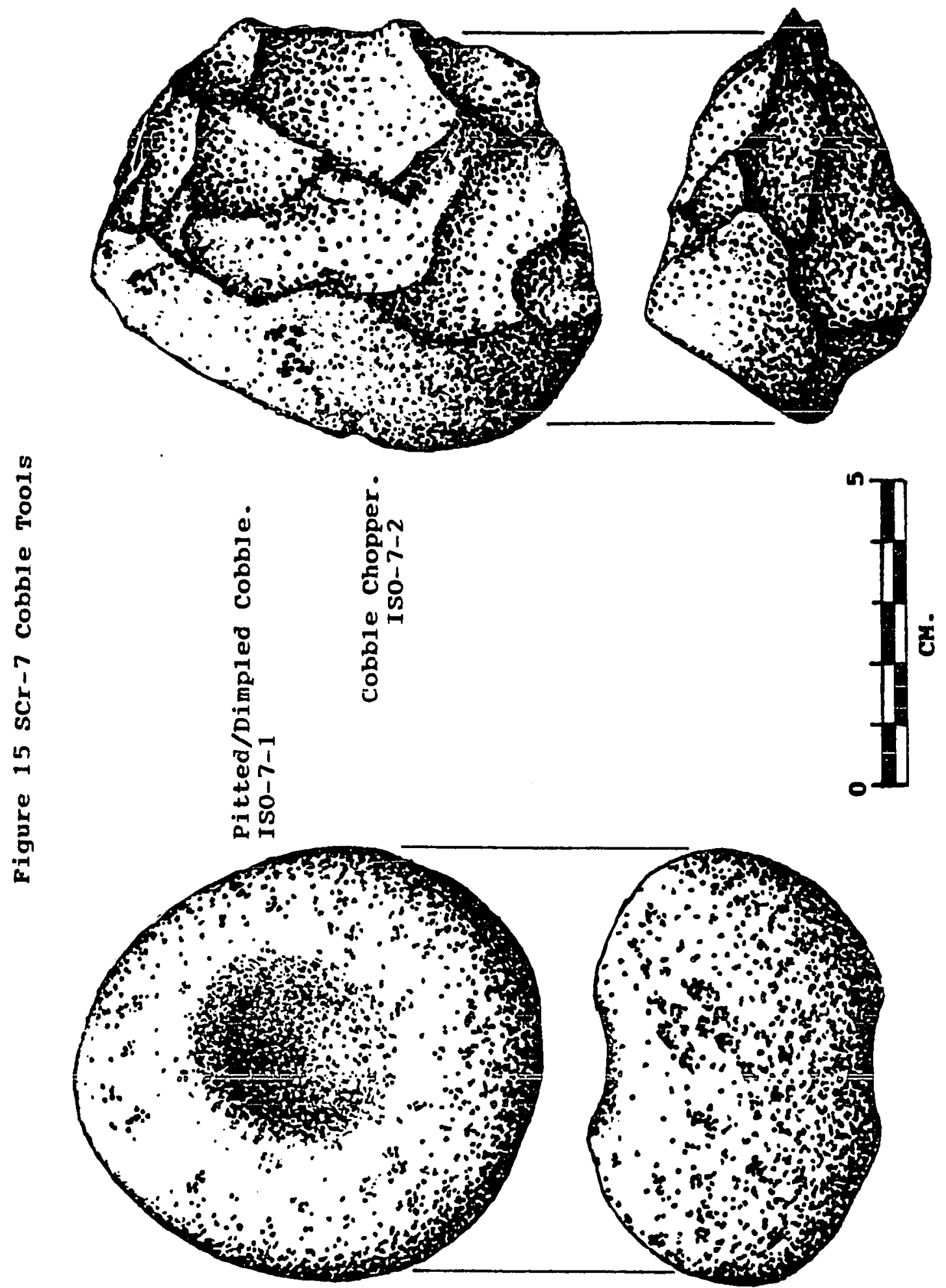


scr-9, the Bonny Doon site

sCr-9 is located on the western slope of the upper reaches of Ben Lomond Mountain near the town of Bonny Doon. The site is situated within a grassland meadow community, and it is within the upland meadow zone defined for this study. Much of the site is surrounded by redwood and mixed hardwood forest. The elevation here is approximately 1300 feet above sea level.

The site, which was tested by this author, is a Middle Period residential base, and contained a wide diversity of artifacts. While the site revealed vertical variations in artifact densities and a range of obsidian hydration readings, the assemblage does not reflect more than one component. No late period artifacts were recovered nor was there a shift in dietary pursuits. The only real differences along these lines was the fact that levels below $40 \mathrm{~cm}$. contained a greater diversity of point types and obsidians from a wider range of sources. The site is a mound, or knoll, formed by the deposition of massive amounts of shell. Pine Flat Road crosses the western edge of the site. A single $1 \times 1$ meter unit and four $1.5 \times 1.5$ meter units were excavated. Table 10 presents the unit dimensions and excavation volume. 
Table 10: Unit Dimensions and Volume from SCr-9

\begin{tabular}{|c|c|c|c|c|}
\hline Unit\# & Dimension & Screen & Method & Cubic Meter \\
\hline $\begin{array}{l}1 \\
2 \\
3 \\
4 \\
5 \\
\text { CU. } 1\end{array}$ & $\begin{array}{r}1 \times 1 \mathrm{~m} . \\
1.5 \times 1.5 \mathrm{~m} . \\
1.5 \times 1.5 \mathrm{~m} . \\
1.5 \times 1.5 \mathrm{~m} . \\
1.5 \times 1.5 \mathrm{~m} . \\
25 \times 25 \mathrm{~cm} .\end{array}$ & $\begin{array}{l}1 / 8 " 1 \\
1 / 8 " 1 \\
1 / 4 " \\
1 / 4^{\prime \prime} \\
1 / 4^{\prime \prime} \\
1 / 8 "\end{array}$ & $\begin{array}{l}\text { Dry } \\
\text { Wet } \\
\text { Wet } \\
\text { Wet } \\
\text { Wet } \\
\text { Wet }\end{array}$ & $\begin{array}{l}1.8 \\
3.0 \\
2.85 \\
2.7 \\
3.0 \\
.5\end{array}$ \\
\hline
\end{tabular}

A total of 13.85 cubic meters of site was excavated. Units 2 through 5 were established adjacent to one another to create a trench measuring 1.5 meters wide by 6 meters long. This was done to provide a continuous stratigraphic profile of the excavation (see Figure 16). Average depth of the trench was 2 meters, although a shell roasting pit (Feature 2) was intrusive into the sterile levels of Unit 2. Map 16 illustrates unit locations and site boundaries.

The first $50 \mathrm{~cm}$. of the midden was composed of a very dark soil with abundant shell fragments, faunal bone and debitage. From $50 \mathrm{~cm}$. to $100 \mathrm{~cm}$. midden constituents increased, and from 100 to $160 \mathrm{~cm}$. lenses of burned earth and baked shells were encountered. The black colored midden ended abruptly at approximately $200 \mathrm{~cm}$. where it overlays a sterile yellow sand matrix. The beach quality sands were auger tested to depths of $350 \mathrm{~cm}$. below ground surface but continue well beyond that depth. The water table was found to be at the sandy level $(210 \mathrm{~cm}$.$) , and shortly after the$ last levels were excavated the water level began to rise in the trench. 
Six radiocarbon dates were derived for this site, one of which was erroneous ( $15 \pm 140$ years B.P.), and is not considered further. Table 11 presents the results.

Table 11: Radiocarbon Dates for SCr-9

WSU\# Provenience, Composition $14 \mathrm{C}$ age(Years B.P.)

$\begin{array}{lllll}3230 & \mathrm{U} .1 / 20-30 \mathrm{~cm} ., & 250 \mathrm{gr} \text {. Mytilus } & 1480 \pm 65 \\ 3171 & \mathrm{U} .5 / 140-150 \mathrm{~cm} ., & 350 \mathrm{gr} \text {. Mytilus } & 2730 \pm 60 \\ 3170 & \mathrm{U} .4 / 130-140 \mathrm{~cm} ., 350 \mathrm{gr} \text {. Mytilus } & 2790 \pm 60 \\ 3203 & \mathrm{U} .2 / 190-200 \mathrm{~cm} ., 200 \mathrm{gr} \text {. Charcoal } & 2790 \pm 85 \\ 3204 & \mathrm{U} .2 / 200 \mathrm{~cm} ., & 350 \mathrm{gr} \text {. Mytilus } & 2940 \pm 60\end{array}$

Column unit CU.1 provides information on shell volume for the site. A total of $40,489.0 \mathrm{gr}$. of shell was recovered equal to $80,978 \mathrm{gr}$. per cubic meter of site. Table 12 presents the results of the column analysis. Unfortunately, shell species were not quantified, although Mytilus californianus clearly dominates the assemblage by an estimated $95 \%$.

olivella shell was recovered from the excavation and included unmodified and modified shells. The results of the olivella shell artifact recovery with the frequencies of the various types by unit and depth have been presented in Appendix B. A total of 68 olivella specimens were recovered, equal to five pieces per cubic meter of site. Only four (6\%) were shaped beads, while $34 \%$ had intact spires, $29.5 \%$ were spire broken, 23.5 \% had ground spires, and $7 \%$ were fragmented. The four shaped beads included a type G6a, a G6b and a G6C saddle bead (bead types after Bennyhoff and Hughes 


\section{Table 12 \\ SCr-9 Column Sample: \\ (Unit CU.1)}

Unit Volume $=.5$ cubic meters. Weights in gr.

Depth Shell(wt.) Bone(wt.) Chipped Stone(\#/wt.)

\begin{tabular}{lrrrr}
$0-10$ & 1270.0 & 19.4 & 29 & 10.7 \\
$10-20$ & 2086.5 & 14.3 & 36 & 76.5 \\
$20-30$ & 2404.5 & 17.9 & 28 & 8.7 \\
$30-40$ & 1633.0 & 10.5 & 23 & 12.7 \\
$40-50$ & 1769.0 & 11.5 & 24 & 9.5 \\
$50-60$ & 1933.0 & 22.0 & 48 & 22.9 \\
$60-70$ & 1020.0 & 9.7 & 20 & 71.5 \\
$70-80$ & 1524.0 & 23.0 & 12 & 2.5 \\
$80-90$ & 1871.0 & 19.0 & 26 & 26.2 \\
$90-100$ & 2118.0 & 21.5 & 35 & 38.1 \\
$100-110$ & 2448.5 & 26.9 & 46 & 9.7 \\
$110-120$ & 2602.0 & 25.5 & 71 & 31.7 \\
$120-130$ & 2138.0 & 22.7 & 46 & 25.3 \\
$130-140$ & 2304.0 & 31.4 & 62 & 23.2 \\
$140-150$ & 1878.0 & 6.5 & 10 & 47.5 \\
$150-160$ & 2385.5 & 15.0 & 32 & 15.6 \\
$160-170$ & 2205.0 & 12.0 & 31 & 59.3 \\
$170-180$ & 2202.0 & 26.2 & 36 & 19.5 \\
$180-190$ & 2338.0 & 25.2 & 25 & 54.6 \\
$190-200$ & 2359.0 & 80.0 & 43 & 19.2 \\
Total & $40,489.0$ & & & \\
\hline
\end{tabular}

Projected Site Volume (M 3):

She11........88,978.0 gr.

Bone.........8.840.0 gr.

Chipped Stone...1,366 pcs.....1,489.8 gr. 
1987) as well as an Olivella shell which had been split in half and polished on the interior facets, but not perforated. These beads are illustrated in Figure 17. Artifacts of Haliotis shell included a perforated pendant fragment (possibly type Qla after Gifford 1940), and a rectangular pendant blank with ground edges and faces exhibiting cutting incisions. These are also illustrated in Figure 17.

Faunal bone elements were abundant and bone preservation was very good, possibly as a result of the neutralizing effects that the alkali rich shell deposit has on the typically acidic surrounding soils. Table 13 presents the results of the analysis of faunal remains from units 2 and 5. These two units recovered a total of 8,866 pieces of bone $(9,556.6 \mathrm{gr}$.$) . This is equal to 1,477.6$ pieces $(1,592.7$ gr.) per cubic meter of site. From this recovered amount, $8 \%$ of the pieces and $35 \%$ of the weight of the bone were identified by species. Of the identified elements, $95 \%$ of the pieces and $96.5 \%$ of the weight were from terrestrial mammals, predominantly odocoileus hemionus (71.7\% of the identifiable bone elements and $75 \%$ of the weight). The distribution of taxa by $10 \mathrm{~cm}$. levels has been presented in Appendix A. 
Table 13

scr-9 Taxa Frequency:

(Units 2 and 5 ; Cetacea and Rodentia Excluded)

\begin{tabular}{|c|c|c|c|c|}
\hline Taxa & \#pcs. & $\underline{\not}$ & $W t \cdot(g r)$ & $\underline{\text { q }}$ \\
\hline $\begin{array}{l}\text { Ottaridae } \\
\text { Enhydra } \frac{\text { lutris }}{\text { Phoca vitulina }} \\
\frac{\text { Zalophus californicus }}{\text { Callorhinus ursinus }}\end{array}$ & $\begin{array}{r}4 \\
2 \\
11 \\
2 \\
9\end{array}$ & $\begin{array}{r}.5 \\
.3 \\
1.6 \\
.3 \\
1.3\end{array}$ & $\begin{array}{r}12.8 \\
2.8 \\
60.6 \\
4.9 \\
32.3\end{array}$ & $\begin{array}{r}.4 \\
.1 \\
2.0 \\
.1 \\
1.0\end{array}$ \\
\hline $\begin{array}{l}\text { Artiodactyl } \\
\text { Cervus nanoides } \\
\text { Odocoileus hemionus } \\
\text { Canis sp. } \\
\frac{\text { Ursus horibilus }}{\text { Felis }} \text { concolor } \\
\frac{\text { Lynx }}{\text { Mephitis }} \text { mephitis } \\
\text { Sylvilagus audubonii }\end{array}$ & $\begin{array}{r}1 \\
23 \\
499 \\
6 \\
5 \\
2 \\
4 \\
1 \\
55\end{array}$ & $\begin{array}{r}3.1 \\
71.7 \\
.8 \\
.7 \\
.3 \\
.5 \\
.1 \\
7.9\end{array}$ & $\begin{array}{r}1.8 \\
605 \cdot 1 \\
2458 \cdot 2 \\
21 \cdot 1 \\
11 \cdot 9 \\
11.9 \\
14 \cdot 1 \\
1.8 \\
20.2\end{array}$ & $\begin{array}{r}.1 \\
18.0 \\
75.0 \\
.5 \\
.5 \\
.5 \\
.5 \\
.1 \\
.5\end{array}$ \\
\hline Aves & 50 & 7.0 & 24.7 & .4 \\
\hline Ichthys & 21 & 3.0 & 3.6 & .1 \\
\hline Unidentifiable & 8171 & 92.0 & 6268.8 & 65.0 \\
\hline Total & 8866 & & 9556.6 & \\
\hline
\end{tabular}

Terrestrial vs Marine:

(Cetacea, Rodentia, Aves and Ichthys Excluded)

\#pcs.\%

Terrestrial

Marine
95.5

4.5
Wt. (gr) \%

96.5

43.5 
A total of 44 bone tool fragments were recovered. The measurements and descriptions of them have been presented in Appendix .C. 25 specimens are illustrated in Figures 18 to 20. Table 14 summarizes the types and frequencies of their occurrence.

Table 14, Bone Tool Types from SCr-9

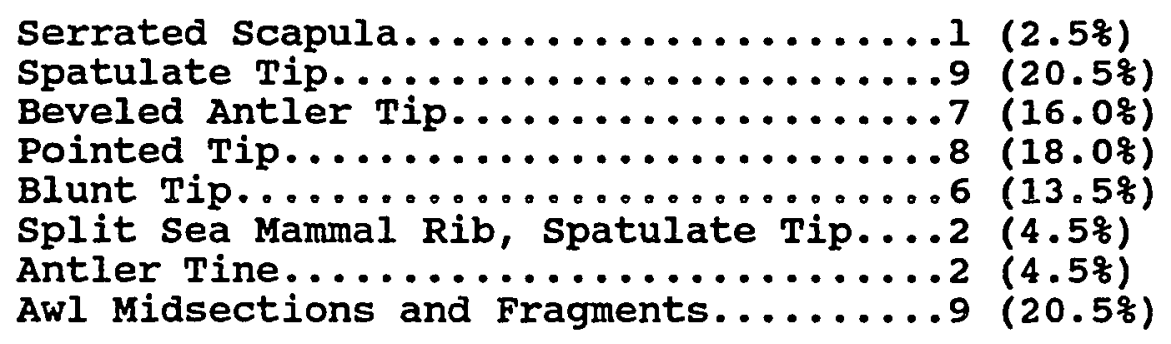

Some of the beveled and polished antler tips (\#s 9-4-2$3,9-2-10-3$ and 9-1-14-3) and one specimen (\#9-3-15-3), a short antler tip with an angled base ground to shape, may have been throwing spear engaging spurs.

Debitage was very abundant at this site. Table 15 presents the number of pieces and weights by unit.

Table 15: Debitage Volume from SCr-9

\begin{tabular}{|c|c|c|c|c|}
\hline $\begin{array}{l}\text { Unit\# } \\
1 \\
2 \\
3 \\
4 \\
5 \\
\text { CU. } 1\end{array}$ & $\begin{array}{l}\# \frac{\text { PCS }}{556} \\
2,558 \\
1,367 \\
1,444 \\
1,372 \\
683\end{array}$ & $\begin{array}{r}\text { 总 } \\
7.5 \\
32.0 \\
17.0 \\
18.0 \\
17.0 \\
8.5\end{array}$ & $\begin{array}{c}\text { WT. (gr.) } \\
2,650.0 \\
7,986.0 \\
6,576.0 \\
6,904.0 \\
7,662.5 \\
744.9\end{array}$ & $\begin{array}{r}\text { 8. } \\
8.5 \\
24.5 \\
20.0 \\
21.0 \\
23.5 \\
2.5\end{array}$ \\
\hline
\end{tabular}

- Debitage from unit 2 was selected for type population analysis. Table 16 summarizes the results. of the debitage 


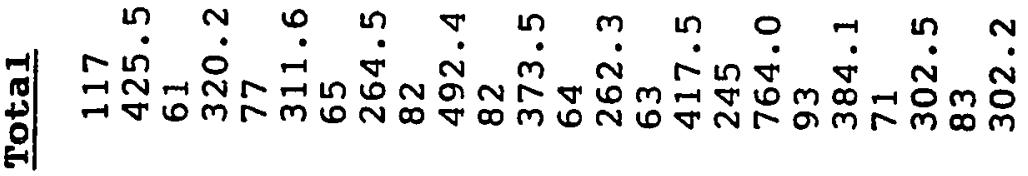

al 00 :

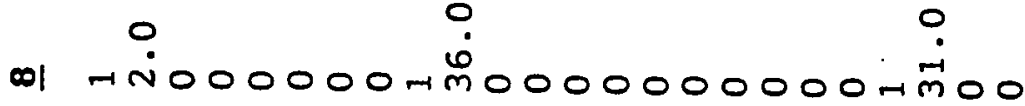

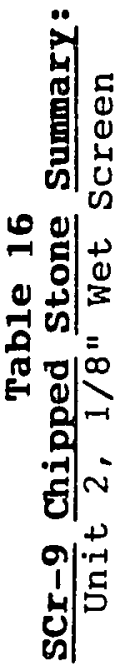

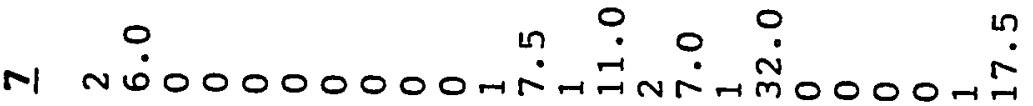

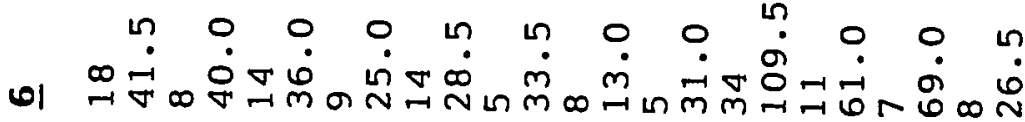

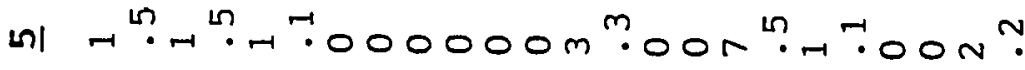

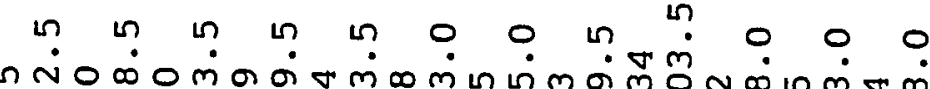

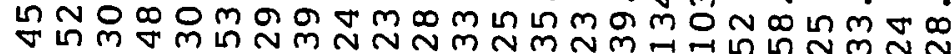

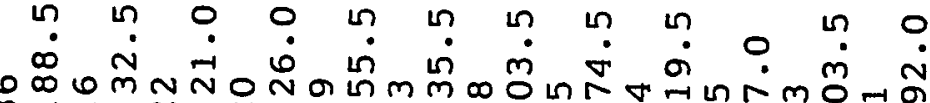

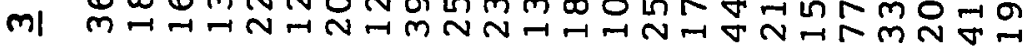

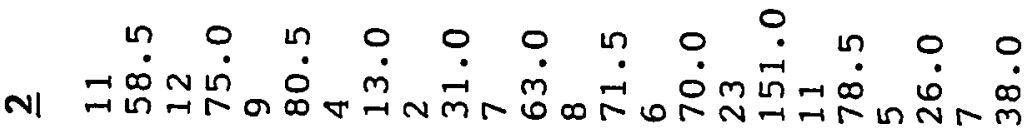

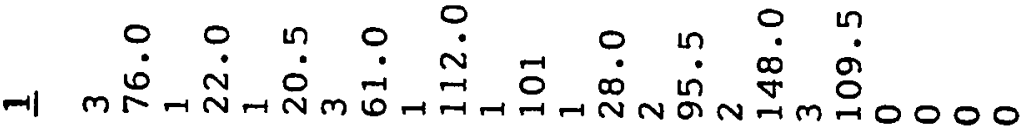

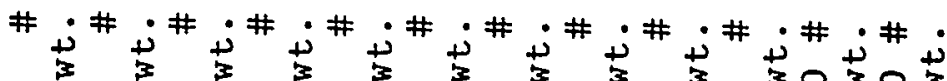

뎨 $ㅇ ㅇ ㅇ ㅇ ㅇ ㅇ ㅇ ㅇ ㄱ$

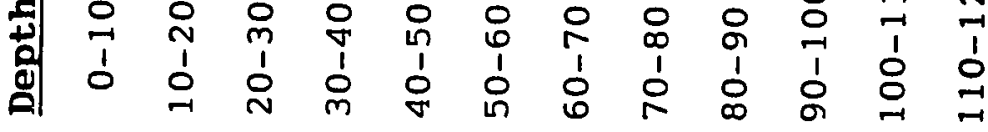




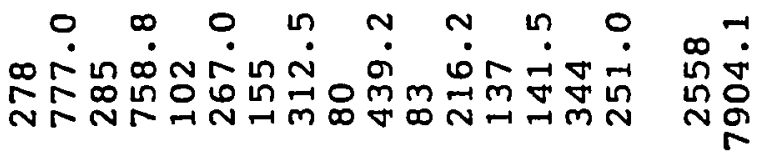

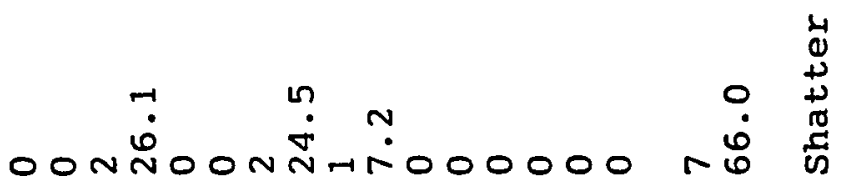

in $\sim$ แै।

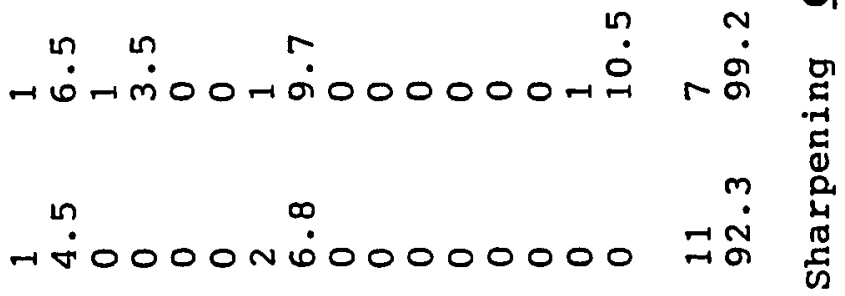

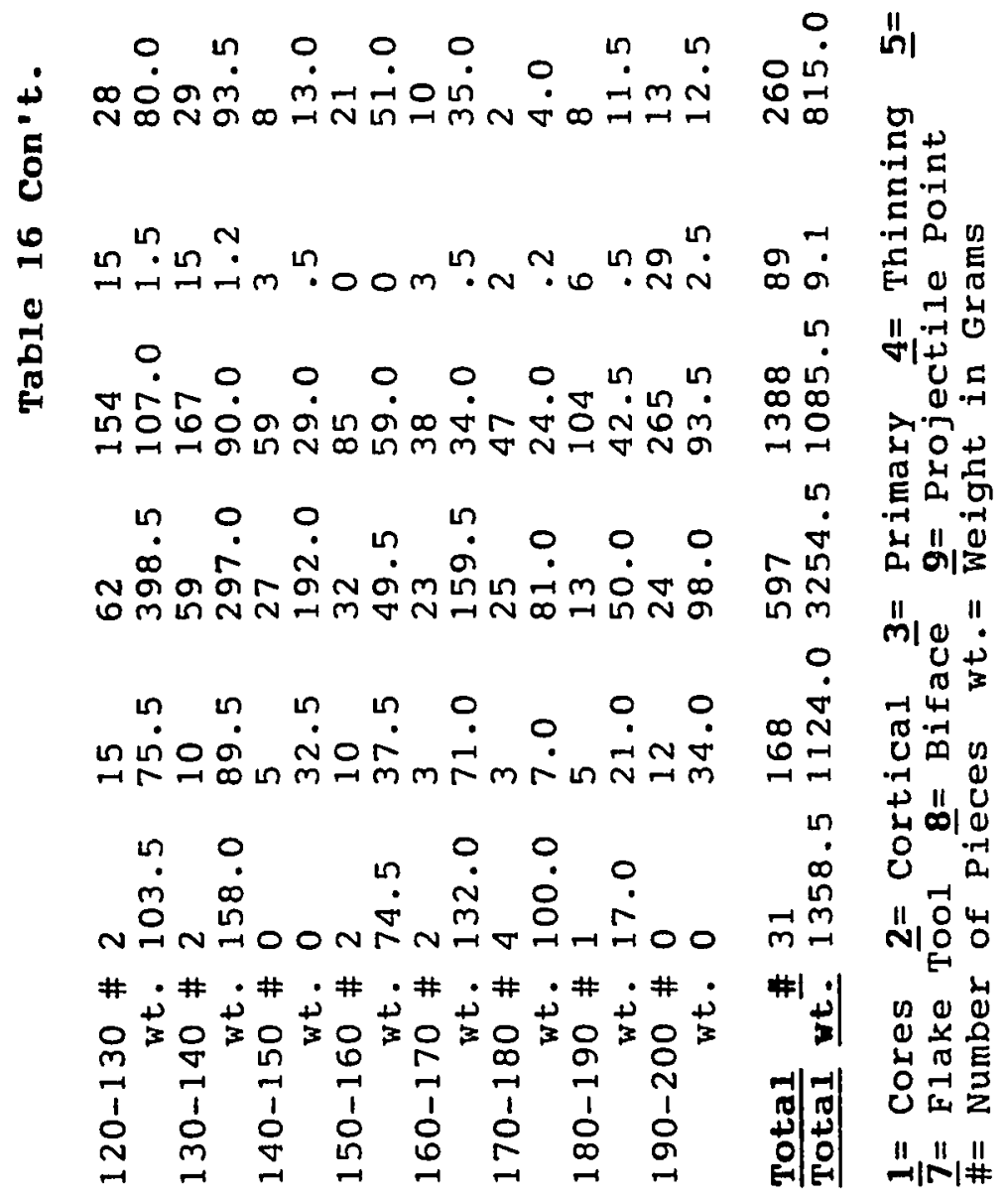


pieces, $31 \%$ represented primary reduction, $58 \%$ reflect secondary reduction, $10 \%$ were shatter debris, $.5 \%$ were informal flake tools, and .5\% were formal tools. Unit 2 provided an amount of debitage equal to 852.5 pieces $(2,634.5 \mathrm{gr}$.$) per cubic meter of site.$

Chipped stone tools were also quite numerous and were made from a wide variety of materials. A total of 78 formal and informal specimens was recovered. Table 17 presents the material composition of this collection.

Table 17: Chipped Stone Tool Material Composition from scr-9

Monterey Chert..........62 (79.5\%)

Obsidian........................... (15\%)

Franciscan Chert.......... (2.5\%)

Red Jasper................. $(2.5 \%)$

Detailed descriptions of the material types, artifact types, measurements and reduction stages have been presented in Appendix D. A total of 48 specimens are illustrated in Figures 21 through 29. In all, 58 projectile points were recovered, 36 of which were complete enough to assign them to specific types. The typed points (reduction stages 4 and

5) from this site are presented in Table 18.

Formal chipped stone tools (reduction stages 4 and 5) constituted $74.5 \%$ of the assemblage with informal tools (stages 1, 2, and 3) comprising 25.5\%. scr-9 produced 18.5 chipped stone tools per cubic meter of site, excluding the surface finds. Contracting stem series points, particularly 
Table 18: Point Types from scr-9 (N= 58)

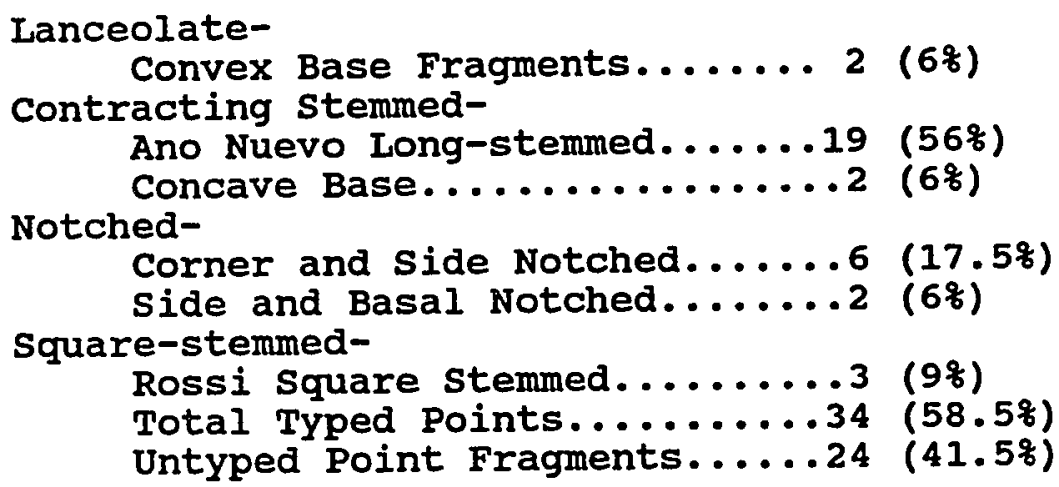

the Ano Nuevo long-stemmed type, were the best represented in the collection. 2 concave base contracting stemmed points were recovered. One was from an upper level $(20-30 \mathrm{~cm} \cdot)$ and the other was from a lower level $(140-150 \mathrm{~cm}$.$) . The others$ were spread throughout the units in the upper and lower levels. Notched points, occurring in several forms, clustered in the middle levels $(70-150 \mathrm{~cm}$.), excluding 2 surface specimen. The 3 square stemmed were from the lower levels (140-160 cm.). The 2 lanceolate base fragments are surface finds. Many of the points exhibited extensive blade reworking and thermal spalls from exposure to heat. One of the concave base contracting stemmed specimen, 9-3-15-5, exhibited asphaltum clumps along the base which retain imprints from the sinew thread used to bind the point to the shaft. These imprints have been photographed and are curated with the artifact. The asphaltum residue shows that at least $40 \mathrm{~mm}$. of the base length from the base up was glued and 
bound. Square stemmed specimen 9-2-16-3 had a serrated blade, which is unique for this type of point. In addition to the points, 4 borers, or drills, were found. These may have been used to hollow out sockets on shafts for hafting contracting stem and lanceolate series points, or for engaging sockets at the base of the shaft for throwing spears (Atlatl). These drills do not appear to have been hafted.

A total of 51 pieces of obsidian were recovered, equal to 25.5 pieces per cubic meter of site. Of these, 17 specimen can be classed as formal tools, and the remaining 34 pieces are pressure and thinning flakes. Fifty of the obsidian pieces were either visually sourced or through XRF analysis. Of these, 44 specimens were subjected to obsidian hydration analysis. Table 19 presents the obsidian inventory for scr-9 and includes artifact descriptions and provenience as well as source and rim hydration readings. Table 20 lists the rim readings by depth and source. Both eastern sierran and northern californian sources occurred at this site. of the 50 sourced specimens 29 (58\%) were from Napa Valley, 12 (24\%) were from Casa Diablo, 6 (12\%) were from Bodie Hills, $1(2 \%)$ was from Mt. Hicks and $2(4 \%)$ were from Annadel. Northern California obsidian composed $62 \%$ of the sample, and eastern sierran sources composed $38 \%$. 


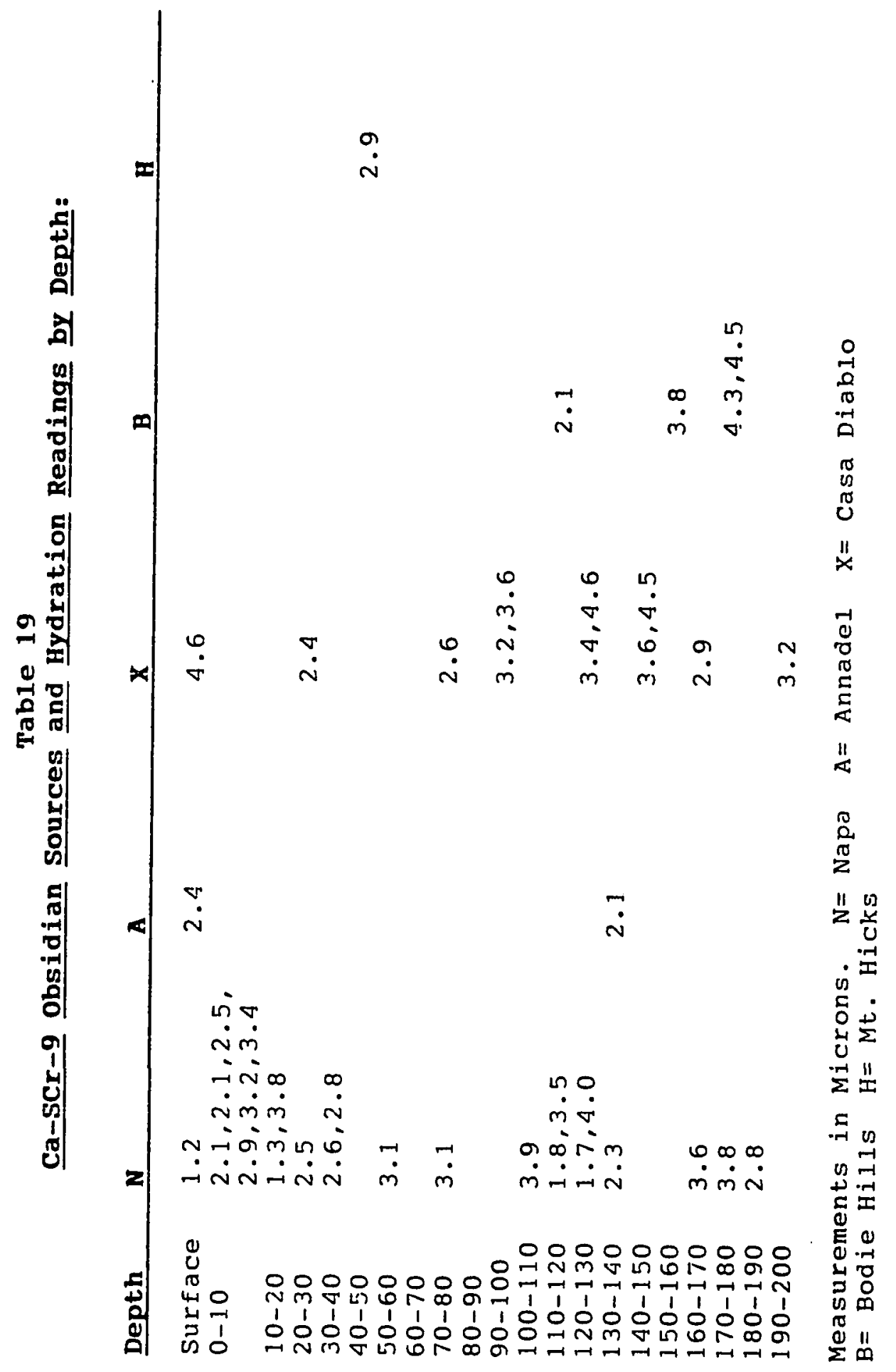




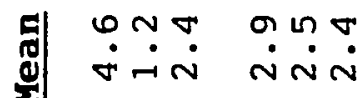

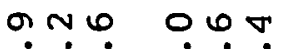

$\dot{\nabla} \dot{\sim} \dot{m} \dot{N}$

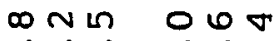

$\dot{\nabla} \dot{\sim} \dot{m} \dot{N}$

$\cot \theta$ o

$\dot{\nabla} \dot{\sim} \dot{N} \dot{N} \dot{N}$

แn $N$ ब $\dot{\sim} \dot{\sim} \dot{\sim} \underset{0}{0} \dot{N}$ $R \rightarrow R \cdot \pi \pi^{2} \pi m$ $\dot{v} \dot{\sim} \cdot \dot{N} \dot{\sim}$ $\nabla \rightarrow m>a m m$ $\dot{\nabla} \dot{\sim} \mathcal{Z} \dot{\sim} \dot{N}$

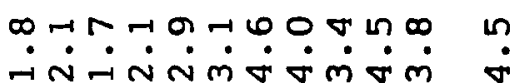

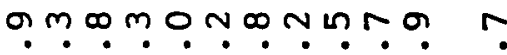
$\dot{\sim} \dot{\sim} \dot{\sim} \dot{m} \dot{\nabla} \dot{\nabla} \dot{\nabla} \dot{\nabla}$

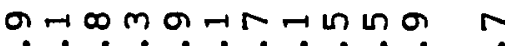
$\dot{\sim} \dot{\sim} \dot{\sim} \dot{m} \dot{\nabla} \dot{\nabla} \dot{\nabla} \dot{m} \dot{\sigma}$

$\infty \pi n-a n+\pi)$

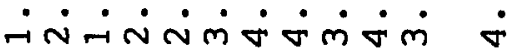

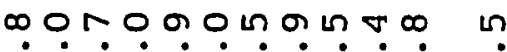
$\dot{-i} \dot{\sim} \dot{N} \dot{\sim} \dot{\nabla} \dot{m} \dot{\nabla} \dot{m}$ DOROGO

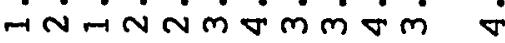

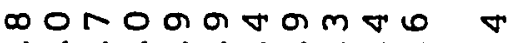
$\dot{\sim} \dot{\sim} \dot{N} \dot{N} \dot{\sim m} \dot{m} \dot{\nabla} \dot{\nabla}$

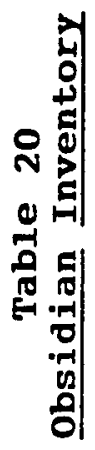

品杂男之兄

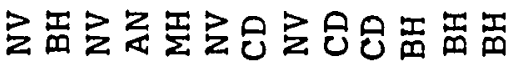

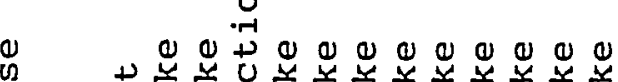

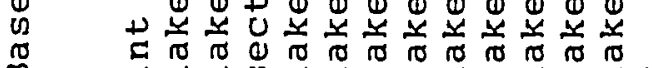

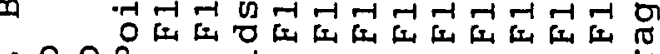

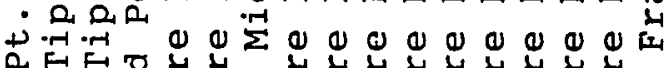

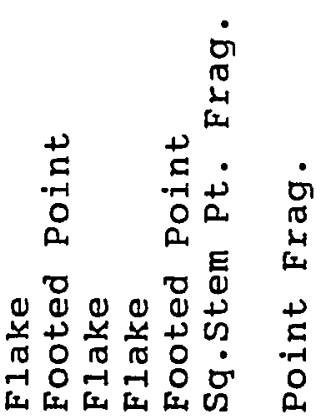

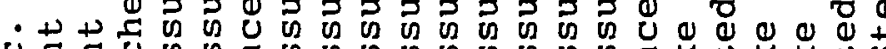
U.

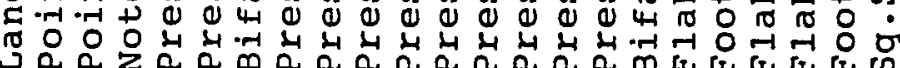

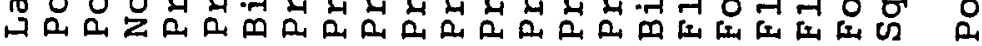

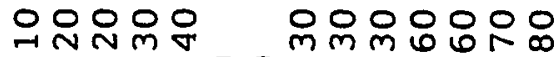

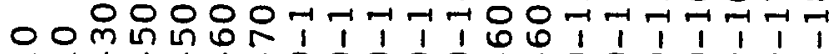

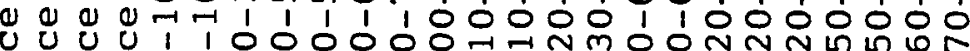
U U U U U

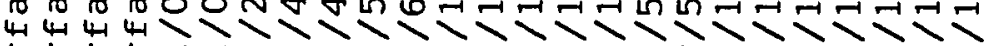
म 行得

点

$\varangle m$

$\nabla$ 承

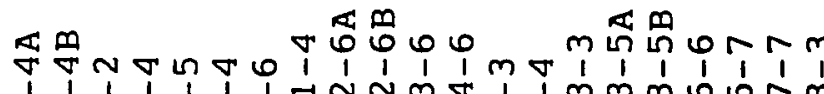

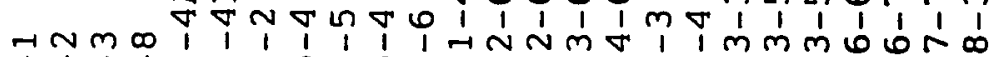

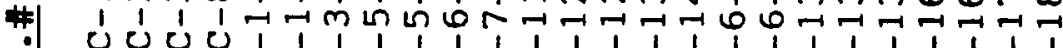

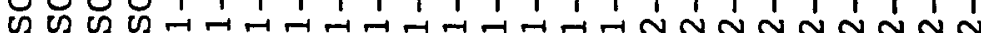

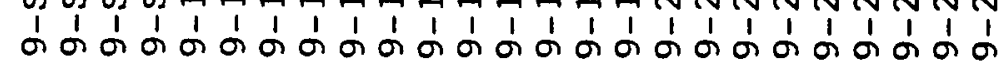




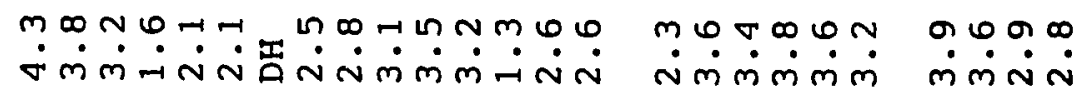

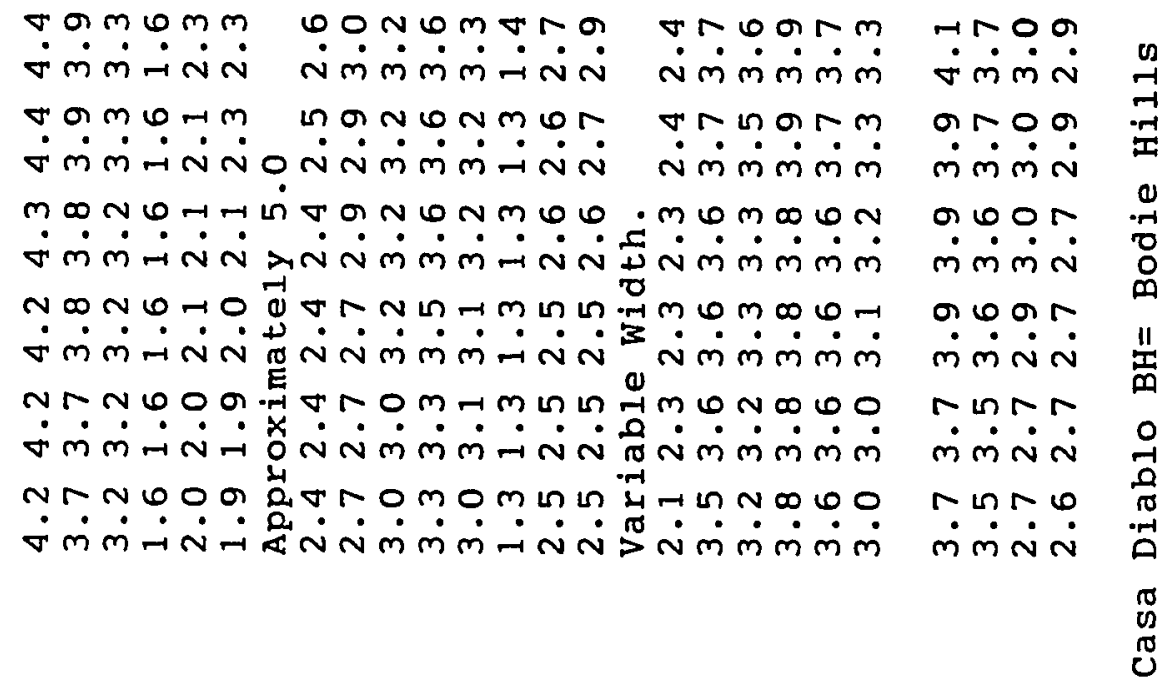

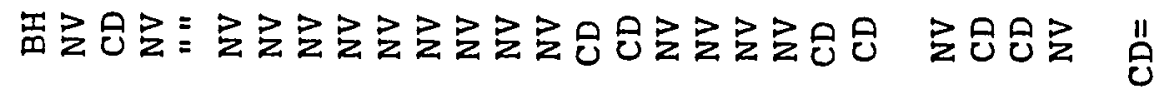

용

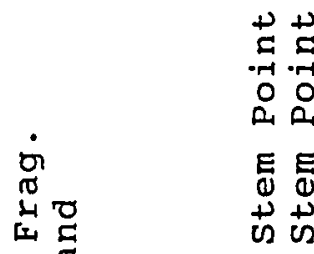

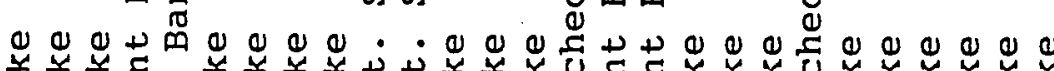

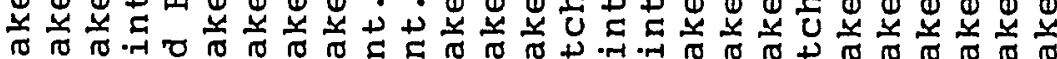

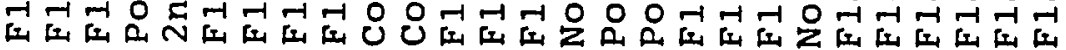

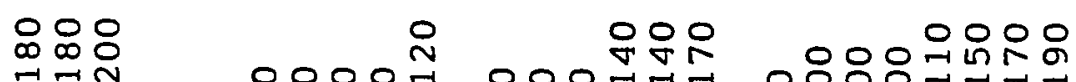

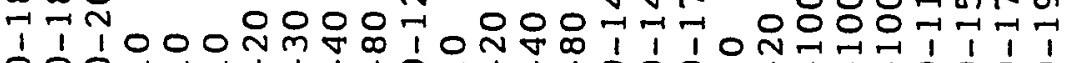

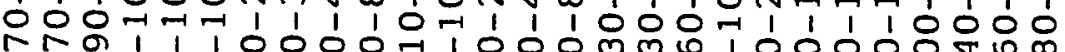

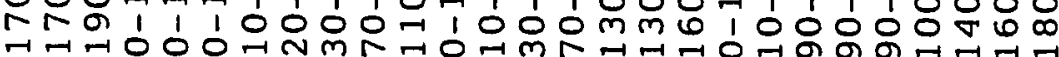

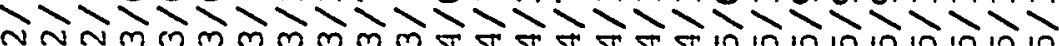

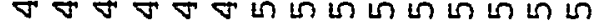

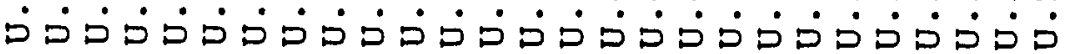

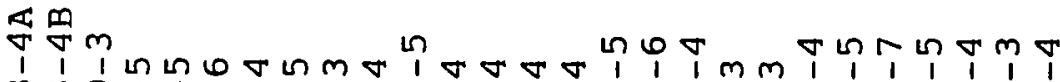

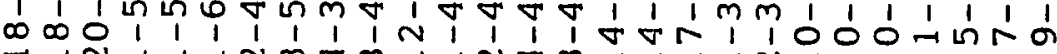
-

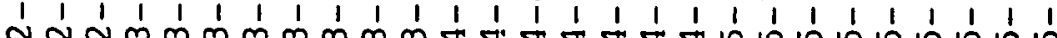
$\hat{1}_{1} \prod_{1} m_{1} m_{1}$

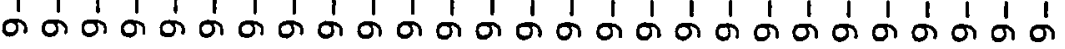


68 cobble tool artifacts were recovered. The artifact descriptions, materials, and measurements have been presented in Appendix E. Eleven cobble tools are illustrated (see Figures 30 to 36 ). Table 21 presents the frequencies of each type within the assemblage.

Table 21: Cobble Artifacts from scr-9 (N=68)

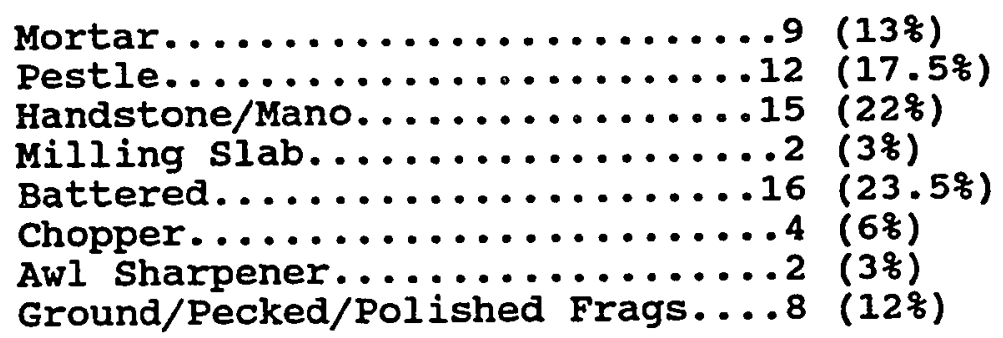

These cobble tools were distributed throughout the levels with no particular clustering of types by depth. These artifacts were made from quartzite, sandstone, granite, andesite, rhyolite, mudstone, and in one case, jade. Both acorn and hard seed milling tools were recovered, with mortars and pestles, handstone and milling slabs found together in the upper, middle and lower levels of the units. Many of the handstones were made of quartzite and were discoidal with flat, vertical shoulders shaped by extensive pecking around the circumrerence. 4 handstones had bifacially pecked axial ends in addition to shaped shoulders which created a somewhat beveled cross section. Specimen 91-14-6 (Figure 33) presents a good example of this modification pattern. Mortars in this collection consisted 
of broken fragments, and the same was true of the pestles. Many of these specimens have been discolored from exposure to heat, and may have been used as cooking stones after they were damaged or worn out. Two awl sharpening stones were recovered which exhibited deep incisions, or grooves on their surfaces. Noticeably absent from this collection were charmstones, pitted/dimpled stones, well defined milling slabs and grooved/notched stones.

Two features were identified during the excavation. Feature 1 was a cluster of rocks in unit 4 at 100 to $120 \mathrm{~cm}$. below ground surface (see Figure 37). This rock cluster consisted of 10 granitic stones arranged in a pile, with the center left open. One of the cobbles is a granite boulder with a worn surface. The wear pattern appears to have resulted from abrasion. A rectangular Haliotis pendant blank (\# 9-4-12-5) was found directly under one of the cobbles. Also, a Haliotis pendant fragment (\# 9-4-12-4) was found near the rock cluster (pendant type Qla after Gifford 1940). The function of this feature was not determined.

Feature 2 was a pit that intruded into the sterile sandy matrix at the basal level of Unit 2, 190 to $200 \mathrm{~cm}$. below ground surface. This pit was filled with baked Mytilus californianus shell, and the discolored tan to orange soils around the pit indicated that it was used to cook shellfish. Also, dozens of Monterey chert pressure flakes were observed 
with the shell, possibly a result of the secondary heat treatment of chipped stone tools, or from tool workers sharpening stone blades by the warmth of the oven. Similar lenses of baked earth and shell were observed in unit floors and stratigraphic profiles of the trench, but these did not have a well defined pit outline like feature 2 had. Samples from this feature were bagged and curated with the rest of the collection, but were not further analyzed for this study. Two of the radiocarbon dates for this site were from feature 2. The first, WSU\# 3203, consisted of a single lump of charcoal weighing $200 \mathrm{gr}$. and the second, WSU\# 3204, was from $350 \mathrm{gr}$. of Mytilus. The results of both dates were within 150 years of each other, and the standard deviation margin allows for the possibiiity that the dates actually overlap. WSU\# 3204 provided a date of $2,940+60$ years B.P., or 1,000 B.C. which represents the oldest dated level of the site.

While the excavation was in progress, the landowner uncovered a human burial while digging a narrow trench for a water sprinkler system. The bone elements observed in situ indicated that the burial was in a flexed position, only 30 $\mathrm{cm}$. below the ground surface. The location of this burial has been plotted on the site map (Map 16). The burial was situated at the very end of the trench, and the landowner decided to reduce the length of the irrigation system to 
avoid further intrusion into the site. The burial, which sustained little damage, was covered with earth and left in its original position. It is very likely that additional human burials are contained in the vicinity of the first one.

scr-9 exhibits two temporal components as evidenced by the radiocarbon dates, obsidian hydration, and stratigraphy; however, the artifact assemblage and terrestrial vs. marine constituents do not reveal any significant variations of adaptive mode. Therefore, this site is essentially a single component assemblage with earlier and later occupations. The abundance and wide diversity of artifacts, their homogeneous vertical distribution to a depth of two meters, and the presence of human remains indicates a repetitive use of the location as a residential base. Hunting pursuits were focused on the deer and elk which would have been concentrated within the upland meadows surrounded by dense redwood forest. The lower level component showed an increase in shell, greater variety of point types and some marine mammal bones. The decrease in materials in the upper levels may indicate a less intensive use of the location at that time. Table 22 on the following page presents the component summary - 
Table 22: Component Summary for scr-9

1) Upper Level: $0-40 \mathrm{~cm}$. Age: Middle Period, 1,480 \pm 65 B.P. Obsidian Hydration Range: Napa (N=11) $1.3-3.8$

Casa Diablo ( $\mathrm{N}=1) \quad 2.4$

Artifacts:

Ano Nuevo long-stemmed Pts. Mortars \& pestles

Handstones \& milling slabs

Awl sharpener

Bone awls

2) Lower Level: 50-200 cm. Age: Middle Period 2,730 \pm 60 to $2,940 \pm 60$ B.P. Obsidian Hydration Range: Napa $(\mathrm{N}=11)$ 1.7-4.0 Casa Diablo $(\mathrm{N}=9)$ 2.4-4.6

Artifacts: Fauna:* Shell Wt(M3):

Ano Nuevo long-stemmed Pts. Rossi square-stemmed Pts. Deer (63\%) Sea mammals $(4.5 \%)$

Shel1 Wt(M3): Notched (side \& corner) Pts. Mortars \& pestles

Handstones \& milling slabs Choppers

Awl sharpener

Bone awls

*= Percentage of identified bone pieces; excluding rodent, bird, fish, and whale bones. 


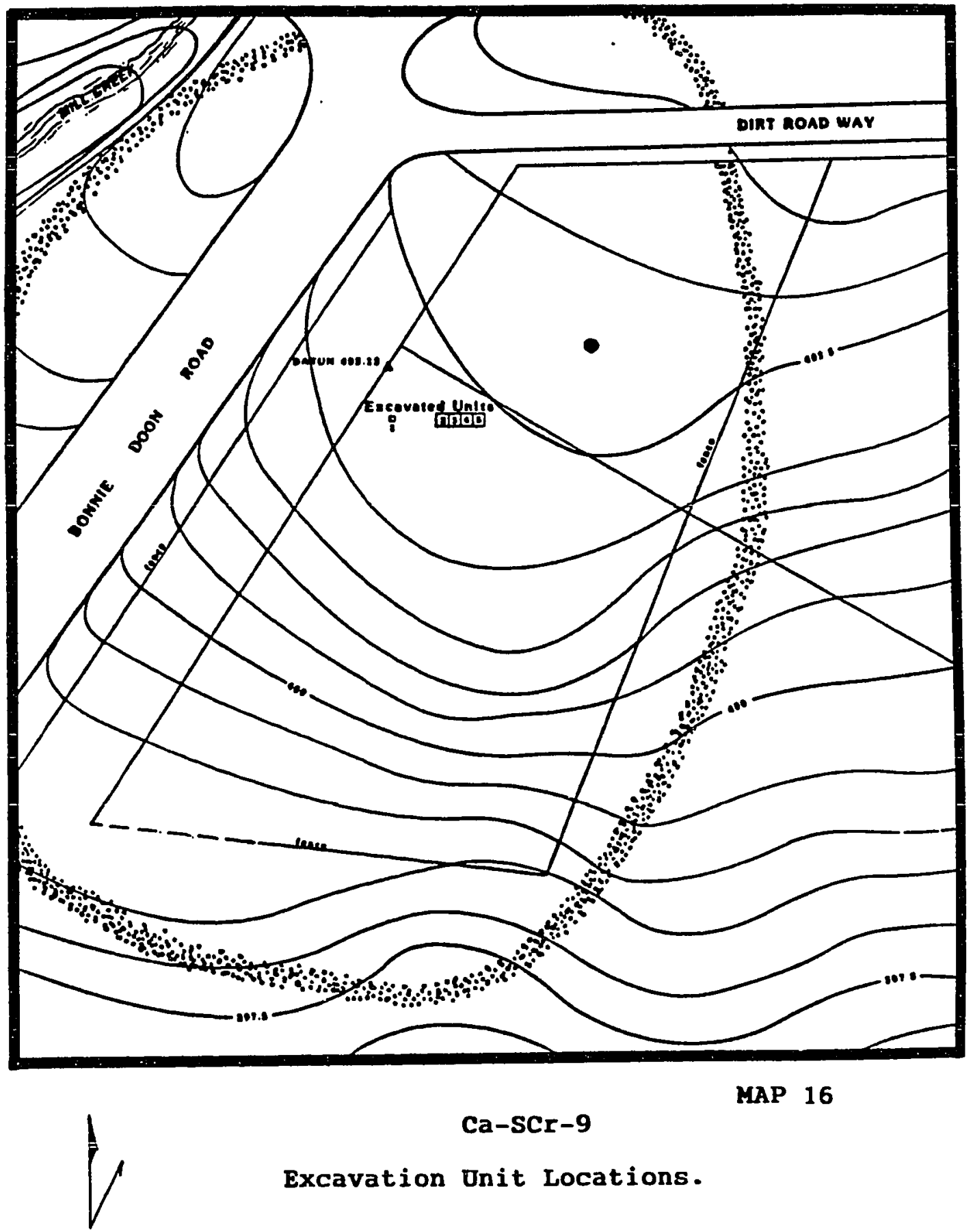

North

Contour Interval $50 \mathrm{~cm}$.

\section{Scale:}

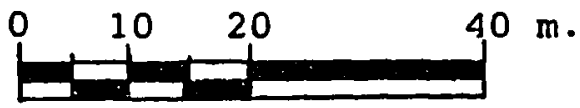

Rey :
$\therefore \because \because$ = Site Boundary.
$\square=$ Unit Location.
- = Human Burial. 

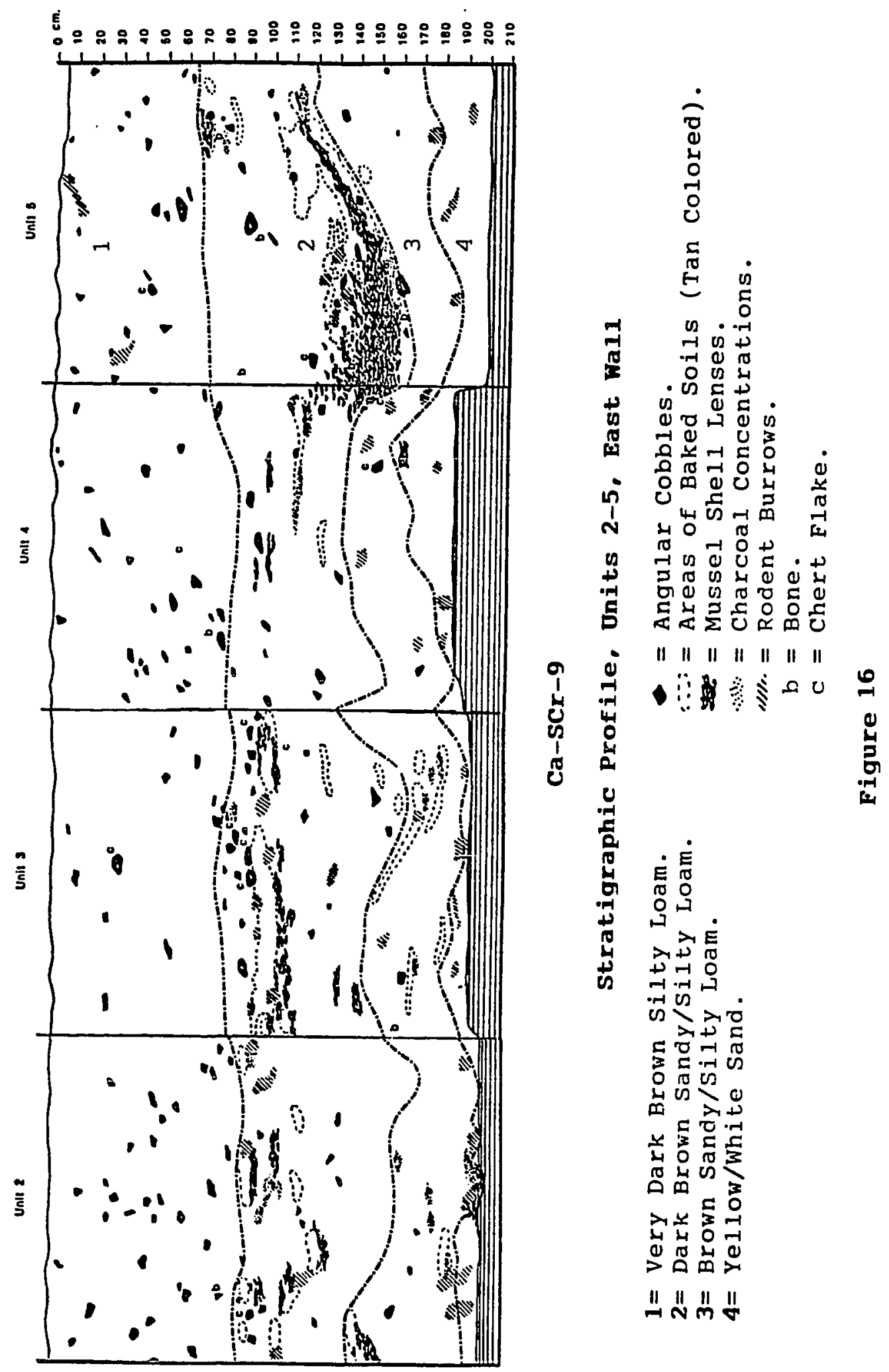

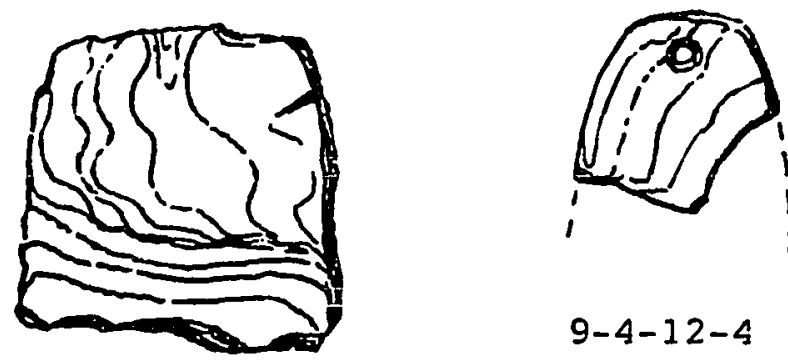

$9-4-12-5$

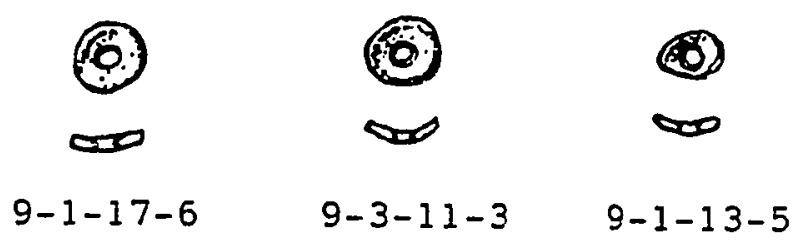

9-4-12-5 Haliotis rufescens Pendant Blank.

9-4-12-4 Haliotis cracherodii Pendant.

9-1-17-6 Olivelia type G6a Saucer Bead.

9-3-11-3 Olivella type G6C Saucer Bead.

9-1-13-5 olivella type G6b Saucer Bead.

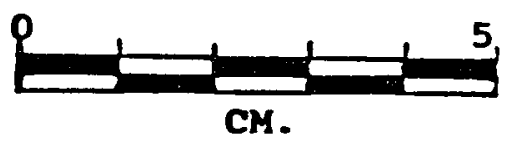

Figure 17

SCr-9 Shell Artifacts 

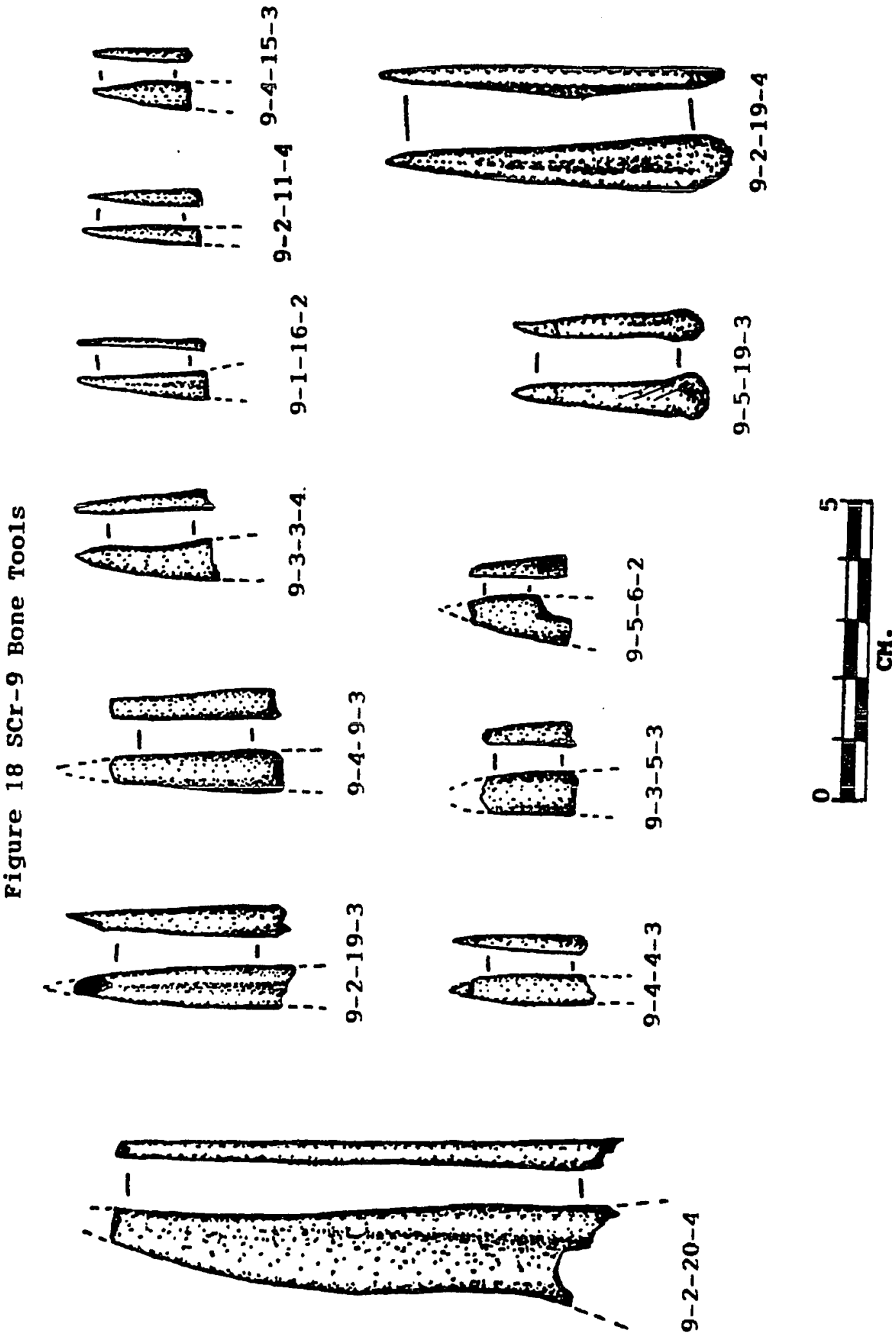

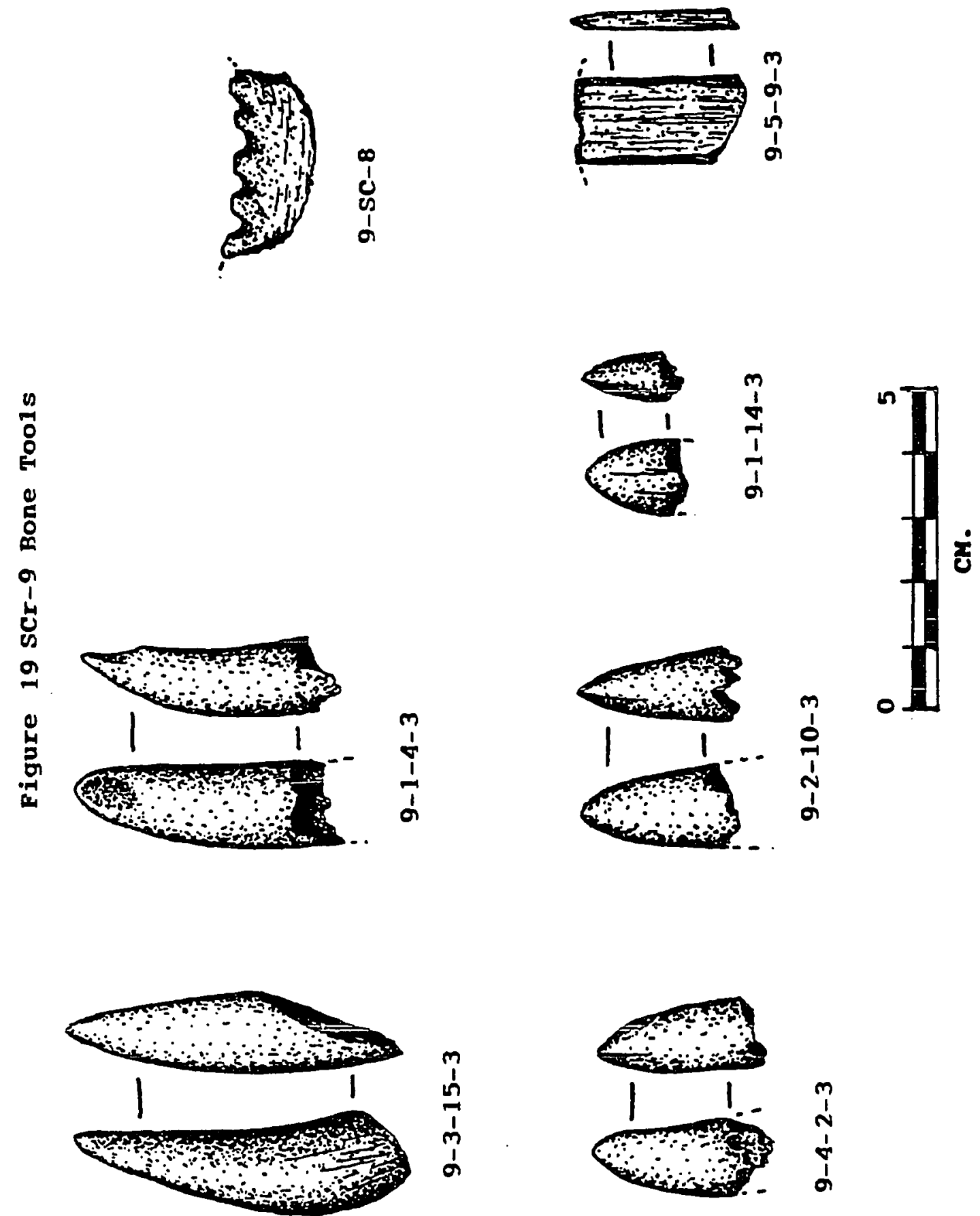

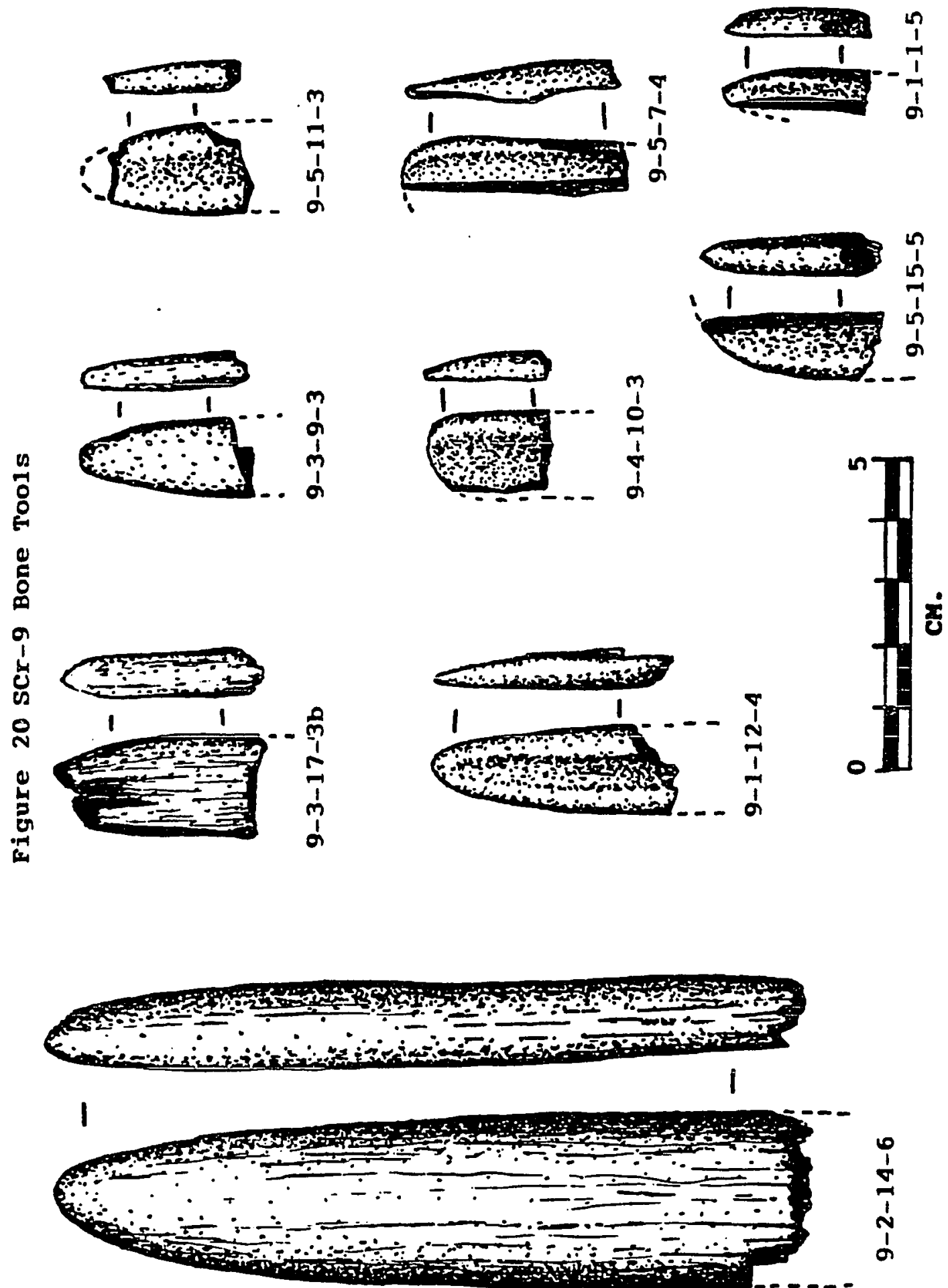

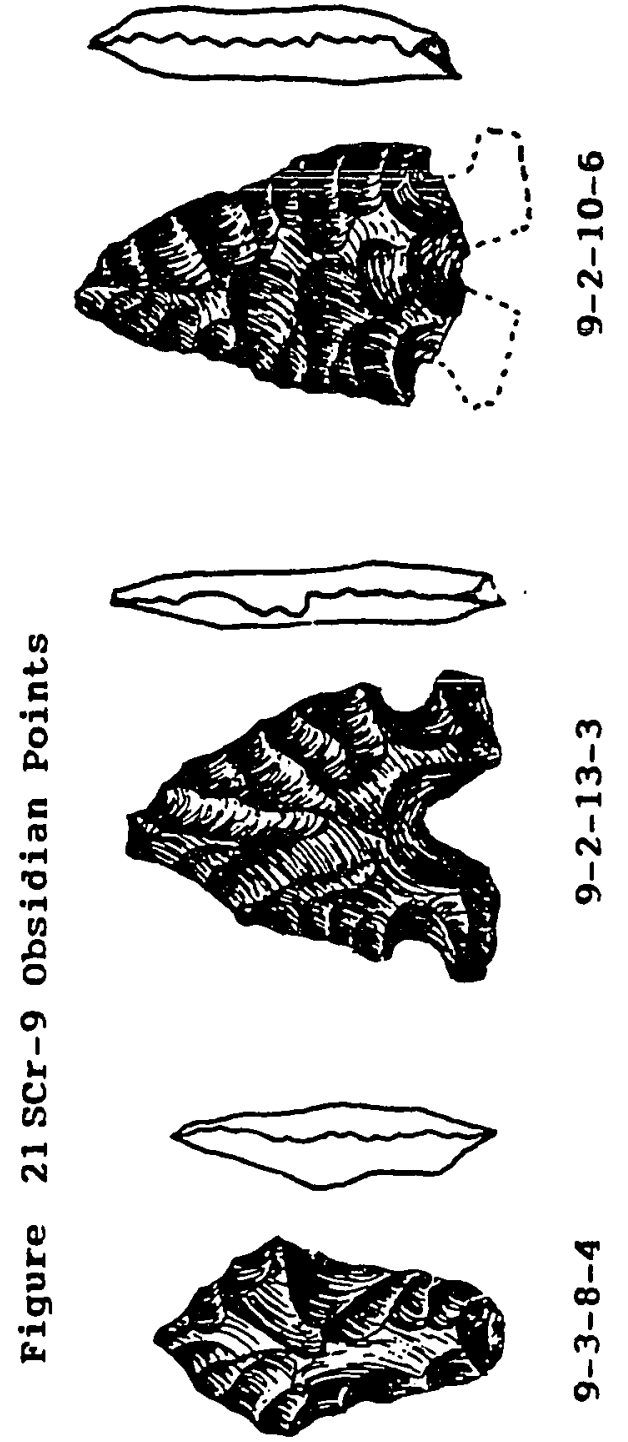

1
1
1
1
1
0
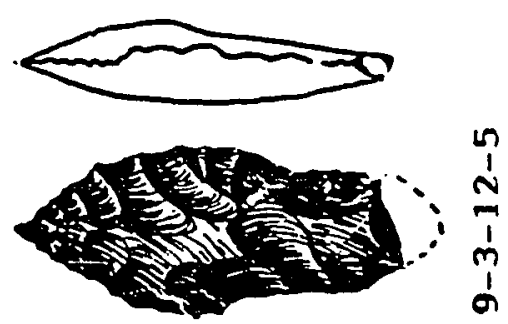

$n$
1
$n$
1
1
$a$
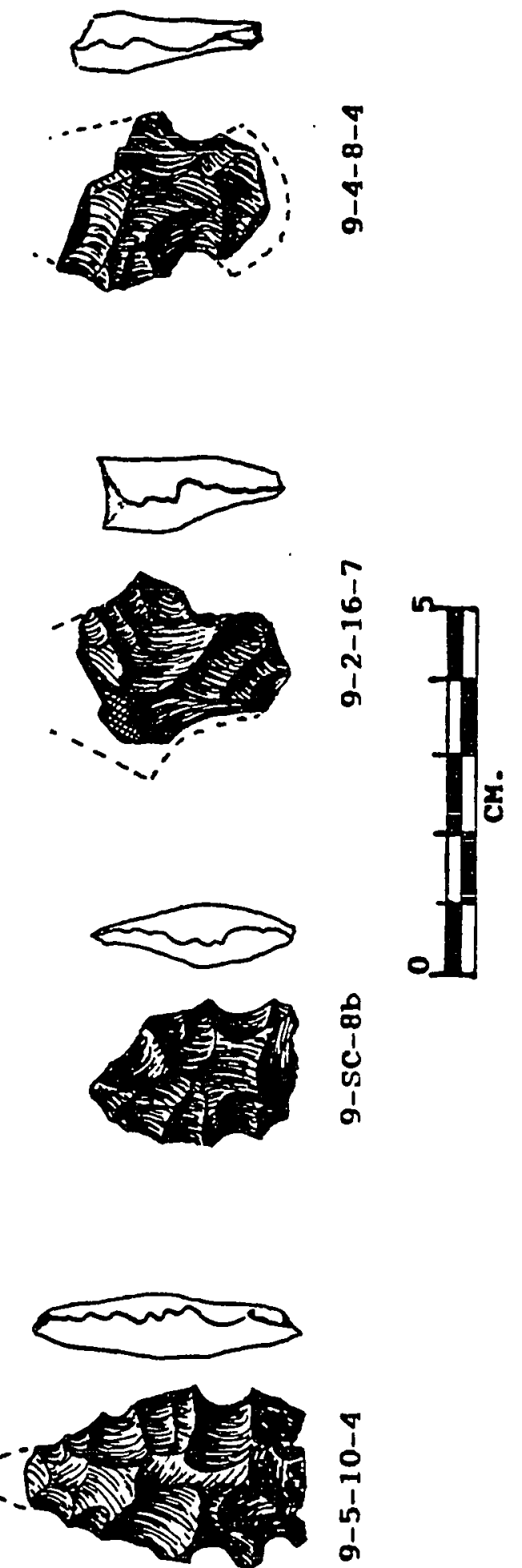


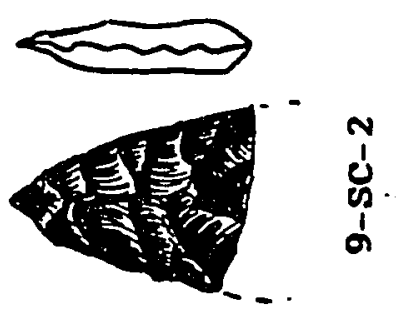

年
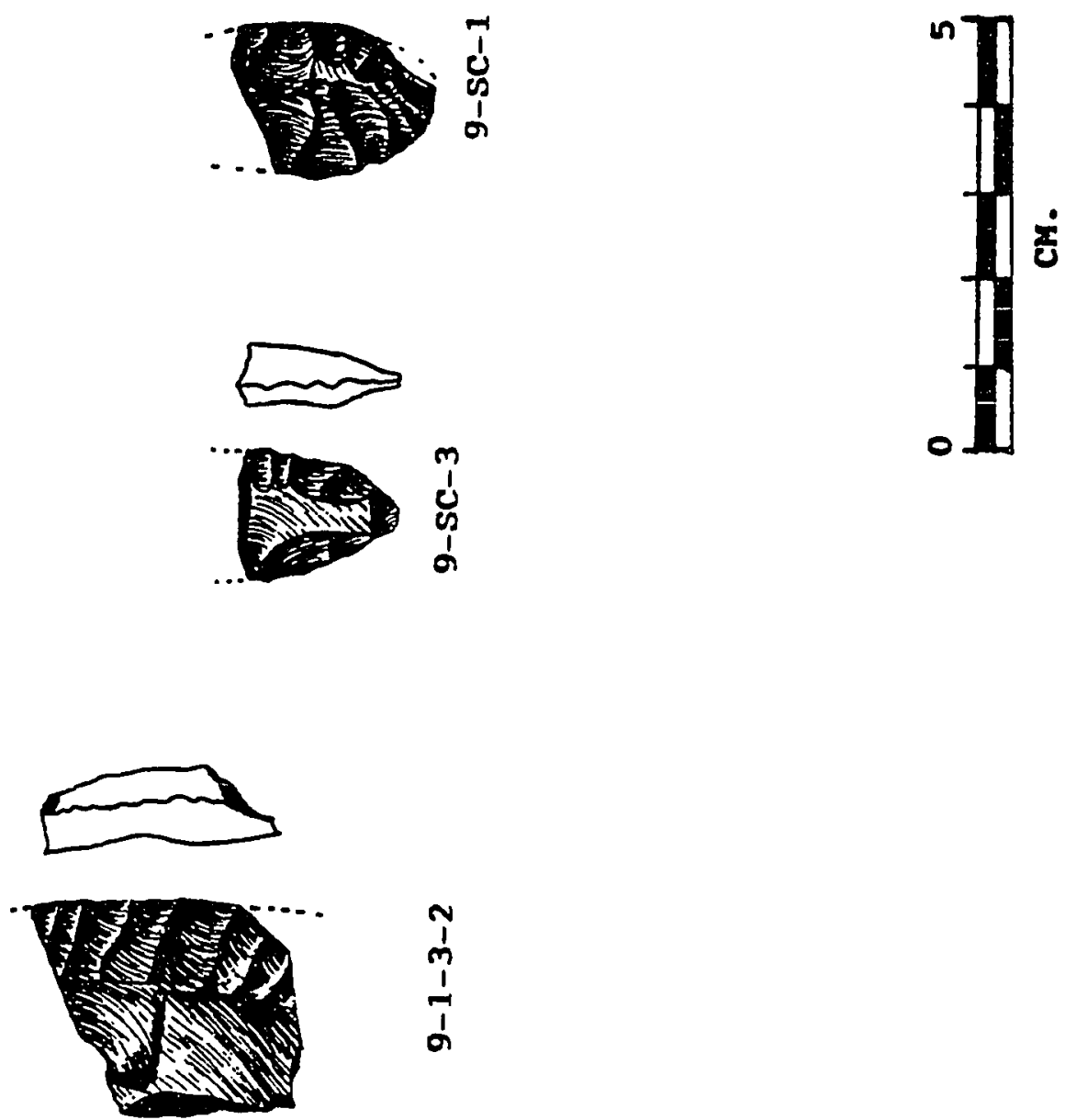


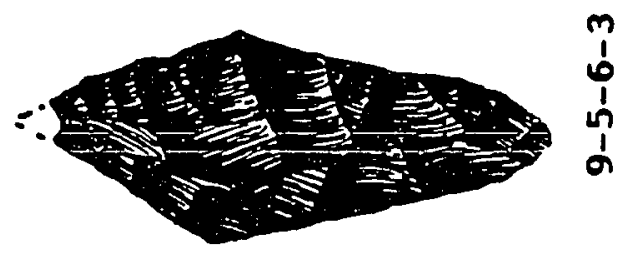

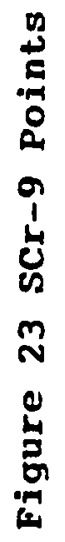
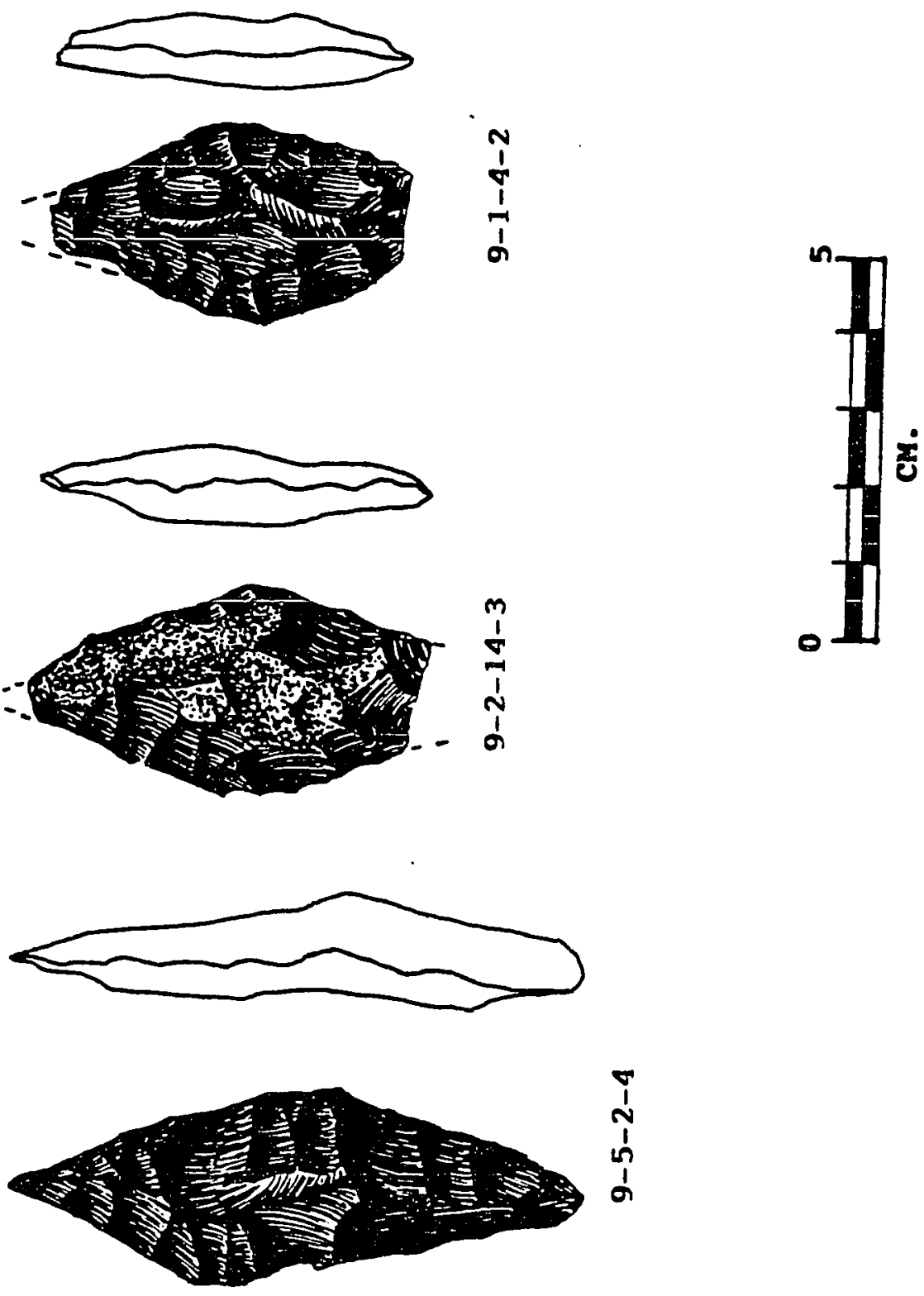

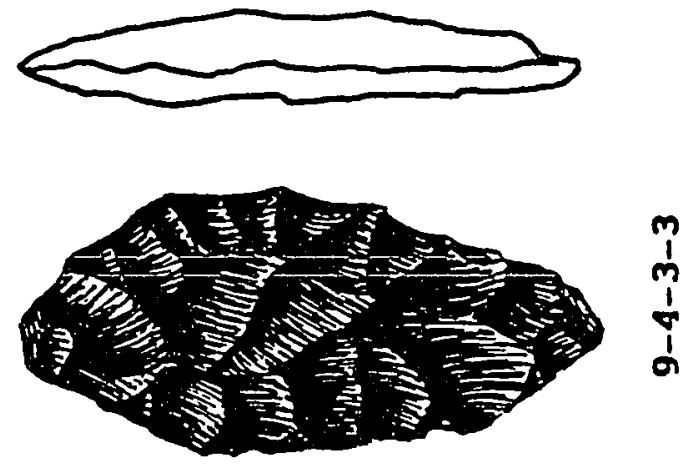

OD
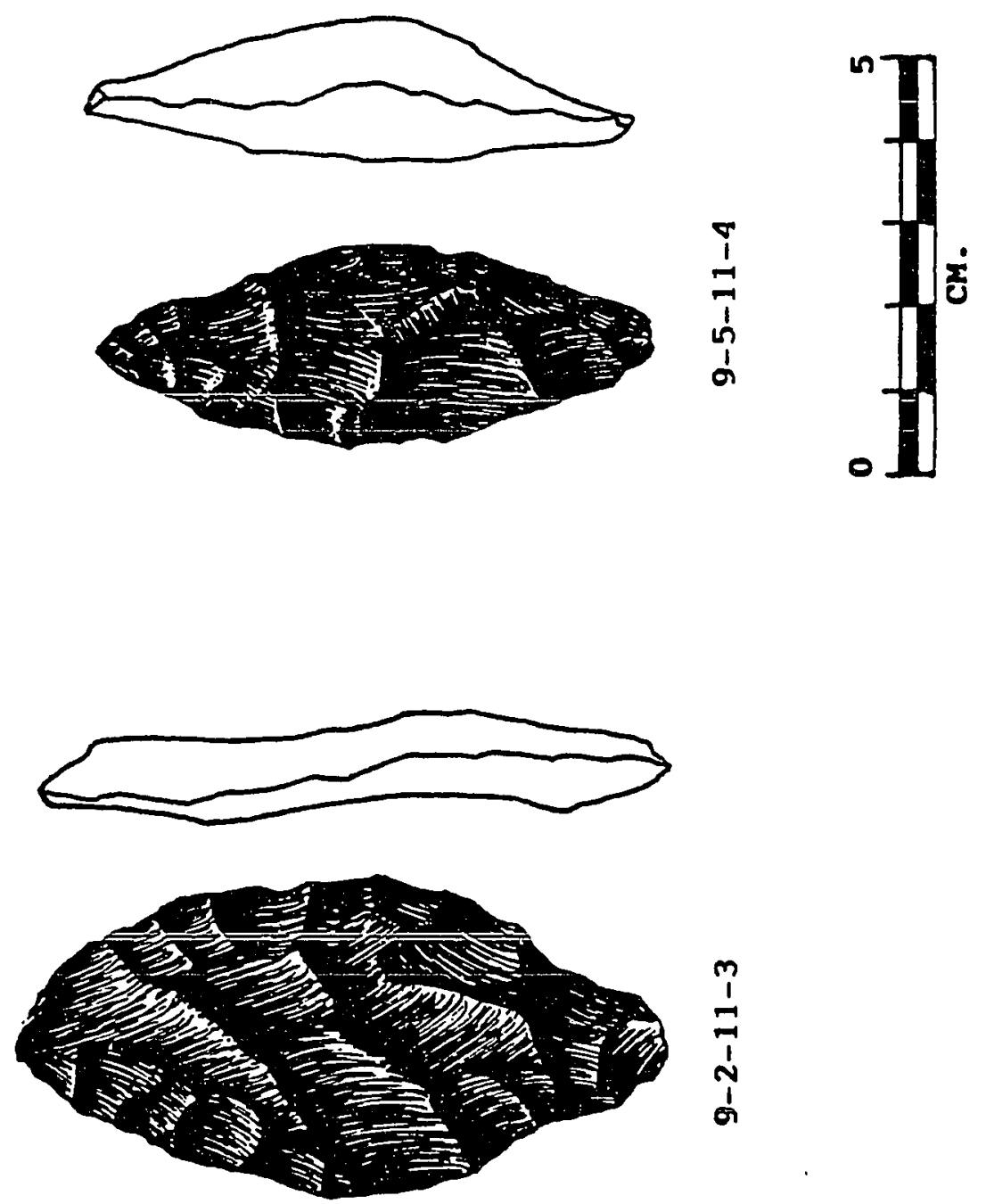

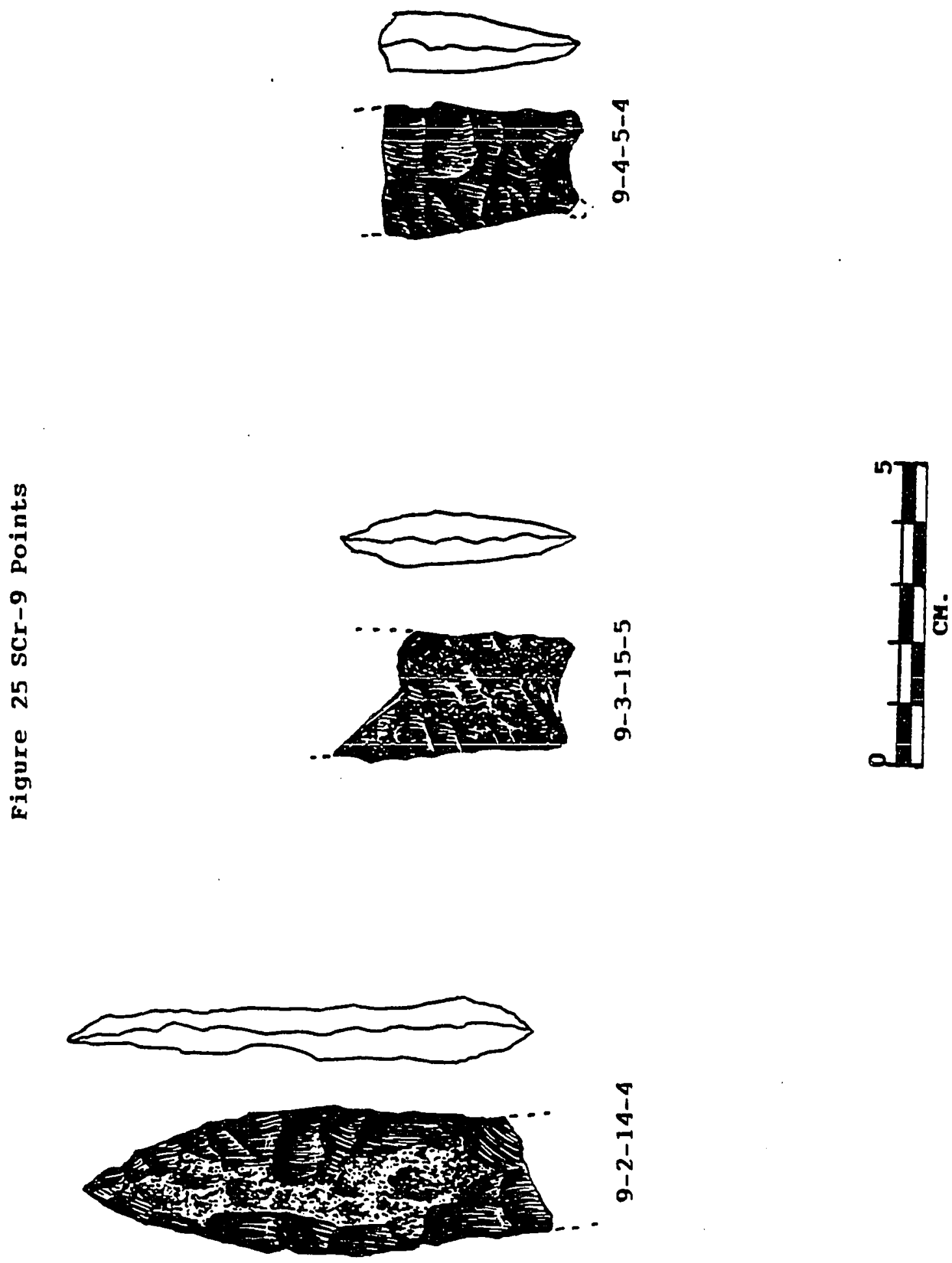

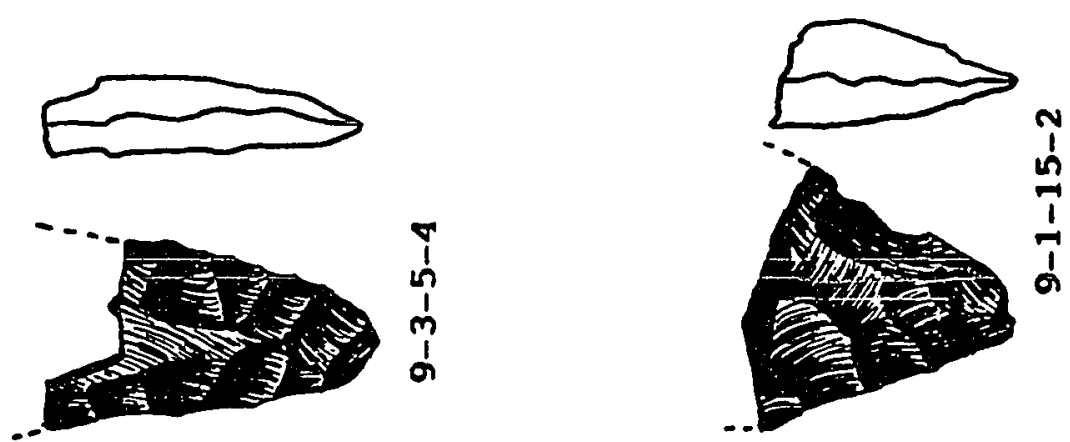

172
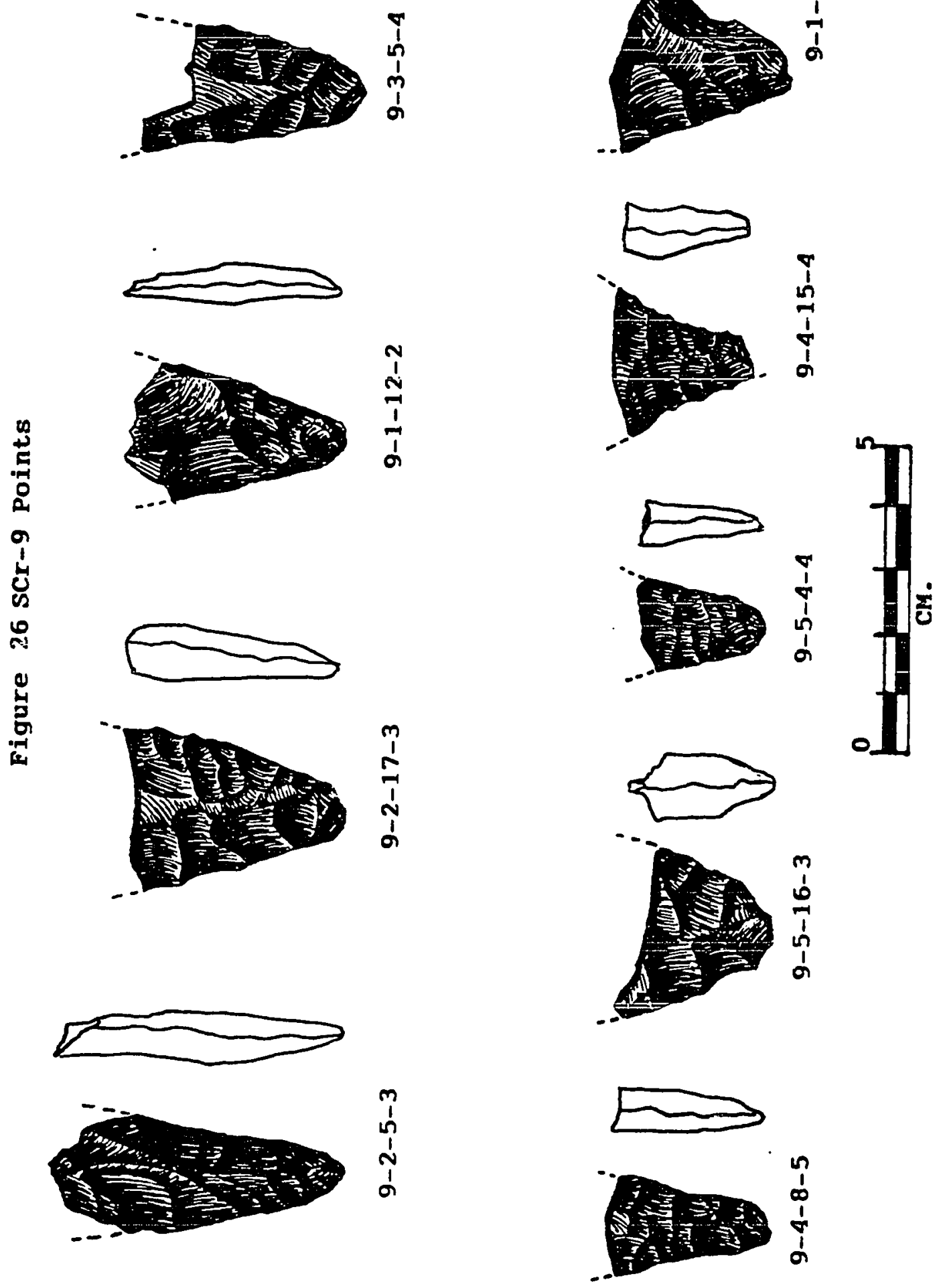

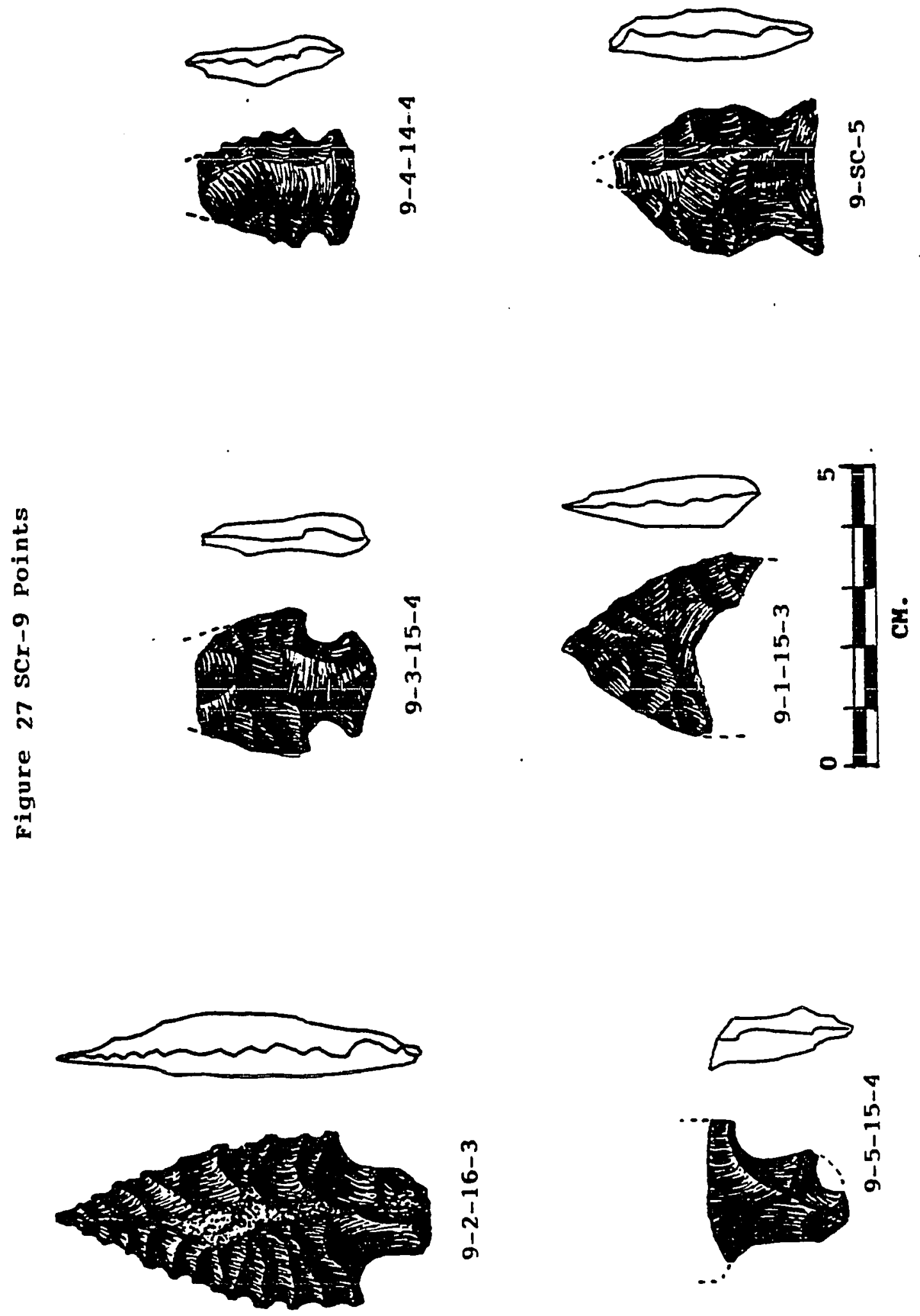


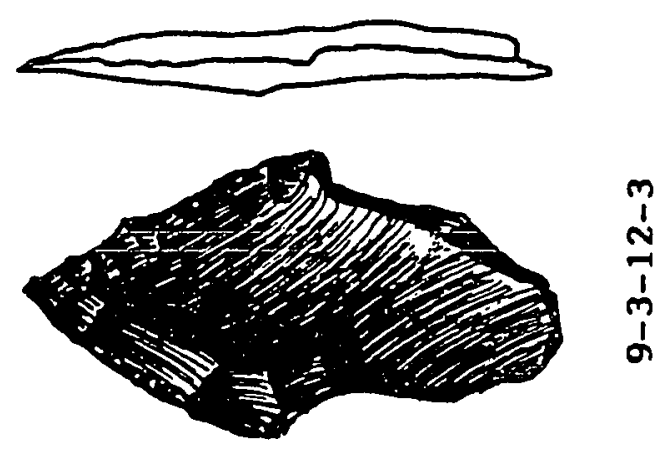

E
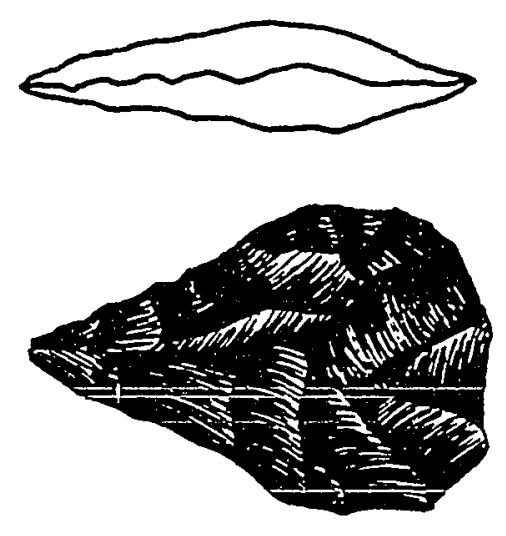

$\frac{n}{1}$
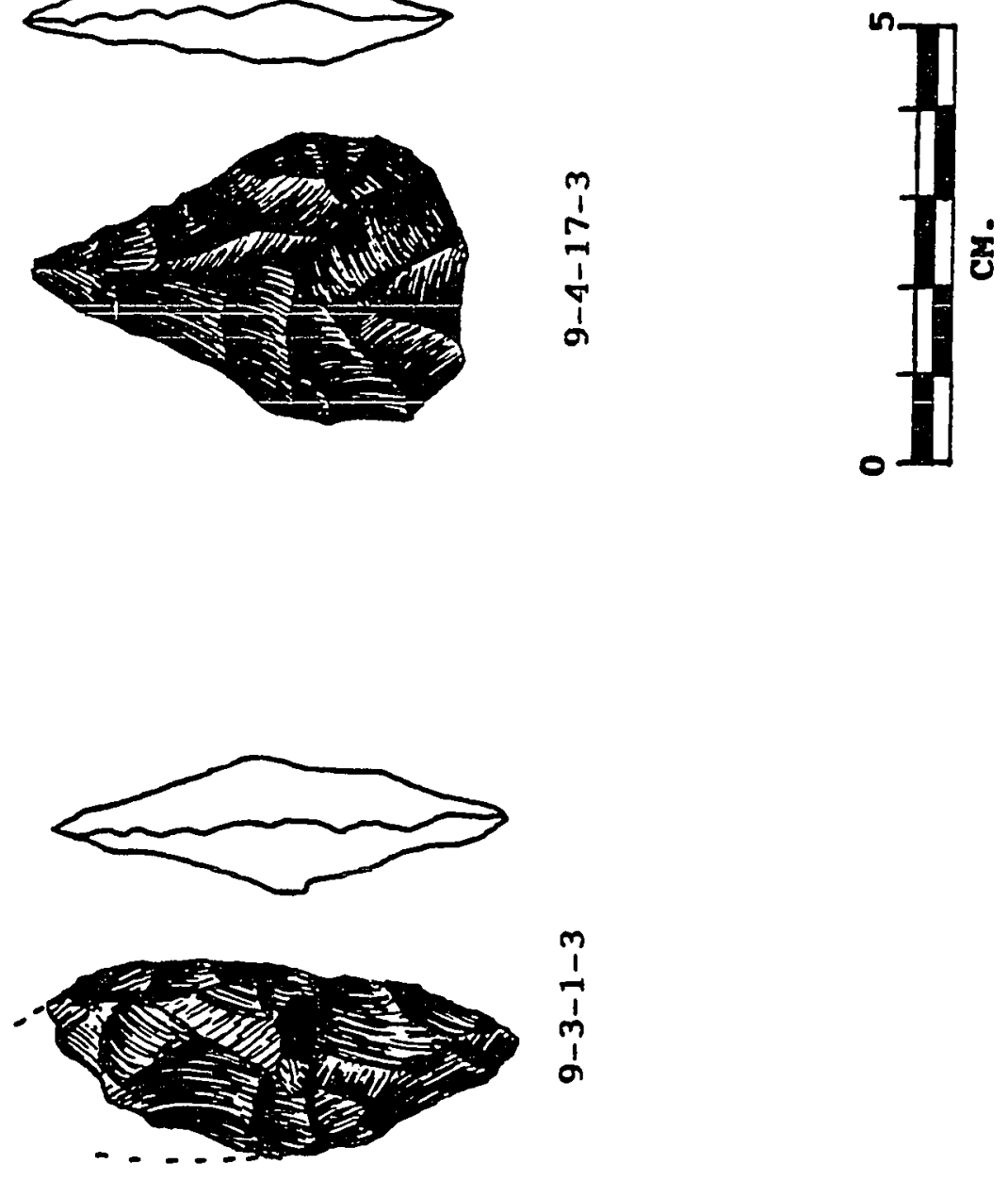

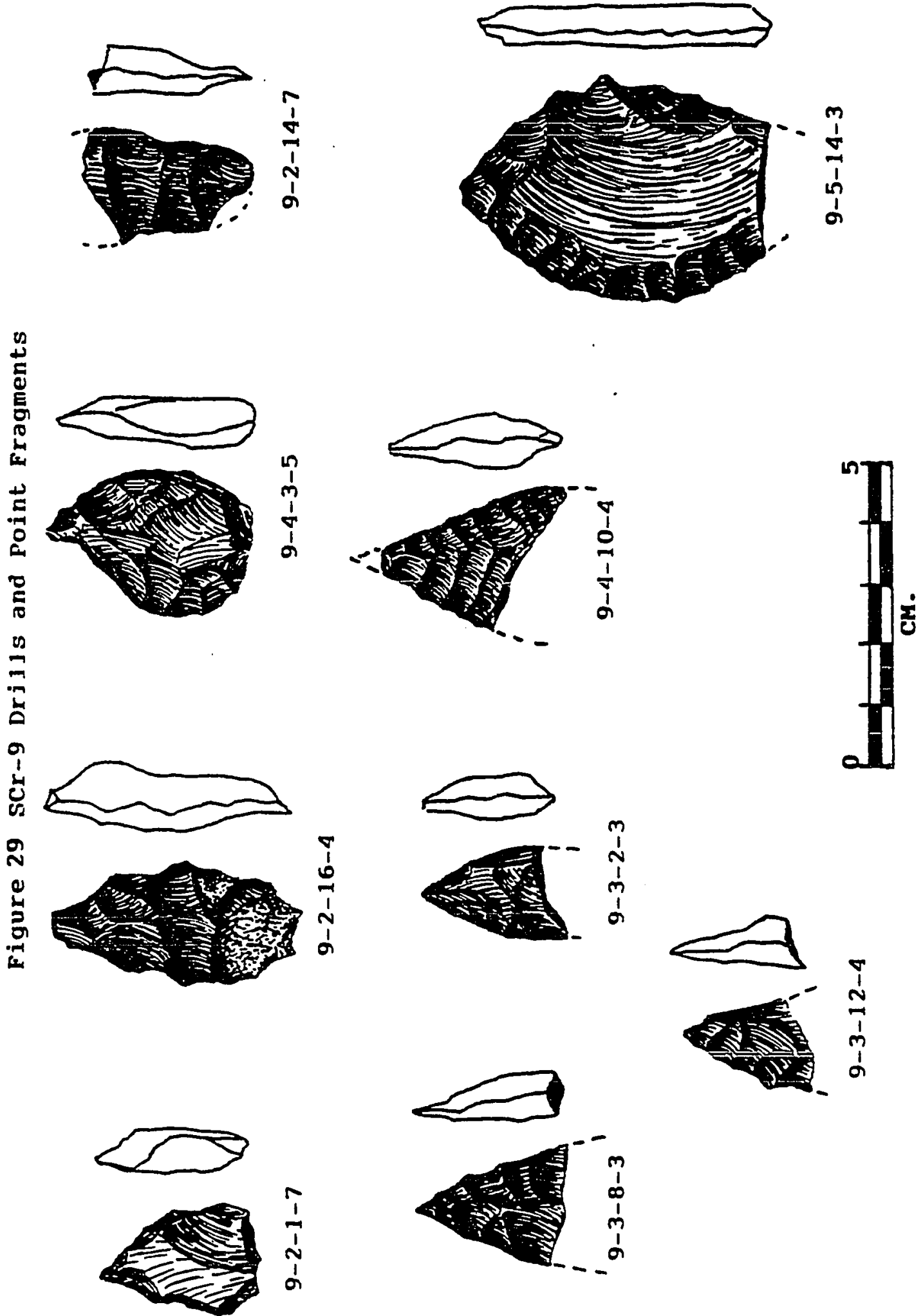


$$
\text { o }
$$




$$
\begin{aligned}
& 01 \\
& 01
\end{aligned}
$$




$$
\begin{aligned}
& 0.9 \\
& 0.0
\end{aligned}
$$




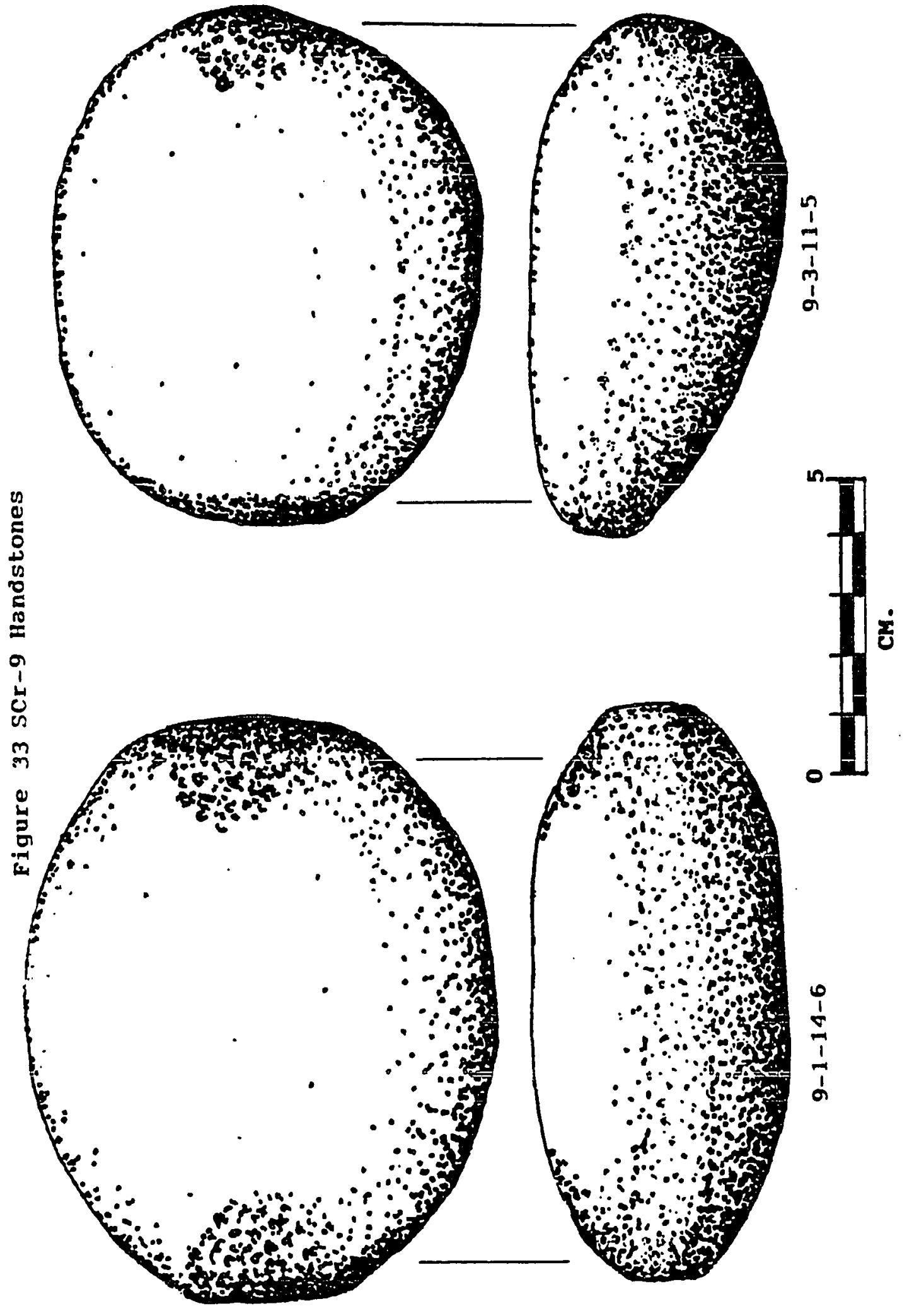




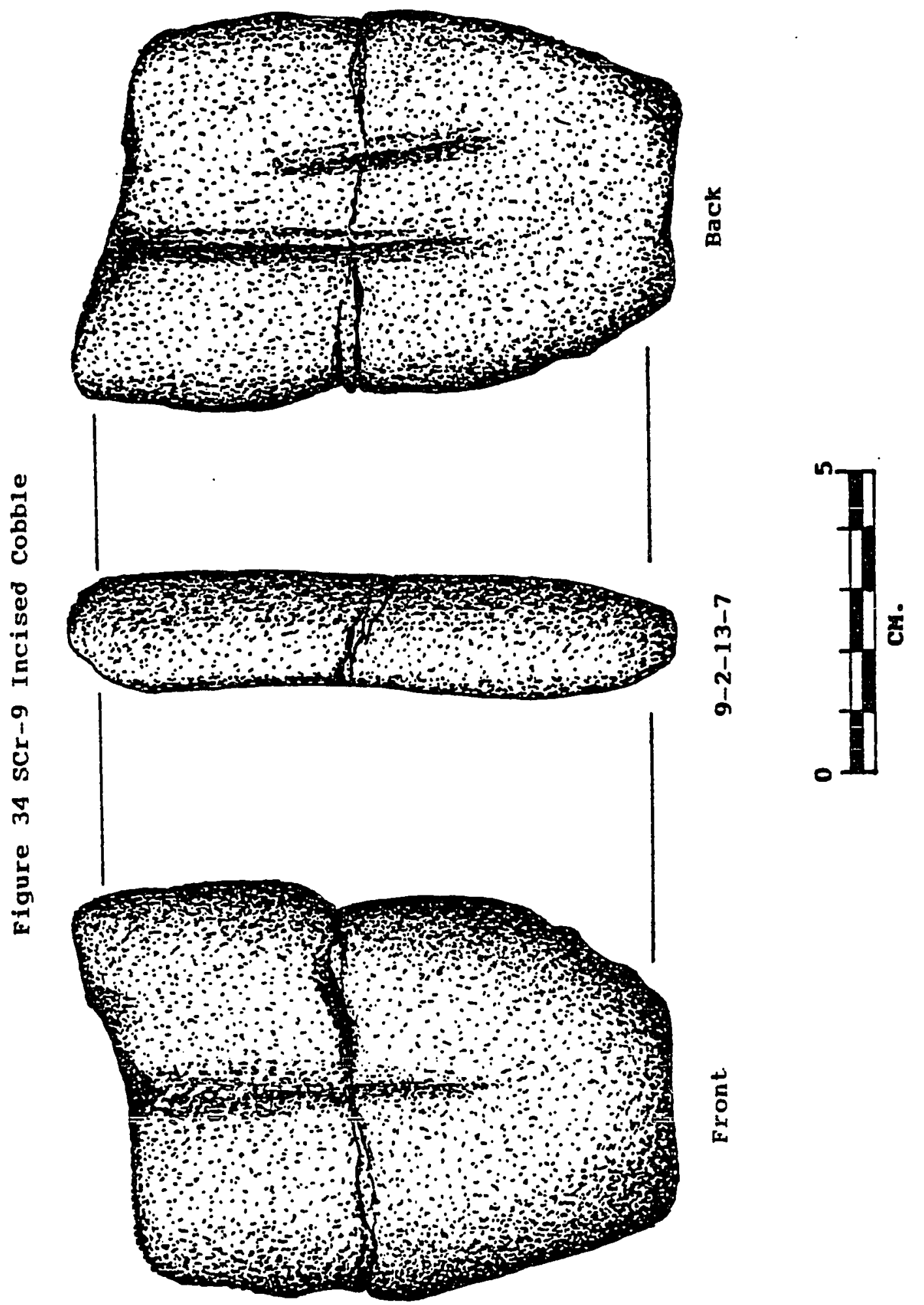




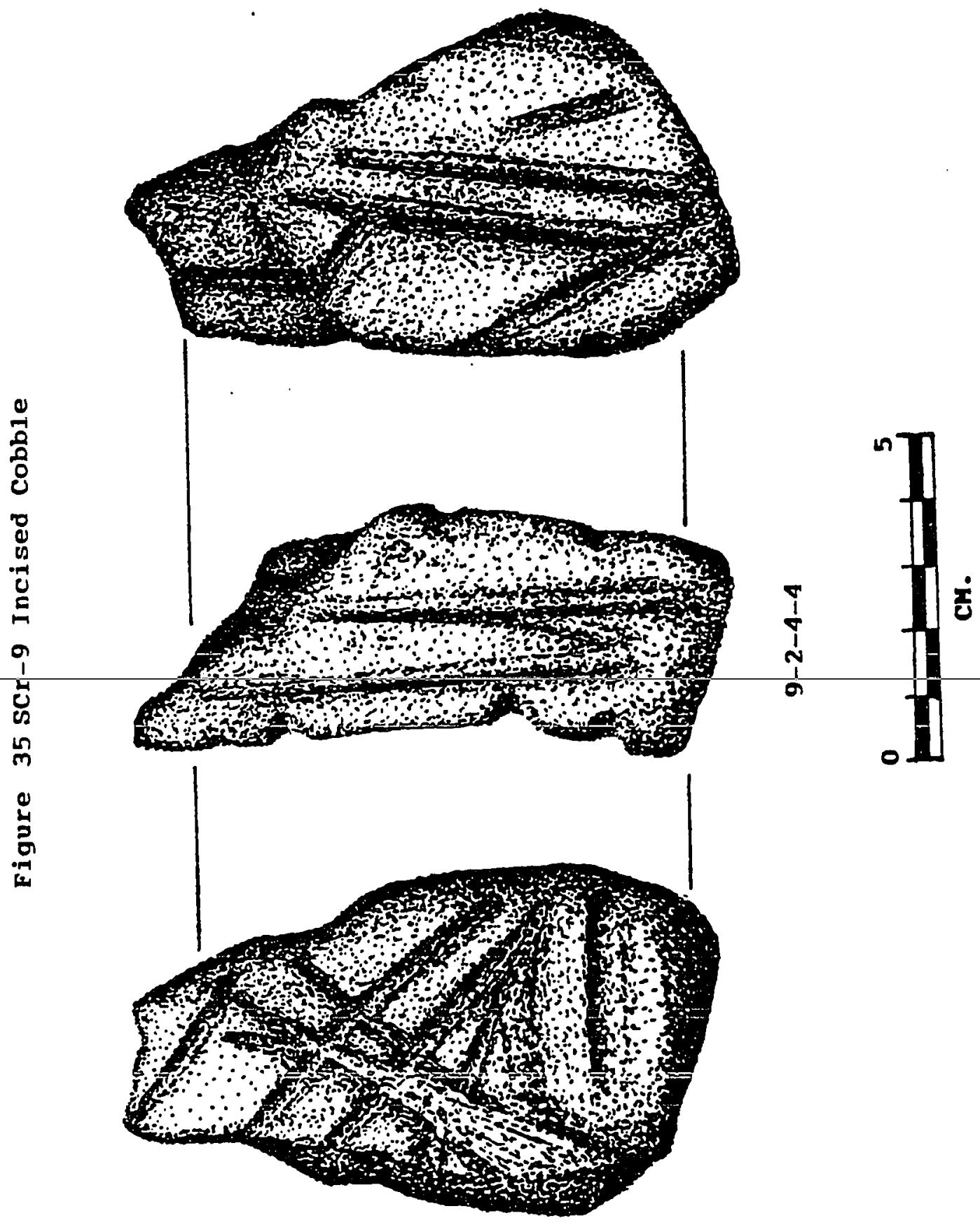




$$
\begin{gathered}
N \\
1 \\
0 \\
1 \\
0
\end{gathered}
$$

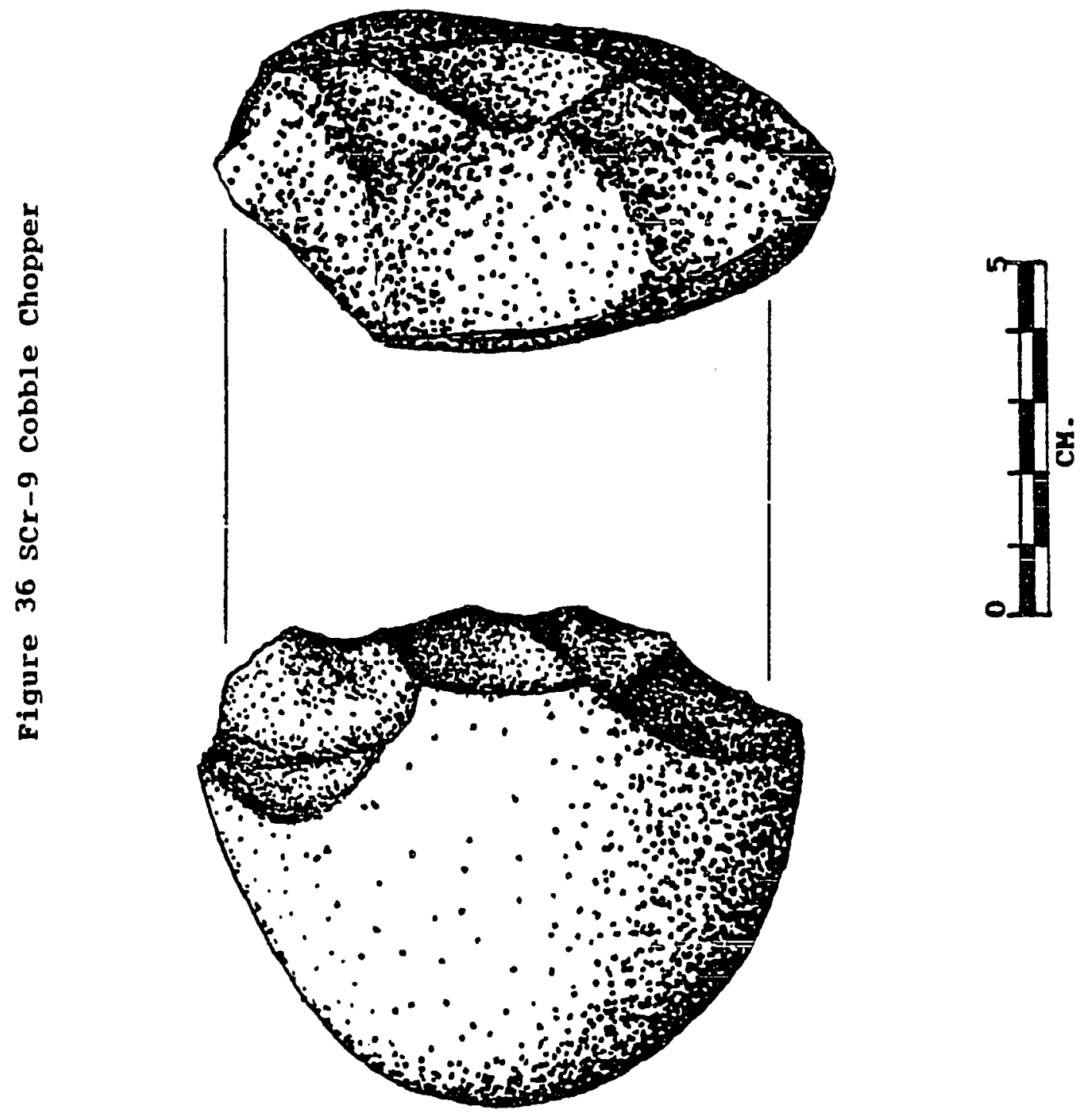


183

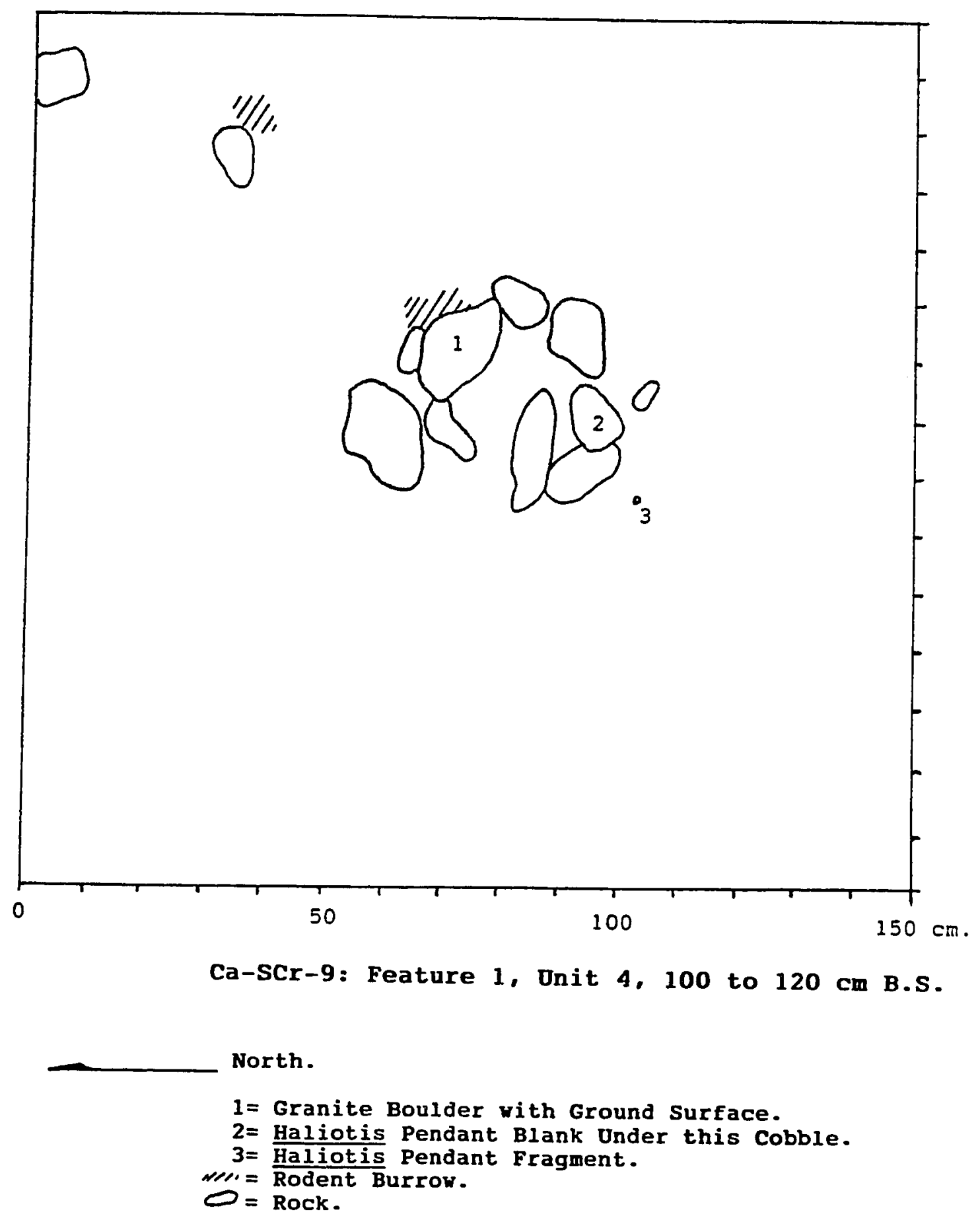

Figure 37 
scr-20, the Brown site

SCr-20 is located on Ben Lomond Mountain near the town of Bonny Doon, and is in the upland meadow zone defined for this study. The upper western slopes of Ben Lomond Mountain maintain springs and open grassy meadows that are usually surrounded by mixed hardwood and redwood forest.

The artifact assemblage was diverse and abundant and included several temporal components. The presence of desert side-notched and stockton serrated points, along with olivella type $M$ rectangle and $E$ lipped beads from the upper levels of the excavation, represent late period indicators. A single radiocarbon date and bead types associated with a number of human burials as well as obsidian hydration results further elaborate the late period context. A middle period assemblage can also be identified by the presence of Ano Nuevo long-stemmed and Rossi square-stemmed points, olivella type $G$ saucer beads, and thicker obsidian hydration rim readings.

This site has been tested by San Francisco state University, Cabrillo college and the University of California at Santa Cruz. A brief review of the findings has been compiled in a master's thesis (Roop 1976).

In 1972 Cabrillo College excavated eight $1 \times 2$ meter units in what was described as the deepest part of the site. Basal depths of the units averaged a little over one meter (Roop 1976: 3), resulting in an excavated volume of 
approximately 16 cubic meters. In 1973 San Francisco state University excavated sixteen $2 \times 2$ meter units, for a volume of 64 cubic meters. While S.F.S U. was testing the Brown site, the University of California at Santa Cruz excavated thirty two $1 \times 1$ meter units for an average volume of thirty two cubic meters. Prior to the previous excavations, Dr. Albert Elsasser excavated a single $1.5 \times 1.5$ meter unit in 1968 but apparently placed it out of the site. Deleting Elsasser's test, an approximate minimum total of 112 cubic meters of site has been excavated.

The presence of artifacts temporally diagnostic of the Late Period has led some researchers to identify this site as the best late period artifact assemblage for the Monterey Bay Area. The presence of larger contracting stem and square stem projectile points and olivella type $G$ saucer beads confirm Roop's contention that the site also contained an earlier component. Eight years after Roop's report, a single radiocarbon date derived from charcoal (floated from the inside of a human cranium) yielded a date of $500 \pm 50$ B.P. (Leventhal 1984). A large square stemmed point was found in questionable association near this burial. At least six human burials were recovered, five from the upper $60 \mathrm{~cm}$. of the site and one at $160 \mathrm{~cm}$. below datum. Two of the upper level burials had olivella type $M$ rectangle beads in association. 
Roop notes that of the Cabrillo college excavations, units 4 and 21 contained the highest frequency of shell. Unit 4 averaged $7486.9 \mathrm{gr}$. per cubic meter and unit 21 averaged $2386.9 \mathrm{gr}$. per cubic meter. Mytilus californianus comprised over 93\% of the total shell recovered (Roop 1976: 43-44). Olivella shell occurred at sCr-20 in the form of intact shells and modified bead types. A summary of the number of olivella beads (using the types proposed in chapter three of this study) are as follows: 147 spire broken/lopped and 224 modified beads (219 type M rectangular, 2 type $\mathbf{E}$ full-lipped, 1 type $G$ saucer and 2 type F saddle) (Bennyhoff and Hughes 1987).

Large numbers of faunal bone were retrieved. The eight units excavated by Cabrilio college provided a total of 4400.4 gr. of bone which was segregated into large mammal, sea mammal, rodent, bird and fish categories. This total averages out to $275 \mathrm{gr}$. per cubic meter, of which $29 \%$ was considered to be from sea mammals, and $62 \%$ were classed as large mammals (deer, elk, antelope, etc.). Bone tools and possible bone tool fragments (pieces exhibiting polish, wear or discoloration from burning) totaled some 952 specimens from both the Cabrillo college and S.F.S.U. excavations. It is difficult to say how many of these are formal tools based on the data in Roop's thesis.

Chipping debris from stone tool production and maintenance was abundantly present, with unit 22 of the 
Cabrillo College excavation yielding some 3549.7 gr. from 3.2 cubic meters of excavated soil (1109.3 gr. per cubic meter). A wide variety of projectile point forms was reported and Roop has sub-typed them into over 18 classes. Using the types discussed in Chapter III, Table 23 presents the types and numbers of specimens gleaned from his thesis (lanceolates include Roop types CS-4, $-5,-11,-16,-17,-27$ and -35 . Contracting stemmed include cs-23, -24 and -25 . Notched points include $\operatorname{CS}-6,-9,-10,-12,-14$, and -15 . Square stem points include $C S-7$ and $(S-36)$.

Table 23: Point types from SCr-20 (N=58)

1) Lanceolateconvex base................. concave base..................... bipoint....................

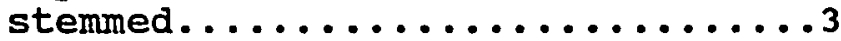

2) Serratedstockton serrated............2

3) Contracting stemAno Nuevo long-stemmed..........10 barbed contracting stem...........

4) Notchedcorner/side................6 desert side-notched..........26

4) Square StemmedRossi square-stemmed...........1 contracting base................

Given the range of point types, scr-20 ciearly exhibits an earlier occupation than has been discussed by others. All of the desert side-notched and stockton serrated points were found in the upper $40 \mathrm{~cm}$. of the site, while the midale period types ranged from the top to the bottom of the site. 
This author obtained 42 obsidian points, bifaces and flakes from Cabrillo College and U.C. Santa Cruz for sourcing and hydration analysis. of these, 24 pieces were sourced and 20 hydrated (in addition to 7 previously sourced and hydrated by $T$. Origer and R. Hughes (Leventhal 1984]). The goal of this analysis was to attempt to isolate the older component at scr-20 by sampling a range of pieces at various depths. The results have been presented in Table 24 . 16 of the cut pieces are illustrated in Figures 38 and 39. The results of the analysis do indicate that the site was occupied during both the middle and late periods.

Napa Valley obsidian specimens ranged from 1.2 to 5.2 microns $(\mathrm{N}=17)$, with most of the readings clustered between 1.6 and 3.2 microns $(N=14)$. Only two specimens were from the Casa Diablo source. One of these was 1.9 microns, the other was 5.6. Two pieces of Bodie Hills obsidian read 1.8 and 2.1 microns. Five specimens of Annadel obsidian ranged from 1.7 to 3.6 microns. None of these pieces clustered into discrete components, possibly because the sample size was too small. Nonetheless, the hydration readings do indicate a greater temporal range than a late period designation alone.

A variety of cobble tools were described in Roop's thesis. These included 14 pestles, 4 mortar fragments, 13 handstones, 1 pitted/dimpled cobble, 1 grooved cobble, 1 awl sharpener, 3 steatite pipe fragments and numerous end 
矛

I $\dot{N} \dot{\sim} \dot{\sim} \dot{-} \dot{N} \dot{N} \dot{\sim} \dot{\sim} \dot{\sim} \dot{N}$

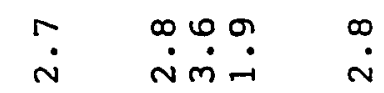

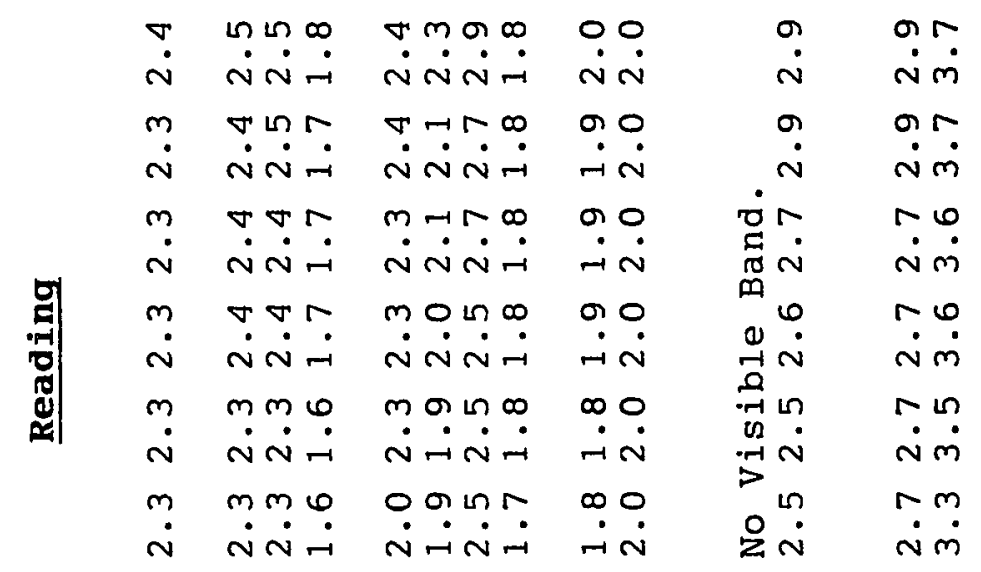

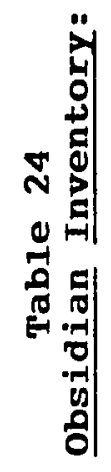

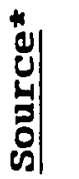

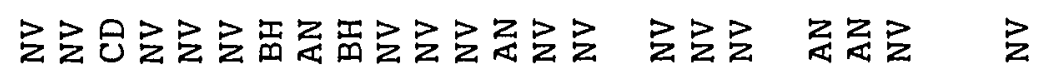

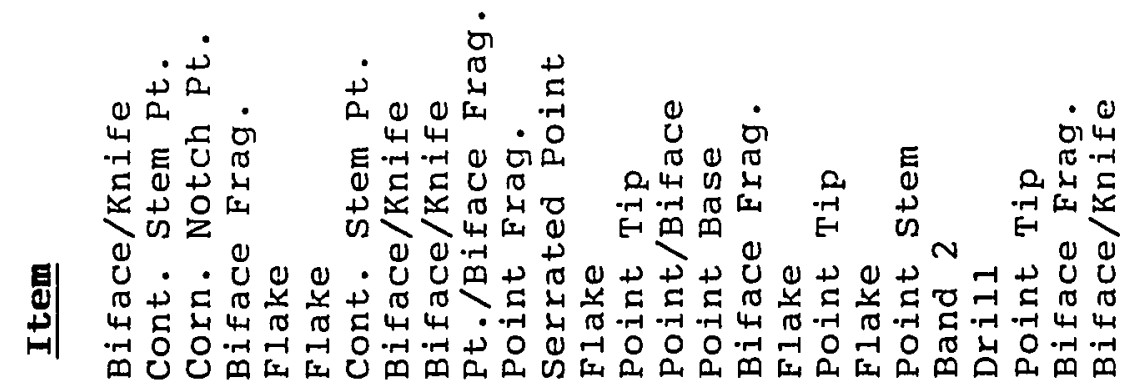

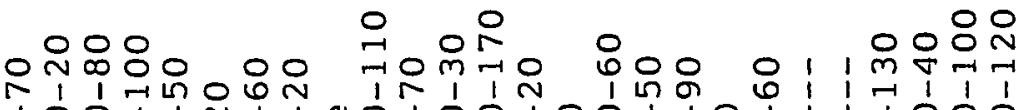
10011N110010010011011 100!

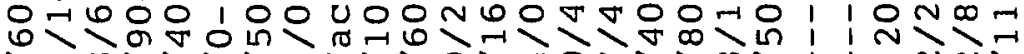
俚

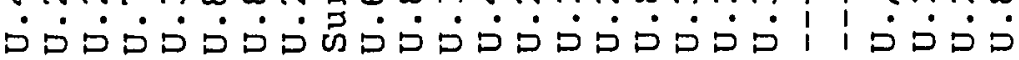

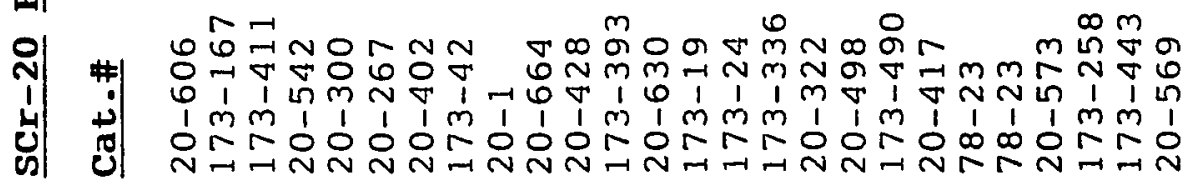




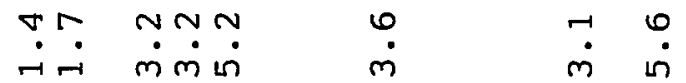

$\because \underset{m \dot{m}}{\sim} \quad \stackrel{\varphi}{m} \quad \because \quad$

- NNm 0

$\because \dot{m} \dot{m} \dot{m} \dot{m} \quad \dot{m} \dot{n}$

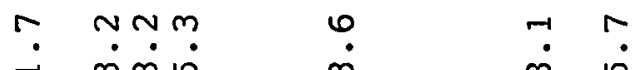

$\rightarrow m m i n m m$ in

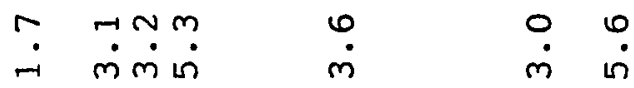

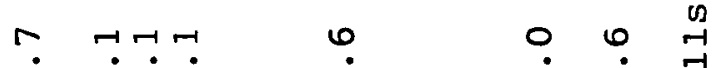

$\therefore \dot{m} \dot{m} \dot{m} \quad \dot{m}$ in

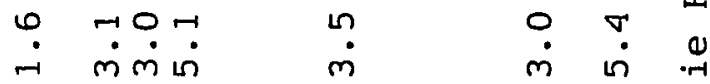

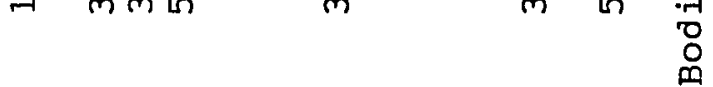

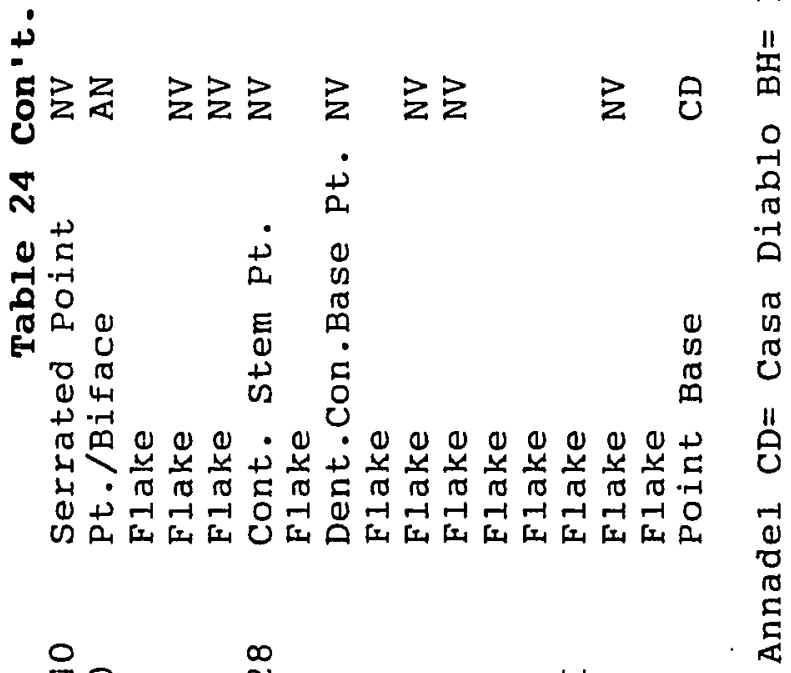

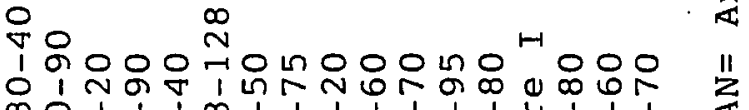

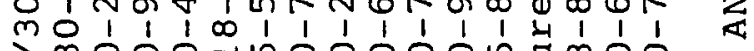

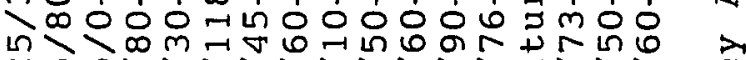

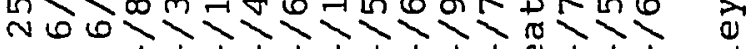

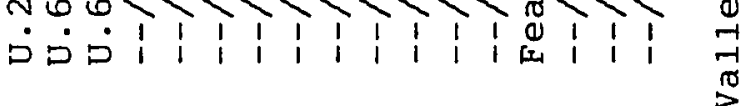

mon

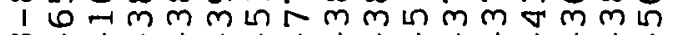

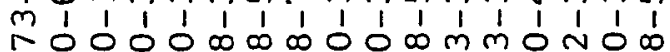
$\rightarrow$ N 
battered cobbles. After reviewing Roop's work it was found that the milling tools reflected both acorn and hard seed food processing activities. Pestles and mortar fragments along with handstones were found to be evenly distributed throughout the upper and lower levels.

At least two components are evident at scr-20. The upper component is younger than the lower one and represents the Late Period. This component may reflect residential use by collectors; however, definitions of adaptive modes based on data provided in the site report remains speculative. The lower component reflects a Middle Period use, probably as a forager residential base. The latter component is similar to that of SCr-9 which is only a mile away. All of the desert side-notched and stockton serrated points were recovered from the upper $50 \mathrm{~cm}$. of the deposit. The burials are a constituent of the upper component, although one intrudes into the lower levels. The single radiocarbon date of $500 \pm$ 50 along with the olivella type $M$ rectangle and olivella type E lipped beads further relate to the Late Period. The lower component is characterized by Middle Period projectile points such as the Ano Nuevo long-stemmed, Rossi squarestemmed, ana notched types. Although none of the Late Period point types were found below $50 \mathrm{~cm}$., some of the Middle Period points were found in the upper levels. This would seem to indicate that a notable shift in hunting technology 
occurred abruptly at sometime in the Late Period. Table 25 summarizes components from scr-20.

Table 25: Component Summary from SCr-20

1) Upper Level: 0-50 cm.

Age: Late Period, $500+50$ B.P.

Obsidian Hydration Range: Napa (N=11) $1.2-2.4$

Artifacts:

Desert side-notched points

stockton serrated points

olivella type $M$ and $E$ beads

Steatite pipe fragments

Mortars \& pestles

Handstones \& milling slab

Grooved cobble

Bone awls

2) Lower Level: $60-200 \mathrm{~cm}$.

Age: Middle Period

Obsidian Hydration Range: Napa ( $N=13) 1.8-5.2$

Casa Diablo $(\mathrm{N}=2) 1.9-5.6$

\section{Artifacts:}

Ano Nuevo long-stemmed points

Rossi square-stemmed points

Notched points

Olivella type $G$ and $F$ beads

Mortars \& pestles

Handstones

Bone awls 

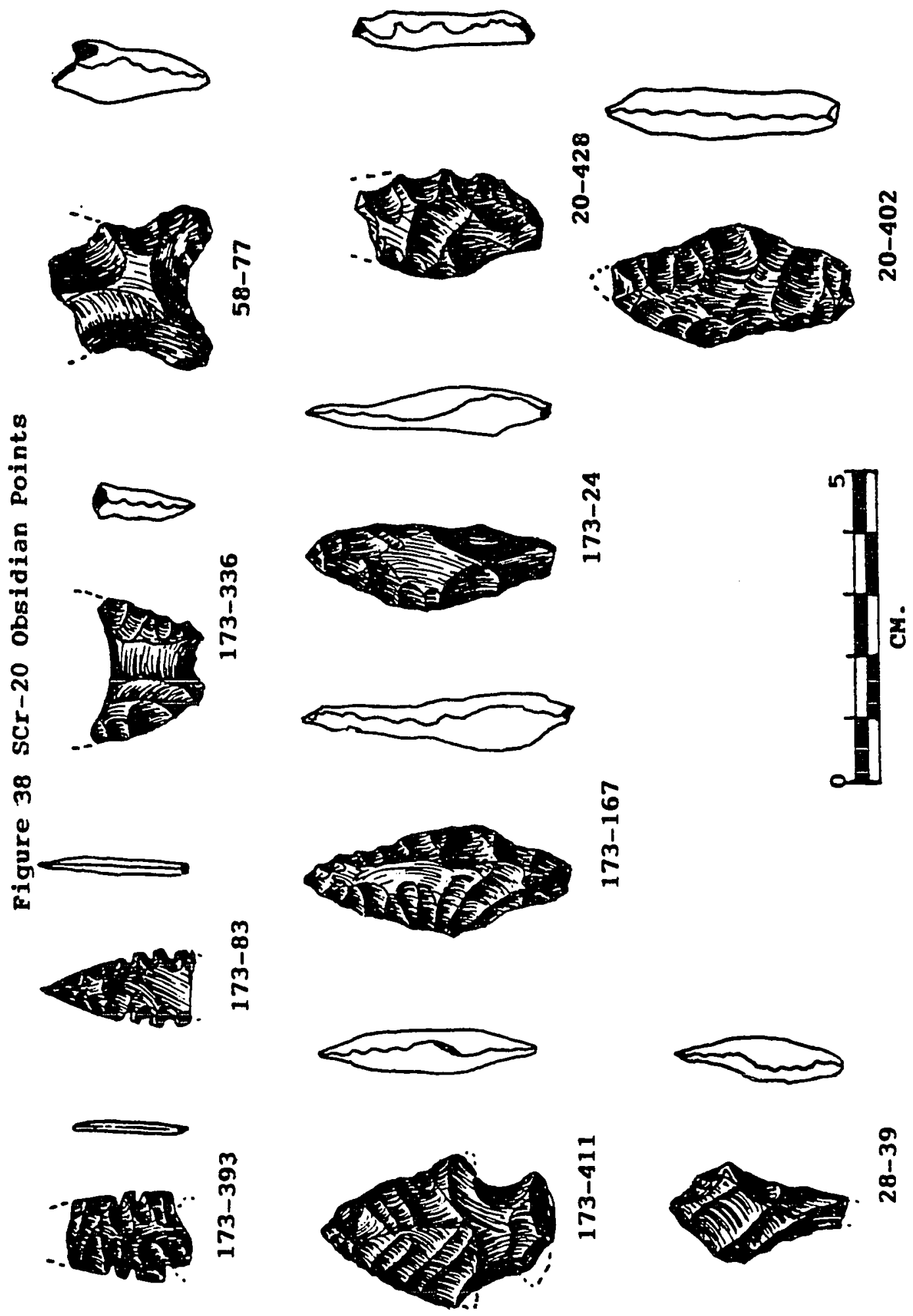

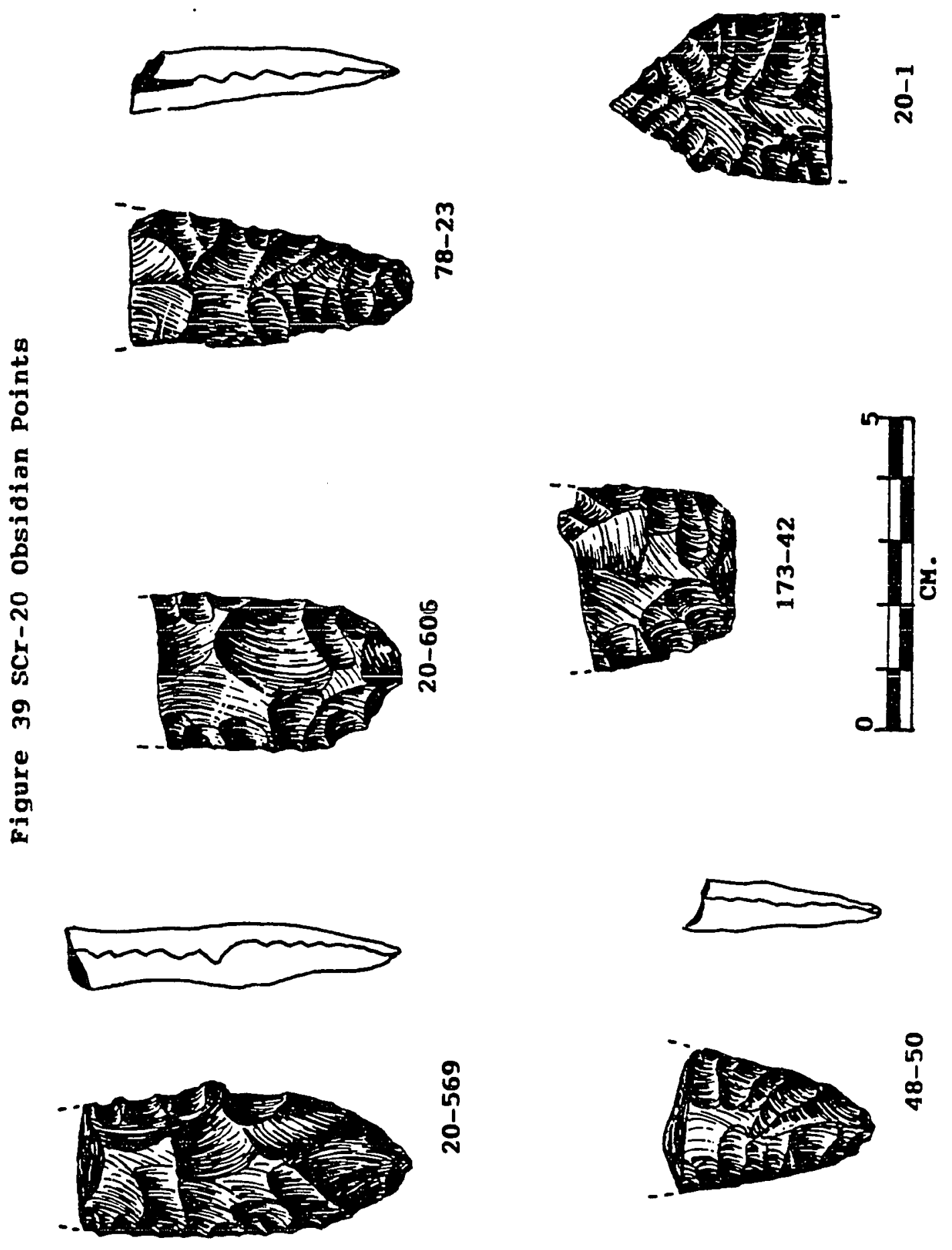

1

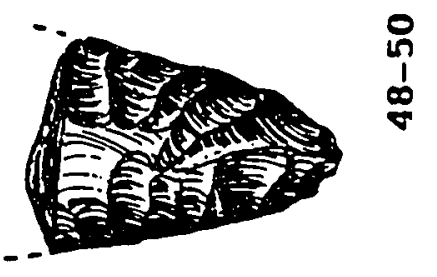


scr-35, the Majors creek site

scr-35 is located at the mouth of Majors creek, and is within the coastal terrace zone defined for this study. This site was initially excavated by Cabrillo college in 1967, and in 1971 and 1975 by the University of California at Santa Cruz. A report of findings was compiled (Gifford and Marshal 1979) and the following description is derived from their report.

This site contained a wide diversity of artifacts, and also contained a number of human burials. The report did not provide any temporal considerations, but the presence of the Ano Nuevo long-stemmed point type implies a Middle Period occupation.

A total of sixty nine $1 \times 1$ meter units were excavated by U.C.S.C. The report provides volumetric data for only forty four units. Twenty-six units were dug to 50 or less $\mathrm{cm}$. in depth, fourteen to 50-100 cm., and four to depths greater than $100 \mathrm{~cm}$. (Gifford and Marshall 1979:15). Much of the recovered artifactual material has been lost for lack of proper curation, and many artifacts have been stolen over the years (Dr. John Rick, personal communication, 1988). It is likely that this site contained a far greater artifact yield than the report would indicate.

A minimum of nine burials were noted in the report, one of which exhibited auditory hyperosteosis. This pathology, also known as divers ear, is a bone growth of the outer ear 
canal resulting from exposure to cold and pressure from swimming or diving. Interestingly, the report mentions that an individual from scr-7 also exhibited divers ear (probably the cranium recovered by Morejohn).

Gifford and Marshall analyzed 9,210 pieces of chipped stone weighing $21.7 \mathrm{~kg}$, , but do not mention which units were reviewed (although it is noted that $1 / 4$ of the sample available to them from the entire collection was studied). The majority of the chipped stone was composed of Monterey chert, with a sparse representation of other materials. only 13 pieces of obsidian were recovered. Three projectile points were described and were the Ano Nuevo long-stemmed type. Numerous other formal and informal chipped stone tools were mentioned and edge wear research was conducted. Only one mortar and one pestle are discussed, a seemingly low number compared to other sites, particularly given the massive volume of soil excavated.

Several private collections from the area of the site (and possibly from the site itself) contain a number of projectile points and handstones. The points range in style and material but are of the same varieties as those at wilder Ranch just south of $\mathrm{SCr}-35$. Because of poor provenience information, these collections are not further described here.

Shell debris was, as expected, quite abundant at this site. Mussel shell dominated the assemblage and comprised 
$93 \%(53,205.9 \mathrm{gr}$.$) , of the analyzed sample (55,506 \mathrm{gr}$.$) . The$ sample was derived from unit $75 / 119$ and contained a volume of shell equaling 3,965 grams per cubic meter.

Faunal bone elements were also abundant, but were not quantified by excavation volume. A list of species was provided which revealed a wide variety of taxa. Excluding birds, rodents and fish, Table 26 lists species present.

Table 26: Faunal Taxa Present at SCr-35

Enhydra lutris
Phoca vitulina
Arctocephalus ursinus
Langenoryhnchus obliquedens
Cervus nanoides
Odocoileus hemionus
Canis latrans
Urocyon cinereoargentus
Felis sp.
Mephitis mephitis
Lepus cal ifornicus
Sylvilaqus bachmani

of particular interest is the occurrence of the northern fur seal. Gifford and Marshall (1979: 85) note that this species was the most abundant in the assemblage. Only three identifiable bone tools were reported. Two of these were spatulate shaped and the third had a pointed tip. Basea on the analyzed materials from the site, Gifford and Marshall proposed that the site was a residential location occupied during the winter. No other temporal consideration has been given to this site. 
SCr-38, SCr-39 and SCr-40, the wilder Ranch sites

The wilder Ranch sites are located on the coastal

terrace above the mouth of wilder creek. These sites are within the jurisdiction of the California Department of Parks and Recreation (DPR), and $\mathrm{SCr}-38$ has been tested by state Park archaeologists and this author. A summary of the excavations is provided here as well as data from two private collections.

DPR has referred to the sites at the ranch headquarters as $\mathrm{SCr}-38 / 123$ because two prehistoric sites overlap at this place. During the course of renovating several victorian period ranch houses and subsurface construction near the Bolkoff adobe building, archaeological monitoring and test excavations recovered information on the prehistoric components here (Hylkema 1987).

Point types recovered from all the sites reflect a Middle Period span of use. Diagnostic points consist of Ano Nuevo long-stemmed, barbed contracting-stemmed, and Rossi square-stemmed types. A series of radiocarbon dates and obsidian hydration readings from $\mathrm{scr}-38 / 123$ indicated that a Late Period component was also present but not well represented. The wide diversity of artifacts reveals an intensively used series of locations.

In 1985, four $1 \times 1.5$ meter units were excavated at scr-38/123 (Reinoehl et al. 1986), and in 1987 a fifth unit measuring $1.5 \times 1.5$ meters was also excavated. Table 27 
presents the unit numbers, dimensions, excavation techniques and ending depths.

Table 27: SCr-38/123 Excavation Unit Dimensions and Volume

Unit\# Dimension Screen Ending Depth Volume(M3)

\begin{tabular}{lllll}
1 & $1 \times 1.5 \mathrm{~m}$. & $1 / 8 \prime \prime$ & $160 \mathrm{~cm}$. & 2.4 \\
2 & $1 \times 1.5 \mathrm{~m}$. & $1 / 8 "$ & $80 \mathrm{~cm}$. & 1.2 \\
3 & $1 \times 1.5 \mathrm{~m}$. & $1 / 8 \prime$ & $180 \mathrm{~cm}$. & 2.7 \\
4 & $1 \times 1.5 \mathrm{~m}$. & $1 / 8 "$ & $120 \mathrm{~cm}$. & 1.8 \\
5 & $1.5 \times 1.5 \mathrm{~m}$. & $1 / 8 \prime$ & $100 \mathrm{~cm}$. & 1.5 \\
$\mathrm{CS} .1$ & $25 \times 25 \mathrm{~cm}$. & $1 / 8 "$ & $100 \mathrm{~cm}$. & .25 \\
\hline
\end{tabular}

In addition to these volumetrically controlled units, a large trench measuring $50 \mathrm{~cm}$. wide by $80 \mathrm{~cm}$. deep extending from the northeast corner of the wilder house to the northeast corner of the Bolkoff adobe was excavated and screened through $1 / 4 "$ mesh screen. The trench was for a proposed natural gas pipeline and a rapid recovery method was used to facilitate the project. Only formed tools and obsidian were retained from the rapid recovery method. Units 1 through 4 were wet screened after about $30 \mathrm{~cm}$. and a bucket (12 qts.) of soil from each $10 \mathrm{~cm}$. level was retrieved for wet screening and recovery of shell and other small sized elements. Because this sampling technique distorted the volumetric sample, unit 5 was excavated to control for debitage and shell frequencies. Soil from unit 5 was dry screened and bone, chipping debris and formed tools were saved. 
A column unit (CS.1) was established adjacent to unit five and excavated soils were wet screened for a controlled shell sample. Table 28 presents the results of the column sample. The quantity of shell from unit cs.l resulted in an estimate of $33,790.8 \mathrm{gr}$. of shell per cubic meter of site. Mytilus californianus was the dominant shell species present in the midden and comprises $82 . \because \%$ of the analyzed sample from units one through four (Reinoehl et al. 1986).

Table 28: Column Sample from SCr-38/123

(Unit Volume $=.25$ cubic meters)

\begin{tabular}{|c|c|c|c|c|c|}
\hline Depth & $\begin{array}{l}\text { Shell } \\
\text { Wt. (gr.) }\end{array}$ & \# & wt. & $\begin{array}{l}\text { Chipped } \\
\text { \# }\end{array}$ & $\begin{array}{l}\text { stone } \\
\text { wt. }\end{array}$ \\
\hline $\begin{array}{c}0-10 \\
10-20 \\
20-30 \\
30-40 \\
40-50 \\
50-60 \\
60-70 \\
70-80 \\
80-90 \\
90-100\end{array}$ & $\begin{array}{r}776.5 \\
892.9 \\
1,054.7 \\
1,544.9 \\
1,305.7 \\
1,176.6 \\
951.5 \\
548.9 \\
172.6 \\
23.3\end{array}$ & $\begin{array}{r}198 \\
298 \\
409 \\
220 \\
199 \\
65 \\
82 \\
53 \\
32 \\
22\end{array}$ & $\begin{array}{r}11.2 \\
10.1 \\
10.2 \\
7.8 \\
5.3 \\
3.2 \\
6.5 \\
13.5 \\
3.8 \\
.6\end{array}$ & $\begin{array}{r}16 \\
3 \\
16 \\
5 \\
6 \\
10 \\
8 \\
5 \\
3 \\
0\end{array}$ & $\begin{array}{r}61.5 \\
.6 \\
84.8 \\
56.2 \\
1.8 \\
78.3 \\
1.7 \\
1.1 \\
.7 \\
0\end{array}$ \\
\hline
\end{tabular}

Shell artifacts recovered included Haliotis and Mytilus crescent-shaped fish hooks, very few olivella spire lopped beads and two olivella type $B$ barrel beads.

Unit 5 provides a volumetric sample of chipping debris, and Table 29, the chipped stone summary, presents the range of debitage populations. A total of 2,722.9 gr. and 148 pieces of chipped stone was recovered equal to 98.5 pieces per cubic meter $(1,815.3 \mathrm{gr.})$. Units 1 through 4 produced a 


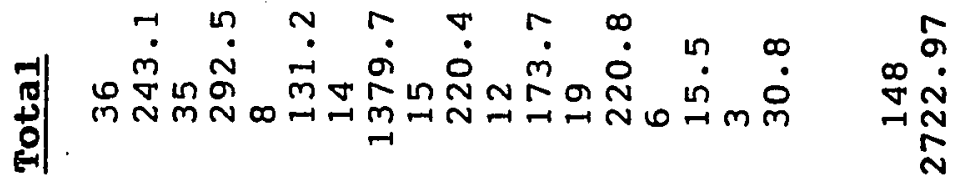

al $00000000000000000000 \frac{\int_{0}^{10}}{n}$

$\$ 1000000000000000000000$

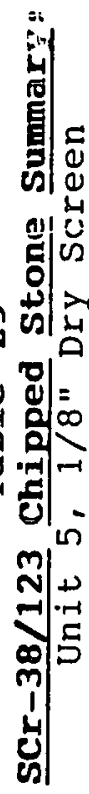

$M 00000000000000000000 \frac{\pi}{n}$

$01000000000000-\frac{1}{n} 0000 \quad$ n

In) 000000000000000000000

$\|$ II

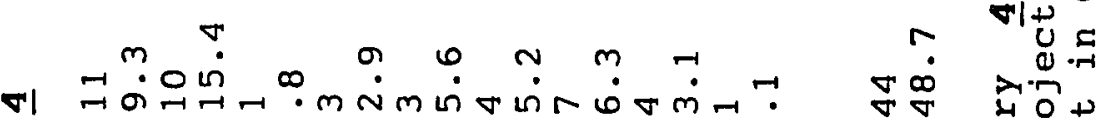

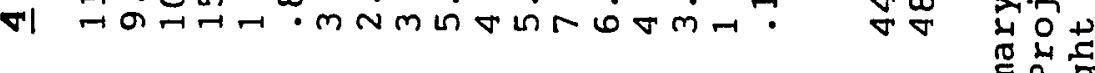

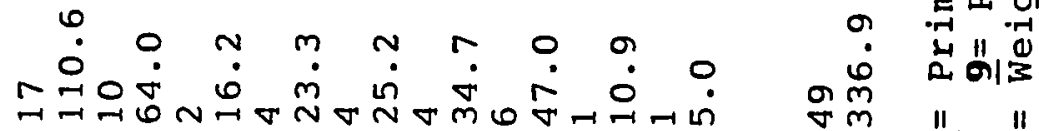

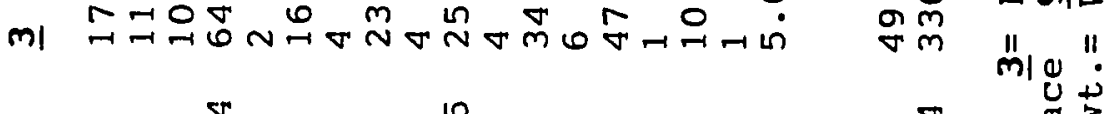

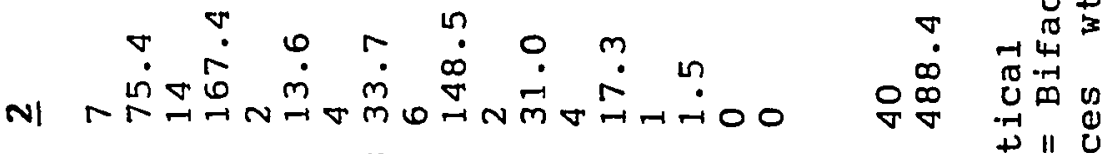

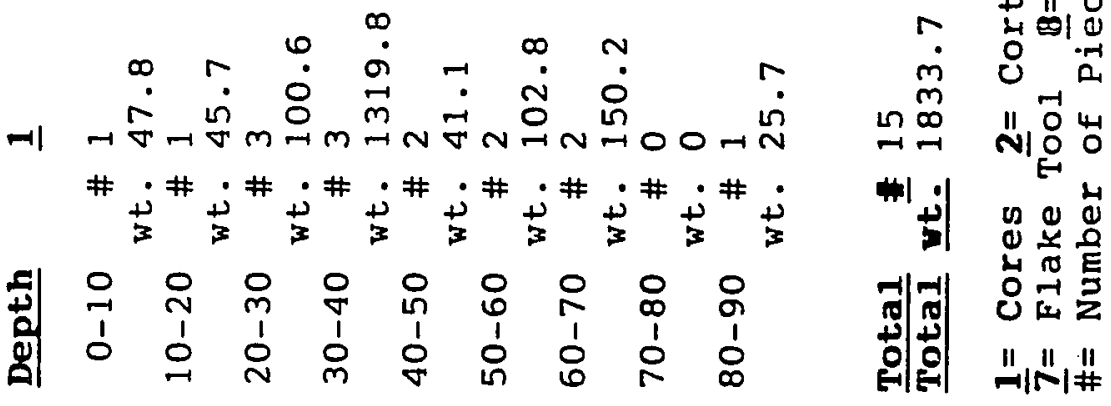


total of 1,221 pieces of chipped stone, or 151 pieces per cubic meter. The column sample retrieved smaller pieces of chipped stone equal to 288 pieces per cubic meter $(1,146.8$ gr.). An analysis of the debitage from units 1 through 4 shows a fairly even ratio of primary to secondary chipped stone tool debris with a low number of cores (Hylkema 1987). Unit 5 shows a greater proportion of primary debris (70\% by number of pieces) over secondary reduction (30\%). Virtually all of the chipped stone debitage and tools are of Monterey chert with the exception of one Franciscan chert point, one red jaspar point and fifteen obsidian flakes.

Although the DPR investigations recovered only nine projectile points and bifaces, a surface collection by the resident ranch foreman, Led Engelsmen, contained four complete points. These, plus two from the Terry Kvenild collection, and four from the DPR excavations, were measured and are described in Appendix D. All of them were illustrated (see Figures 40 and 41). Two other sites, scr-39 and sCr-40, form a series of sites (which begin with sCr38), along the terrace above the north bank of wilder creek. Projectile points from these sites in the Terry Kvenild collection have also been included in this study and their descriptions are presented in Appendix D. These total 26 specimens. Given the point styles, it is likely that all three sites are contemporaneous, and they may actually represent one very large use area (see Figures 40 to 44 ). 
Table 30 presents the point types recovered from the wilder Ranch sites.

Table 30: Point Types from the wilder Ranch Sites

Barbed Contracting Stemmed-

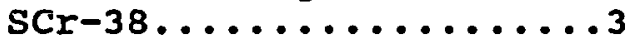

scr-40................

Ano Nuevo Long-stemmed-

scr-39..................

$\mathrm{sCr}-40 \ldots \ldots \ldots \ldots \ldots \ldots$

Rossi Square-stemmed-

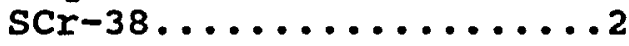

sCr $-39 \ldots \ldots \ldots \ldots \ldots \ldots \ldots$

sCr-40................

Lanceolate-

scr-38..............

scr-40...............

Notched-

scr-38...............

$\mathrm{sCr}-40 \ldots \ldots \ldots \ldots \ldots . \ldots 1$

Many cabble tools have been removed from the site by collectors. The wilder family and Led Englesmen, the ranch foreman, have mentioned that many mortars and pestles were formerly present at the ranch. The DPR has documented the presence of end battered cobbles, handstones, grooved cobbles, pestles, mortars (including a small bowl mortar, possibly used for pigments or tobacco), an incipient charmstone, a perforated discoidal cobble, and others. Both acorn and seed grinding implements are present, but it could not be determined if these technologies co-occur.

Radiocarbon dates and obsidian sourcing and hydration analysis have provided chronometric data. The problem here is that the five excavation units are in the lower alluvial 
stream terrace, where $\mathrm{scr}-123$ is also located, and site boundaries between them have not been defined. Further complicating this situation is the fact that the upper terrace midden of $\mathrm{scr}-38$ has been slumping down onto the lower stream terrace midden, possibly mixing the two sites. The results of the radiocarbon analysis have been presented in Table 31.

Table 31: Radiocarbon Dates from SCr-38/123

WSU\#\# DPR Provenience $\quad \underline{14 \mathrm{C}}$ age, lyears B.P.)

$\begin{array}{llll}3532 & \text { P676-35-5 U. 3/40-50 cm. } & 1600 \pm 60 \\ 3533 & \text { P676-36-8 U. } 3 / 40-50 \mathrm{~cm} . & 1920 \pm 110 \\ 3534 & \text { P676-49-7 U. 3/110-120 cm. } & 3010 \pm 110 \\ 3535 & \text { P676-51-6 U. 3/110-120 cm. } & 3370 \pm 50 \\ 3536 & \text { P676-60-4 U. } 3 / 160-170 \mathrm{~cm} . & 3480 \pm 120 \\ 3537 & \text { P676-61-6 U. } 3 / 160-170 \mathrm{~cm} . & 3060 \pm 85 \\ 3538 & \text { P676-80-5 U. } 4 / 100-110 \mathrm{~cm} . & 1470 \pm 70\end{array}$

The radiocarbon dates reveal two temporal clusters. The first from the upper level of unit 3 and the lower level of unit 4 ranges from approximately 480 to 50 A.D., and the second, from the lower levels of unit 3 ranges from 1060 to 1950 B.C. It is likely that the more recent date from unit 4 was overlain by the slumping of older shell deposits from the midden directly above the unit. All of these dates were derived from Mytilus californianus shell samples weighing over $100 \mathrm{gr}$.

A total of six obsidian specimens were sourced and hydrated from unit 3 (see Table 32 ). All of the specimens 


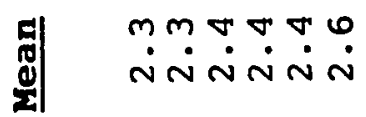

$m \nabla$ m n NंN $\dot{N} \dot{N}$

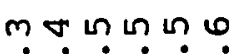
NंN $\dot{N} \dot{N}$ $m m \nabla v \nabla 0$ iि

의 $m m m m$ जن $\mathrm{Nm} \mathrm{N} N \mathrm{n}$ ن NNNNNE

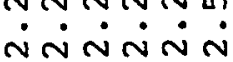
式

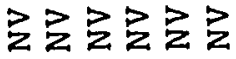

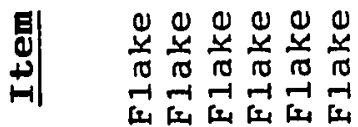

0
0
0
0

$\ddot{n}$

怘

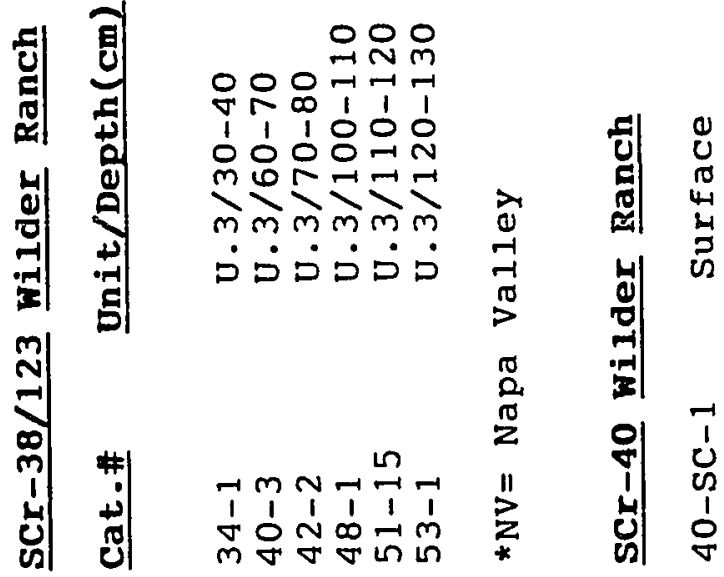


were from the Napa source and clustered at 2.3 to 2.6 microns.

While many bone fragments were recovered from the excavated units and monitoring phases, the faunal analysis was not completed. Many fish bones were recovered as well as bird, terrestrial and marine mammal bone. Bone tools were fairly abundant around the ranch headquarters and included pointed and spatulate tipped awls. Most of them were made from split and polished deer tibia and had broad spatulate tips.

scr-38/123 appears to contain a single component assemblage as evidenced by radiocarbon dates, obsidian hydration readings, and artifact types. Unfortunately, due to the lack of clearly identified site boundaries between SCr-38 and SCr-123, both sites overlap and have been treated as one. This prevents an accurate assessment of component definitions. Nonetheless, the author feels that this location represents a Middle Period forager residential base and Table 33 presents a tentative component summary. 
Table 33: Component summary from sCr-38/123

1) Upper and Lower Levels: $0-100 \mathrm{~cm}$.

Age: Middle Period, 1,470 \pm 70 to $3,480 \pm 120$ B.P. Obsidian Hydration Range: Napa $(\mathrm{N}=6) 2 . \overline{3}-2.6$

Artifacts:

Ano Nuevo long-stemmed pts. Rossi square-stemmed pts. Barbed contracting-stemmed pts. olivella type $B$ beads Mytilus \& Haliotis fishooks Mortars \& Pestles Handstones Doughnut stone Grooved cobbles Bone awls
Shel1 wt. (M3): $33,790.8 \mathrm{gr}$. 
208
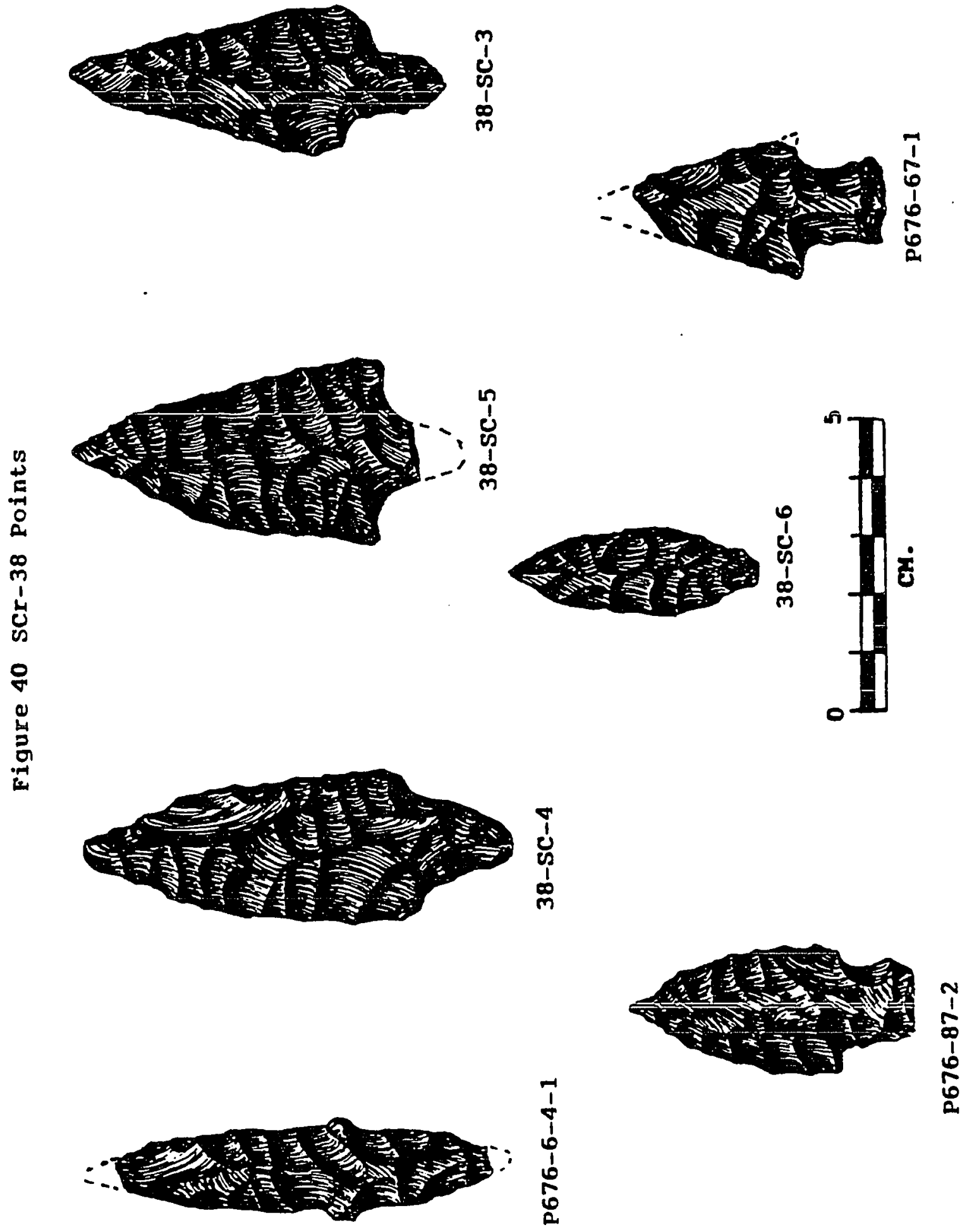

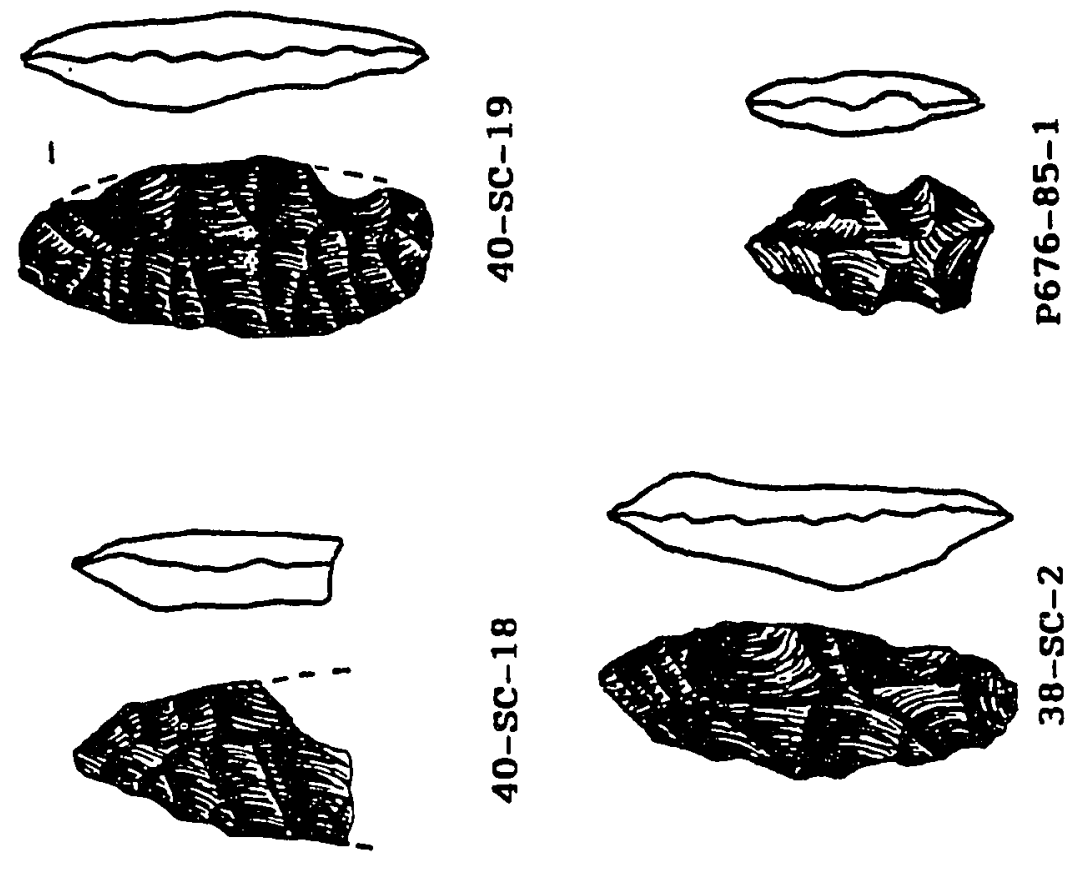

0
0
0
0
0
0

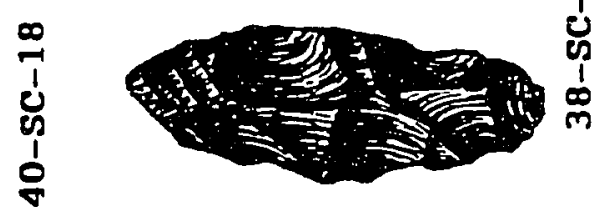

ป

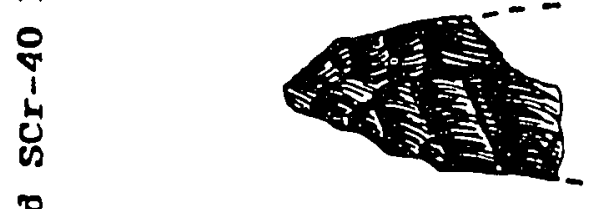

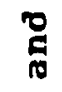
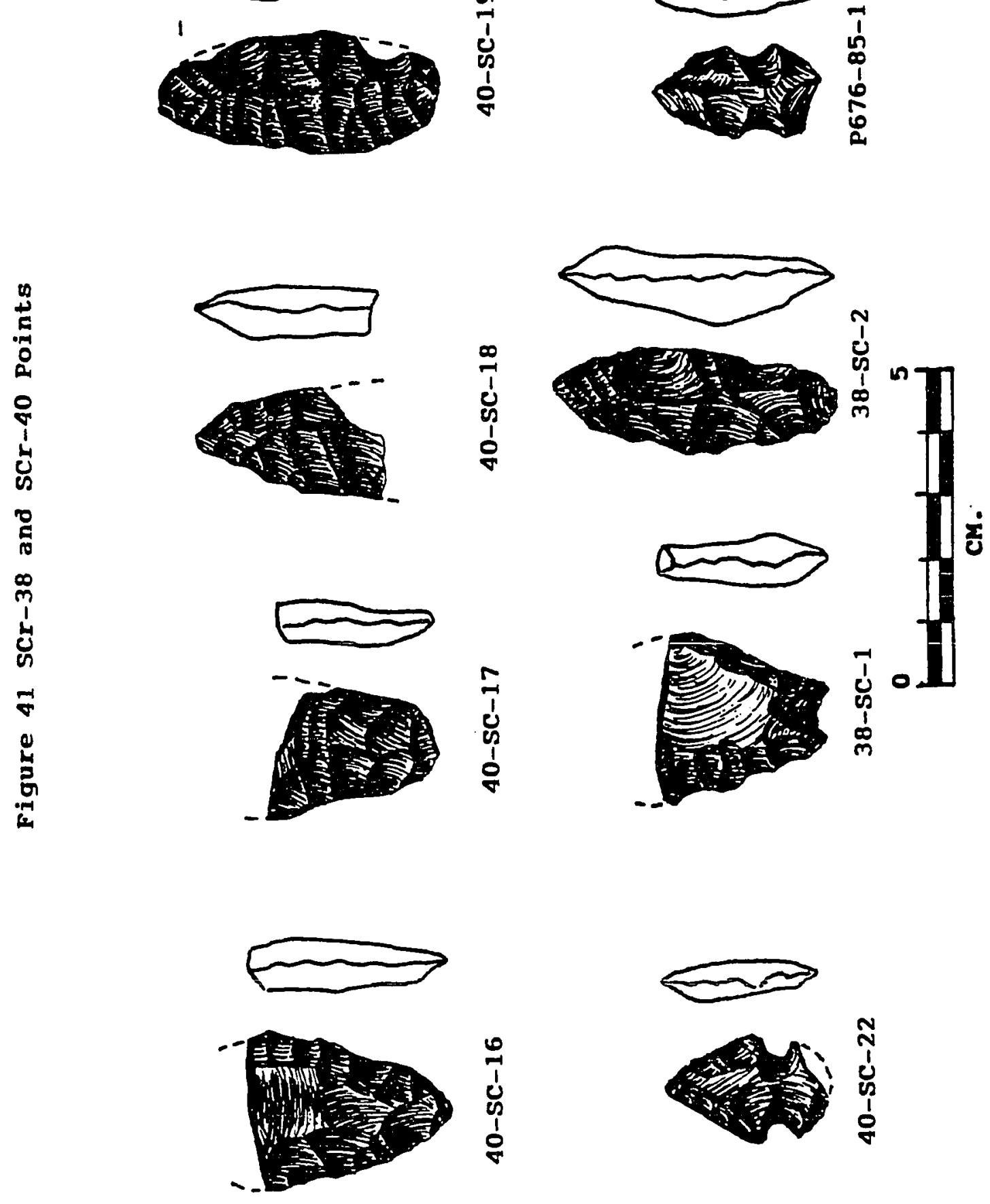

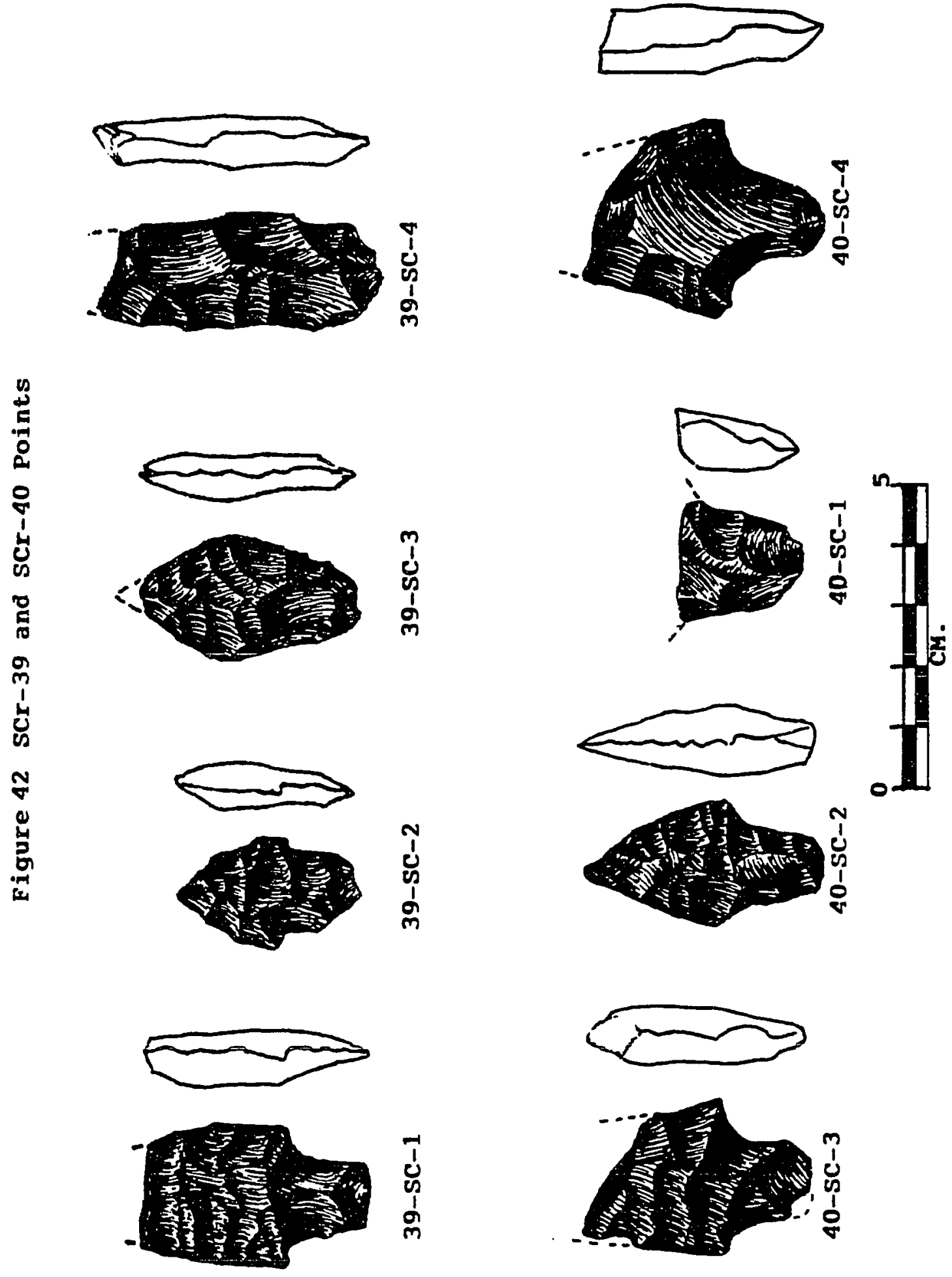

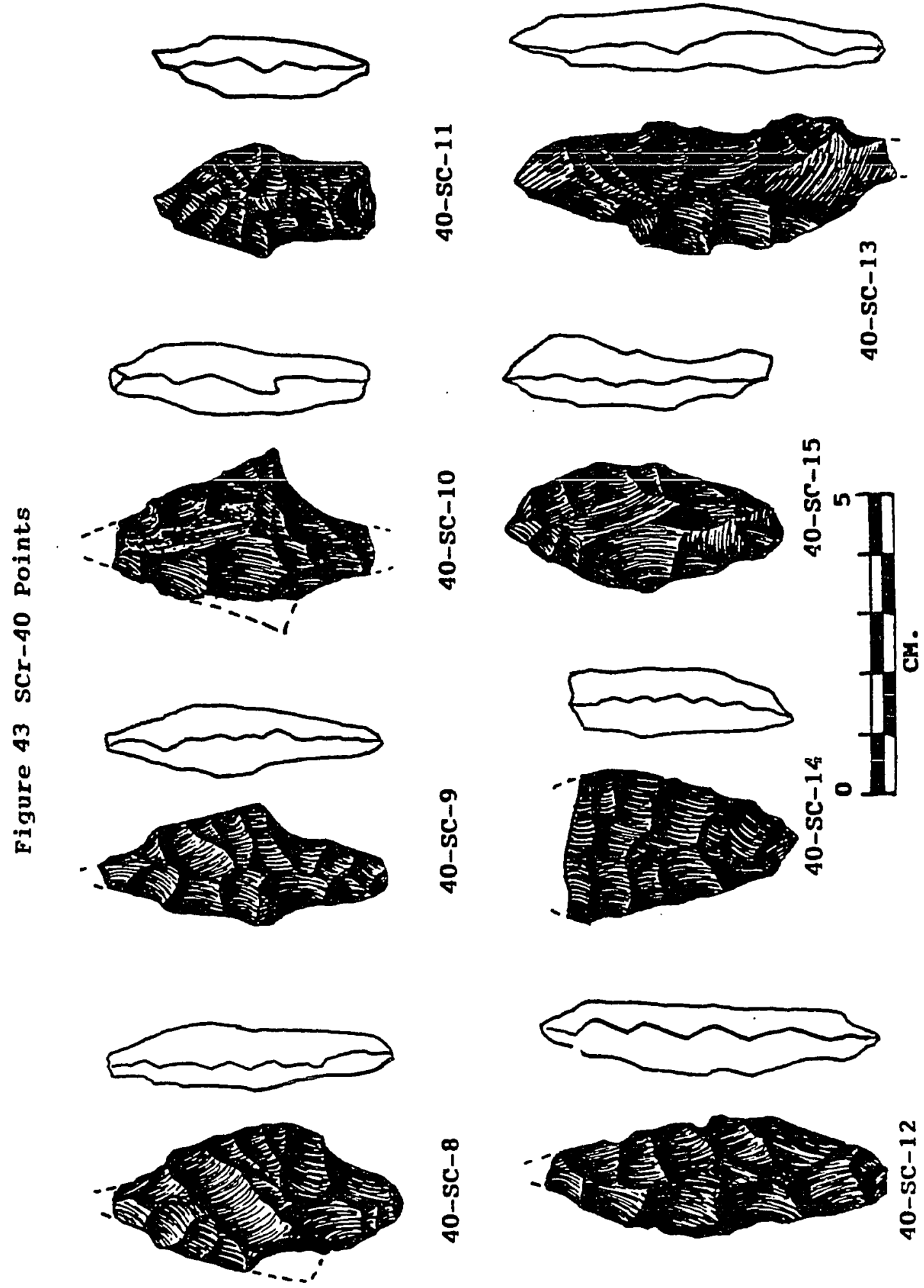

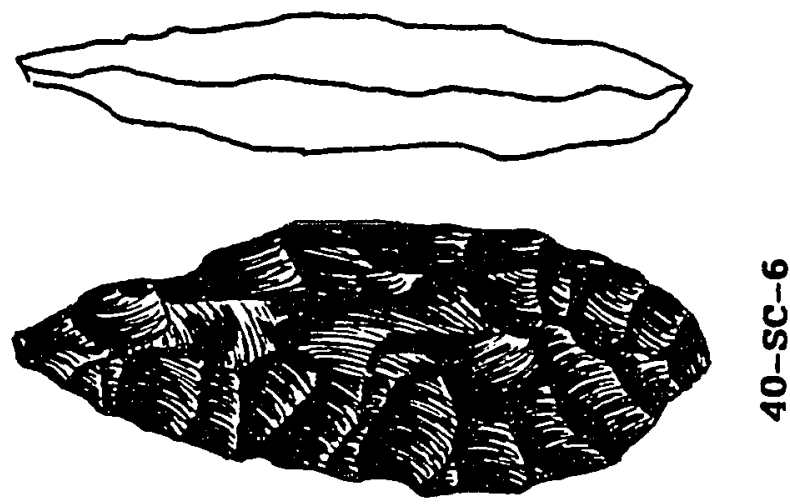

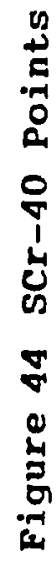
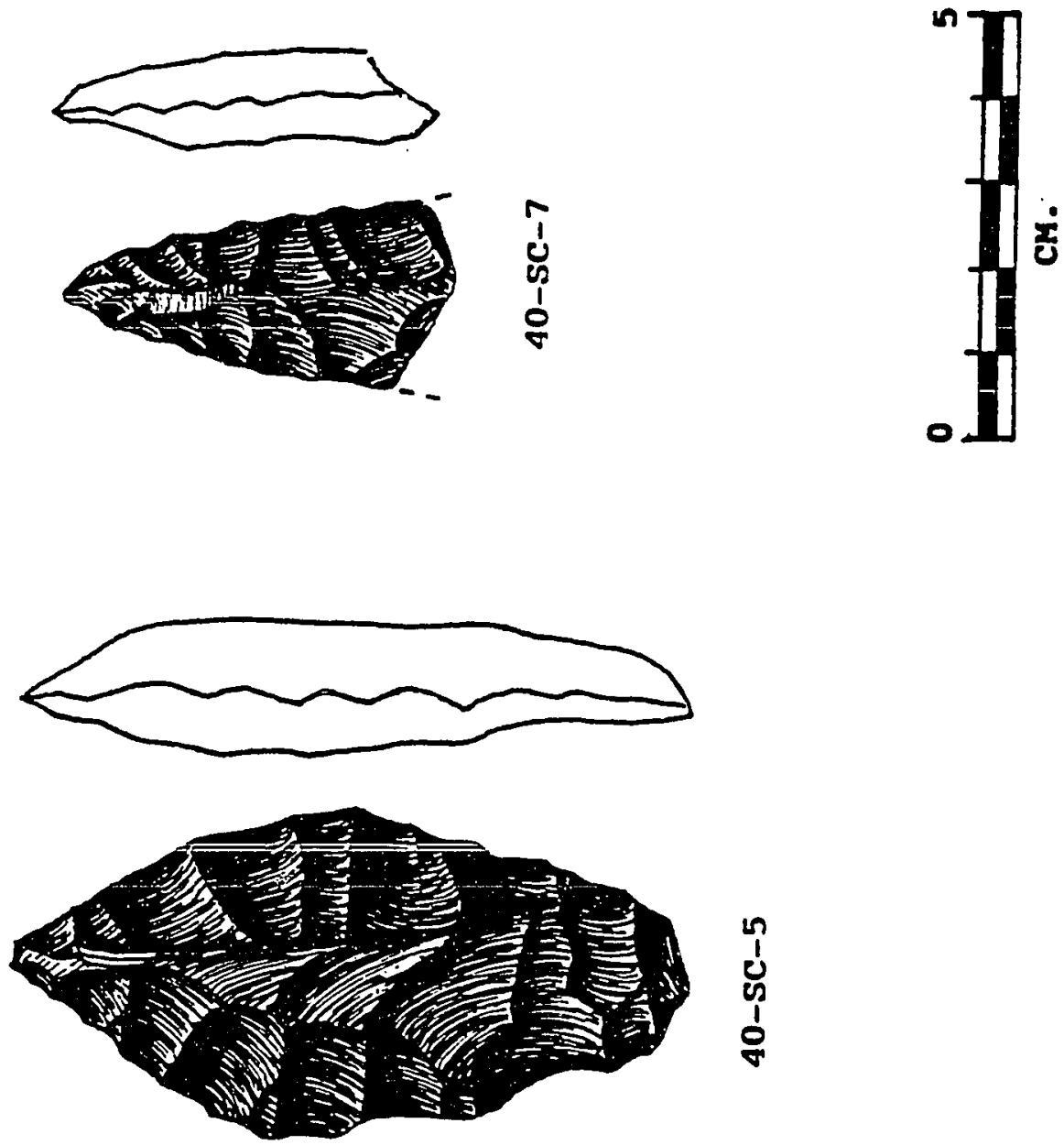
SCr-93, the Sunflower House site

scr-93 is located on the coastal terrace, north of the mouth of the San Lorenzo River, in the city of Santa Cruz. The site is adjacent to Nearys Lagoon and was first tested in 1981 (Breschini and Haversatt 1981), then again in 1985 (Bourdeau et. al 1986).

A single 1 x 1 meter unit was excavated in 1981 (1.8 cubic meters), and in 1985 another one was excavated (1.1 cubic meters). As a result of construction at the site, a monitoring program involved with the project managed to recover additional artifacts. A total of 2.9 cubic meters of site had been excavated through volumetrically controlled sampling, and all of the soils were sifted through 1/8" mesh screens.

The combined excavations at scr-93 have recovered 16 modified olivella shell beads. These consisted of 2 type $\mathrm{E}$ lipped, 4 type $\mathrm{F}$ saddle, 9 type $\mathrm{G}$ saucer and 1 type I rectangle beads (Bennyhoff 1988 ). In addition to these beads, 2 type B barrel beads and 48 type A spire lopped beads were retrieved. Two Haliotis ring beads and a single Mytilus fish hook were also noted. Unit 1, of the 1985 excavation, provided data on shell frequencies. A total of $227,707.2 \mathrm{gr}$. of shell are reported, equal to $207,006.5 \mathrm{gr}$. per cubic meter of site. This incredible amount of shell was composed of $78 \%$ Mytilus. 
Both terrestrial and marine faunal elements were recovered. Results from unit 1 of the 1985 testing indicate that 1,812 pieces were reviewed $(1,1184 \mathrm{gr}$.$) , equal to$ $1,647.3$ pieces per cubic meter of site $(1,016.7 \mathrm{gr})$. of these, $26 \%$ by number of pieces and $32 \%$ by weight were identifiable. Table 34 lists the results of the faunal analysis, which was conducted by Jeffrey Hall and Dr. David Huelsbeck. The results indicated that terrestrial mammals dominated the collection $(87 \%$ by number of pieces and weight), and that fishing was also an important activity. 42 fragments of polished and burned bone tool fragments were noted from the two excavations. Two specimens were pointed awl tips and one was an antler tip.

Debitage recovered from the 1985 excavation included 496 pieces $(1,317.4 \mathrm{gr}$.$) equal to 451$ pieces per cubic meter of site $(1,197.5 \mathrm{gr}$.$) . Of this sample, 96 \%$ of the pieces were of Monterey chert, and $1.5 \%$ are of obsidian. The obsidian specimens were sourced and hydration analysis results have been presented in Table 35. 22 additional obsidian specimen were retrieved during the monitoring phase.

Projectile points consisted of 3 Ano Nuevo longstemmed, 1 other contracting stem, 1 Rossi square-stemmed, and 2 side notched projectile points (Bourdeau et al. 1986). Also, 29 bifaces were recovered during the monitoring phase. 
Table 34

SCr-93 Taxa Frequency:

Unit 1, $1 / 8 "$ Dry Screen

\begin{tabular}{|c|c|c|c|c|}
\hline Taxa & \#pcs. & $\%$ & Ht.(gr) & \% \\
\hline$\frac{\text { Enhydra }}{\text { Zalophus }} \frac{\text { lutris }}{\text { Ottaridae }}$ & $\begin{array}{l}6 \\
1 \\
2\end{array}$ & $\begin{array}{r}1.3 \\
.2 \\
.5\end{array}$ & $\begin{array}{r}10.5 \\
28.0 \\
2.2\end{array}$ & $\begin{array}{r}3.0 \\
8.0 \\
.5\end{array}$ \\
\hline $\begin{array}{l}\text { Cervus nanoides } \\
\frac{\text { odocoileus }}{\text { Sylvilaqus }} \text { hemionus } \\
\text { Lepus californicus }\end{array}$ & $\begin{array}{r}3 \\
41 \\
13 \\
2\end{array}$ & $\begin{array}{r}.5 \\
9.0 \\
2.5 \\
.5\end{array}$ & $\begin{array}{r}36.2 \\
220.0 \\
4.9 \\
12.0\end{array}$ & $\begin{array}{r}10.0 \\
61.0 \\
1.5 \\
3.5\end{array}$ \\
\hline Aves & 4 & 1.0 & 8.8 & 2.5 \\
\hline Ichthys & 396 & 84.5 & 37.8 & 10.5 \\
\hline Unidentifiable & 1343 & 74.0 & 758.0 & 68.0 \\
\hline Tota 1 & 1812 & & 1118.4 & \\
\hline
\end{tabular}

Terrestrial vs Marine:

(Rodentia, Aves and Ichthys Excluded)

\#pcs.\%

wt. (gr) \%

Terrestrial

87

87

Marine

13

13 


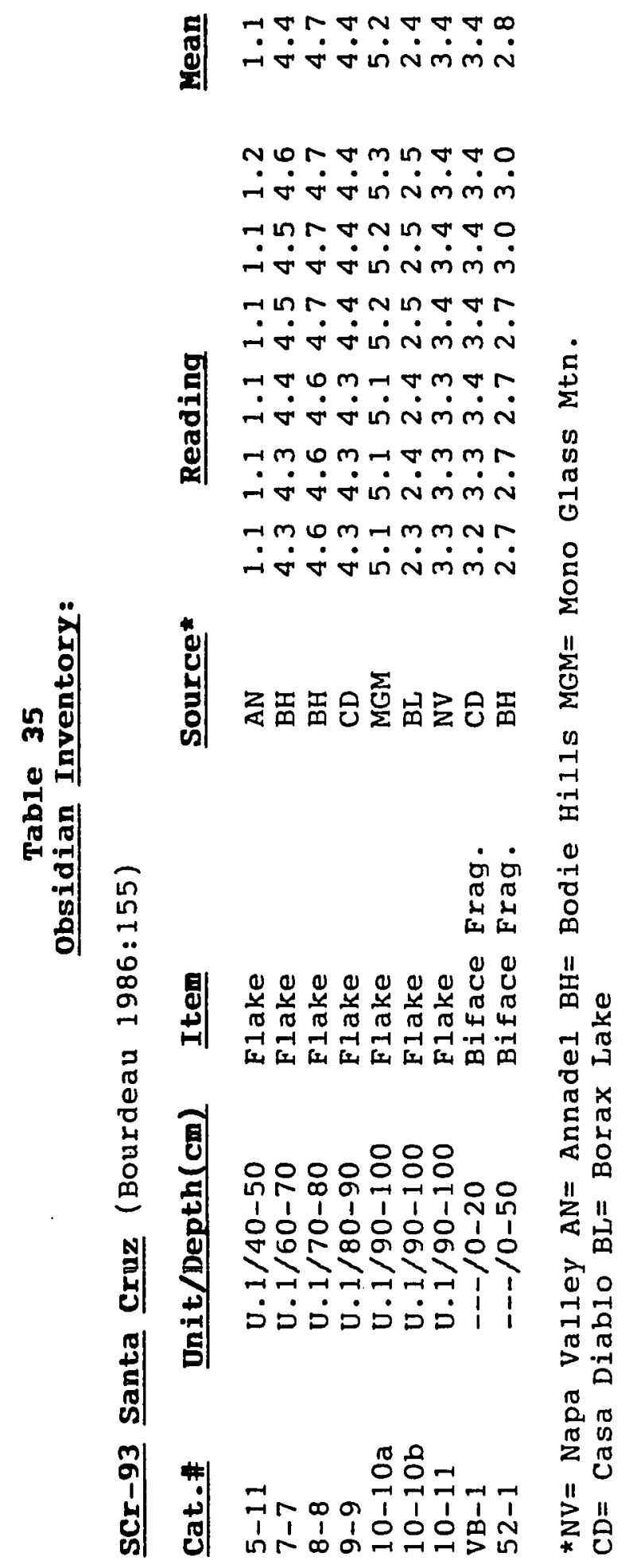


The analysis of the debitage resulted in the finding that a bi-polar core reduction technique was evident at this site. The generally small size of the Monterey chert pebble cores made the bi-polar method an optimal technique here. It is likely that the native people at this location would have had to acquire larger cores, biface preforms and projectile points from distances away from the site.

Cobble tools recovered from this site included 5 mortars (two are small and classified as paint mortars), 1 handstone, 2 edge notched stones, 4 end battered cobbles, and over 26 fragmentary pieces of stone with polish or battered surfaces. The proximal end of a perforate, phallicshaped charmstone was also found (type $V$ after Beardsley 1954: 10). The cobble tool assemblage reflects a range of activities such as fishing with the use of nets and hook and Iine (notched cobbles), acorn foods (mortars), hard seed foods (handstone), tool production (end battered cobbles), and spiritual pursuits (charmstone and paint mortars).

Several radiocarbon dates have been derived from scr93. The combined results of the two excavations are presented in Table 36. 
Table 36: Radiocarbon Dates from scr-93

\begin{tabular}{|c|c|c|}
\hline WSU\# & Provenience, Composition & aqe, (years B.P.) \\
\hline $\begin{array}{l}3450 \\
3451 \\
3179\end{array}$ & $\begin{array}{l}\text { U.1/10-20 cm., Mixed shell } \\
\text { U.1/40-50 cm., Mytilus sp. } \\
\text { U.1/0-10 cm., Charcoal }\end{array}$ & $\begin{array}{l}1760 \pm 70 \\
1960 \pm 70 \\
2055 \pm 105\end{array}$ \\
\hline $\begin{array}{l}2552 * \\
3178 \\
3177 \\
2551 * \\
3452\end{array}$ & $\begin{array}{l}100-110 \mathrm{~cm} ., \\
\text { Feature } 2 / 105-110 \mathrm{~cm} \cdot \mathrm{cm}^{\prime} \text { Charcoal } \\
\text { Feature } 1, \quad \text { Mixed Shell } \\
160-180 \mathrm{~cm} ., \quad \text { Mixed Shell } \\
\mathrm{U} .1 / 90-100 \mathrm{~cm} .\end{array}$ & $\begin{array}{l}2720 \pm 90 \\
2725 \pm 75 \\
2830 \pm 75 \\
3210 \pm 100 \\
3700 \pm 60\end{array}$ \\
\hline
\end{tabular}

Bennyhoff (1988: 53-55) observed two basic temporal patterns and six, possibly seven, components based upon bead typologies and radiometric data. He noted that the site was occupied from Early Period times (1,750 B.C.) through the Late Middle period (A.D. 500).

While Bennyhoff was able to distinguish several temporal components on the basis of variable olivella bead types, the assemblage as a whole is homogeneous. It is this author's opinion that sCr-93 represents an Early to Middle Period single component forager residential location that was occupied intermittently over many years. Variation in bead types probably relates to changing economic or stylistic events taking place away from the study area. Table 37 on the following page summarizes the component definition for this site. 
Table 37: Component summary from scr-93

1) Upper and Lower Levels: 0-180 cm.

Age: Early to Middle Period, $1,760 \pm 70$ to $3,700 \pm 60$ obsidian Hydration Range: Napa $(\mathrm{N}=\overline{1}) 3.4$

Casa Diablo $(\mathrm{N}=2) \quad 3.4-4.4$

Mono Glass Mtn. ( $\mathrm{N}=1) 5.2$

Bodie Hills ( $\mathrm{N}=3)$ 2.8-4.7

Borax Lake $(\mathrm{N}=1) 2.4$

\section{Artifacts:}

Ano Nuevo long-stemmed pts. Rossi square-stemmed pt. Notched (side) pts. olivella type $B, E, F$, $G$ and $L$ beads Mytilus fishook

Mortars

Handstones

Edge notched cobbles Perforate charmstone Bone awls

*= Percentage of identifiable bone pieces.
Shell wt. (M3):

Sea otter $(1.38) \quad 207,000 \mathrm{gr}$.

Deer $(9.0 \%)$

Rabbits ( $3.0 \%)$

Fish $(84.5 \%)$ 
Scr-132, the scott Creek site

sCr-132 is located on a river terrace along scott creek, and is approximately four miles inland from the stream's mouth at the beach. This is within the riverine zone defined for this study. The stream terrace is open and covered by grassland. Mixed hardwood forest trees surround the grassy flat while dense redwood forest covers the steep slopes and the narrow river bottom. The site, which was tested by this author, is on land owned by Big Creek Lumber Company and permission to conduct an excavation here was granted by the Mccrary family.

A total of four $1.5 \times 1.5$ meter units were excavated. In addition to these, two column units were excavated measuring $50 \times 50 \mathrm{~cm}$. and $25 \times 25 \mathrm{~cm}$. Total excavation volumes equaled 4.4 cubic meters. Table 38 presents the unit dimensions, screen mesh sizes and unit volumes.

Table 38: SCr-132 Excavation Unit Dimensions and Volume Unit Dimension screen Method cubic Meter

$\begin{array}{lrrrrl}1 & 1.5 \times 1.5 \mathrm{~m} . & 1 / 4 " & \text { Dry } & 1.05 \\ 2 & 1.5 \times 1.5 \mathrm{~m} . & 1 / 8 " & \text { Dry } & .75 \\ 3 & 1.5 \times 1.5 \mathrm{~m} . & 1 / 4 " & \text { Dry } & .9 \\ 4 & 1.5 \times 1.5 \mathrm{~m} . & 1 / 4 " & \text { Dry } & 1.2 \\ \text { T.U. } 1 & 50 \times 50 \mathrm{~cm} . & 1 / 8 " \text { Dry } & .3 \\ \text { C.U.1 } & 25 \times 25 \mathrm{~cm} . & 1 / 8 " \text { Wet } & .2\end{array}$

The excavation plan (Map 17) shows the location of the units. The surface distribution of shell and debitage defined the areal extent of the site and excavation units 
were placed in the center where the greatest midden depth was thought to be. Ultimately, the site was found to lack significant depth. The deepest deposit was in units 4 and CU.1, where basal depths were reached at $80 \mathrm{~cm}$. below the ground surface. The first $50 \mathrm{~cm}$. of the matrix consisted of dark brown, silty loam soils with many shell fragments and debitage pieces. From 50 to approximately $70 \mathrm{~cm}$. the soil became lighter in color and angular mudstone rocks increased in number. Yellow colored sandy silt soils with compact angular mudstine blocks formed the basement of the midden. The soil profile (Figure 44) illustrates the stratigraphy visible in unit 1 and was typical for this site.

Two radiocarbon samples were submitted from $\mathrm{sCr}-132$. The first was derived from a complete shell of Haliotis cracherodii associated with Feature 1. The second sample was from charcoal fragments recovered from $20 \mathrm{~cm}$. below the feature. The radiocarbon dating results are as follows: wsU\# 3205 from unit 4 at $30-40 \mathrm{~cm}$. consisting of $98.5 \mathrm{gr}$. of Haliotis, resulted in a date of $1900 \pm 50$; WSU\# 3231, also from unit 4 at $60-70 \mathrm{~cm}$. consisting of $14.0 \mathrm{gr}$. Charcoal, resulted in a date of $5240 \pm 100$.

The older date, taken from multiple bits of charcoal collected from over 20 centimeters below Feature 1, is too old to date the occupation of the site accurately. The more recent date taken in association with the feature works well with the obsidian hydration results. 
A total of 12 obsidian pressure flakes were sourced and hydrated. All of them were from the Napa Valley source. The average mean hydration rim reading for these specimens was 2.5 microns. Table 39 presents the results of the obsidian analysis.

A total of 12 olivella shells were recovered. No modified beads were recovered although a single spire broken shell was found in association with burial 1. In all, 25\% had intact spires, $41.5 \%$ were spire broken, $25 \%$ had ground spires and $8.5 \%$ were fragments. This number is equal to 3 specimens per cubic meter of site (excluding TU.I and CU.I). The olivella distributions by unit and type are presented in Appendix B.

Column unit $C U .1$, which was excavated from the side wall of unit 4 , provided volumetric information for shell fragments in the midden. Excavated soils were wet screened through $1 / 8$ " mesh. Table 40 presents the results of the column sample. Bone weights were not included because the sample was misplaced. A total of $709.5 \mathrm{gr}$. of shell was recovered equal to $3,547.5 \mathrm{gr}$. per cubic meter of sj.te. A brief review of the shell species present indicated that Mytilus californianus composed approximately $95 \%$ of the sample. 


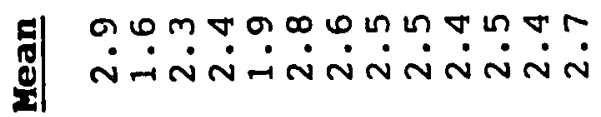

ont mathomitat $\dot{m} \dot{\sim} \dot{N} \dot{\sim} \dot{N} \dot{N} \dot{N} \dot{N} \dot{N}$ or m-ivi $\dot{\sim} \dot{N} \mathbf{N} \dot{N} \dot{N}$ ด $\dot{m} \dot{i} \dot{N} \dot{\sim} \dot{N} \dot{N} \dot{N} \dot{N} \dot{N}$ का naninanananna

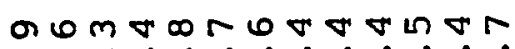
$\dot{N} \dot{\sim} \dot{N} \dot{N} \dot{N} \dot{N} \dot{N} \dot{N}$ ก. $\dot{N} \dot{\sim} \dot{N} \dot{N} \dot{N} \dot{N} \dot{N} \dot{N} \dot{N}$
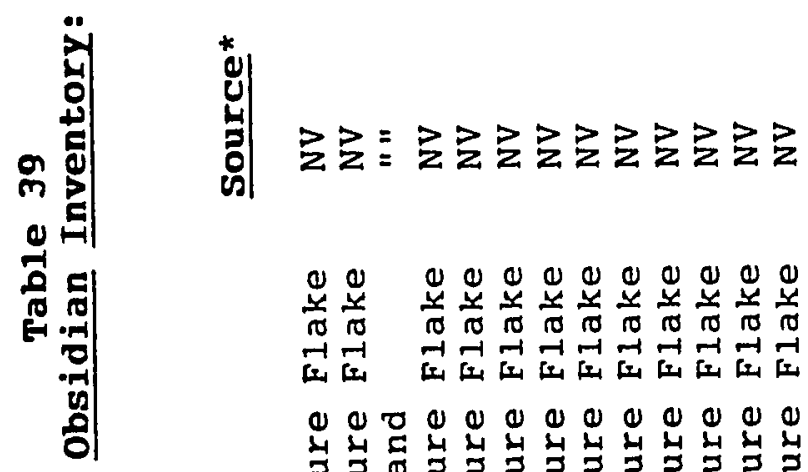

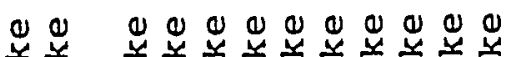

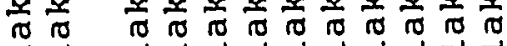

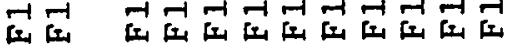

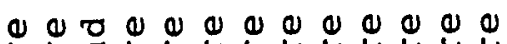

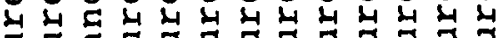

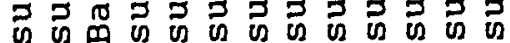

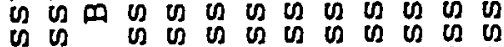

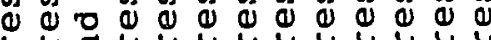

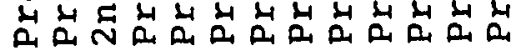

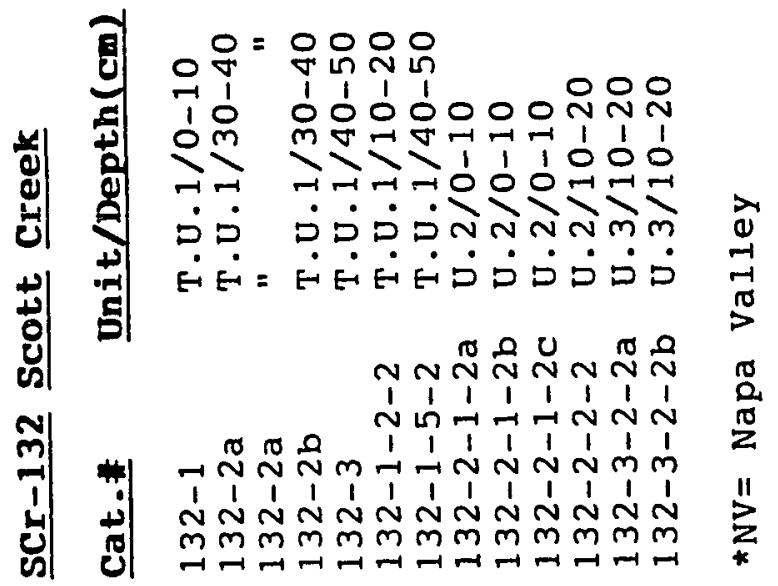


Table 40: Column Sample Results from SCr-132

(Unit volume $=.2$ Cubic Meters)

\begin{tabular}{rrrrr} 
& \multicolumn{2}{c}{ Shell } & \multicolumn{2}{c}{ Debitage } \\
Depth & Wt.(gr.) & & \# & Wt. \\
\cline { 4 - 5 } $0-10$ & 41.5 & & 48 & 26.7 \\
$10-20$ & 51.0 & 21 & 34.5 \\
$20-30$ & 77.5 & 17 & 6.8 \\
$30-40$ & 79.0 & 21 & 12.3 \\
$40-50$ & 167.0 & 29 & 5.0 \\
$50-60$ & 197.0 & 23 & 10.2 \\
$60-70$ & 86.0 & 7 & 12.2 \\
$70-80$ & 10.5 & 6 & 1.5 \\
& & & & 110.2
\end{tabular}

Shell volume Per Cubic Meter $=3,547.5 \mathrm{gr}$.

Debitage Volume Per Cubic Meter $=860$ Pieces (551.0 gr.)

The identification of the faunal bone revealed a reliance on both marine and terrestrial species. Table 41 presents the results of the faunal analysis for the site. Taxa listed by unit and depth (excluding $C U .1$ ) have been presented in Appendix A. Terrestrial mammals constituted $64 \%$ of the identified pieces and $35 \%$ of the weight (excluding rodents, birds and $f(s h)$. Marine mammals reflected the opposite ratio ( $36 \%$ of the pieces and $65 \%$ of the weight). An amount of bone equal to $72.0 \mathrm{gr}$. per cubic meter of site was recovered from the test units (excluding CU.1). Deer remains dominated the identifiable terrestrial elements and sea mammals consisted of four different species of pinnipedea, along with sea otter remains. No bone tools were recovered.

Debitage was abundant and pieces from units 1 and $\mathrm{CU} .1$ were chosen as the representative sample for type analysis 


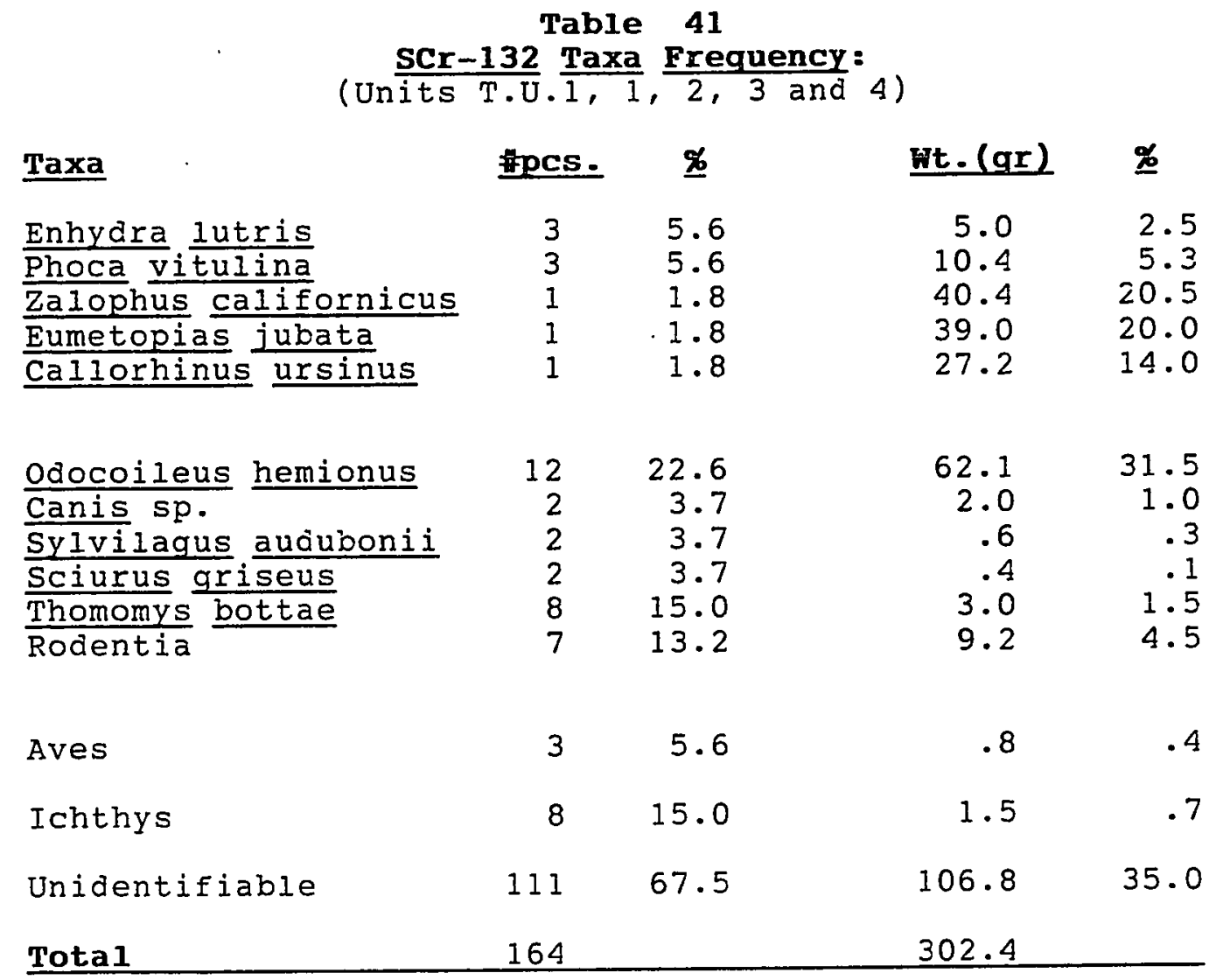

Terrestrial vs Marine:

(Rodentia, Aves and Ichthys Excluded)

\#pcs.\%

Terrestrial

Marine
64.0

36.0 wt. (gr) \%

35.0

65.0 
(see Tables 42 and 43 ). Table 44 presents the number of pieces and weights by unit for the combined unit totals.

\begin{tabular}{|c|c|c|c|c|}
\hline Unit & \# pcs. & $\underline{q}$ & wt. (ar.) & 8 \\
\hline $\begin{array}{l}1 \\
2 \\
3 \\
4 \\
\text { TU. } 1 \\
\text { CU. } 1\end{array}$ & $\begin{array}{l}996 \\
706 \\
739 \\
926 \\
296 \\
172\end{array}$ & $\begin{array}{r}26.0 \\
18.5 \\
19.0 \\
24.0 \\
8.0 \\
4.5\end{array}$ & $\begin{array}{r}2,529.7 \\
1,650.0 \\
2,411.5 \\
3,251.0 \\
414.0 \\
110.2\end{array}$ & $\begin{array}{l}24.5 \\
16 \\
23 \\
31.5 \\
4 \\
1\end{array}$ \\
\hline
\end{tabular}

The combined total for these units equals 871 pieces (356.0 gr.) per cubic meter of site. This total number of pieces was very close to the projected counts from $\mathrm{CU}$. 1 but was four times the weight. Debitage from unit 1 was composed of $23.5 \%$ primary reduction, $64.0 \%$ secondary reduction, $12.0 \%$ shatter debris and .5\% formal tools. No informal tools were recovered. CU. 1 produced different results, and the debitage represented $12 \%$ primary reduction, secondary reduction $73.0 \%$ and shatter debris $15.0 \%$. No informal or formal tools were recovered. Both of these estimates indicated that chipped stone tools were being shaped at the site, but the initial stages of tool construction were done elsewhere. All of the debitage was of Monterey chert, except for the 12 obsidian pressure flakes.

Bifaces and projectile points were not abundant, and of 14 specimens recovered, only $9(64 \%)$ were formal tools (represented by reduction stages 4 and 5), and 5 (36r) were 


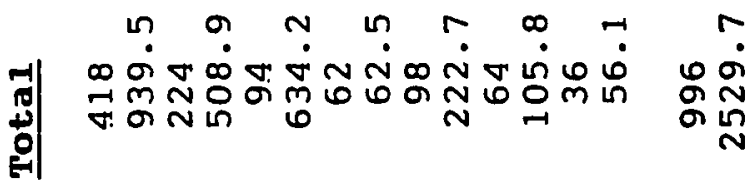

al $0000000000000000 \frac{1}{n}$

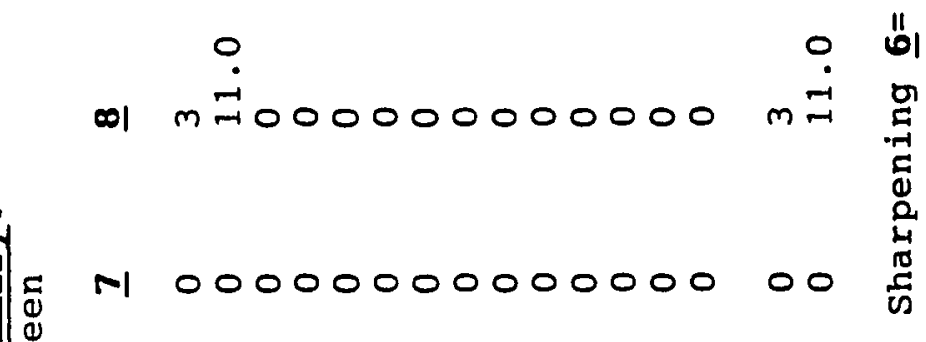

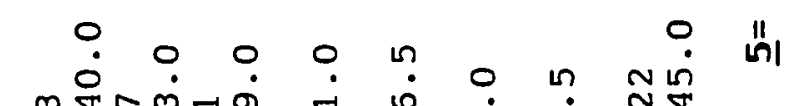

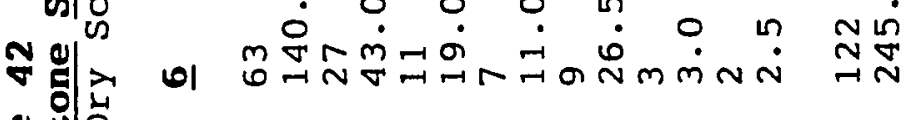

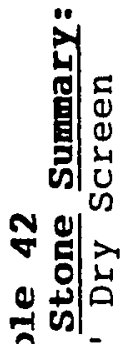

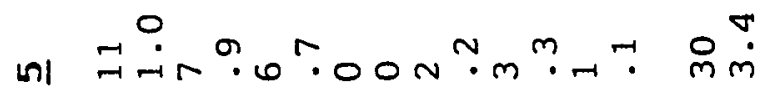

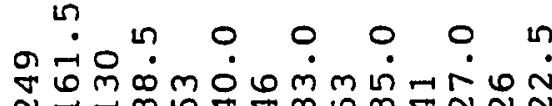

in $11 \rightarrow-10$

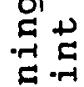

등

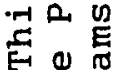

riñ

성 언

ED б

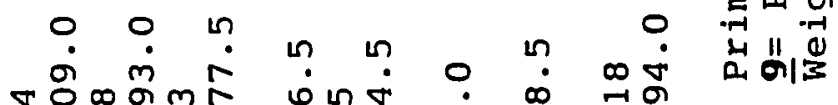

mI mंmmiñ

$\dot{\nabla} \quad \dot{\nabla} \quad 0 \quad 0 \quad 0 \quad 0 \quad$ n

N|

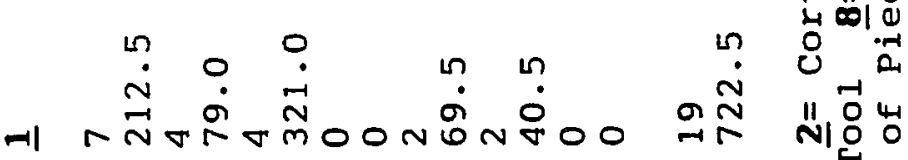

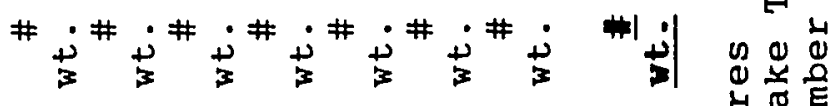

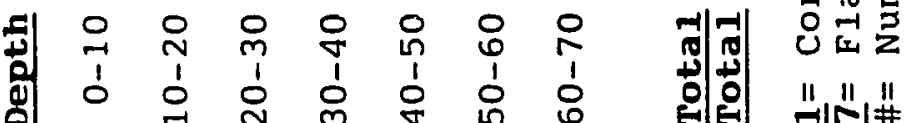




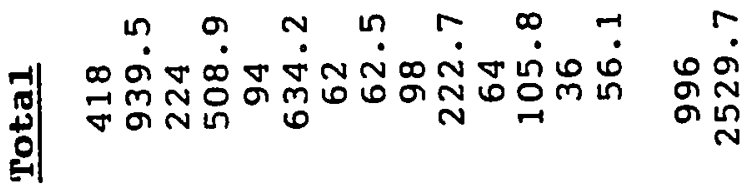

al $0000000000000000 \frac{\pi}{n}$

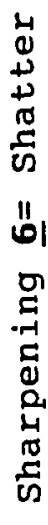

인

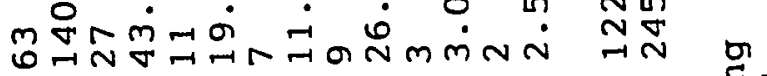

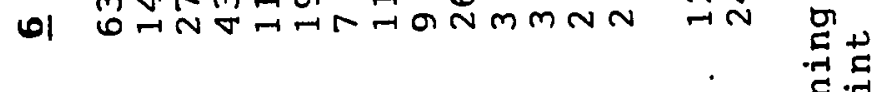

ôे

的的

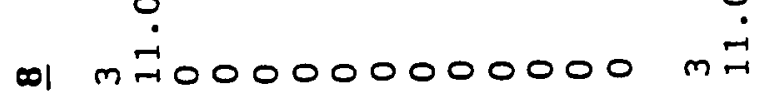

$M 0000000000000000$ :

임

o 0 h n

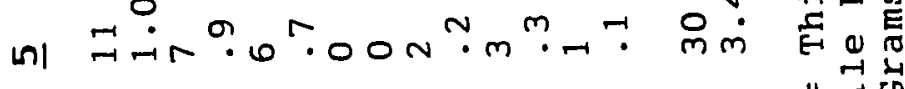

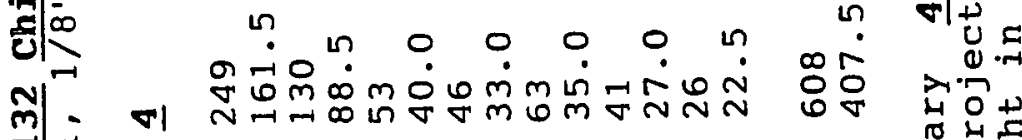

U1

نํำ

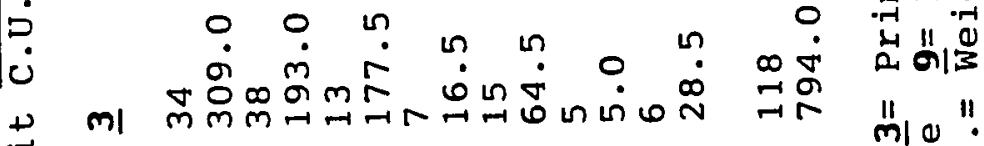

ס

हम

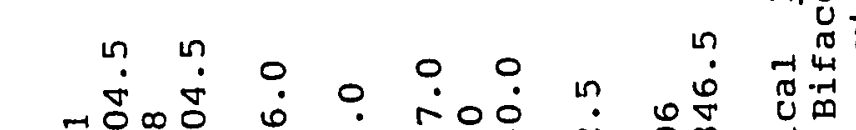

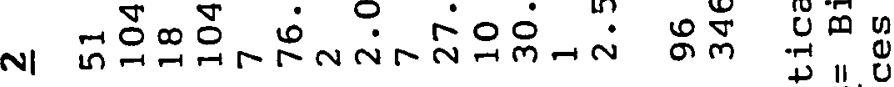

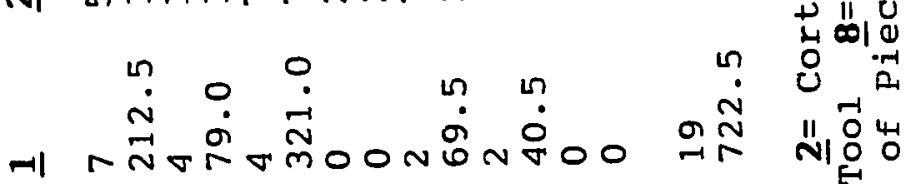

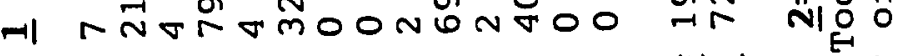

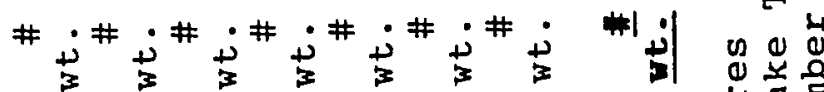

$4 \pi$

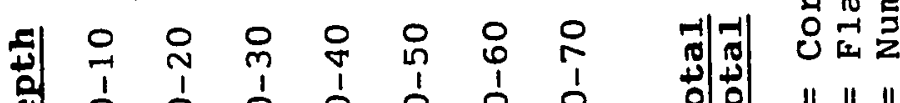

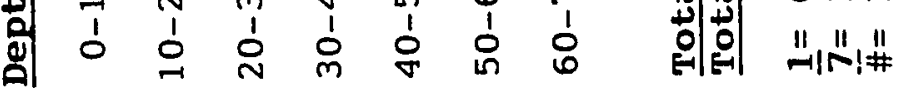


informal tools (reduction stages 2 and 3 ). Typed projectile points included 2 Ano Nuevo long-stemmed and one very large Rossi square-stemmed red jasper point with an expanding base. Many of the untyped point and biface fragments appear to represent the Ano Nuevo long-stemmed type. The chipped stone tool inventory in Appendix $D$ presents the measurements, descriptions and reduction stages for this category of artifacts. Ten tools have been illustrated in Figures 45 and 46. Many of the chipped stone tools exhibited thermal spall scars from exposise to heat. In all, sCr-132 produced 3 chipped stone tools per cubic meter of site.

A total of 13 cobble artifacts were recovered. Their descriptions and measurements have been presented in Appendix E. Table 45 presents the cobble artifact types and their occurrence at scr-132.

Table 45: Cobble Artifacts from SCr-132 (N=13)

\begin{tabular}{|c|c|}
\hline 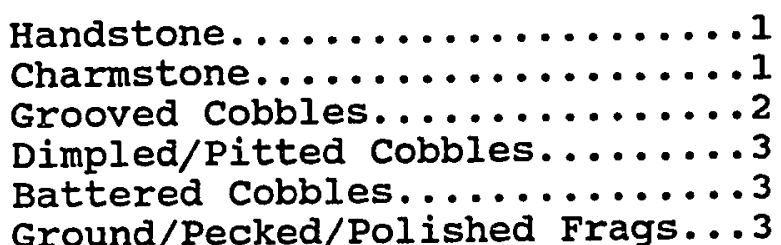 & $\begin{array}{l}(7.5 \%) \\
(7.5 \%) \\
(16.0 \%) \\
(23.0 \%) \\
(23.0 \%) \\
(23.0 \%)\end{array}$ \\
\hline
\end{tabular}

The two grooved cobbles and the charmstone have been illustrated in Figure 47 . The charmstone was a complete specimen which was tear drop shaped, nippled on the distal end, and exhibited a tapering flat, semi-flanged proximal end. Asphaltum stains were visible around the neck of the 
proximal end. This specimen resembles type IB2b, knob-piled plummet (after Beardsley 1954), and was made of andesite. The single handstone and the absence of mortars and pestles would seem to indicate an emphasis on hard seed food resources. A small paint mortar was recovered many years ago by the landowner while digging a narrow trench through the site for a water pipe. This small bowl was made of sandstone and retained red pigment stains within the bottom. This artifact was not included in this study of cobble tools because it was unavailable for further measurements. The dimpled/pitted cobbles and grooved cobbles were identical to specimens found throughout the study area.

A human burial was found in the lower level of unit 1. The ohlone Indian crew who discovered the burial granted permission to recover the individual and analyze the remains for osteological study, but the bone was too fragile and no attempt was made to remove the skeleton. The in situ remains were examined by physical anthropologist Dr. Robert Jurmain of San Jose State University. Osteological observations made in the field have been presented in Table 46. The individual appeared to have been an adult female buried in a flexed position, with the head oriented west and the face looking south (vertebral column aligned 120 degrees east/west). Figure 48 illustrates the burial. This individual was buried in a pit which intruded into the yellow soil and angular stone floor of the unit. The top of the cranium was at 50 


\section{Table 46}

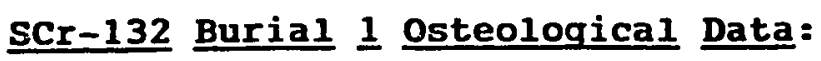

Provenience: Unit 1 , northeast quarter of unit, 50 to $80 \mathrm{~cm}$.

Burial Type: Primary inhumation, semi-flexed, right side.

Orientation: Cranium to west, vert. column 120 degrees E/W.

On Site Osteological Inventory

$$
\text { ( } C \text { = Complete; } \mathrm{P}=\text { Partial; } \mathrm{L}=\text { Left; } \mathrm{R}=\mathrm{Right} \text { ) }
$$

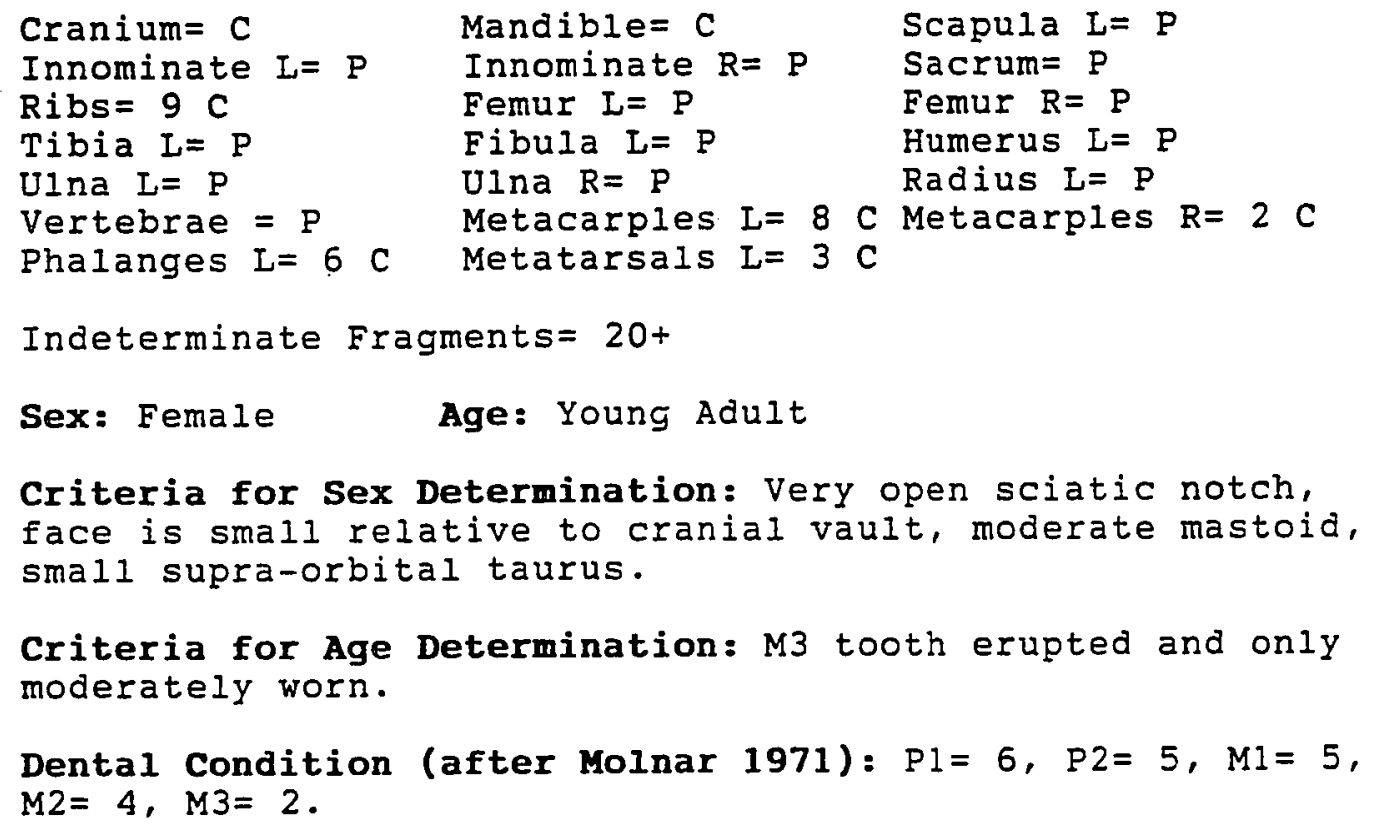

Criteria for Age Determination: M3 tooth erupted and only moderately worn.

Dental Condition (after Molnar 1971): $P 1=6, P 2=5, M 1=5$, $M 2=4, M 3=2$. 
$\mathrm{cm}$. below the ground surface and the bottom of the pit was at $80 \mathrm{~cm}$. A single olivella spire-broken shell was found within the rib cage and may have been a bead.

A level with a concentration of cultural elements was encountered in unit 1 at $30-40 \mathrm{~cm}$. , and was identified as Feature 1. This feature contained a number of river cobbles, three battered cobble hammerstones, Monterey chert flakes, several large sea mammal bones, an intact Haliotis shell, charcoal concentrations and a spire ground olivella shell bead. This feature was basically a scattering of elements at a level which may have been the ground surface at the time of occupation. Figure 49 illustrates the distribution of these artifacts.

SCr-132 represents a single component Middle Period forager residential location. Table 47 presents a summary of component definitions.

Table 47: Component summary from scr-132

1) Upper and Lower Levels: $0-80 \mathrm{~cm}$. Age: Middle Period, 1,900 \pm 50 B.P. obsidian Hydration Range: Napa ( $\mathrm{N}=12$ ) 1.9-2.9

Artifacts: Fauna:*

Shell we. (H3):

Ano Nuevo Iong-stemmed pts. Rossi square-stemmed pt. Handstone Sea otter $(5.6 \%)$ $3,547.5 \mathrm{gr}$. Pitted/Dimpled cobbles Harbor seal (5.6\%) Grooved cobbles

Piled charmstone *= Percentage of identifiable pieces. 


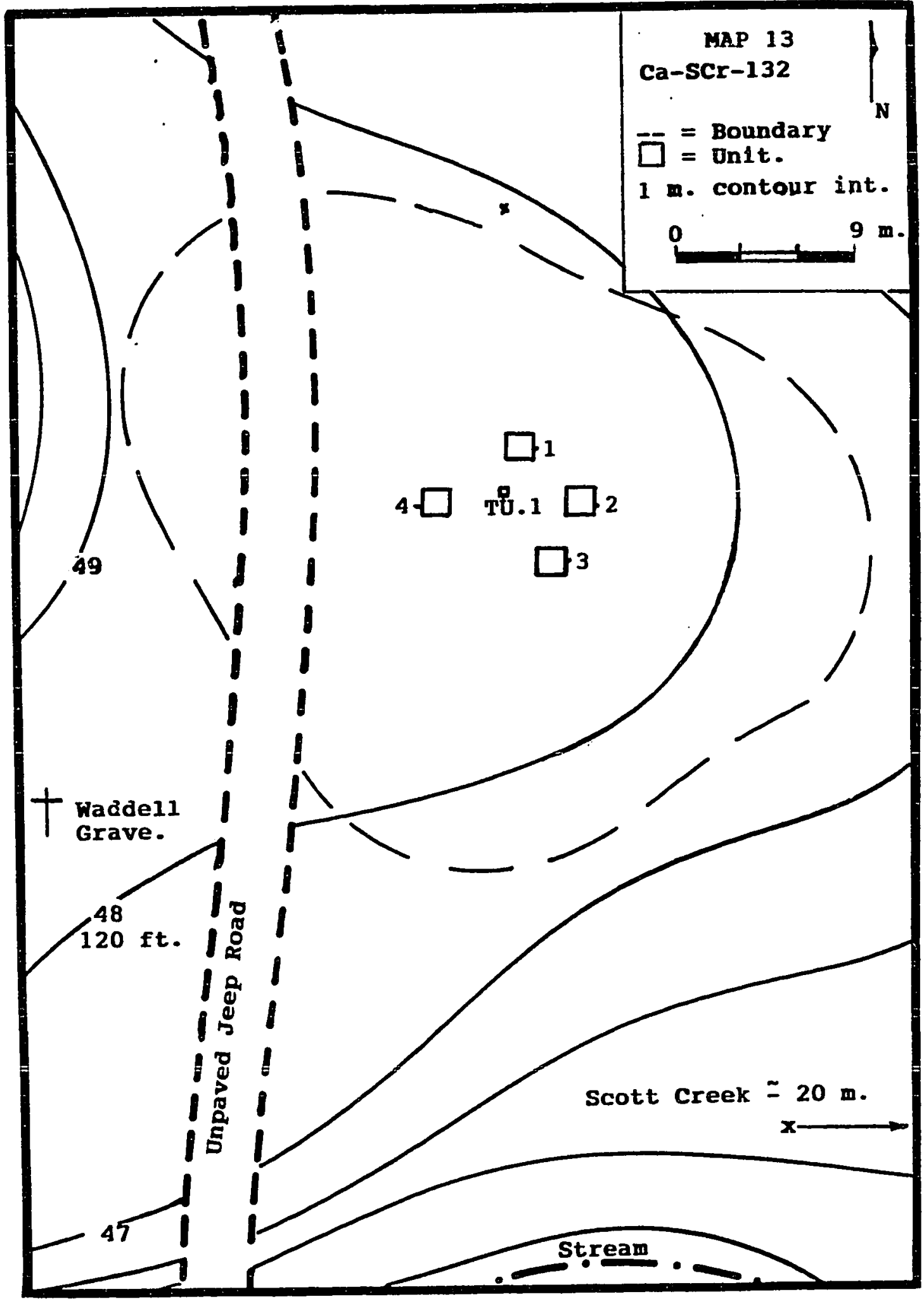




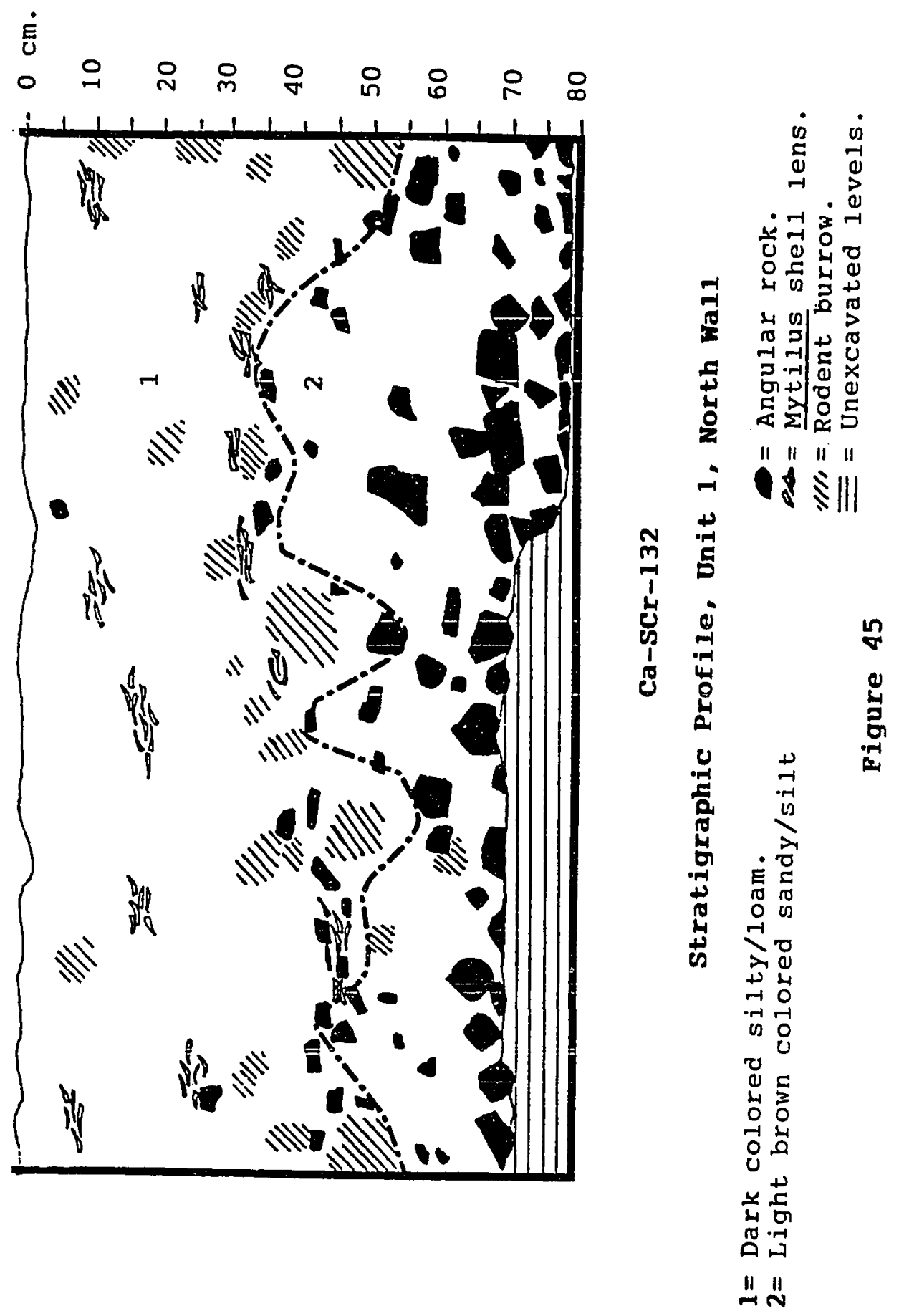




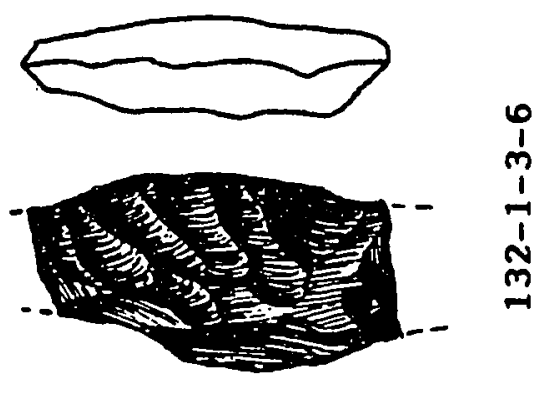

最
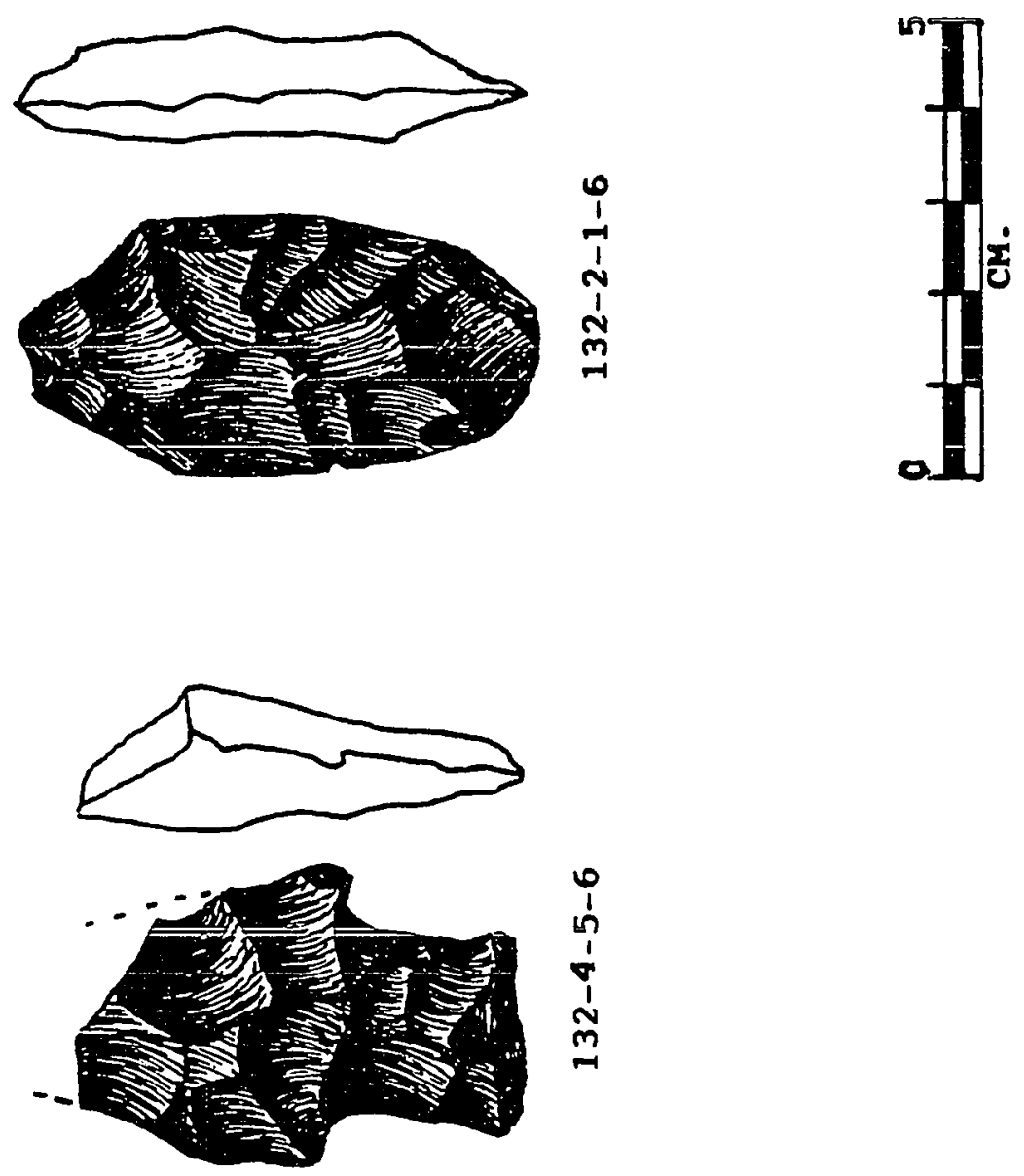

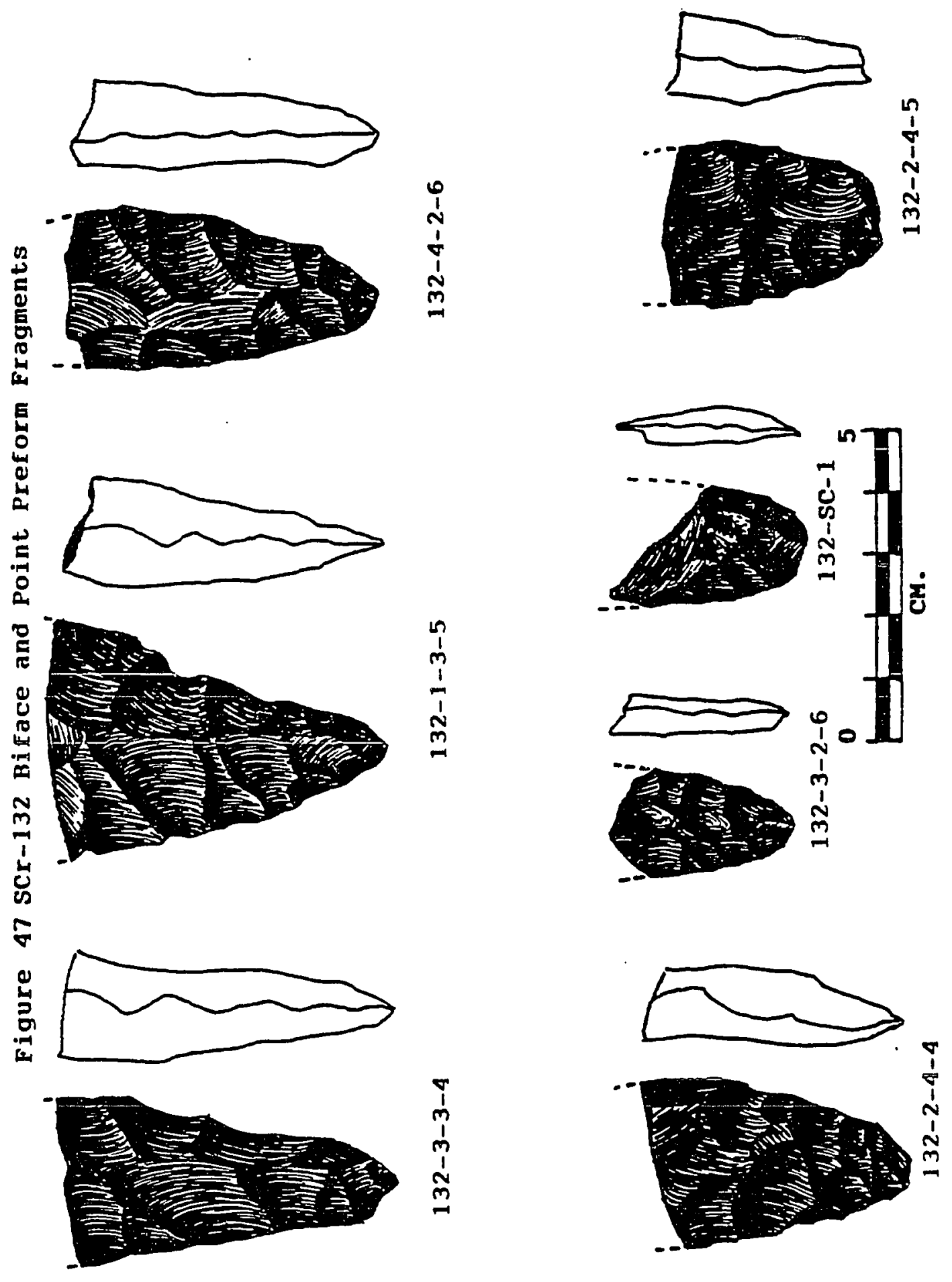


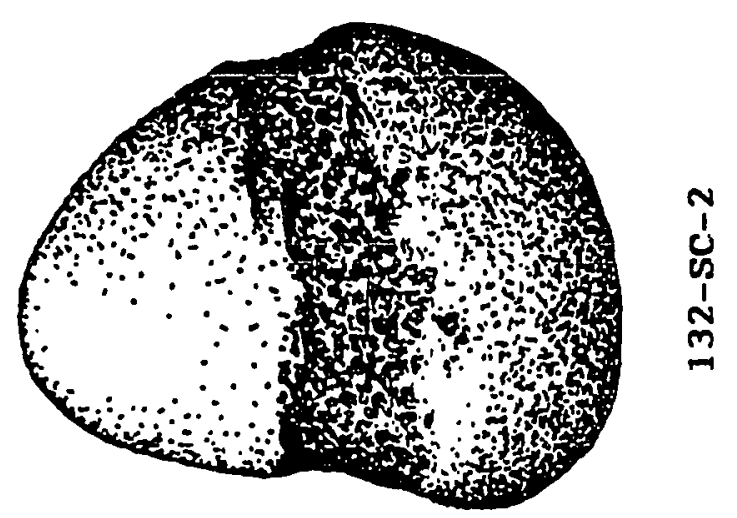

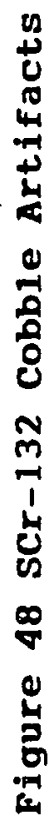
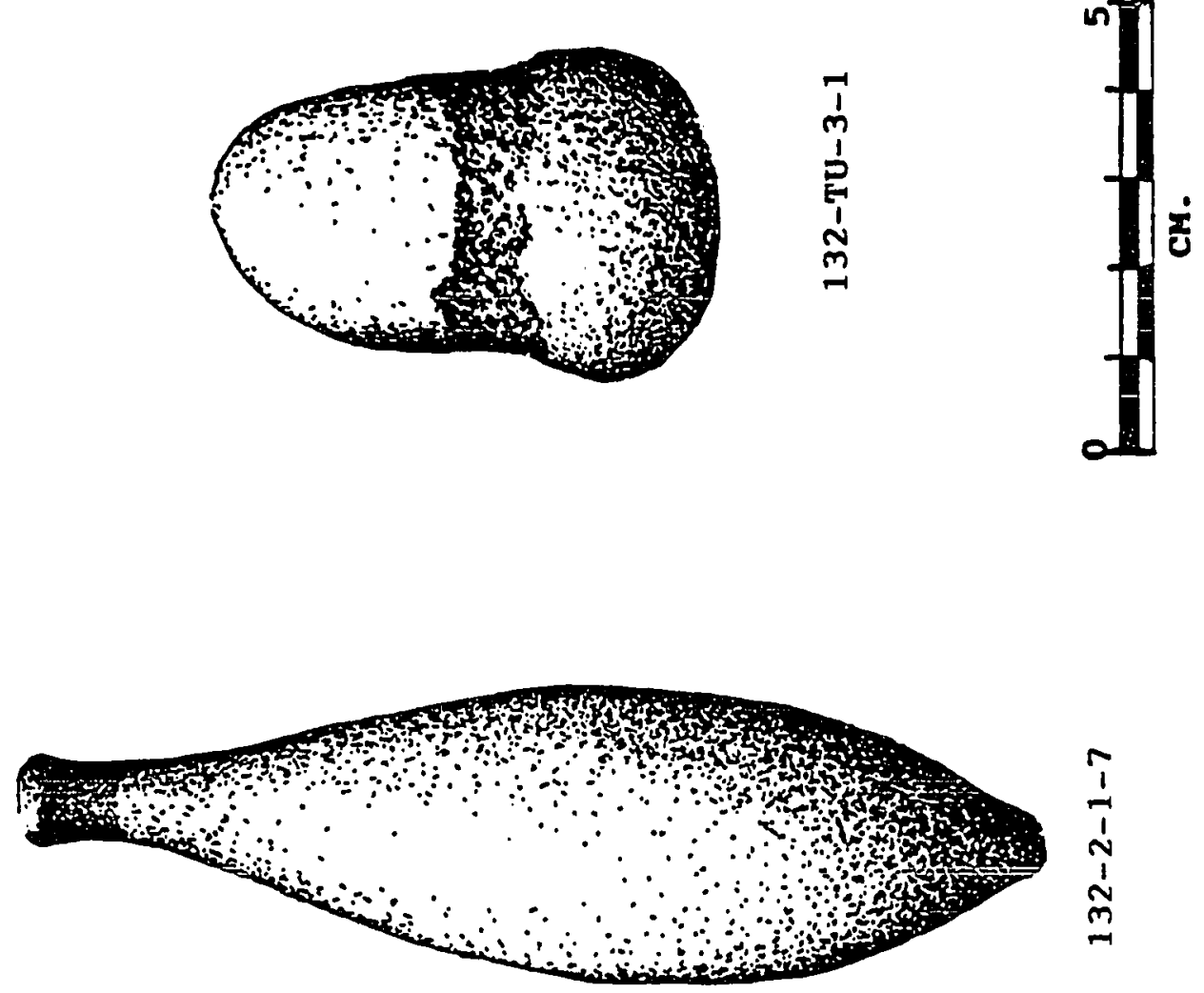


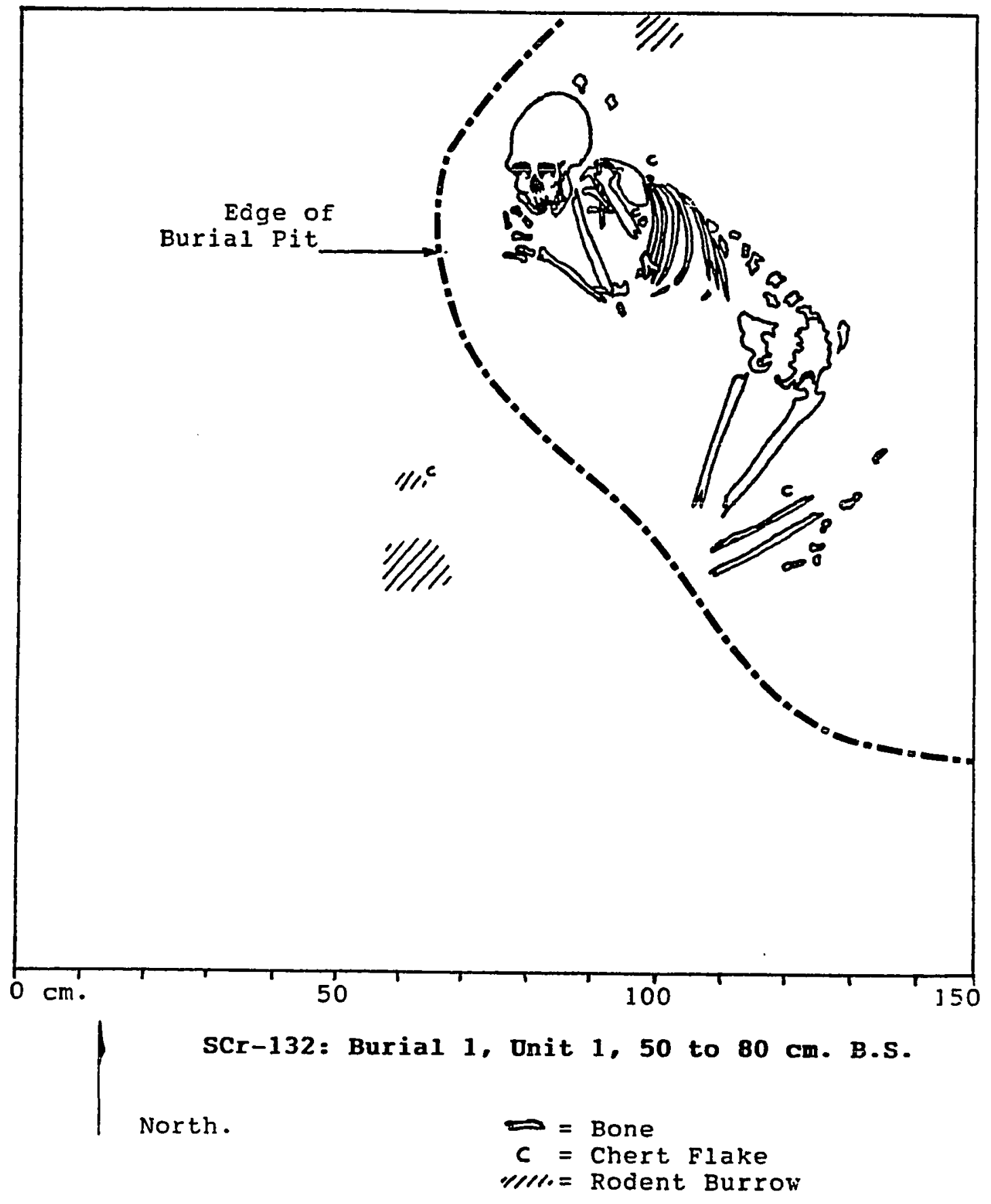

Figure 49 


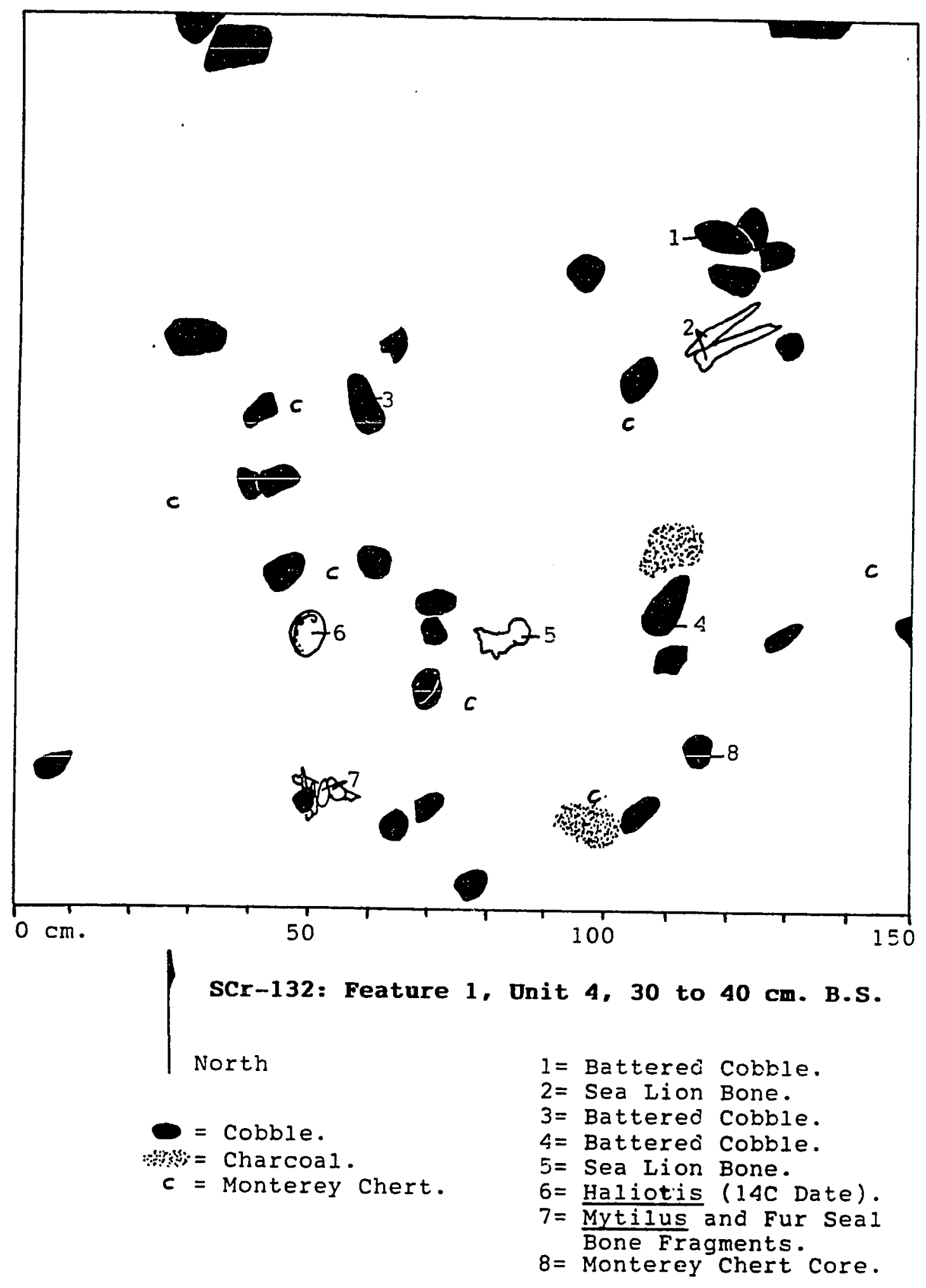

Figure 50 
SMa-22, the Princeton Mound site

SMa-22 is located at Pillar Point, which is the

northern limit of Half Moon Bay. The site is situated within a sand dune field adjacent to a marsh, near the beach. The presence of multiple human burials and a diversity of artifacts indicate that this was a residential base.

SMa-22 was first recorded by Nels Nelson in 1909, and was later excavated by Lewellyn Loud in 1915. Beardsley (1954: 94) reviewed Loud's investigations and speculated that the site was a Middle Period extension of his proposed "Coastal Province," and was comparable to sites on the Marin county coast. The site was again tested in 1961 (Phebus 1973), and additional data was generated.

Volumetric data from Loud's work was not located for this study; however, Phebus excavated a trench, which was segmented into three adjacent units, near the eastern edge of the midden. This trench measured $4.5 \times 1.5$ meters, with the depth varying from 75 to $100 \mathrm{~cm}$. Phebus observed several artifact hunters' trenches at the site, and this author is aware of a collection from here which contains beads, points, cobble tools and even several human burials. Phebus noted that mortuary features at this site were common and recovered 3 burials in addition to Loud's 8 . All except one were flexed, with the single exception being a semi-extended burial. One of the burials had four piled charmstones in association (type IIIb after Beardsley 1954: 
10) as well as several awls and a Haliotis ornament. Another individual had red ochre, a Haliotis ornament (type MEla after Beardsley 1954), and a convex base corner notched point. The third burial did not have any associated artifacts. Loud's investigations noted one burial with associated artifacts. This one had 33 olivella beads (type F full saddle and round saddle beads after Bennyhoff and Hughes 1987), an edged bone knife, and nine bone hairpins (types B3, BI and AlbII, Gifford 1940). Four of these bone artifacts were reviewed by this author at the Lowie Museum of Anthropology at U.C. Berkeley and they are illustrated in Figure 50 .

In addition to the burial-associated artifacts, many other types were recovered from the excavation units and on the surface of the site. These included nine projectile points, 17 pitted/dimpled cobbles, 4 whale bone wedges, 4 antler wedges, 6 split cannon bone "fiber strippers," 4 pointed ulna awls and 14 miscellaneous pieces, including antler tines and other untyped fragments. The point types are presented in Table 48 .

Table 48: Point Types from SMa-22 (N=10)

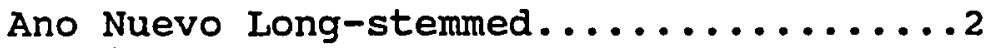

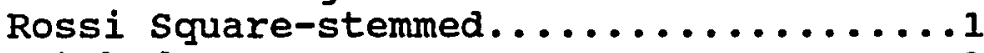

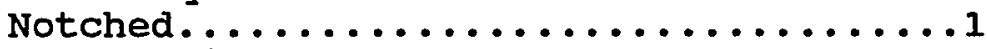

Undetermined Types................6 
Faunal remains from Phebus's excavation were not quantified but it was noted that the upper levels of SMa-22 were composed of an abundance of Mytilus californianus. The lower levels contained an abundance of Haliotis rufescens. This is the only coastal site in the study area reporting more than a trace of Haliotis shell, and it is described as being "particularly evident" (Phebus 1973: 72). Most of the mammal remains were composed of terrestrial species and those reported are presented in Table 49.

Table 49: Fauna Represented at SMa-22

\begin{tabular}{ll} 
Enhydra lutris & $(2$ pieces) \\
Cervus nanoides & (10 plus pieces). \\
Odocoileus hemionus & $(20$ plus pieces). \\
\hline Canis sp. & (2 pieces).
\end{tabular}

Phebus concurred with Beardsley's analysis that the site dated to Middle Horizon times, and added that he personally felt the site had an antiquity of 2,000 years B.P. (Phebus 1973: 55). Later in the report, Phebus contradicts this supposition because of unsourced obsidian hydration measurements with average rim readings of 2.02 , 2.55 and 4.16 microns. At the time when he wrote the report, these readings were thought to date to A.D. 870,470 and 970 B.C., as ascribed by Pennsylvania State University (Catalog \#s 7422, 7421 and 7420). Phebus noted that his previous agreement with Beardsley's temporal findings may have been premature. Given the presence of the Ano Nuevo long-stemmed 
and Rossi square-stemmed points, along with the full saddle olivella type $F$ beads, a Middle Period designation for this site is appropriate. No Late Period artifact types were recovered from SMa-22.

SMa-22 appears to represent a single component Middle Period forager residential location. This conclusion is based upon diagnostic artifact types, the diversity of faunal bones, and the presence of human remains. Table 50 summarized component definitions for this site.

Table 50: Component summary from SMa-22

1) Stratigraphic depths are undefined Age: Middle Period

Artifacts:

Ano Nuevo long-stemmed points Rossi square-stemmed point Notched (corner) point olivella type $F$ beads Haliotis type MEla pendants Pitted/Dimpled cobbles Piled charmstones Bone awls Bone wedges 


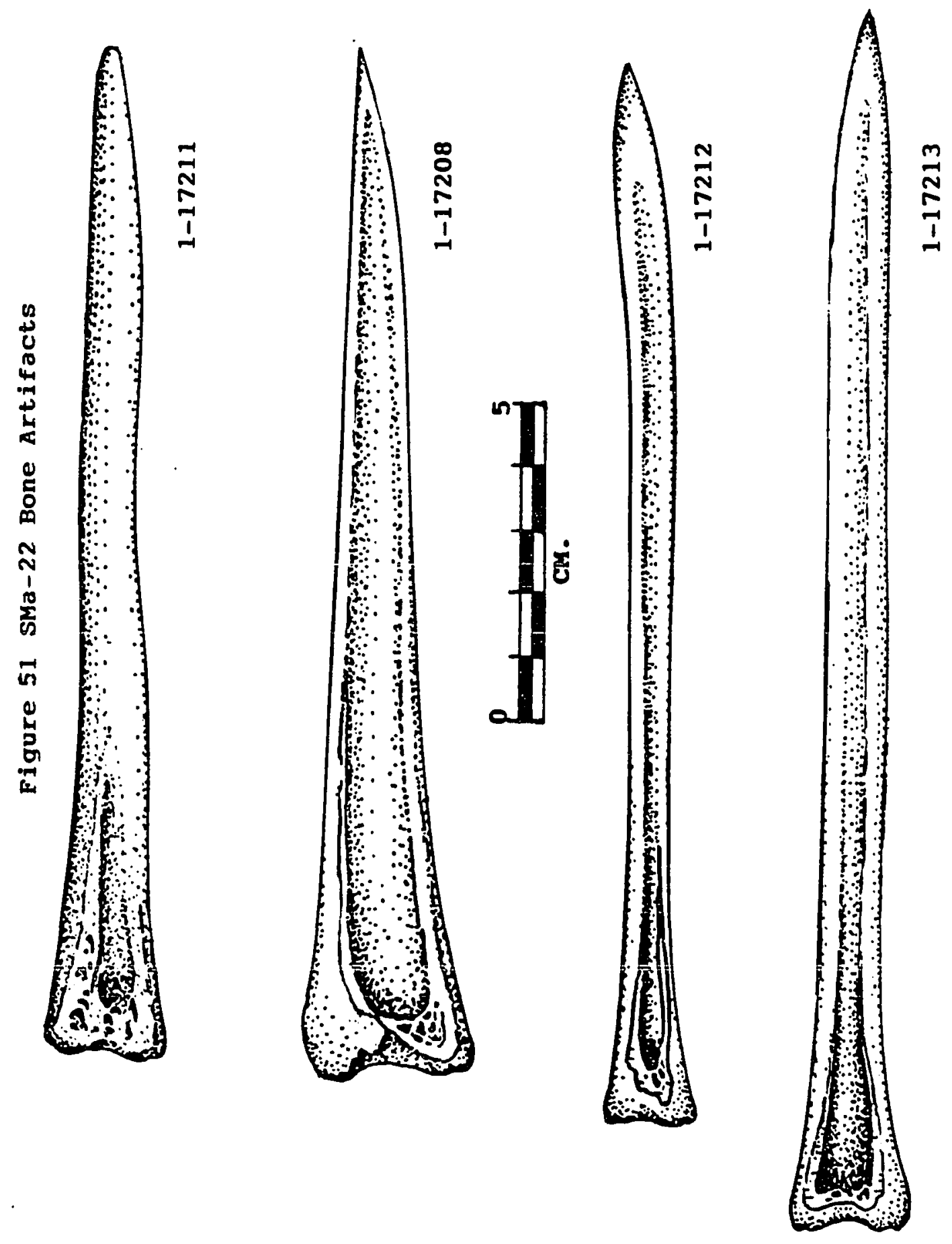


SMa-97, the Ano Nuevo Creek site

SMa-97 is located on the coastal terrace above Ano Nuevo Bay, east of the point where Highway 1 crosses Ano Nuevo creek. The site is currently situated in the cultivated fields of Coastways Ranch. Ano Nuevo Creek has cut a deep channel through the terrace and the site, which is on the east bank of the stream, has been partially disturbed by the construction of Highway 1 . The author was granted permission to test the site by the Hudson family. They have also loaned surface collected artifacts for inclusion in this study. At the time of the excavation most of the site was under cultivation and the test units were established between the edge of the field and Ano Nuevo Creek. Although this was not the center of the site, it was an area that was not so severely disturbed. Recently, pine trees have been planted on the site for a Christmas tree farm.

A total of seven $1.5 \times 1.5$ meter, one $50 \times 50 \mathrm{~cm}$. and one $25 \times 25 \mathrm{~cm}$. excavation units were established. These units resulted in a total excavation volume of 7.5 cubic meters of site. Table 51 presents the unit dimensions, screen methods and volume. 
Table 51: Unit Dimensions and Excavation Volume from SMa-97 Unit Dimensions Screen Method Cubic Meter

\begin{tabular}{|c|c|c|c|c|c|}
\hline $\begin{array}{l}1 \\
2 \\
3 \\
4 \\
5 \\
6 \\
7 \\
\text { TU. } 1 \\
\text { CU. } 1\end{array}$ & 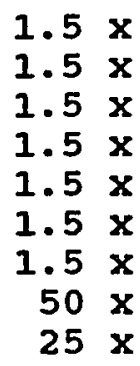 & $\begin{array}{l}1.5 \mathrm{~m} . \\
1.5 \mathrm{~m} . \\
1.5 \mathrm{~m} . \\
1.5 \mathrm{~m} . \\
1.5 \mathrm{~m} . \\
1.5 \mathrm{~m} . \\
1.5 \mathrm{~m} . \\
50 \mathrm{~cm} . \\
25 \mathrm{~cm} .\end{array}$ & $\begin{array}{l}1 / 8^{\prime \prime} \\
1 / 4^{\prime \prime} \\
1 / 4^{\prime \prime} \\
1 / 8^{\prime \prime} \\
1 / 4^{\prime \prime} \\
1 / 4^{\prime \prime} \\
1 / 4^{\prime \prime} \\
1 / 8^{\prime \prime} \\
1 / 8^{\prime \prime}\end{array}$ & $\begin{array}{l}\text { Dry } \\
\text { Dry } \\
\text { Dry } \\
\text { Dry } \\
\text { Dry } \\
\text { Dry } \\
\text { Dry } \\
\text { Wet } \\
\text { Wet }\end{array}$ & $\begin{array}{l}1.05 \\
1.2 \\
1.05 \\
.9 \\
.9 \\
.9 \\
.9 \\
.3 \\
.2\end{array}$ \\
\hline
\end{tabular}

Map 18 illustrates unit orientations. The site was generally shallow with a very dark brown colored silty loam layer resting on a slightly lighter brown colored silty loam, deposit which in turn overlays a tan colored sandy silt matrix (see Figure 51). Average depth of the site was from 50 to $80 \mathrm{~cm}$.

A single radiocarbon date for this site was derived from a Haliotis rufescens shell. This shell was one of several which formed a layer, and a sandstone pestle (\# 974-3-6) was under it. Table 52 presents the resulting date.

Table 52: Radiocarbon Date from SMa-97

WSU\# Provenience, Composition $\quad$ 14C aqe(Years B.P.) 3232 U.4/20-30 cm., 168 gr. Haliotis $1040 \pm 70$

Column unit $\mathrm{CU} .1$, located adjacent to unit 4 , recovered $3,391.5 \mathrm{gr}$. of shell, which is an amount equal to $16,957.5$ gr. per cubic meter of site. Bone fragments from the column sample totaled 436 pieces $(46.2 \mathrm{gr}$. ) of bone, which is equal to 2,180 pieces (231.0 gr.) per cubic meter. Debitage totaled 370 pieces (268.1 gr.), which is equal to 1,850 pieces $(1,340.5 \mathrm{gr}$.$) per cubic meter. Table 53$ presents the 
results of the column sample. Individual shell species were not quantified from this sample; however, Mytilus californianus was the most common (estimated to be $80 \%$ of the species present), with Tequla funebralis composing the bulk of the rest. A large number of olivella shell fragments were observed in the sample, but were not quantified.

Table 53: Column Sample from sMa-97

(Unit Volume $=.2$ Cubic Meters)

\begin{tabular}{rlrrrr} 
& \multicolumn{2}{c}{ Shell } & \multicolumn{2}{c}{ Bone } & \multicolumn{2}{c}{ Debitage } \\
Depth & Wt.(ar.) & \# & wt. & \# & Wt. \\
$0-10 \mathrm{~cm}$. & 359.4 & 80 & 7.0 & 76 & 37.0 \\
$10-20$ & 325.0 & 36 & 5.7 & 25 & 18.6 \\
$20-30$ & 548.3 & 62 & 6.8 & 47 & 17.2 \\
$30-40$ & 672.0 & 70 & 5.9 & 56 & 58.8 \\
$40-50$ & 415.8 & 41 & 3.5 & 34 & 16.3 \\
$50-60$ & 615.3 & 70 & 7.1 & 68 & 96.9 \\
$60-70$ & 257.8 & 54 & 5.6 & 47 & 15.2 \\
$70-80$ & 198.2 & 23 & 4.6 & 17 & 8.1 \\
Total & $3,391.5$ & 436 & 46.2 & 370 & 268.1
\end{tabular}

Shell Volume Per Cubic Meter $=16,957.5 \mathrm{gr}$.

Bone Volume Per Cubic Meter= 2,180 pcs., $231.0 \mathrm{Gr}$. Debitage Volume Per Cubic Meter= 1,850 pcs., 1,340.5 gr.

No shell beads or pendants were recovered, but a large number of olivella shell (relative to other sites) was obtained from the excavation units. A total of 611 pieces (535.7 $\mathrm{gr.}$ ) was retrieved. This amount is equal to 87.3 specimens per cubic meter of site (excluding $C U$. 1 and TU. 1) The results of the olivella shell summary have been presented in Appendix B. Of this sample, 74.58 had intact spires, 3.5\% had broken spires, $1 \xi$ had ground spires, .5\% 
were modified (one spire broken specimen was filled with asphaltum), and $20.5 \%$ of the sample consisted of broken pieces. As previously mentioned, a large number of small olivella fragments was observed in the column sample, and it is likely that considerably more olivella was present. Although no modified bead types were found, the abundance of Olivella shells indicated that they were a component of the economy at this location. A thin layer of Haliotis shell was found in unit 11, and a pestle was recovered under and in contact with them. The radiocarbon date for this site was derived from this layer.

A total of 620 pieces $(1,275.6 \mathrm{gr})$ of bone was recovered from units 1 through 4. The others, which included units 5 through $7, T U .1$ and $C U .1$, were not analyzed. The recovered bone was equal to 175.5 pieces $(315.0 \mathrm{gr}$.$) per$ cubic meter of site. CU.I had a greater projected number of bone pieces because the unit had been wet screened through $1 / 8$ " mesh. Of the identifiable pieces (36\% of the number of pieces, and $64 \%$ of the weight), terrestrial and marine mammals were almost equally represented. Fish bone was abundant at this site and composed $40.5 \%$ of the number of identifiable faunal elements but only $3.5 \%$ of the weight. Table 54 presents the taxa frequencies. The numbers elements by unit and depth have been presented in Appendix A. 


\section{Table 54 \\ SMa-97 Taxa Frequency: \\ (Units $1,2,3$ and 4 )}

\begin{tabular}{|c|c|c|c|c|}
\hline Taxa & \#pcs. & $\underline{\boldsymbol{q}}$ & Wt. (gr) & $\underline{\text { q }}$ \\
\hline $\begin{array}{l}\text { Pinnipedea } \\
\text { Ottaridae } \\
\text { Enhydra } \frac{\text { lutris }}{\text { Phoca vitulina }} \\
\text { Zalophus californicus } \\
\text { Callorhinus ursinus }\end{array}$ & $\begin{array}{r}3 \\
19 \\
8 \\
6 \\
7 \\
5\end{array}$ & $\begin{array}{l}1.5 \\
8.5 \\
3.7 \\
2.5 \\
3.0 \\
2.0\end{array}$ & $\begin{array}{r}12.2 \\
170.8 \\
18.3 \\
52.7 \\
85.5 \\
47.0\end{array}$ & $\begin{array}{r}1.5 \\
21.0 \\
2.0 \\
6.5 \\
10.5 \\
6.0\end{array}$ \\
\hline $\begin{array}{l}\text { Artiodactyl } \\
\text { Cervus } \\
\text { Odocoileus hoides } \\
\frac{\text { Canis sp. }}{\text { Mephitis mephitis }} \\
\text { Sylvilagus audubonii }\end{array}$ & $\begin{array}{r}1 \\
2 \\
24 \\
3 \\
2 \\
27\end{array}$ & $\begin{array}{r}.5 \\
1.0 \\
10.5 \\
1.5 \\
1.0 \\
12.0\end{array}$ & $\begin{array}{r}2.8 \\
23.2 \\
313.8 \\
5.3 \\
3.3 \\
38.3\end{array}$ & $\begin{array}{r}.5 \\
3.0 \\
38.3 \\
.5 \\
.5 \\
4.9\end{array}$ \\
\hline Aves & 26 & 11.5 & 10.2 & 1.0 \\
\hline Ichthys & 90 & 40.5 & 29.1 & 3.5 \\
\hline Unidentifiable & 397 & 64.0 & 456.1 & 36.0 \\
\hline Total & 620 & & 1275.6 & \\
\hline
\end{tabular}

Terrestrial vs Marine:

(Cetacea, Rodentia, Aves and Ichthys Excluded)

$\begin{array}{lcc} & \text { \#pcs. } \% & \text { wt.(gr) } \% \\ \text { Terrestrial } & 55.0 & 50.5 \\ \text { Marine } & 45.0 & 49.5\end{array}$


Bone tools from this site included a split deer tibia which had been polished and ground to form a spatulate shaped tip, in addition to a smaller spatulate tip fragment, two pointed tip fragments, an awl midsection and a polished splinter fragment. All of these specimens appeared to have been burned and then polished. These tools are described in greater detail in Appendix C. Four specimens are illustrated in Figure 52 .

Unit 1 was selected for debitage analysis (see Table 55), and this unit contributed $20 \%$ of the total pieces recovered from the site. Table 56 presents the debitage volume from all of the units.

Table 56: Debitage Volumes from SMa-97

\begin{tabular}{lclll} 
Unit & \# & 字 & Wt.(Gr.) & 字 \\
1 & 1,678 & 20 & $7,981.5$ & 21 \\
2 & 1,546 & 17 & $7,824.5$ & 20.5 \\
3 & 1,040 & 11.5 & $5,023.5$ & 13 \\
4 & 1,075 & 12 & $3,573.5$ & 9.5 \\
5 & 1,208 & 13.5 & $4,626.0$ & 12.5 \\
6 & 1,178 & 13 & $5,733.5$ & 15 \\
7 & 617 & 7 & $1,848.5$ & 5 \\
TU.1 & 182 & 2 & $1,134.0$ & 3 \\
CU.1 & 370 & 4 & 268.1 & .5 \\
\hline
\end{tabular}

Collectively, the units recovered 8,894 pieces $(8,013.1$ gr.), which is an amount equal to 1,186 pieces $(5,068.5 \mathrm{gr.})$ per cubic meter of site. Debitage from unit 1 indicated that $34 \%$ of the pieces represented primary reduction, $50 \%$ reflected secondary reduction, $15.5 \%$ were shatter debris, 


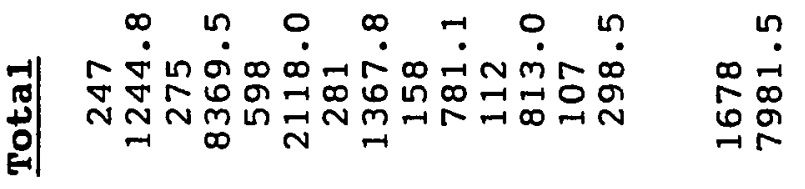

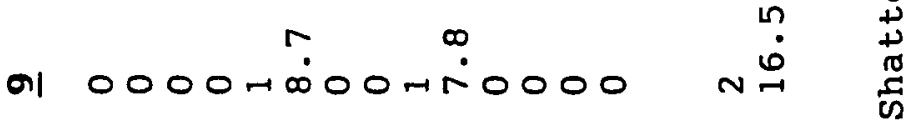

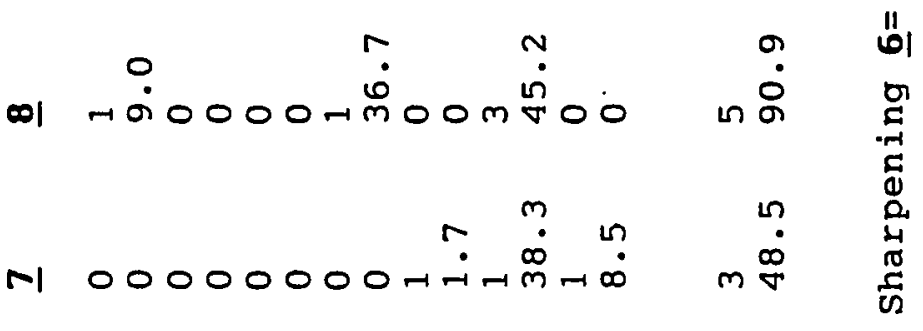

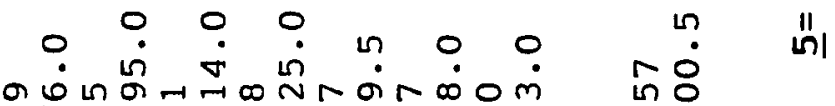

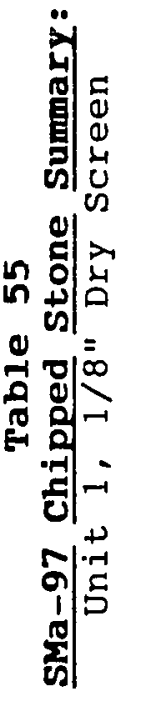

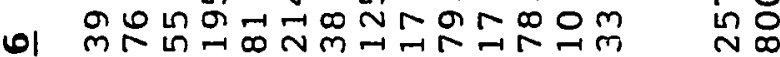

N

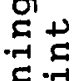

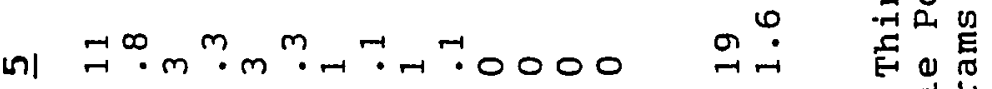

n

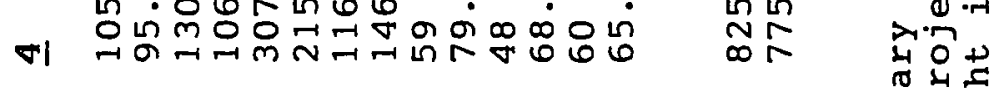

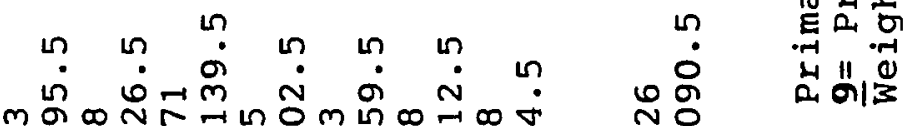

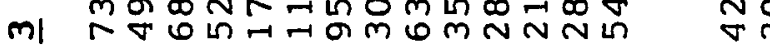

in

mI

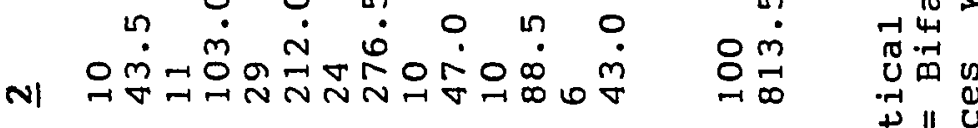

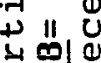

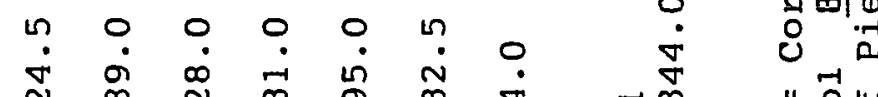

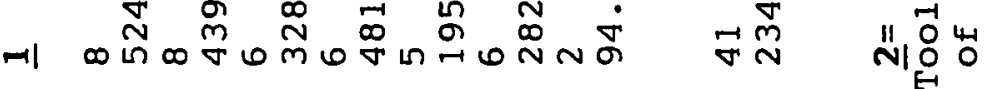

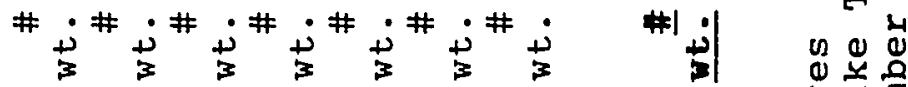

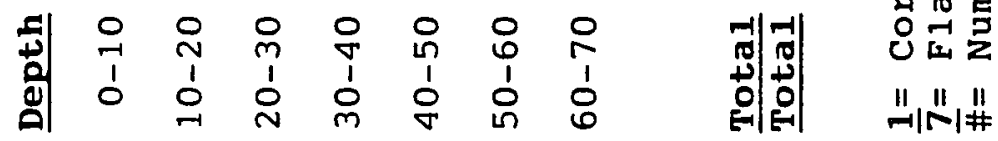


$.1 \%$ were informal flake tools and .48 were formal stone tools. All of the debitage was of Monterey chert, except for seven obsidian pressure flakes, which are not included in the above totals.

Chipped stone tools from this site were made from both Monterey chert and obsidian. A total of 39 formal and informal tools are described in Appendix D. Of these, 21 are illustrated in Figures 53 to 57. Of the 21 points recovered (reduction stages 4 and 5), 12 were typed, and are presented in Table 57.

Table 57: Point Types from SMa-97 ( $\mathrm{N}=12)$

Lanceolate-

concave base........................ (16.5\%)

convex base..............4 (33.5\%)

slightly stemmed............. (16.5\%)

bipoint..............................

Contracting stem-

barbed................................. (8\%)

Ano Nuevo Long-stemmed........ (8.5\%)

of the 39 chipped stone tools, reduction stages 4 and 5 composed $54 \%$ of the sample, with informal tools (stages 1, 2 and 3 ) composing $46 \%$. SMa-97 produced 3.5 chipped stone tools per cubic meter of site (excluding surface finds). Included in this stuayy were 5 obsiaian projectile points from the land owners' collection. These have been cataloged as VAN-27, $-29,-30,-31$ and -32 . Two of these specimens were concave base lanceolate types with deep basal depressions. Both are obsidian from the Casa Diablo source. 
The other three are convex base lanceolates from Napa Valley sources. Specimen \#VAN-29 was a large, well shaped, lanceolate; this point type has been related more directly to wealth than actually serving as a hunting tool. Such large obsidian blades are rare within the study area. No points reflective of bow and arrow technology were founa. Two borers, or drills were also recovered. These may have been used to hollow out sockets on shafts to fasten large points.

A total of 17 obsidian pieces were sourced and hydrated. Of these, 13 specimens were from the Napa Valley source, 1 from Annadel, 2 from Mono Glass Mountain and one was not reviewed. The Napa Valley pieces had readings which ranged from 1.2 to 2.7 microns, averaging 2.1 microns. The two concave base points of Casa Diablo obsidian ranged from 6.0 and 6.2 microns. Table 58 presents the results of this study.

Cobble tools from SMa-97 have been described in Appendix E. Of these, 7 specimens are illustrated in Figures 58 to 60 . Table 59 presents the cobble tool types and their occurrence. 


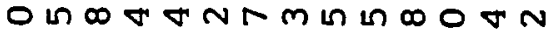

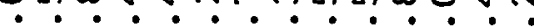

on $\ln 0$

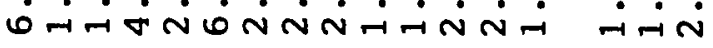

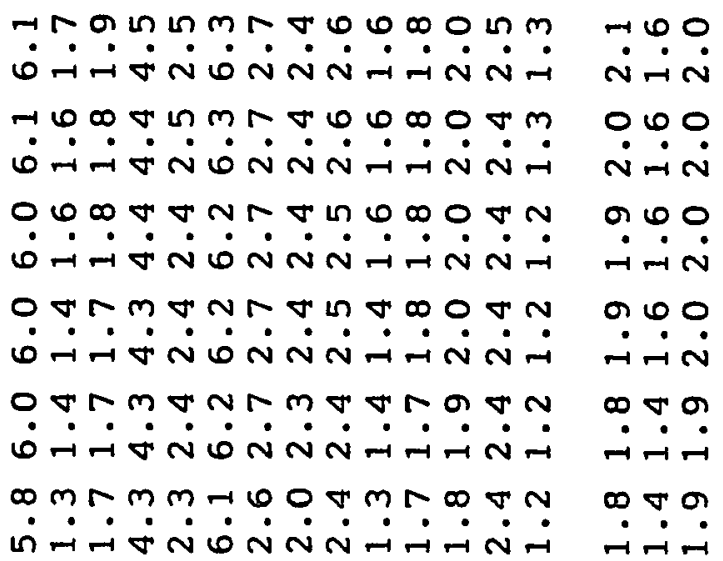

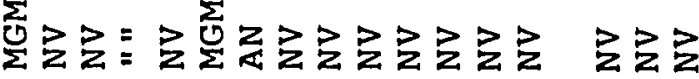

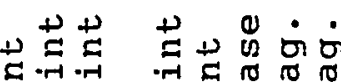

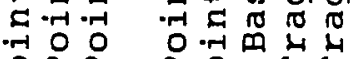

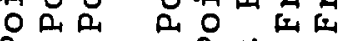
a म 山 U

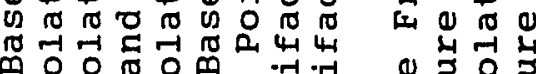

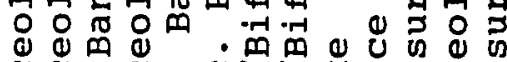

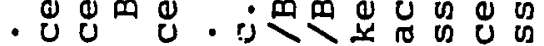

दE

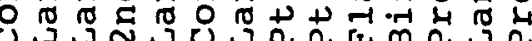

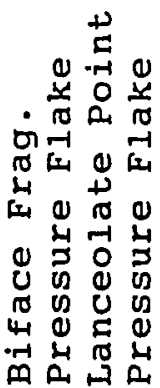

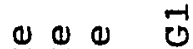

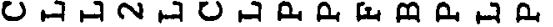

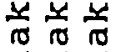

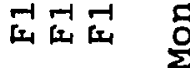

000 낭 is कि की os o (1) \& 1

मे th A R R

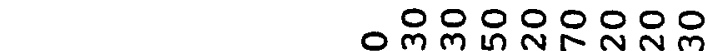

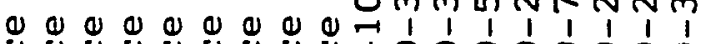

UU U U U U U U 100000000 ब

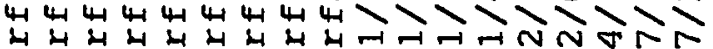
मू

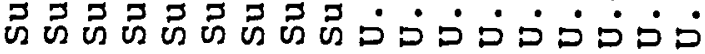

울

NoO

$\omega$ เก 0 เก เก เก แก เ

$1_{1}^{1}, 1,1,1,1$ Tmm nNNNNm

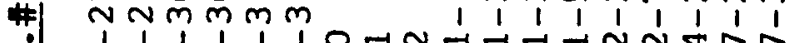

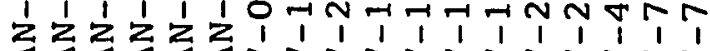

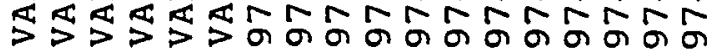


Table 59: Cobble Artifacts from SMa-97 (N=23)

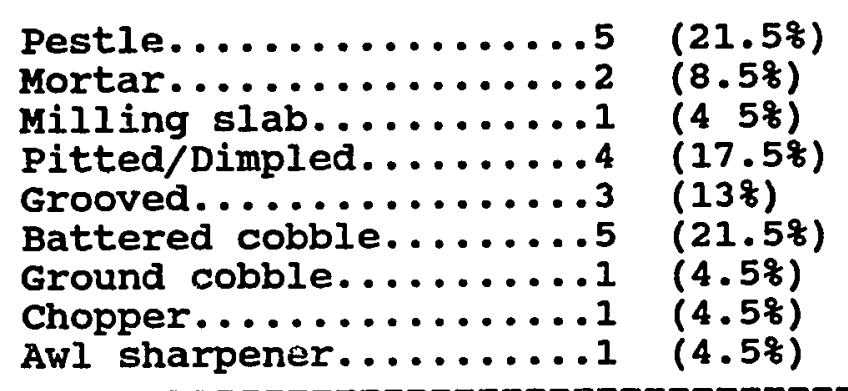

In addition to those recovered during from the excavation, the land owner has collected at least three large, well shaped granite bowl mortars, several pestles and the midsection of a large tubular stone pipe. The pipe fragment was nearly $14 \mathrm{~cm}$. long and $4 \mathrm{~cm}$. in width, tapering slightly. The brown colored stone is not steatite, but may be a local indurated mudstone. The number of mortars and pestles at this site indicate that acorn processing was a primary component to the diet. Excluding the surface finds, SMa-97 produced 2.5 cobble tools per cubic meter of excavated site.

sMa-97 exhibits a single Late Period component as evidenced by the shallow deposition, radiocarbon date, obsidian hydration readings, and artifact types. The diversity of faunal remains along with artifacts similar to those of other sites in the study area has led to the conclusion that this site represents a forager residential location. While the site covers a large area, it is a very shallow deposit. It is likely that repetitive use created the high archaeological visibility, and was the result of 
foragers being attracted to the local resources. The location of the site places it in an ideal position for residents to exploit the rich marine and terrestrial fauna of Point Ano Nuevo. Further, the nearby Monterey chert source and olivella strewn beaches provided a wealth of raw material for exchange and personal use. The presence of the large obsidian lanceolate blades and raw olivella shells reflects the economic viability of this sites residents. Contradictory to the model of forager behavior, the numerous bowl mortars and pestles from the site contrast with the absence of handstones and milling slabs. Contemporaneous sites near to SMa-97 frequently contain handstones and millingslabs. It is possible that acorn affluence was beginning to encroach into the local lifeway, but only supplemented an already optimal adaptive strategy. Table 60 presents the component summary.

Table 60: Component summary from sMa-97

1) Upper and lower levels: $0-80 \mathrm{~cm}$.

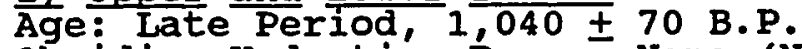
Obsidian Hydratión Range: Napa $(\dot{N}=13) 1.2-2.7$

$$
\text { Annadel (N= } \left.1) 2 \cdot 7^{1}=2\right) 6.0-6.2
$$

\section{Artifacts:}

Obsidian lanceolate pts. Ano Nuevo long-stemmed pt. Barbed contract.-stemmed pt. Mortars \& pestles Grooved cobbles Pitted/Dimpled cobbles Awl sharpener Bone awls $*=$ Percentage of identifiable

\section{Eauna:*}

Shell wt. (M3)

Sea otter $(3.7 \%) \quad 16,957.5 \mathrm{gr}$. Sea lion $(3.0 \%)$

Harbor seal (2.5\%)

Fur seal (10.5\%)

Deer (10.5\%)

Elk (1.0\%)

Rabbits (12.0\%)

Fish (40.5\%) 


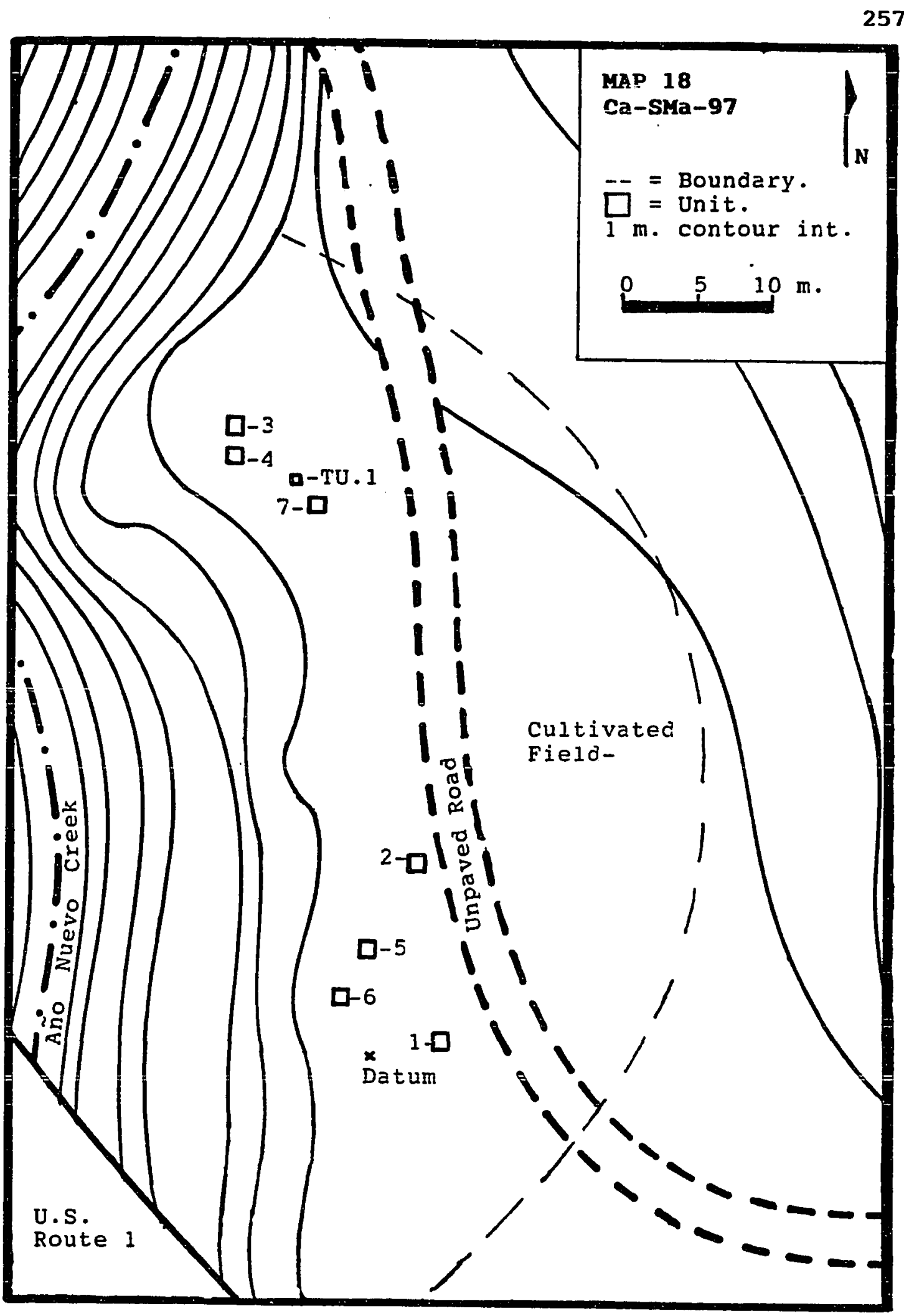




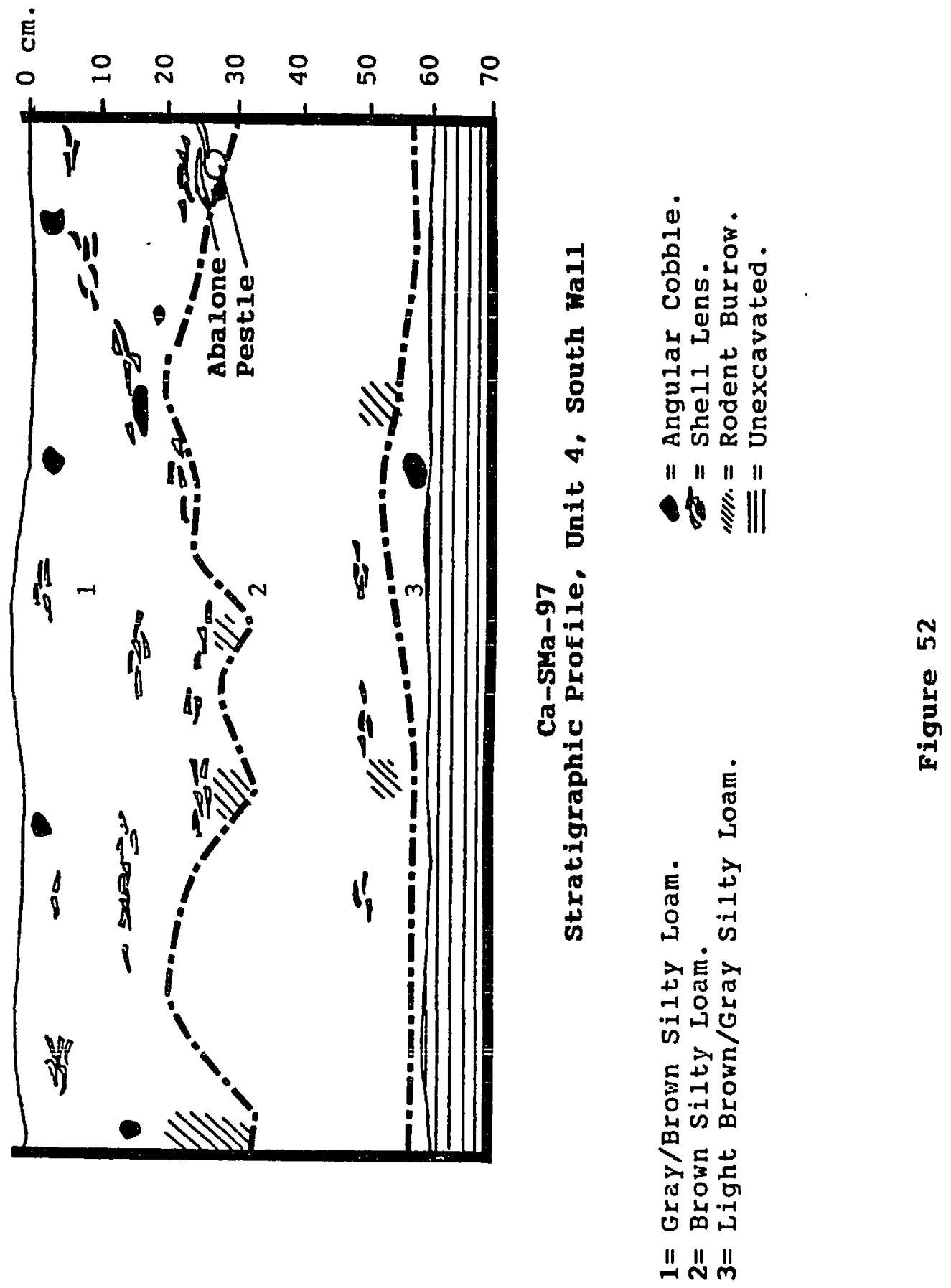



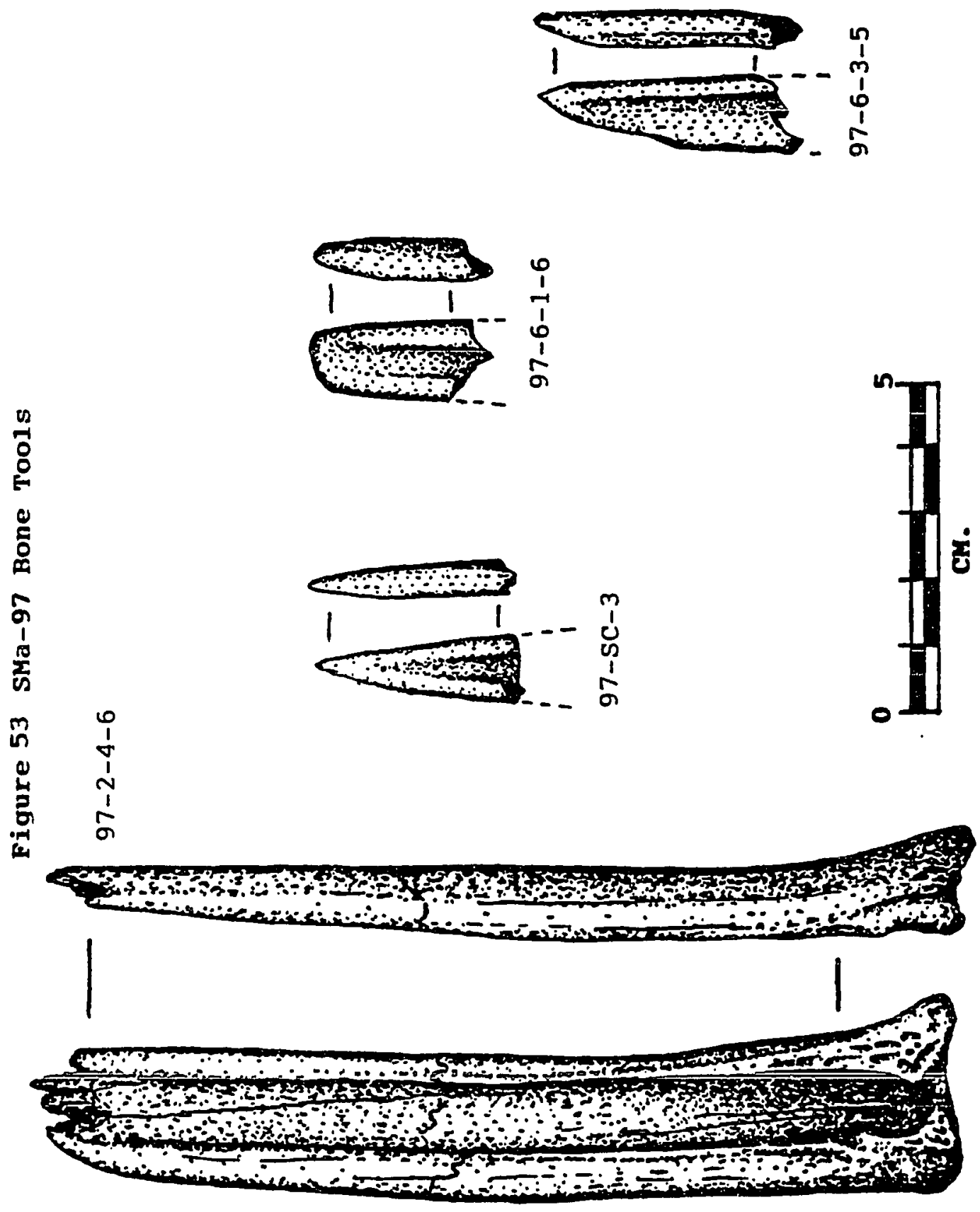

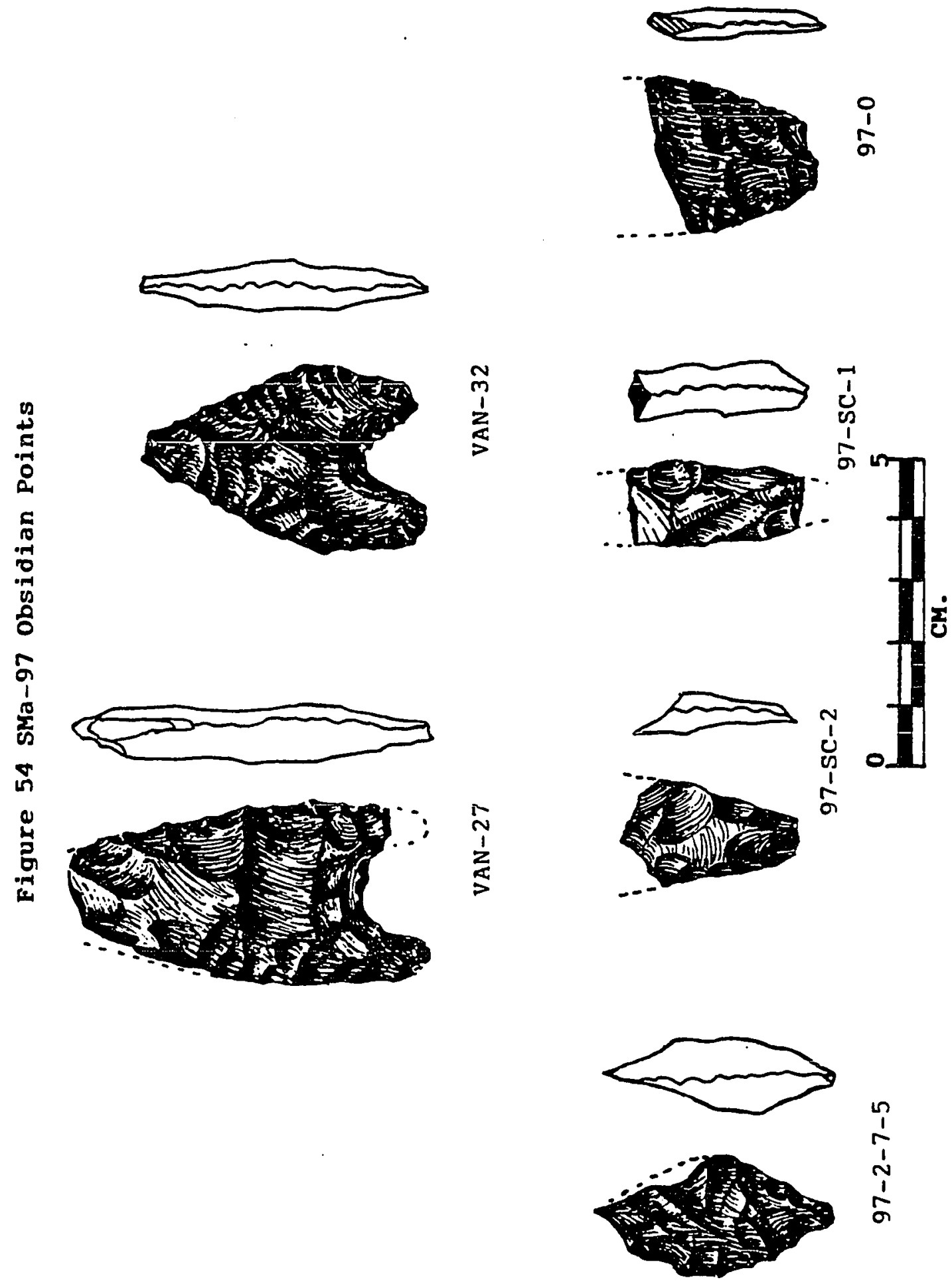

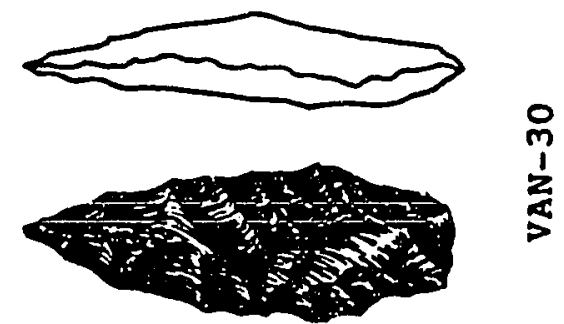

0
+
0
0
0
0
0
0
0
0
0
0
0
0
0
0
0
0
0

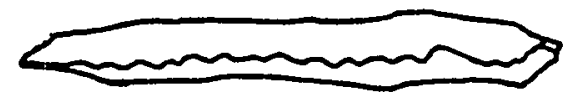

0
1
1
1
1
$\frac{1}{a}$
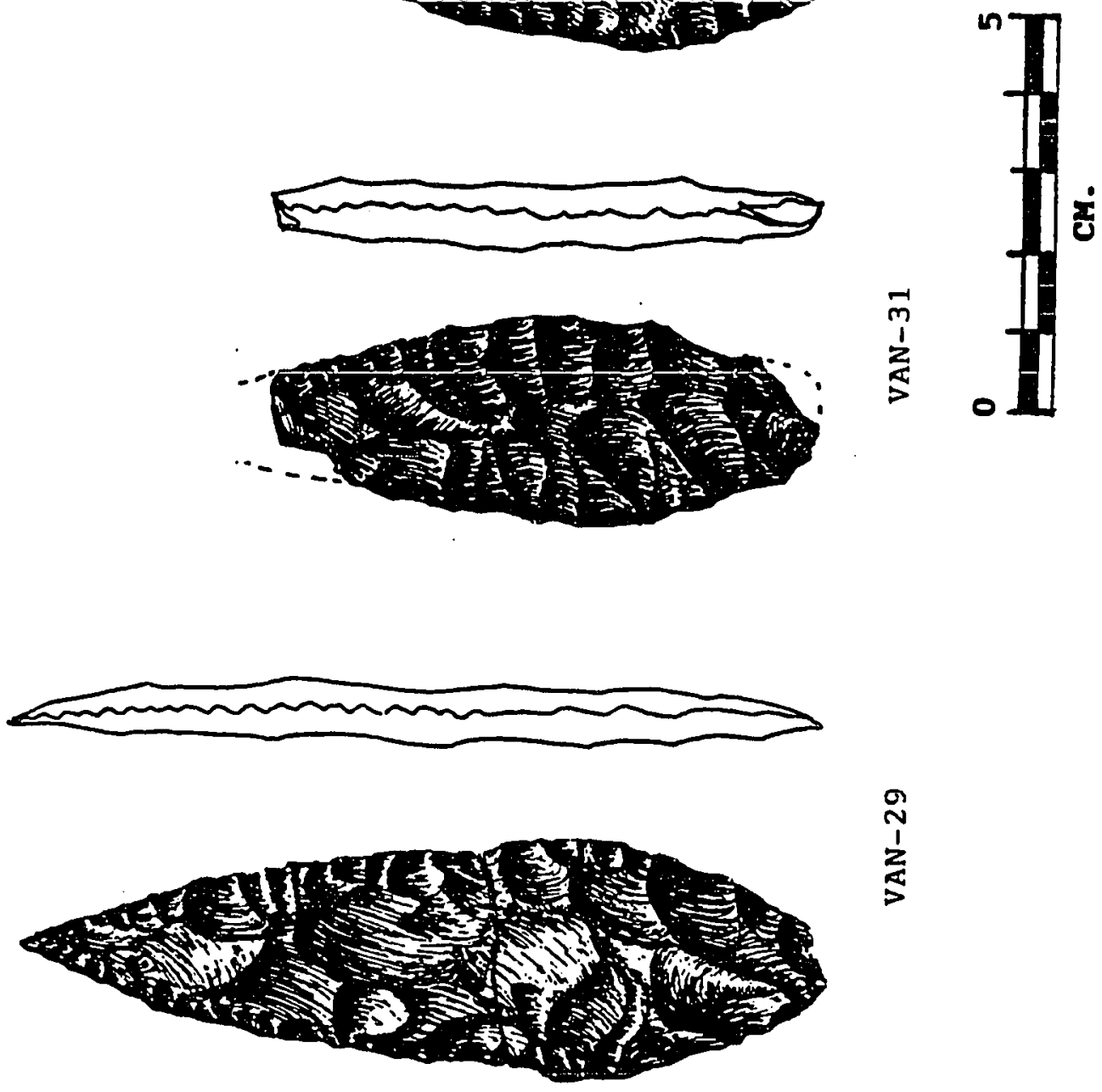

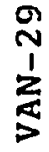



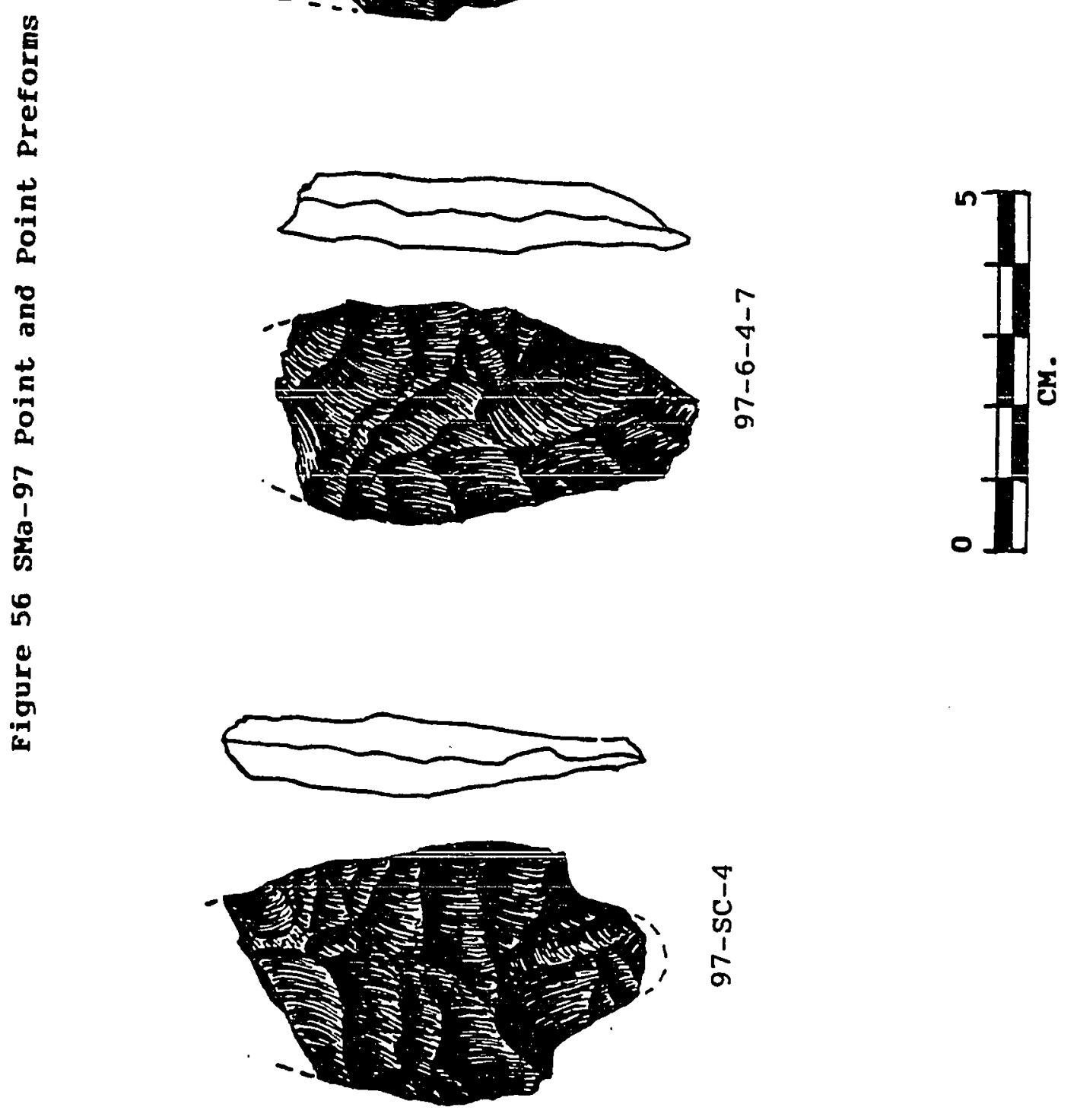
告
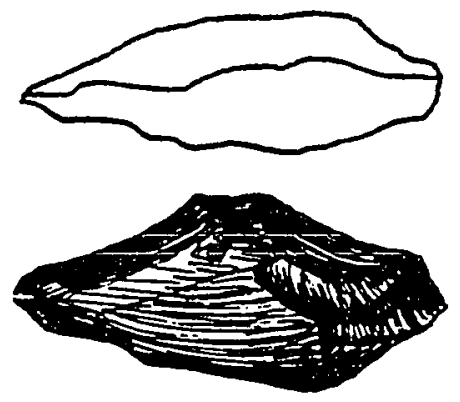

$n$
1
1
$\frac{1}{1}$
$\frac{1}{2}$
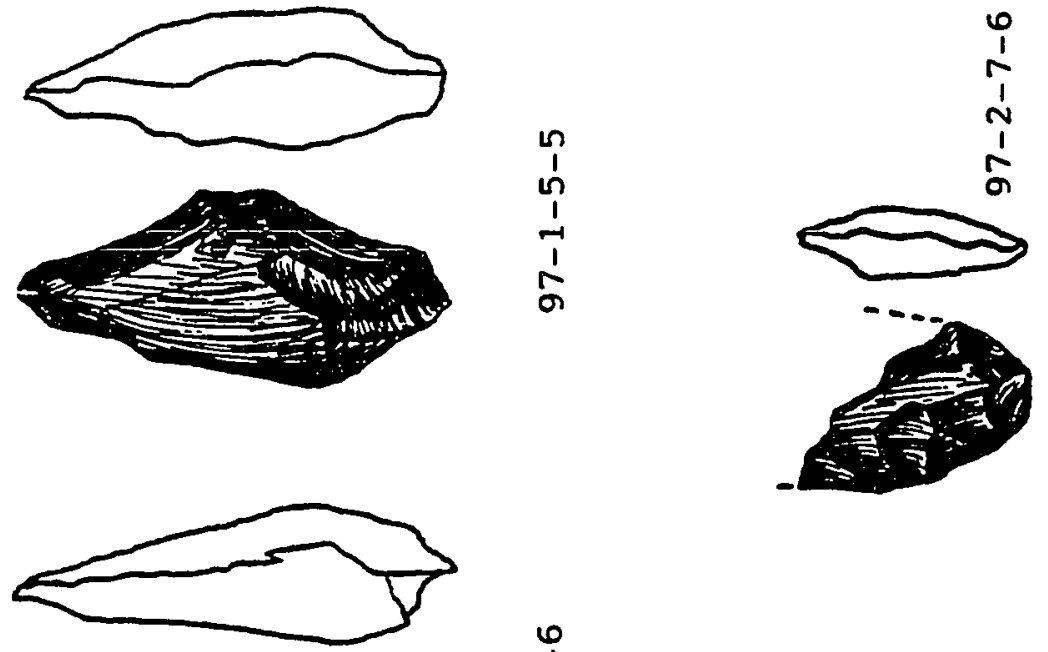

0
1
1
1
1
0

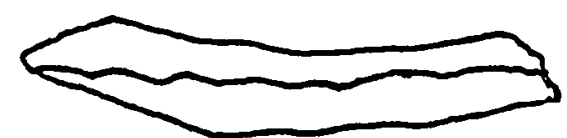

0
1
0
1
0
0
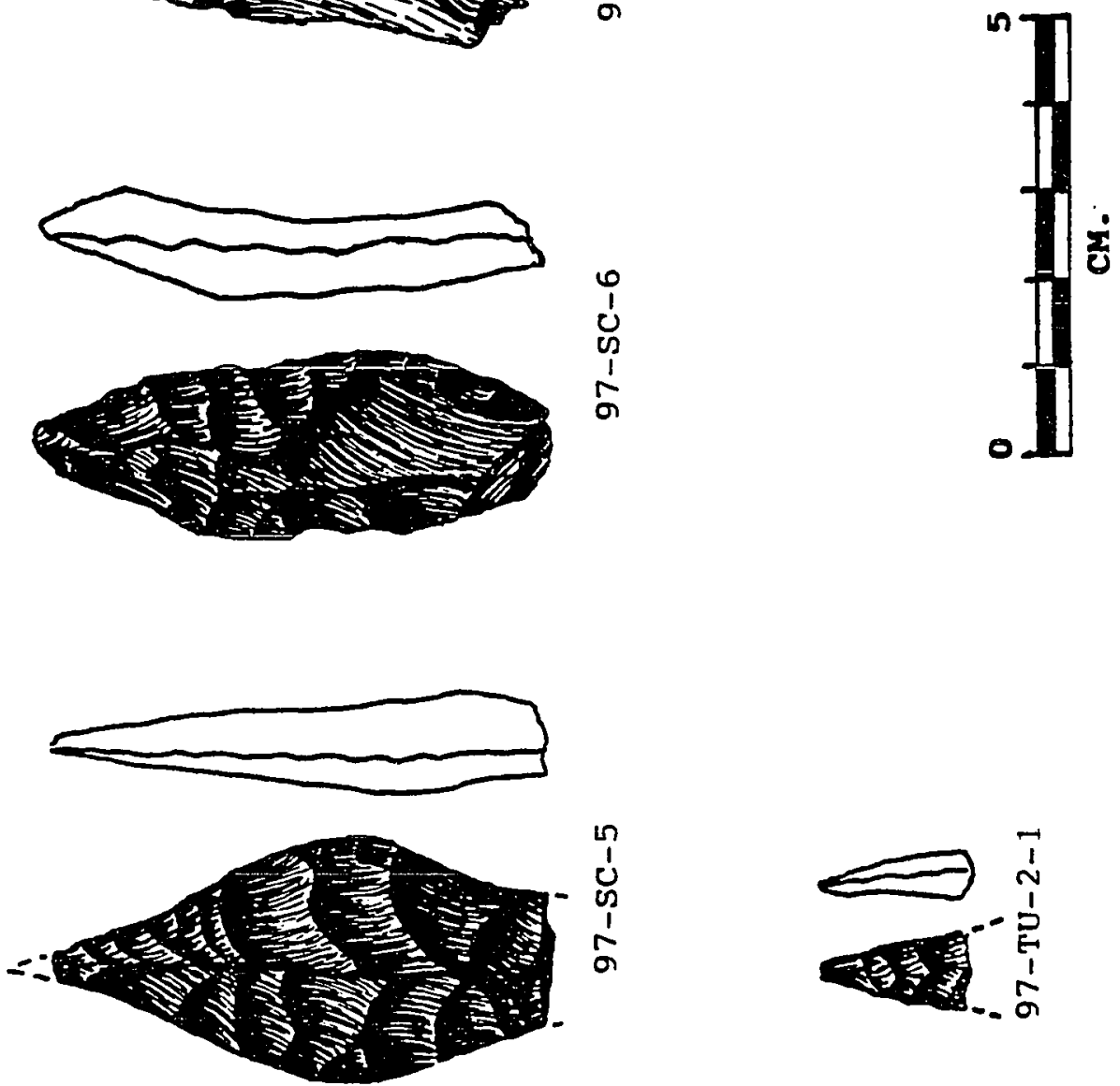

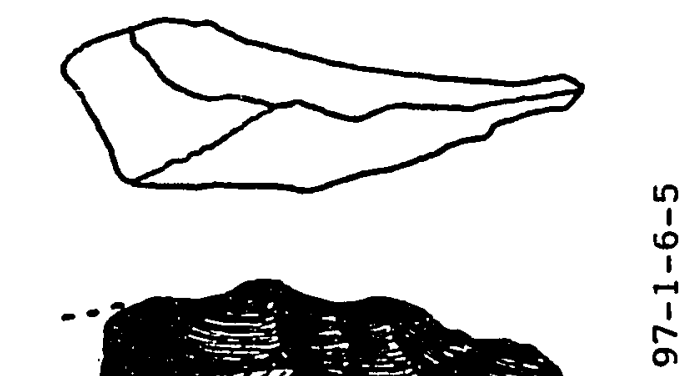

告
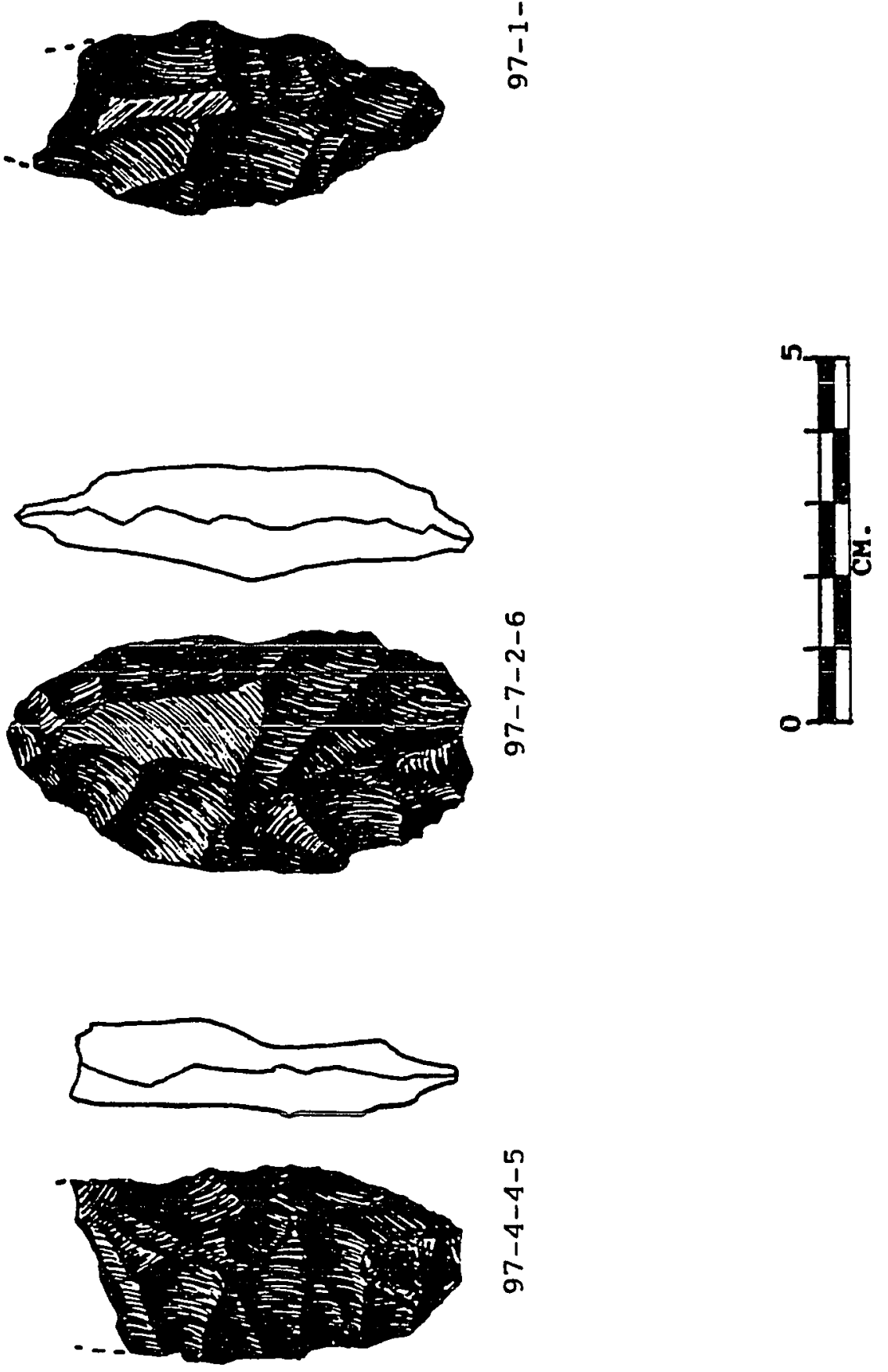

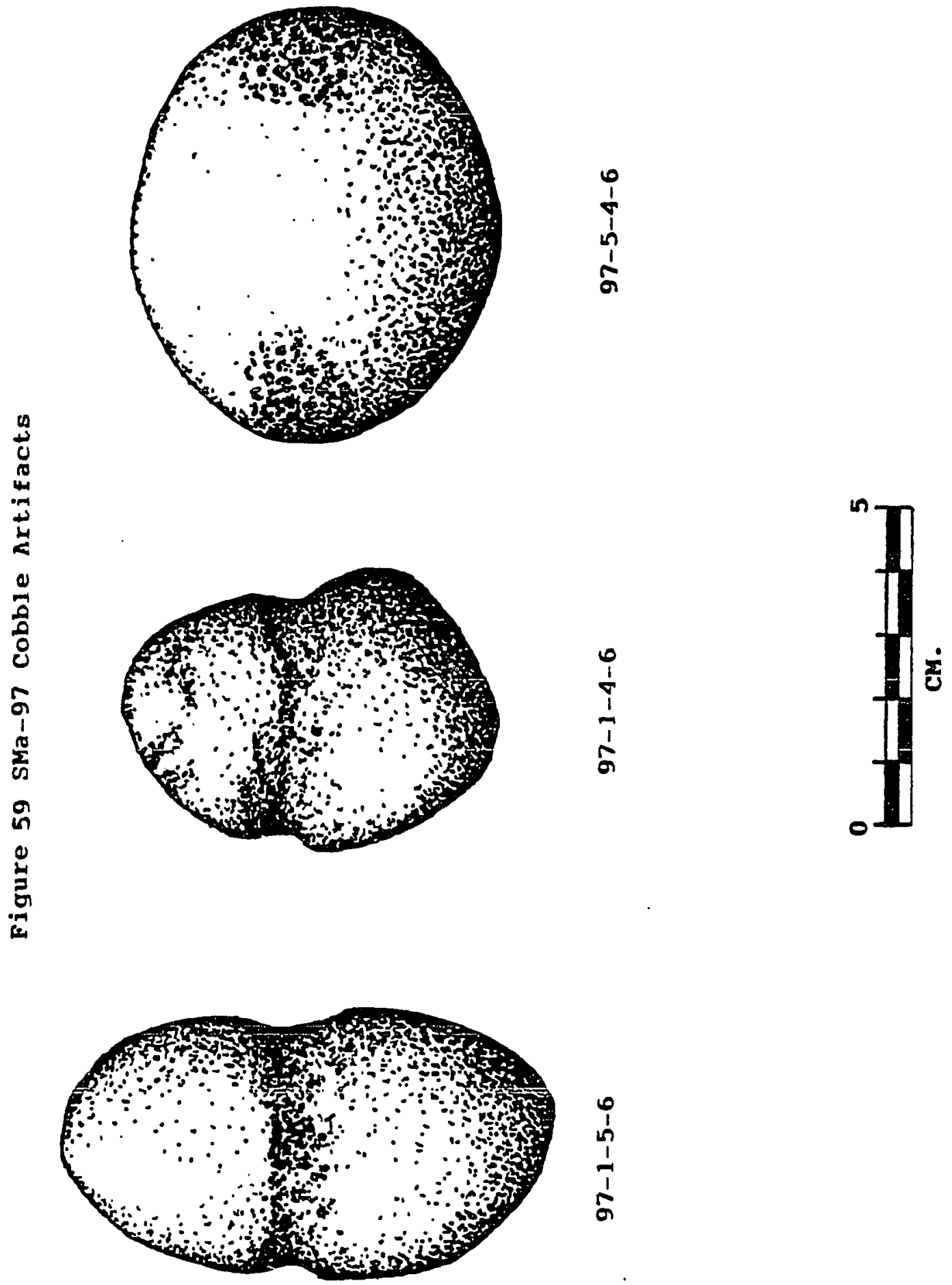

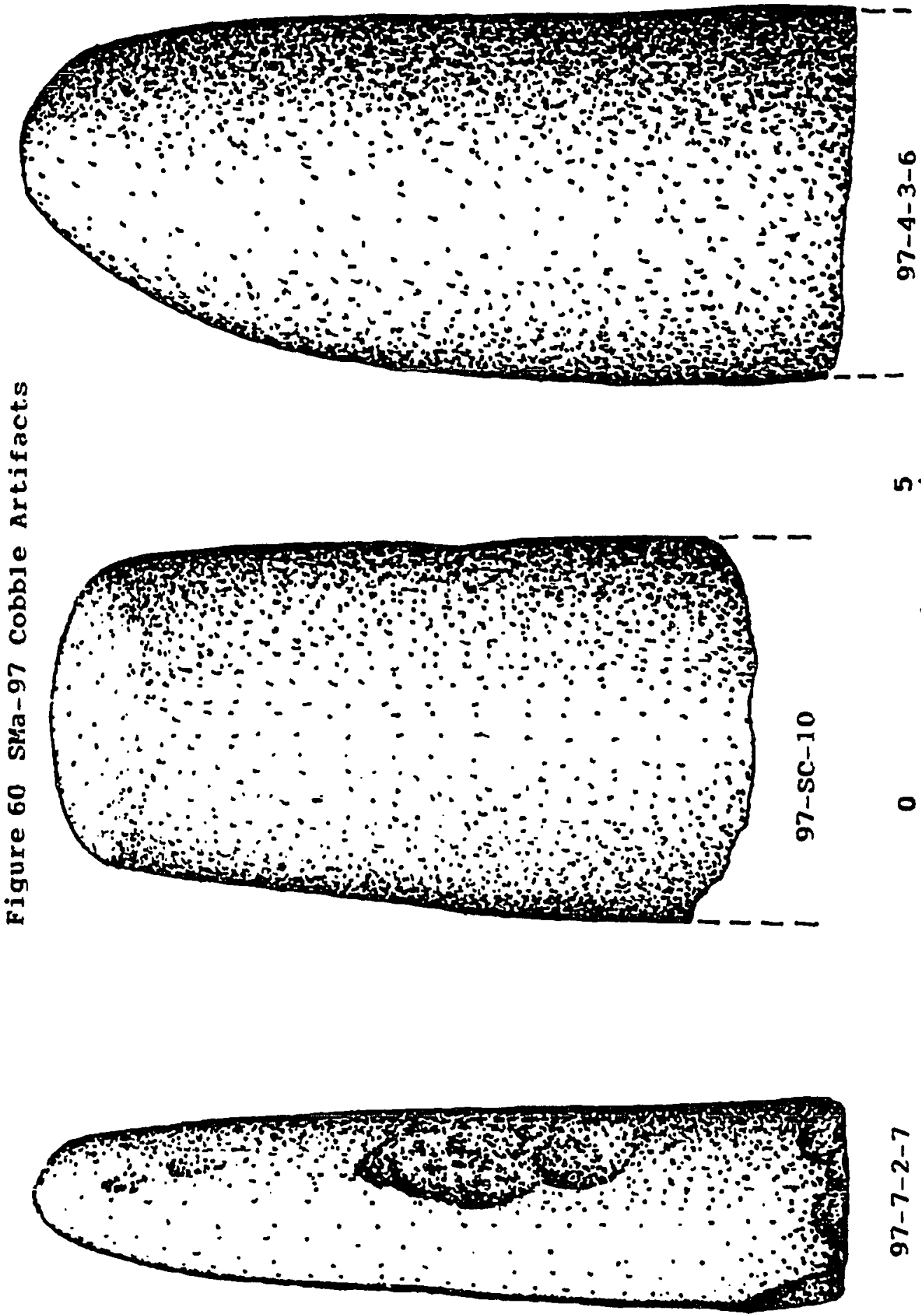

$\frac{1}{1}$ 


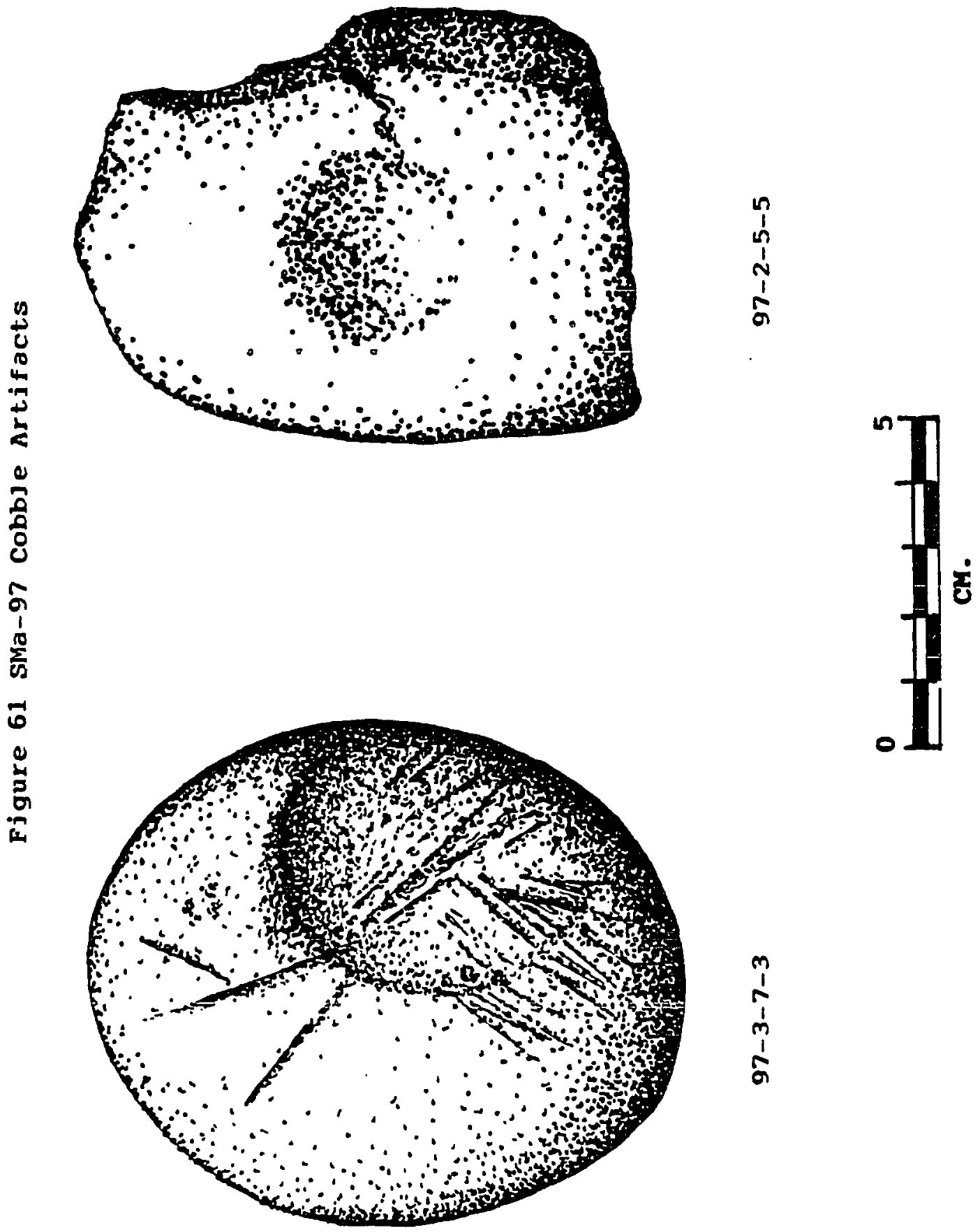


SMa-110, the Pilarcitos creek site

SMa-110 is located on the coastal terrace near the mouth of Pilarcitos Creek, very near the town of Half Moon Bay. This site was tested in the late 1960 s and a report of findings was compiled in 1971 (Asturias in Moratto 1971: 4955). The following summary is derived from the report.

A total of four $1 \times 2$ meter excavation units were tested for a total of 6.6 cubic meters of site. Unfortunately, screen mesh sizes were not described. A large number of artifacts were recovered, and human burials were identified as well. In all, three burials were noted, but their orientations were not provided in the report.

Burial A had a handstone in association (described as a waterworn cobble with small circular use surfaces and classed as a hammerstone). Burial B was a cranium placed on several large stones, and had chert scrapers, a spire lopped olivella shell and 67 modified olivella saddle beads in association. Burial $\mathrm{c}$ had a chert scraper and a spire lopped olivella shell in association. A total of 24 spire-lopped Olivella shell beads and 67 olivella saddle beads (type F after Bennyhoff and Hughes 1987) were recovered. The saddle beads were in association with a burial A. Several cut pieces of Haliotis rufescens and a single Haliotis circular pendant with incised lines around the edges (type K2bII after Gifford 1940) were noted. 
A total of 8 bone artifacts were recovered, one of which was described as a whale bone wedge, another as bipointed (possibly a fish gorge), and yet another as a blunt tipped fragment. The rest are of undetermined types.

Cobble tools included 8 charmstones ( 3 type IA plummets, 2 type lBla piled plummets, 1 type $2 \mathrm{Al}$ spindle and two specimen not typed [types after Beardsley 1954]), 7 pestles, and 2 mortar fragments. In addition to these, 19 cobble artifacts exhibiting ground surfaces and battered shoulders (described as non-pitted hammerstones) may have been handstones for seed grinding. A total of 15 pitted/dimpled cobbles were recovered, 10 of which were pitted on opposite faces (bi-pitted). Three grooved cobbles and an anvil stone were also recovered. Table 61 summarizes the cobble tools from SMa-118.

Table 61: Cobble Artifacts from SMa-110

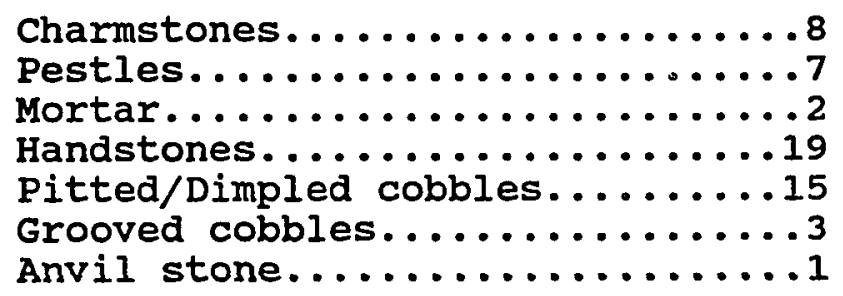

SMa-110 exhibits a Middle Period component and is probably a forager residential location. This conclusion is based on the presence of human remains, the temporally diagnostic artifact types, and the similarity of the 
assemblage to other sites in the study area. Table 62

presents a summary of component definitions.

Table 62: Component summary from SMa-110

1) Upper and lower levels: $0-80 \mathrm{~cm}$.

Age: Middle Period

Artifacts:

Olivella type $F$ beads

Haliotis type K2bII pendants

Piled charmstones

Mortars \& pestles

Handstones

Grooved cobbles

Pitted/Dimpled cobbles

Bone Awls

Bone wedge 
SMa-115, the Montara state Beach site

Sma-115 is located on the coastal terrace of Montara state Beach and is at the edge of eroding cliffs which are collapsing onto the beach below the site. This site is currently on property under the jurisdiction of the California Department of Parks and Recreation (DPR) .

SMa-115 was first tested by this author and volunteers from San Jose State University in 1983, after severe storms had caused a large portion of the coastal terrace to collapse and wash out to sea. The S.J.S.U. team was asked by DPR to recover some site data before further loss was sustained. The following discussion is derived from the site report (Hylkema and Hall 1985).

A total of four $1.5 \times 1.5$ meter excavation units were established adjacent to the cliff edge. In addition to these units, a $25 \times 25 \mathrm{~cm}$. shell column unit was established adjacent to unit $7 \mathrm{~N} / 6 \mathrm{~W}$, which was located on top of the mounded portion of the site. A total of 5.5 cubic meters of site was excavated and sifted through $1 / 8$ " mesh screens. A single radiocarbon date was derived from $200 \mathrm{gr}$. of Mytilus californianus which came from a shell lens at 120 to $130 \mathrm{~cm}$. This date was the first radiocarbon date for the San Mateo coast, and is presented in Table 63 . 
Table 63: Radiocarbon Date from SMa-115

WSU\# Provenience

$14 \mathrm{C}$ age(years B.P.)

3104 P596-10-6 U. 7N/6W $705 \pm 130$

Very few artifacts were found; however, a considerable amount of faunal material was recovered, the most abundant of which were fragmented shells. Much of the mound was composed of piled shell and thermally altered granite cobbles. The column unit recovered $17,251.0 \mathrm{gr}$. of shell, equal to $49,288.5 \mathrm{gr}$. per cubic meter. It was estimated that 80 to $90 \%$ of the sample was composed of Mytilus californianus, although a systematic quantification of shell species present was not completed.

Bone elements were also abundant and represented a wide variety of species. Unidentified bone weights were not presented in the report, but of 211 identified bone pieces $(1,372.5 \mathrm{gr}$.$) , bird species and sea otter dominated the$ assemblage. Table 64 presents the taxa frequencies. Excluding rodents, birds and whales, marine mammals composed $69 \%$ of the bone pieces, or $65.5 \%$ of the bone weight. Unit $7 \mathrm{~N} / 6 \mathrm{~W}$ yielded 116 pieces ( $980.1 \mathrm{gr}$.$) , which is equal to 75$ pieces (653.5 gr.) of bone per cubic meter of site. only 17 pieces of debitage were recovered (4 pieces per cubic meter of site). Of the 17 pieces, 15 were of Monterey chert and 2 were of Franciscan chert. 
Table 64 SMa-115 Taxa Frequencies:

(Identifiable Elements, All Units)

\begin{tabular}{|c|c|c|c|c|}
\hline Taxa & pcs. & $\underline{\underline{x}}$ & wt. (gr) & $\%$ \\
\hline $\begin{array}{l}\frac{\text { Enhydra }}{\text { Phoca vitulis }} \\
\frac{\text { Zalophus californicus }}{\text { Eumetopias jubata }} \\
\text { Callorhinus ursinus } \\
\text { Otariidae/sea Lion } \\
\text { Otariidae/Fur Seal } \\
\text { Otariidae } \\
\text { Pinnipedea }\end{array}$ & $\begin{array}{r}55 \\
2 \\
2 \\
3 \\
1 \\
4 \\
2 \\
9 \\
9\end{array}$ & $\begin{array}{r}26.9 \\
1.0 \\
1.0 \\
1.5 \\
.5 \\
2.0 \\
1.0 \\
4.4 \\
4.4\end{array}$ & $\begin{array}{r}347.4 \\
13.0 \\
28.8 \\
56.1 \\
4.1 \\
15.0 \\
10.2 \\
32.2 \\
15.2\end{array}$ & $\begin{array}{r}39.5 \\
1.5 \\
3.0 \\
6.5 \\
.5 \\
1.5 \\
1.0 \\
3.5 \\
2.0\end{array}$ \\
\hline $\begin{array}{l}\text { Cervus nanoides } \\
\text { Odocoileus hemionus } \\
\text { Antilocapra americana } \\
\text { Artiodactyla } \\
\text { Canis sp. } \\
\text { Carnivora } \\
\text { Sylvilagus audubonii } \\
\text { Rodentia }\end{array}$ & $\begin{array}{r}5 \\
10 \\
1 \\
8 \\
2 \\
5 \\
8 \\
37\end{array}$ & $\begin{array}{r}2.5 \\
4.5 \\
.5 \\
4.0 \\
1.0 \\
2.5 \\
4.0 \\
18.0\end{array}$ & $\begin{array}{r}69.5 \\
99.3 \\
6.7 \\
67.9 \\
23.1 \\
3.9 \\
3.4 \\
14.7\end{array}$ & $\begin{array}{r}8.0 \\
11.0 \\
1.0 \\
7.5 \\
2.5 \\
.5 \\
.5 \\
1.5\end{array}$ \\
\hline Aves & 42 & 20.0 & 71.7 & 8.0 \\
\hline Total & 205 & & 882.2 & \\
\hline
\end{tabular}

Terrestrial vs Marine:

(Rodentia, Aves and Cetacea Excluded)

\#pcs.\%

Terrestrial

Marine
31.0

69.0 wt. (gr) \%

34.5

65.5 
Three cobble tools were found. Two of these were elongated cobbles which had been split perpendicular to their axial lengths, with the split surface exhibiting wear from pounding and abrasion. The third artifact is a grooved stone, which probably functioned as a net or a hook and line fishing weight. A total of 80 granitic cobbles were recovered, mostly from unit $7 \mathrm{~N} / 6 \mathrm{~W}$. These were thermally affected and were probably used to facilitate shellfish roasting.

SMa-115 was summarized as a single component late Period temporary special use site (Hylkema and Hall 1985) and reflects the collector model of adaptive behavior. Overall, the site exhibited an intensive focus on shellfish roasting and sea otter butchering, and lacked artifact diversity. Table 65 presents a summary of this component. Table 65: Component Summary from SMa-115

1) Upper and lower levels: $0-150 \mathrm{~cm}$. Age: Late Period, $705 \pm 130$ B.P.

Artifacts:

Grooved cobble Cobble mauls
Fauna:*

Sea otter (26.9\%) Deer $(4.5 \%)$

Birds (20.0\%)
Shell wt. (M3) $49,288.5 \mathrm{gr}$.

*= Percentage of identifiable bone pieces. 
SMa-118, the Bean Hollow state Beach site

SMa-118 is located on the coastal terrace of Bean Hollow state Beach. The site is situated on a sand dune which rests upon a sandstone point. Because the point protrudes into the sea, and is exposed to occasional wave action, it is rapidly eroding away.

This site was first tested in 1983 by this author and volunteers from San Jose State University after human remains were observed eroding out of the site. This was a direct result of severe winter storms, and the aeolian deflation of a trail which cut a saddle through the vegetation holding the midden in place. The following discussion is derived from the site report (Hylkema 1989).

A total of thirteen $1.5 \times 1.5$ meter and two $50 \times 50 \mathrm{~cm}$. excavation units were established, for a total volume of 14.85 cubic meters. Excavated soils were sifted through $1 / 8$ " mesh screens. Several food processing features were identified and three complete human burials documented. The burials were analyzed at S.J.S.U., and later reinterred near the site in accordance with the desires of the ohlone crew members.

Two radiocarbon dates were funded by volunteer contributions. One of the dates was derived from human bone. Permission to sample the human bone was granted by the Ohlone consultants to the study. Table 66 presents the results. 
Table 66: Radiocarbon Dates from SMa-118

WSU\# Provenience

$14 \mathrm{C}$ age(years B.P.)

3102

3103

U.3.5N/2.5W $75 \mathrm{~cm}$. Human Bone U.4.5S/2E Charcoal, Feature 2

$380 \pm 45$

$635 \pm 70$

Debitage from SMa-118 included Monterey chert, jasper, chalcedony, quartzite, andesite, siltstone, rhyolite, basalt and other materials. Table 67 presents the relative percentages of materials.

Table 67: Material Composition of Debitage from SMA-118 $(\mathrm{N}=300)$

Monterey Chert.......65\%

Jasper................

Chalcedony............2\%

siltstone.............1\%

Quartzite..............9\%

Andesite...............

Rhyolite..............6\%

Basalt...................

Igneous/other..........2\%

Interestingly, no obsidian and no formal chipped stone tools were recovered. This is an unusual aspect of this site, given the abundance of chipped stone tools at other local sites. Despite the lack of points and bifaces, 3 borers and 11 informal flake tools were noted. Of the 300 pieces of debitage, $87.5 \%$ represented primary reduction stages, 8.5\% represented secondary reduction stages and $4 \%$ were informal tools. No pressure flakes were recovered.

Several cobble tool types were recovered and are presented in Table 68. The presence of milling slabs and a handstone, in contrast with the absence of mortars and 
pestles, implies an economic pursuit focused on seeds instead of acorns. The large number of pitted/dimpled cobbles and the abundance of turban snails in the shell debris may be related: the cobbles may have served as anvils for splitting the snail shells open.

Table 68: Cobble Artifacts from SMa-118

Grooved/Notched cobbles............4

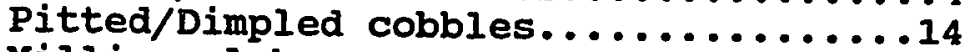

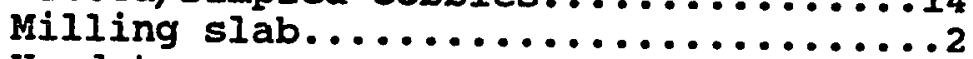

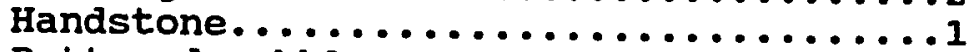

Battered cobbles......................

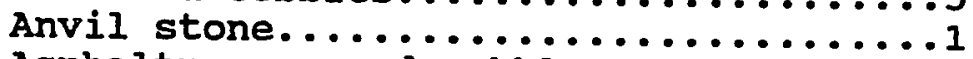

Asphaltum covered cobble..................

A large number of faunal bone elements were recovered. In all, 2,054 $\mathrm{gr}$. of bone was recovered, of which $70 \%(1,411$ gr.) was identifiable. Table 69 presents the taxa frequencies, but excludes the whale element. Marine mammals dominated the assemblage $(70.58$ of the pieces and 80.58 of the weight), with harbor seal composing $65.5 \%$ of the identified marine mammal elements ( $58 \%$ by weight). Bone from column unit $4.5 \mathrm{~S} / \mathrm{IW}$ equaled 136.5 grams per cubic meter of site. 
Table 69

SMa-118 Taxa Frequencies:

(Cetacea not included)

Taxa

Enhydra lutris

Phoca vitulina

Zalophus californicus

Callorhinus ursinus

Arctocephalus townsendi

Otariidae/sea Lion

Otariidae/Fur seal

Otariidae

Mirounga anqustirostris

Pinnipedea

Cervus nanoides

odocoileus hemionus

Artiodacty 1 a

Canis sp.

Carnivora

Mustela frenata

Sylvilagus auduboni

Rodentia

Aves

Total tocs. $\underline{x}$

95.0

80

3

1

1

1

3

16

1

7

1

5

1

3

1

2

15

20

173

.6

4.0

8.5

8.5

11.5
Nt.(gr) $\%$

$16.3 \quad 1.4$

$541.0 \quad 46.6$

$86.8 \quad 7.5$

$14.8 \quad 1.3$

$11.4 \quad 1.0$

$51.8 \quad 4.5$

$39.1 \quad 3.3$

$130.6 \quad 11.2$

$11.5 \quad 1.0$

$32.1 \quad 2.8$

20.9

131.9

31.8

1.9

3.0

.8

.8

3.2

30.0

3.0

Terrestrial vs Marine:

(Rodentia, Aves and Cetacea Excluded)

\section{\#pcs.\%}

Terrestrial

Marine
11.5

88.5 wt. (gr) \%

17.0

83.0 
Shell was noted as being very abundant. The column unit $(4.5 \mathrm{~S} / \mathrm{lW})$ recovered $3,621.4 \mathrm{gr}$. of shell equal to $6,035.5$ gr. per cubic meter of site. of this sample, Tegula funebralis composed $46 \%$ and Mytilus californianus $37 \%$ of the total species identified. This was the only coastal site in the study area to yield a shellfish species which outweighed the mussel. Chiton sp. composed $11 \%$ of the sample.

SMa-118 was described in the report as a Late Period seasonal occupation site (Hylkema 1989: 86). Recently, additional human remains have eroded out of the site and DPR has attempted to stabilize the location. In a short time, the rest of this site will be lost to erosion. While both SMa-118 and SMa-115 are roughly contemporaneous, they differ greatly in assemblage. SMa-118 represents a Late Period forager residential location. This conclusion is based on the radiocarbon dates, artifact types, the diversity of faunal bones, and the presence of human remains. Table 70 presents the component summary definitions. 
Table 70: Component summary from SMa-118

1) Upper and lower levels: $0-100 \mathrm{~cm}$.

Age: Iate Period, $380 \pm 45$ to $635 \pm 70$ B.P.

Artifacts:

Pitted/Dimpled cobbles Grooved/Notched cobbles Handstones \&

Milling slabs
Fauna: *

Harbor seal (46.2\%)

Sea otter $(5.0 \%)$

Fur seals (11.0\%)

Deer (1.5\%)

Rabbits (1.0\%)

Birds (11.5\%)

Shell Wt. (M3)

*= Percentage of identifiable bone pieces. 
SMa-139, the Frenchmans Creek site

SMa-139 is located on the coastal terrace near the mouth of Frenchmans Creek just west of the town of Half Moon Bay. The site is located on property under the jurisdiction of the California Department of Parks and Recreation (DPR). The DPR tested the site prior to the construction of a bridge over a portion of it. A report of findings is in progress (orlins n.d.). In 1987, four 1 y 1 meter units were established and excavated to some $50 \mathrm{~cm}$. depth. Faunal remains were abundant, but information regarding taxa frequencies is not yet available. Three radiocarbon dates have been derived from Mytilus californianus samples and are presented in Table 71.

Table 71: Radiocarbon Dates from SMa-139

Beta\# Provenience, Composition $14 \mathrm{C}$ age(years B.P.)

$\begin{array}{rlr}24535 & \text { U.Cl/20-30 cm., Mytilus } & 860 \pm 70 \\ 24534 & \text { U.A3/30-40 cm., Mytilus } & 1040 \pm 90 \\ 24533 & \text { U.A3/10-20 cm., Mytilus } & 1120 \pm 80\end{array}$

In addition to the radiocarbon dates, 15 pieces of obsidian were recovered and subjected to sourcing and hydration analysis. The results are presented in Table 72 . The only Borax Lake specimens identified within the study area were recovered here and included 5 pieces. While the Napa Valley sources have thin rim readings, possibly reflecting a Late Period site use, the Borax Lake specimens 


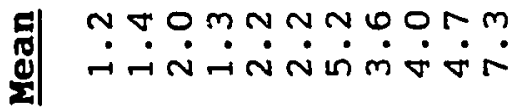

$m \pi n d n m n R T h$ m $-\dot{\sim} \dot{\sim} \dot{N} \boldsymbol{N} \dot{m} \dot{\sigma}$

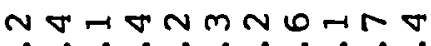
$\dot{-i N} \dot{\sim} \dot{N} \dot{m} \dot{\nabla} \dot{\sigma}$ n. $\dot{-i} \dot{\sim} \dot{\sim} \dot{N} \dot{N} \dot{m} \dot{\sigma} \dot{\nabla}$

NOMm Nomonm A-n N RUNANA

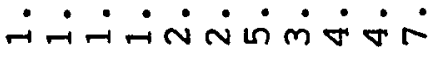
ก) -

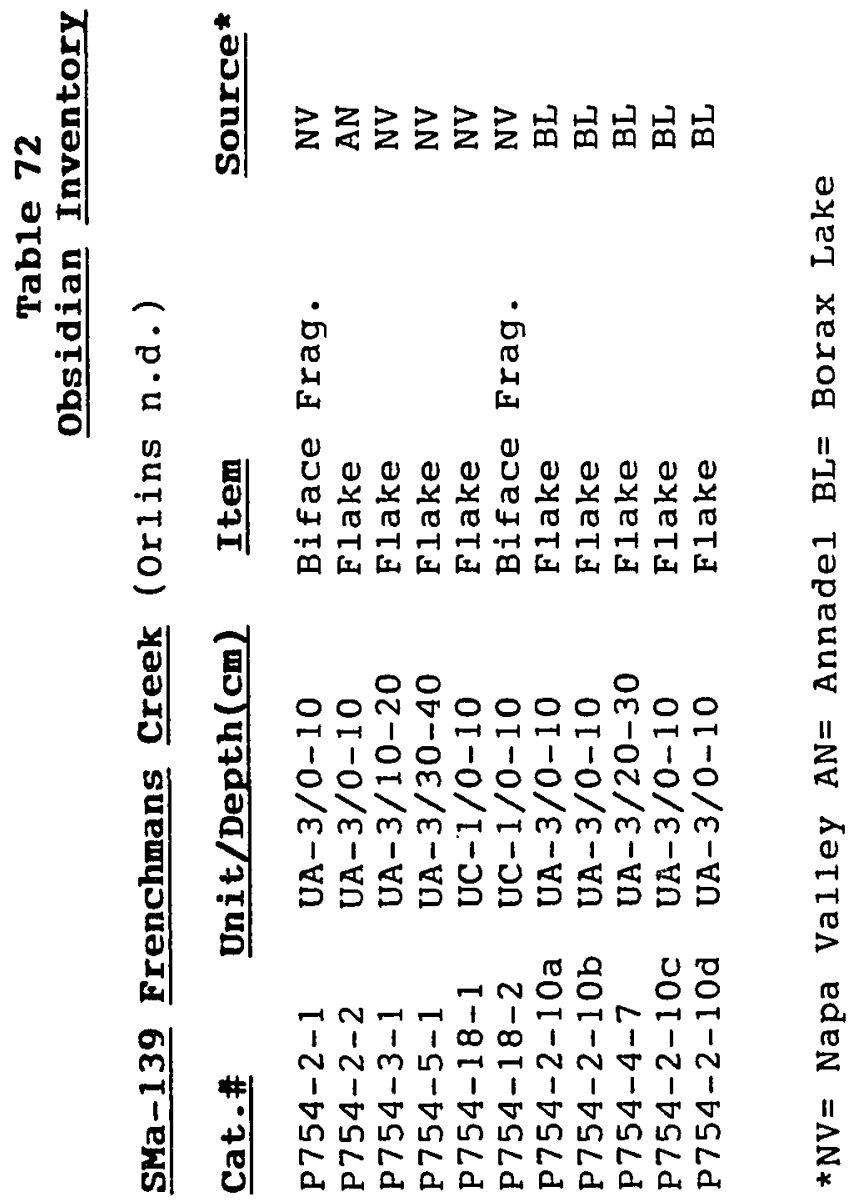


have very thick rim reacings and may represent an older use of the site. In either case, both sources were mixed in the soil and do not sort out stratigraphically. Component definitions must await the completion of the site report; however, the range of radiocarbon dates, shallow stratigraphy, and obsidian hydration readings clearly identify a Late and Middle Period span of time. 
SMa-140. the Denniston Creek site

SMa-140 is located on the coastal terrace midway

between Denniston and San vicente creek, about a mile north of the town of Half Moon Bay.

San Francisco State University first excavated this site in 1970 in response to potential impacts to it resulting from urban development. The following description is derived from the site report (Moratto et al. 1971).

A total of nine $2 \times 2$ meter units were excavated, with soils sifted through $1 / 4 "$ mesh screen. A total of 10.8 cubic meters of site was excavated, and several artifact types were recovered.

Thirty pitted/dimpled cobbles were found, all of them pitted bifacially. A single proximal end fragment of a charmstone was recovered.

of the chipped stone tools, 4 polyhedral chert cores and 29 informal flake tools were noted. Unfortunately, the material composition was not described nor were debitage counts provided. Two complete projectile points and 9 fragments were described, and all of them were obsidian. The points included a lanceolate and an "ovate-bladed biface of opaque black obsidian with moderate shoulders which produce a broad, straight-sided stem" (Moratto 1971: 65). This last point may actually be an Ano Nuevo long-stemmed type.

only 6 spire lopped olivella shell beads were retrieved, which implies that these shells were not passing 
through this location in great numbers. On the other hand, other shell fragments composed a large proportion of the midden. Shell samples from two $20 \mathrm{~cm}$. levels out of unit 096 were recovered through 1/4" mesh screen. The large screen mesh size and undetermined sample size prevents the volumetric comparison of these results with those of other coastal sites. Despite the difficulties with comparative sampling volume, the two $20 \mathrm{~cm}$. levels $(20$ to $40 \mathrm{~cm}$, and 40 to $60 \mathrm{~cm}$.) recovered $1,176.0 \mathrm{gr}$. of Mytilus californianus which represented $81 \%$ of the recovered shell. Tequla funebralis composed 10\%. Shell volume from this sample equals 7,222 gr. of shell per cubic meter of site. No inventory of faunal bone was provided, but bone was noted as having been present.

A total of 10 obsidian specimens were sourced from this site. Of these, 6 were from the Napa source, 2 were from Annadel and one was from an undetermined source believed to be east of the Sierra Nevada Mountains.

The site report does not provide sufficient information with which to determine component definitions. The abundance of pitted/dimpled cobbles, obsidian lanceolates and Mytilus shell volume is similar to that of SMa-97. This may indicate that the site was occupied during the transitional time between the Middle and the Late Period. The presence of a charmstone fragment and the diversity of tools leads to the 
conclusion that this site was probably a multi-use residential base. 
SMa-218, the Ano Nuevo State Reserve site

SMa-218, which was tested by the author, is located within the extensive dune fields of Ano Nuevo state Reserve. Various grasses and shrubs have established themselves in this region, and they hold the dunes in place. However, large areas of the dune fields are not covered, and they are constantly deflating as the sands shift with the wind. Ano Nuevo Reserve contains at least 42 archaeological locations, some of which contain distinctly different cultural deposits, while others may be related but have been separated by erosion or sand dune cover. These sites have been a focal point for artifact hunters for years. The abundance of artifacts and their visibility on the surface have resulted in a significant loss of artifacts. This is evidenced by the numerous large private collections known to have come from here.

SMa-218 was included in the study after a large collection of Monterey chert points, point preforms and bifaces was donated to San Jose state University by Mrs. Patricia Harris. She had collected them from a single location years ago and was able to identify SMa-218 as the place of her collection's origin. The exciting aspect of her collection was the large number of points that were identical to those recovered from the University Village site, SMa-77, in Palo Alto. SMa-77 produced an artifact assemblage dated to 3,200 years B.P. (Gerow and Force 1968). 
Further, the particular style of points from SMa-77 and SMa218 were commonly seen in a number of other collections from sites within the study area. Gerow, at the time of his research at SMa-77, was unable to find comparable points with which to evaluate their meaning. The abundance of the point type, now defined as the Ano Nuevo long-stemmed (Jones and Hylkema 1988) led to the questioning of their temporal range. Either sites along the coast with these points were contemporaneous or the type persisted later in time on the coast than elsewhere.

A permit to test SMa-218 was obtained from the California Department of Parks and Recreation in order to address the temporal context of the point type at this site and to examine the stages of their construction. The specimens in the Harris collection indicated that the entire range of core to point reduction stages was present at this site.

The site consisted of an extensive scatter of chipped stone, tools, debitage, shell fragments, bone fragments and heat affected cobbles spread over the surface of a large, deflating sand dune. Cultural elements were found in concentrations over the surface. Artifacts were also observed in the grasslands adjacent to the site, and it was not determined if these were part of SMa-218. Many other large sites are present within a short distance of sMa-218. 
A 1/2" mesh screen was found hidden in the bushes at the site, left there by collectors.

Three recovery methods were used: rapid recovery units, controlled excavation units and random surface collecting. The purpose of the rapid recovery units was to locate areas with intact midden deposits and high artifact yields. Once these areas had been identified, controlled excavation units were established in them. Random surface collection of tools and identifiable bone elements was conducted because of the abundance of these items in the deflated dune areas. Table 73 presents the excavation unit dimensions, recovery techniques and volumes.

Table 73: Excavation Unit Dimensions and Volume from SMa-218

\section{Unit Dimension}

$1 \quad 1.5 \times 1.5 \mathrm{~m}$.

$2 \quad 2.0 \times 4.0 \mathrm{~m}$.

$3 \quad 1.5 \times 1.5 \mathrm{~m}$.

$43.0 \times 3.0 \mathrm{~m}$.

$5 \quad 10.0 \times 1.0 \mathrm{~m}$.

$6 \quad 1.0 \times 1.0 \mathrm{~m}$.

$7 \quad 1.0 \times 1.0 \mathrm{~m}$.

CU.1 $25 \times 25 \mathrm{~cm}$.
Recovery Method

1/4" Rapid Recovery

3/4" Rapid Recovery

1/4" Controlled

1/4" Rapid Recovery

2/4" Rapid Recovery

1/8" Controlled

$1 / 8$ " Controlled

1/8" Controlled Wet Screen

Cubic Meter

\section{$----$}

Map 19 illustrates unit locations. A total of 11.4

cubic meters of site was tested using rapid recovery units. These units were generally excavated to a depth of $40 \mathrm{~cm}$, and produced cultural elements only in the upper $10 \mathrm{~cm}$. of sand. The excavation of these units did succeed in locating intact deposits of dark black midden soils which had not yet 
deflated. A total of 1.5 cubic meters of these areas was tested in controlled $10 \mathrm{~cm}$. levels. Overall, the intact portions of the site were very shallow, and consisted of a thin layer of black, charcoal rich sandy matrix, which was covered by white windblown sand. The black colored matrix was deposited over the white sand dune, and excavation ceased upon finding this level (see Figure 61), Units 6, 7 and CU.I were dry screened in the field, and later wet screened at the $1 \mathrm{ab}$.

A single radiocarbon date for this site was derived irom a concentration of intact Mytilus californianus shells in unit 3 . The result is presented in Table 74 .

Table 74: Radiocarbon Date from SMa-218

WSU\# Provenience, Composition $\quad \underline{14 \mathrm{C}}$ age(Years B.P.)

3425 U.3/20-30 cm., 350 gr. Mytilus $2880 \pm 75$

The date and the artifact assemblage compares well with the dated assemblage at $\mathrm{SMa}-77$.

A considerable amount of shell was mixed with the dark, charcoal-rich midden. Most of the shell was composed of very fragmented Mytilus californianus, with occasional concentrations of intact shells. A single olivella modified bead was recovered from unit 2 and was typed G6a (after Bennyhoff and Hughes 1987). This type has been noted as a Middle Period marker in the Monterey Bay area (Bennyhoff, personal communication, 1988). This bead had a conically 
drilled aperture. In addition to the modified bead, 9 spire broken, 2 spire ground, 1 intact and 2 partially fragmented olivella shells were recovered. This low number equals 1.5 specimens per cubic meter of site.

Faunal elements were abundant, and many pieces of bone were recovered from the surface recovery and excavation units. Bone from the random surface collection and from units 1 and 2 was reviewed. This sample consisted of 2,576 pieces $(2,631.6 \mathrm{gr}$.$) of bone. The sample from units 1$ and 2 equaled 610 pieces (575.0 gr.) per cubic meter of site (although the amount would have been greater if less sterile sandy matrix had been excavated in unit 2). Table 75 presents the results of the taxa frequencies. The unit totals have been presented in Appendix $A$. Of the identified taxa, marine mammals composed $75.0 \%$ of the pieces and $82.0 \%$ of the weight (excluding rodents, birds and fish). Northern fur seal remains (Callorhinus ursinus) dominates the assemblage nearly to the exclusion of other species. Only 2 bone artifacts were recovered, and these have been described in Appendix C. Both are illustrated in Figure 62. These included a short split deer tibia (proximal end), with a pointed tip and a rounded spatulate tip fragment which had been polished and burned. 
Table 75

SMa-218 Taxa Freguency:

\begin{tabular}{|c|c|c|c|c|}
\hline Taxa & \#pcs. & $\underline{\boldsymbol{q}}$ & Wt. (gr) & $\underline{\underline{\phi}}$ \\
\hline $\begin{array}{l}\text { Callorhinus } \\
\frac{\text { Phoca vitulina }}{\text { Enhydra }} \text { lutris }\end{array}$ & $\begin{array}{r}142 \\
1 \\
5\end{array}$ & $\begin{array}{r}48.0 \\
.5 \\
1.5\end{array}$ & $\begin{array}{r}752.4 \\
3.4 \\
6.4\end{array}$ & $\begin{array}{r}77.0 \\
.3 \\
.6\end{array}$ \\
\hline $\begin{array}{l}\frac{\text { Cervus }}{\text { Ursus }} \frac{\text { nanoides }}{\text { Oorribilus }} \\
\frac{\text { Odocoileus }}{\text { Sylvilagus }} \frac{\text { hemionus }}{\text { audubonii }} \\
\text { Rodentia }\end{array}$ & $\begin{array}{r}1 \\
2 \\
20 \\
26 \\
30\end{array}$ & $\begin{array}{r}.5 \\
.5 \\
7.0 \\
9.0 \\
10.0\end{array}$ & $\begin{array}{r}2.2 \\
19.9 \\
131.4 \\
16.3 \\
10.8\end{array}$ & $\begin{array}{r}.2 \\
2.0 \\
13.5 \\
1.5 \\
1.0\end{array}$ \\
\hline Aves & 21 & 7.0 & $26 \cdot 3$ & 2.7 \\
\hline Ichthys & 46 & 20.0 & 10.5 & 1.0 \\
\hline Ióentifiable & 294 & 11.5 & 979.3 & 37.0 \\
\hline Unidentifiable & 2277 & 88.5 & 1652.3 & 63.0 \\
\hline Total & 2576 & & 2631.6 & \\
\hline
\end{tabular}

Terrestrial vs Marine:

(Rodentia, Aves and Ichthys Excluded)

$\begin{array}{lcc} & \frac{\# \text { pcs.\% }}{\text { Wt. }(\text { gr }) \%} & \text { 18.0 } \\ \text { Terrestrial } & 25.0 & 82.0 \\ \text { Marine } & 75.0 & \end{array}$


Debitage from SMa-218 was extremely abundant. Nonterey chert was readily available along the nearby beach and all of the stages of core to point reduction were in evidence here. Debitage was not retained from units 3 and 5 because of the large amount already recovered. Table 76 presents the debitage volume from the excavation units.

Table 76: Debitage Volumes from SMa-218

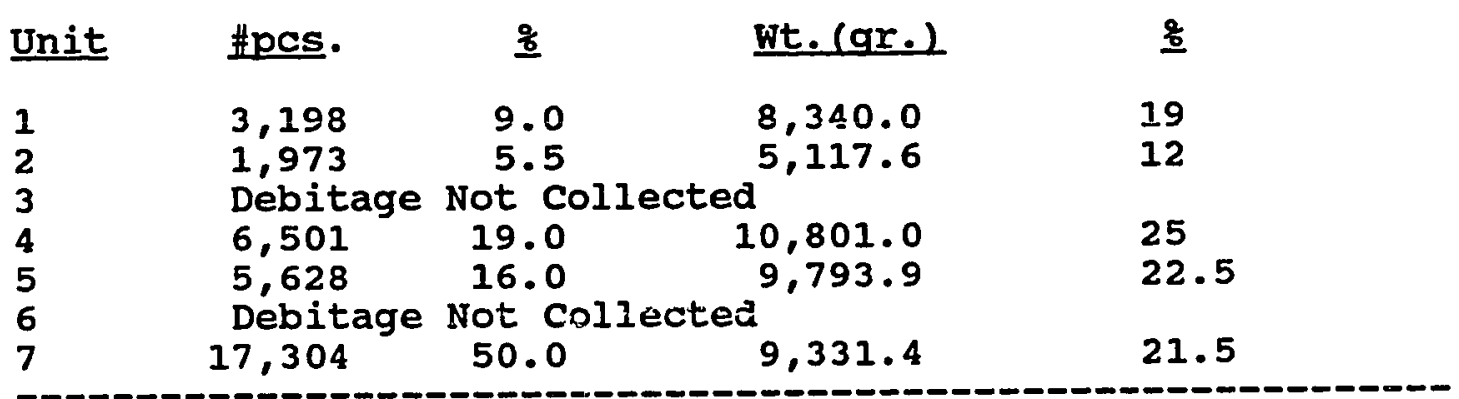

A total of 34,554 pieces $(43,383.9 \mathrm{gr}$.$) , of chipped$ stone was recovered from the above listed units. Unit 7 was selected for debitage analysis. This unit recovered an amount of debitage equal to 43,260 pieces $(108,459.5 \mathrm{gr}$. per cubic meter of site. All of these pieces were of Monterey chert; however, 45 obsidian pressure flakes were recovered but not included in this total. Table 77 presents the results of this analysis. of the sample from unit $7,5 \%$ of the pieces represented primary reduction, $91 \%$ represented secondary reduction, $4 \%$ were shatter debris and $.1 \%$ were formal tools. It was evident from the results of the debitage analysis that chipped stone tools have been shaped, 


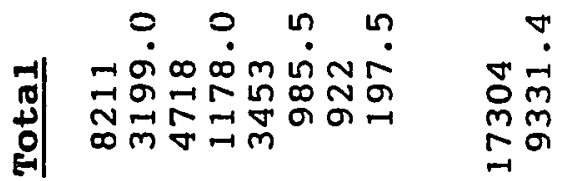

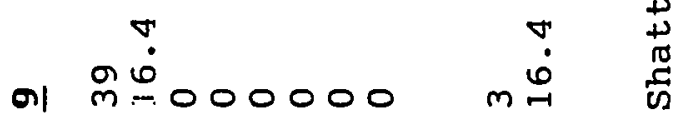

0 in 0 in

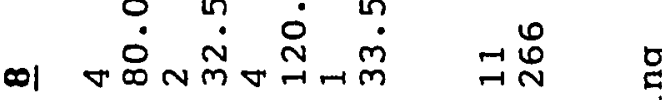

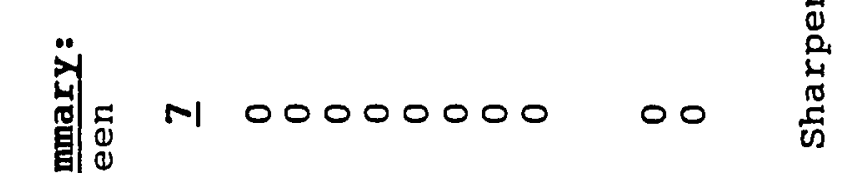

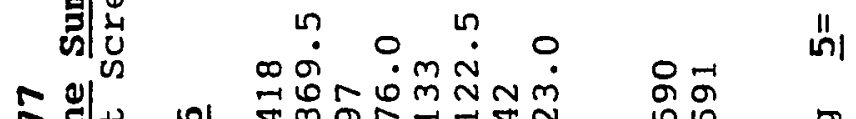

₹

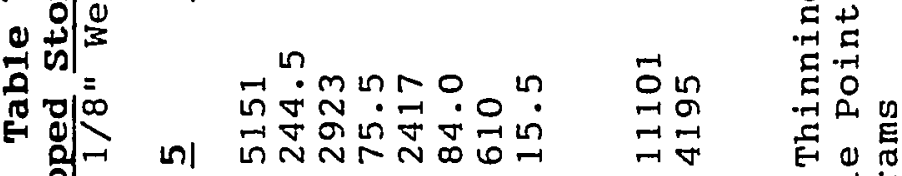

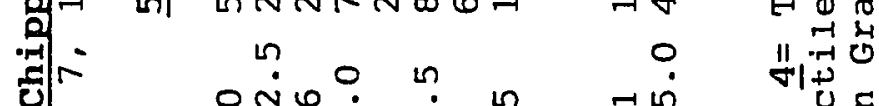

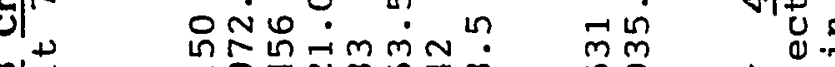

典:

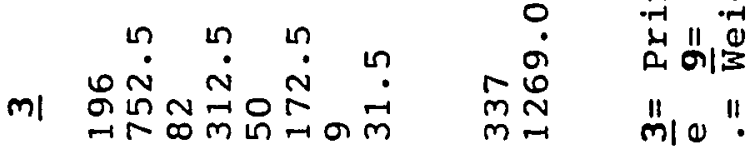

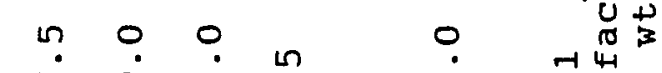

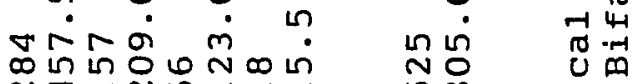

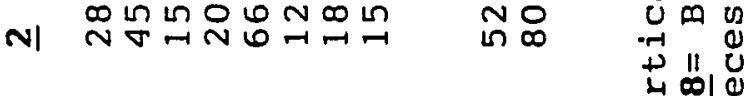

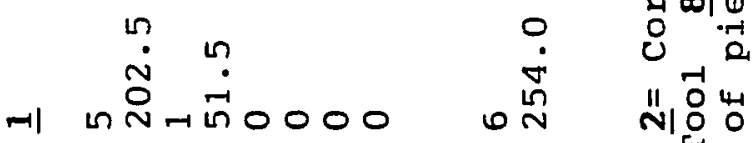

\# \#. \# \#. \# \# \#

\#|

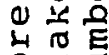

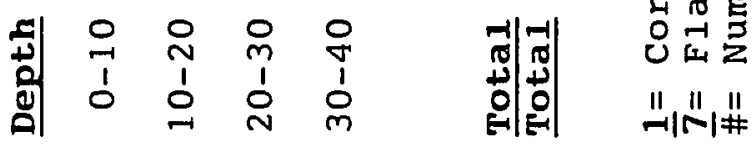


sharpened and maintained in large numbers at this site. This observation was confirmed by the presence of many formal tools and their various stages of reduction

Chipped stone tools from the Harris collection and those recovered for this study have been organized into the five reduction stages described in chapter IV. Stages ranged from bifacial cores to projectile points. Descriptions of the artifacts have been presented in Appendix D. Figures 63 through 68 illustrate 86 specimens, and these are included to help clarify the proposed reduction stages. Artifacts from the Harris collection were denoted by the letters AN-, and those from this study's excavations use the DPR designation P648-.

A total of 339 specimens were reviewed and the frequencies of the reduction stages are presented in Table 78. The reduction stages used in this study were defined on the basis of the large collections from this site.

Table 78: Point Reduction Stages from SMa-218 ( $N=339)$

$\begin{array}{lccl}\text { RS\# } & \text { \# } & \underline{\text { S }} & \text { See Fiqure: } \\ 1 & 19 & 5.5 & 64 \\ 2 & 73 & 21.5 & 65 \\ 3 & 125 & 37 & 66,67,68,69 \\ 4 & 68 & 20 & 70,71,72,73,74,75,76 \\ 5 & 54 & 16 & 77,78,79,80,81,82\end{array}$

Tabular pieces of Monterey chert were collected from the beach and were heat treated to improve their knapping qualities. Many of the artifacts exhibited thermal spalls 
and discoloration from the heating process. Most of the recovered chipped stone artifacts had been split across their midsections and probably represent tools broken during the course of reduction. This was particularly true for stage three and four artifacts. The principal point type produced here was the Ano Nuevo long-stemmed type. These contracting stem points occasionally retain asphaltum stains along a significant portion of their stems. This is noteworthy because specimens of this type maintain a midsection with maximum width closer to the tip (which is generally wide and slightly rounded, occasionally exhibiting an apiculate apex), and the long stem frequently resembled a tip and blade. The asphaltum stains resolved the problem of determining which end was the tip. This style of point was the dominant form seen in collections from Ano Nuevo state Reserve. The steele family, who formerly owned the reserve, has collected an extremely large number of points from this area. Although their collection was not included here, most of the points have been measured and photographed (Parsons, personal communication). The steele collection contains some of the finer specimens of this type. In addition to the points from sMa-218, three bifacially shaped knives, two borers/drills and one flake tool with distinctive edge wear were recovered. These are illustrated in Figure 82. In addition to the Monterey chert items, three obsidian projectile point fragments were recovered (see Figure 83). 
One of these was a concave base lanceolate series point. In all, 54 points were found of which 33 could be assigned to a type. Table 79 presents the point types from the excavation.

Table 79: Stage 5 Point Types from SMa-218 ( $N=33)$

Contracting stem-

Ano Nuevo long-stemmed..........27 (82\%)

Lanceolate-

convex base.................. (6r)

concave base................... (3q)

bipoint..................... (3q)

Notched-

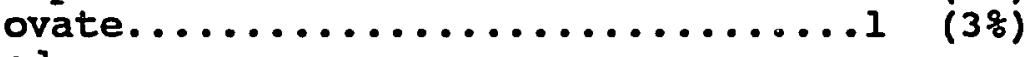

side (wide notches) ............... (3\%)

The above total represents $61 \%$ of the stage 5 types described in Appendix D. Many of the point fragments

described as untyped were almost certainly of the Ano Nuevo long-stemmed type. These fragments exhibited wide, rounded midsections with tapered angles where the stem has broken at the junction with the blade. Also, several of the fragments retained an apiculate tip, which is a characteristic feature of the Ano Nuevo long-stemmed type that have not had their tips extensively re-worked (which is also typical). During the course of the excavation, it was thought that obsidian tools were not present. However, after wet screening units 6 and 7 in the lab it was discovered that while obsidian tools were not evident at the site, extensive edge maintenance debitage was. A total of 108 tiny pressure flakes were recovered from .8 cubic meters. This amount equals 135 pieces per cubic meter of site. Unfortunately, 
only eleven of these have been sourced, and three of these hydrated. Five of the eleven pieces were from the Casa Diablo source five were from Napa Valley and one was from Bodie Hills. Rim readings from two biface fragments from the Casa Diablo source measured 3.1 and. 3.5 microns, and one of the Napa Valley thinning flake measured 2.7 microns. An inventory of the obsidian pieces is presented in Table 80. Very few cobble tools were recovered despite the large number of heat affected cobbles visible at the site. All of the cobbles were brought to the site by the prehistoric inhabitants and do not occur naturally in the sand dune. These were not quantified; however, the majority of them were andesite and rhyolite, with a few quartzite, sandstone and basalt pieces. Most of these were discolored and exhibited thermal spalls. These cobbles were probably used to line hearths for roasting shellfish and other meats as well as to heat Monterey chert cores. Only 6 cobble tools were found and these have been described in Appendix E. They include 2 choppers, 1 milling slab fragment, 1 mortar rim fragment, 1 bifacially pitted/dimpled cobble and one large basalt cobble spall with wear on the edge opposite the bulb of percussion. Figure 84 illustrates one of the choppers. 
䍖

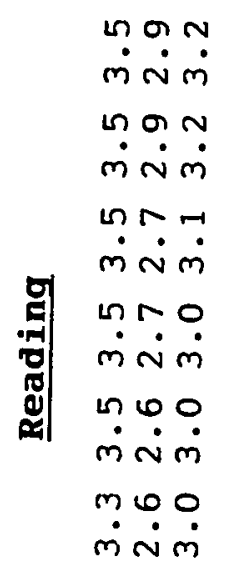

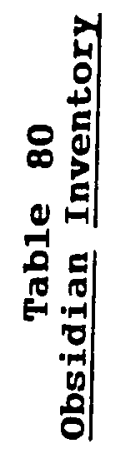

敂

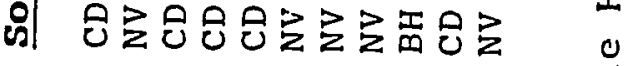

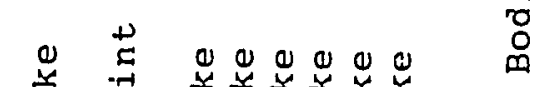

- 离. 舟

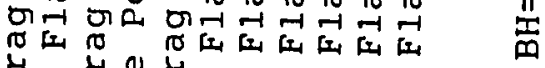
मे मे क्ष

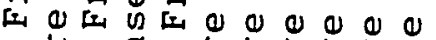

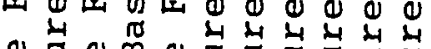

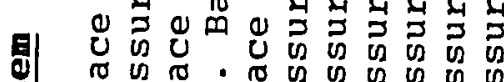

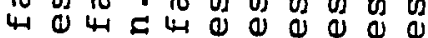

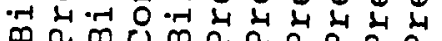

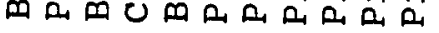

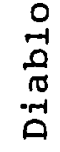

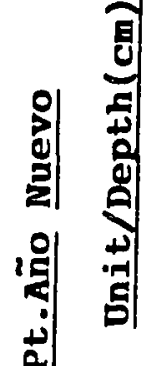

유유NㅇNㅇN윳

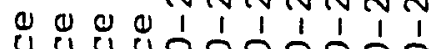

U U U U U

山4

山 म

थै

$\rightarrow \sim m$ no 0

$\begin{array}{llllllll}1 & \sim & m & 0 & \infty & 0 & 1 & 1 \\ 1 & \sim & 1 & 1 & 1 & 1 & 1\end{array}$

章

nNNNNNN

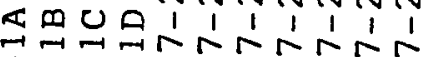

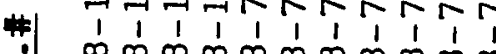

భ

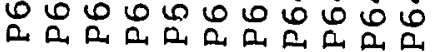

0
0
0

光

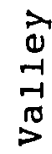

$\frac{10}{20}$

$\sum_{*}^{11}$ 
Only one feature was found. This consisted of a biface cache in unit $6,20-30 \mathrm{~cm}$. Six bifaces were found clustered together in a $10 \times 10 \mathrm{~cm}$. space. Some were 1 ying on top of others. They included one stage 3 biface and five stage 4 preforms. None of these exhibited any edge wear and were nearly pointed on both axial ends. Specimen P648-6-3-2E had been split perpendicular to the axial length, and the others were intact (P648-6-3-2A, -2B, $-2 \mathrm{C},-2 \mathrm{D}$ and $-2 \mathrm{~F}$ ).

SMa-218 represents a single component Middle Period forager site which served as a production center for Monterey chert chipped stone tools, and was also an intensively used hunting base. The single radiocarbon date derived from a Mussel roasting feature and the distinctive Ano Nuevo long-stemmed points compare well with other Middle Period sites, sira-77 in particular. The large number of northern fur seal remains indicates that the site was primarily used during winter, and many of the chipped stone tools being produced here were also used to butcher the seasonally abundant fur seals. The presence of terrestrial mammal remains shows that a wide range of habitats were exploited while the site was in use. Table 81 summaxizes component definitions for SMa-218. 
Table 81: Component Summary from SMa-218

1) Homogeneous strata: 0-50 cm. Age: Middle Period, $2,880 \pm 75$ B.P. Obsidian Hydration Range: Napa $(\mathrm{N}=1) 2.7$

Casa Diablo $(\mathrm{N}=2) 3 \cdot 3-3 \cdot 5$

Artifacts:

Fauna:*

Ano Nuevo long-stemmed points Notched (side) point olivella type G6a bead Mortar

Milling slab

Pitted/Dimpled cobble

Northern fur seal (48\%)

Sea otter $(1.5 \%)$

Elk (.5\%)

Deer (7\%)

Rabbits (9\%)

Cobble choppers

Bone awls

Fish (20\%)

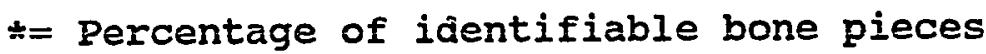




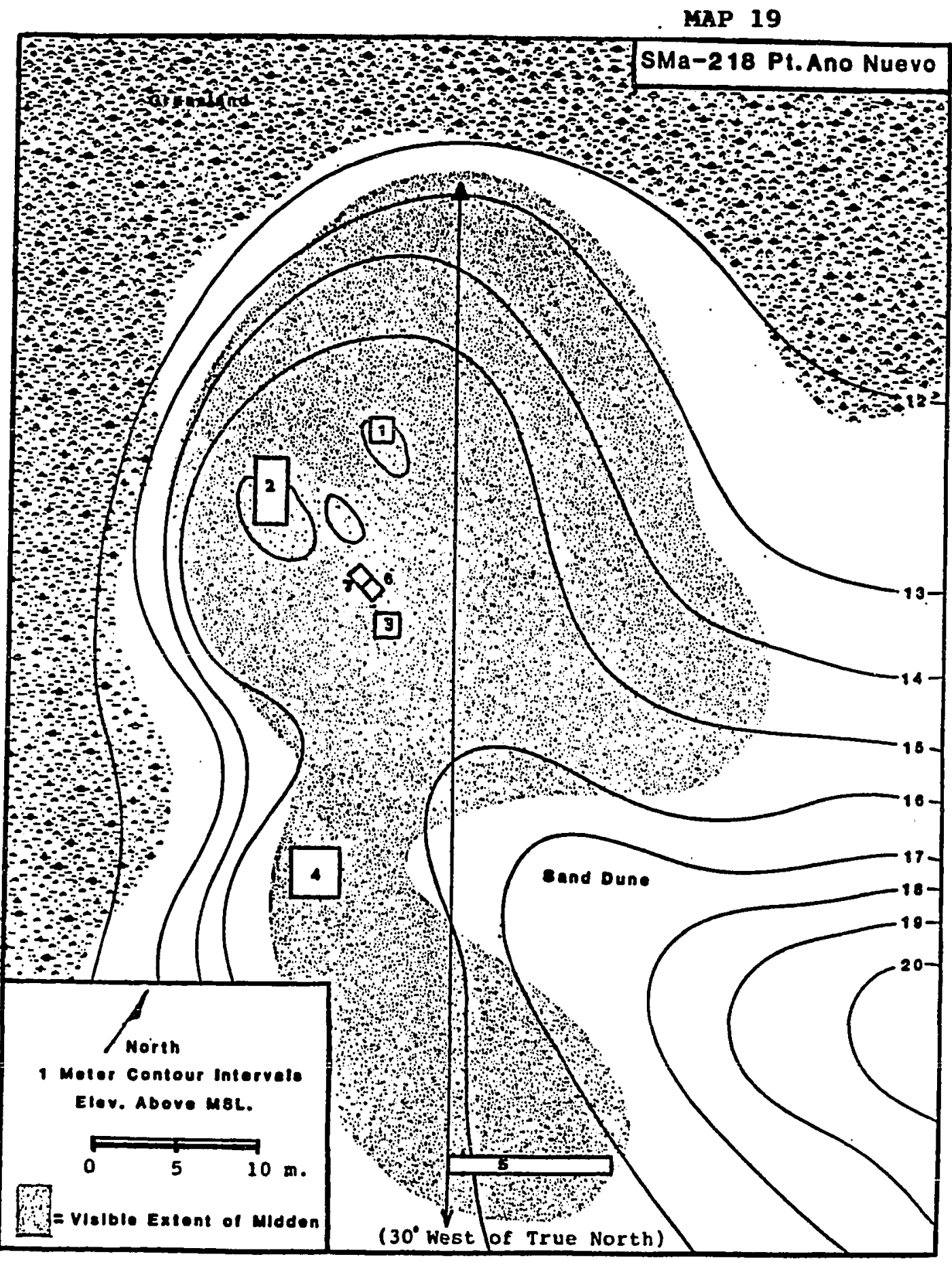




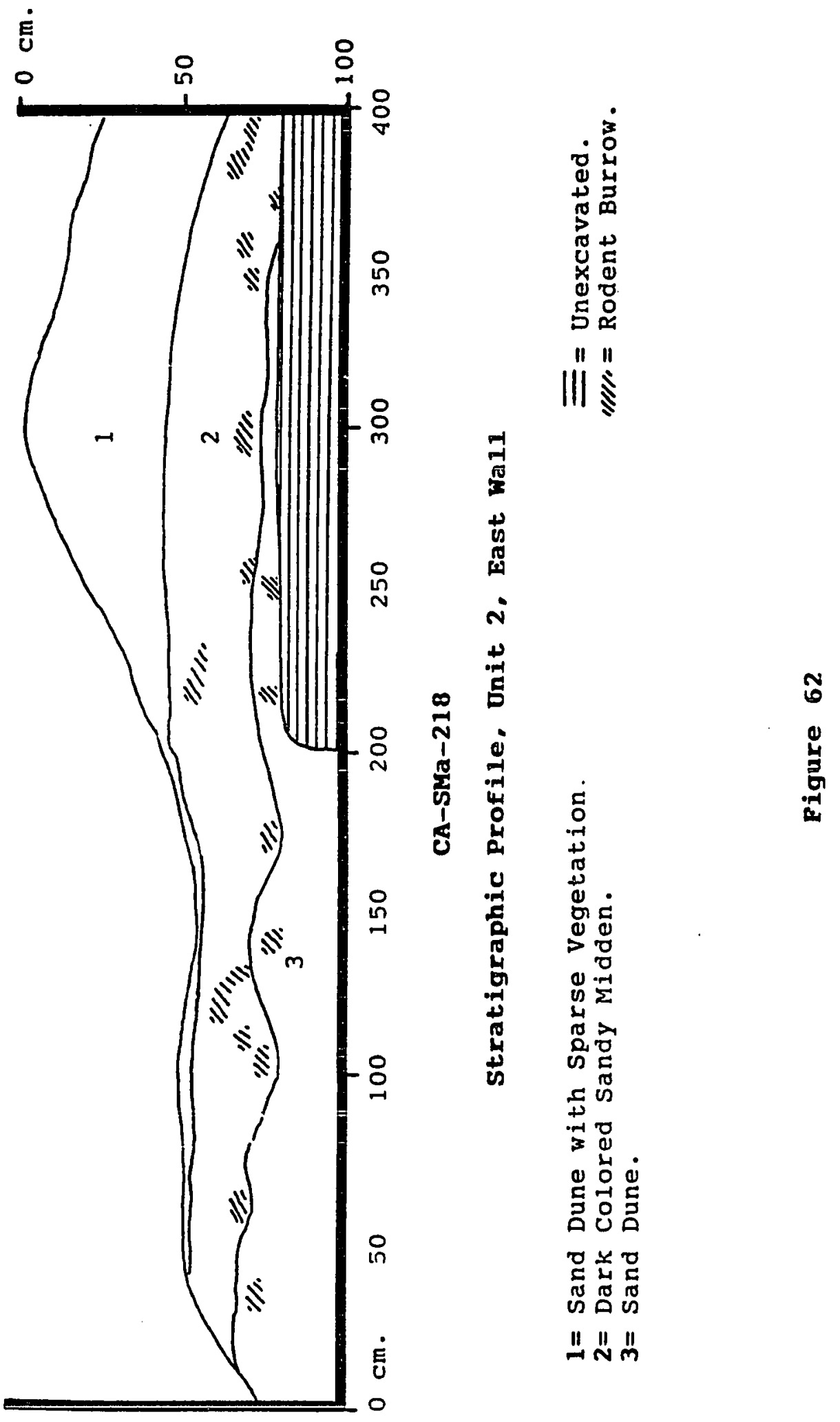



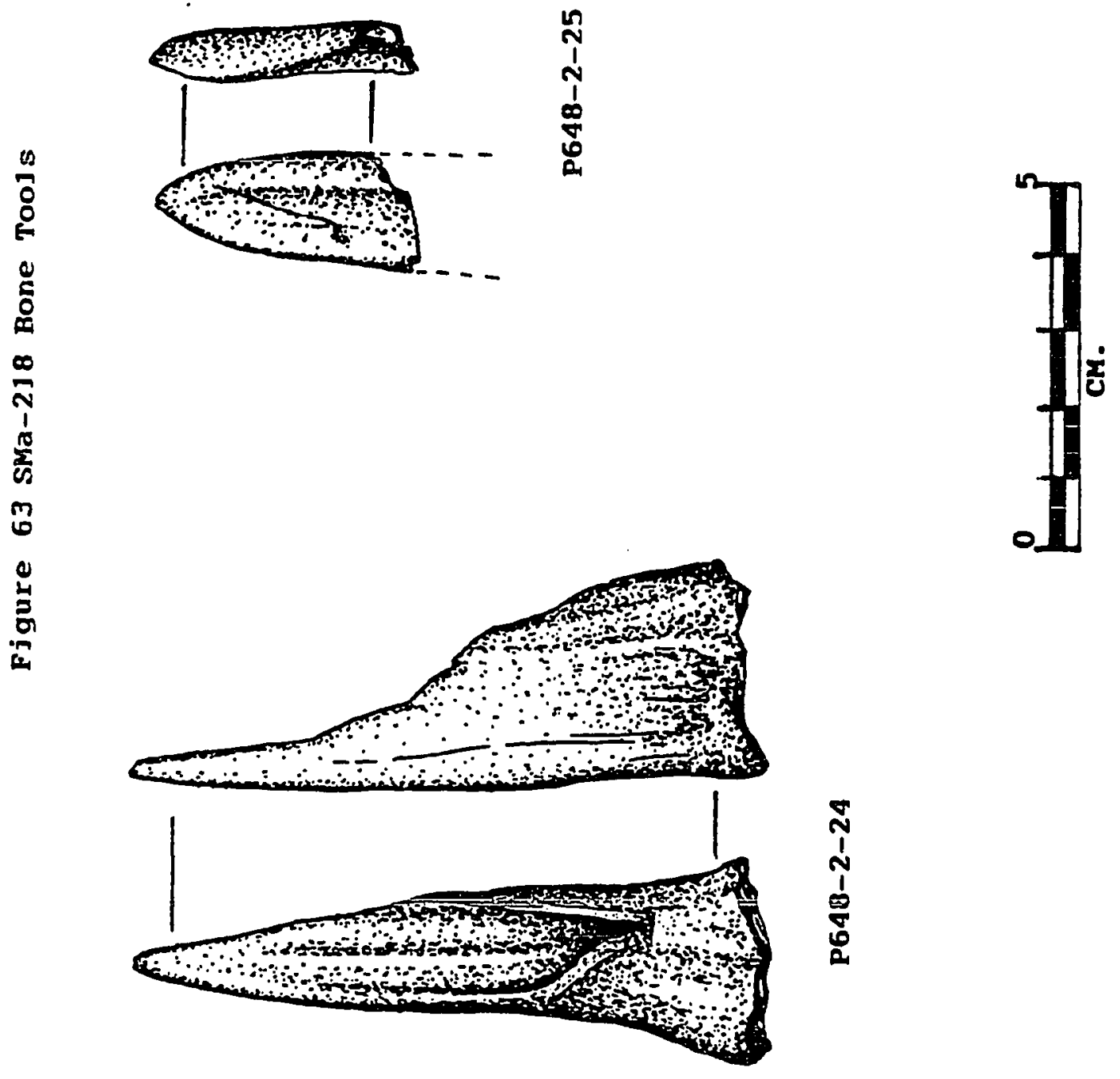


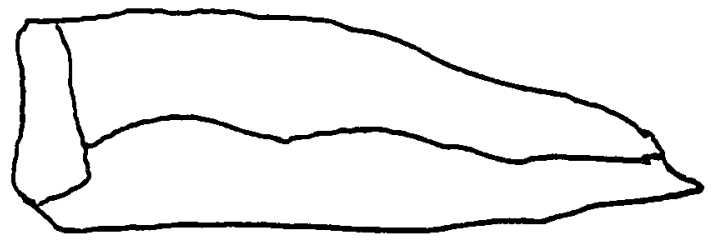

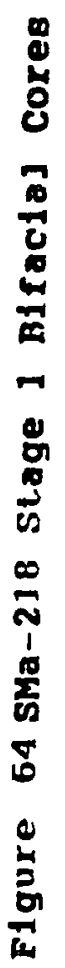

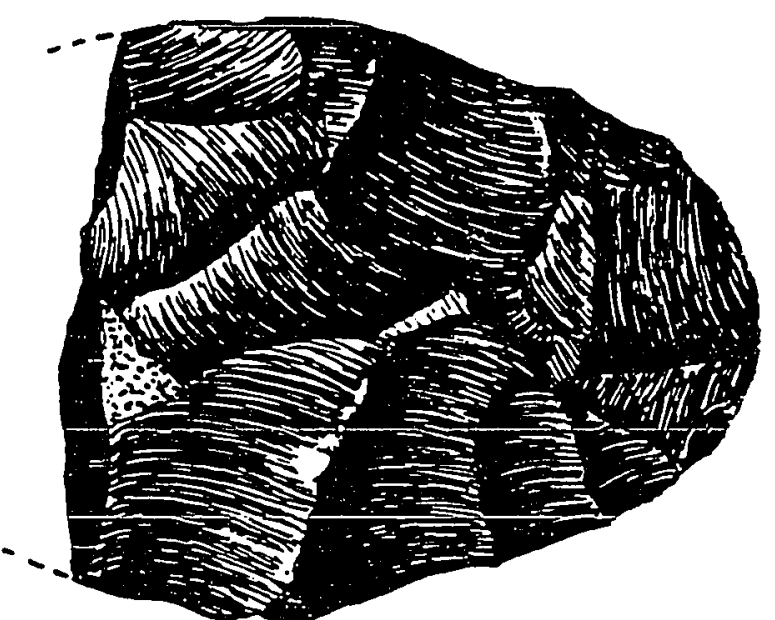

n
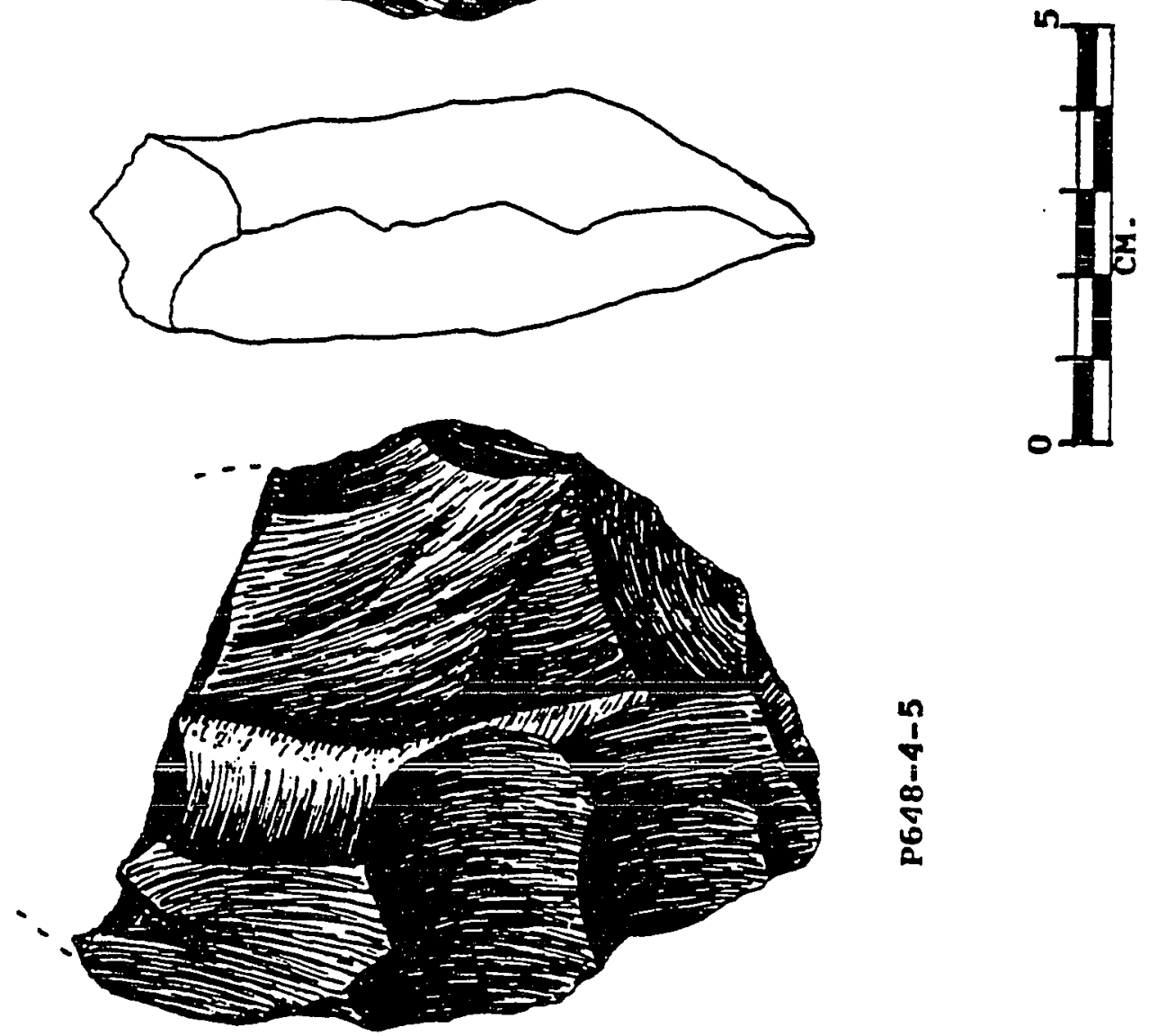


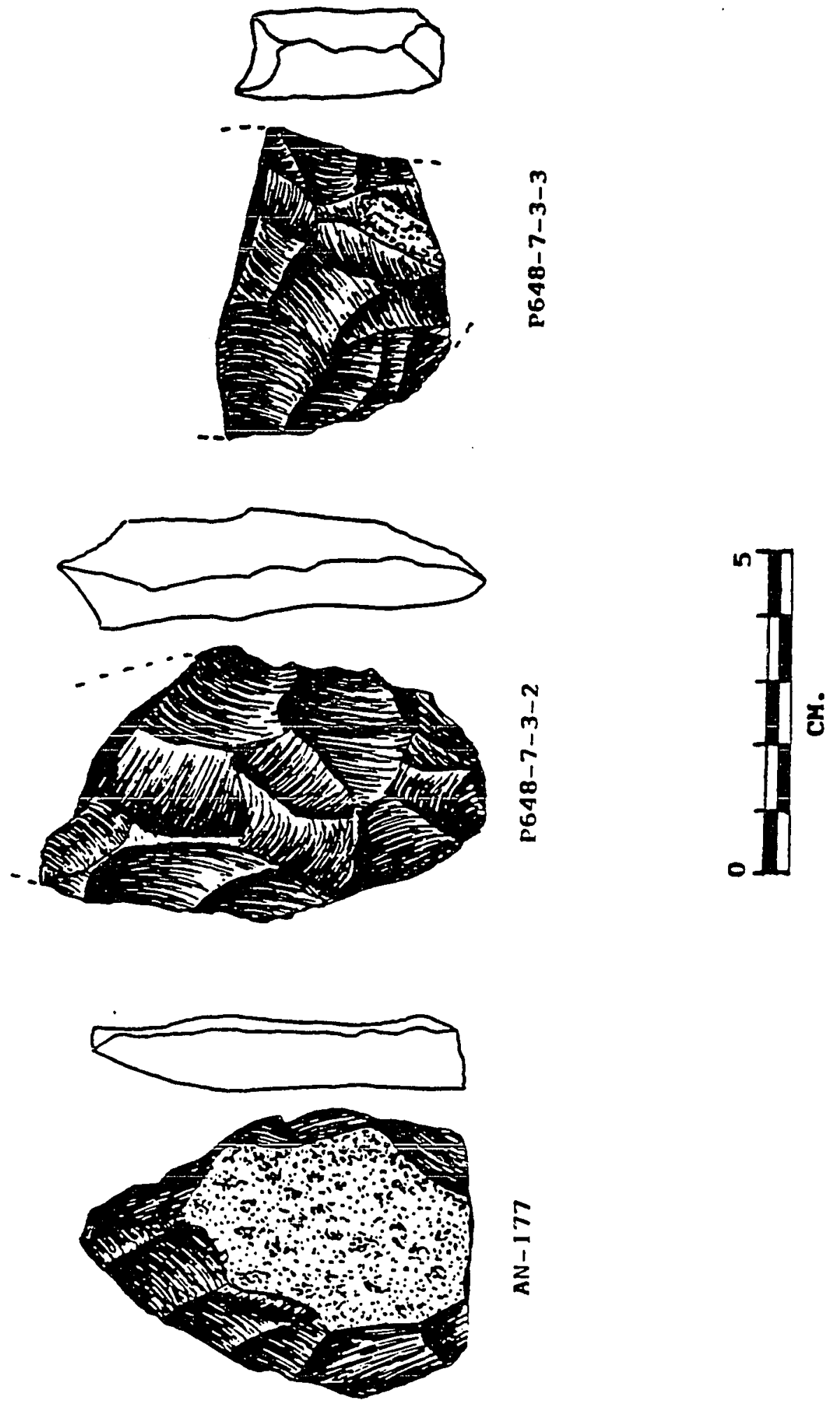



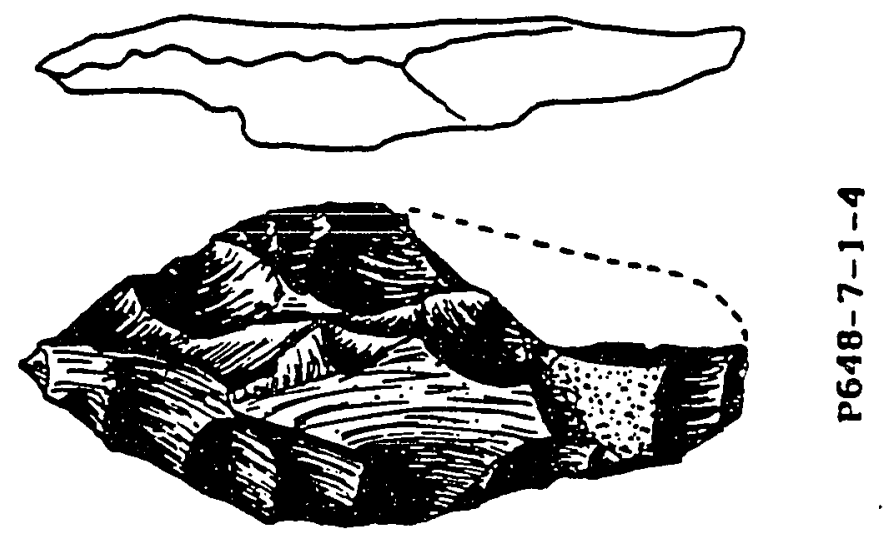


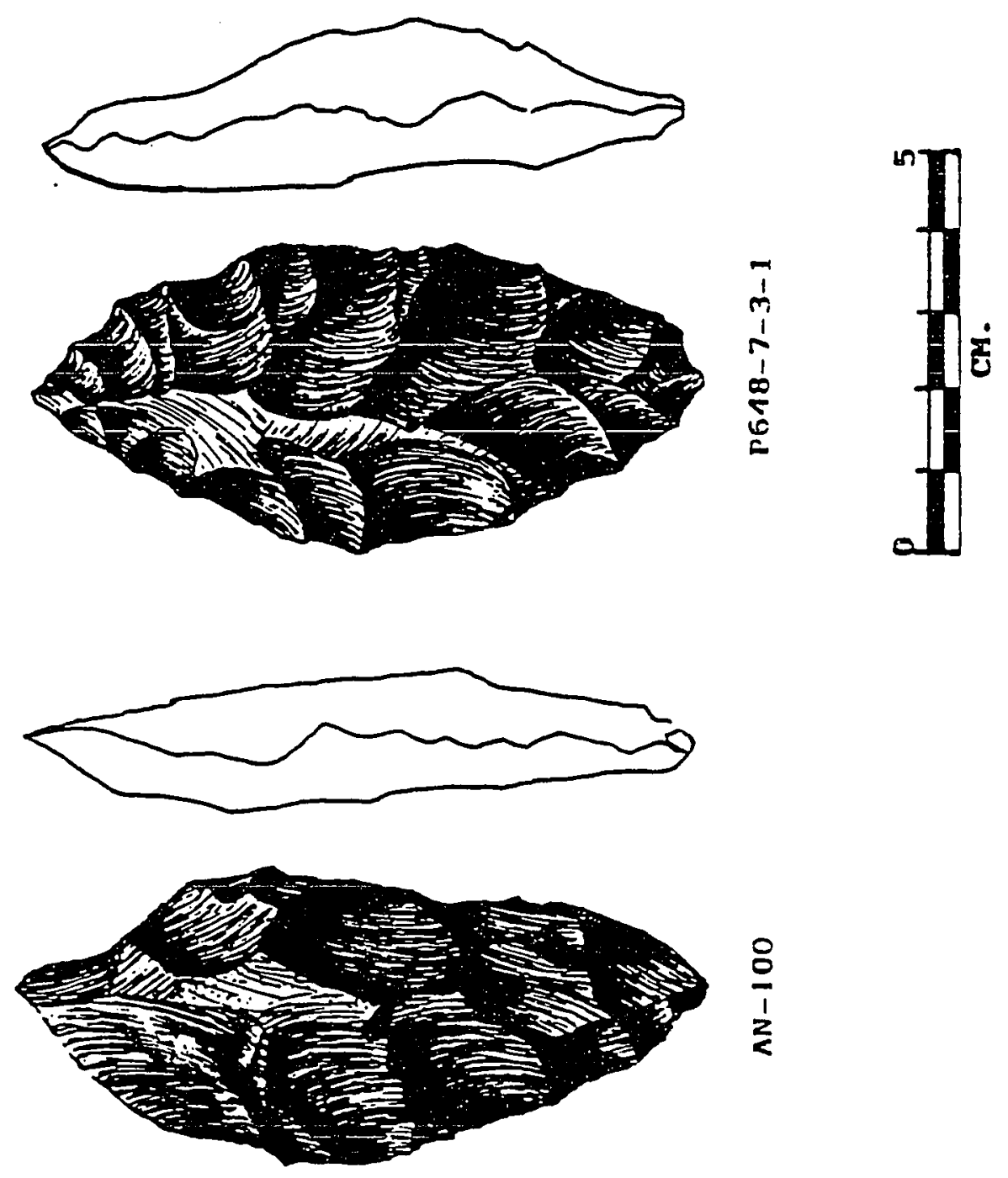

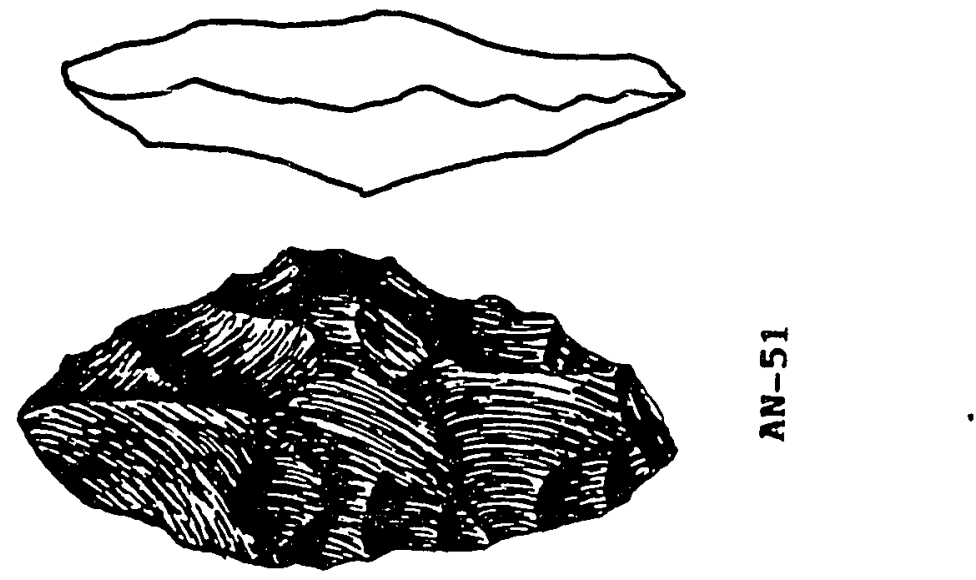


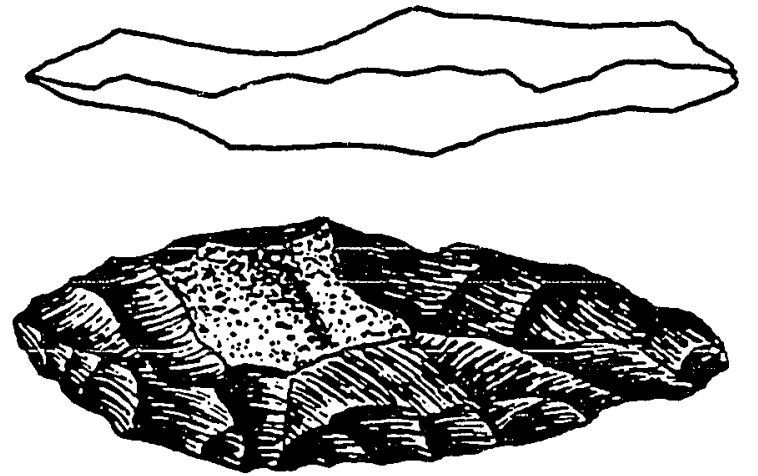

0
0
1
0
0
1
0
0
0
0
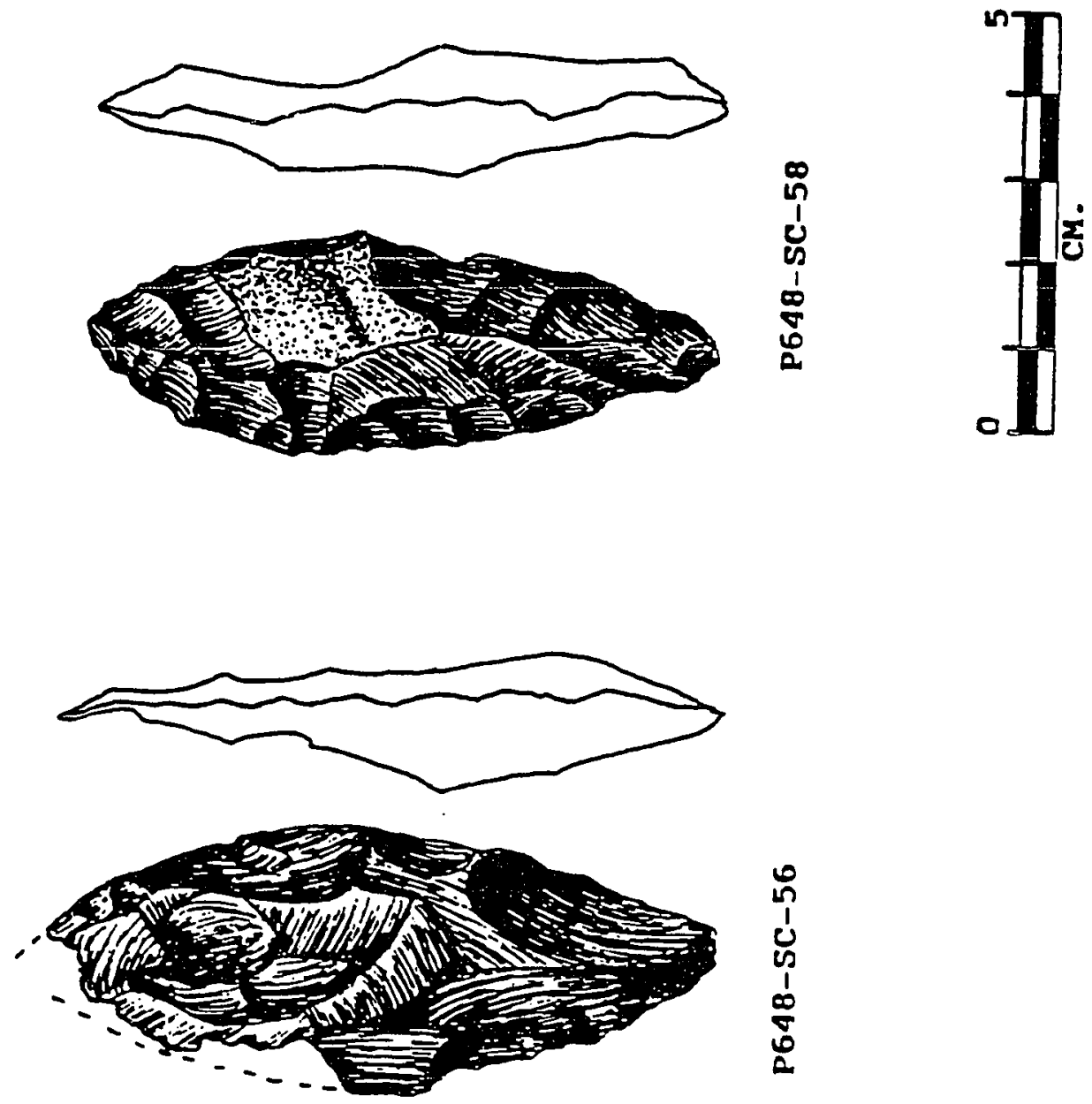

0
1
1
0
1
0
5
0 


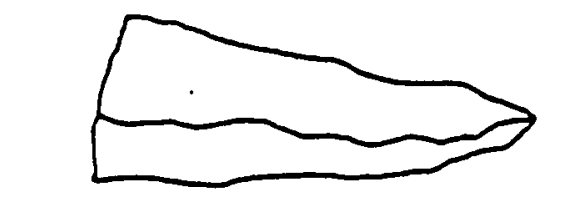

$\infty$
1
$\sim$
0
0
0
0

告
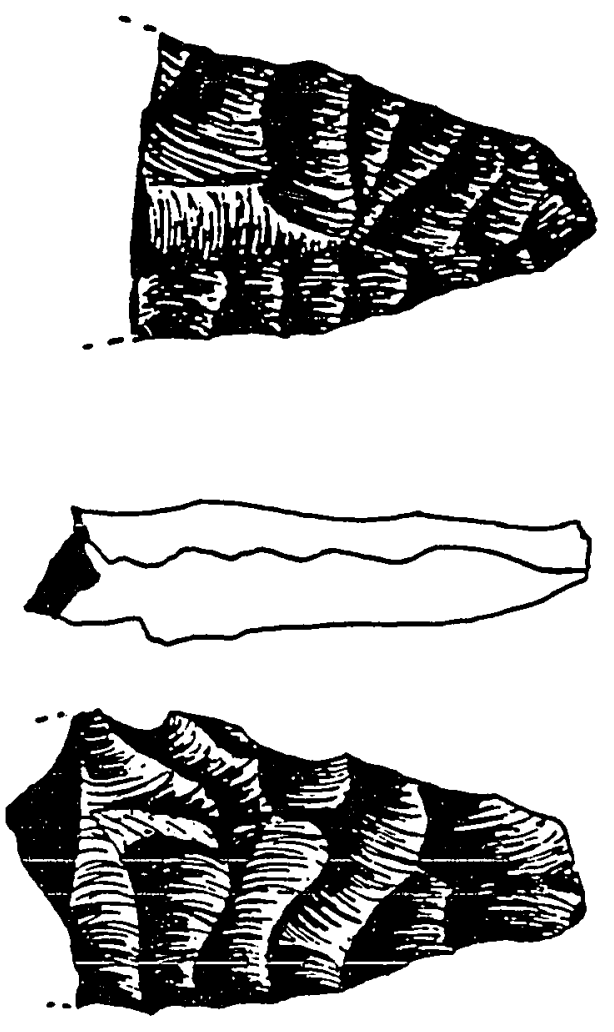

$n$
1
1
1
0
0
0
2
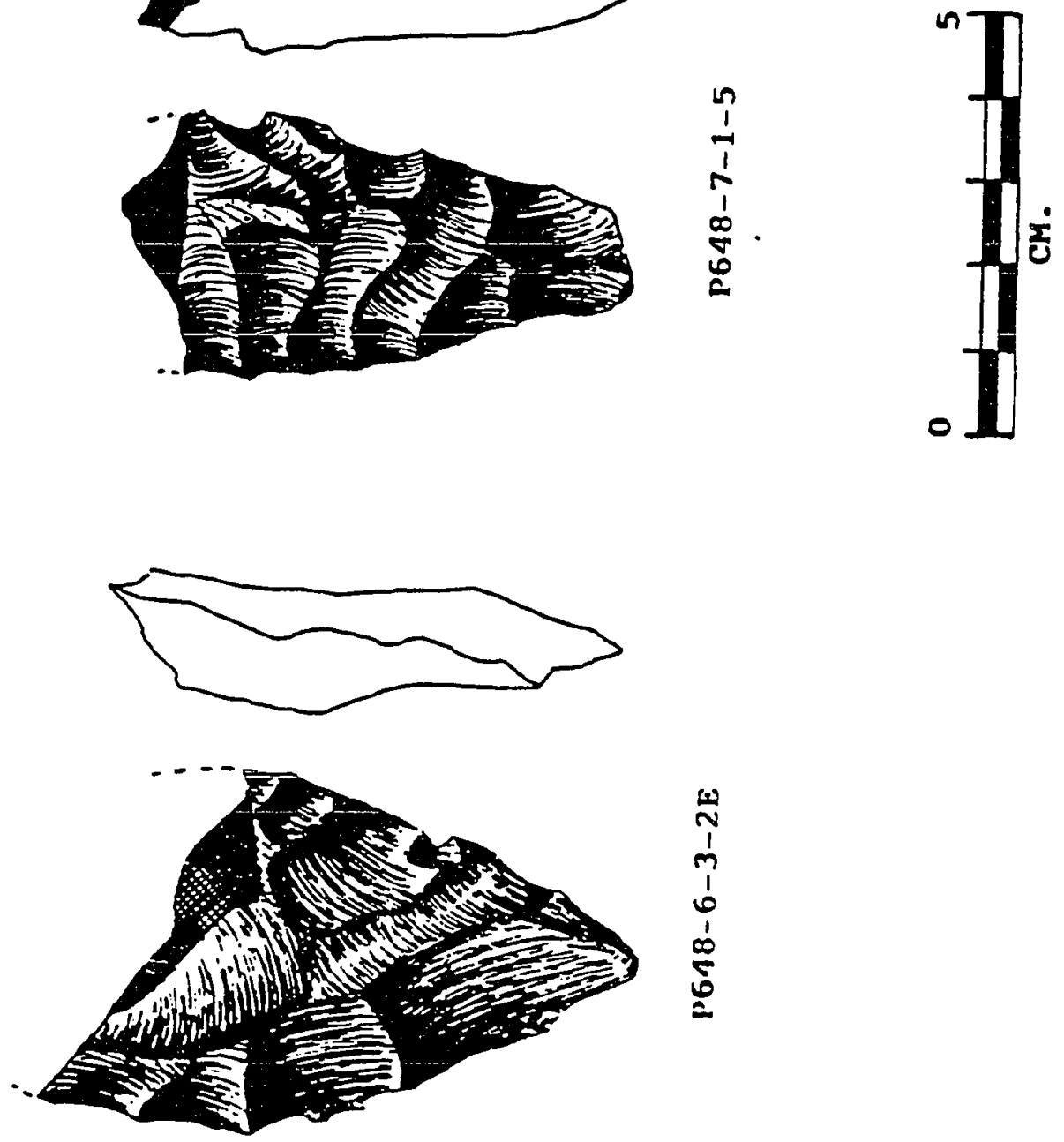

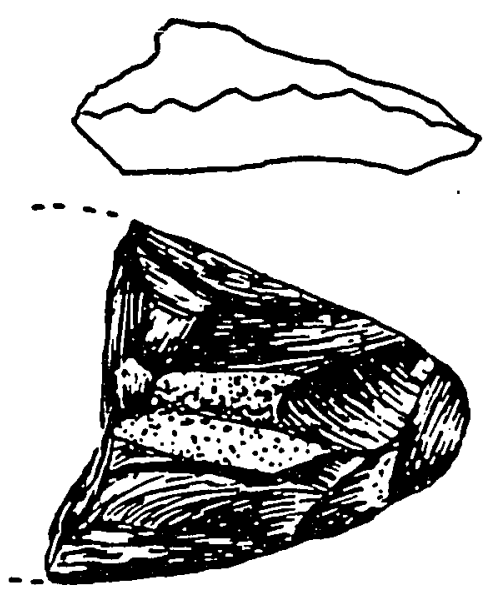

0
1
1
1
0
0
0
0
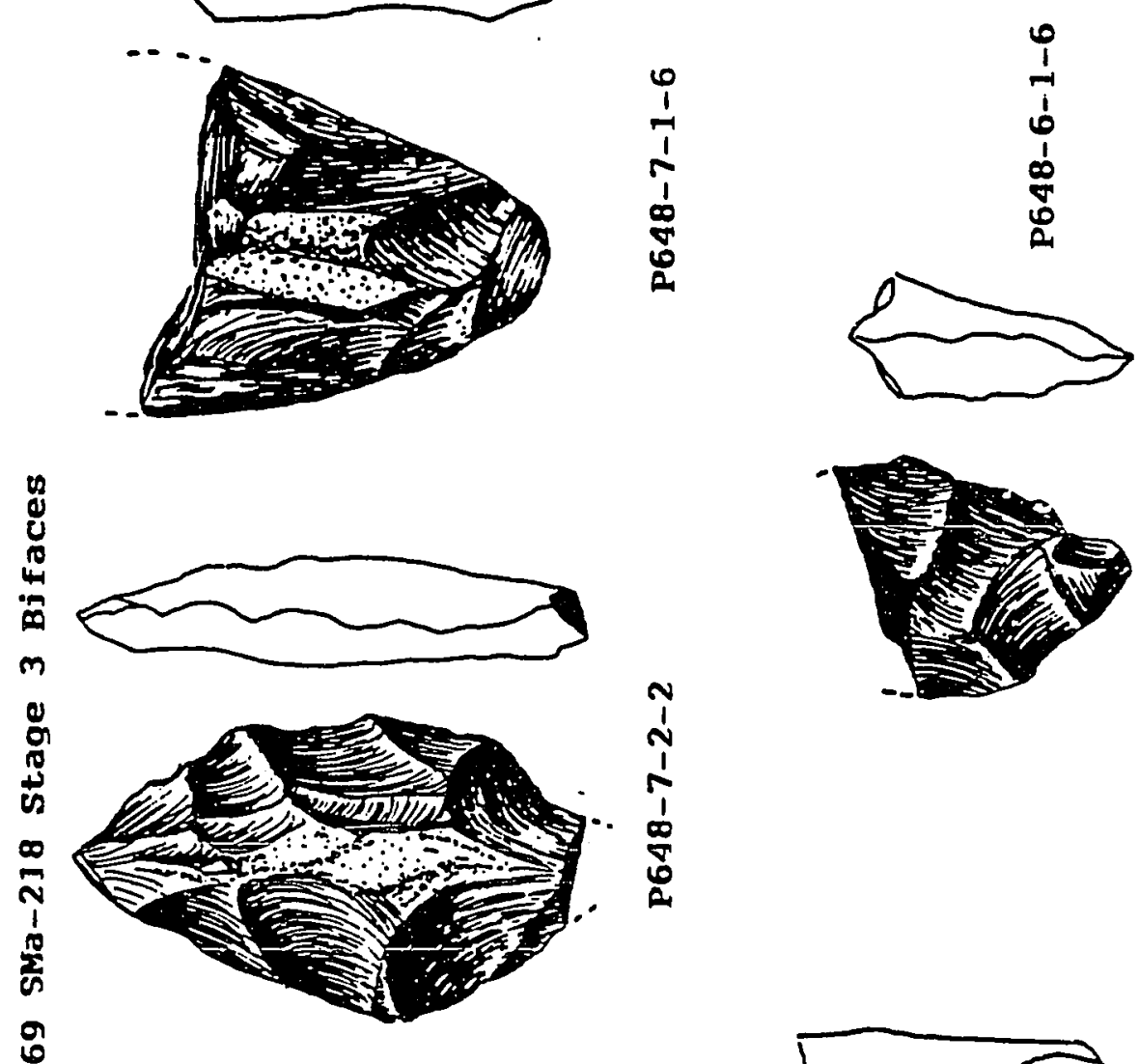

$N$
1
1
1
1
0
0
0
0
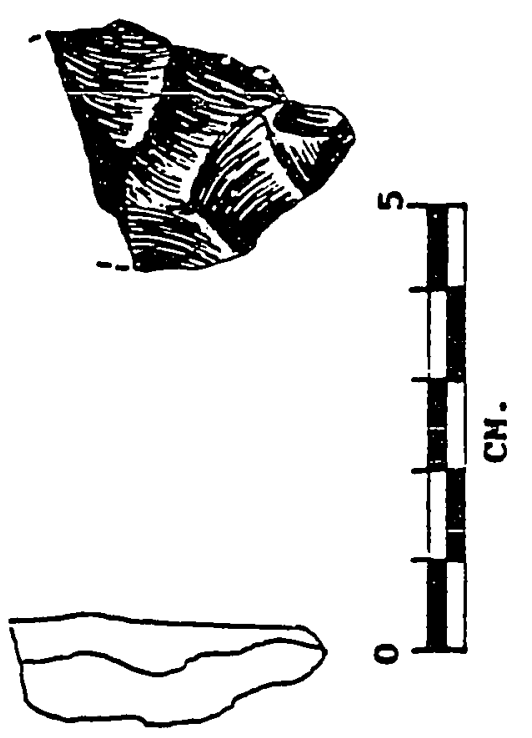

들
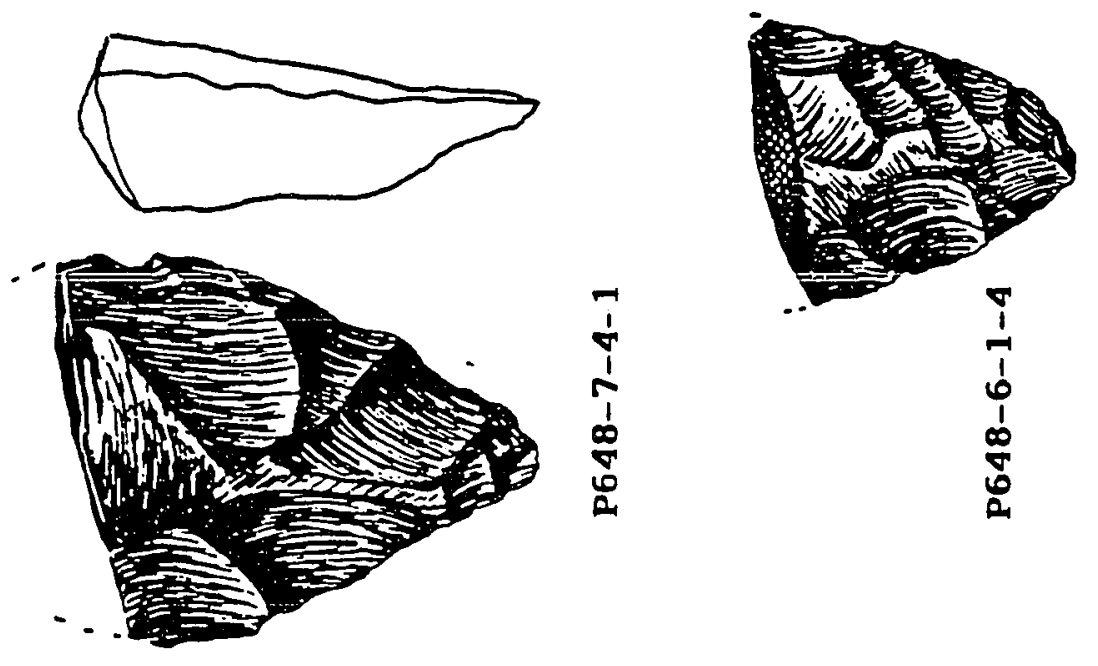

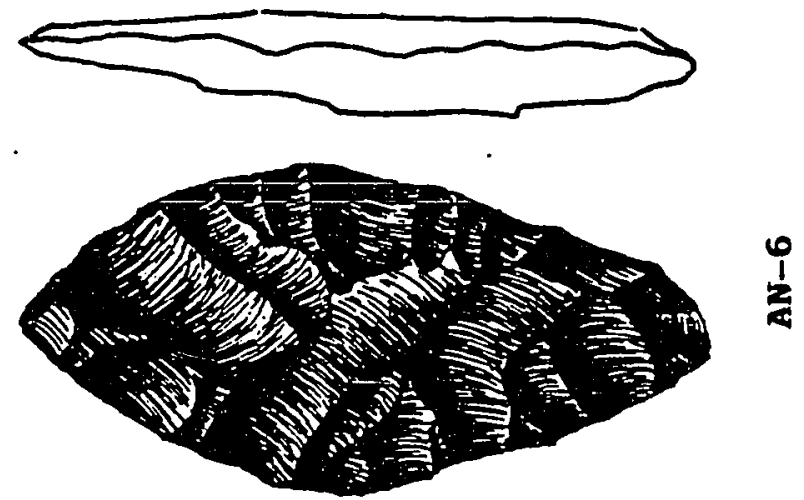

是
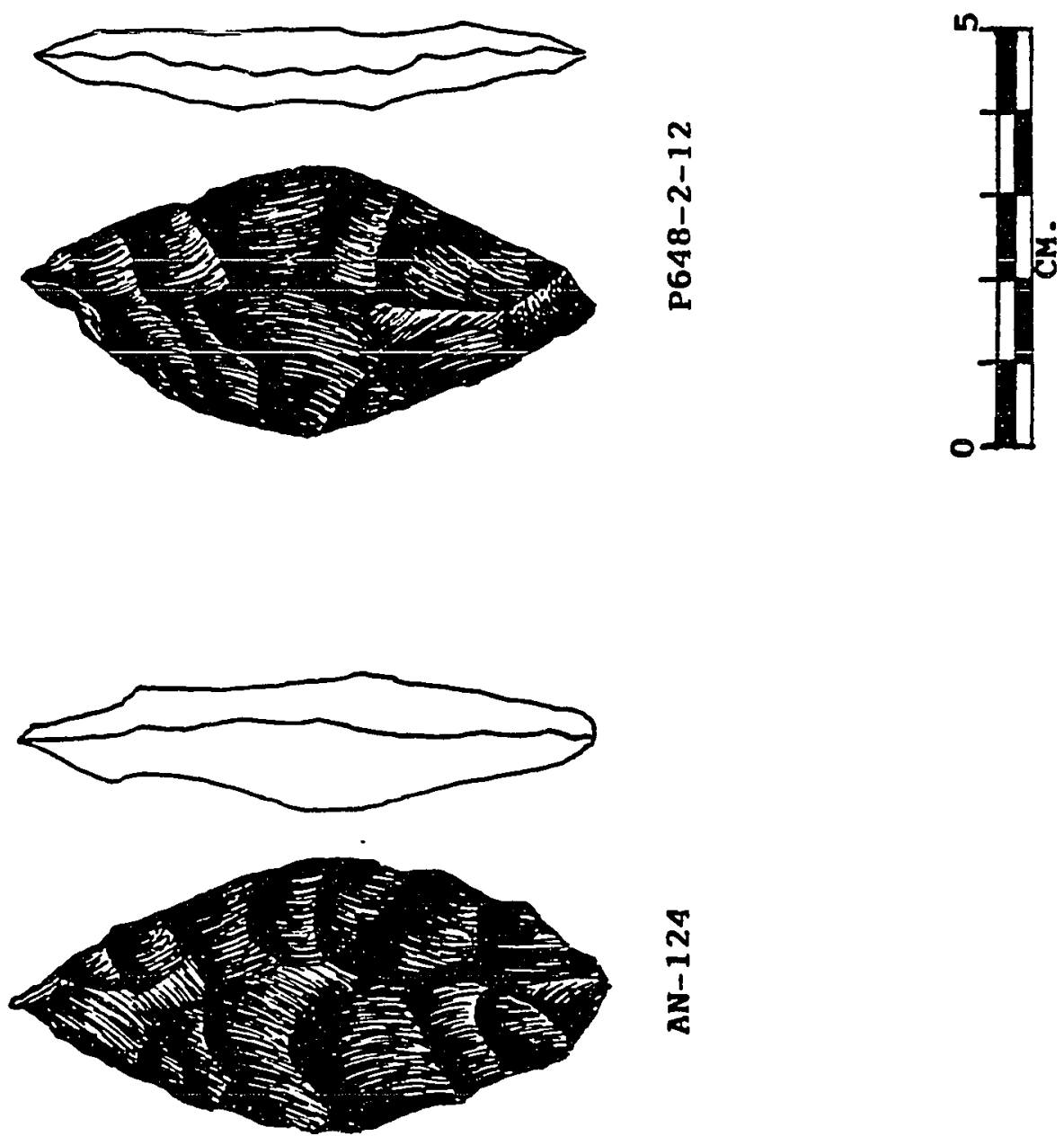

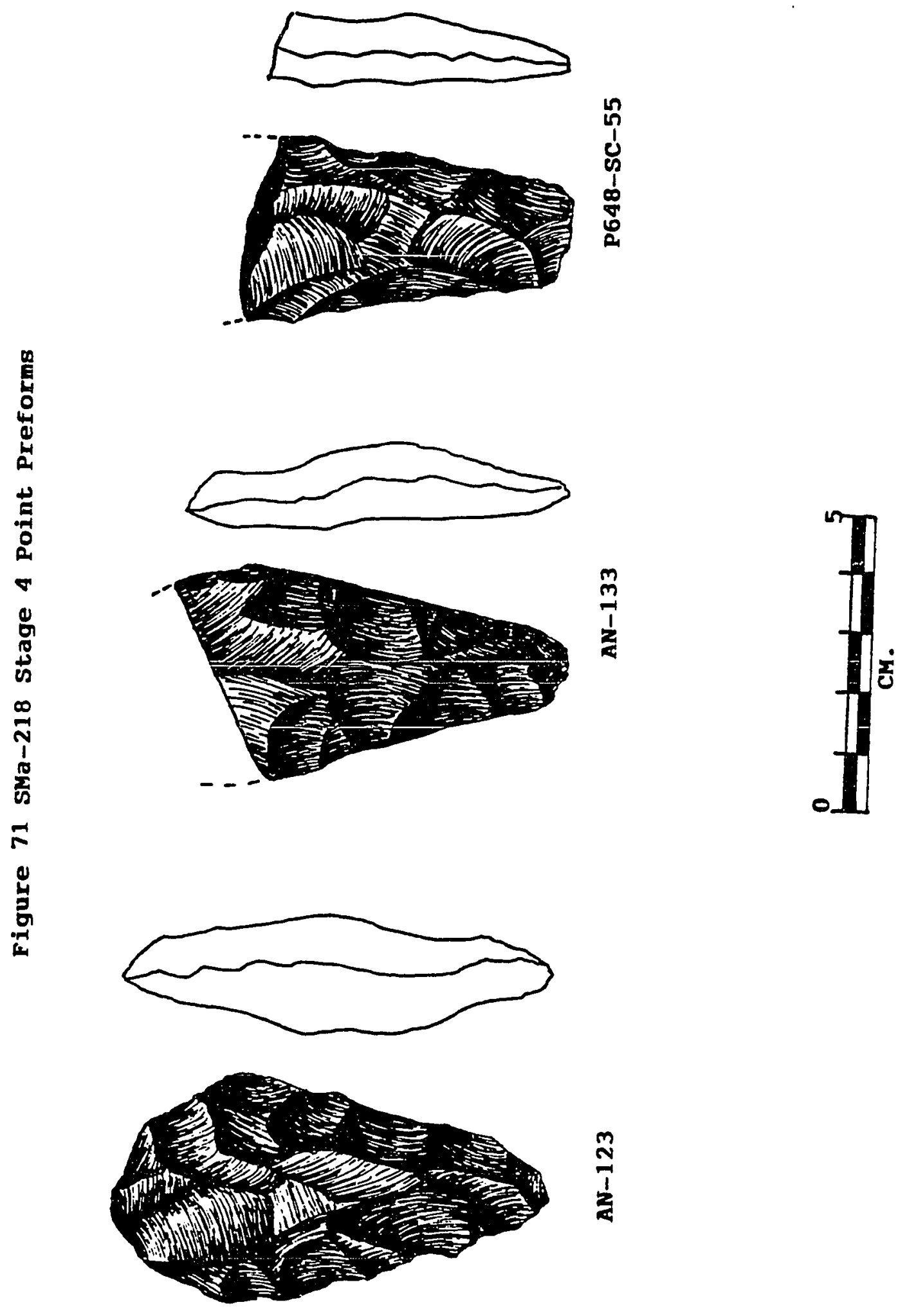

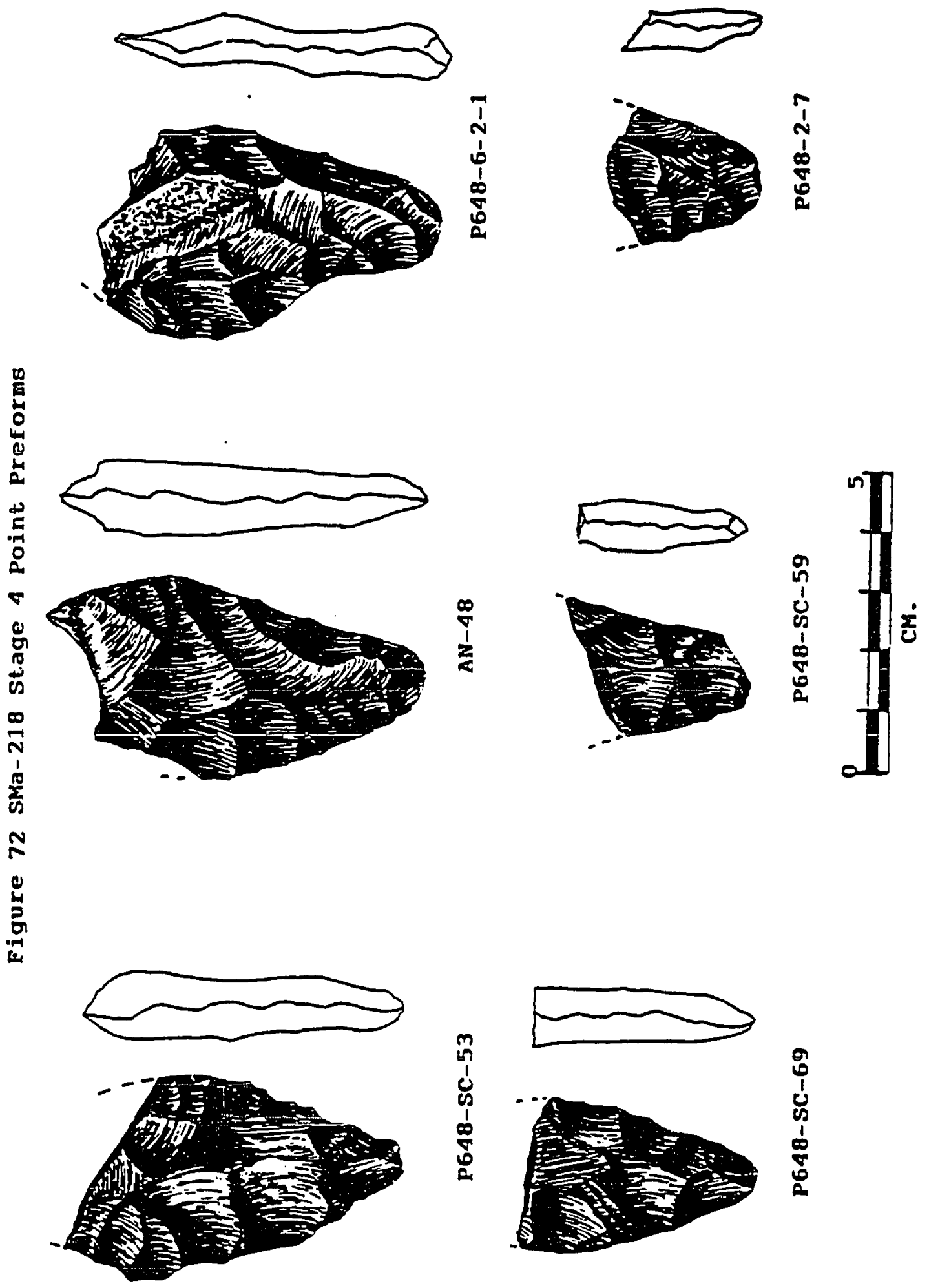


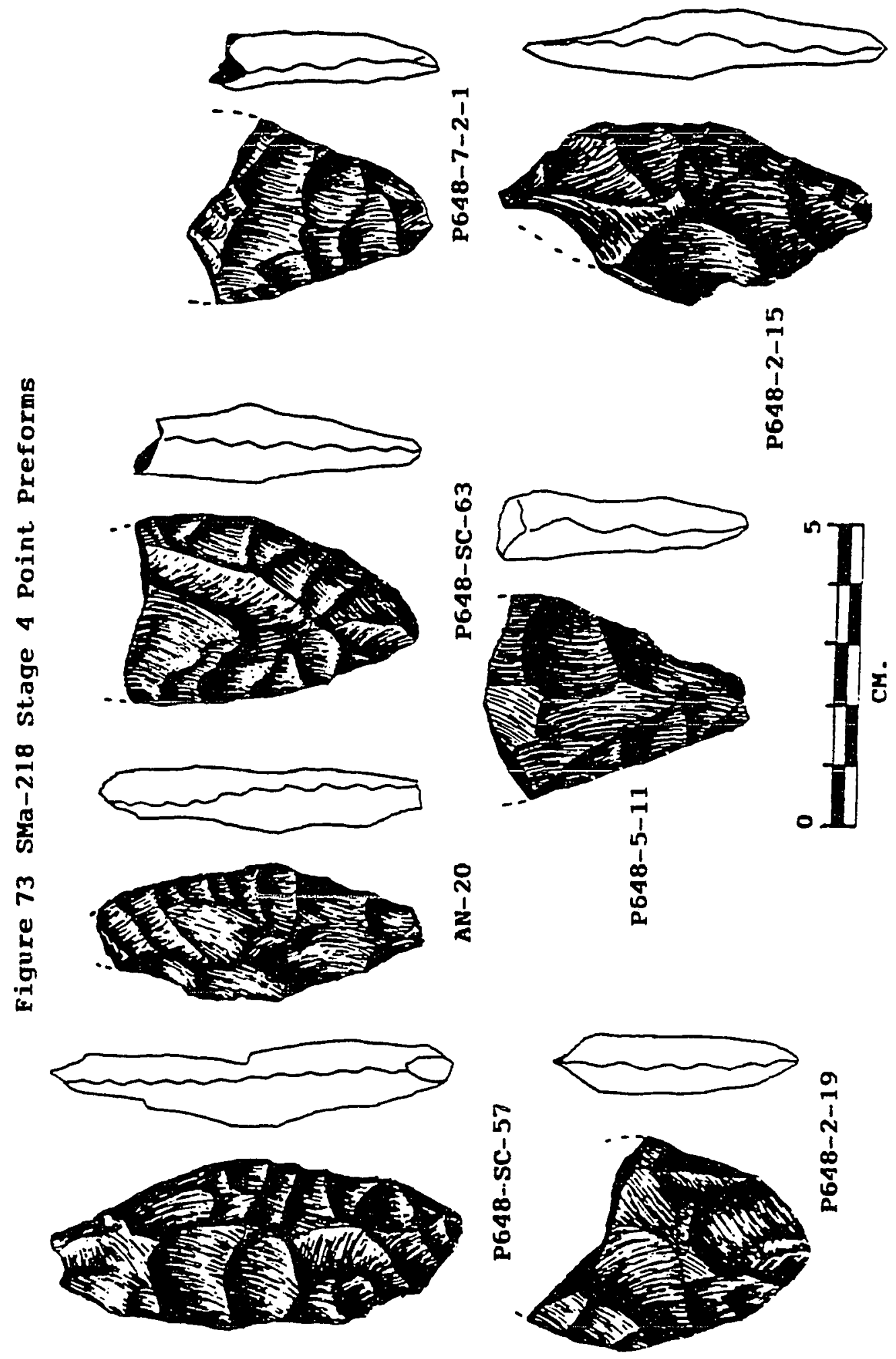



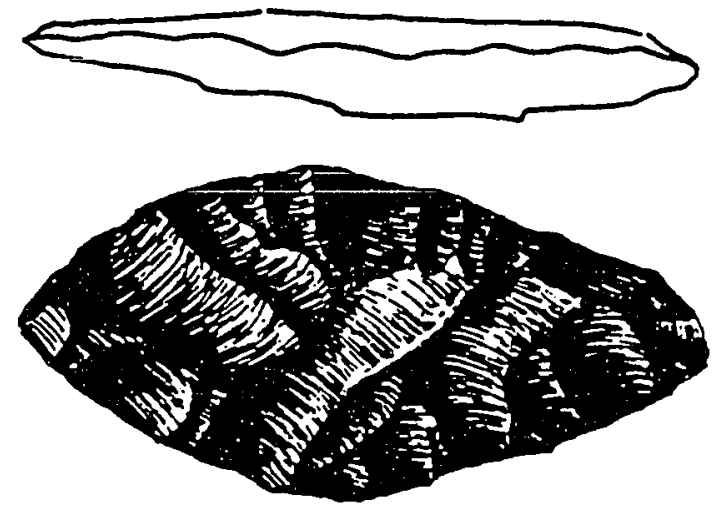

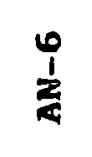

告
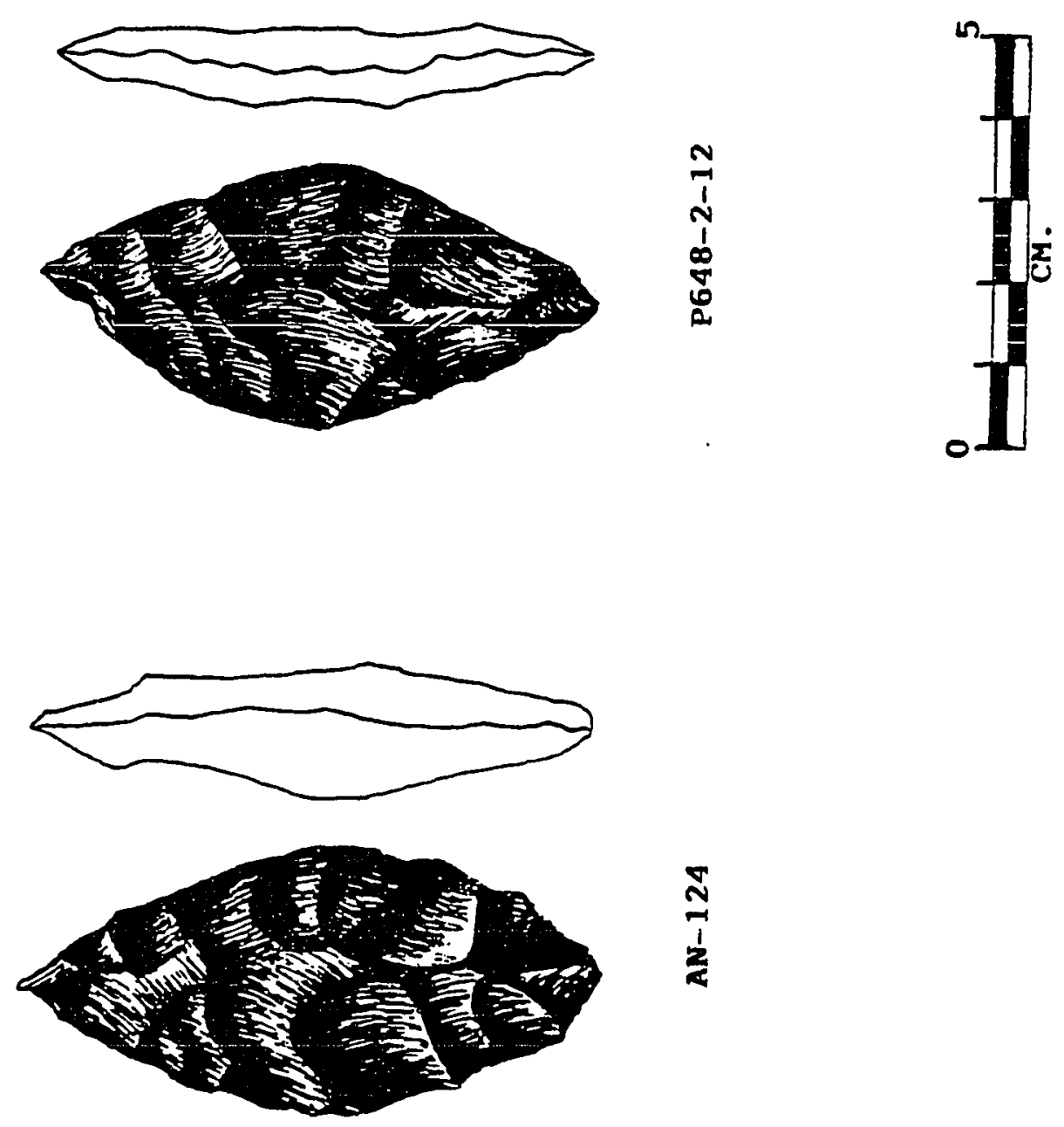


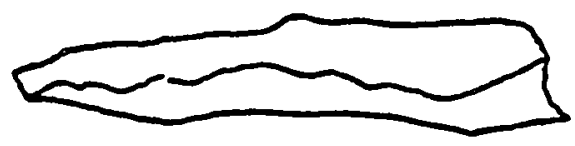

告
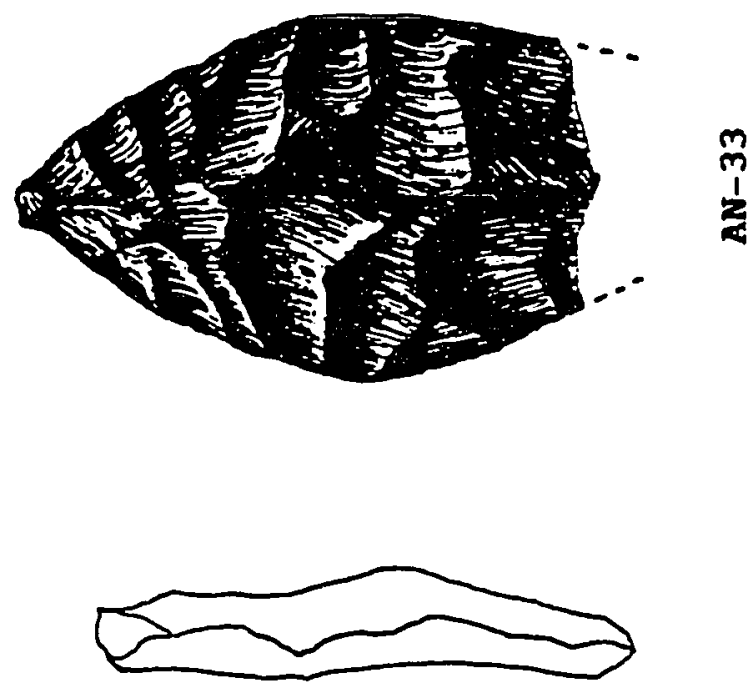

$m$

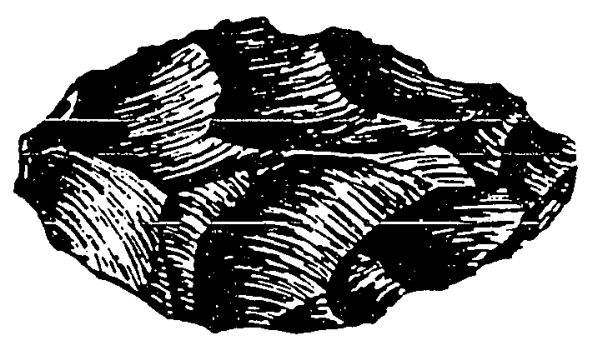

1
1
1
1
1
0
0
0
0
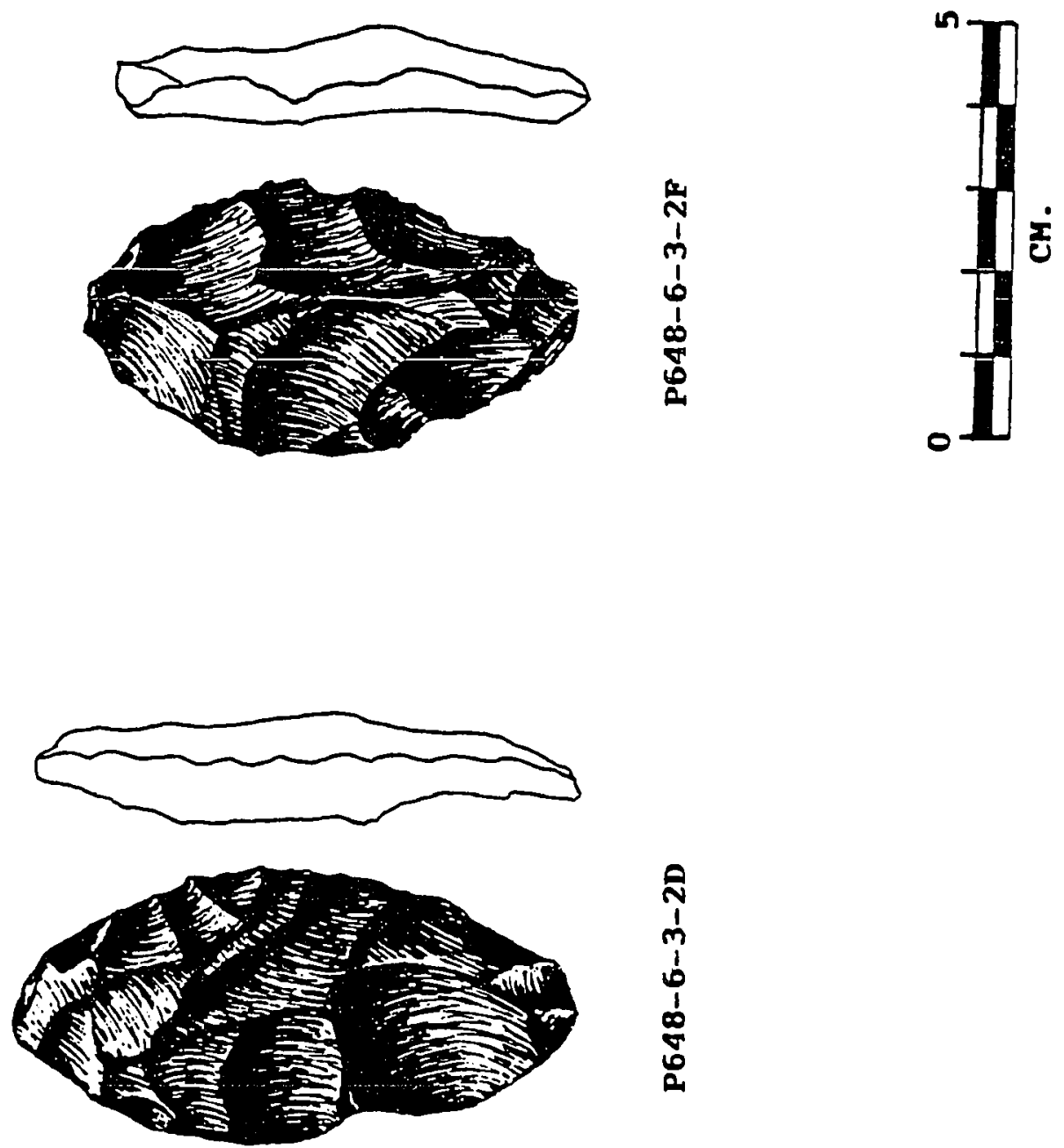

$a$
1
1
$b$
1
0
0
0 

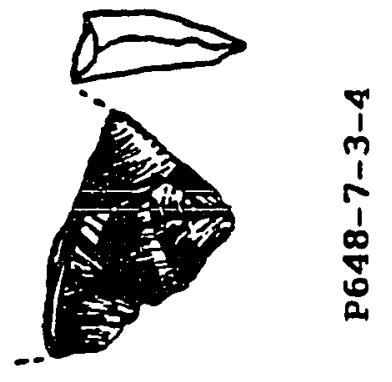

是
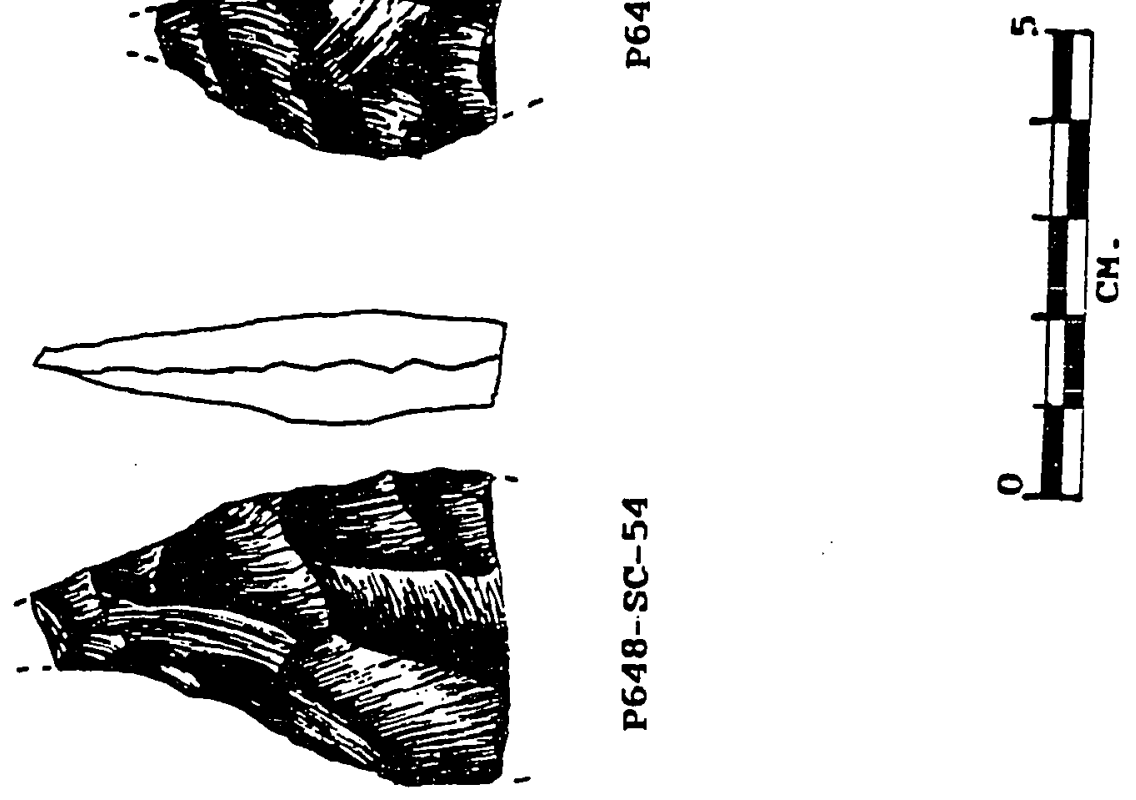

\begin{tabular}{l}
\multirow{0}{0}{} \\
1 \\
0 \\
1 \\
1 \\
0 \\
0 \\
0
\end{tabular}

7
1
0
0
$\vdots$
0
0

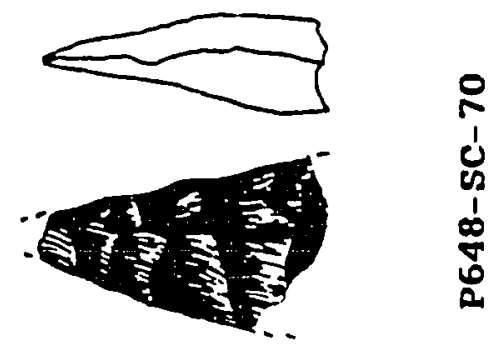


年
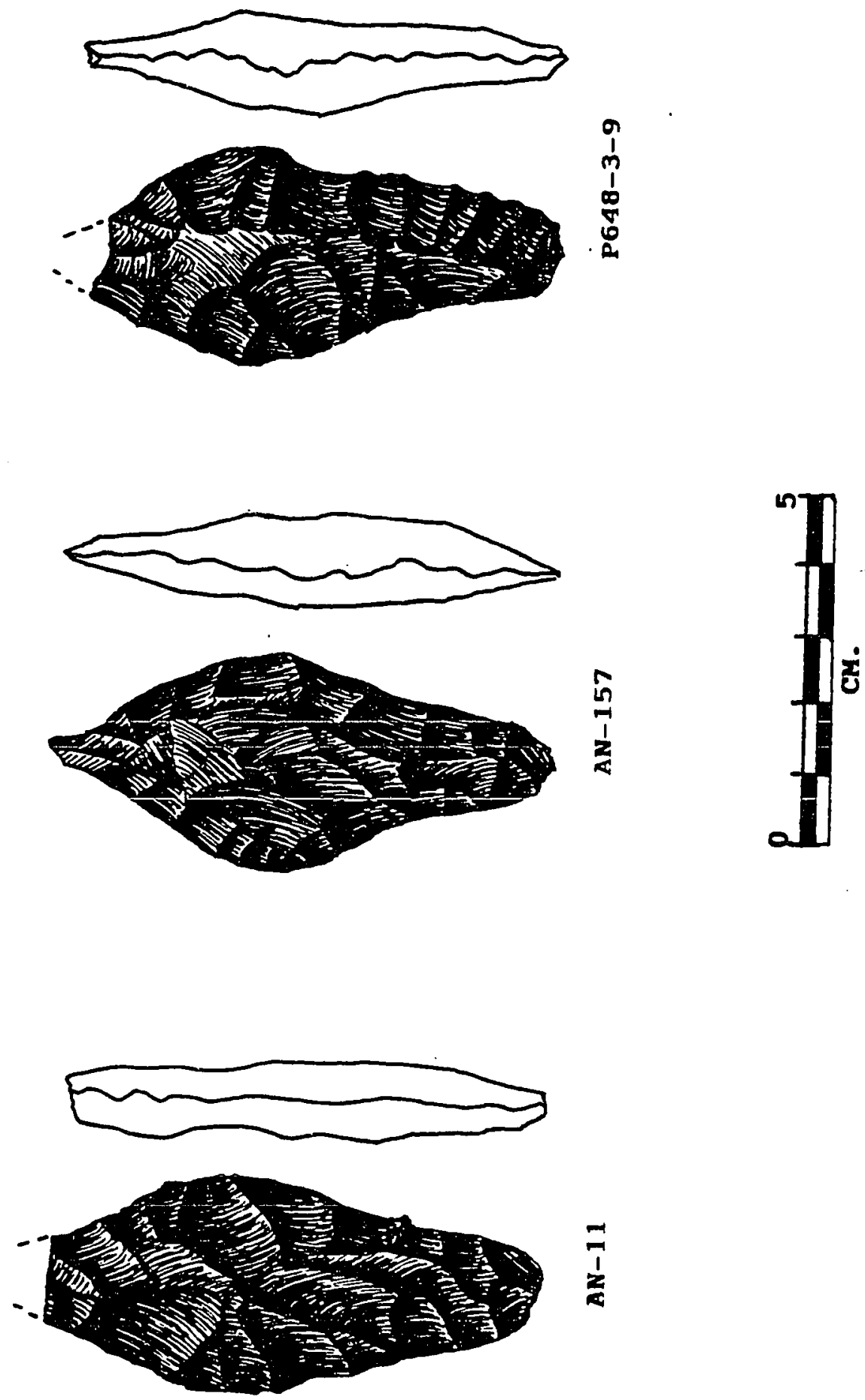

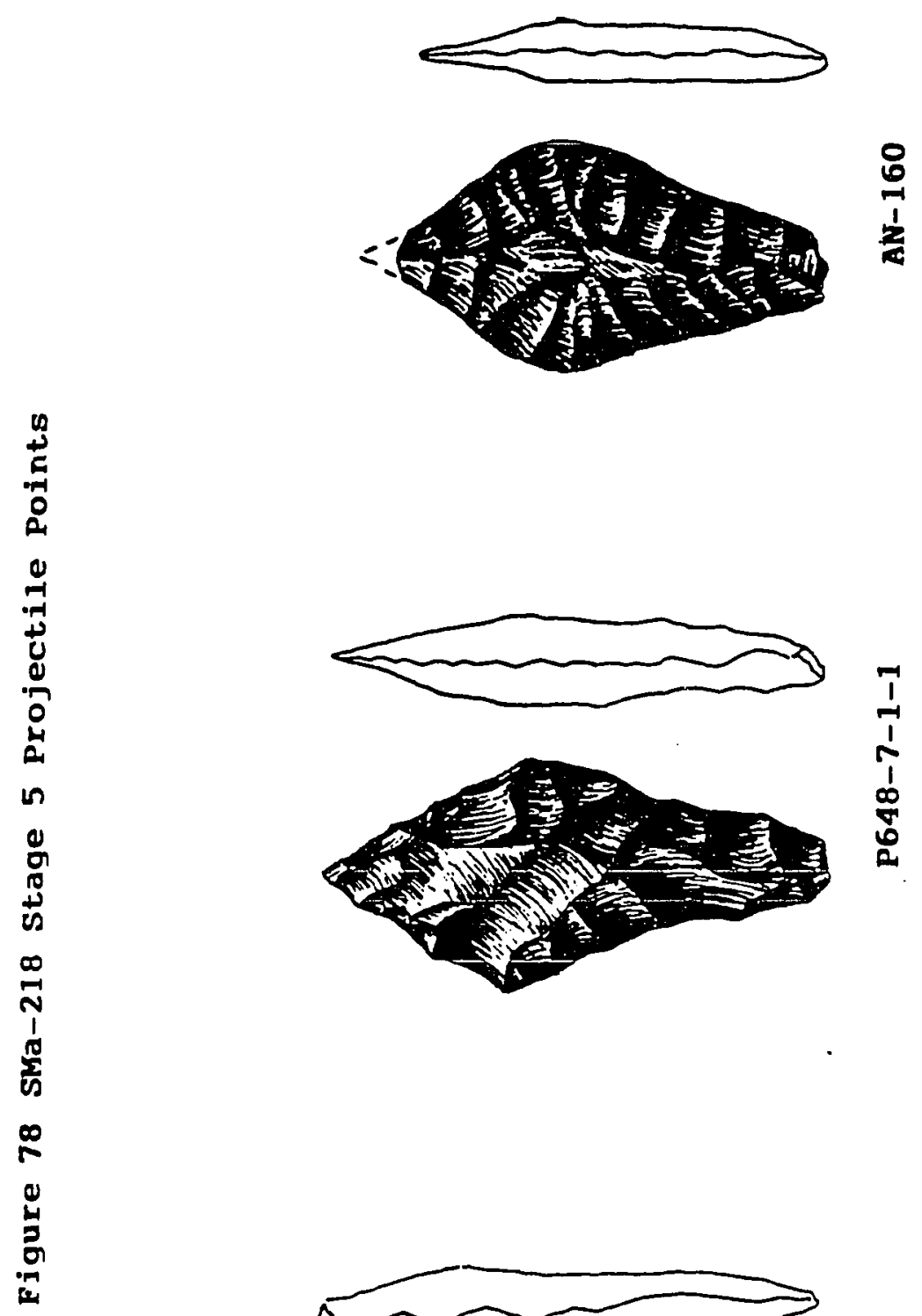

7
1
1
1
0
0
0
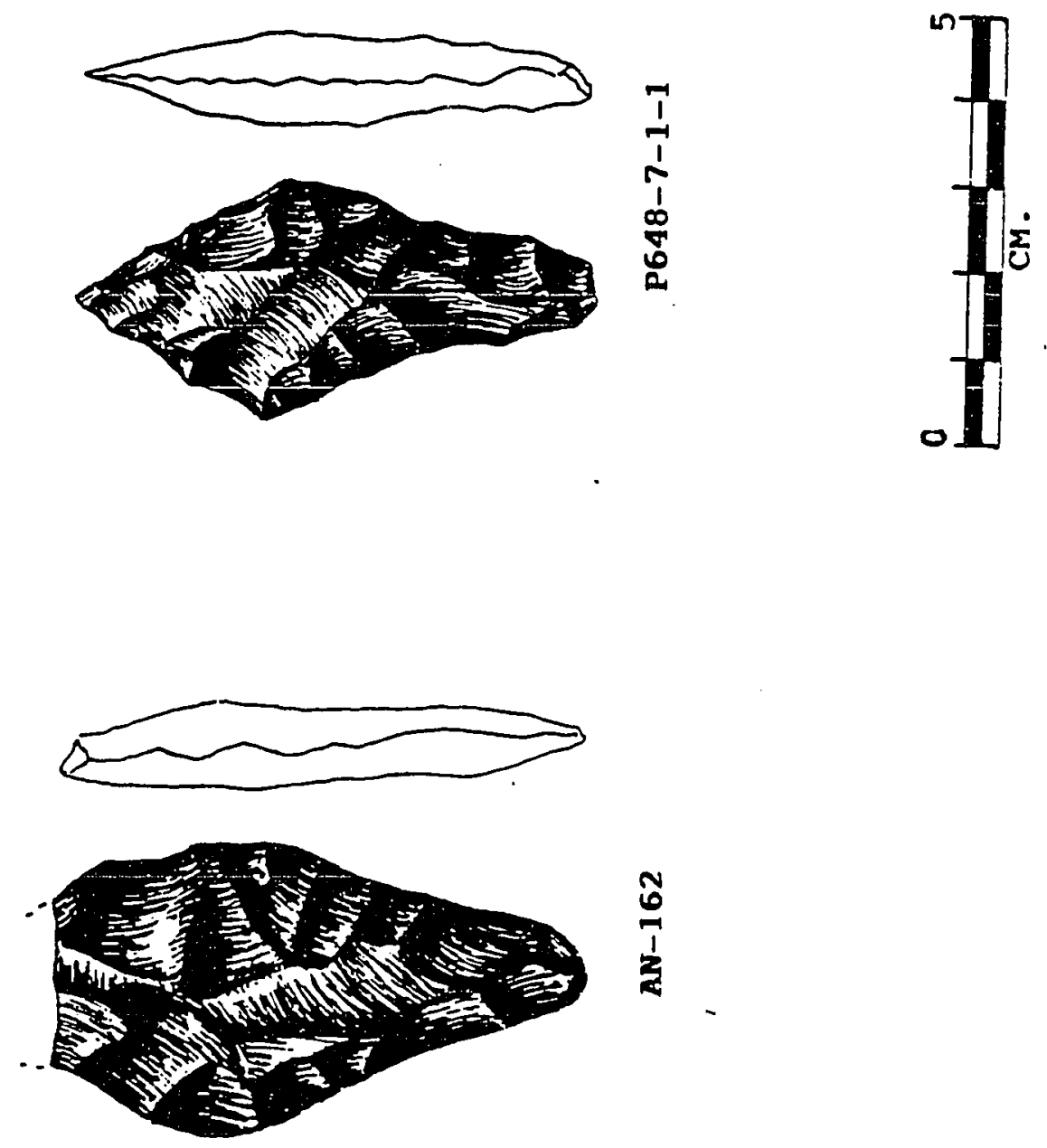

$\mathfrak{6}$
1
1
2 

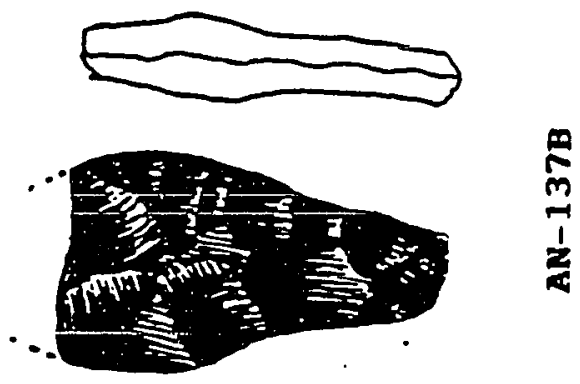

年
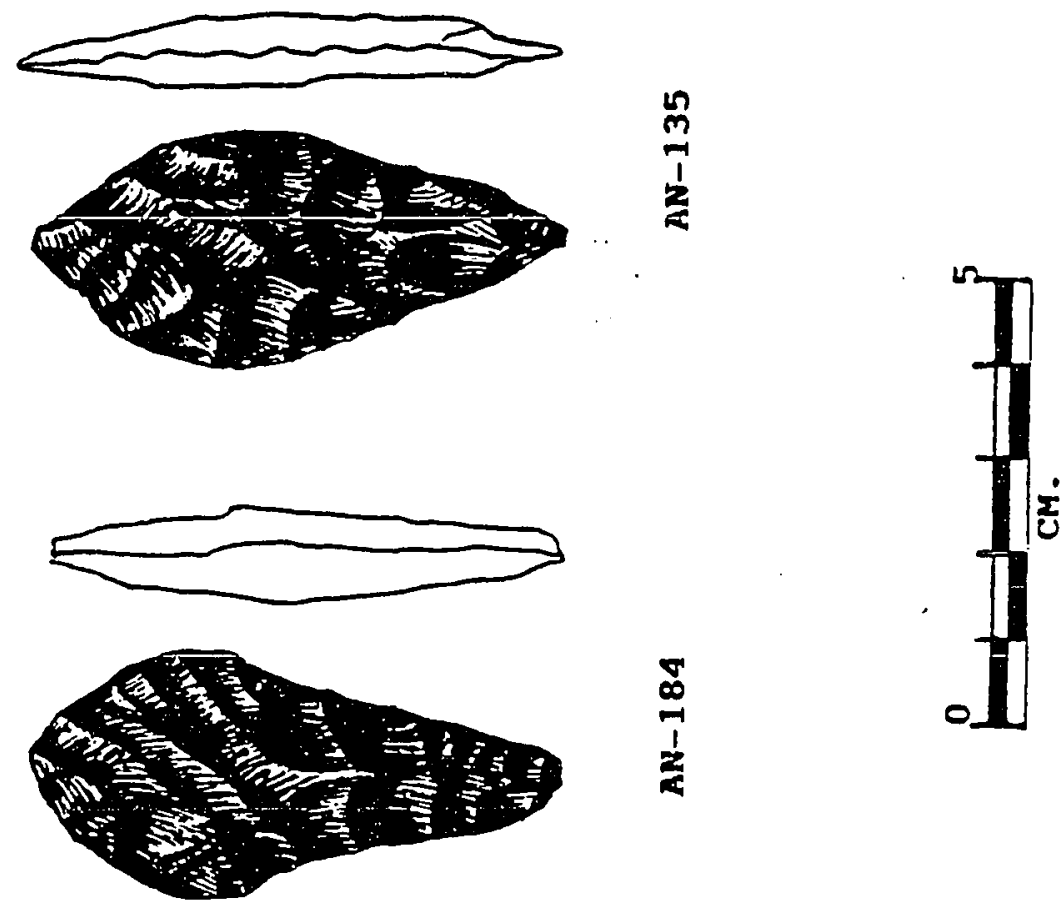

$\frac{1}{2}$

$\frac{1}{n}$

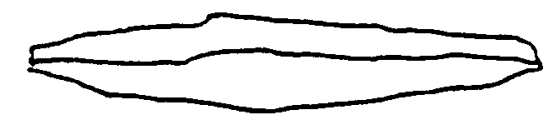

¿্่

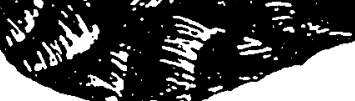



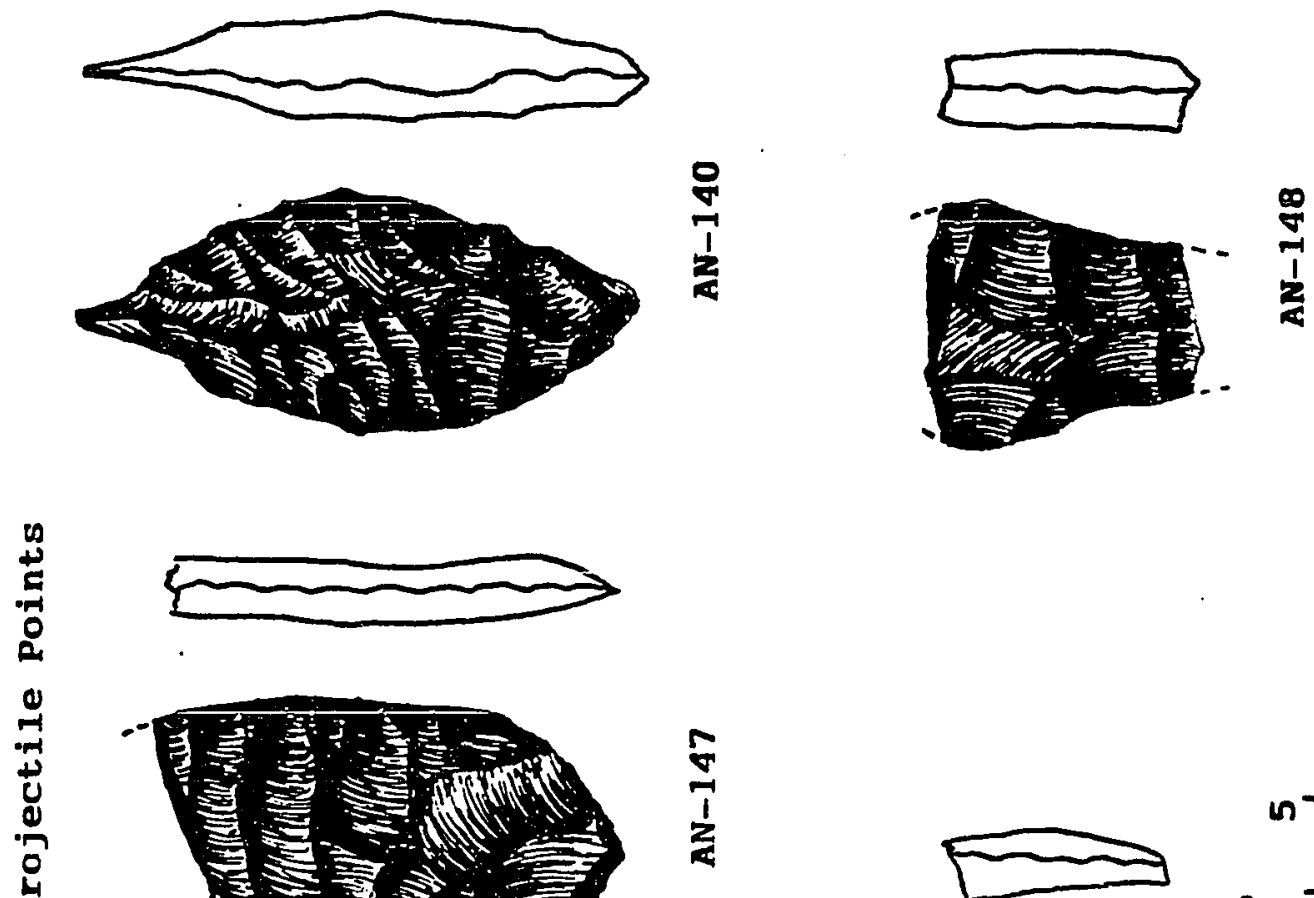

1
$\frac{1}{2}$
2
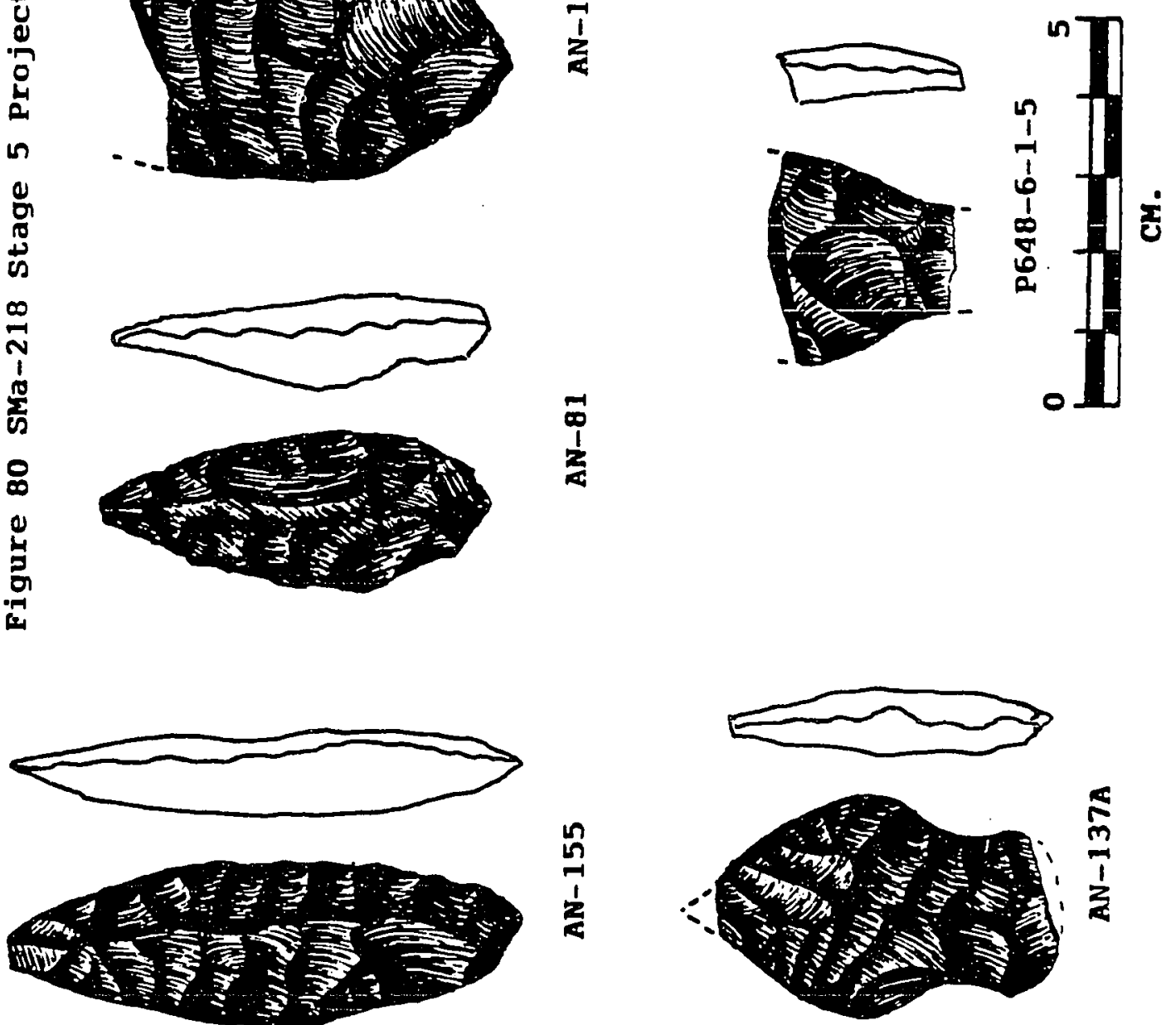

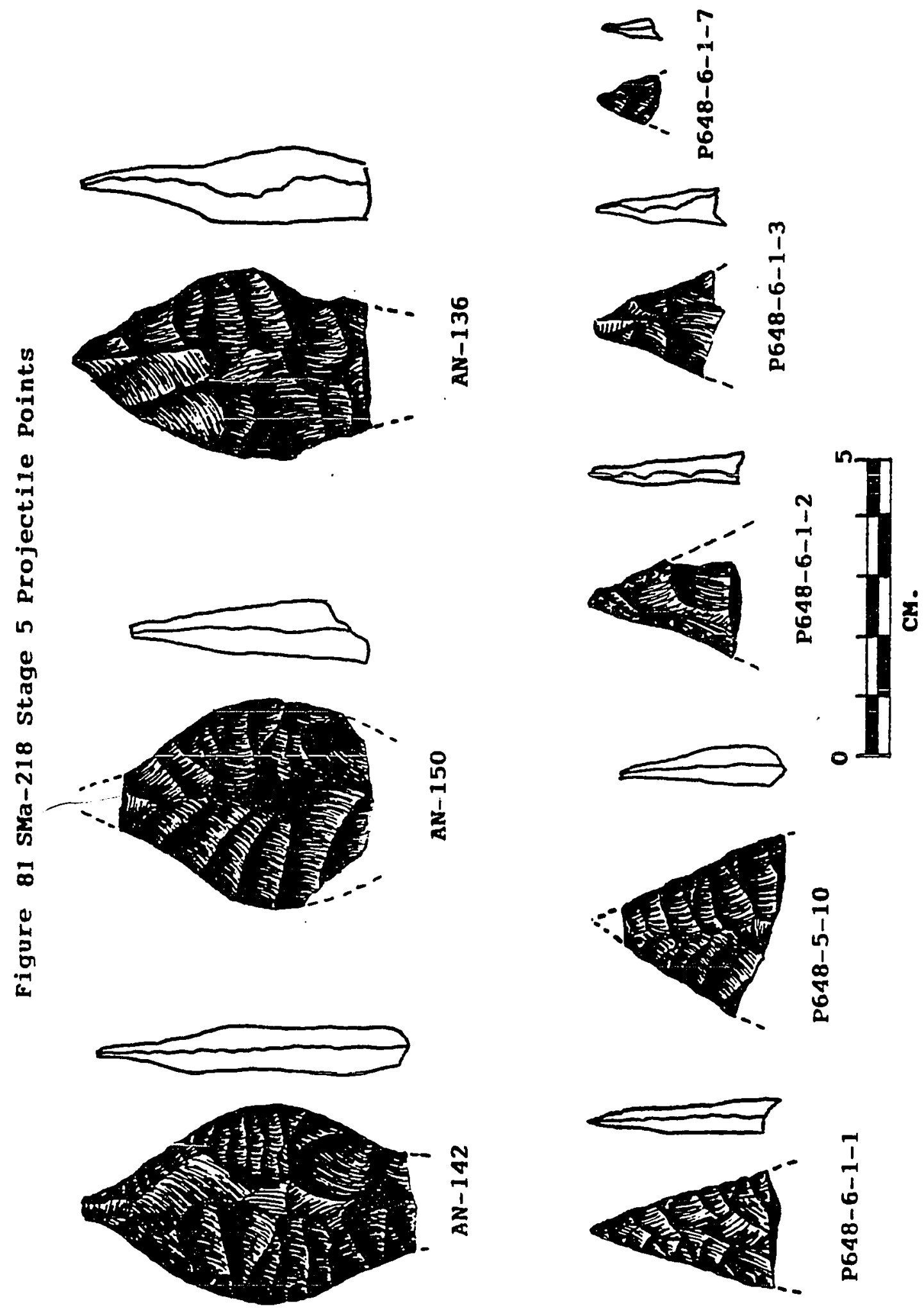

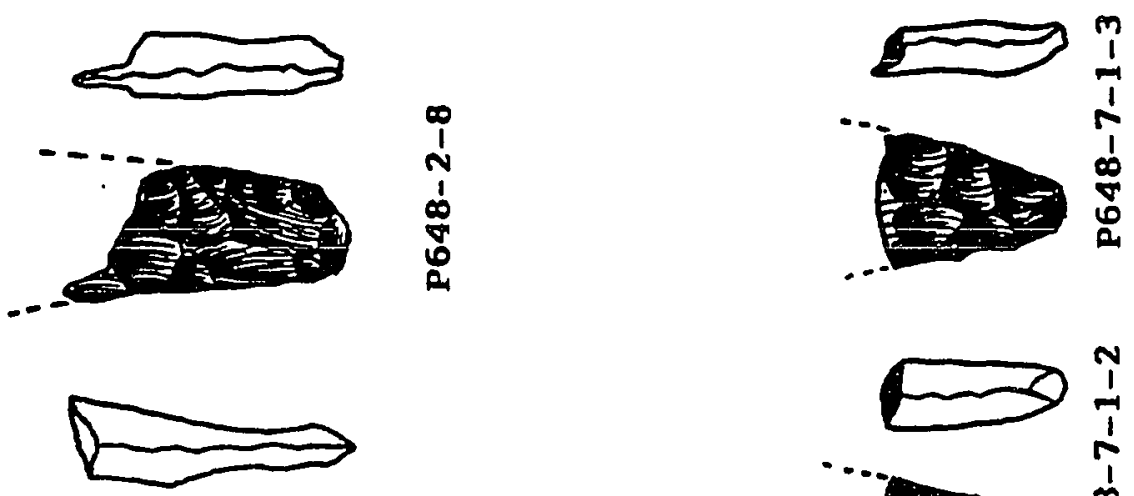

$\underset{v}{1}$
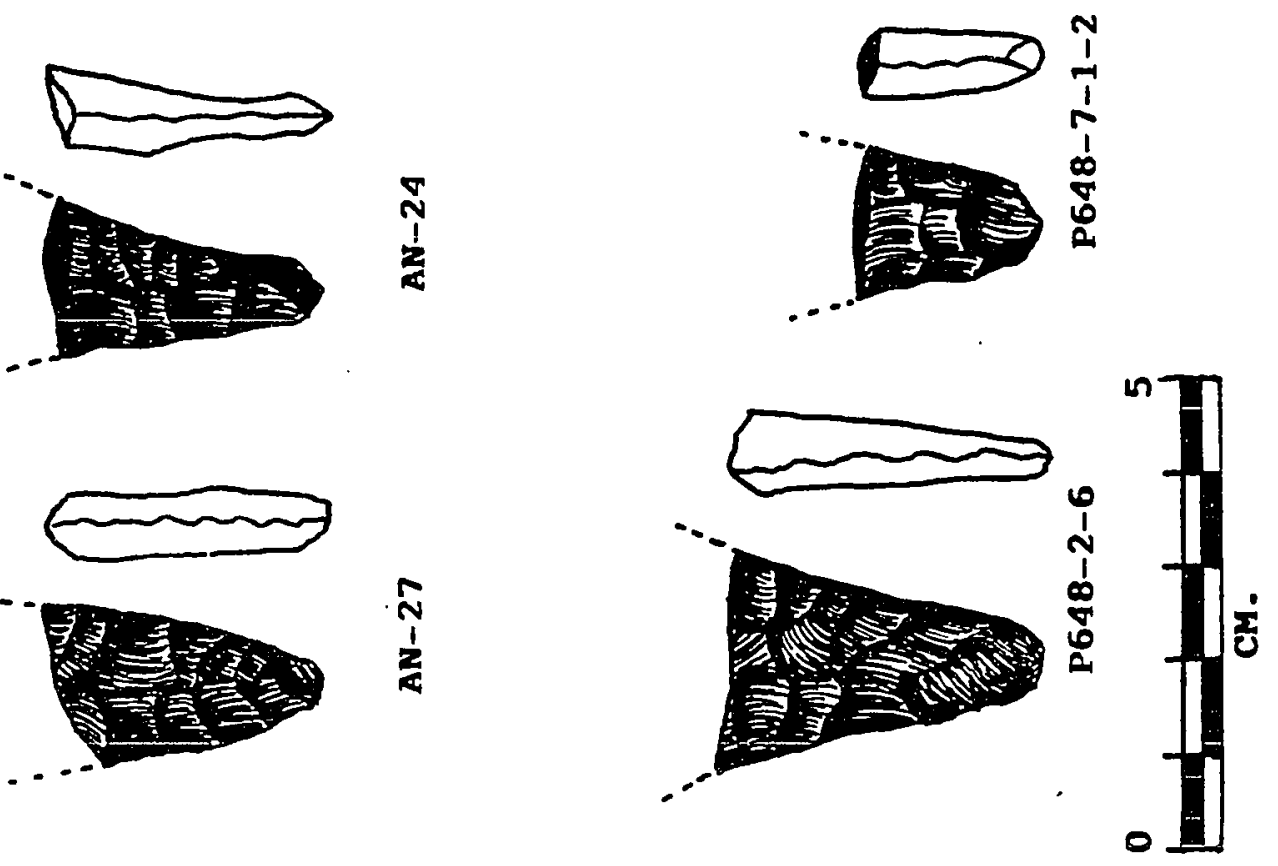

$\frac{N}{1}$

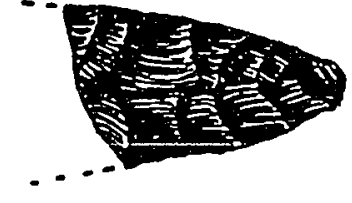

赵
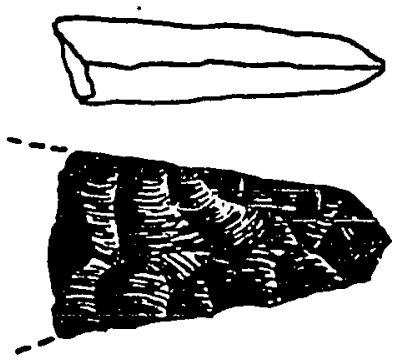

$\underset{1}{0}$
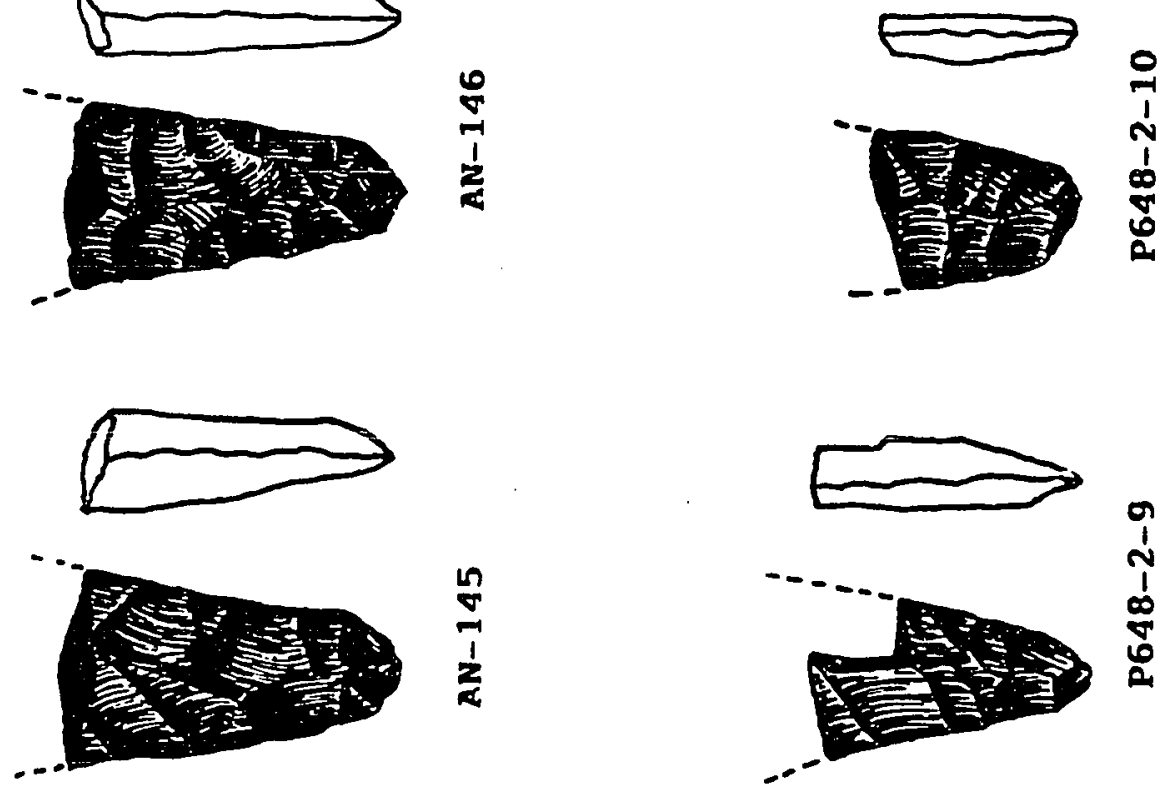

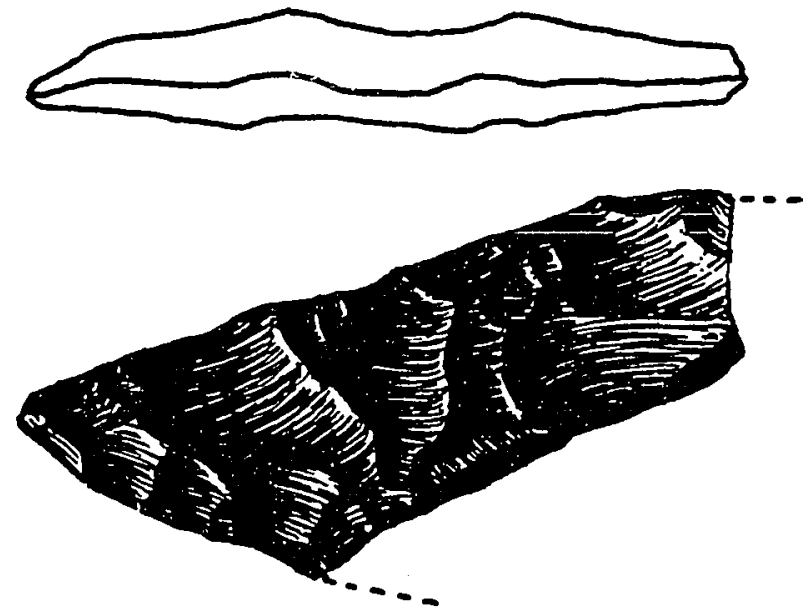

$\frac{1}{2}$


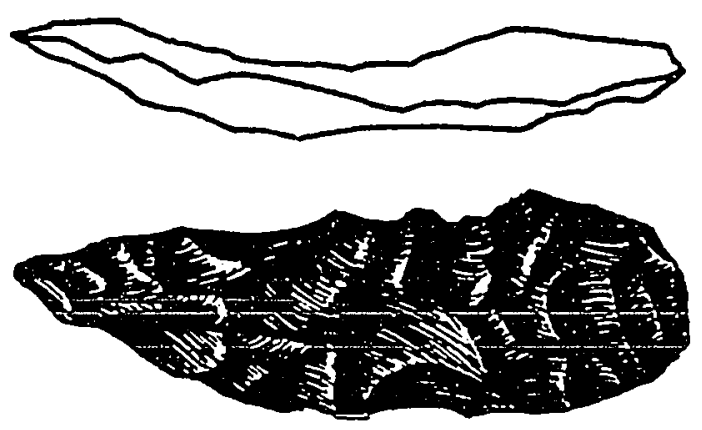

$\frac{1}{1}$
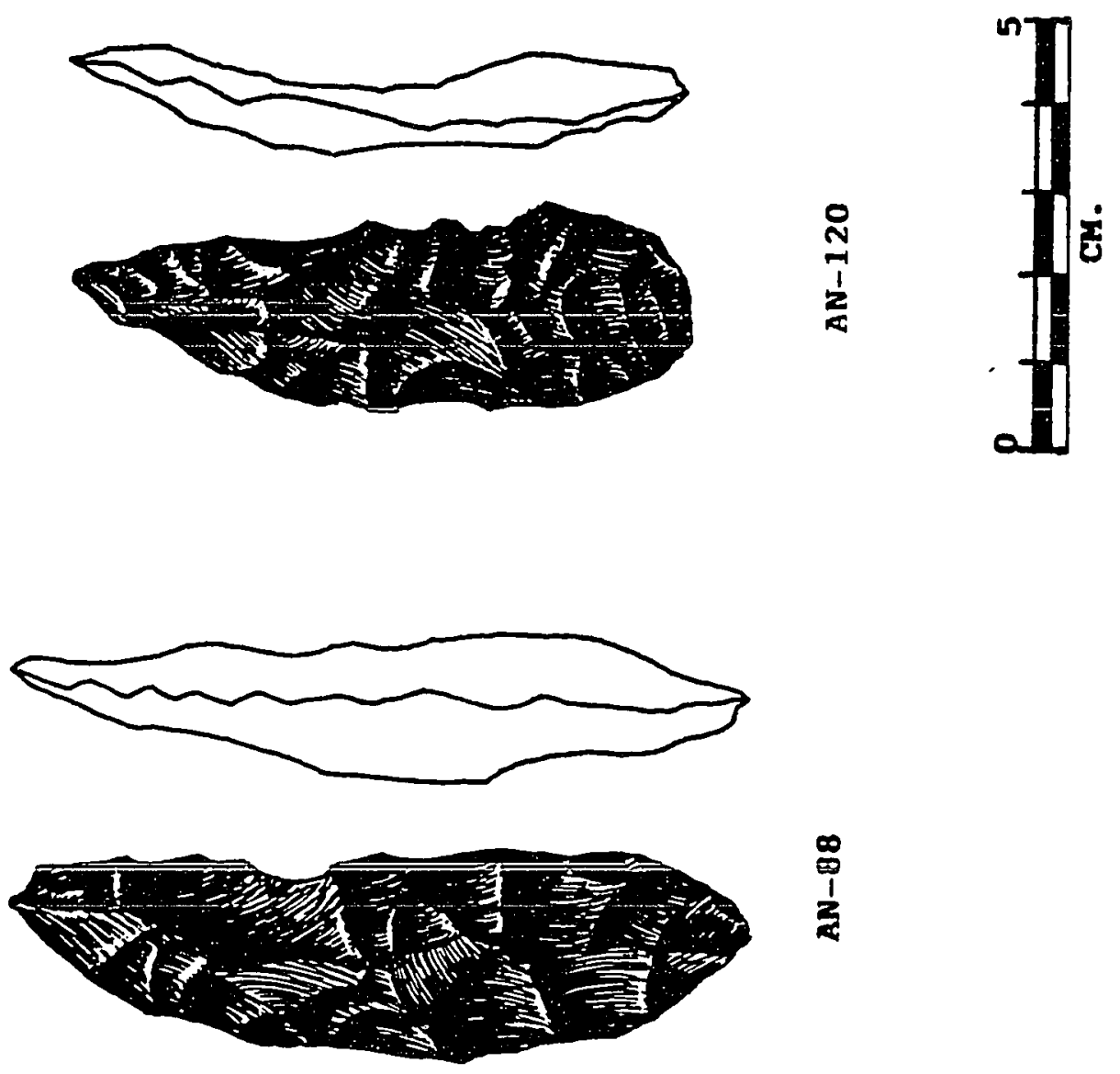


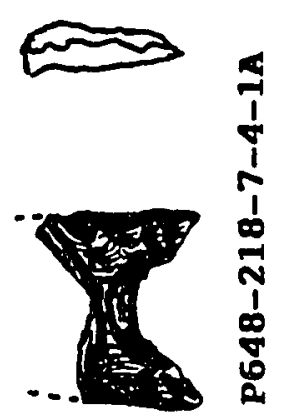

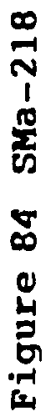
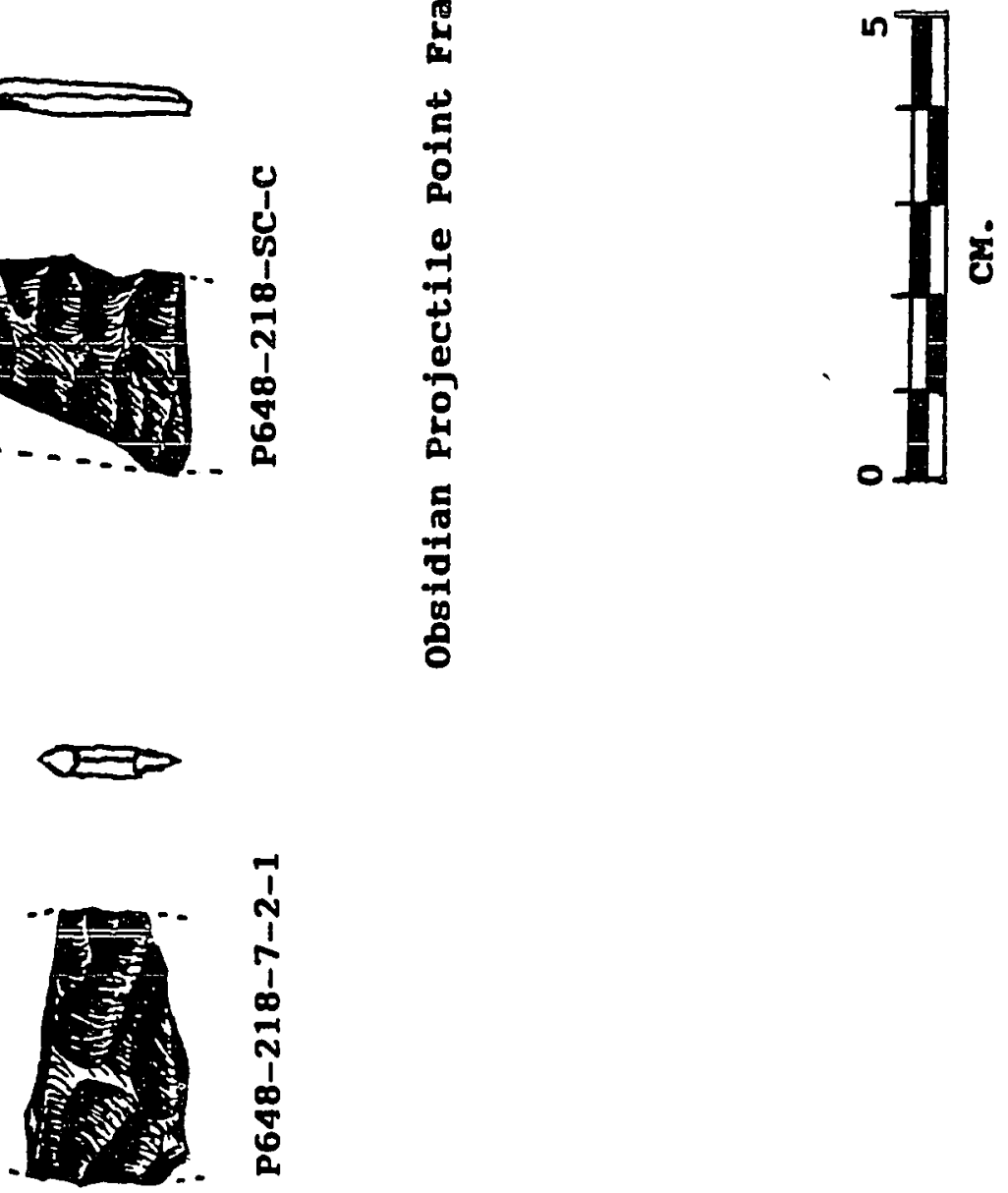
0
0
0
0
0
0
1
0
0
0
0
0
0

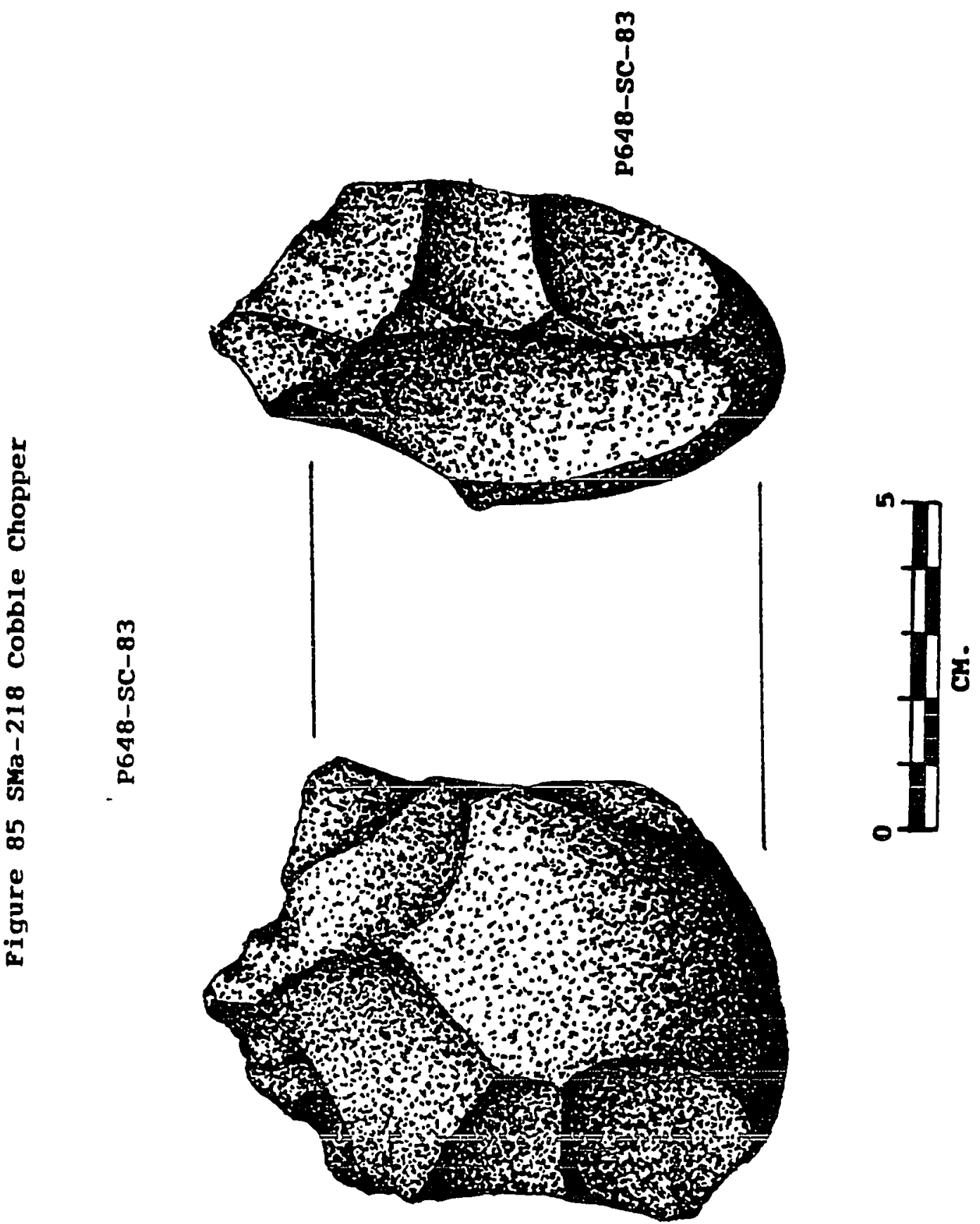


SMa-238, the Ano Nuevo Point site

SMa-233 is located at the south point of Ano Nuevo State Reserve and was tested by this author. As is the case for most of the sites on the reserve, this one has been picked over by collectors. Currently, the bulk of the public visiting the reserve walk over this to reach the beach and to observe the newly established elephant seal population. These enormous seal have further affected the site as they churn the sand after hauling out to bask in the sun. of even greater impact to the site is its close proximity to the ocean. Exceptionally high tides and winter storms have repeatedly taken a toll on this resource. A significant portion of it has recently eroded away. A permit to recover data from here was obtained from the California Department of Parks and Recreation.

The site consisted of a shallow midden deposit, which has been exposed by erosion at a point where the dunes rest upon a sandstone terrace. The terrace has been cut abruptly at the beach, and is only a little over a meter above the beach. The terrace where the site is situated is some fifteen meters from the ocean. Because the remaining midden deposit was only $30 \mathrm{~cm}$. deep, a rapid recovery method was used to obtain formed tools and faunal elements. Table 82 presents the unit dimensions, screen methods and excavation volume. 
Table 82: Excavation Unit Dimensions and Volumes from SMa-238

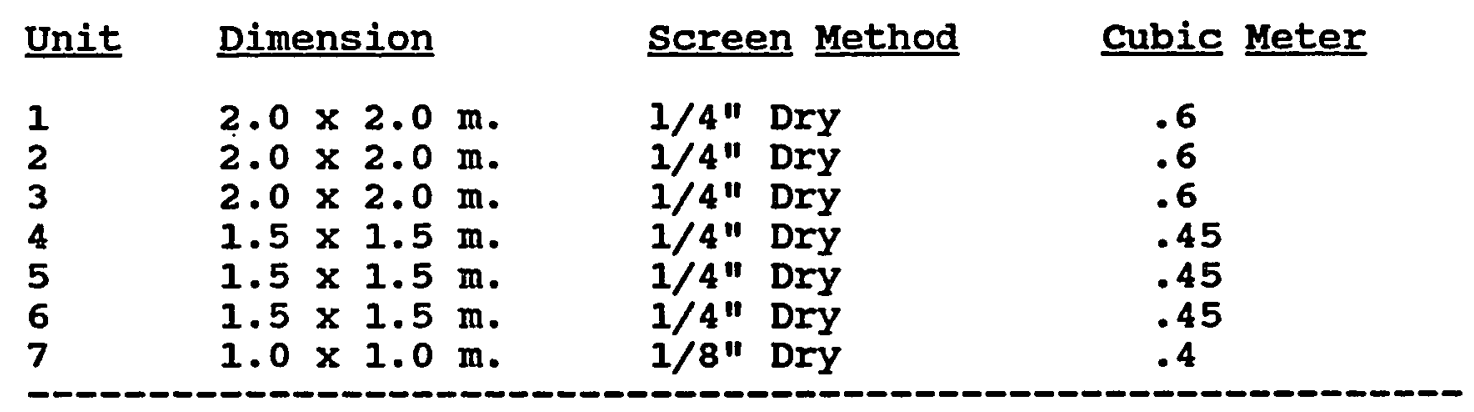

A total of 3.55 cubic meters of site was excavated. Map 20 illustrates unit orientations. Because of the disturbed nature of the site, only formed tools and features have been described.

Shell was not quantified because it was difficult to segregate the prehistoric shell from more recent deposits. High tides have added pieces to the base of the site and may occasionally deposit shell on it. Mytilus californianus and Tequla funebralis were the most prevalent species observed in the screens. A great number of olivella shells (spire intact and spire broken) were recovered from the screened soils. Several Haliotis shells were also recovered, and one of these was large and full of asphaltum. This specimen of Haliotis cracherodii measured $220 \mathrm{~mm}$. in length and was found in unit $4,20-30 \mathrm{~cm}$. Several intact Myiilus shelis were noted in association with Burial 1, along with a rectangular shaped Haliotis pendant that had incised edges (see Figure 85). This specimen has been described in Appendix A. A single radiocarbon date was derived from the 
Mytilus shells found in association with the burial. These shells were recovered from a buried and intact portion of the site. Table 83 presents the result.

Table 83: Radiocarbon Date from sMa-238

WSU\# Provenience, Composition $\quad$ 14C age(Years B.P.)

3510 Unit 7, Burial 1, $150 \mathrm{Gr}$. Mytilus $1150 \pm 80$

Faunal remains included both prehistoric and recent bones from sea mammals, fish and birds. Iike the shell, it was difficult to differentiate the prehistoric bone from the recent faunal remains. The author has observed the carcasses of various fauna on the site. During a single visit, several elephant seal pups, one harbor seal, one sea otter and several birds were seen decomposing on the site. Despite the mixing, fish bone was pariicularly abundani, and was collected from the screened soils.

Six bone tools were recovered and included 4 blunt awl tips, 1 pointed awl tip and 1 split sea mammal rib that had a spatulate tip. These have been described in Appendix $c$. All of them are illustrated in Figures 86 and 87. Moderate amounts of debitage were scattered throughout the site. All of it was of Monterey chert. Debitage from unit 1 was used as the representative sample for analysis. This unit recovered 368 pieces $(3,250.7 \mathrm{gr}$.$) , which is an$ amount equal to 613 pieces $(5,418 \mathrm{gr}$.$) per cubic meter of$ site. Table 84 presents the results of this study. Of the 
debitage, $59 \%$ reflected primary reduction stages, $21.5 \%$ represented secondary reduction (almost entirely thinning flakes), 198 were shatter debris and only 1 informal tool (.25\%) was found. The informal tool was a borer/drill made from a primary flake. The debitage at this site indicated that initial reduction and assaying of cores was the focus of chipped stone work here.

Many cobble tools were visible on the surface of the site. These include pitted/dimpled stones and grooved cobbles. Several of these were collected on the surface of the excavation units and from the screened soils. Many more have been observed at this site after the excavation had been completed. A total of 14 artifacts have been described in Appenaix E. Of these, 7 specimens are illustrated in Figures 88 and 89 . An average of 4 cobble tools per cubic meter of site was recovered. Table 85 presents a summary of the cobble tools from this site.

Table 85: Cobble Artifacts from SMa-238 $(\mathrm{N}=14)$

Pitted/Dimpled colbile.........5 (35.5\%)

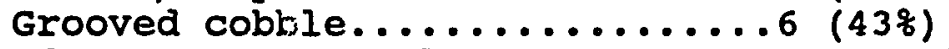

Edge notched cobble............ (14.5\%)

Battered cobble............... (7t) 
$\left.\begin{array}{l}n \\ 0 \\ 0 \\ 0\end{array}\right)$

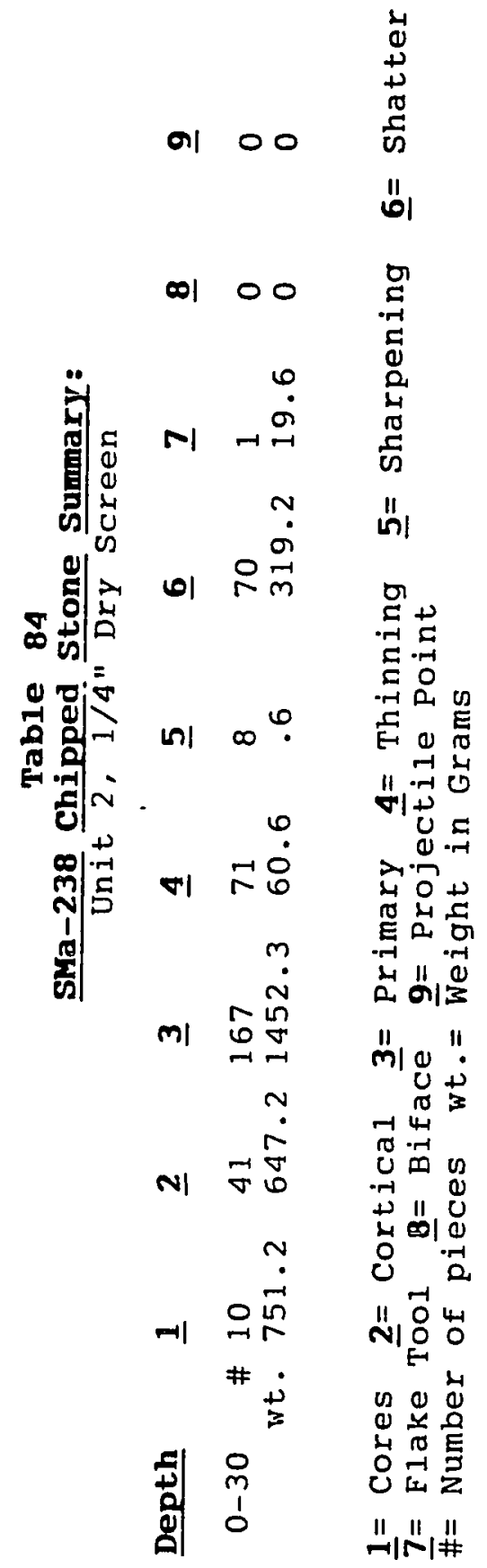


Three features were identified. These included two clusters of thermally affected cobbles and baked sand and a human burial.

Feature 1, found in unit 1, contained a large cluster of thermally affected cobbles with a chert core in the middle. The cluster was enclosed by baked sand and appeared to be the result of heating Monterey chert cores. All of the cobbles exhibited thermal spalls and discoloration from exposure to fire. A mudstone slab with a pitted surface was near the cluster and apparently was a platform for percussion work. A single bone tool was also found near the cobble cluster. Figure 90 illustrates this feature.

Feature 2 was found in unit 2, which was adjacent to unit 1. This feature was identical to the other one and has been illustrated in Figure 91.

Feature 3 was a human burial found in unit 7. This unit was established on the slope of a small sand dune, at the edge of the site and will soon be lost to erosion. The initial purpose of this unit was to find an area with greater depth. The burial was found entirely by chance. The individual was not complete and the remaining elements gave it the appearance of a secondary interment. Table 86 presents the osteological summary for this individual. It is possible that this person was exposed and reinterred prehistorically. The individual was a young adult, judging 
Table 86

\section{SMa-238 Buriai 1 Osteological Data:}

Provenience: Unit 7,30 to $50 \mathrm{~cm}$. below unit datum.

Burial Type: Secondary inhumation, partial remains.

Orientation: Face is down and oriented west.

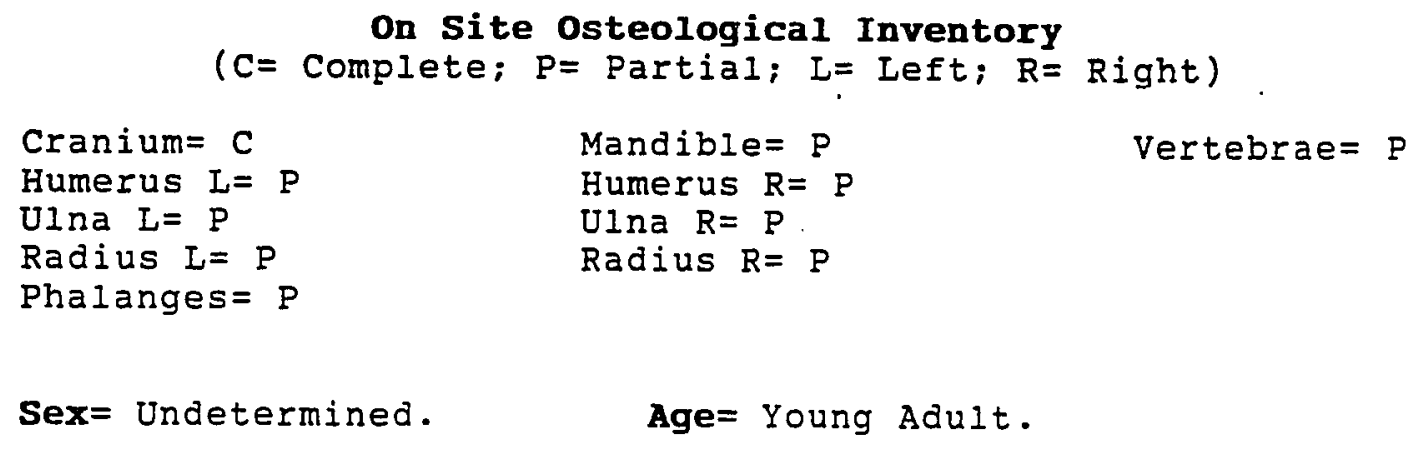


by the condition of the teeth and size of the bone elements. A Haliotis pendant, having two drilled perforations and incised edges, was found in association near the cranium. Also in association were several intact and spire broken olivella shells, a pitted/dimpled cobble, several intact Mytilus shells and an intact Haliotis shell. The burial has been illustrated as Feature 3 in Figure 92 . The burial has been reinterred near the site in an area not threatened by immediate erosion.

SMa-238 represents a transitional time between the Middle and Late Periods. The assemblage reflects a great deal of similarity to Late Period site SMa-118, which was dated to much more recent times. The presence of a human burial, the radiocarbon date, well defined activity features, and the artifact assemblage has led to the conclusion that this site was a forager residential location. Table 87 summarizes component definitions.

Table 87: Component Summary from SMa-238

1) Homogeneous deposit: $0-70 \mathrm{~cm}$. Age: Middle to Late Transitional Period, 1,150 180 B.P. No obsidian.

\section{Artifacts:}

Haliotis type Q4bIII pendant

Pestle

Pitted/Dimpled cobbles

Edge Notched cobbles

Grooved cobbles

Bone awls 


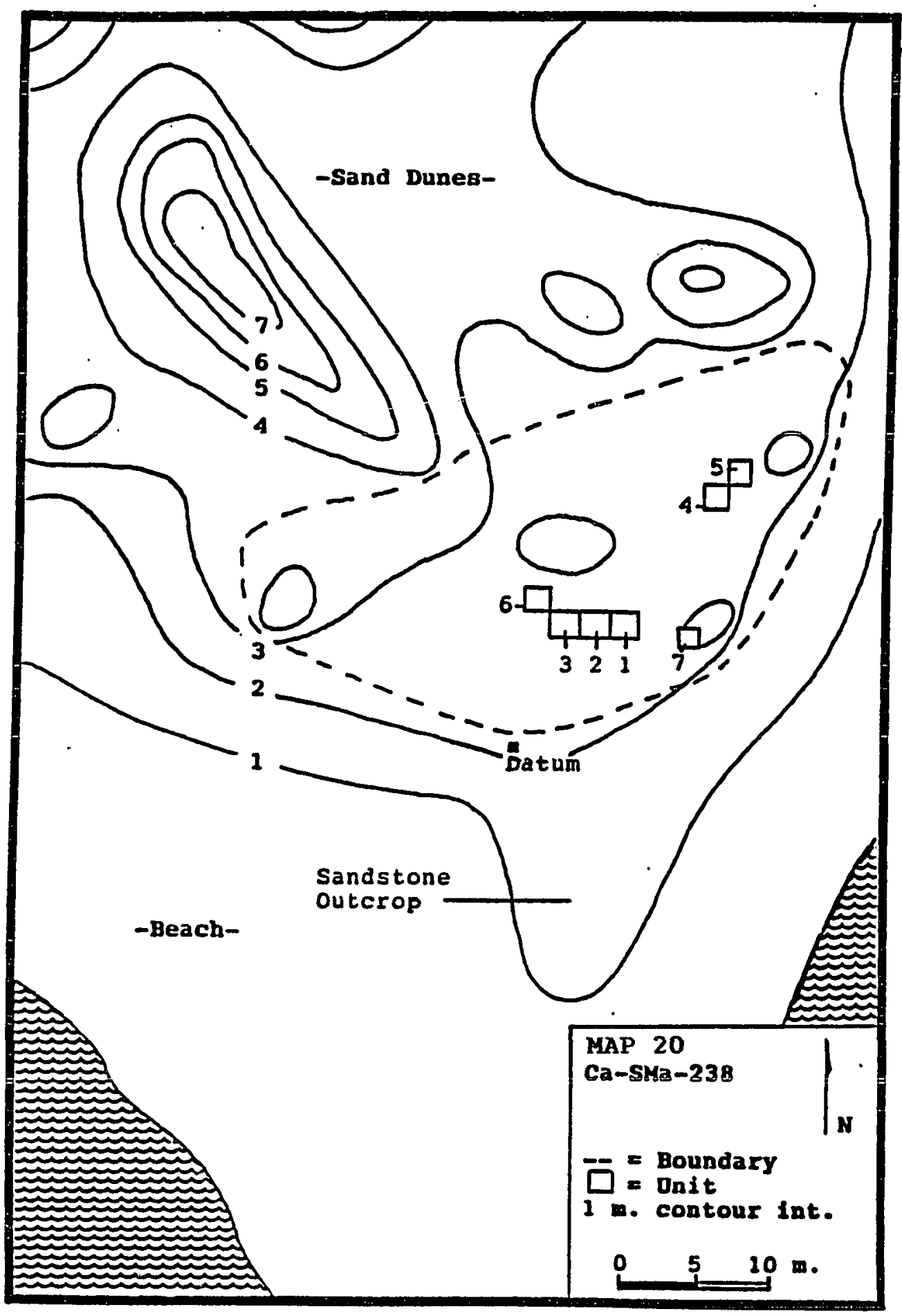


Haliotis Pendant Associated with Burial 1: P647-7-B1

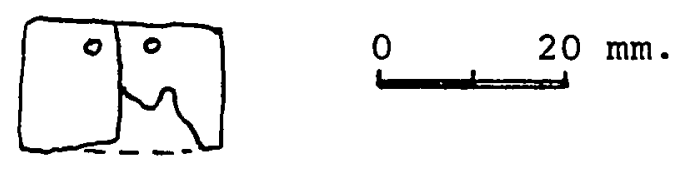

Enlarged View:

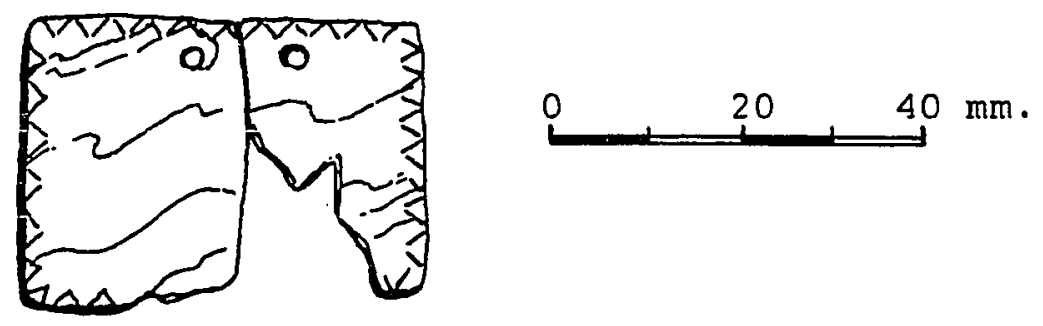

Figure 86 SMa-238 

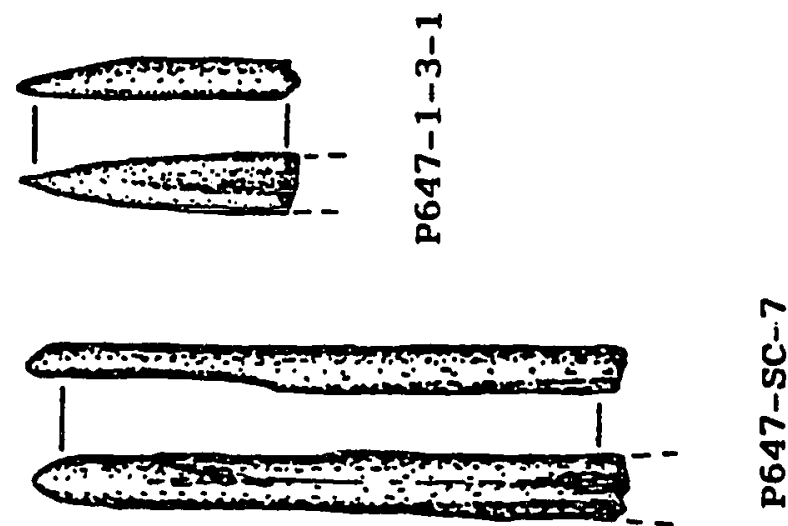

$n$
0
1
0
0
0
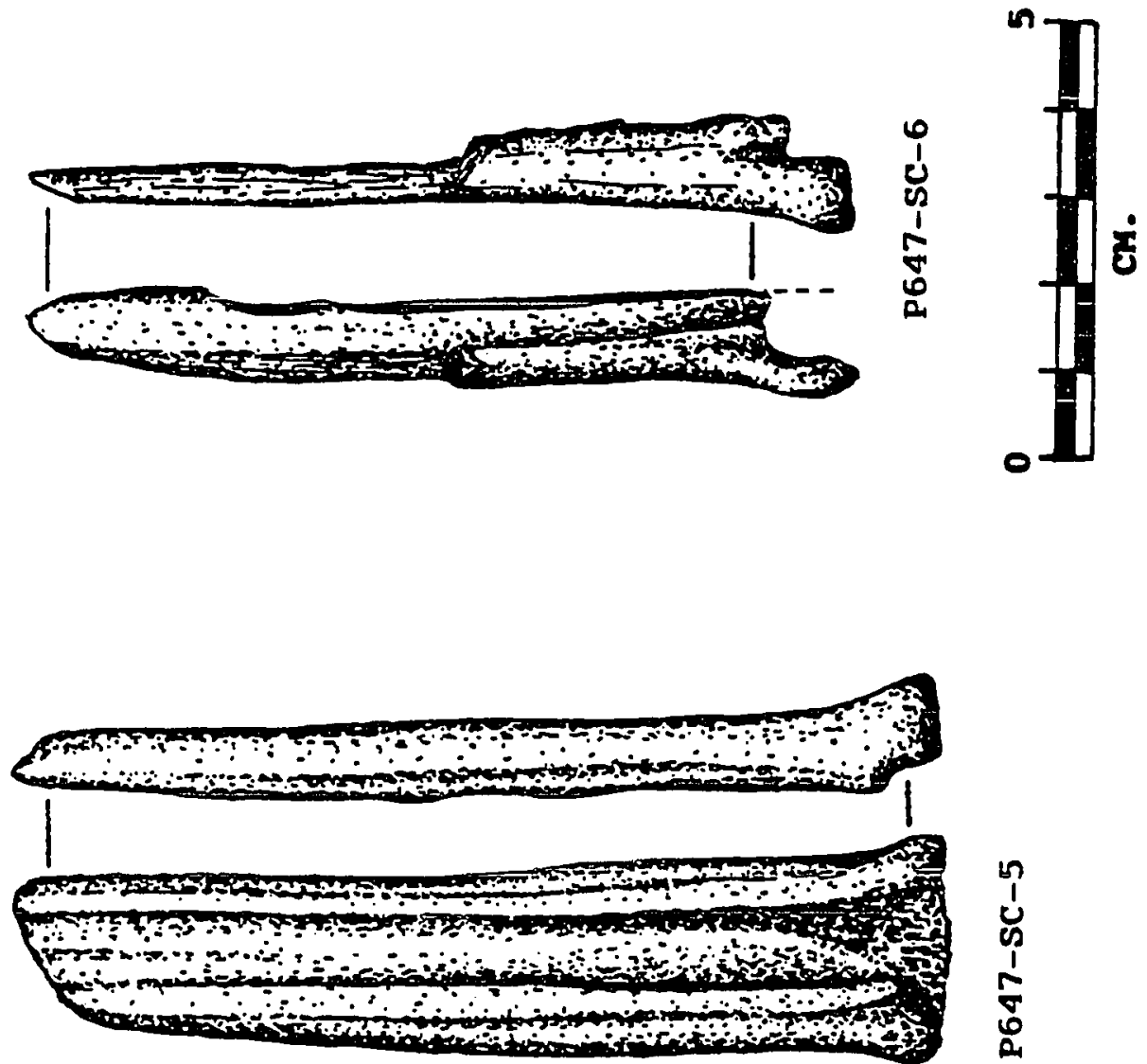

1
1
0
1
0
0
0 


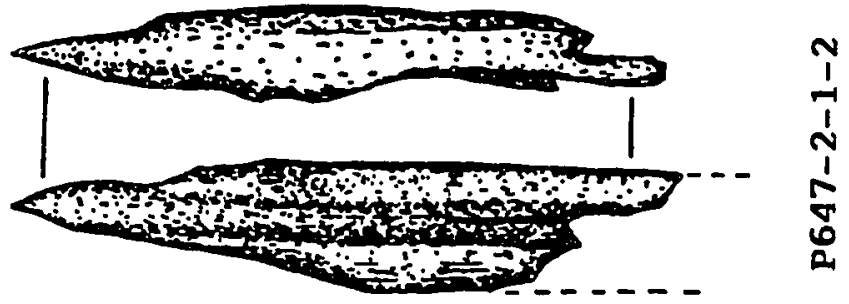

告
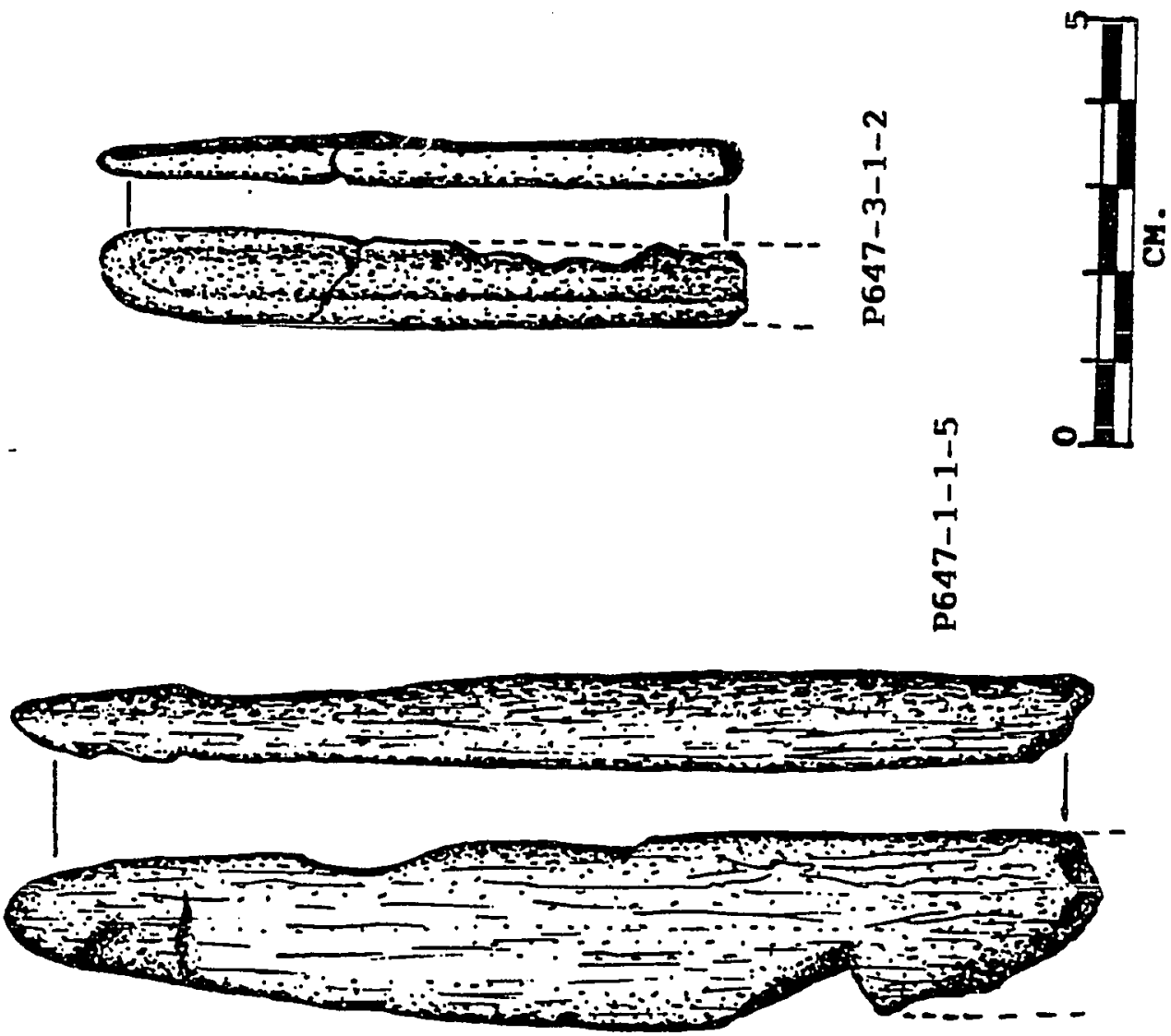


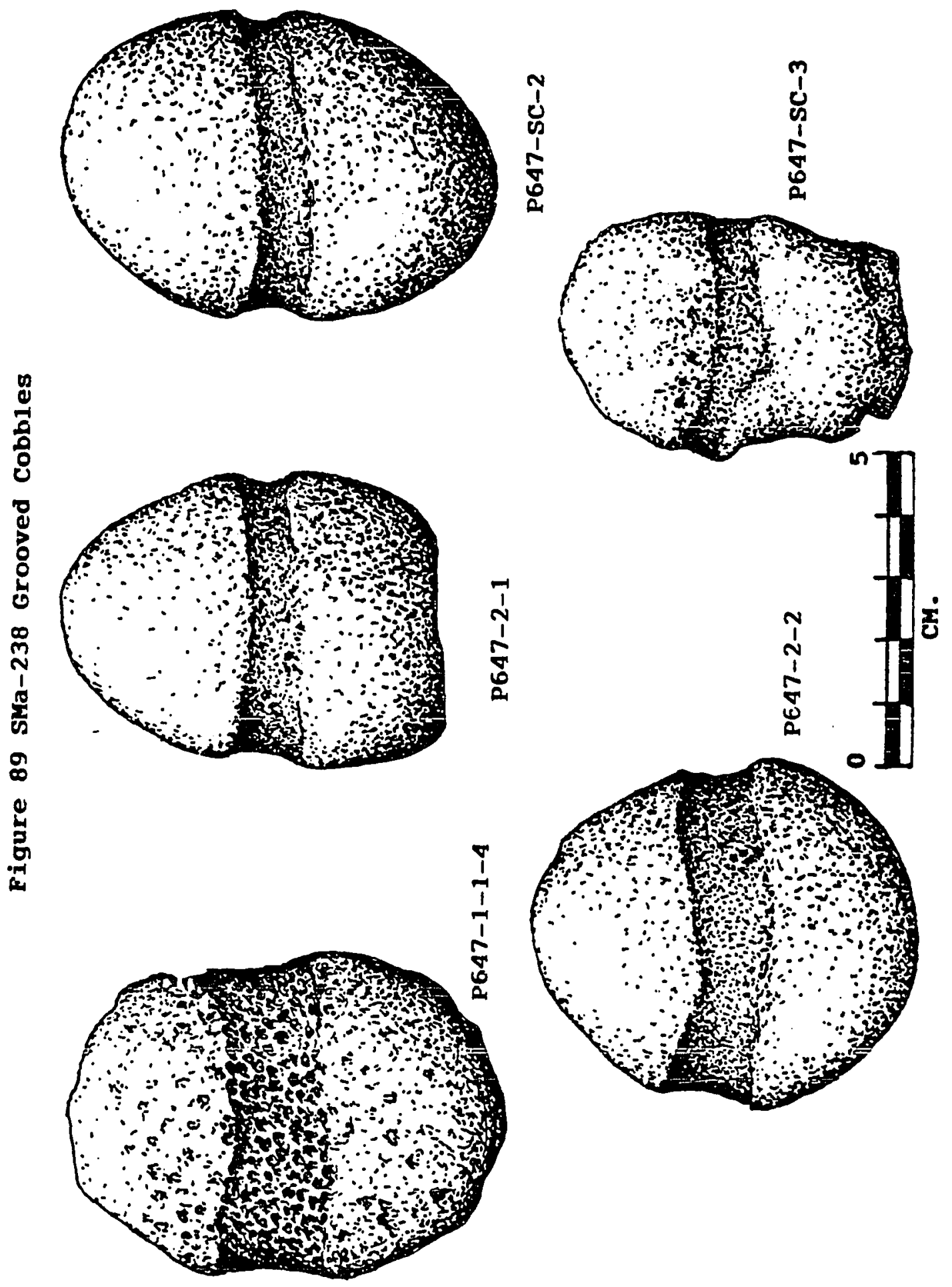


过
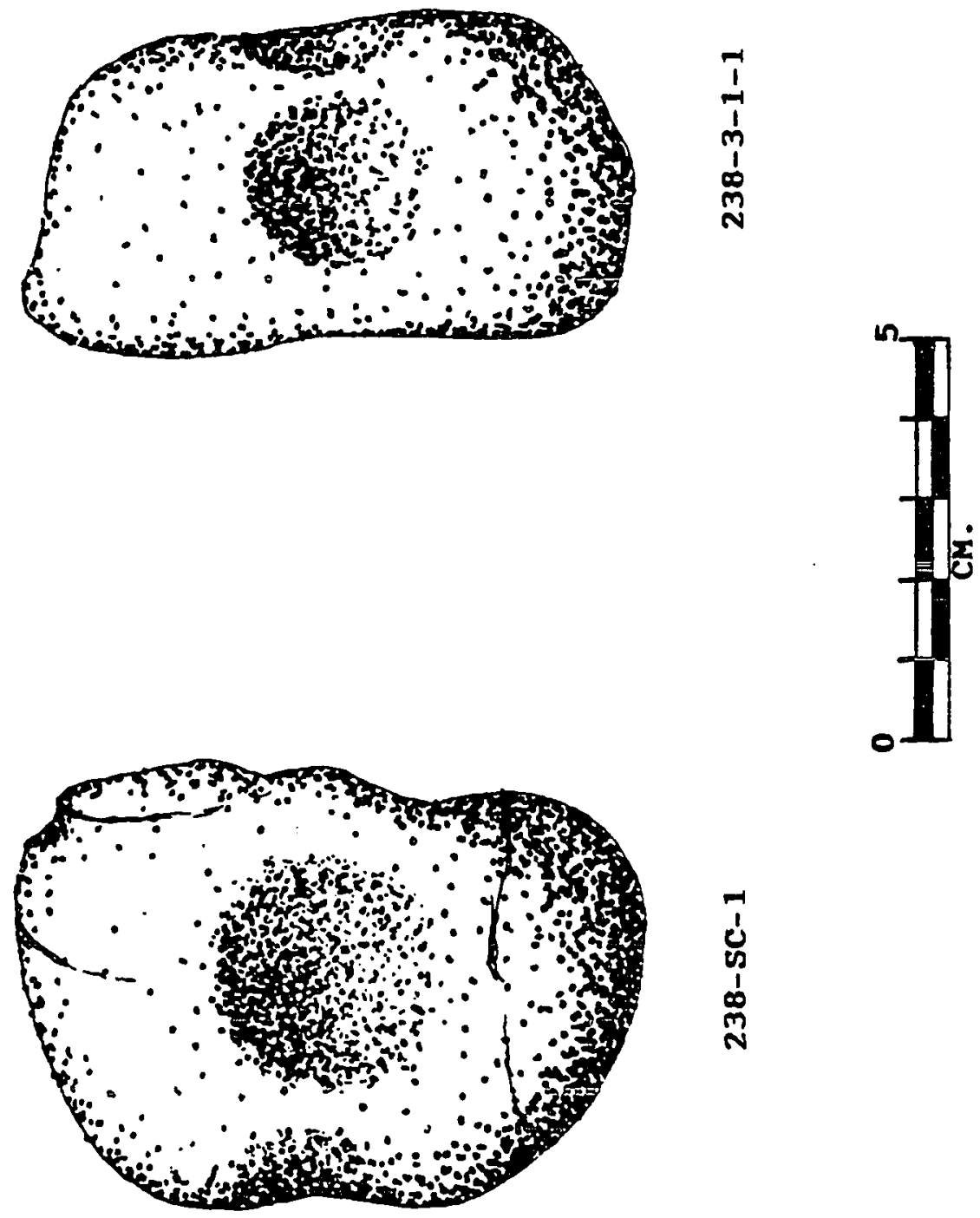


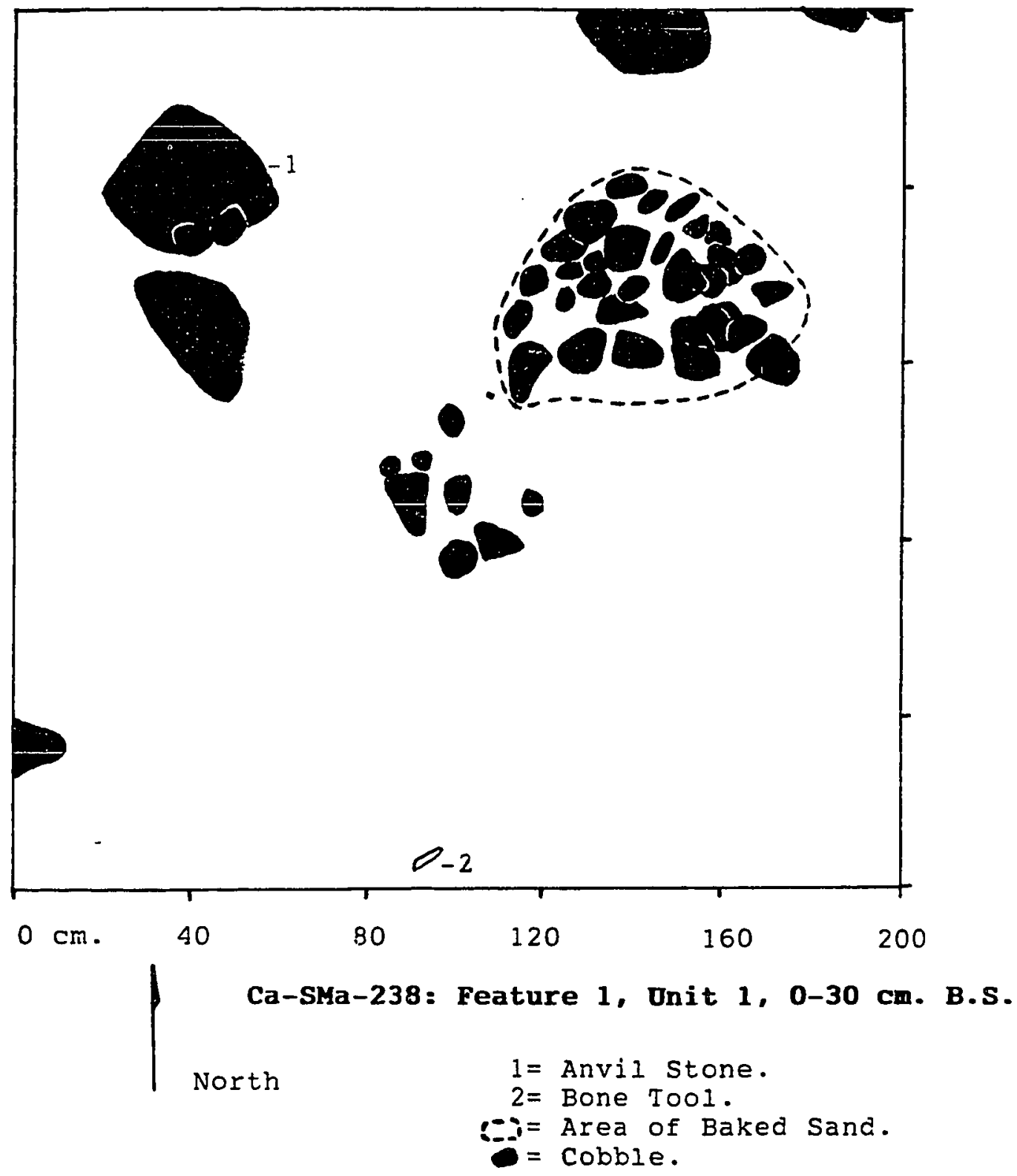

Figure 91 


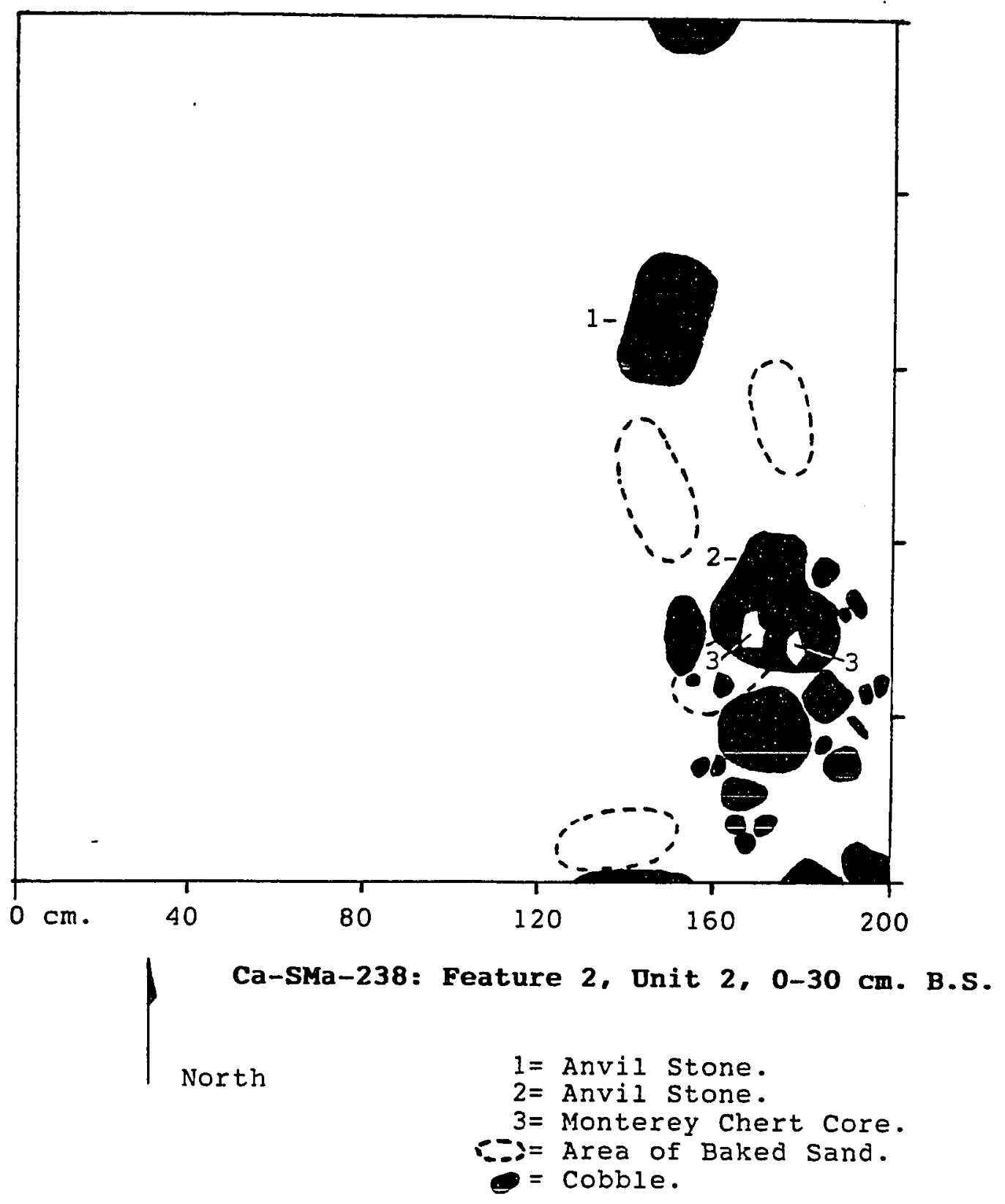

Figure 92 


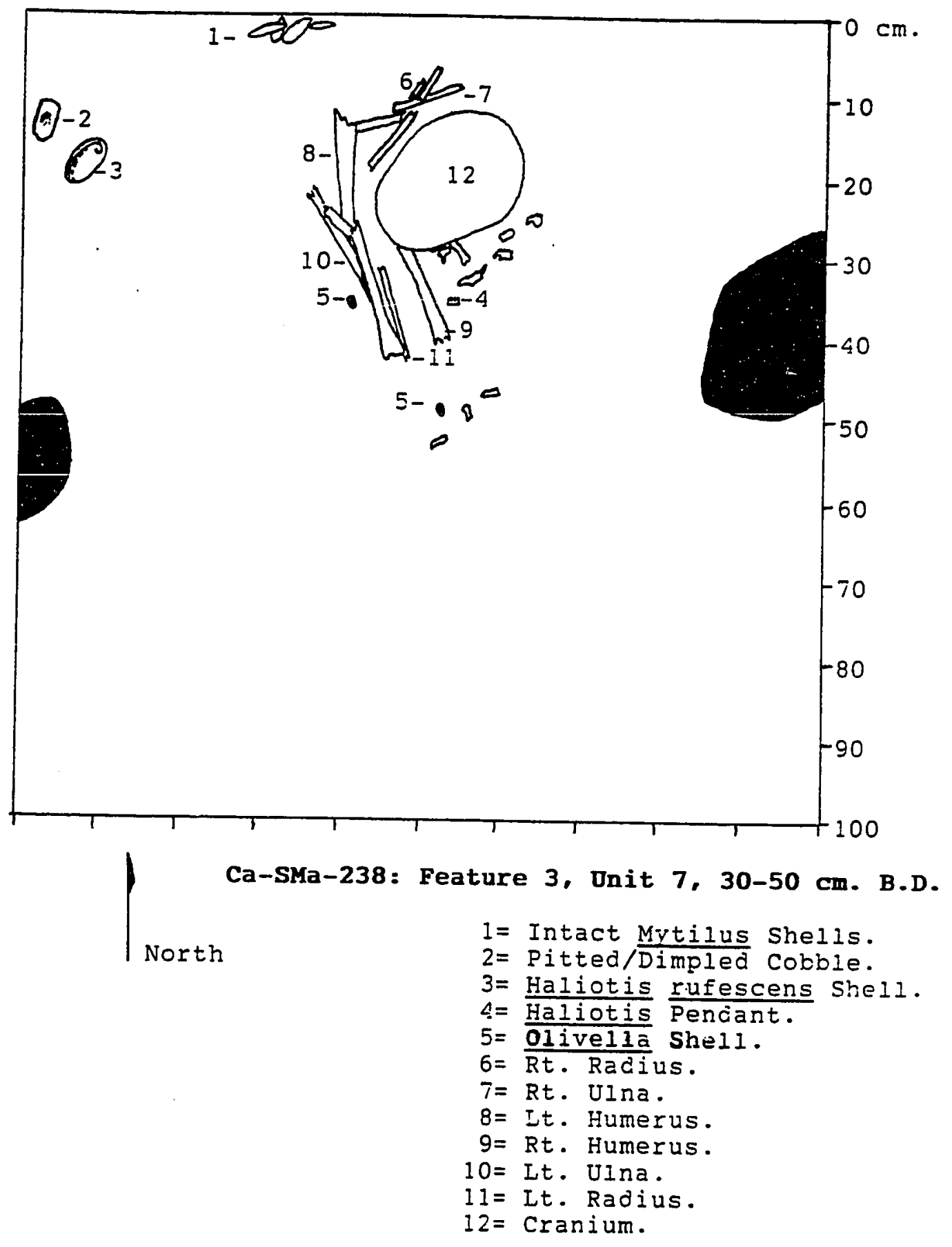

Figure 93 
SMa-244. the Butano Ridge site

SMa-244 is located at the headwaters of Gazos Creek, along a narrow ridge which leads from Butano Ridge to the shoreline, and was tested by this author. The site is within the ridge system habitat defined for this study. Butano Ridge intersects with Castle Rock Ridge via Waterman Gap and would have been a natural trail route for exchange between the coast and the Santa clara Valley. The site is adjacent to a spring and is within dense redwood forest; however, there are also occasional patches of mixed hardwood forest in the vicinity.

Recently, large areas of this site have been affected by the harvesting of old growth redwood trees. A jeep road was graded through the center of the site, and several logging skid trails have gouged through it as well. Because of this, intact portions of the midden were difficult to find.

A total of ten excavation units were established, one of which was a column sample unit. Units 1, 2 and 3 were controlled recovery units from which all cultural constituents were recovered (except unmodified shell). Units 4 through 9 were rapid recovery units excavated in $20 \mathrm{~cm}$. levels, from which only artifacts and debitage were retained. Map 21 illustrates unit locations and site boundaries. Table 88 presents the unit dimensions, recovery techniques and excavated unit volume. 
Table 88: Excavation Unit Dimensions and Volumes from SMa-244

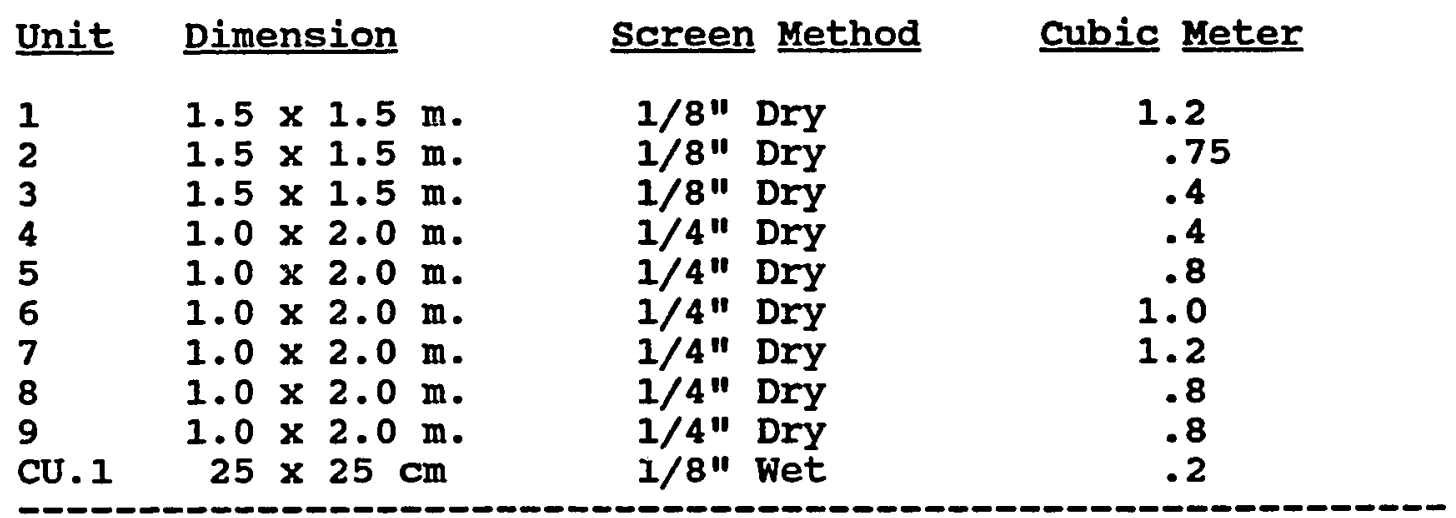

A total of 7.55 cubic meters of site was excavated. Only unit 1 and $C U .1$ contained intact stratigraphic levels. The other units were shallow in depth due to surface alterations from logging at the site. The soil profile of unit I revealed ]ayers of shell fragments and lenses of charcoal from the upper levels to approximately $70 \mathrm{~cm}$. Basal depths of all of the units were reached when a tan colored clay matrix was encountered during excavation (see Figure 93). Column Unit 1 was adjacent to Unit 1.

The recovered artifact types and the obsidian hydration results indicate that the site represented a Late Period assemblage. Therefore, no radiocarbon samples were submitted for analysis.

Shell fragments were abundant at this site and were dominated by Mytilus californianus. Most of the shell appeared to nave been roasted. A total of $1,546.3 \mathrm{gr}$. of shell was recovered from CU.1. This amount is equal to 
7,731.5 gr. per cubic meter of site. Table 89 presents the results of $\mathrm{CU} .1$.

Table 89: Column Sample from SMa-244

(Unit Volume $=.2$ Cubic Meters)

\begin{tabular}{rrrrrr} 
& Shell & \multicolumn{2}{c}{ Bone } & \multicolumn{2}{c}{ Debitage } \\
Depth & Wt.(gr.) & \# & Wt. & \# & Wt. \\
$0-10$ & 389.2 & 30 & 3.0 & 15 & 23.0 \\
$10-20$ & 300.0 & 20 & 1.0 & 11 & 9.4 \\
$20-30$ & 336.5 & 20 & 1.0 & 9 & 2.0 \\
$30-40$ & 117.4 & 27 & 1.5 & 11 & 3.0 \\
$40-50$ & 126.7 & 71 & 7.5 & 17 & 41.3 \\
$50-60$ & 120.0 & 35 & 1.3 & 17 & 6.5 \\
$60-70$ & 141.5 & 27 & 3.5 & 9 & 6.5 \\
$70-80$ & 15.0 & 0 & 0 & 2 & .5 \\
Total & $1,546.3$ & 230 & 18.8 & 91 & 92.2
\end{tabular}

Shell Volume Per Cubic Meter $=7,731.5 \mathrm{gr}$.

Bone Volume Per Cubic Meter= 1,150 pcs., 94.0 gr. Debitage Volume Per Cubic Meter $=455$ pcs., $461.0 \mathrm{gr}$.

A large number of olivella shells were recovered, but none of them were modified types. In all, 352 specimens were obtained from 6.55 cubic meters of site (54 pieces per cubic meter). Of these, $75 \%$ had intact spires, $9.5 \%$ had broken spires, $1.5 \%$ were spire ground and $13 \%$ were fragments (see Appendix B). Olivella shells were cached at this site in large numbers and they clearly played an important economic role here.

Faunal remains were recovered from units 1,2 and 3 . Table 90 presents the summary of taxa frequencies. The faunal inventory for individual units by depth has been presented in Appendix A. A total of 238 pieces of bone 


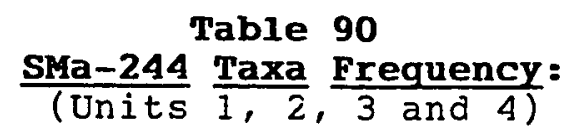

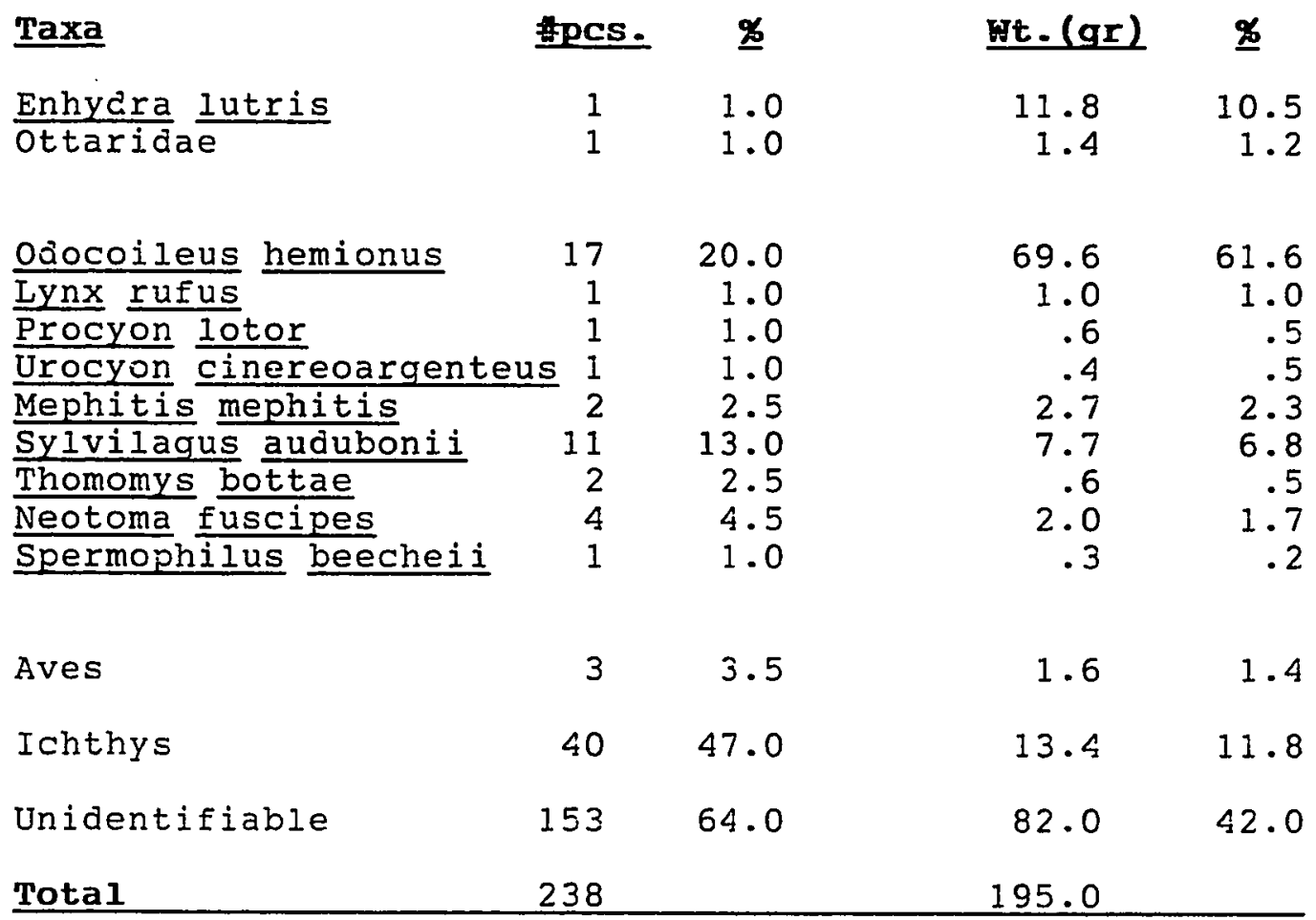

Terrestrial vs Marine:

(Rodentia, Aves and Ichthys Excluded)

\#pcs.\% wt.(gr) $\%$

Terrestrial

94.0

86.0

Marine

6.0

14.0 
(195.0 gr.) were recovered. This amount is equal to 101.2 pieces (83.4 gr.) per cubic meter of site. CU.l recovered a greater number of projected bone pieces per cubic meter $(1,150)$, but the projected weight is near that of unit 1 (91.0 gr.). Deer, rabbits and fish dominate the faunal assemblage. While marine faunal remains were present, the occupants of this site were principally focusing on smaller terrestrial mammals and fish. Excluding rodents, fish and birds, the terrestrial mammals composed $94 \%$ of the identified fauna by number of pieces, and $86 \%$ of the weight. only two bone tools were recovered. One of these was a thin, split sea mammal rib with a rounded spatulate shaped tip. The other was a fragment of a blunt tipped awl which has been burned and polished. Both of these are illustrated in Figure 94. The measurements and the descriptions of these artifacts has been presented in Appendix $c$.

Debitage was abundant at this site although chipped stone tools were not. All of the debitage, with the exception of eight specimens, were of Monterey chert. These eight pieces were of obsidian and include a biface fragment, five small serrated points and two pressure flakes. Five of the serrated points were visually sourced and identified as having originated at the Napa Valley source. Four of the five provided rim hydration readings which clustered around 1.5 microns, and the fifth one yielded unreliable results. The results of this study are presented in Table 91 . The 


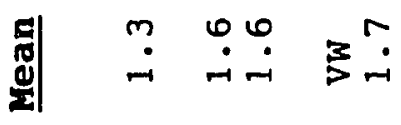

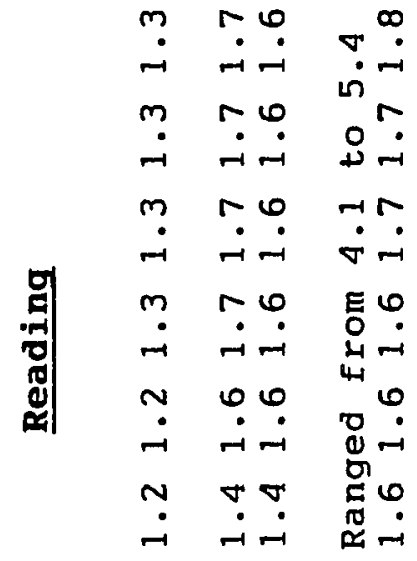

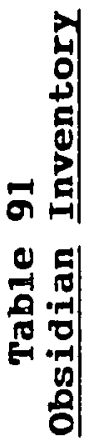

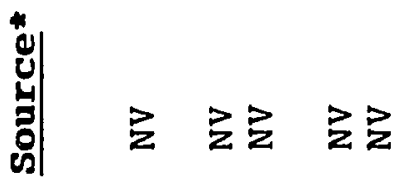

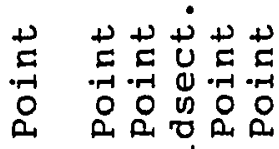

(ס)

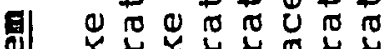

† त

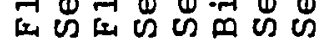

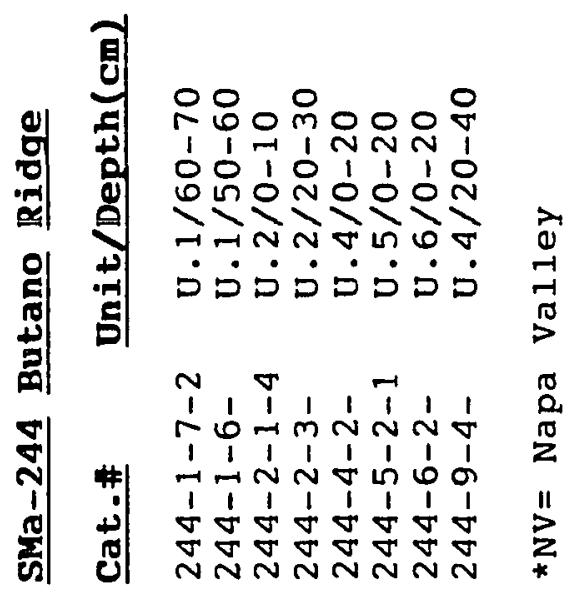


points, referred to as stockton serrated types (see Figure 95) are well known Late Period markers associated with a bow and arrow technology. These are described in Appendix D. Excluding the obsidian pieces, a total of 2,624 pieces of debitage $(11,869.2 \mathrm{gr}$.$) was recovered. All was of$ Monterey chert. Table 92 presents the number of pieces and weights for each unit.

Table 92: Debitage Volume from SMa-244

\begin{tabular}{|c|c|c|c|c|}
\hline Unit & 昔 & 糔 & wt. (ar.) & $\underline{q}$ \\
\hline $\begin{array}{l}1 \\
2 \\
3 \\
4 \\
5 \\
6 \\
7 \\
8 \\
9 \\
\text { CU.1 }\end{array}$ & $\begin{array}{l}294 \\
328 \\
496 \\
138 \\
218 \\
359 \\
222 \\
201 \\
277 \\
91\end{array}$ & $\begin{array}{r}11.5 \\
12.5 \\
19 \\
5 \\
8.5 \\
13.5 \\
8.5 \\
7.5 \\
10.5 \\
3.5\end{array}$ & $\begin{array}{r}1,575.0 \\
2,342.5 \\
1,736.0 \\
566.0 \\
878.0 \\
1,611.0 \\
711.5 \\
1,183.5 \\
1,173.5 \\
92.2\end{array}$ & $\begin{array}{l}13 \\
20 \\
14.5 \\
5 \\
7.5 \\
14 \\
6 \\
9.5 \\
10 \\
.5\end{array}$ \\
\hline
\end{tabular}

Debitage from unit 1 was selected for analysis. Table 93 summarizes the results. This unit produced an amount of debitage equal to 367.5 pieces $(1,968.7 \mathrm{gr}$.$) per cubic meter$ of site. CU.l produced 455 pieces ( $461.0 \mathrm{gr}$. ) of debitage per cubic meter of site. The debitage study from unit 1 indicated that primary reduction accounted for $52 \%$ of the sample, secondary reduction equaled $30.5 \%$ and shatter debris composed $17.5 \%$. No formal or informal tools were recovered from this sample. 


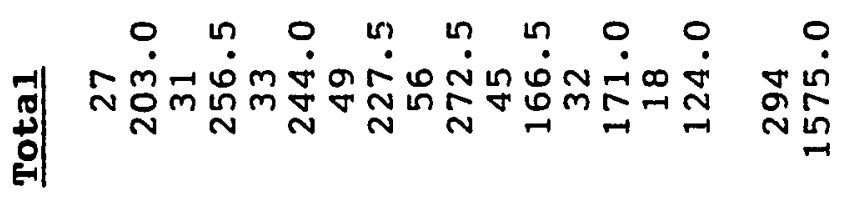

ol 000000000000000000 疍

"I)

$\infty 1 m 00000000000000000$

$N 000000000000000000 \frac{\pi}{\pi}$

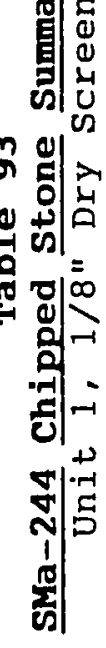

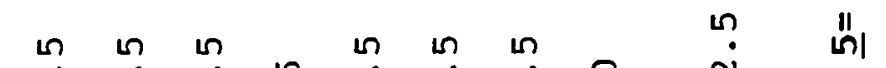

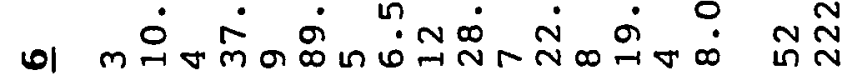

몰.

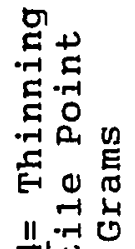

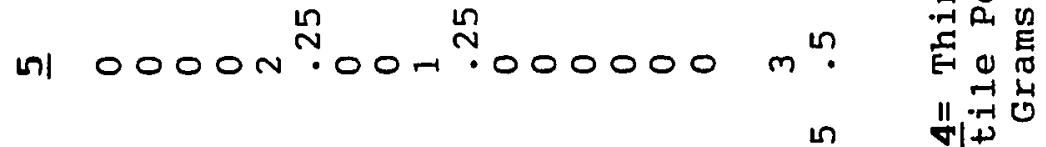

ه 0 o

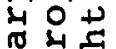

ह 응

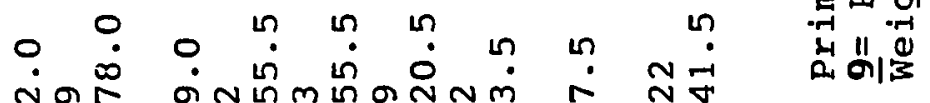

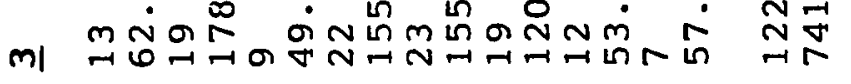

mi

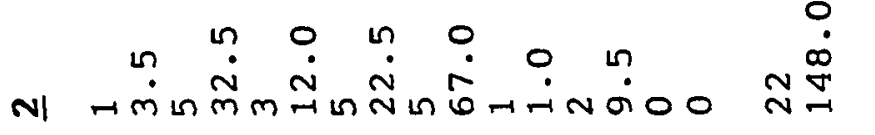

$\rightarrow \underbrace{\infty}$

(1)

$\begin{array}{ccc}u & 0 \\ -1 & 0 & 0 \\ +1 & 0 & 0\end{array}$

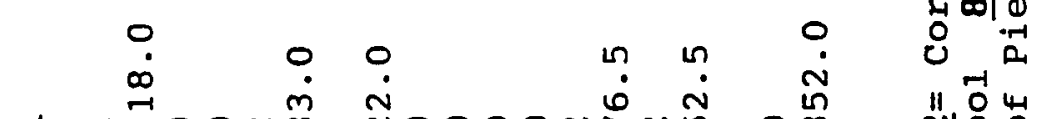

-1 N $\stackrel{\infty}{\text { r }}$ ON $\dot{m}$ -

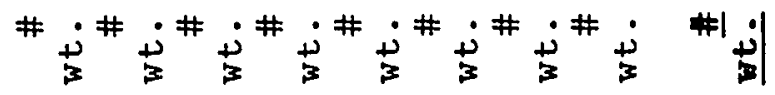

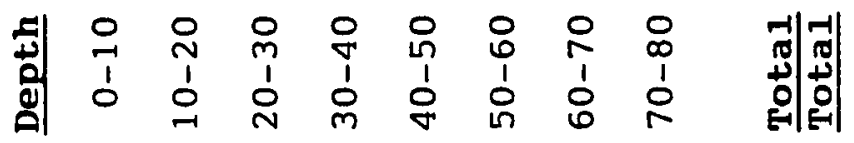

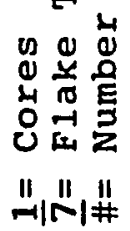


Fifteen cobble artifacts were found. These included milling tools reflective of both acorn and hard seed processing technologies. SMa-244 produced 5 cobble artifacts per cubic meter of site. Cobble tools have been described in Appendix E. Table 94 presents the types of cobble tools from this site.

Table 94: Cobble Artifacts from SMa-244 (N= 15)

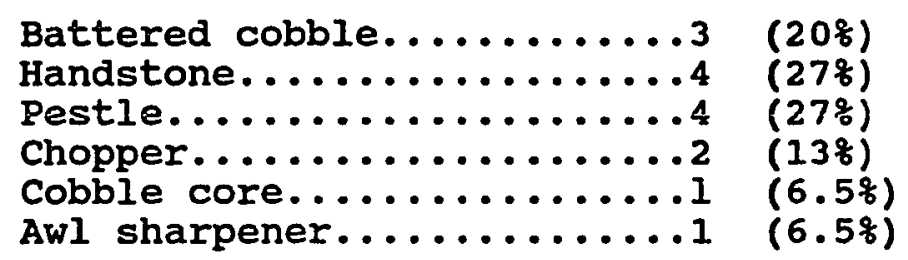

Fifteen stone beads were also recovered from SMa-244. These were of gray to gray green colored steatite, and were disc shaped with straight, perpendicular shoulders. Both conically and bi-conically drilled apertures were noted, and many of the specimens exhibited a shallow groove on one or both faces of the bead. These grooves crossed over the face of the bead at the aperture. These grooves gave the bead an appearance of having been fastened to something by tying the bead on so that it rested flat on the object. They did not appear to have been strung on a line face to face. These beads are described in Table 95.

Several large lumps of asphaltum were retrieved from unit 2. They had no definitive shape and were fragmented. The asphaltum may have been collected for exchange with 


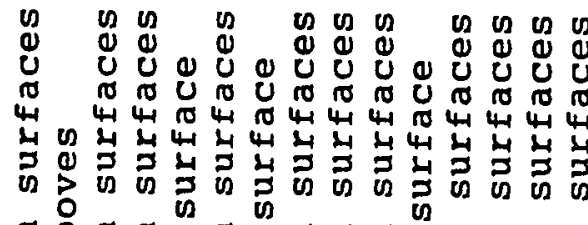

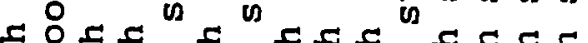

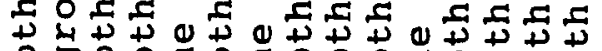
م

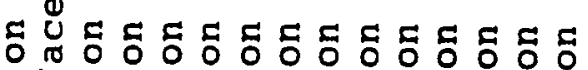
4

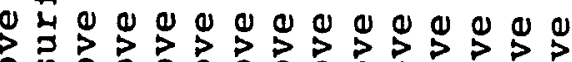

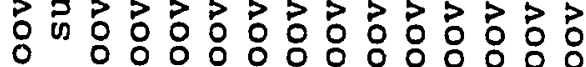

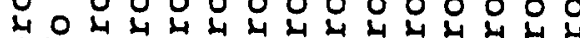

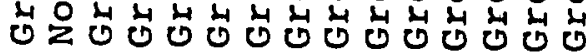

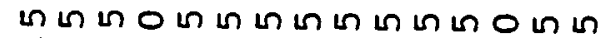
$\dot{N} \dot{N} \dot{N} \dot{N} \dot{N} \dot{N} \dot{N} \dot{N} \dot{N} \dot{N}$

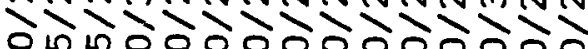
$\dot{N} \sim \dot{m} \dot{m} \dot{m} \dot{m} \dot{m} \dot{m} \dot{m}$

চ O - $\begin{aligned} 0 \\ 0\end{aligned}$

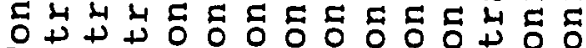

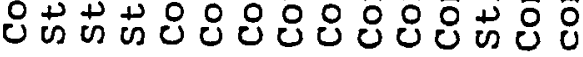

市

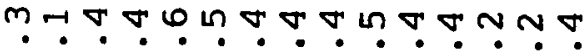

- n!no $\dot{N} \dot{-i} \dot{\dot{r}} \dot{\nabla} \dot{m} \dot{m} \dot{m} \dot{m} \dot{m} \dot{N} \dot{N} \dot{m}$ ln 00000 in 000 in 0000

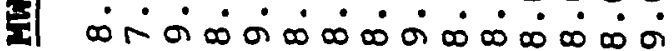

I) 0 in o. o. o in o o in in un o in ம $\dot{0} \dot{\sigma} \dot{\sigma} \dot{\sigma} \dot{\infty} \dot{\sigma} \dot{\sigma} \dot{\infty} \dot{\infty} \dot{\infty} \dot{\infty}$

舟

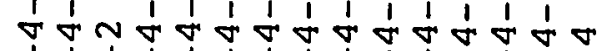

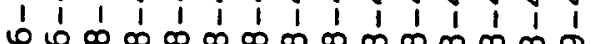

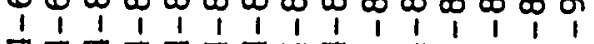

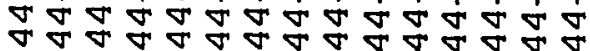

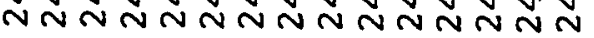

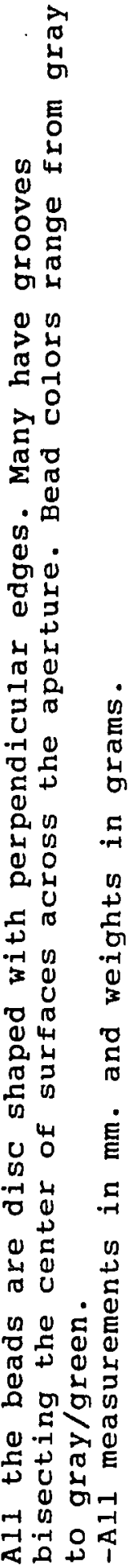


interior groups along with the olivella shells. The asphaltum probably came from the seep still visible today near the town of Davenport.

SMa-244 represents a single component Late Period forager residential base. This conclusion is based upon the site stratigraphy, artifact types, and obsidian hydration readings. The abundance of asphaltum and raw olivella shells implies that the site may have been located in an area from which exchange items passed to and from the interior santa Clara Valley. The number of obsidian stockton serrated points and steatite beads are evidence of exotic materials being acquired from the interior people. Abundant Monterey chert debitage and the absence of chert stone tools may indicate that Monterey chert cores were being processed prior to their export. The debitage study does show a high percentage of initial reduction stage pieces. A wide diversity of terrestrial fauna and fish bones were recovered and may reflect the need for mobility along the exchange route. Table 96 summarizes component definitions for this site. 
Table 96: Component summary from SMa-244

1) Homogeneous deposit : $0-80 \mathrm{~cm}$. Age: Late Period

Obsidian Hydration Range: Napa (N=5) $1.3-1.7$

Artifacts:

Fauna:*

Shell wt. (M3)

stockton serrated points steatite beads

Deer (20\%)

Rabbit (13\%)

$7,731.5 \mathrm{gr}$.

Pestles

skunk (2.5\%)

Handstones

Sea otter (1\%)

Cobble choppers

Fish (47\%)

Awl sharpener

Bone awls

${ }^{*}=$ Percentage of identifiable bone pieces 


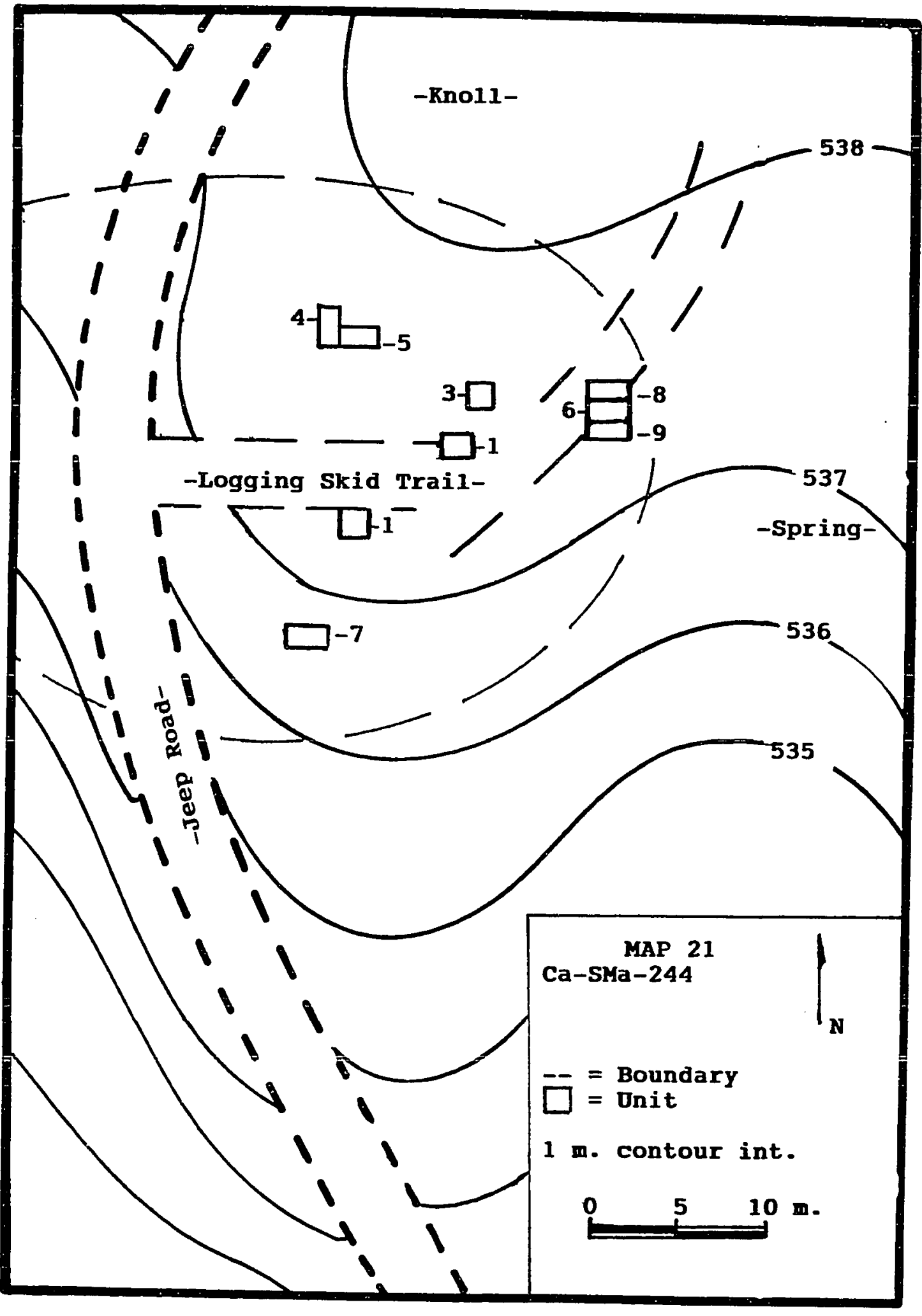



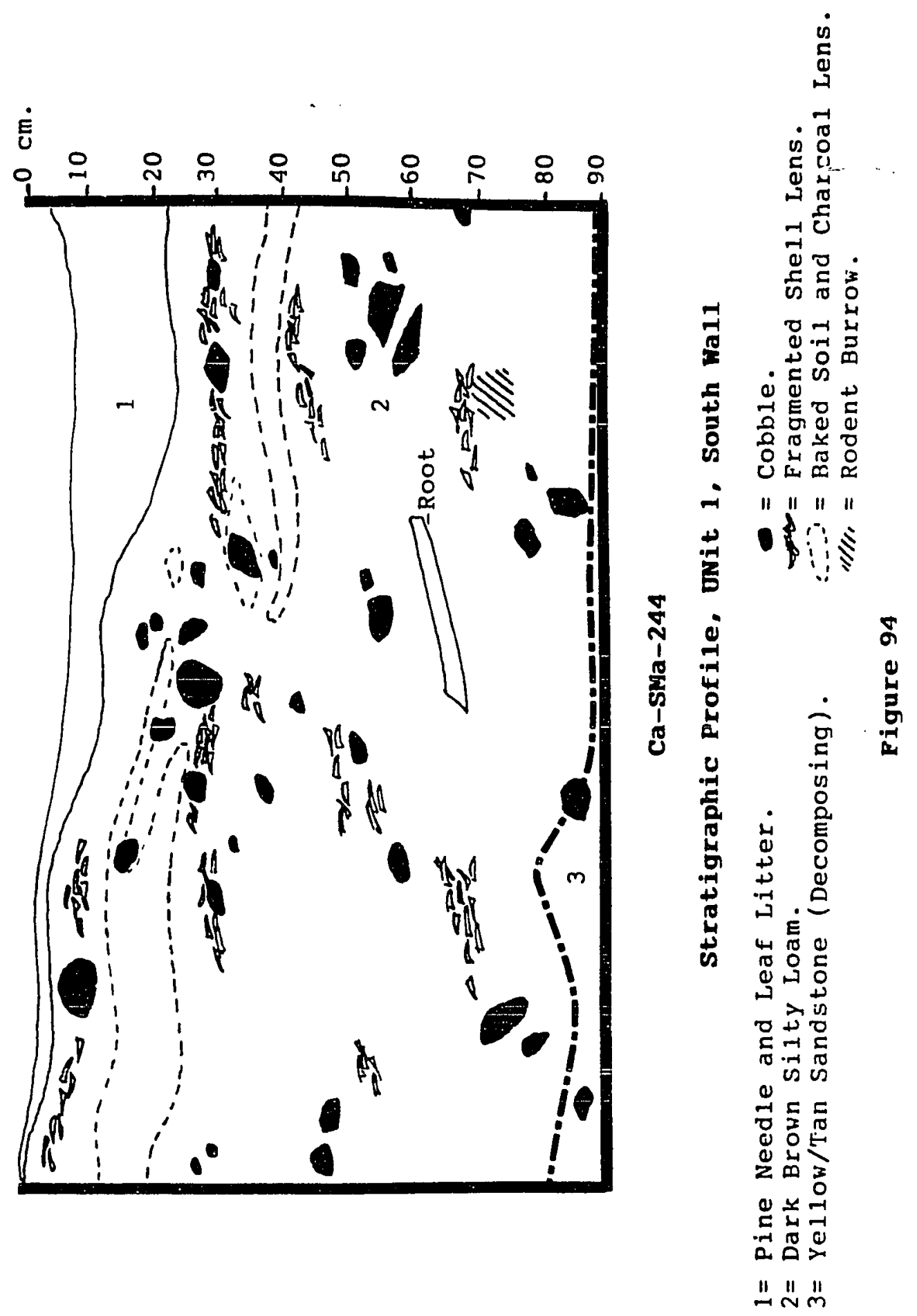


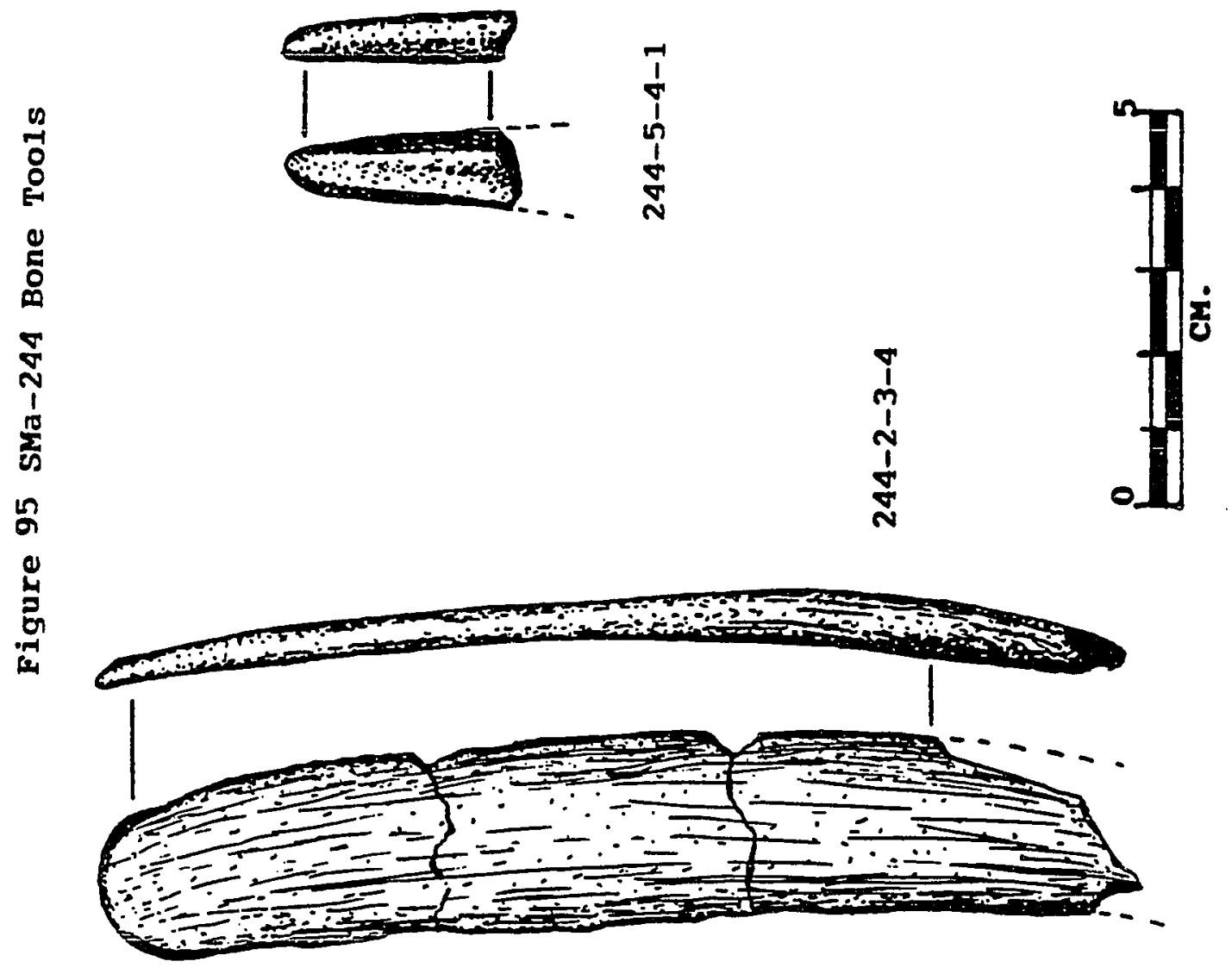




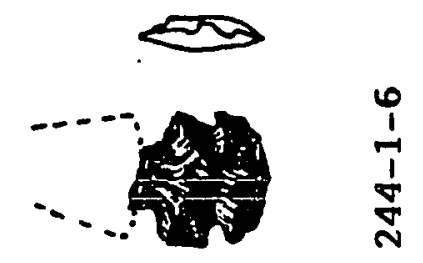

$n$
+1
0
0

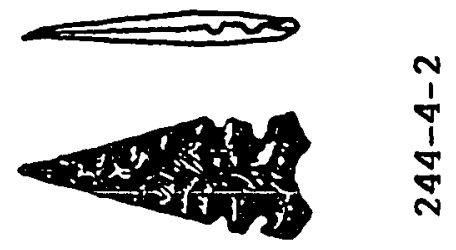

告
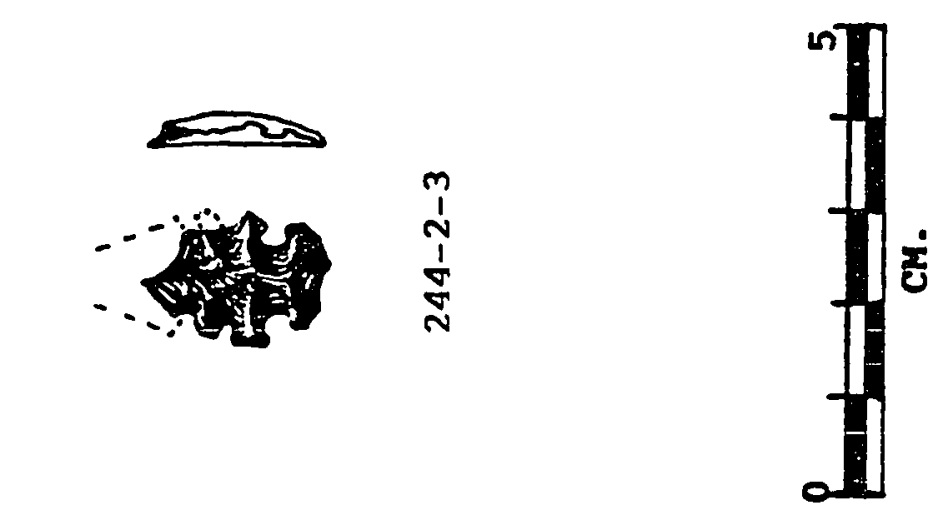

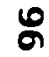

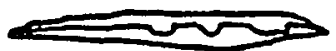

$\frac{\substack{N \\ \frac{1}{2}}}{1}$

है

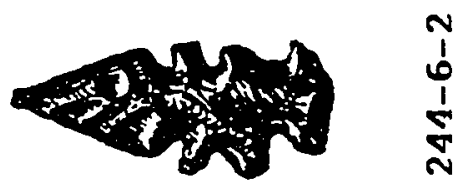

$\underset{n}{n}$

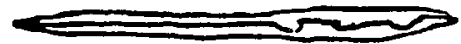

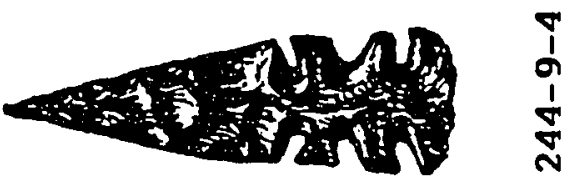




\section{CHAPTER VI}

\section{RESULTS AND CONCLUSIONS}

This chapter summarizes the findings from the excavated sites within the study area and addresses the model of forager and collector adaptive strategies. Chronological relationships of site components and their respective artifact assemblages have been established through radiocarbon dating, obsidian sourcing, obsidian hydration analysis, and cross dating ciagnostic artifact types. Adaptive patterns reflected by the recovered faunal and artifact assemblages are developed through the organization of sites into task specific and multi-use categories. The role of terrestrial and marine resources through time within these sites has facilitated the description of adaptive patterns within the study area.

This study has concluded that a generalized economic focus characteristic of a forager adaptive strategy, with an emphasis on both terrestrial and marine resources, began sometime before the Middle Period and continued well into the Late Period. This pattern required that consumers make frequent residential moves within the coastal terrace, riverine, ridge, and upland meadow ecological zones of the study area. A collector strategy characterized by consumers focusing on storable terrestrial resources, with residential bases that were occupied for longer periods of time and 
centrally located in areas where resources could be stored for redistribution, was present by the Late Period. However, the collector pattern with a narrow economic focus in which acorns played a major part was an adaptive strategy which developed outside the study area, primarily in areas where oak woodlands were extensive.

The Dietz and Jackson (1981) model which proposed that the collector strategy replaced the forager strategy sometime around 2,000 years B.P. does not hold true for the coastal region of San Mateo and Santa Cruz Counties. Both adaptive patterns co-existed, perhaps until the time of European contact.

\section{Summary of Radiocarbon Dating Results}

A total of 86 radiocarbon dates have been reported for 11 sites within the project area. Sample materials included direct associations with features as well as unassociated materials derived from midden contexts. Radiocarbon dates from the sites described in this chapter are summarized in Table 97.

The most recent dates were obtained from sites Ca-SCr20, SMa-97, SMa-115, SMa-118, SMa-139 and SMa-238. Uncorrected dates from these sites span a period ranging from circa A.D. 1500 to 800 . These sites have been assigned to the Late, or Emergent, Period as defined for other central California sites. Site SMa-238 provided a date older 
:

$\rightarrow \quad N N$

$\nabla \nabla$

n

in in

ח

in in in in in

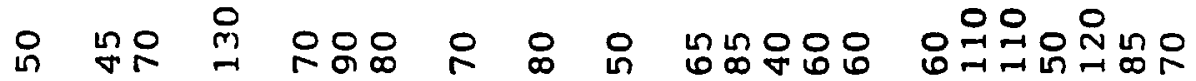

의 $+1+1+1+1+1+1+1+1+1+1+1+1+1+1+1+1+1+1+1+1+1+1$

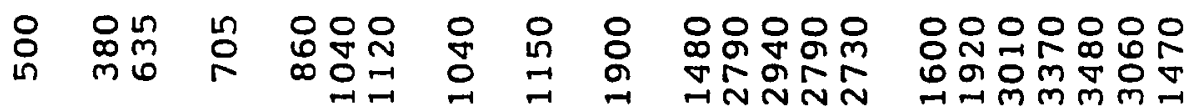

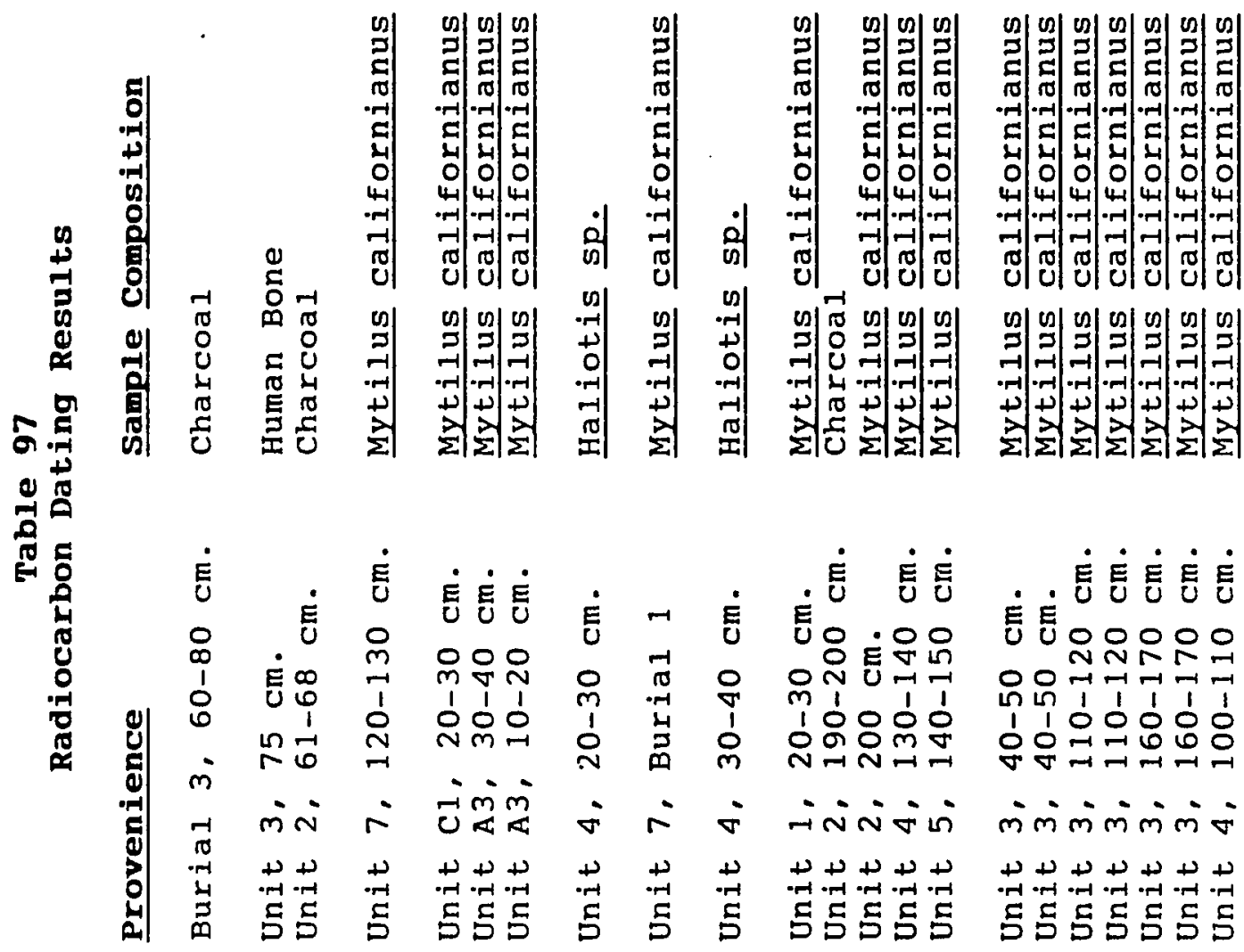

L $\nabla m$

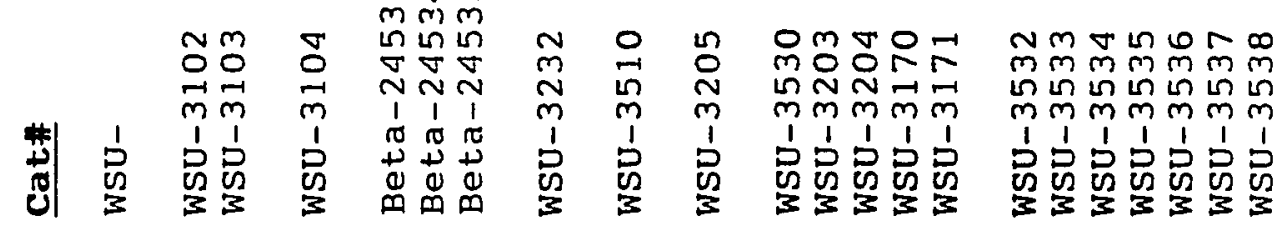

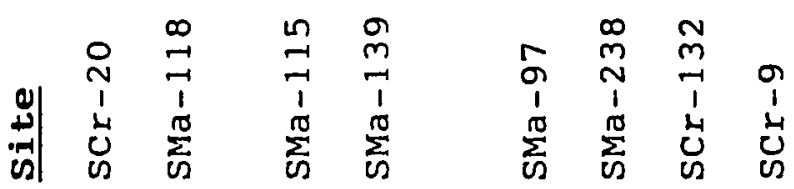

$\stackrel{m}{\stackrel{m}{\sim}}$ 
bourwort in warano

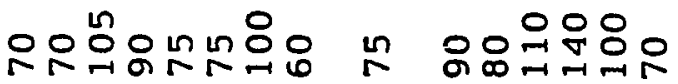

$+1+1+1+1+1+1+1+1+1+1+1+1+1+1+1$

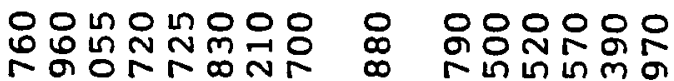

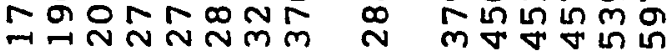

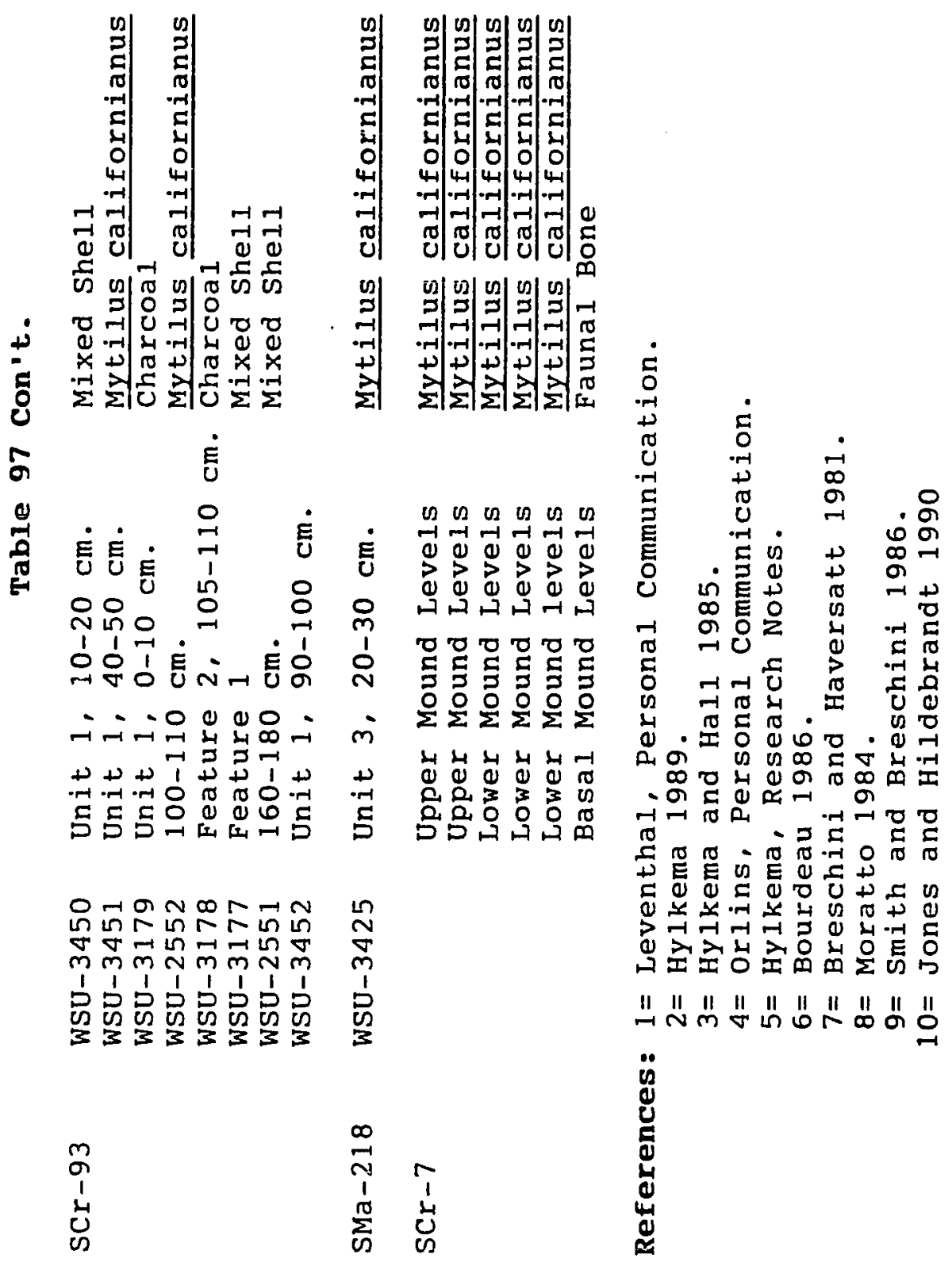


than the others, but retained an identical cobble artifact assemblage to that of the more recent Bean Hollow state Beach site, SMa-118. Both SMa-118 and SMa-238 contained human remains, grooved and pitted/dimpled cobble tools, asphaltum residues, and rock features; they lacked projectile points and obsidian, and are situated in identical locational settings.

Sites revealing greater antiquity include $\mathrm{Ca}-\mathrm{SCr}-9$, SCr-93, SCr-38/123, SCr-132 and SMa-218. These are assigned to the Middle or Upper Archaic Period which ranges from circa A.D. 700 to some time between 1000 and 1800 B.C. The only site with radiocarbon dates which may relate to an Early or Lower Archaic Period is Ca-SCr-7, which also produced projectile point types known to occur in the Middle and Late Periods. SCr-7 bears the distinction of having produced the greatest diversity of projectile point types, many of which were notched and made from exotic stone materials such as Franciscan chert and obsidian.

Several archaeological deposits provided a range of dates and temporally diagnostic artifacts reflecting repeated use of a location over a long span of time. Ca-sCr7, sCr-9, sCr-20, sCr-93 and sCr-38/123 contained various projectile point types, along with a diversity of radiocarbon dates indicating the presence of more than one temporal cluster. SCr-132, SMa-97, SMa-115, SMa-118, SMa133, SMa-218 and SMa-238 appear to represent a narrow range 
of time. Although no radiocarbon dates were submitted for SMa-244 the recovered artifact assemblage clearly identifies this site as being of Late Period age. Summary of obsidian Sourcing and Hydration Results A total of 147 obsidian specimens from 9 sites were sourced either visually or through XRF analysis. Of these, 137 were subjected to obsidian hydration analysis. The readings showed that $76 \%$ were from Northern California obsidians. Table 98 illustrates this relationship. Dietz, Hildebrandt and Jones (1986) have developed a sequence of cultural periods for the Monterey Bay region which established a Late Period represented by Napa Valley and Casa Diablo obsidians with hydration rim readings between 0.8 and 2.2 microns. A Middle Period was marked by Napa Valley hydration measurements between 2.3 and 4.1 microns and Casa Diablo measurements from 2.3 to 4.5 microns. An earlier temporal period was defined by Napa Valley readings of 4.2 to 5.6 microns and Casa Diablo readings of 4.6 to 6.1 microns. The obsidian hydration measurements from this project compare well with those from the Monterey Bay region and are tabulated in Table 99. of the Late Period sites, SMa-97 and SMa-244 contained the best single component obsidian rim readings. Of 20 specimens cut, 17 were from the Napa Valley source and had 


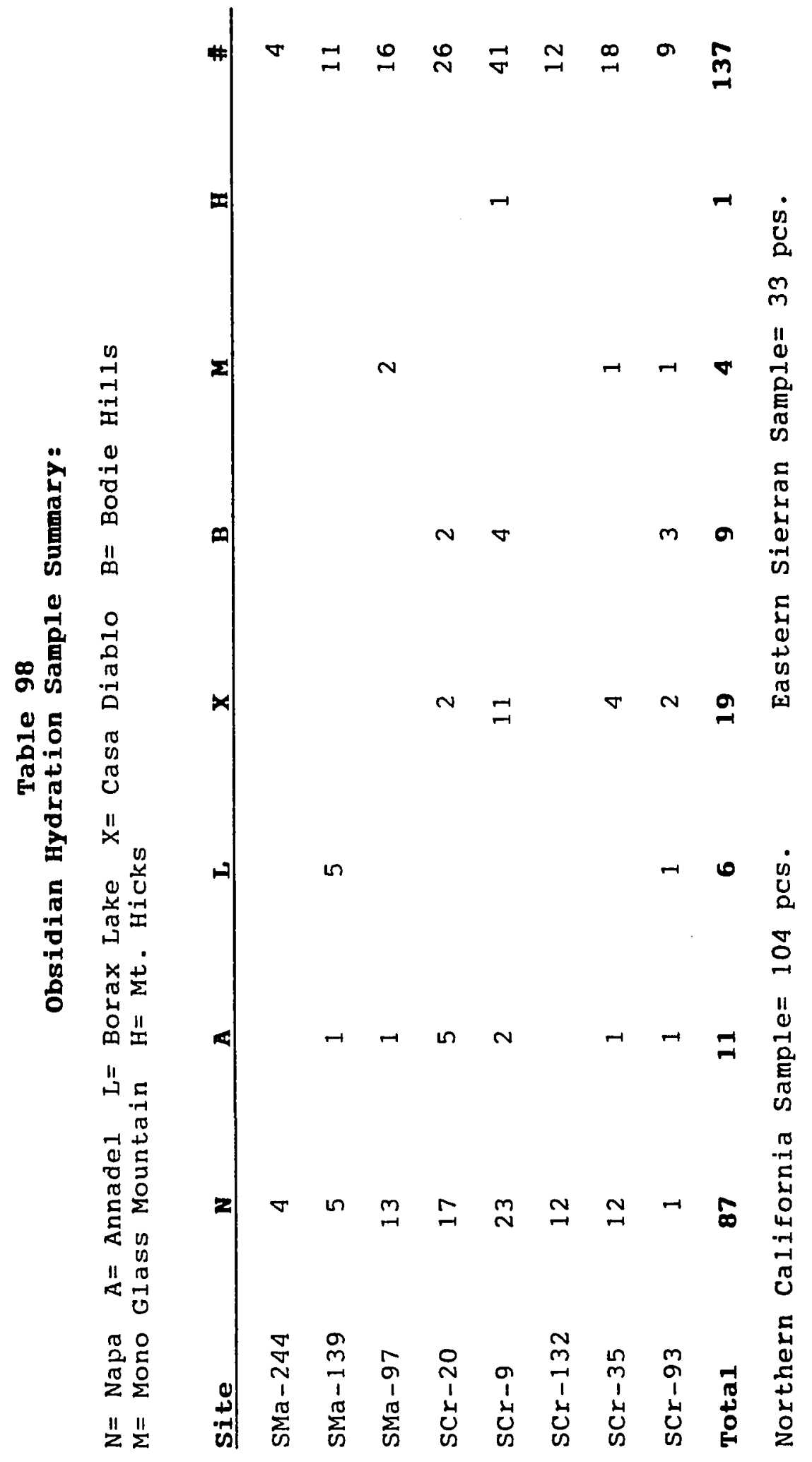




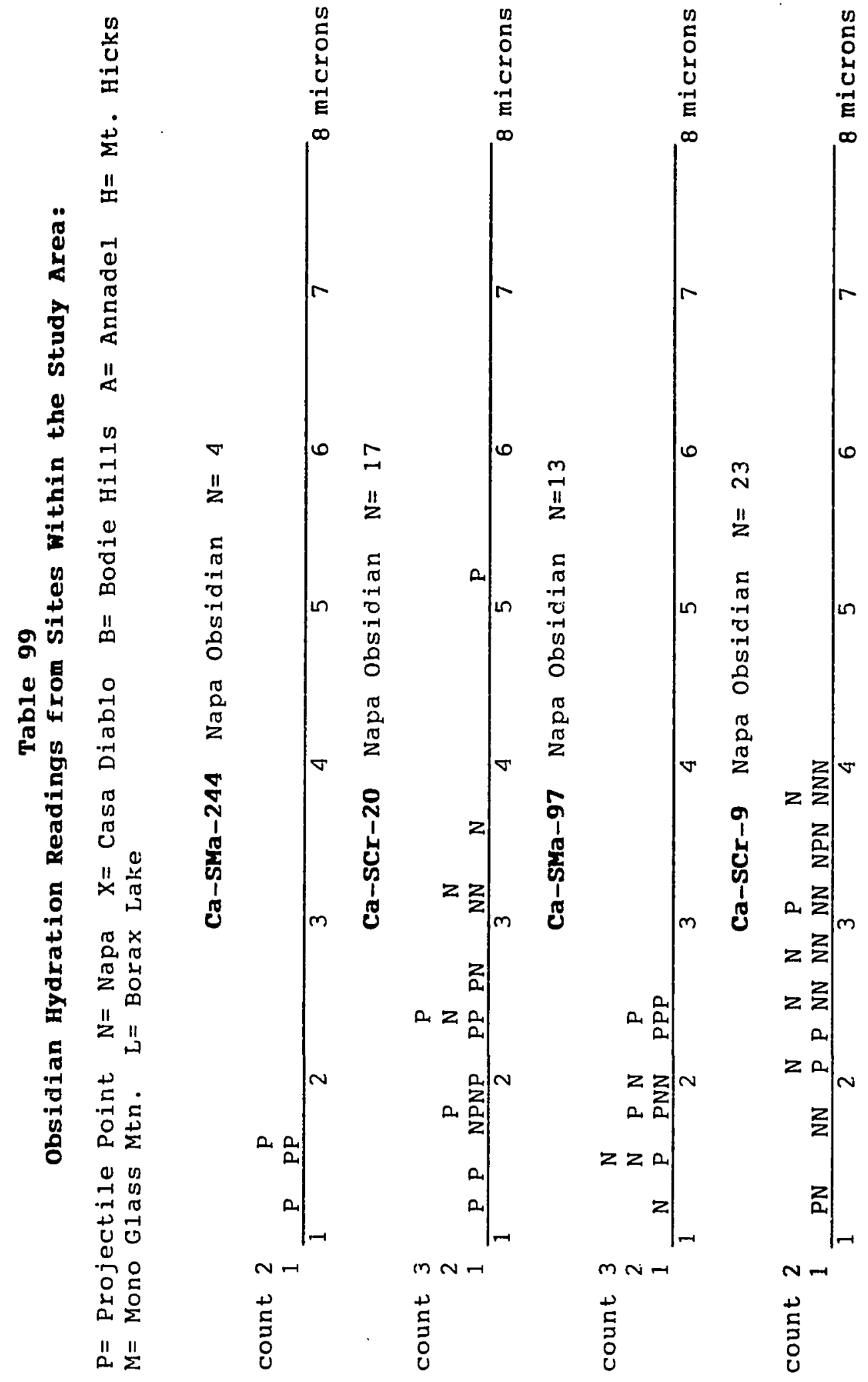




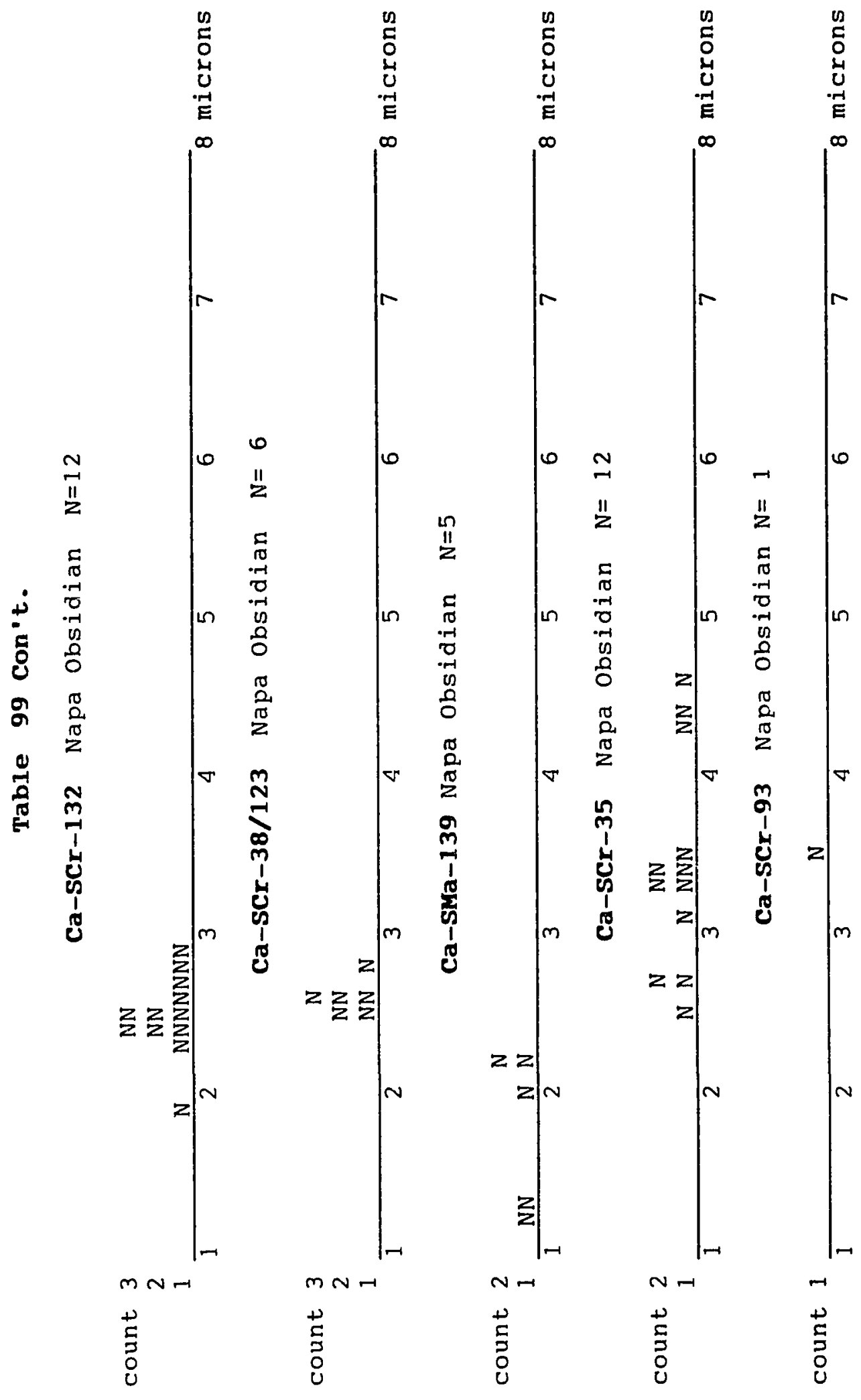




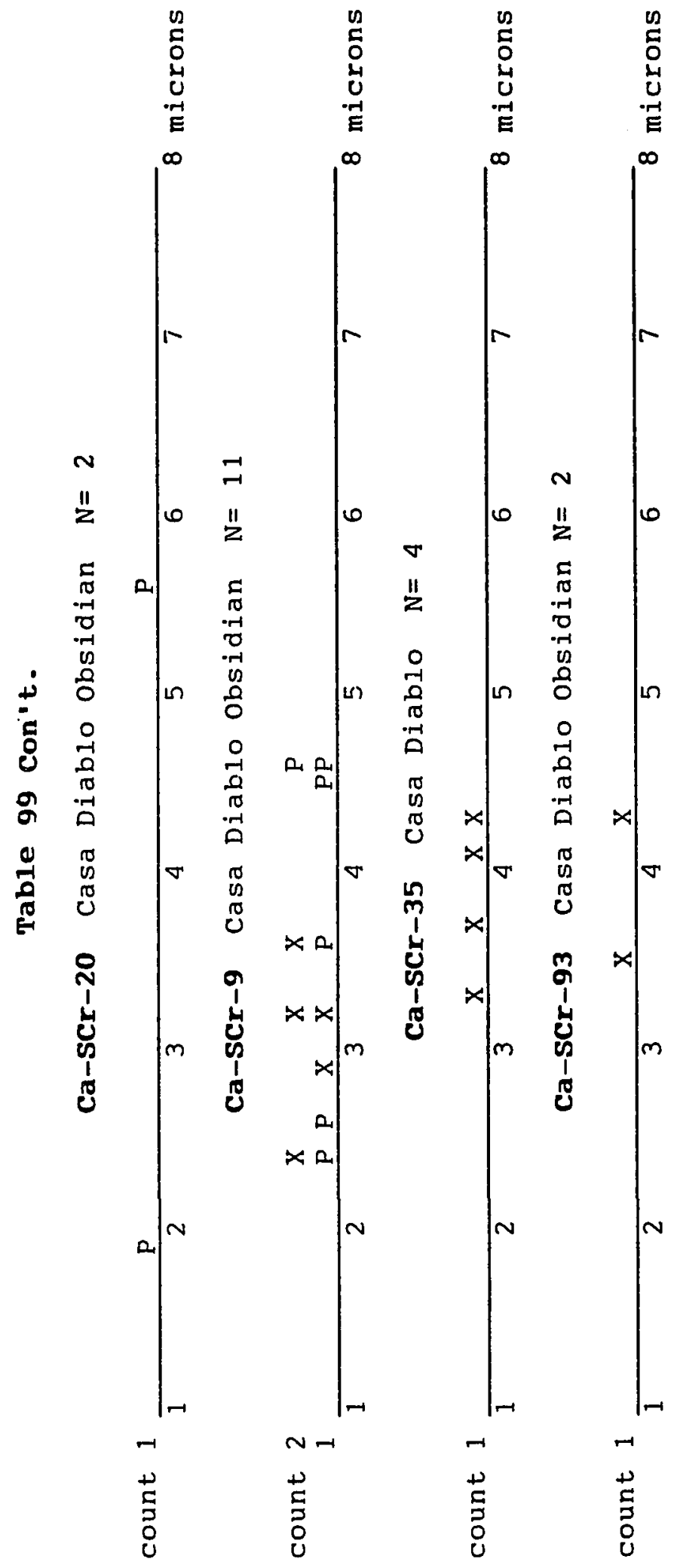




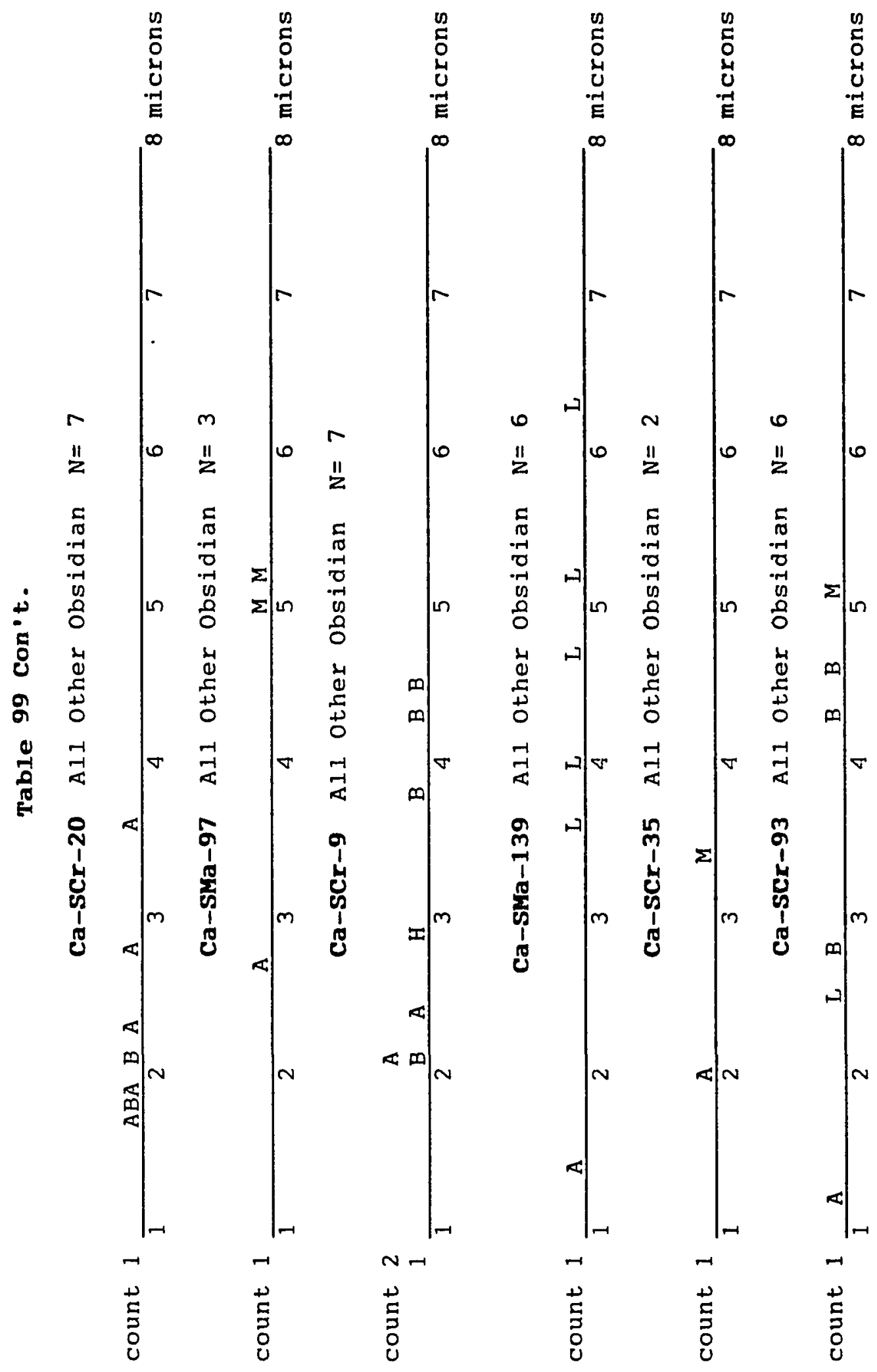


readings of 1.2 to 2.5 microns, 13 of which were 2.0 or less. Obsidian projectile points from SMa-97 consisted of leaf shaped lanceolate types, not present at sMa-244, five of which ranged from 1.5 to 2.7 microns. It is possible that these points mark a transitional time between the Middle and Late Periods.

SCr-20 exhibited an assemblage of projectile points associated with the Late Period in the upper levels of the site. Together SMa-244 and SCr-20 yielded a total of 7 obsidian stockton serrated points. Six were cut and provided rim readings of $1.2,1.3,1.4,1.6,1.6$ and 1.7 microns. This projectile point type is a well known Late Period indicator and the rim readings derived from SCr-20 and SMa244 are consistent with their proposed temporal designation. other multi-temporal sites with Late Period rim readings included SCr-9 (10\% of the sample was less than 2.0 microns and were all Napa Valley) and possibly SMa-139 (54.5\% of the sample was less than 2.2 microns, all but one was Napa, the one exception being from the Annadel source). Despite the presence of Late Period obsidian debitage at SCr-9 no artifacts diagnostic of the Late Period were found. Middle Period (Upper Archaic Period) sites with obsidian points providing hydration rim readings included sCr-9 and scr-20. Points manufactured from Napa Valley obsidian included three contracting stem specimens with readings of $3.1,3.5$ and 5.2 microns. Points from Casa 
Diablo obsidian included two footed and basal notched types similar to the Elko eared type of the Great Basin with readings of 4.6 and 4.5 microns and 2 notched types with readings of 2.6 and 3.6 microns. Obsidian points from other sources were also cut and the results are presented in Table 99.

SCr-9 contained obsidian from Napa Valley with readings ranging from 1.2 to 4.0 microns. Table 99 shows that of the six Napa pieces with readings of less than 2.2 microns, over half were found in the upper $20 \mathrm{~cm}$. of the midden. None of the Casa Diablo pieces in the upper levels were less than 2.4 microns. Of the Napa pieces with readings of 2.3 or more microns ( 17 pieces total), $53 \%$ were from levels below $40 \mathrm{~cm}$. $82 \%$ of the Casa Diablo pieces with readings greater than 2.4 microns occurred below $40 \mathrm{~cm}$. These rim readings with the radiocarbon dates have led to the following temporal component definition: an upper level from $40 \mathrm{~cm}$. to the ground surface and a lower level from 40 to $200 \mathrm{~cm}$. below the ground surface. Nearly all the Eastern Sierran specimens were found in the lower component levels (14 of 16 pieces). Shell volume peaked at $30 \mathrm{~cm}$., dropped and then peaked once again at $120 \mathrm{~cm}$. with a large volume steadily maintained from levels between 100 to $200 \mathrm{~cm}$. As mentioned in the site report, these two temporal components do not separate the artifact assemblage nor do they evidence any change in 
adaptive mode. They simply identify an older and more recent deposit within the Middle Period.

sCr-132, another Middle Period site, contained a single temporal component distribution of obsidian with 12 readings all from Napa Valley obsidian that clustered around 2.5 microns. The rim readings were all from debitage as no obsidian tools were found. Chronological sequencing of Selected Coastal sites

Based upon the radiocarbon dates, obsidian sourcing, hydration results, and cross dated artifact types, the temporal arrangement of the sites described in this chapter are presented in Table 100.

A Lower Archaic Period from 3300 to 5000 B.C. and a potenifially older Paleo-Indian Period may be evident at scr177 (Cartier 1989) located in scotts valley just outside of the study area. This site contained a single Monterey chert crescent-shaped chipped stone artifact and several ovate bipoints; also it produced a series of radiocarbon dates the earliest being $12,520 \pm 740$ B.P. Fourteen additional dates range from 6,550 to 10,570 B.C.

The Middle Archaic Period from 1100 to 3200 B.C., defined by Monterey Bay Area sites with olivella bead types Ila and L2, frequent occurrence of square-stemmed points, large barbed contracting-stemmed points, Ano Nuevo long- 


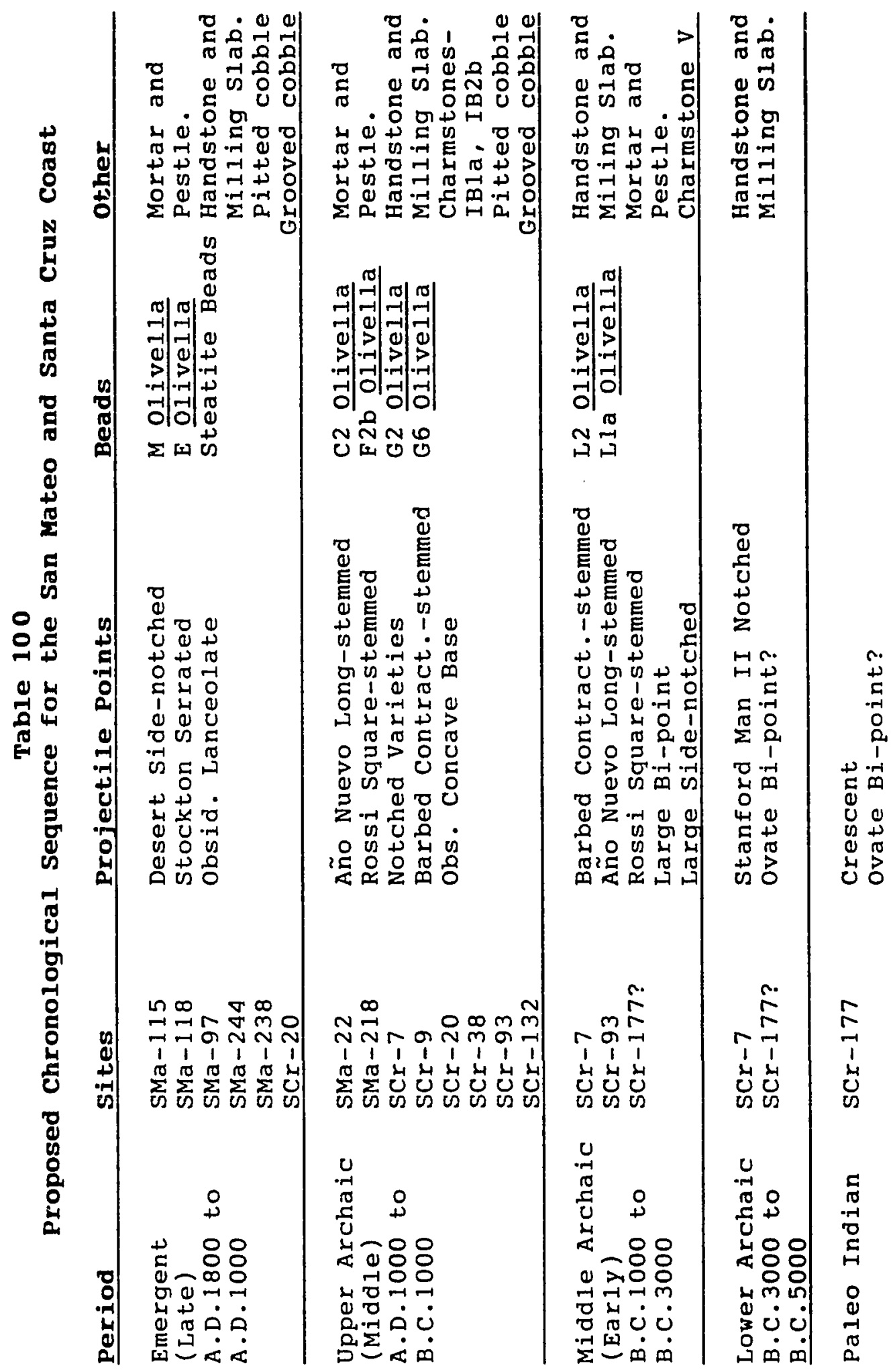


stemmed points, and possibly by large bi-points, may be present at sites found in the study area. The sand Hill Bluff site, sCr-7, produced such points as well as the Stanford Man II type. This latter point type which is typically large, notched, and exhibits a diamond shaped base was first identified in association with a human burial along San Francisquito Creek for which two radiocarbon dates on bone collagen have been reported. These dates are $2450 \pm$ 270 and $2400 \pm 125$ B.C. (Moratto 1984: 267). Interestingly, all of the stanford Man II points were made from Monterey chert. None of the sites examined for this study can adequately define this period. Obsidian hydration readings attributable to this temporal span are not available but Napa Valley readings between 4.1 and 5.6 and Casa Diablo readings from 4.6 to 6.1 microns may possibly be attributed to this time (Dietz, Hildebrandt and Jones 1986: 391).

A Middle or Upper Archaic Period spans circa A.D. 900 to 1000 B.C. and is marked by greater variation in projectile point types and materials. Dominant point types include the Ano Nuevo long-stemmed, notched forms, Rossi square-stemmed, obsidian concave base and the barbed contracting-stemmed. Olivella bead types consist of $\mathrm{C2}$, F2b, G2 and G5. Obsidian rim readings range from 2.3 to 4.0 microns for Napa Valley and 2.3 to 4.5 microns for Casa Diablo. 
A Late Period or Emergent Period for the study area comprises a time spanning circa A.D. 1769 (the time of first European contact) back to approximately A.D. 1000. This period is characterized by desert side-notched, stockton serrated and obsidian lanceolate points, Olivella type $M$ beads and steatite disk beads, and Napa Valley obsidian with rim readings between 0.8 and 2.3 microns.

Although some artifacts and obsidian hydration rim readings provide enough similarities with other Late Period central California sites, the overall adaptive strategy, reflected by location, terrestrial vs. marine economic modes, task specific vs. multi-use site distributions, and artifact assemblages as a whole, shows little deviation from the older sites. Both Middle and Late Period sites reported in the study area resemble multi-use residential bases characteristic of foragers as defined by Dietz, Hildebrandt and Jones (1986: 401). SMa-115, the Montara State Beach site, was the only radiocarbon dated site which exhibited a task specific morphology.

\section{Excavated Site Components}

Component definitions for most of the excavated sites have been presented in Chapter V. As previously mentioned, several temporal periods can be distinguished on the basis of radiocarbon dates, obsidian hydration measurements, and artifact assemblages; however, very little change in economic orientation can be discerned through time. A 
pattern of multi-use occupation sites distributed throughout the four general ecological zones defined in chapter I of this study was already established before the Middle Period and it continued well into the Late Period. The only distinctive variation in adaptive pattern appeared at site SMa-115.

SMa-115 exhibits intensive harvesting of shellfish and sea otters. The relatively complete skeletal remains of the sea otter suggests that they were harvested for their pelts. This task specific site is been dated to circa 1200 A.D. and it contrasts markedly with other coeval sites such as SMa118 .

scr-20 is quite similar to other multi-use sites within the study area; however, artifacts such as desert sidenotched points and olivella type $M$ and $E$ beads found in association with several human burials suggest that some sort of intensification of upland meadow habitat exploitation was occurring. Desert side-notched points constituted the majority of points recovered from this site. They were not found in other coastal contexts within the study area, a single specimen from the surface of $\mathrm{sCr}-7$ being the only exception. All desert side-notched points were made from the locally available Monterey chert. Late Period and Middle Period sites along the coastal terrace zone produced a varied assemblage of cobble tools which were equally distributed among them. These artifacts 
include mortars and pestles, handstones and milling slabs, pitted/dimpled cobbles, grooved and notched cobbles, awl sharpeners, choppers and informal cobble tools. Upland meadow sites have the same cobble tools but pitied/dimpled cobbles, grooved cobbles, and edge notched cobbles are fewer in number. The limited occurrence of pitted/dimpled, edge notched, and grooved cobbles in the upland meadow zone probably related to coeval activities along the coastal terrace zone. SCr-9 produced a large volume of mussel shells, as did scr-20, which indicates that the occupants of those sites continued to rely on marine resources despite their hunting focus on terrestrial herbivores. Middle Period projectile points consisting of the Ano Nuevo long-stemmed, Rossi square-stemmed, notched forms, and other distinctive points were not restricted to specific ecological zones. Ano Nuevo long-stemmed points were most abundant. They were almost always made from locally available Monterey chert, and were recovered at sites with a focus on terrestrial game as well as at sites focused on marine game.

Faunal remains recovered from the Middle Period sites reflected the range of species available in the immediate vicinity of any given site. While marine mammals and shellfish from the coastal terrace zone were present in upland meadow sites, terrestrial fauna dominated. Conversely, coastal terrace sites were dominated by marine 
species, but terrestrial herbivores continued to be exploited as well. The same was true of the Late Period sites. The dominance of one species over others at a given site was found to be offset by species at coeval sites in other ecological zones. This fits the pattern of forager behavior where groups of people are moving from one resource location to another, obtaining seasonally abundant species. Adaptive Modes

Dietz and Jackson proposed that early foraging populations organized into small groups who made residential moves among a series of resource locations in the coastal and interior regions, gathering resources on an encounter basis. The mobile nature of this adaptation precluded the need for stored food resources. It was expected that people would locate themselves in places providing a high diversity of resources.

Multi-use forager residential bases were predicted to be adjacent complex coastlines with both terrestrial and marine resources. The productive nature of these places would lead to their repeated use resulting in formation of rich midden deposits. Residential sites would contain a diversity of artifacts, features, exchange items, evidence of tool production, food processing tools and human skeletal remains.

It was thought that at some time before 2000 years ago a second population, characterized as collectors, entered 
the Monterey Bay area (Breschini 1983; Dietz and Jackson 1981; Dietz et al. 1986). The collectors' adaptive mode consisted of food storage during part of the year, logistically organized resource procurement labor groups, intensive utilization of task-specific procurement stations, and semi-sedentary residence in villages centrally located among various resources.

These researchers argued that collector residential bases served as centers from which resource gathering parties originated and where most processing, storage, manufacturing and maintenance activities took place. Moreover, collector villages would be found along interior drainages within mixed hardwood forest habitats where acorn producing oaks were readily available. The storage of acorns was thought to be the basis for this adaptive strategy. Thus sites along the coast would typically reveal more taskspecific types of pursuits.

Breschini (1981: 4) has argued that the main influx of the collectors' adaptive lifeway became established in the Monterey Bay Area while the Santa Cruz Mountains continued to support a forager adaptive pattern. He concluded that the replacement of the foragers by collectors was facilitated by better technology (storage of foods), larger population and a more integrated social structure.

A forager strategy is most efficient in regions where the energy expended in gathering and storing foods, 
especially acorns, becomes too labor intensive. Within the study area a wide range of abundant resources prc vided for varied dietary and utilitarian needs, thereby offsetting the need to focus on specific resources. In contrast, a collector strategy requires that the society be organized into labor specific groups which extract local resources and return them to a central location for redistribution. Institutions must develop to manage the redistribution of these resources, and social stratification can result. As Basgall (1987) has stated in regard to acorn economies:

The level of subsistence production possible is extremely high, the potential for storage is great, and the nutritional payoffs are more than adequate. Accordingly, once established, such an adaptation would have had important effects on demographic patterns, on mobility strategies, and on the organization of intragroup relations. Conversely, intensive acorn use can be expected to emerge as a consequence of very specific conditions, not because of some inherent quality of the resource itself. (Basgall 1987: 41)

Basgall further clarifies the social implications by stating that:

Broad-spectrum economies do not have the same structural imperatives as those focused on one or a few products, and they are more resilient to fluctuation in resource availability... Perhaps most importantly, diffuse economies lack the high demands on organization that accompany more specialized ones (for harvesting, storage, territorial demarcation). (Basgall 1987: 42)

Because of the dispersed nature of mixed hardwood forest in the study area, coastal populations needed to focus on a diversity of terrestrial and marine resource zones. While acorns were indeed incorporated into the 
economy, this resource did not become a staple to the extent evident at other central California sites. The dispersed nature of the mixed hardwood forest, in contrast to the reliability and diversity of alternate resources in the study area, rendered a collector strategy inefficient.

The mixed hardwood forest covers $37 \%$ of the study area but it is a mosaic pattern throughout the uplands and along ridges. Further, in addition to acorn producing oaks, this type of forest includes a variety of hardwood trees that do not produce food crops. The coastal prairie covers $28 \%$ of the study area but is distributed along the coastal terrace zone in a continuous range. The extensive scrub prairie of the coastal terrace with its grass seeds, marine resources, terrestrial herbivores, and moderate climate encouraged a foraging adaptive strategy.

Ethnohistoric documents note that the Indians burned the coastal terrace grasslands to increase seed production and improve the browse for herbivores. Both acorn and grass seeds were described as composing a significant portion of the native diet (Bolton 1927; Lewis 1973). The frequent occurrence of mortars and pestles together with handstones and milling slabs at single component sites confirms the observation that both vegetal resources maintained equal importance throughout the Middle and Late Periods. While shell volumes varied from one site to the other, they were present at every one within the study area. 
Interestingly, Middle Period multi-use sites contained greater volumes of shell than the Late Period ones, except for the Late Period task-specific site SMa-115. Shell species from both kiddle and Late Period sites were dominated by Mytilus californianus. Only one site proved to be the exception; SMa-118 was mostly Tequla funebralis.

The relationship between marine and terrestrial hunting was examined for many of the sites by quantifying amounts of bone by identified taxa. Faunal remains from excavated sites did not reveal any particularly noteworthy shifts between terrestrial and marine species through time. Taxa contributions from four Late Period sites were compared to four Middle Period sites and are presented in Table 101. Coastal terrace sites contained a range of species from both terrestrial and marine habitats while upland meadow and ridge sites show a greater emphasis on terrestrial fauna. Late Period coastal terrace site SMa-115 had a high frequency of sea otter bone and SMa-118 had a large number of harbor seal bones while ridge site sMa-244 had a greater number of deer and fish bones. Middle Feriod upland meadow site SCr-9 had a very large number of deer bones. Middle Period coastal terrace site $\mathrm{scr}-93$ had a greater frequency of fish bones while SMa-218 had a very large number of northern fur seal remains. These patterns are consistent with a forager strategy which would be gathering these species on an encounter basis. It is likely that prehistoric 


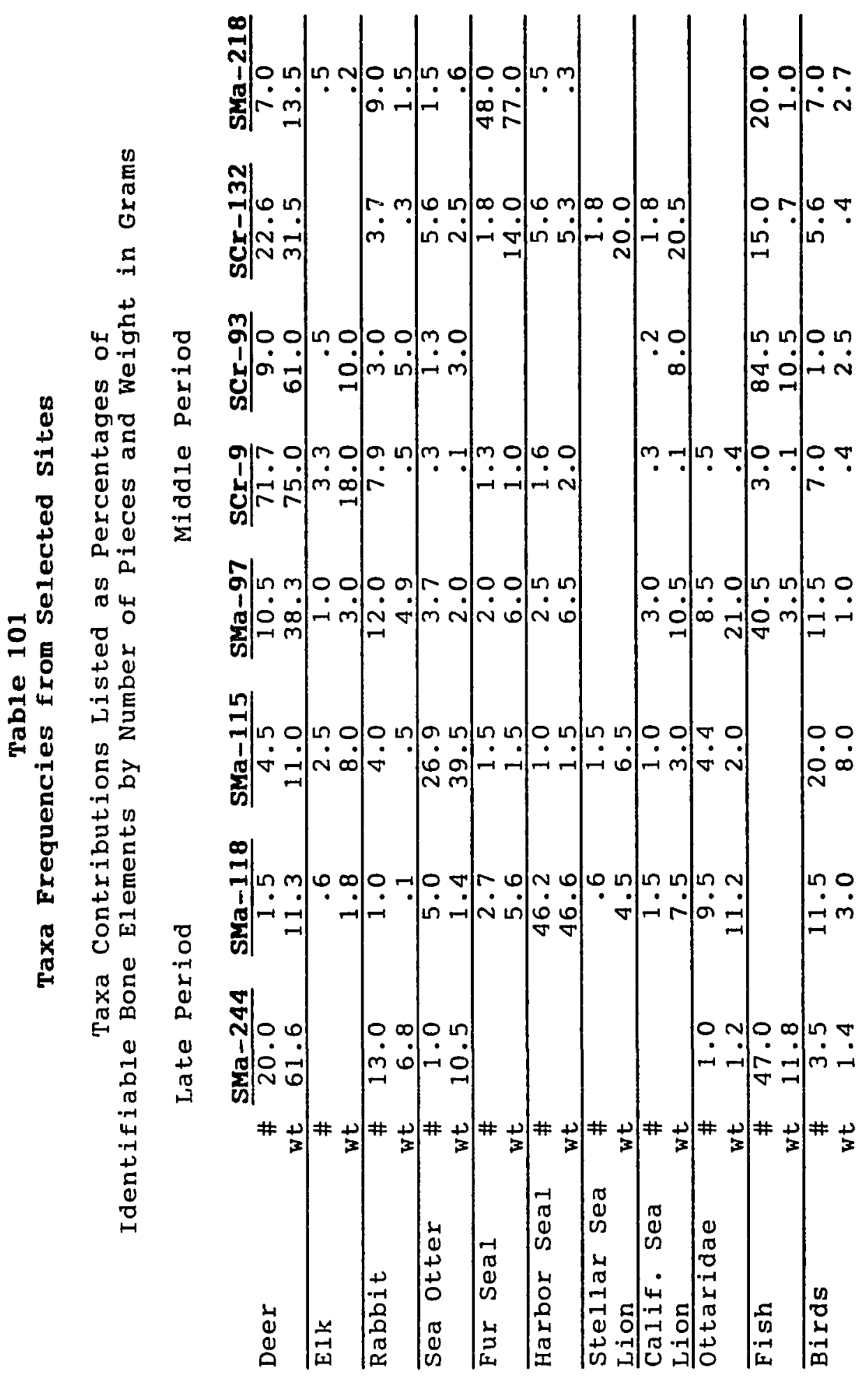


hunters knew where each species could be found in the greatest concentrations at a given time. The faunal data from these sites simply show that terrestrial and marine species do not replace one or the other during the Middle and Late Periods.

It is interesting to note that no elephant seal (Mirounga anqustirostris) bones were recovered, except for a single fragment from SMa-118 which may be recent and intrusive into the midden. Currently Ano Nuevo state Reserve has become a major rookery for these creatures after a breeding pair was first observed here in 1955 (Le Boeuf 1981).

of further interest is the large number of northern fur seal (Callorhinus ursinus) remains from SMa-218 at Ano Nuevo state Reserve. This species breeds along the Pribilof Islands of Alaska with the cows and pups migrating to the south as far as California during winter, but they remain offshore some 30 to 70 miles, rarely hauling out along the California coast (orr and Helm 1989). The very large number of their remains at SMa-218 indicate that prehistoric hunters were either going out to sea in boats to obtain them, or the behavior of the species has changed, possibly from predation by people. Since there is no evidence of a maritime adaptation at any of the coastal sites, it appears that the behavior of the species has changed. It is also possible that competition with other species resulted in the 
alteration of the fur seal's habits. Late Period site SMa118 which is just to the north of Ano Nuevo contained a large number of harbor seal (Phoca vitulina) with few northern fur seal remains. Harbor seals are year round residents, and they keep their newborn pups on shore between March and early May (Orr and Helm 1989). The timing of their reproduction may have overlapped with the migration of the northern fur seal and could possibly account for their current pelagic behavior. It is possible that the change in the northern fur seal's availability occurred between 900 B.C. and 1300 A.D. Both fur seal and harbor seal remains were present together but in far fewer numbers throughout the other Middle and Late Period sites.

The dominance of Monterey chert points and debitage through time at all of the coastal sites reflects the independence of the coastal people from groups that had greater access to Franciscan chert and obsidian. Ano Nuevo was the primary point of distribution of Monterey chert. sites nearest to this source contained exceptionally large amounts of debitage and tools in all stages of construction. It is very clear that coastal groups managed this resource and exported Monterey chert cores, bifaces and points. At SMa-218 alone over 339 chipped stone artifacts were recovered from the surface and 11.4 cubic meters of excavated site. Five stages of point construction were identified at this site, and they range from bifacial cores 
to finished points. These stages were repeated at all of the Middle Period coastal sites, with a noticeable decrease in the initial core/biface reduction stages, and an increase in exhausted polyhedral shaped bi-polar cores at sites farther away from the main source.

Monterey chert was also available to a limited degree south of Point Ano Nuevo. Chert cobbles, driven by tidal action, wash up along the beaches south of the point and sort out by particle size. Chert cobbles become smaller with greater distance from the primary source. It is likely that coastal groups within the Santa Cruz region of Monterey Bay would rely on exchange of biface tools as well as bi-polar reduction techniques in order to optimize the limitations of the resource. Middle Period site sCr-93, located at the southern end of the chert drift range, produced a great deal of bi-polar debitage.

Table 102 presents a summary of the relative frequencies of site constituents. Model of Adaptive Behavior for the Study Area

Task-specific procurement stations along the coast used by collectors were established only where they were still in range of interior residential bases large enough to furnish stored staple resources. The organization of procurement groups and the distribution of stored materials required greater political cohesion which in turn generated a need 


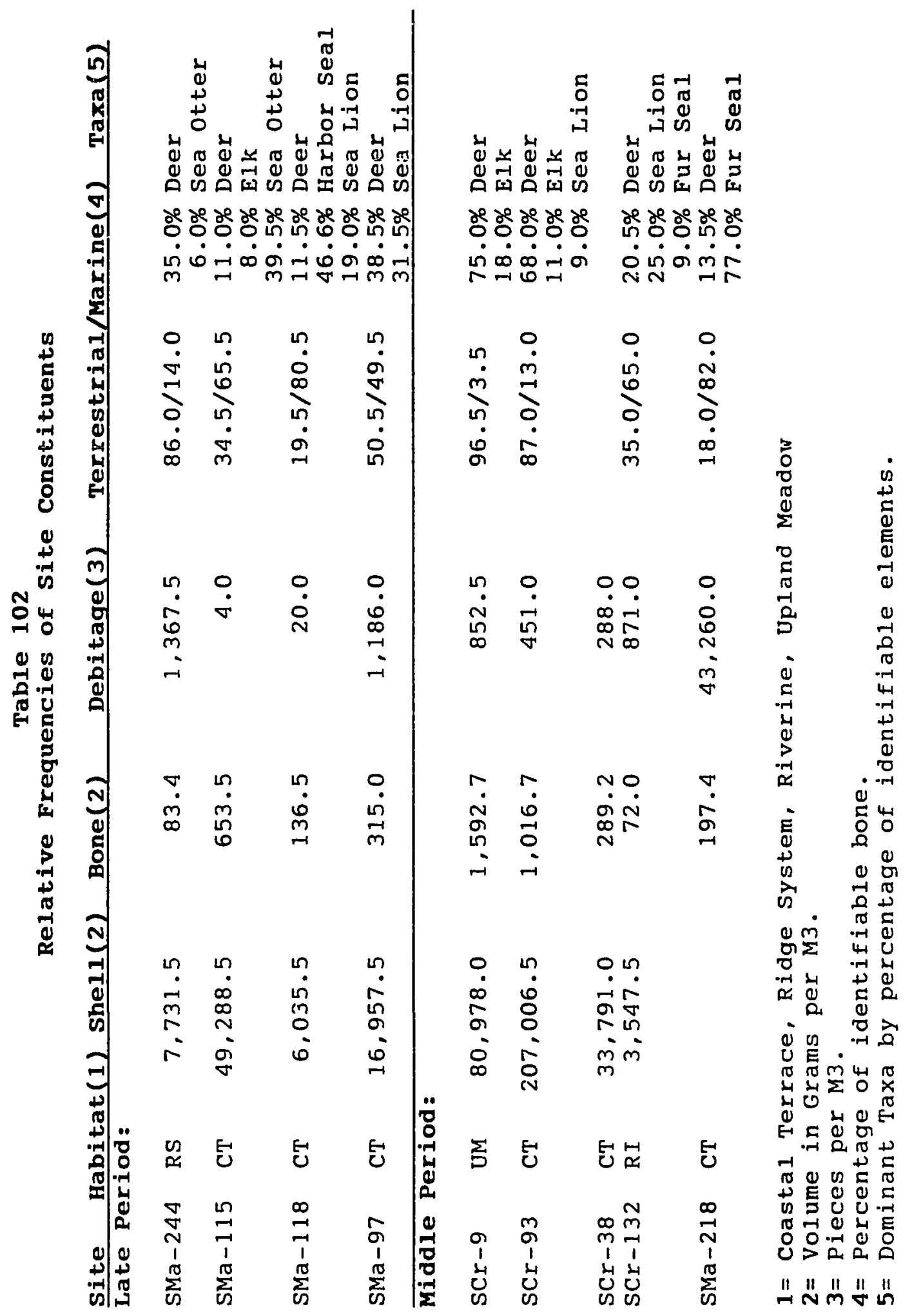


for refined socioeconomic mechanisms that provide access to a wider variety of resources.

Ethnographic and archaeological investigations within the area of the Monterey Peninsula and Carmel Valley support this observation (Broadbent 1972; Dietz and Jackson 1981). The Rumsen tribelet maintained their residential bases within the Carmel valley near the acorn bearing oak woodlands, and maintained task specific procurement stations along the coast to supplement their dietary needs. Mission register research has shown that a single Rumsen leader held the various villages together through subordinate headmen (Broadbent 1972; Milliken 1981).

Along the San Francisco Peninsula several large sites were centrally located where the residents could have access to the coast, oak groves, and bayshore habitats. Within the San Andreas Valley the large village sites of SMa-125 and SMa-147 (Morejohn and Galloway 1983; Salzman 1984) reflect the ability of Late Period San Francisco Bay groups to manipulate both the coast and bayshore in collector fashion. These sites are strategically located in the uplands of the northern extent of the Santa Cruz Mountains where the peninsula is narrow, providing easy access to villagers from the Half Moon Bay and San Francisco Bay Areas. Both coastal and interior villagers would benefit from a collector strategy and the attendant socioeconomic exchanges between them. Late Period sites in this area should reflect task 
specific activities used by residents from less mobile residential bases. So far the only Late Period site adequately documented in the Half Moon Bay Area is SMa-115, and it is task specific in nature.

The central region of the study area contained greater marine and terrestrial resource diversity but is separated from the interior by steep convoluted ridge systems and dense redwood forest. The results of this study have led to the conclusion that villagers in this region maintained a stable economic pattern over a long period of time. The residents controlled the export of raw shell for beads and ornaments, a vital economic element to the various people of Central Caiifornia. They had a reliable source of raw materials for stone tool production and export, with a ready market for these and other coastal goods to the interior (collector) groups. This relationship allowed them to continue with their foraging way of life, import exotic goods such as obsidian, and establish kinship outside of the immediate village communities.

Kinship studies based on mission records have been conducted for the San Francisco Peninsula (Milliken 1983). Milliken has shown that the area of Crystal springs was governed by a multi-village tribelet called the salshon. This group was referred to as a nation and probably resembled the political structure of the Rumsen. Marriage relations were established among the numerous local villages 
but ciecreased dramatically beyond 7.5 miles (Milliken 1983: 125).

The co-occurrence of mortar and pestle milling tools with handstones and milling slabs at sites from both the Middle and Iate Periods, the distribution of multi-use sites over a wide range of ecological zones and the generalized hunting pattern within these zones through time leads to the conclusion that a forager strategy along the coast of san Mateo and Santa Cruz Counties co-existed with a collector strategy which surrounded the study area.

Social relations established through kinship between members of groups in divergent habitats bolstered exchange networks. Well established kinship relationships and the assurance of reliable exchange systems are probabiy the primary factors which resulted in the development of cultural complexity within the various societies composing the Costanoan interaction sphere. These groups were not homogeneous and composed a system of interacting populations supported by a range of adaptive patterns that adjusted to variable ecological productivity and resource demands. Middle and Late period sites within the study area reveal that Native Americans maintained a forager adaptive strategy which co-existed with a collector strategy that had developed in surrounding areas. 


\section{REFERENCES}

Asturias, M.

1971 A Brief Account of Archaeology at SMa-110. In Treganza Anthropology Museum Papers No. 8. M. J. Moratto ed. San Francisco State University.

Barbour, M. G., and J. Majors (eds.)

1977 Terrestrial Vegetation of California. John Wiley and Sons, New York.

Barret, S. A., and E. W. Gifford

1933 Miwok Material Culture. Bulletin of the Public Museum of the City of Milwaukee 2(4): 117-376. Milwaukee, wis.

Basgall, M. E.

1987 Resource Intensification Among Hunter-Gatherers: Acorn Economies in Frehistoric California. Research in Economic Anthropology, Vol.9: 21-52.

Baumhoff, M. A., and J. S. Byrne 1959 Desert Side-Notched Points as a Time Marker in California. University of California Archaeological Survey 48: 32-65. Berkeley.

Beardsley, R. K.

1954 Temporal and Areal Relationships in Central California Archaeology. University of California Anthropological Records 24 and 25. Berkeley.

Beechey, F. W.

1831 Narrative of a Voyage to the Pacific and Berring Strait, Vol. II. London: Henry Colburn and Richara Bently.

Bennyhoff, J. A.

1950 Californian Fish Spears and Harpoons. University of California snthropological Records $9(4): 294-337$. Berkeley.

1988 Shell Artifacts from Ca-sCr-93, Santa Cruz County, California. In Archives of California Prehistory, No. 23., Breschini and Haversat eds. Coyote Press, salinas. 
Bennyhoff, J. A., and D. A. Fredrickson

1967 A Typology of Shell and stone Beads from central California. Manuscript on file with the California Department of Parks and Recreation, Sacramento.

Bennyhoff, J. A., and R. E. Hughes

1987 Shell Bead and ornament Exchange Networks Between California and the Western Great Basin. Anthropological Papers of the merican Museum of Natural History, Vol 64: Part 2. New York.

Berger, R., E. Taylor, and W. F. Libby

1966 Radiocarbon Content of Marine Shells from California and the Mexican Coast. Science: $153(3738):$ 864-866.

Bergthold, J.

1982 Prehistoric Settlement and Trade Models in the santa Clara Valley, California. Masters Thesis. Department of Anthropology, San Francisco State University.

Bickel, P. MCW.

1978 Changing Sea Levels along the California Coast: Anthropological Implications. In The Journal of California and Great Basin Anthropology 5(1): 6-20.

1981 San Francisco Bay Archaeology: Sites Ala-328, Ala-13 and Ala-12. Contributions of the University of California Archaeological Research Facility No. 43. Berkeley.

Binford, L. R.

1988 Willow Smoke and Dog's Tails: Hunter-Gatherer Settlement Systems and Archaeological Site Formation. American Antiquity No. 45: 4-20.

Blake, w. P.

1856 Notice of Remarkable strata Containing the Remains of Infusoria and Polythalamia in the Tertiary Formation of Monterey, California. Philadelphia Academy of Natural Science Proceedings Vol. 7: 17251767.

Blinmann, E.

1974 An Analysis of the Faunal Remains from SCr-42. Manuscript on file with the Department of Anthropology, University of California, Santa Cruz.

Bolton, H. E.

1911 Expeditions to San francisco Bay in 1770: Diary of Pedro Fages. Academy of Pacific Coast History Publications 2(3): 141-159. 
1926 Historical Memoirs of New California by Fray Francisco Palou, 0.F.M. Vols. 1-4. University of California Press, Berkeley.

1927 Fray Juan Crespi. Missionary Explorer on the Pacific Coast, 1769-1774. Vols. 1-4. University of California Press, Berkeley.

1930 Anza's California Expeditions. Vols. 1-5. University of California Press, Berkeley.

1931 Font's Complete Diary, 1775-1776. University of California Press, Berkeley.

Bourdeau, L.

1986 Report on Archaeological Investigations at Sunflower House: Ca-SCr-93, with Recommendations for cultural Resource Management. Report on File with the city of Santa Cruz Planning Department.

Brabb, E. E.

1960 Geology of the Big Basin Area, Santa Cruz Mountains, California. Doctoral Dissertation, stanford University.

Brabb, E. E., J. C. Clark, and C. B. Throckmorton

1977 Measured Sections of Paleogene Rocks from the California Coast Ranges. U.S. Geological survey open File Report 77-714. Menlo Park.

Breschini, G. S.

1981 Models of Population Movements in Central California Prehistory. Coyote Press. Salinas.

Breschini, G. S., and T. Haversat

1979 Archaeological overview of the central coast Counties: Draft for Comment. Manuscript Prepared for the Central Coast counties Regional office, Aptos, California.

1980 Preliminary Archaeological Report and Management Recommendations for Ca-Mnt-170, on Pescadero point, Monterey County, California. Report on File at the Northwest Information Center of the California Archaeological Inventory, Sonoma State University.

1981 Archaeological Test Excavations at Ca-sCr-93, with a discussion of Models of Central California Prehistory. Coyote Press. Salinas. 
1982 Monterey Bay Prehistory. Paper Presented at the Annual Meeting of the Society for California Archaeology, Sacramento.

Breschini, G. S., T. Haversat, and J. Erlandson

1984 California Radiocarbon Dates. Third Edition. Coyote Press. Salinas.

1985 California Radiocarbon Dates. Fourth Edition. Coyote Press. Salinas.

Brechini, G., T. Haversatt, J. Shepard, and P. Wigand

1985 Radiocarbon Determinations from Ca-SCr-79, Capitola, California. Paper Presented at the Annual Meeting of the Society for California Archaeology. San Diego.

Broadbent, S. M.

1972 The Rumsen of Monterey, an Ethnography from Historical sources. Contributions of the University of California Archaeological Research Facility No. 14: 45-93. Berkeley.

Brown, A. K

1973 Indians of San Mateo County. In La Peninsula: Journal of the San Mateo County Hictorical Association 17 (4).

Cartier, R.

1989 Scotts Valley Chronology and Temporal stratigraphy. In Proceedings of the society for California Archaeology Vol. 2: 81-112.

1984 The Saunders Site (Ca-MNt-391): Excavation and Preliminary Analysis. Paper read at the 1984 Society for California Archaeology Northern California Data Sharing Meeting, Aptos.

1979 Archaeological Recovery Program, Caltrans ol-Mon-165.8, Site Ca-Mnt-185, Soberanes Creek. Report on file at the Northwest Information Center of the California Archaeological Inventory, Sonoma state University, Rohnert Park.

Chartkoff, J. L., and K. K. Chartkoff

1984 The Archaeology of California. Stanford University Press. Stanford.

Chorley, R. J., and B. A. Kennedy

1971 Physical Geography: A Systems Approach. PrenticeHall, Englewood Cliffs, New Jersey. 
Clark, J. C., and J. D. Reitman

1973 oligocene Stratigraphy, Tectonics, and

Paleogeography Southwest of the San Andreas Fault, Santa Cruz Mountains and Gabilan Range, California Coast Ranges. United States Geologic Survey

Professional paper 783. Menlo Park.

Clark, M. C.

1986 Archaeological Investigations of the Mussel Rock Site, Ca-SMa-72, San Mateo County, California. Coyote Press. Salinas.

Coberly, M. B.

1973 The Archaeology of the Ryan Mound, Site Ala-329, a Central California Coastal village site. University of Northern Colorado Museum of Anthropology occasional publications in Anthropology, Archaeology Series 4.

Cooley, T. S.

1984 Biface Reduction Technique at a Southern California Quarry Workshop Site Ca-IAn-844. Pacific Coast Archaeological society Quarterly 20 (3). San Luis Obispo.

Cooper-Clark and Associates

1975 Preliminary Map of Landslide Deposits in Santa Cruz County, California. In Seismic safety Element, An Element of the Santa Cruz County General Plan. Manuscript on File with the Santa Cruz County Planning Department.

Costanso, $M$.

1910 The Narrative of the Portola Expedition of 17691770. A. van Hemert and F. Teggert eds. Publications of the Academy of Pacific Coast History 1(4): 3-69.

Crabtree, D. E.

1972 An Introduction to Flintworking. Occassional Papers of the Idaho State University Museum 28 (I and II). Boise Idaho.

1971 A Glossary of Flintworking Terms. Tebiwa: Journal of the Idaho State University Museum No 14: 32 98.

Davis, J. T., and A. E. Treganza

1959 The Patterson Mound: A Comparative Analysis of Site Ala-328. University of California Archaeological Survey Report No. 47, Berkeley. 
Dietz, S. A.

1985 Final Report Archaeological Test Excavations Ca-Mnt101. Ca-Mnt-298, Ca-Mnt-929 and El Castillo at the Presidio and city of Monterey, Monterey county. Report on file at the Northwest Information Center of the California Archaeological Inventory, Sonoma state University, Rohnert Park.

Dietz, S. A., and T. L. Jackson

1970 An Archaeological and Historical Survey of a Portion of the San Mateo County Coastside. Manuscript on file at the Northwest Information Center of the california Archaeological Inventory, Sonoma state University.

1981 Report of Archaeological Excavations at Nineteen Archaeological sites for the stage 1 Pacific GroveMonterey Consolidation Project Regional sewerage system. Vols. 1-4. Report Prepared for EngineeringScience, Inc. Berkeley.

Dietz, S. A., T. Jones, and W. R. Hildebrandt

1986 Final Report of Archaeological Data Recovery Program at Ca-Mnt-229, Moss Landing, Monterey County, California. Report on file with the California Department of Transportation. Sacramento.

Dondero, $\mathbf{s}$.

1984 Preliminary Report on Archaeological Testing at CaMnt-229. Report on File with the California Department of Transportation, District 5. San Luis obispo.

Elsasser, A.

1986 Review of the Prehistory of the Santa clara Valley Region, California. Archives of California prehistory No. 7. Coyote Press, Salinas.

Fages, $P$.

1937 A Historical, Political, and Natural Description of California (November 20, 1775). H. E. Priestly, trans. University of California Press. Berkeley.

Flenniken, J. J., and J. C. Haggarty

1980 Trampeling as an agency in the Formation of Edge Damage: An Experiment in Lithic Technology. Northwest Anthropological Research Notes No 13: 208214 . 
Fredrickson, D. A.

1968 Archaeological Investigation at CCO-30 Near Alamo, Contra Costa County, California. Center for

California Archaeological Research at Davis, No 1. Davis.

1974 Cultural Diversity in Early Central California: A view from the North Coast Ranges. In The Journal of California Anthropology, 1(1): 41-53.

Galloway, J. P.

1976 An Analysis and Comparison of Burial Data from CaSMa-125. Masters Thesis. San Francisco State University.

Gerow, B. A.

1967 The Problem of culture Sequences in central California Archaeology. Paper Presented to the Spring rieeting of The $\bar{A}$. $\bar{L}$. Kroeber Society. Berkeley.

1974 Co-Traditions and Convergent Trends in Prehistoric California. Occassional Papers of the San Luis obispo County Archaeological Society No. 8.

Gerow, B. A., with R. B. Force

1968 An Analysis of the University Village Complex with a reappraisal of Central California Archaeology. Stanford University Press, Stanford.

Gibson, R. O., and G. Fenenga

1978 A Preliminary Analysis of the Shell Beads and ornaments from Ca-SCl-128. In Archaeological Investigations at the Holiday Inn site, J. C. Winter ed. Report Submitted to the Redevelopment Agency, City of San Jose, California.

Gibson, R. O., A. Lonnberg, J. Morris, and W. Roop

1976 Report on the Excavations at Kirk Creek (4-Mnt-238), Monterey County, California. Report on file with the California Department of Transportation, Sacramento.

Gifford, E. W.

1916 Composition of California Shellmounds. University of California publications in American Archaeology and Ethnology No. 12. Berkeley.

1926 Miwok Cults. University of California Publications in American Archaeology and Ethnology 18(3): 391408. Berkeley. 
1940 California Bone Artifacts. University of California Archaeological Research Facility No. 3: 153-237. Berkeley.

1947 Californian Shell Artifacts. University of California Anthropological Records 9(1): 1-114. Berkeley.

Gifford, D. P., and F. Marshall

1984 Analysis of the Archaeological Assemblage from CaSCr-35, Santa Cruz County, California. Archives of California Prehistory No. 2. Coyote Press, Salinas.

Gordon, B. L.

1977 Monterey Bay Area: Natural History and Cultural Imprints. Boxwood Press. Pacific Grove, California.

Greengo, R.

1951 Molluscan Species in California Shell Middens. University of California Archaeological Survey Reports No. 13. Berkeley.

Hall, C. A., D. I. Jones, and S. A. Brooks

1959 Pigeon Point Formation of Late Cretaceous Age, San Mateo County, California. American Association of Petroleum Geologists Bulletin 43(12): 2885-2859.

Harrington, J. P.

1942 Culture Element Distributions XIX: Central California Coast. University of California Anthropological Records No 7: 1-46. Berkeley.

Heizer, R. F.

1949a Curved Single-Piece Fishhooks of Shell and Bone in California. In American Antiquity, $15(2): 89-97$.

1949b The Archaeoloay of Central California I: The Early Horizon. University of California Anthropological Records No. 12. Berkeley.

1953 The Archaeology of the Napa Region. University of California Archaeological Research Facility $12(6)$ : 225-358. Berkeley.

1974 The Costanoan Indians. Local History studies, Vol. 18. De Anza College Local History Center. Cupertino.

Hildebrandt, $\mathbf{w}$. R.

1983 Archaeological Research of the Southern Santa clara Valley Project. Report Prepared for the California Department of Transportation, District 4. San Francisco. 
Hoover, R. I., and W. B. Sawyer

1977 The Los Osos Junior High Site, SLo-214. San Luis Obispo Archaeological Society Occasional Paper II, San Luis Obispo.

Hylkema, M. G.

1989a The Archaeology of Ca-SCr-38/123: Lithic and Radiocarbon Dating Analysis, Wilder Ranch State Park, Santa Cruz County, California. Report Prepared for the California Department of Parks and Recreation. Sacramento.

1989b Archaeological Survey Report, California Forest Vegetation Management Program RX-4-002 SBU, Iands of Carney Controlled Burn Project, San Benito county. California. Report on file with the California Department of Forestry and Fire Protection, Sacramento.

1985 The Archaeological Excavation of Ca-SMa-118, Bean Hollow state Beach. San Mateo county, California. Report Prepared for the California Department of Parks and Recreation, Sacramento.

Hylkema, M. G., with J. T. Hall

1985 Preliminary Report on the Archaeological Data Recovery Excavation at SMa-115, Montara state Beach. Report Prepared for the California Department of Parks and Recreation, Sacramento.

Jackson, R. H.

1983 Disease and Demographic Patterns at Santa Cruz Mission, Alta California. In Journal of California and Great Basin Anthropology $5(1$ and2): 33-57.

Jackson, T. T.

1974 The Economics of Obsidian in Central California Prehistory: Applications of X-Ray Flouresence Spectrography in Archaeology. Masters Thesis. Stanford University.

Jones, D., and W. R. Hildebrandt

1990 Archaeological Excavation at Sand Hill Bluff: Portions of Prehistoric site $\mathrm{Ca}-\mathrm{SCr}-7$, santa Cruz County, California. Far Western Anthropological Research Group. Report on file with the California Archaeological Inventory Northwest Information Center at Sonoma State University. 
Jones. T.

1984 The Big Creek Reserve Survey: Settlement Pattern Trends on the Big sur coast. Paper Presented at the Society for California Archaeology, Salinas.

Jones, T., and H. G. Hylkema

1988 Two Proposed Projectile Point Types for the Monterey Bay Area: The Ano Nuevo Long-stemmed and Rossi Square-stemmed. In The Journal of California and Great Basin Anthropology $10(2): 163-186$

Jones, T., S. Anderson, M. Brown, A. Garsia, K. Hildebrand, 1989 Surface Archaeology at Landells-Hili Big Creek Reserve and the Gamboa Point Properties. University of California at Santa Cruz Environmental Field Program Publication No. 18.

Keeley, L. H.

1980 Experimental Determination of stone Tool Uses. University of Chicago Press. Chicago.

King, c.

1981 Prehistoric and Early Historic California Beads. ornament 5(1). Los Angeles.

King, T. F.

1974 The Evolution of Status Ascription Around San Francisco Bay. In: 'Antap, California Indian Political and Economic Organization. L. Bean and $T$. F. King eds. Ballena Press Anthropological papers No. 2 .

Kotzebue, 0 . von

1816 Saint Francis' Bay. In The Western Gate, A San Francisco Reader. J. H. Jackson ed. 1952. New York.

Kroeber, A. A.

1925 Handbook of the Indians of California. Bureau of American Ethnology Bulletin No. 78. Washington D. C.

Kuchler, A. W.

1977 Natural Vegetation of California. Map. In Terrestrial Vegetation of California. M. G. Barbour and J. Major eds. John Wiley and Sons, New York.

La Perouse, J. F. de

1786 The Journals of Jean Francois de la Perouse. In Monterey in 1786, by Malcolm Margolin, 1989. Heyday Books. Berkeley. 
Langsdorff, G. H.

1814 Voyages and Travels in Various Parts of the World. Henry Colburn Publishers. London.

Le Boeuf, B. J., and K. Stephanie

1981 The Natural History of Ano Nuevo. Boxwood Press, Pacific Grove, California.

Leo, W. G.

1967 Plutonic and Metamorphic Rocks of the Ben Lomond Mountain Area. Santa Cruz County, California. Divisions of Mines and Geology special Report No. 91: 27-43.

Leventhal, A., and G. Seitz

1986 Lithic Analysis of Flaked stone Materials from Site Ca-SCr-93. In Report on Archaeological Investigations at Sunflower House: Ca-sCr-93. I. Bourdeau ed. Report Prepared for the City of Santa Cruz Planning Department.

Leventhal, A., G. Seitz, and R. Giles

1989 Lithic Analysis. In The Archaeological Excavation of Ca-SMa-118, Bean Hollow State Beach, San Mateo County, California. M. Hylkema ed. Report Prepared for the California Department of Parks and Recreation. Sacramento.

Levy, R.

1978 Costanoan. In Handbook of North American Indians Vol 8. California. Smithsonian Institute. Washington D.C.

Lewis, H. T.

1973 Patterns of Indian Burning in California: Ecology and Ethnohistory. L. Bean ed. Ballena Press Anthropological Papers No. 1: 1-10.

Lillard, B., R. F. Heizer, and F. Fenenga

1939 An Introduction to the Archaeology of Central California. Sacramento Junior College Department of Anthropology Bulletin 2. Sacramento.

Loud, L. L.

1915 Fieldnotes Concerning Excavations at the Princeton Site SMa-22. Manuscript on file at the University of California Archaeological Research Facility, Berkeley. 
Mikkelsen, P.

1985 A Study of Millingtool Form and Function Applied to North Coast Ranges, California. Masters Thesis. Sonoma state University.

Milliken, R. T.

1981 Ethnohistory of the Rumsen: The Mission Period. In Report of Archaeological Excavations at 19 Archaeological sites for the stage 1 Pacific GroveMonterey Consolidation Project of the Regional Sewerage System. S. Dietz and T.Jackson 1981. Volume 1. Report Prepared for the City of Monterey, California.

1983 The Spatial Organization of Human Population on Central California's San Francisco Peninsula at the Spanish Arrival. Masters Thesis. Sonoma State University.

Morejohn, G. V.

1976 Evidence of the Survival to Recent Times of the Extinct Flightless Duck, Chendytes lawii. In Collected Papers in Avian Paleontology Honoring the goth Birthday of Alexander Westmore. S. L. Olsen ed. Washington D. C.: Smithsonian Contributions to Paleontology Vol.27: 207-211.

Morejohn, G. . V., and J. P. Galloway

1983 Identification of Avian and Mammalian Species Used in the Manufacture of Bone Whistles Recovered from a San Francisco Bay Area Site. In Journal of

California and Great Basin Anthropology 5(1 and 2): 87-97.

Moratto, M. J.

1984 California Archaeology. Academic Press, New York.

1971 Contributions to the Archaeology of San Mateo County, California. Treganza Anthropology Museum Papers No. 8. San Francisco State University.

Nelson, N. C.

1909 Shellmounds of the San Francisco Bay Region. University of Cal ifornia Publications in American Archaeology and Ethnology 7(4): 309-356. Berkeley.

1910 The Ellis Landing Shellmound. University of California Publications in American Archaeology and Ethnology 7(5): 357-426. Berkeley. 
Nova \#1420

1987 Secrets of the Lost Red Paint People. Public Broadcast System. WGBH Transcripts, 125 Western Avenue. Boston, Massachusetts.

Olson, W. H., and L. A. Payen

1969 Archaeology of the Grayson Site, Herced County, California. California Department of Parks and Recreation, Archaeological Reports No. 12. Sacramento.

1968 Archaeology of the Little Panoche Reservoir, Fresno County, California. California Department of Parks and Recreation, Archaeological Reports No. 11. Sacramento.

Orr, R. T., and R. C. Helm

1989 Marine Mammals of California. California Natural - History Guides No. 29. University of California Press. Berkeley.

Parsons, G. A.

1987 Thermal Alteration of Monterey Banded Chert: An Analytical Study with Emphasis on Archaeological Sites of the Central California Coast. In Archives of California Prehistory No. 11: 1-40. Coyote Press. Salinas.

Phebus, G. Jr.

1973 Contributions to Costanoan Archaeology:

Archaeological Investigations at Ala-330 and SMa-22. Treganza Antll ropology Museum Papers No. 12. San Francisco State University.

Pilling, A.

1950 The Archaeological Implications of an Annual Coastal Visit for Certain Coastal Groups. In American Anthropologist 52(3): 438-440.

Pohorecky, Z. S.

1976 Archaeology of the South Coast Ranges of California. University of California Archaeological Research Facility No. 34: 1-235. Berkeley.

Pritchard, W. E.

1984 Preliminary Archaeological Investigations at Ca-Mnt101, Monterey, California. In Archives of California prehistory No. 3:1-42. Coyote Press. Salinas. 
1970 Archaeology of the Menjoulet Site, Merced County, California. California Department of Parks and Recreation. Archaeological Reports No. 13. Sacramento.

Ragir, s.

1972 The Early Horizon in Central California Prehistory. Contributions to the University of California Archaeological Research Facility No. 15. Berkeley.

Reinoehl, G. et al.

1986 Preliminary Draft: Wilder Ranch State Park Cultural Resource Management Report, Phase I. Manuscript on File with the California Department of Parks and Recreation. Sacramento.

Robinson, S. W., and G. Thompson

1981 Radiocarbon Corrections for Marine shell Dates with Application to Southern Pacific and Northwest Prehistory. Syesis No. 14: 45-57.

Roop. W.

1976 Adaptation on Ben Lomond Mountain: Excavation at CasCr-20. Masters Thesis. San Francisco State University.

Salzman. S.

1984 SMa-147: Archaeological Research in San Mateo County, California. Masters Thesis. San Francisco state University.

Saxe, A. W.

1875 Observations of a Shellmound at Laguna Creek, Six Miles North of Santa Cruz. Proceedings of the California Academy of Sciences No. 5: 157.

Schenck, W. E.

1926 The Emeryville Shellmound:Final Report. University of California publications in American Archaeology and Ethnology 23(3): 147-282. Berkeley.

Schenk, W. E., and E. J. Dawson

1929 Archaeology of the Northern San Joaquin Valley. University of California Publications in American Archaeology and Ethnology 25(4): 289-413. Berkeley.

Smith, C., and G. Breschini

1988 Preliminary Cultural Resource Reconnaissance of a Portion of Parcel APN 59-023-08, Santa cruz county, California. M.S. on file Northwest Information Center California Archaeological Inventory, Soncma state University. 
Swernoff, $M$.

1982 Intensive Cultural Resources survey, Upper stone Valley, El Piojo Valley and San Antonio River Valley, Fort Hunter Ligett, California. Manuscript on file with the United states Army Corps of Engineers. Sacramento.

Stanger, F. M., and A. K. Brown

1969 Who Discovered the Golden Gate? San Mateo County Historical Association. San Mateo.

Thomas, D. H.

1979 Archaeology. Holt, Rinehart, and winston. New York.

1978 Arrowheads and Atlatl Darts: How the stones Got the Shaft. In American Antiquity 43(3): 461-472.

1970 Archaeology's Operational Imperative: Great Basin Projectile points as a Test Case. University of California Archaeological Survey Reports No. 12: 2760. Berkeley.

Uhle, M.

1907 The Emeryville Shellmound. University of California Publications in American Archaeology and Ethnology No. 7: 1-106. Berkeley.

Wallace, พ. J.

1970 Archaeological Investigations at Hidden Reservoir, Madera County, California. Archaeological Research Associates, Contributions to California Archaeology No. 7:1-46. Los Angeles.

Wallace, W. J., and D. W. Lathrop

1975 West Berkeley (CA-ALa-307): A Culturally stratified Shellmound on the East Shore of San Francisco Bay. Contributions to the University of California Archaeological Research Facility No. 29. Berkeley.

Weissner, $P$.

1983 Style and Social Information in Kalahari san Projectile Points. American Antiquity 48(2): 253276 .

White, G., T. Jones, J. Roscoe, and L. Weigel

1982 Temporal and Spatial Distribution of Concave Base Projectile Points from the North Coast Ranges, California. Journal of California and Great Basin Anthropology 4(1): 67-79. 
APPENDICES 
APPENDIX A

Faunal Inventories for sites SCr-9, SCr-132, SMa-97, SMa-218, and SMa-244. 
SCr-9 Faunal Inventory:

Unit 2, 1/8" Wet Screen

\begin{tabular}{|c|c|c|c|}
\hline Depth & Taxa & $\#($ pcs $)$ & Nt. (gr) \\
\hline $0-10$ & $\frac{\text { Odocoileus hemionus }}{\text { Unidentifiable }}$ & $\begin{array}{r}1 \\
52\end{array}$ & $\begin{array}{r}2.4 \\
34.1\end{array}$ \\
\hline \multirow[t]{5}{*}{$10-20$} & Odocoileus hemionus & 1 & .3 \\
\hline & Ursus horibilus & 1 & 2.9 \\
\hline & Sciurus griseus & 1 & .6 \\
\hline & Neotoma Euscipes & 1 & .3 \\
\hline & $\frac{\text { Thomomys }}{\text { Unidentifiable }}$ & $\begin{array}{r}2 \\
75\end{array}$ & 45.0 \\
\hline \multirow[t]{5}{*}{$20-30$} & odocoileus hemionus & 3 & 15.2 \\
\hline & Mephitis mephitis .. & 1 & 1.8 \\
\hline & Sylvilaqus audubonii & 1 & .5 \\
\hline & Thomomys bottae & 5 & 1.5 \\
\hline & $\begin{array}{l}\text { Ichthys } \\
\text { Unidentifiable }\end{array}$ & 65 & 49.1 \\
\hline \multirow[t]{4}{*}{$30-40$} & odocoileus hemionus & 7 & 27.3 \\
\hline & $\frac{\text { Canis }}{\text { Cetacea }} \frac{\text { sp. }}{a}$ & $\begin{array}{l}1 \\
1\end{array}$ & $\begin{array}{r}.5 \\
201.1\end{array}$ \\
\hline & Sylvilagus audubonii & $\overrightarrow{1}$ & .5 \\
\hline & Thomomys $\frac{\text { bottae }}{\text { Unidentifiable }}$ & $\begin{array}{r}5 \\
140\end{array}$ & $\begin{array}{r}1.2 \\
90.5\end{array}$ \\
\hline \multirow[t]{4}{*}{$40-50$} & odocoileus hemionus & 7 & 60.6 \\
\hline & Ottaridae & 1 & 2.4 \\
\hline & Thomomys bottae & $\begin{array}{l}2 \\
3\end{array}$ & .4 \\
\hline & $\begin{array}{l}\text { Ichthys } \\
\text { Unidentifiable }\end{array}$ & 97 & 100.6 \\
\hline \multirow{3}{*}{$50-60$} & Odocoileus hemionus & 8 & 77.9 \\
\hline & Thomomys bottae & 2 & .4 \\
\hline & Aves & $\begin{array}{r}2 \\
25\end{array}$ & $\begin{array}{r}1.0 \\
113.1\end{array}$ \\
\hline \multirow[t]{5}{*}{$60-70$} & odocoileus hemionus & 11 & 64.7 \\
\hline & Canis sp. & 1 & .8 \\
\hline & Thomomys bottae & 2 & .6 \\
\hline & Ichthys & 1 & $\cdot 1$ \\
\hline & Unidentifiable & 128 & 100.7 \\
\hline \multirow{7}{*}{$70-80$} & odocoileus hemionus & 14 & 121.3 \\
\hline & Cervus nanoides & 1 & 23.3 \\
\hline & Canis sp. & $\frac{1}{2}$ & $1 \cdot 1$ \\
\hline & Sylvilaqus aidubonii & 2 & 1.0 \\
\hline & Neotoma fuscipes & 1 & 2.0 \\
\hline & Aves & $15 \frac{3}{6}$ & $\begin{array}{r}.5 \\
127.3\end{array}$ \\
\hline & Unident & 50 & \\
\hline
\end{tabular}




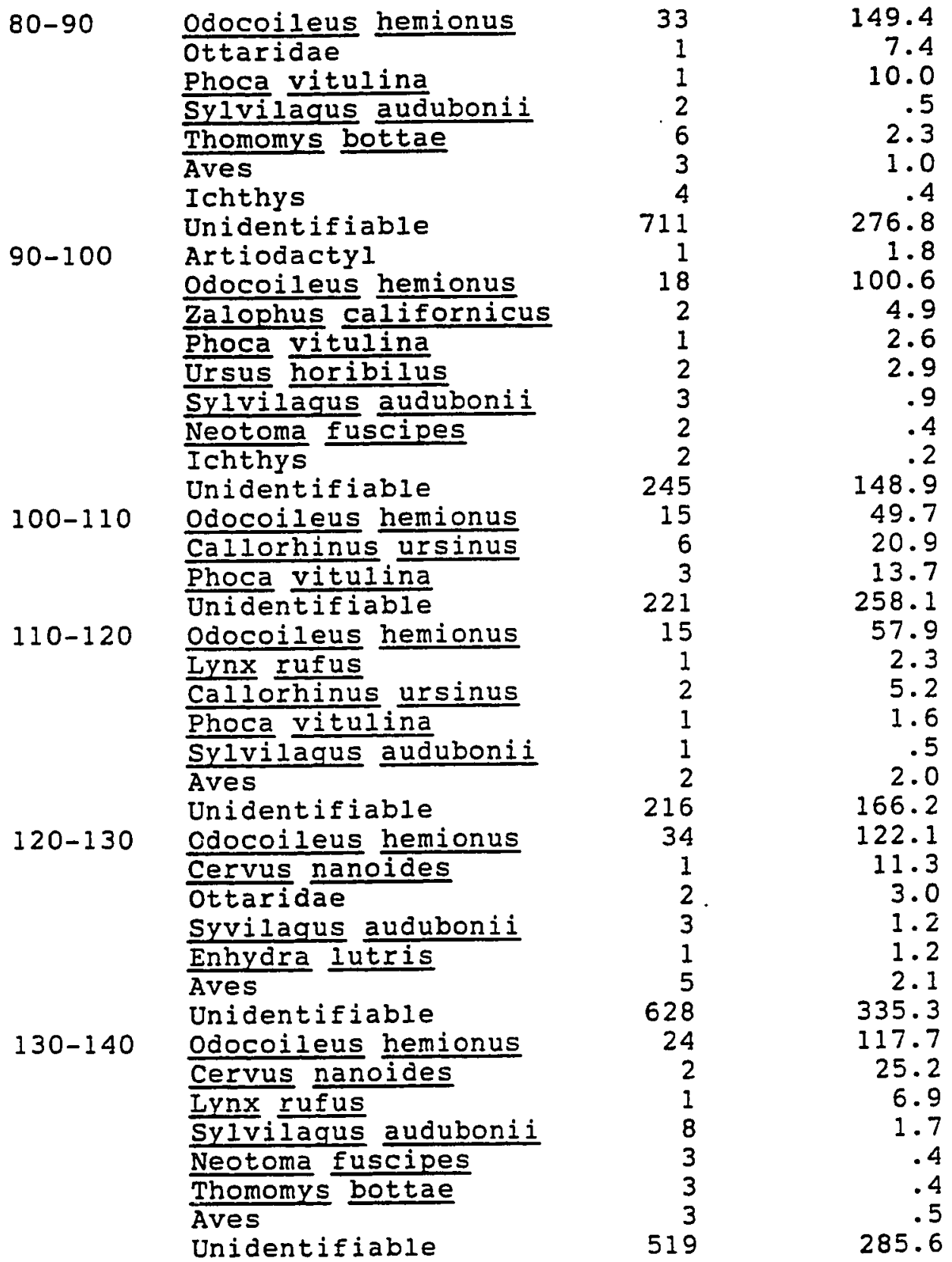




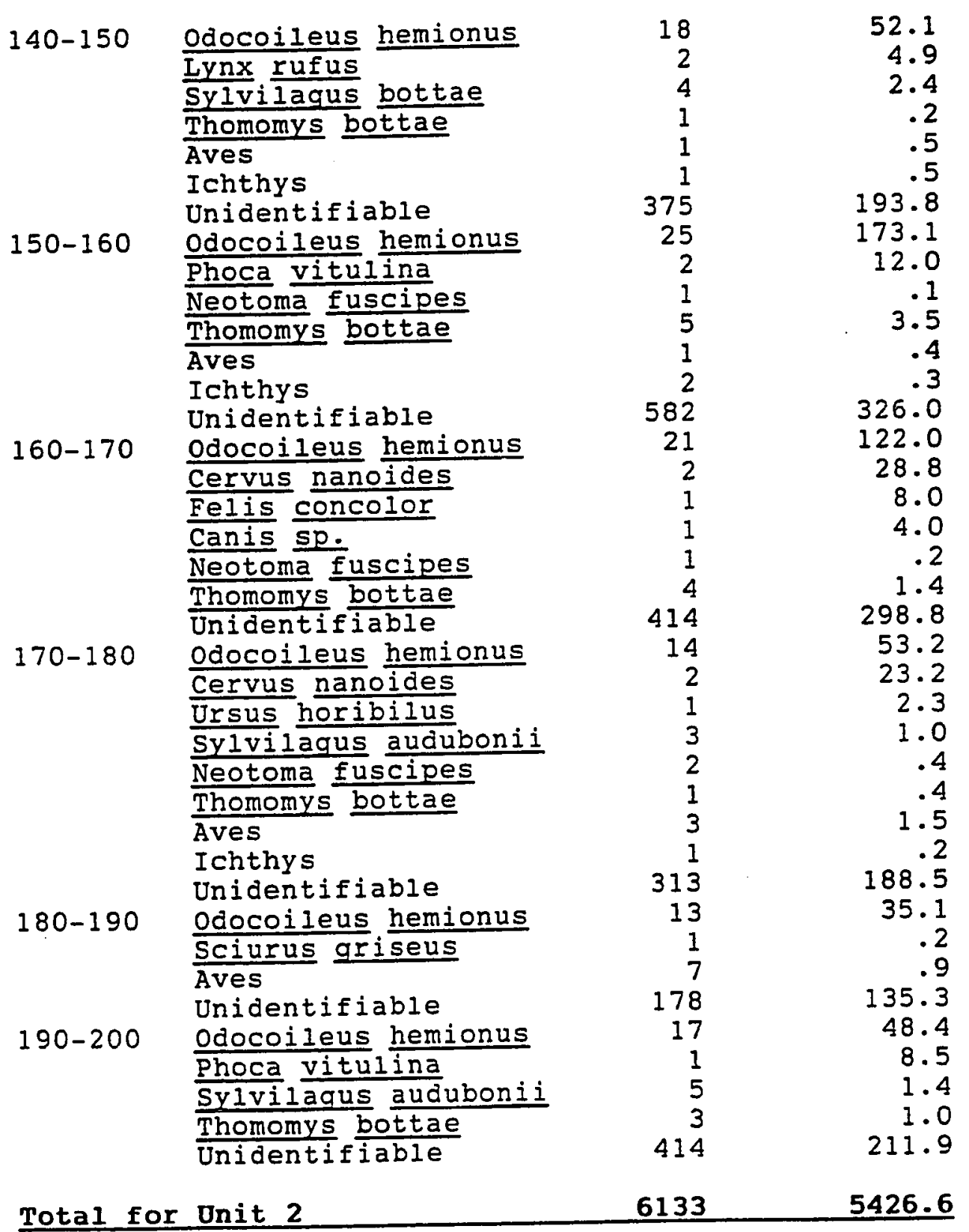


SCr-9 Faunal Inventory

Unit 5, 1/4" Wet Screen

(Rodentia Excluaed)

\begin{tabular}{|c|c|c|c|}
\hline $0-10$ & $\frac{\text { Odocoileus hemionus }}{\text { Unidentifiable }}$ & $\begin{array}{r}3 \\
57\end{array}$ & $\begin{array}{r}8.5 \\
71.0\end{array}$ \\
\hline \multirow[t]{3}{*}{$10-20$} & Odocoileus hemionus & 6 & 20.5 \\
\hline & $\frac{\text { Sylvilaqus }}{\text { Ichthys }}$ & $\begin{array}{l}1 \\
9\end{array}$ & $\begin{array}{l}1.1 \\
1.0\end{array}$ \\
\hline & Unidentifiable & 49 & 92.5 \\
\hline \multirow{4}{*}{$20-30$} & Odocoileus hemionus & 6 & 14.9 \\
\hline & Sylvilagus audubonii & 3 & 1.0 \\
\hline & Ichthys & 3 & 1.0 \\
\hline & Unidentifiable & 78 & $75 \cdot 3$ \\
\hline \multirow{2}{*}{$30-40$} & Odocoileus hemionus & 1 & 2.6 \\
\hline & $\frac{\text { Sylvilagus }}{\text { Unidentifiable }}$ & $\begin{array}{r}1 \\
47\end{array}$ & $23 \cdot 1$ \\
\hline \multirow[t]{5}{*}{$40-50$} & odocoileus hemionus & 2 & 14.5 \\
\hline & Cervus nanoides & 2 & 33.8 \\
\hline & Sylvilagus audubonii & 3 & 1.1 \\
\hline & Aves & 1 & .4 \\
\hline & Unidentifiable & 84 & 118.1 \\
\hline \multirow[t]{3}{*}{$50-60$} & odocoileus hemionus & 10 & $78 \cdot 3$ \\
\hline & Sylvilaqus audubonii & 1 & .6 \\
\hline & $\begin{array}{l}\text { Aves } \\
\text { Unidentifiable }\end{array}$ & 102 & $\begin{array}{r}2.4 \\
157.0\end{array}$ \\
\hline \multirow[t]{2}{*}{$60-70$} & odocoileus hemionus & 10 & 26.1 \\
\hline & $\frac{\text { Cervus }}{\text { Unidentifiable }}$ & $\begin{array}{r}4 \\
136\end{array}$ & $\begin{array}{l}176.1 \\
130.9\end{array}$ \\
\hline \multirow[t]{2}{*}{$70-80$} & odocoileus hemionus & 4 & 29.6 \\
\hline & $\frac{\text { Cervus nanoides }}{\text { Unidentifiable }}$ & 52 & $\begin{array}{l}83.3 \\
68.6\end{array}$ \\
\hline \multirow{4}{*}{$80-90$} & odocoileus hemionus & 14 & 69.9 \\
\hline & Sylvilaqus audubonii & 1 & .1 \\
\hline & Aves & 5 & $\begin{array}{r}2.0 \\
177.3\end{array}$ \\
\hline & Unidentifiable & 64 & $\begin{array}{l}177.3 \\
101.5\end{array}$ \\
\hline \multirow{4}{*}{$90-100$} & $\frac{\text { Odocoileus }}{\text { Cervus nanoides }}$ & $\begin{array}{r}15 \\
1\end{array}$ & $\begin{array}{r}101.5 \\
13.7\end{array}$ \\
\hline & Felis concolor & 1 & 3.9 \\
\hline & Phoca vitulina & 2 & 12.2 \\
\hline & Aves & 1 & .2 \\
\hline \multirow{7}{*}{$100-i 10$} & Odocoileus hemionus & 14 & 85.5 \\
\hline & Cervus nanoides & 1 & 69.0 \\
\hline & Canis sp. & 1 & 7.9 \\
\hline & Sylvilaqus audubonii & 4 & 2.0 \\
\hline & Enhydra lutris & 1 & 1.6 \\
\hline & Aves & 1 & 1.4 \\
\hline & Unidentifiable & 201 & 248.7 \\
\hline
\end{tabular}




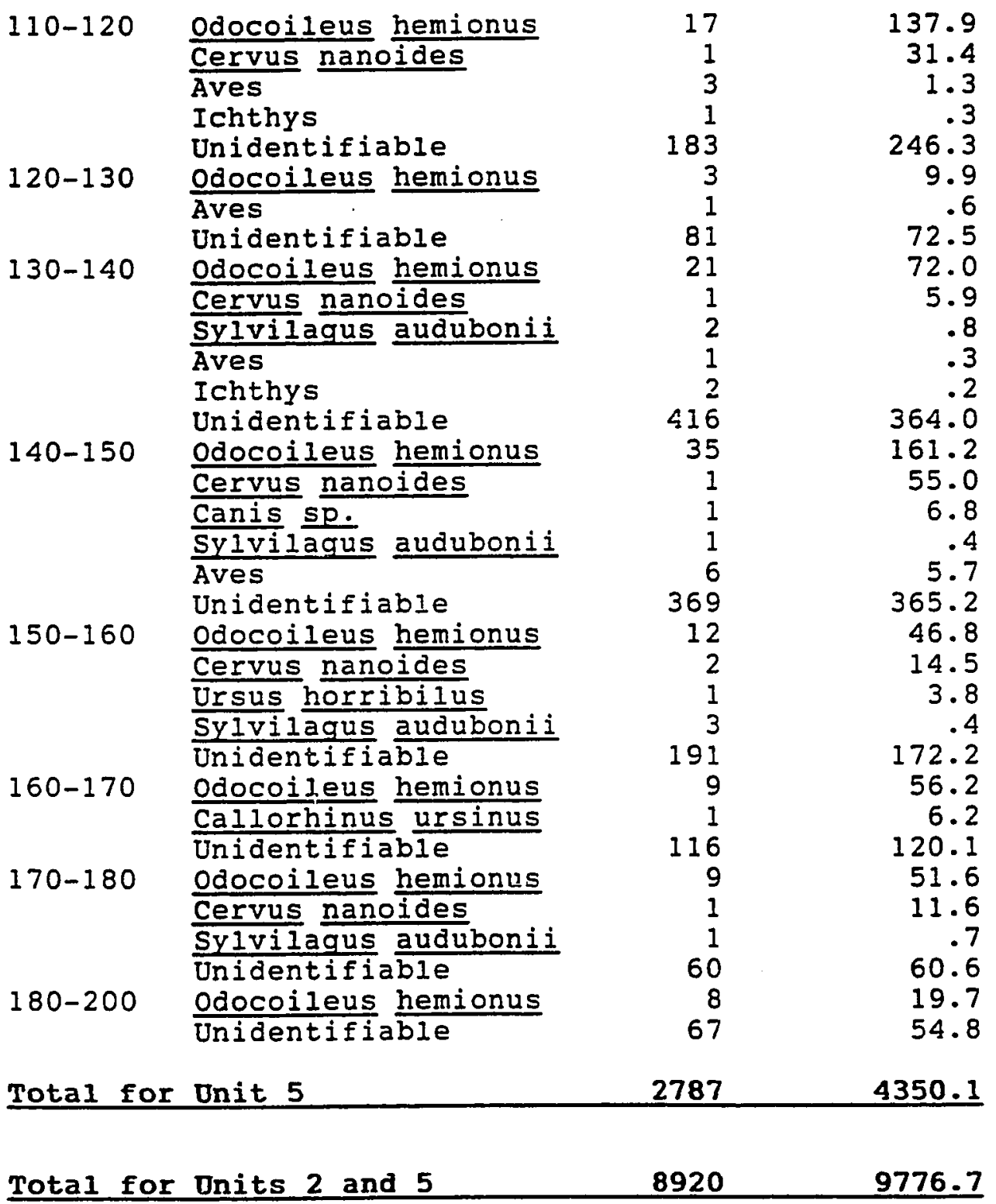


SCR-132 Faunal Inventory:

Test Unit $\frac{\text { I, 1/8" Dry Screen }}{1,}$

Depth

$\underline{\text { Taxa }}$

$\#$ (pcs)

ㅂt. $(g r)$

$0-10$
$10-20$
$30-40$
$40-50$
$50-60$

Canis sp.

Unidentifiable

Rodentia

Unidentifiable

Rodentia

Unidentifiable

Unidentifiable

Thomomys bottae

Sciurus griseus

Rodentia

Ichthys

Unidentifiable

1.5

.5

.5

1.0

.2

1.3

.9

.9

.3

2.4

.2

.6

Unit 1, 1/4" Dry Screen

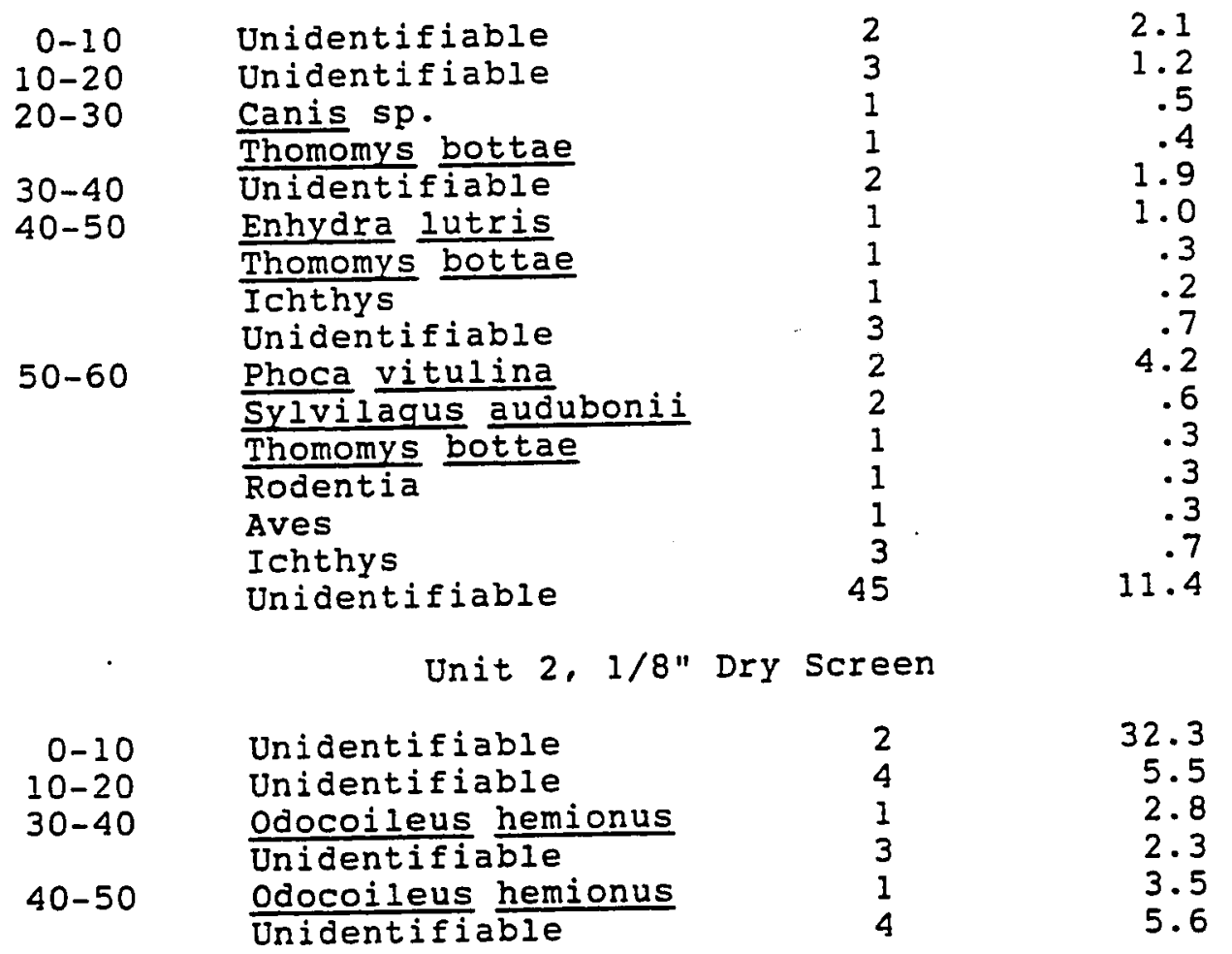


Unit 3, 1/4" Dry Screen

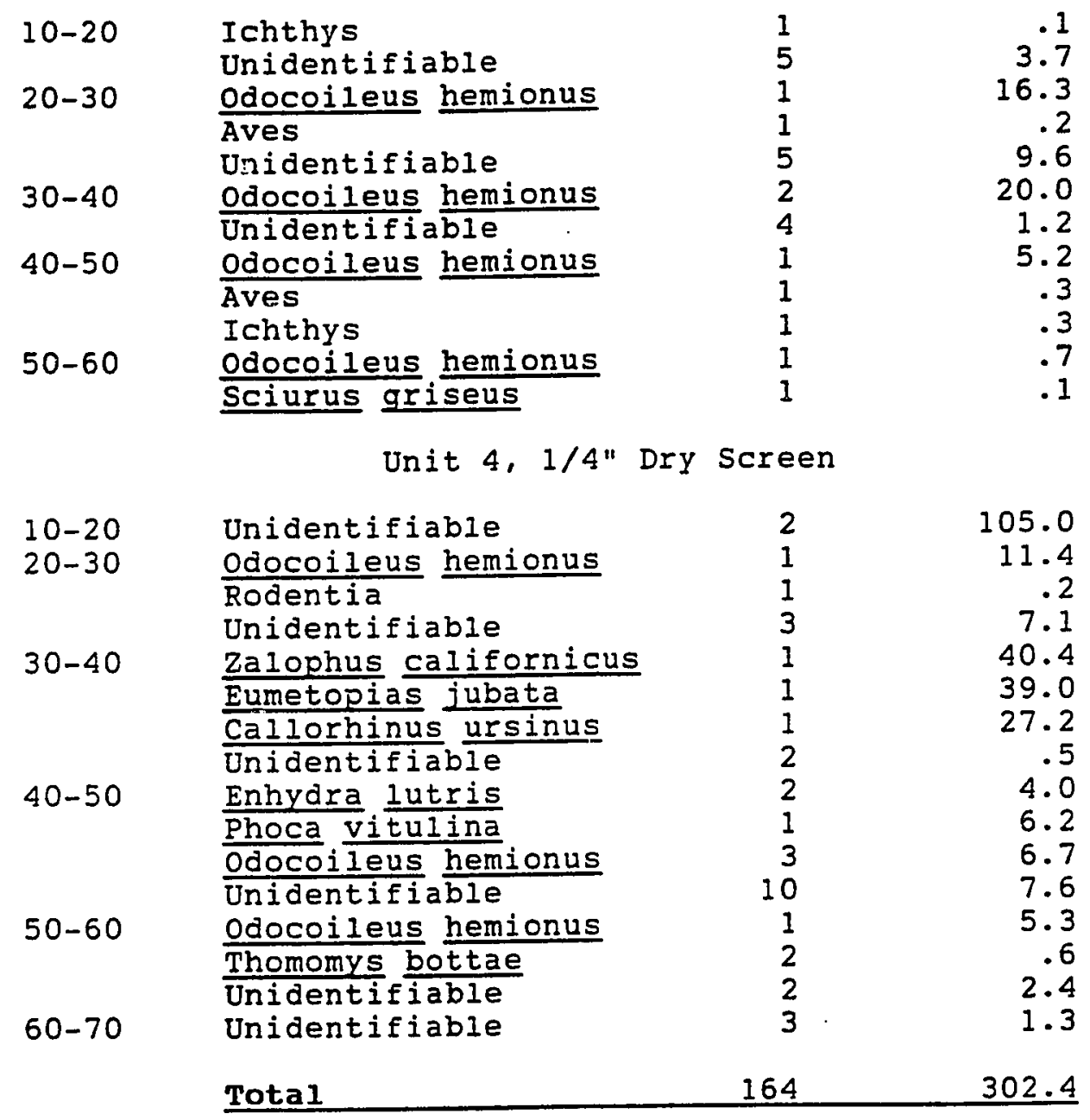


SMa-97 Fauna1 Inventory:

Unit 1, 1/8" Dry Screen

\begin{tabular}{|c|c|c|c|}
\hline Depth & Taxa & $\#(p c s)$ & Ht. (qr) \\
\hline \multirow{3}{*}{$0-10$} & Artidactyl & 1 & 2.8 \\
\hline & Ichthys & 1 & .3 \\
\hline & Unidentifiable & 10 & \\
\hline \multirow[t]{4}{*}{$10-20$} & Pinnipedea & 1 & 7.7 \\
\hline & Zalophus californianus & 1 & 5.0 \\
\hline & Ichthys & 1 & .7 \\
\hline & Unidentifiable & 4 & 14.8 \\
\hline \multirow[t]{4}{*}{$20-30$} & Zalophus californianus & 4 & 70.0 \\
\hline & odocoileus hemionus & 2 & 5.8 \\
\hline & Ichthys & 8 & 3.0 \\
\hline & Unidentifiable & 16 & 26.4 \\
\hline \multirow[t]{7}{*}{$30-40$} & Pinnipedea & 2 & 4.5 \\
\hline & Callorhinus ursinus & 1 & 3.5 \\
\hline & Eumetopias jubatas & 1 & 2.9 \\
\hline & odocoileus hemionus. & 1 & 10.7 \\
\hline & Sylvilagus audubonii & 1 & .6 \\
\hline & Neotoma fuscipes & 1 & .5 \\
\hline & Unidentifiable & 26 & 36.9 \\
\hline \multirow{5}{*}{$40-50$} & Zalophus californianus & 1 & 7.6 \\
\hline & odocoileus hemionus. & 2 & 17.3 \\
\hline & Sylvilagus audubonii & 2 & .8 \\
\hline & Aves & 1 & .8 \\
\hline & Unidentifiable & 29 & 48.4 \\
\hline \multirow[t]{3}{*}{$50-60$} & Sylvilagus audubonii & 13 & 31.1 \\
\hline & Ichthys & 1 & 1.1 \\
\hline & Unidentifiable & 12 & 30.6 \\
\hline \multirow[t]{7}{*}{$60-70$} & Callorhinus ursinus & 2 & 16.6 \\
\hline & Enhydra lutris & 1 & .2 \\
\hline & odocoileus hemionus & 1 & 7.8 \\
\hline & Neotoma fuscipes & 1 & .3 \\
\hline & Aves & 1 & $\cdot 1$ \\
\hline & Ichthys & 3 & .2 \\
\hline & Unidentifiable & 32 & 37.5 \\
\hline
\end{tabular}

Total

184

405.9

Unit 2, 1/4" Dry Screen

0-10 Otariidae

Odocoileus hemionus 2

Mephitis mephitis 1

Neotoma fuscipes

Aves

Ichthys

$\begin{array}{rr}1 & 7.8 \\ 2 & 16.3 \\ 1 & 2.3 \\ 1 & .5 \\ 4 & 1.1 \\ 1 & .1\end{array}$




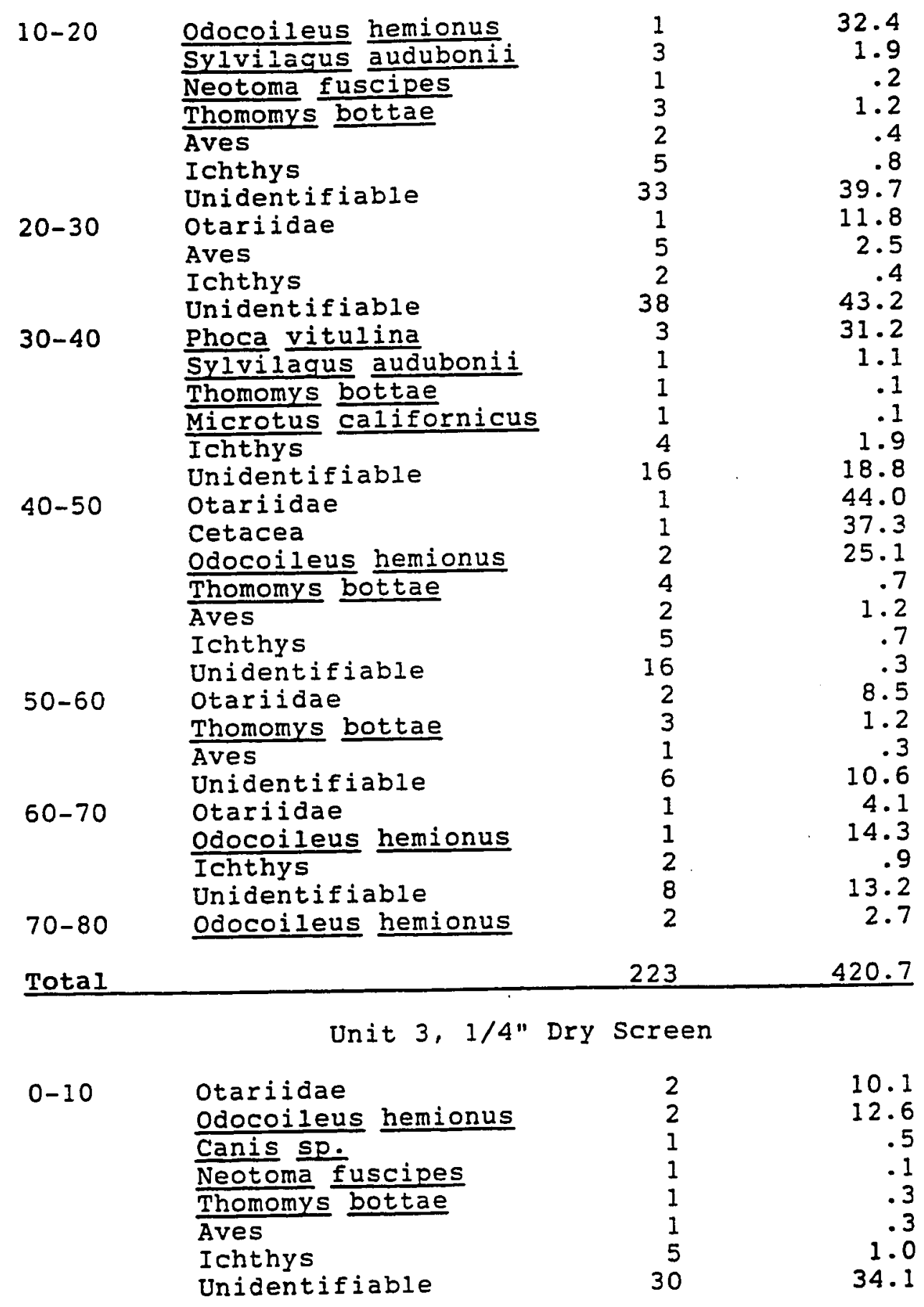




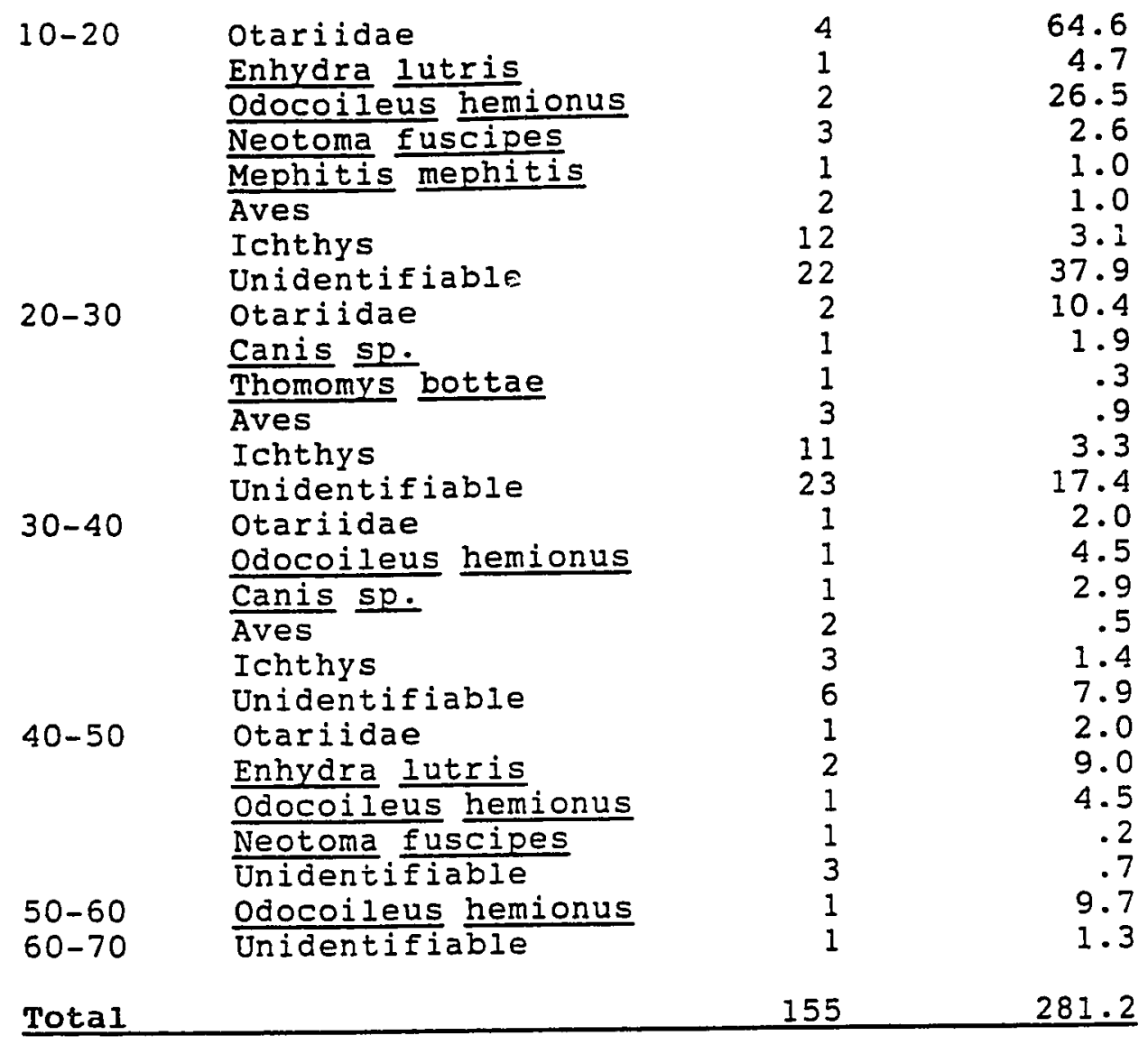

Unit 4, 1/8" Dry screen

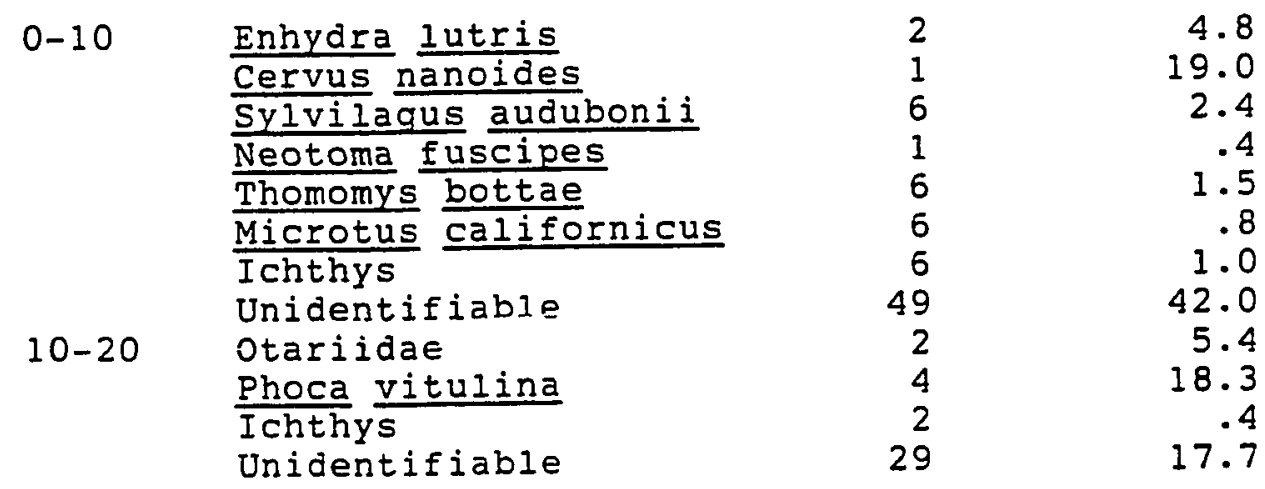




\begin{tabular}{|c|c|}
\hline \multirow[t]{3}{*}{$20-30$} & Zalophus californianus \\
\hline & $\frac{\text { Enhydra }}{\text { Cervus nanoides }}$ \\
\hline & Ichthys \\
\hline \multirow[t]{5}{*}{$30-40$} & Otariidae \\
\hline & Phoca vitulina \\
\hline & odocoileus hemionus \\
\hline & Aves \\
\hline & Unidentifiable \\
\hline $40-50$ & Enhydra lutris \\
\hline & Sylvilagus audubonii \\
\hline & Unidentifuse \\
\hline $50-60$ & $\frac{\text { Neotoma }}{\text { Intherpes }}$ \\
\hline & Unidentif \\
\hline
\end{tabular}

$\begin{array}{rr}2 & 26.9 \\ 1 & 1.4 \\ 1 & 14.2 \\ 8 & 1.1 \\ 15 & 12.2 \\ 1 & .4 \\ 1 & 3.2 \\ 2 & 21.1 \\ 1 & .3 \\ 2 & .7 \\ 15 & 14.6 \\ 1 & 3.1 \\ 1 & .4 \\ 3 & 1.6 \\ 1 & .4 \\ 2 & .1 \\ 5 & .1\end{array}$

Total

215.5

Total of Units $1,2,3$, and $4 \quad 738 \quad 1323.3$ 
SMa-218 Faunal Inventory:

Surface coliection

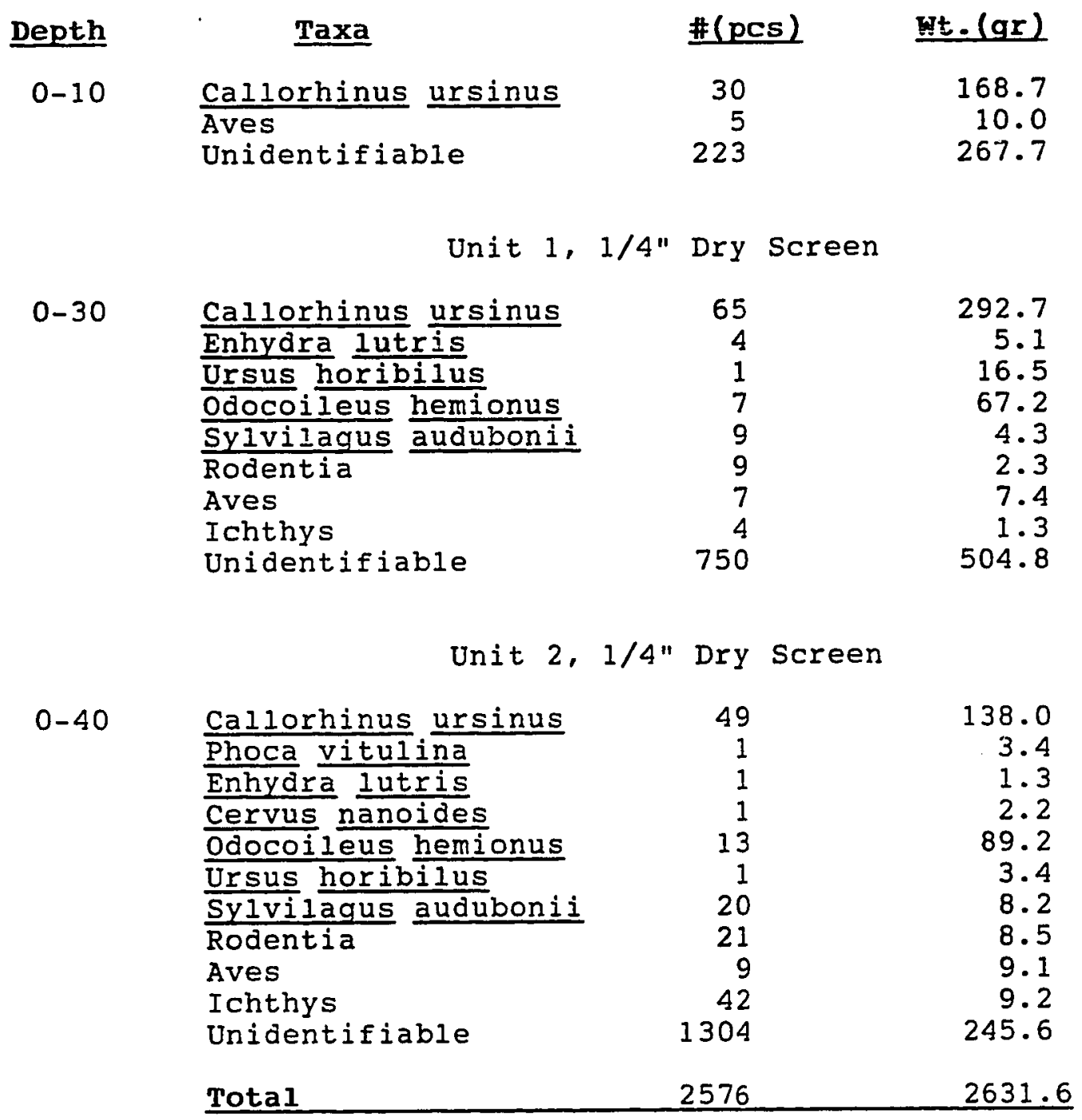


SMa-244 Faunal Inventory: Unit 1, 1/8" Dry Screen

\begin{tabular}{|c|c|c|c|}
\hline Depth & Taxa & $\#(\mathrm{pcs})$ & wt. (gr) \\
\hline \multirow[t]{2}{*}{$0-10$} & Ichthys & 1 & 1.7 \\
\hline & Unidentifiable & 1 & 1.0 \\
\hline \multirow[t]{3}{*}{$10-20$} & Sylvilagus audubonii & 1 & 1.2 \\
\hline & $\overline{\text { Ichthys }}$ & 2 & .9 \\
\hline & Unidentifiable & 9 & 15.2 \\
\hline \multirow[t]{3}{*}{$20-30$} & odocoileus hemionus & 3 & 24.6 \\
\hline & Ichthys & 2 & .6 \\
\hline & Unidentifiable & 7 & 7.9 \\
\hline \multirow[t]{2}{*}{$30-40$} & Ichthys & 5 & 2.2 \\
\hline & Unidentifiable & 6 & 9.2 \\
\hline \multirow[t]{4}{*}{$40-50$} & odocoileus hemionus & 3 & 7.7 \\
\hline & Sylvilagus audubonii & 1 & .7 \\
\hline & Ichthys & 1 & .4 \\
\hline & Unidentifiable & 4 & 2.5 \\
\hline \multirow[t]{6}{*}{$50-60$} & Enhydra lutris & 1 & 11.8 \\
\hline & Mephitis mephitis & 1 & 1.3 \\
\hline & Sylvilagus audubonii & 1 & .7 \\
\hline & Thomomys bottae & 1 & .3 \\
\hline & Ichthys & 2 & .5 \\
\hline & Unidentifiable & 12 & 5.7 \\
\hline \multirow[t]{4}{*}{$60-70$} & odocoileus hemionus & 1 & 2.5 \\
\hline & Sylvilagus audubonii & 2 & 1.1 \\
\hline & Ichthys & 1 & .4 \\
\hline & Unidentifiable & 9 & 10.0 \\
\hline \multirow[t]{4}{*}{$70-80$} & ottaridae & 1 & 1.4 \\
\hline & Sylvilagus audubonii & 2 & 1.1 \\
\hline & & & \\
\hline & Unit $2,1 / 8 "$ Dry & Scren & \\
\hline \multirow[t]{3}{*}{$0-10$} & Lynx rufus & 1 & 1.0 \\
\hline & Ichthys & 2 & .8 \\
\hline & Unidentifiable & 4 & 6.4 \\
\hline \multirow[t]{4}{*}{$10-20$} & Sylvilagus audubonii & 1 & 1.1 \\
\hline & Neotoma fuscipes & 1 & .3 \\
\hline & Ichthys & 3 & 1.5 \\
\hline & Unidentifiable & 23 & 10.7 \\
\hline \multirow[t]{3}{*}{$30-40$} & odocoileus hemionus & 2 & 6.7 \\
\hline & Urocyon cinereoargenteus & 1 & .4 \\
\hline & Unidentifiable & 1 & 1.0 \\
\hline $40-50$ & Mephitis mephitis & 1 & 1.4 \\
\hline
\end{tabular}


Unit 3, 1/4" Dry Screen

\begin{tabular}{|c|c|c|c|}
\hline \multirow[t]{4}{*}{$0-10$} & Odocoileus hemionus & 1 & 6.2 \\
\hline & Neotoma fuscipes & 1 & .6 \\
\hline & Aves & 1 & \\
\hline & Unidentifiable. & 29 & 46.4 \\
\hline \multirow{7}{*}{$10-20$} & odocoileus hemionus & 5 & 10.7 \\
\hline & Procyon 1otor & 1 & 6 \\
\hline & Sylvilagus audubonii & 1 & \\
\hline & Thomomys bottae & 1 & \\
\hline & $\frac{\text { Spermophilus beecheil }}{\text { Aves }}$ & 1 & \\
\hline & $\begin{array}{l}\text { Aves } \\
\text { Ichthys }\end{array}$ & $\frac{1}{6}$ & 1. \\
\hline & Unidentifiable & 41 & 45 . \\
\hline \multirow[t]{5}{*}{$20-30$} & odocoileus hemionus & 2 & 11. \\
\hline & Sylvilagus audubonii & 3 & 1. \\
\hline & Neotoma bottae & 2 & 1 . \\
\hline & $\overline{\text { Ichthys }}$ & 12 & 2 . \\
\hline & Unidentifiable & 6 & 4 . \\
\hline \multirow{2}{*}{$30-40$} & Unidentifiable & 1 & .5 \\
\hline & Total & 238 & 195. \\
\hline
\end{tabular}


APPENDIX B

Olivella shell and other shell artifact inventories for sites SCr-9, SCr-132, SMa-97, and SMa-244. 


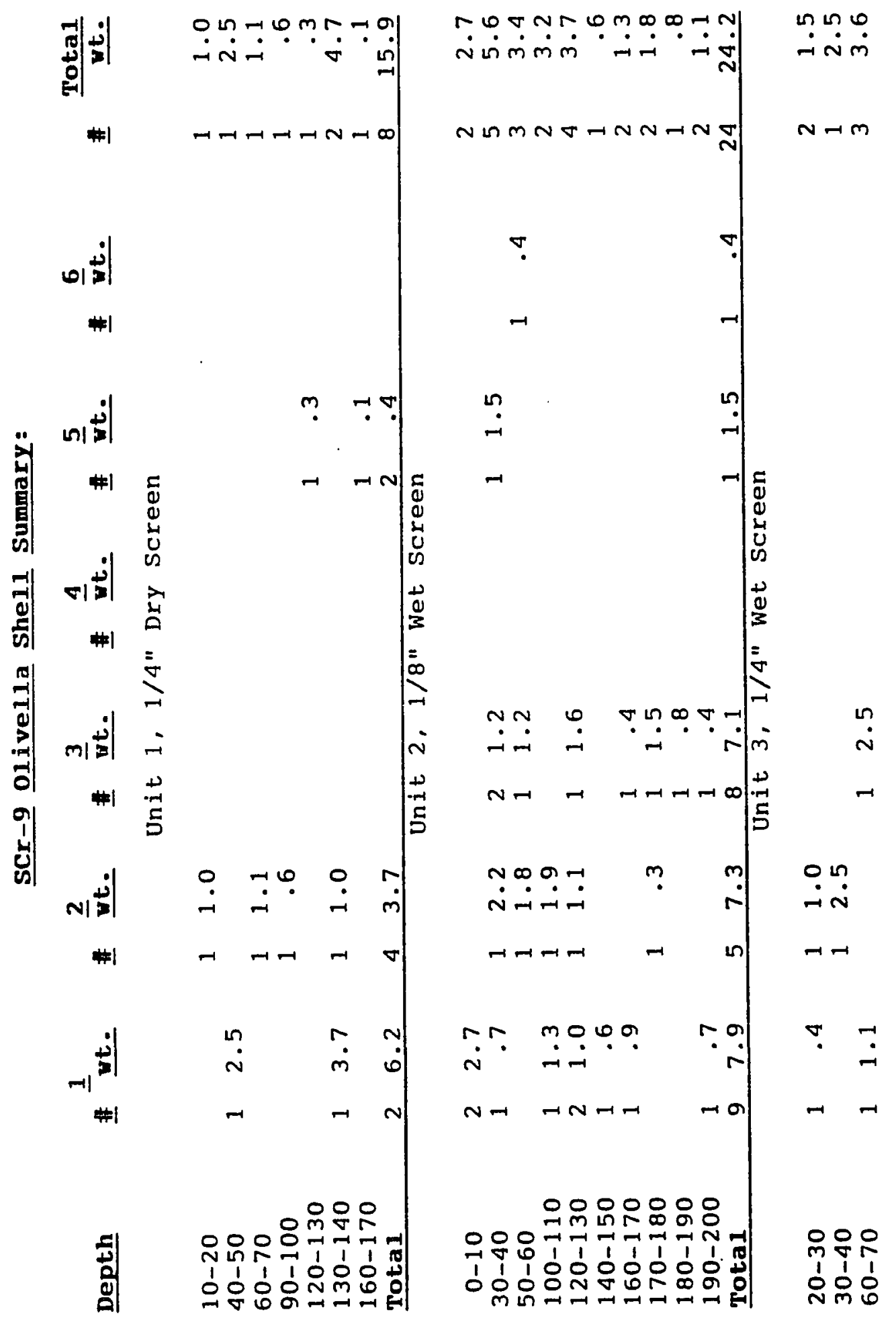




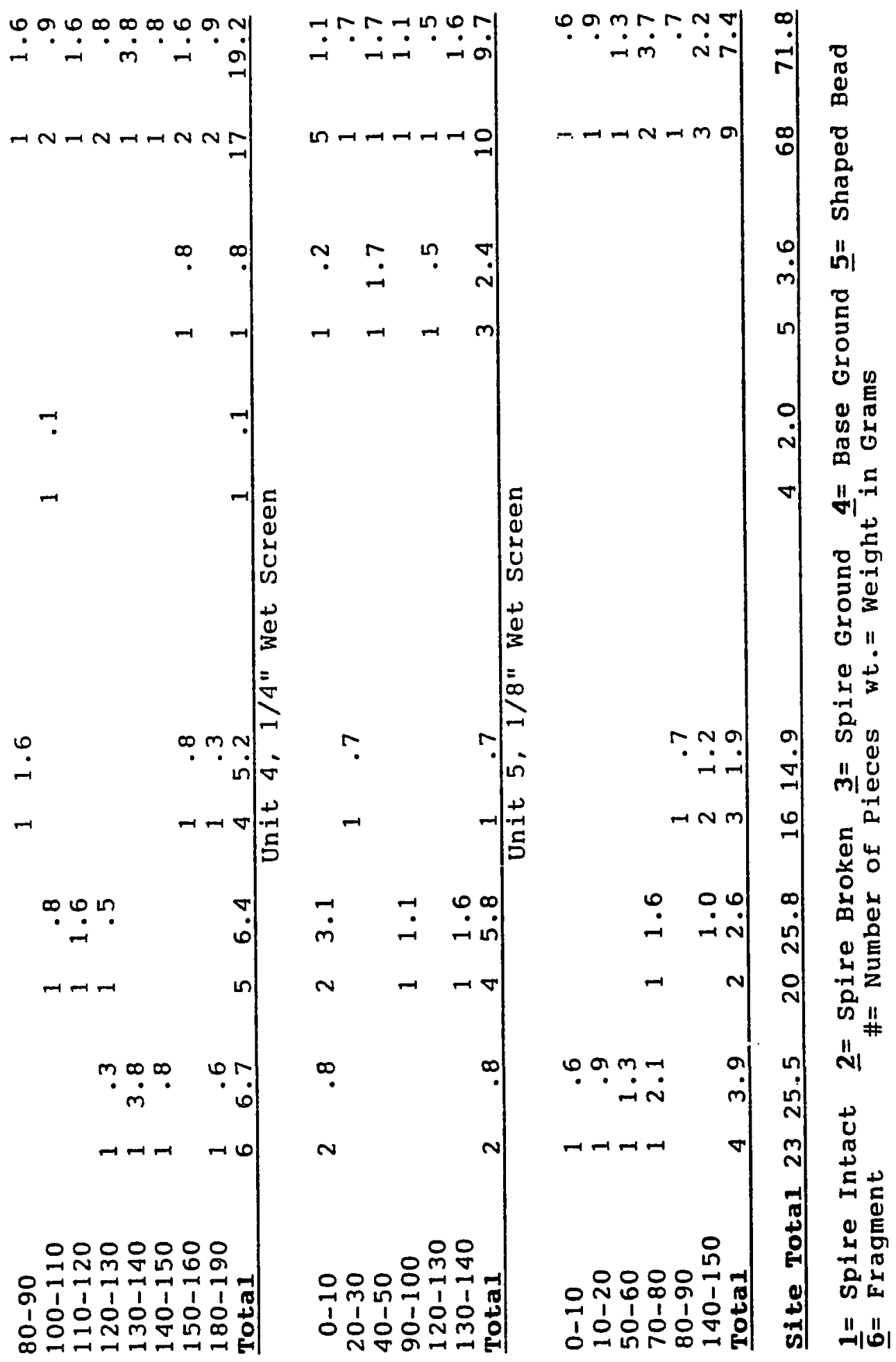




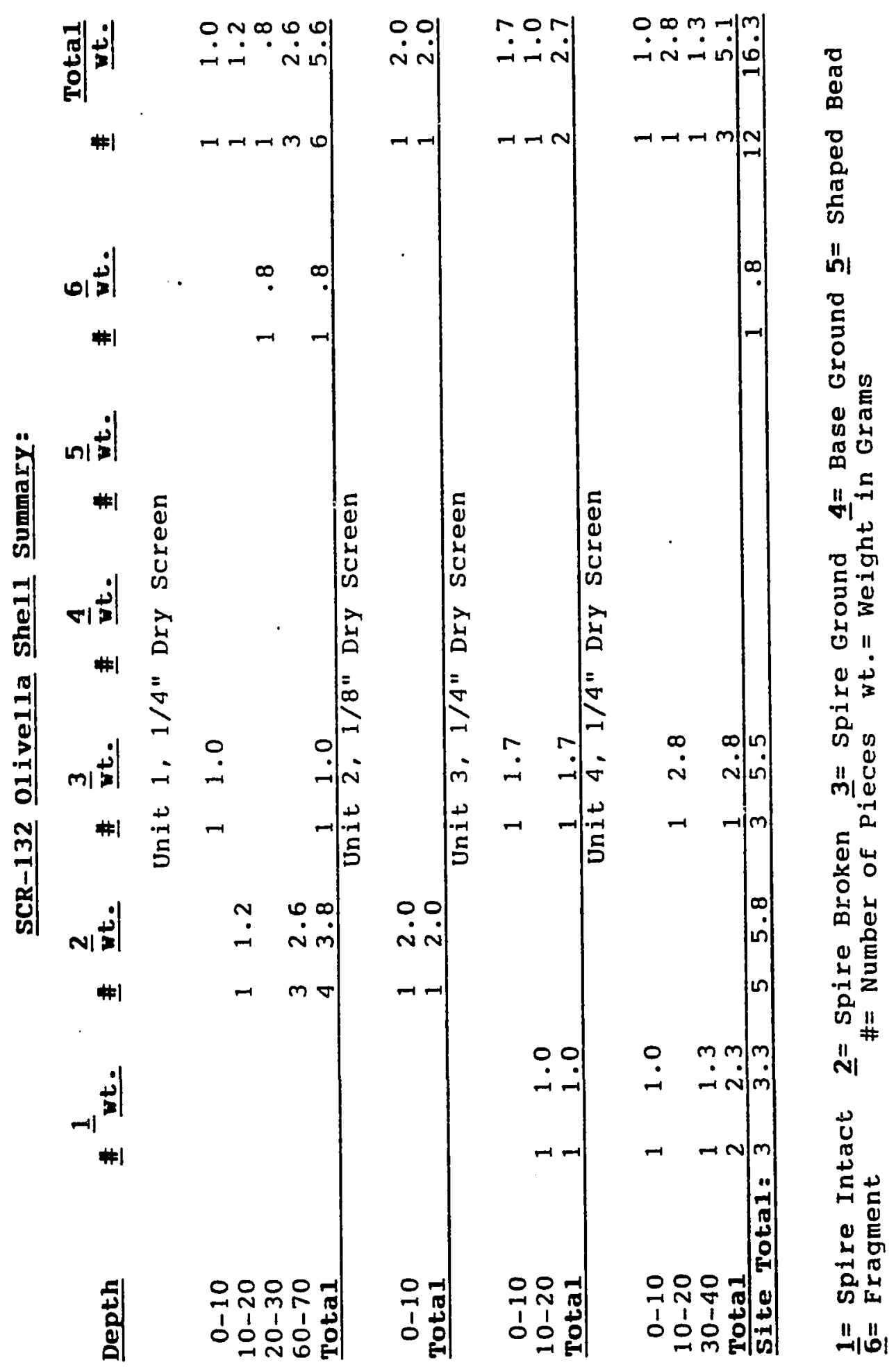




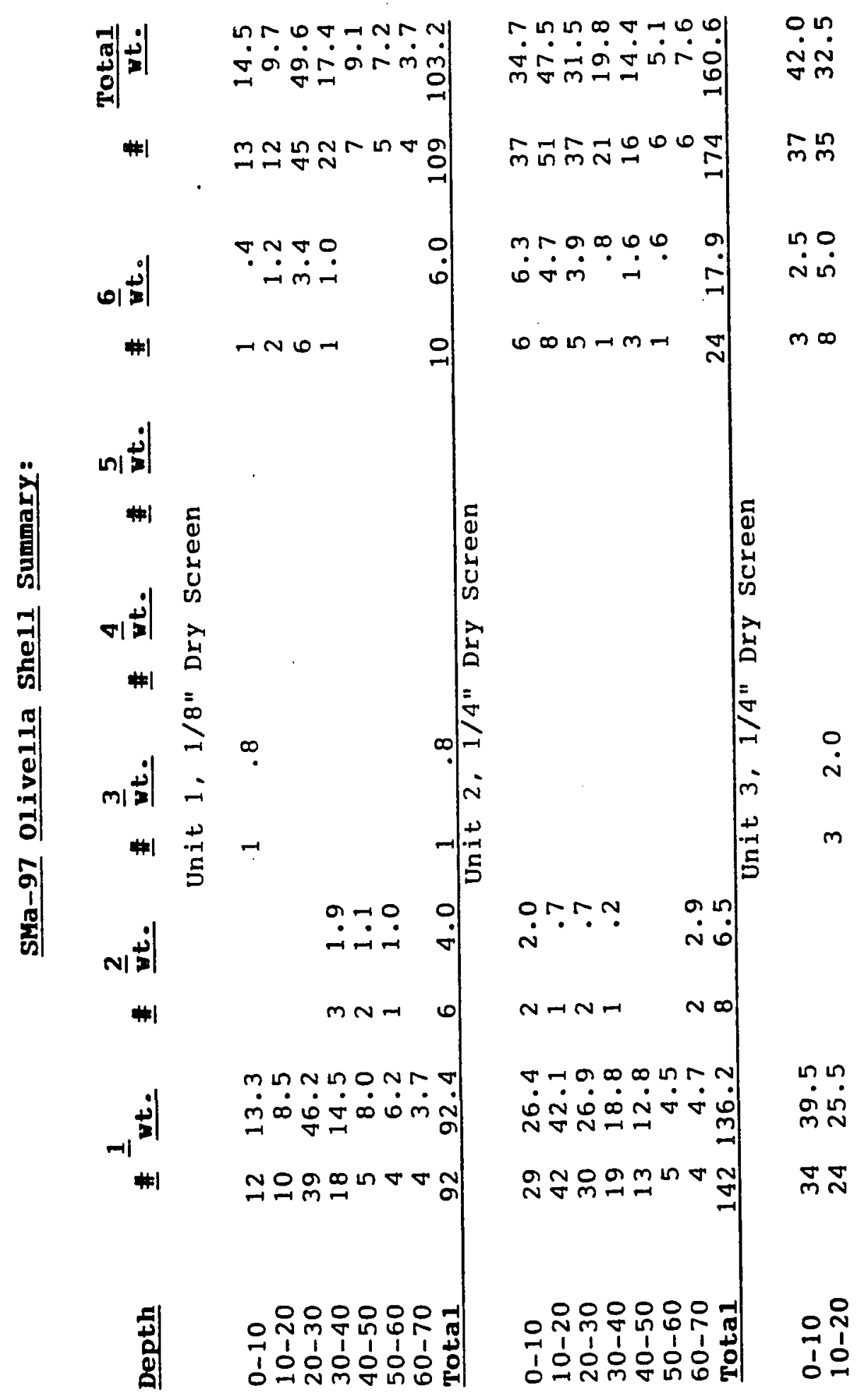




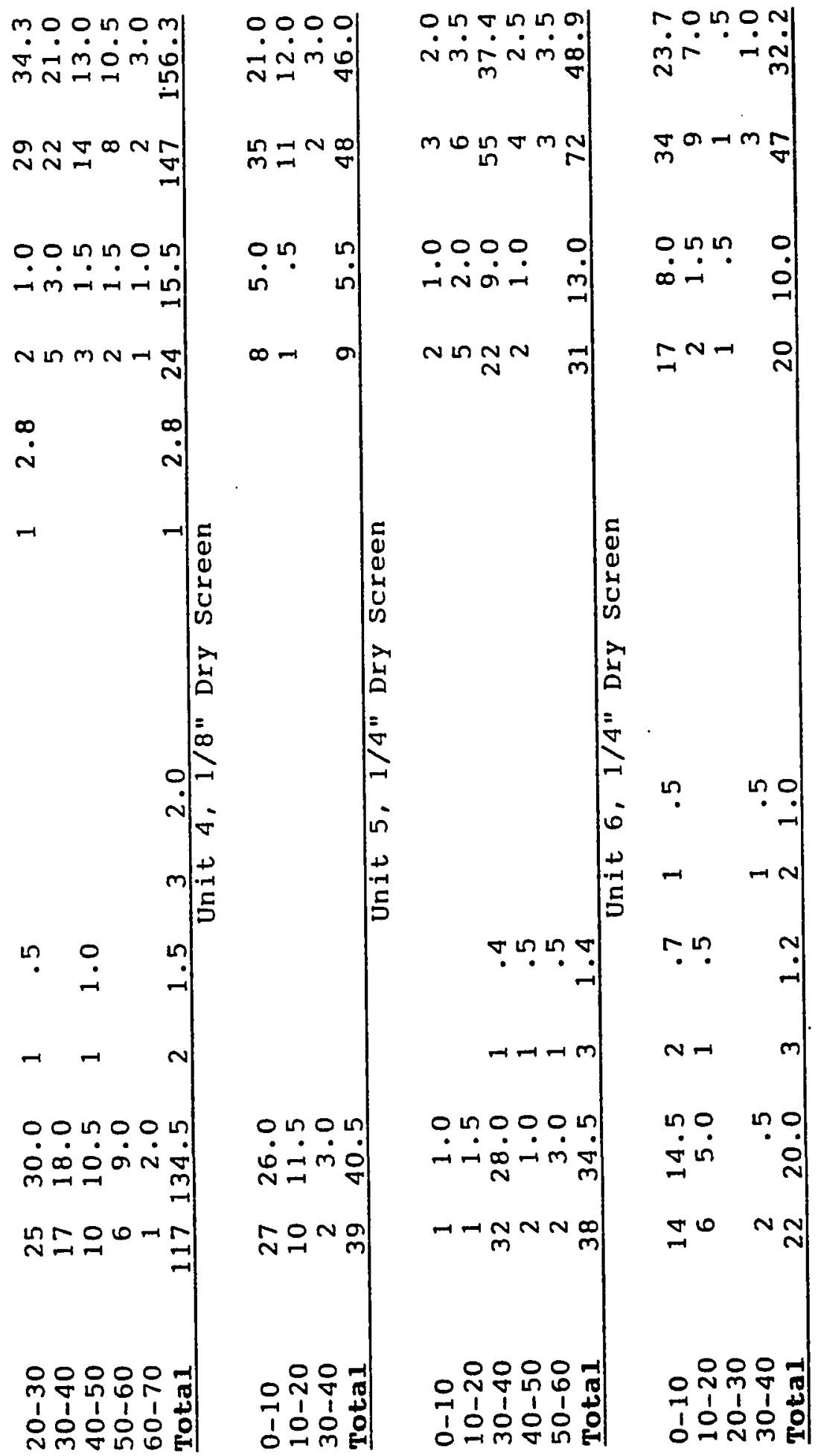




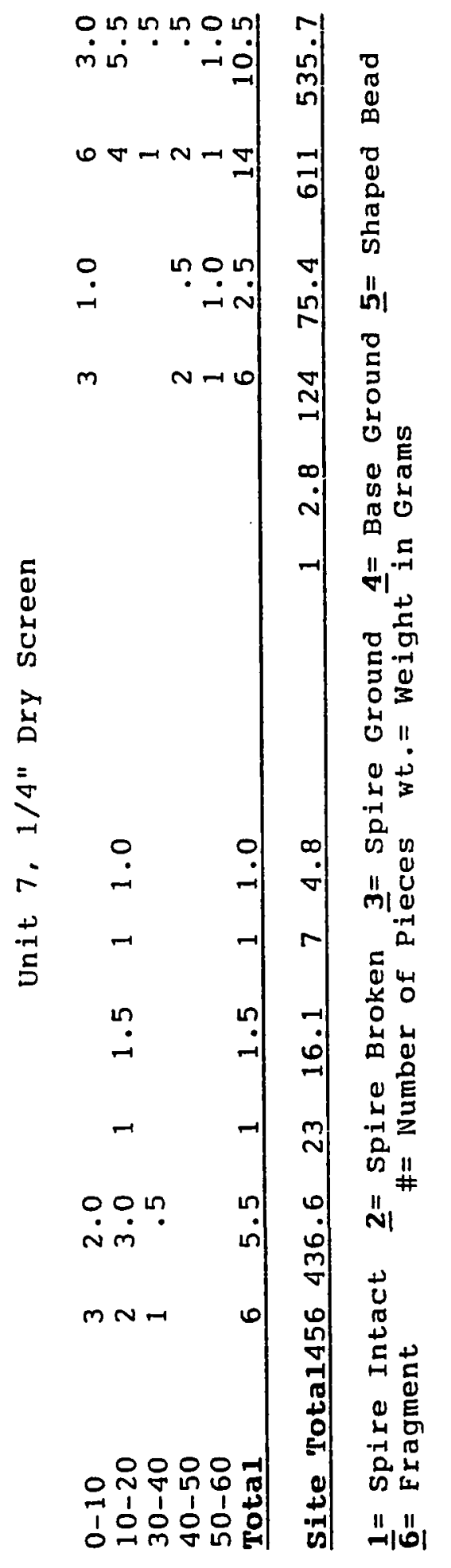




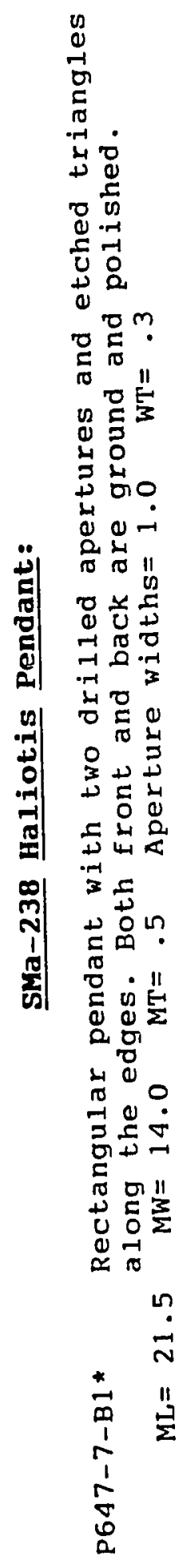




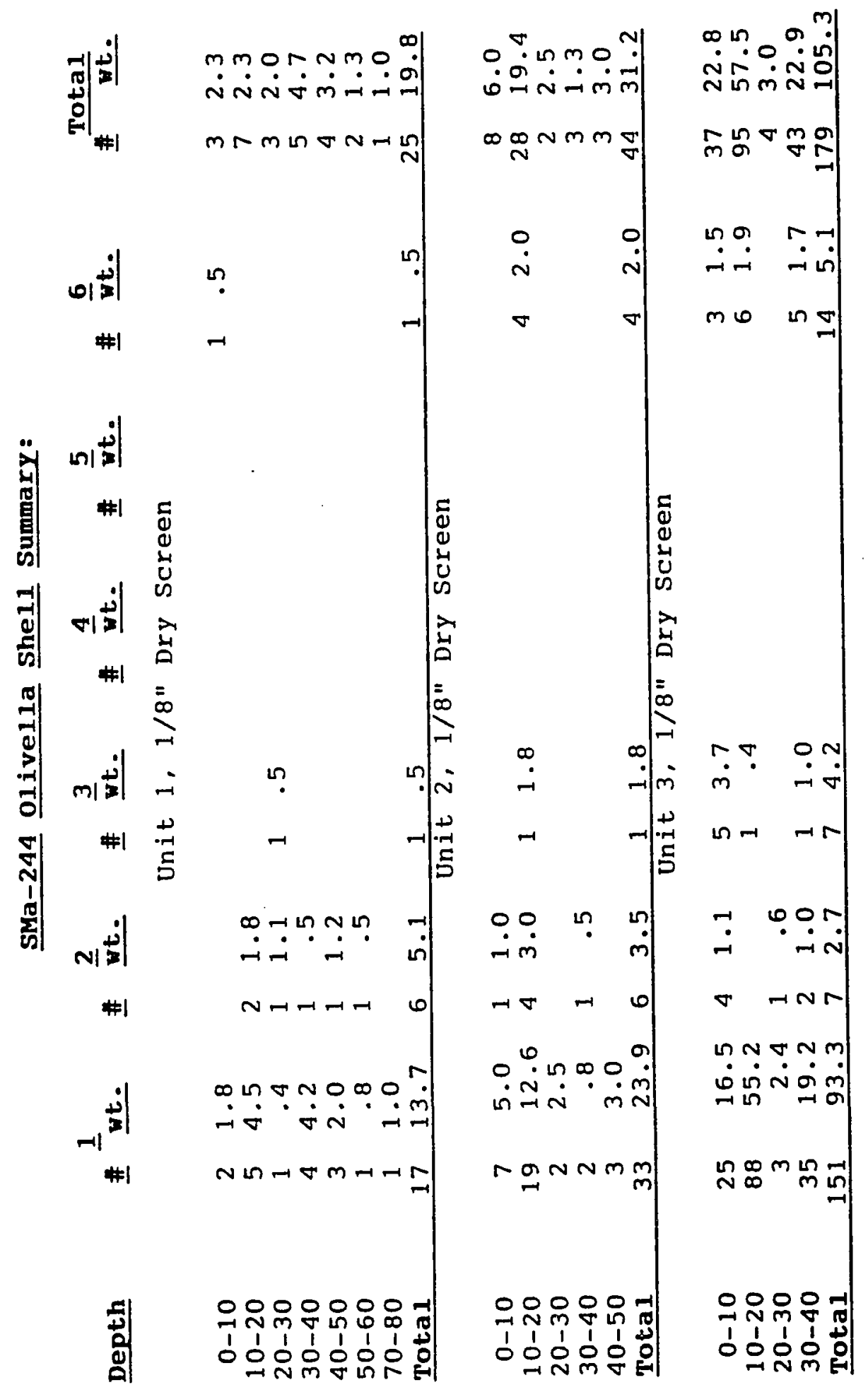




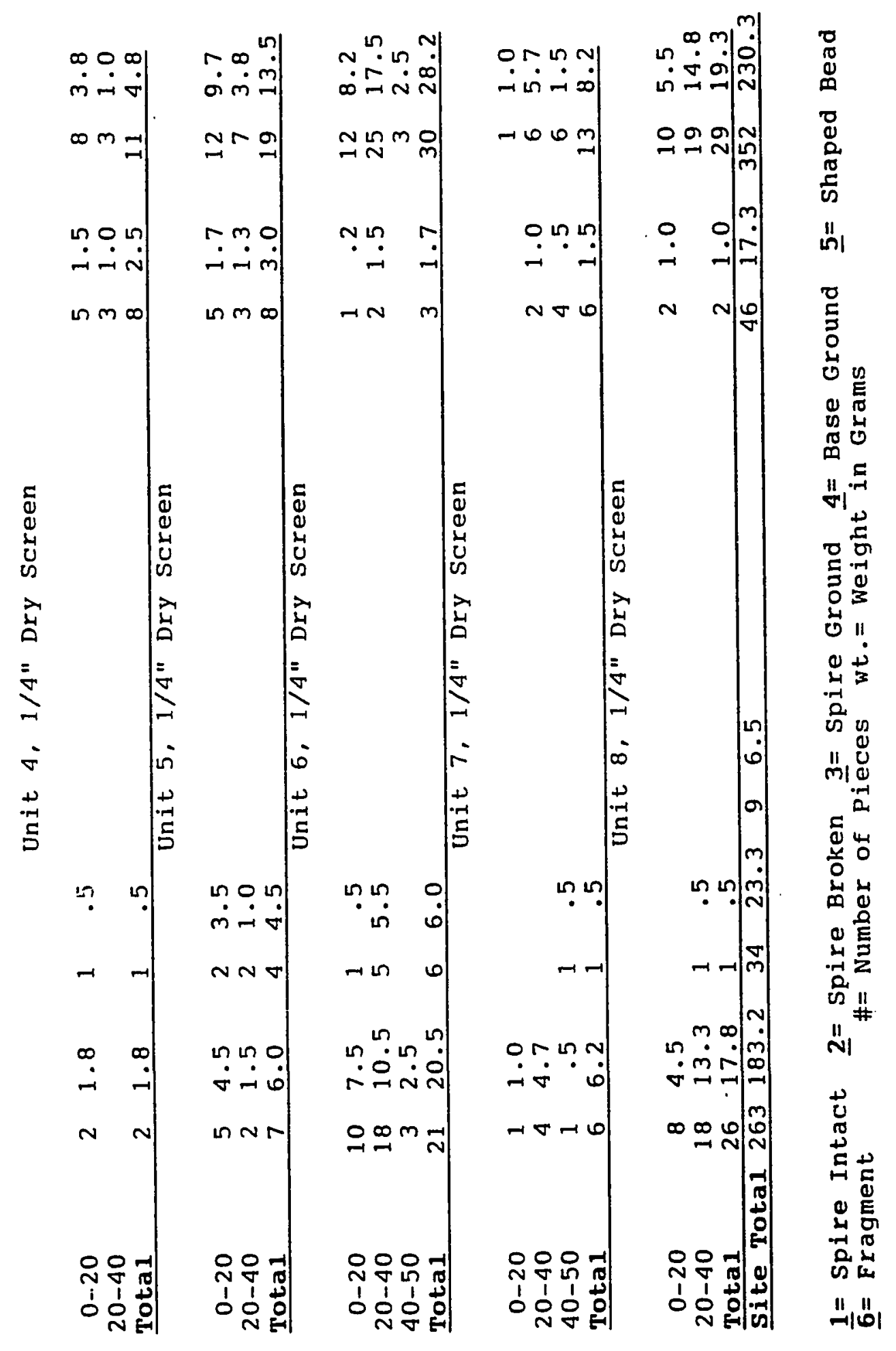


APPENDIX C

Bone tool inventories for sites SCr-9, SMa-97, SHa-218, SMa-238, and SMa-244. 


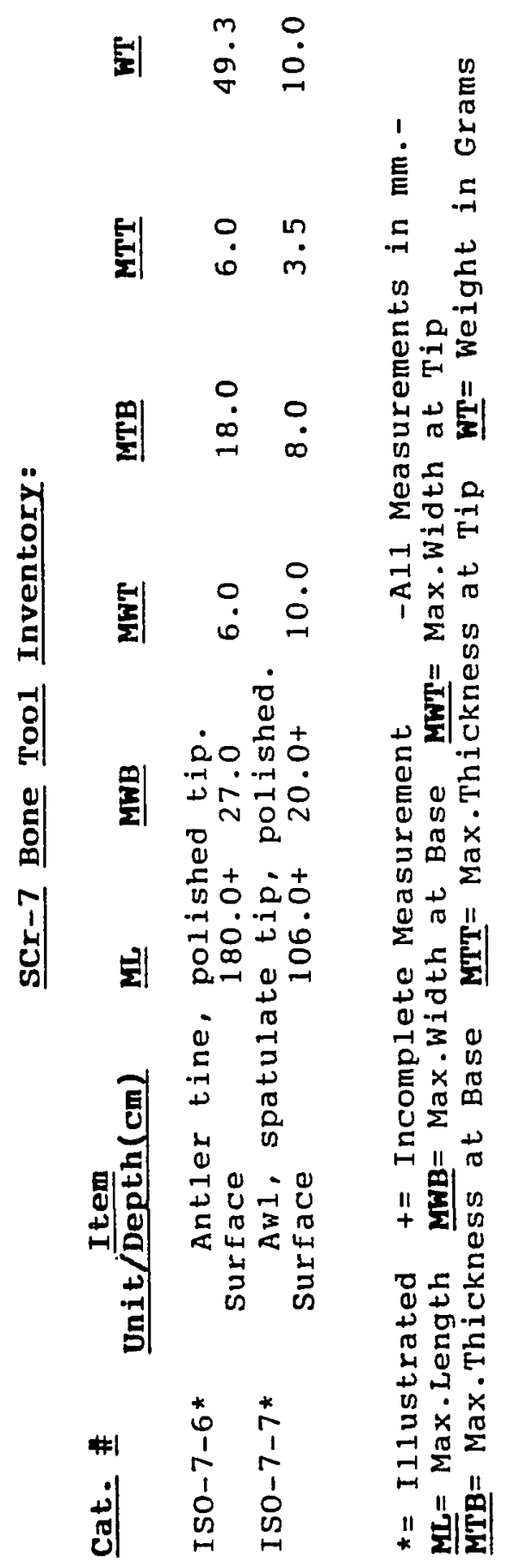




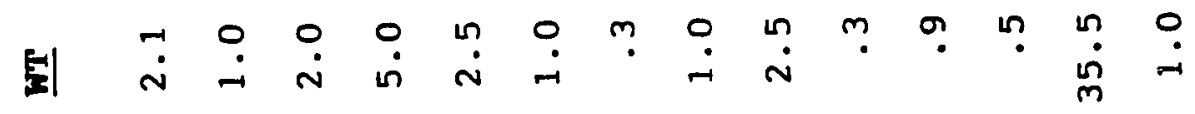

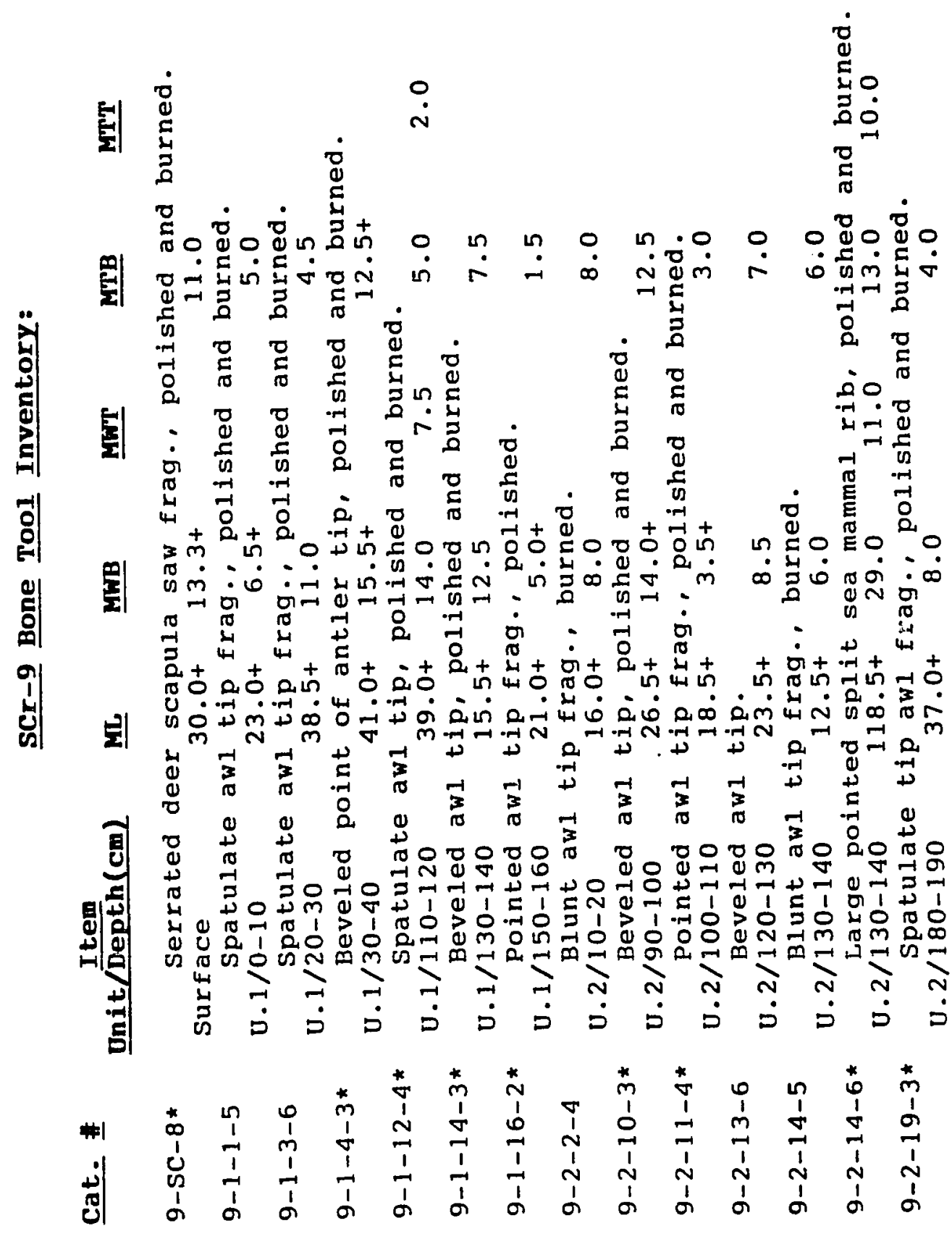




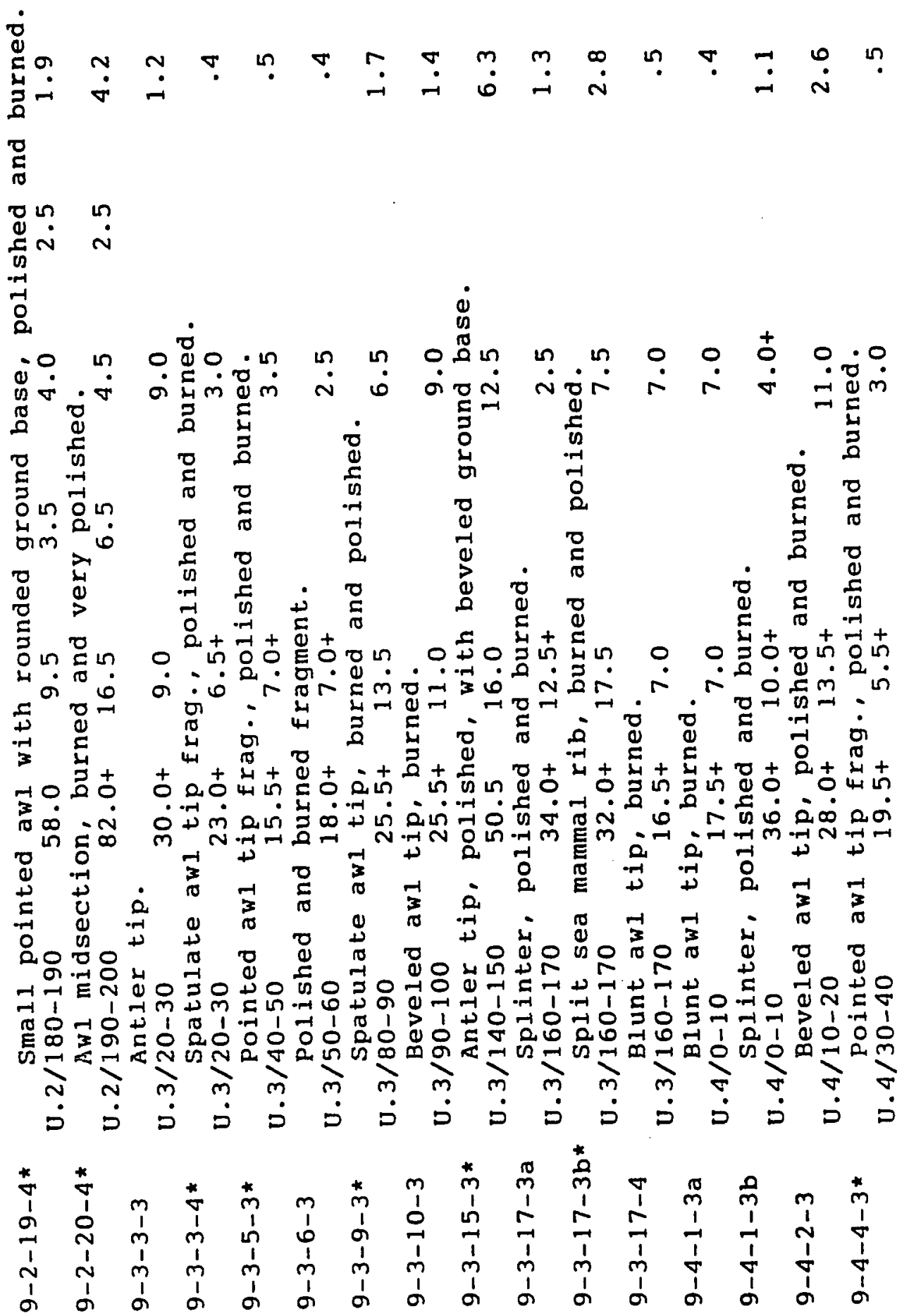




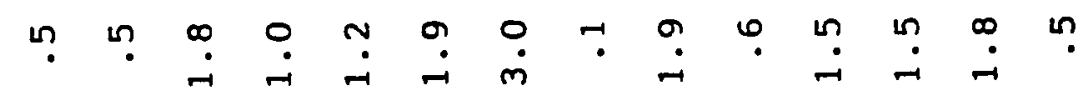

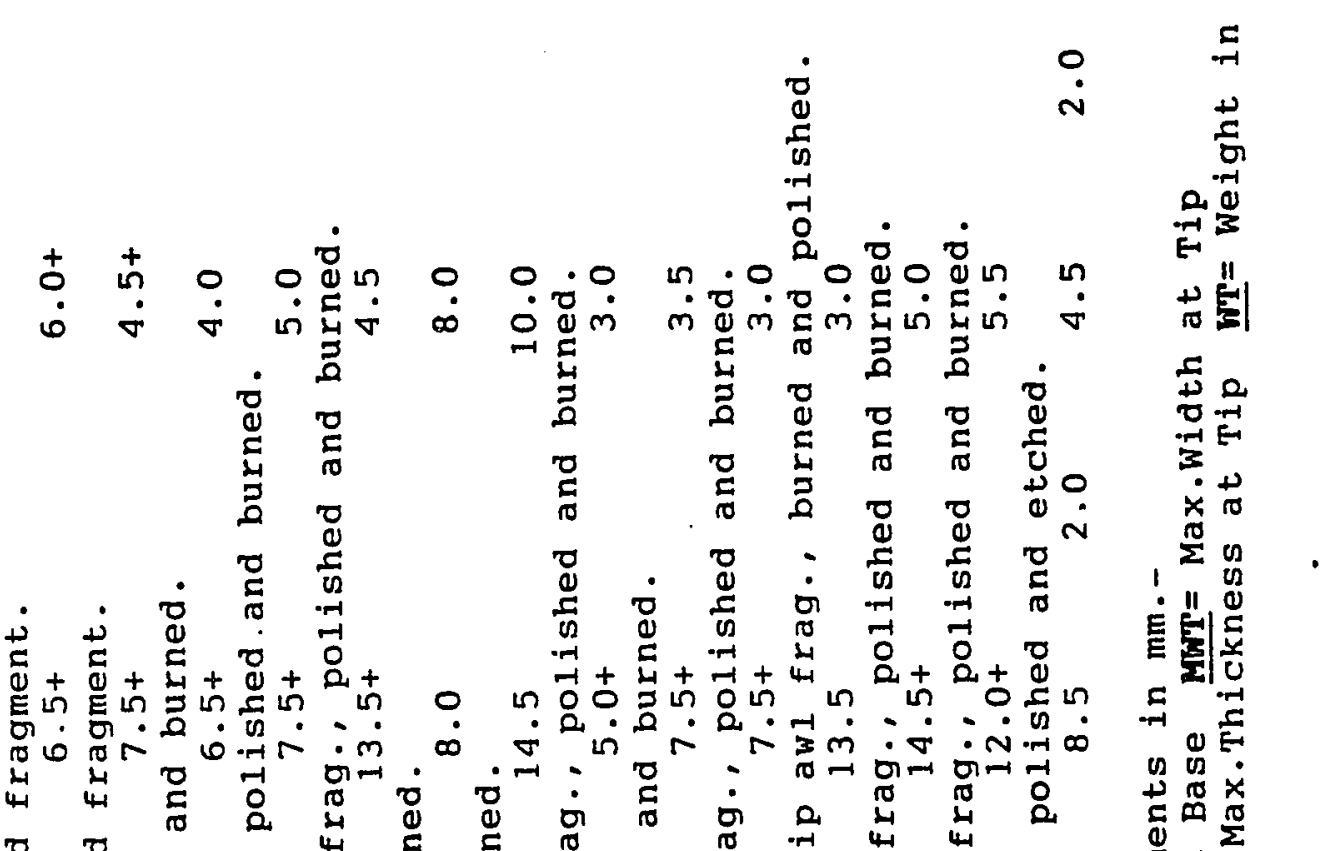

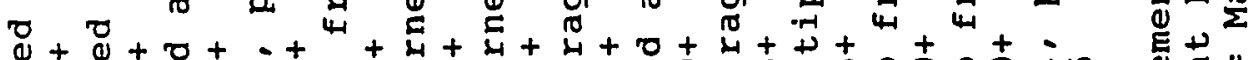

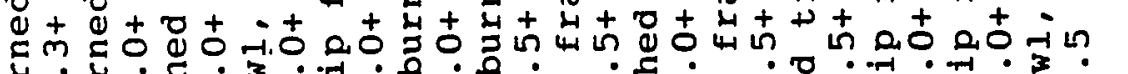

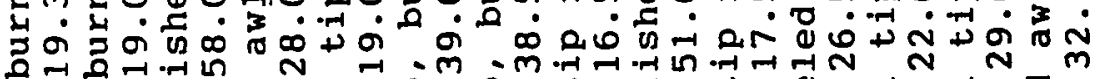

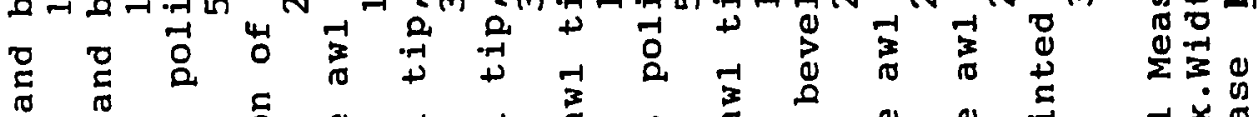

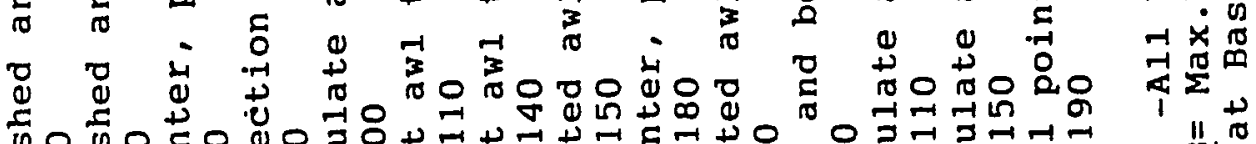

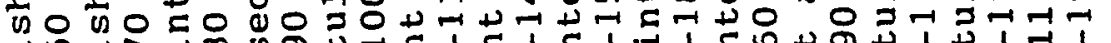

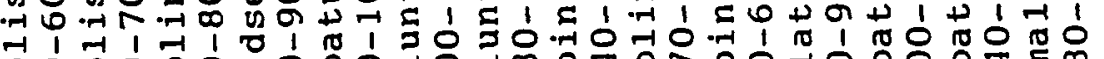
-1 1 1

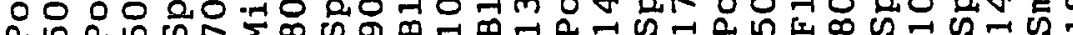

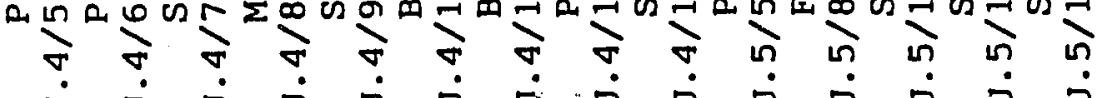

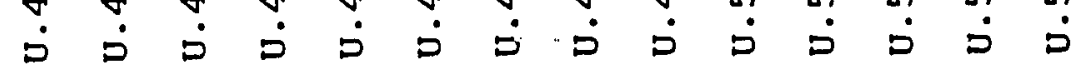

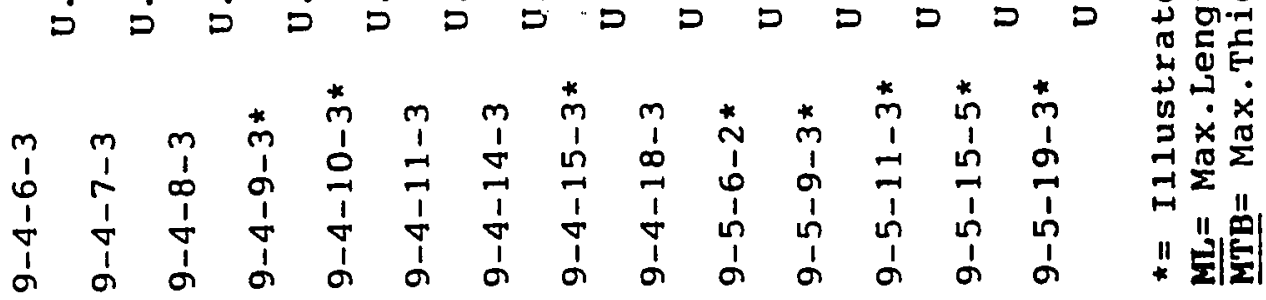




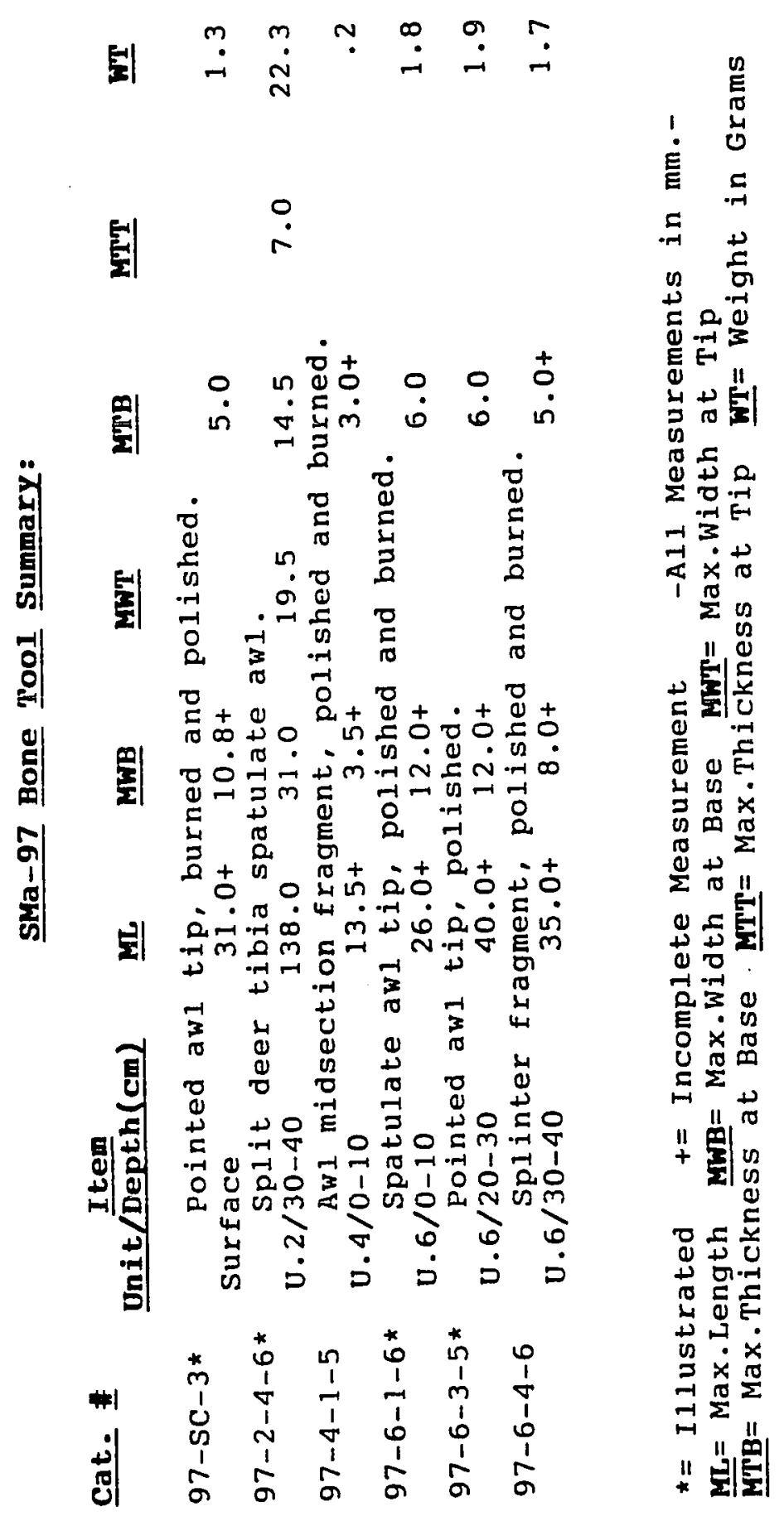




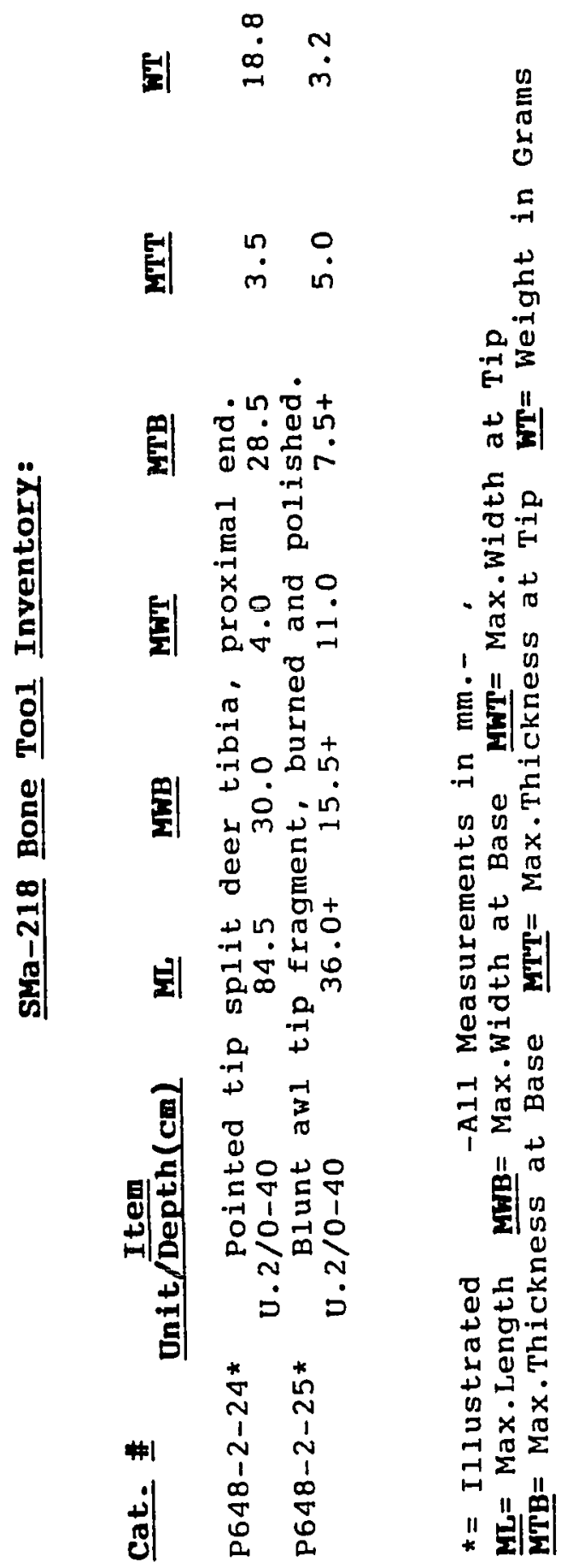




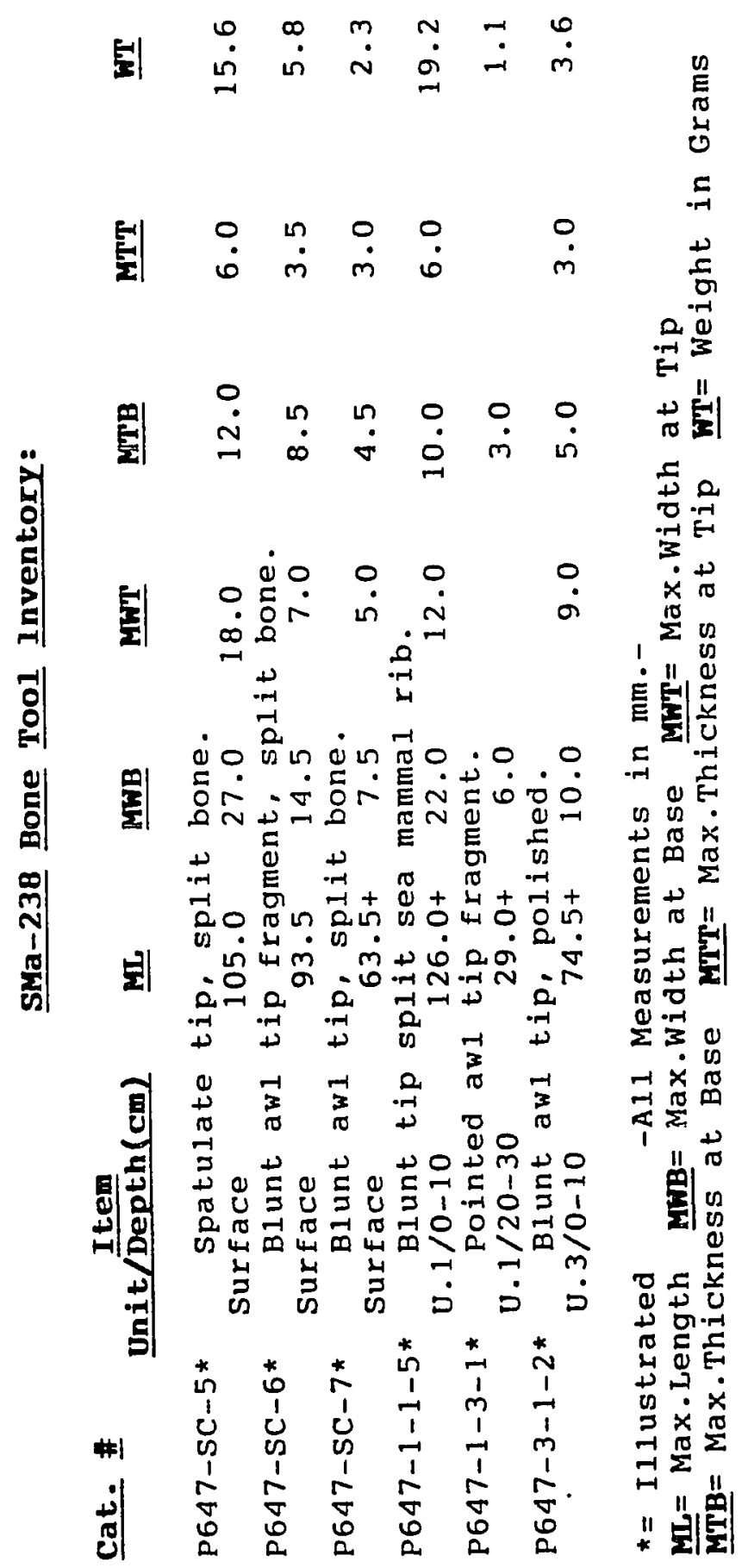




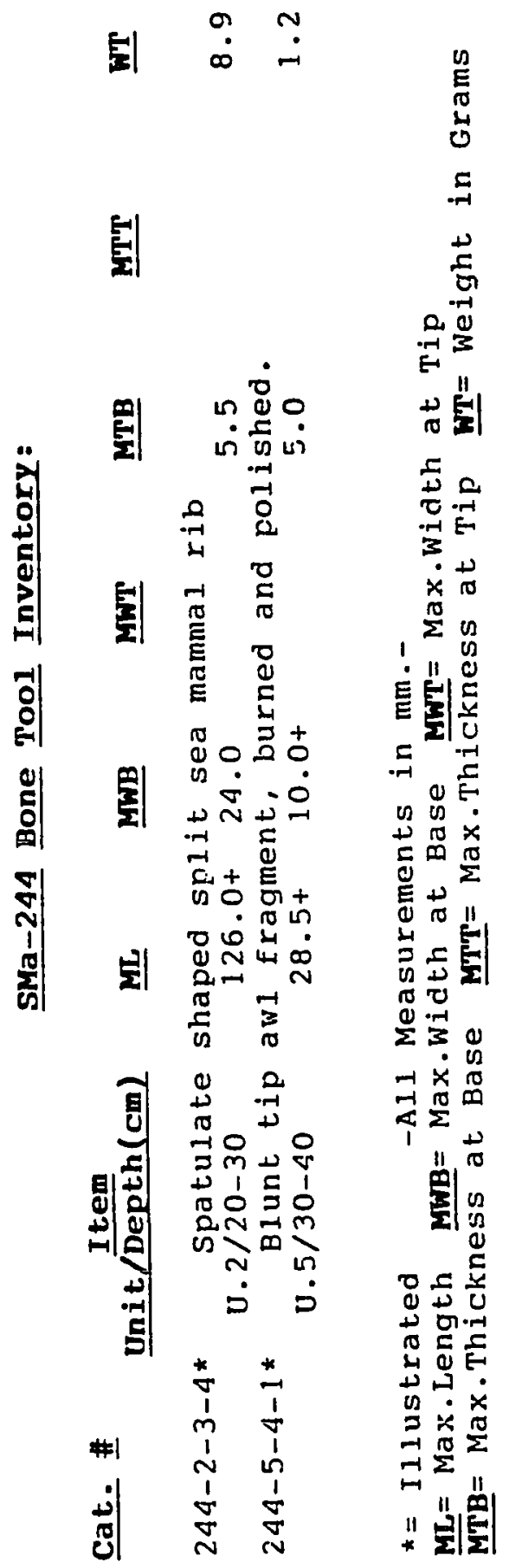




\author{
APPENDIX D \\ Chipped stone tool inventories for sites scr-7, sCr-9, \\ SCr-38, SCr-39, SCr-40, SCr-132, SMa-97, SMa-218, \\ and SMa-244
}




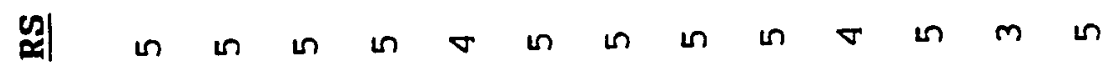

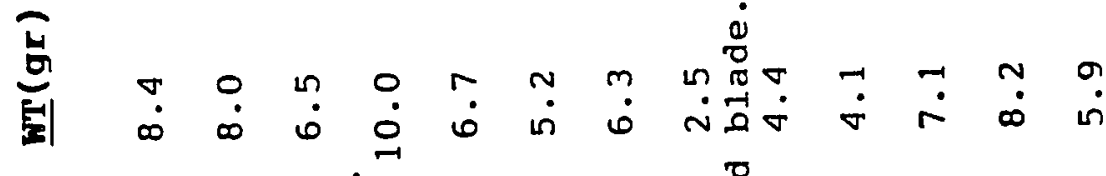

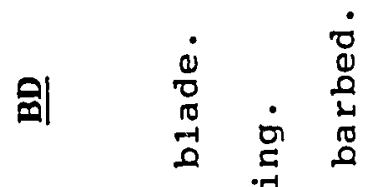

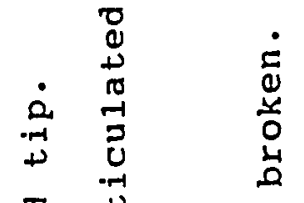

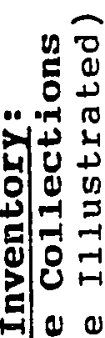

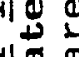

อ.

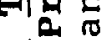

空

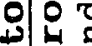

放政

䟚

记

a.

穵国

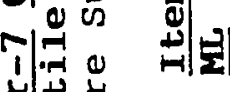

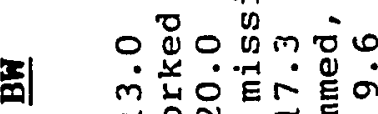

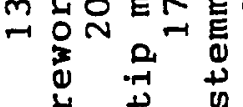

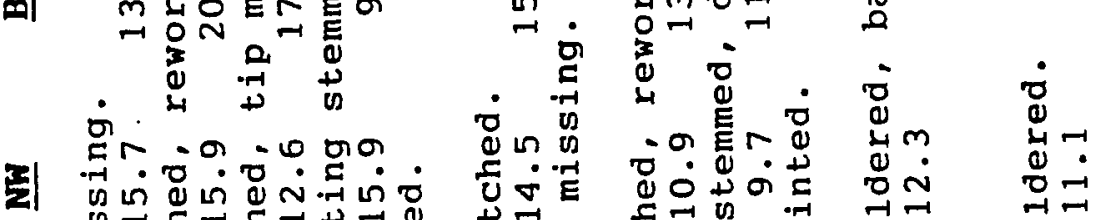
E ० 0 ह

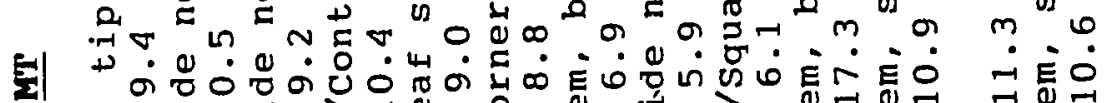

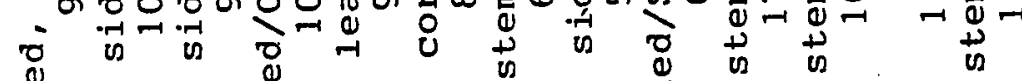
E

子

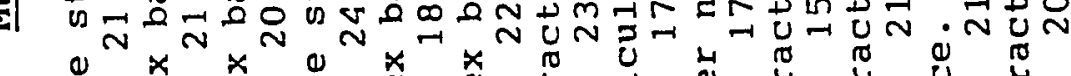

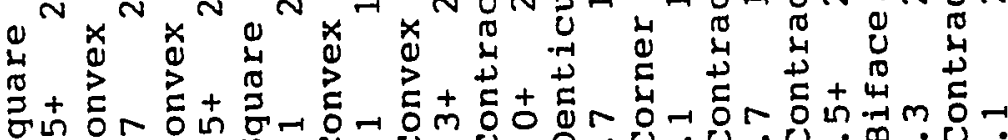
ט U⿺辶一 की

${ }^{2}=1$

th

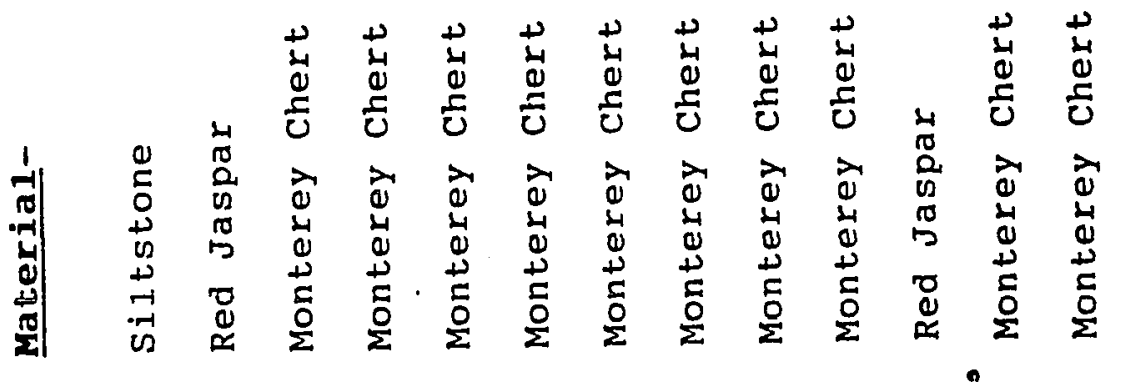

\# 
$\nabla$ in in in in in in $\nabla$ in in in $\nabla$ in in in in

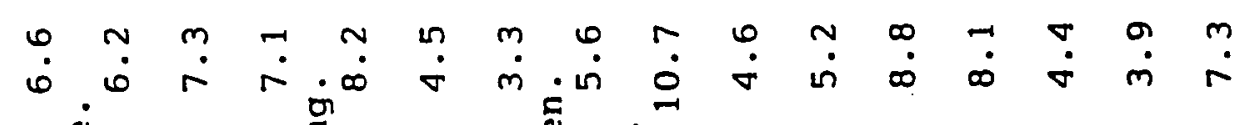

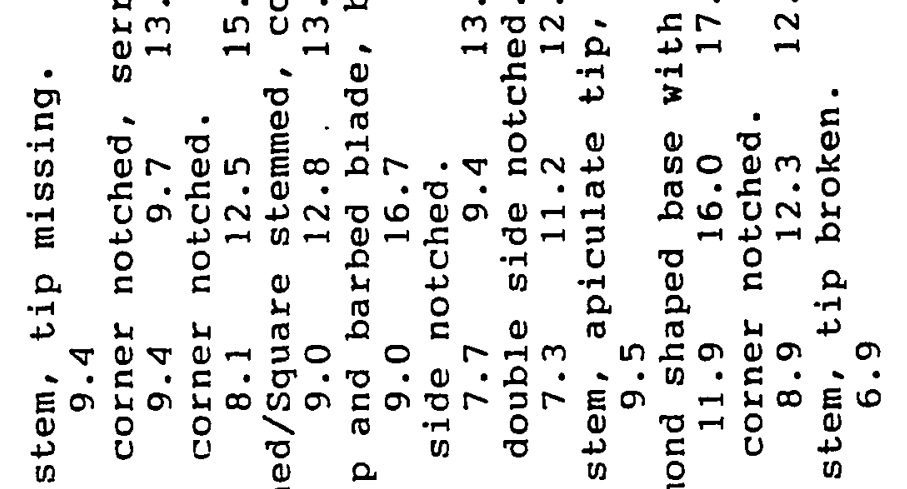

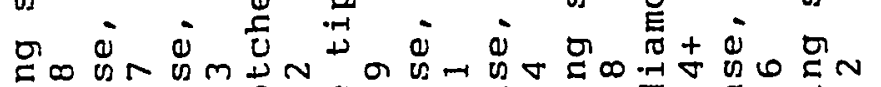

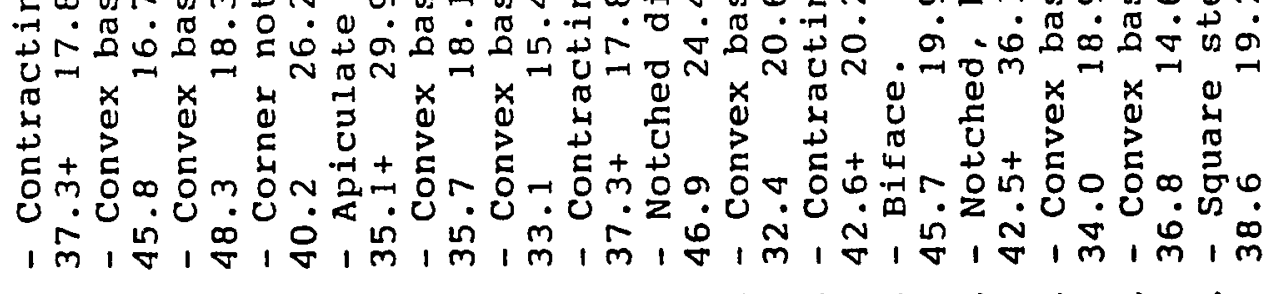

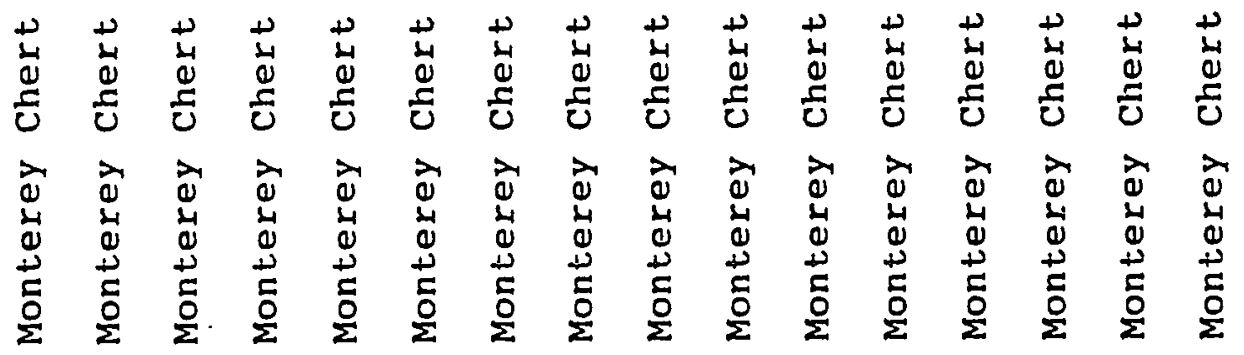

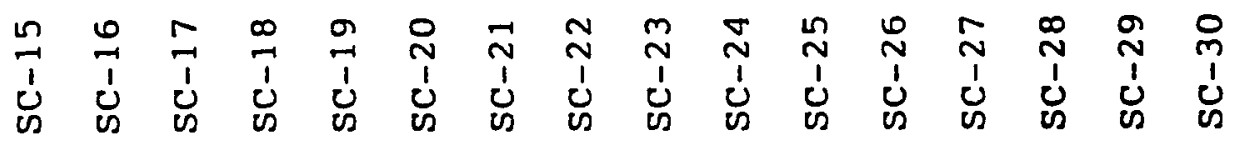




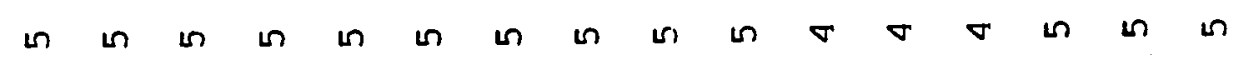

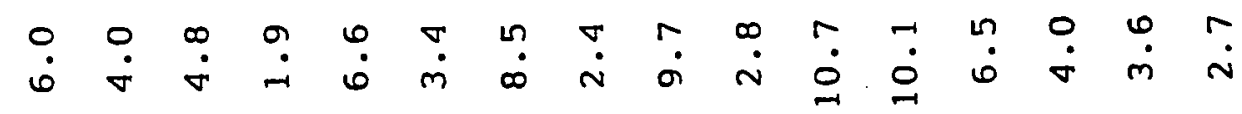

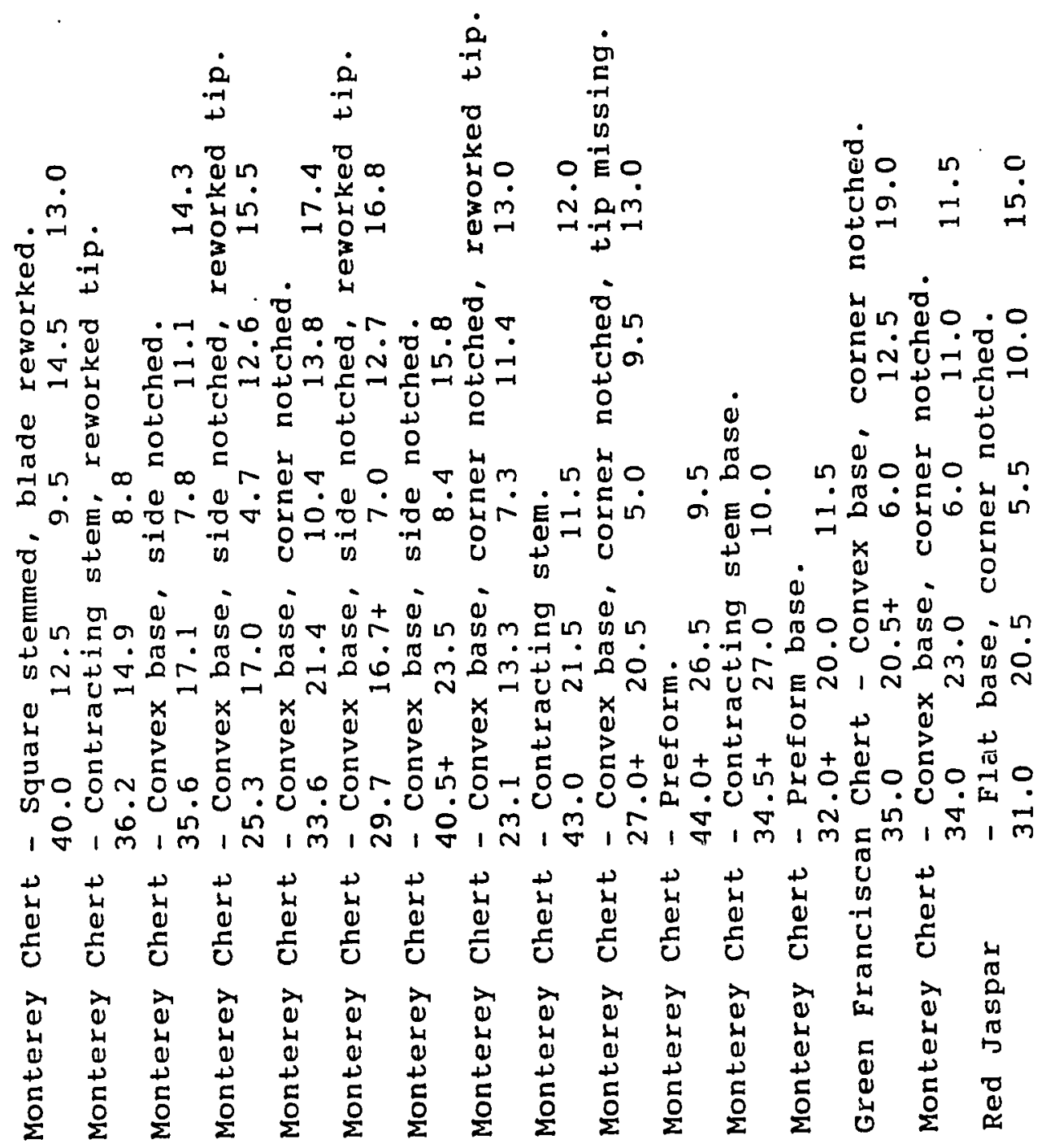

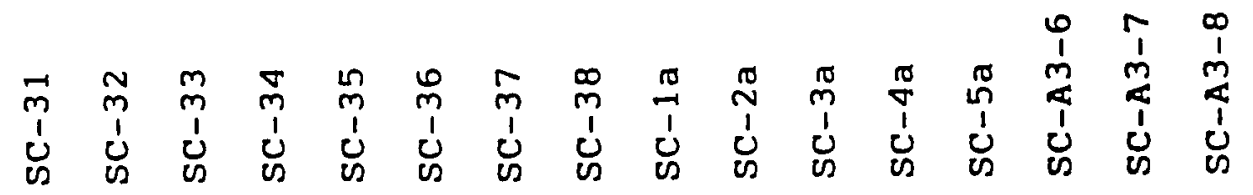


in in in in in in in $\ln$ in $\ln$ in $\ln$ in $\ln$ in $\mathrm{n}$

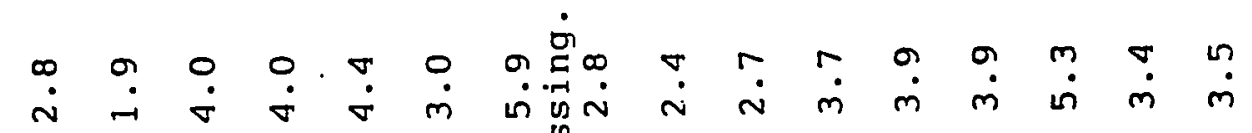
$\stackrel{\sim}{\text { U }}$

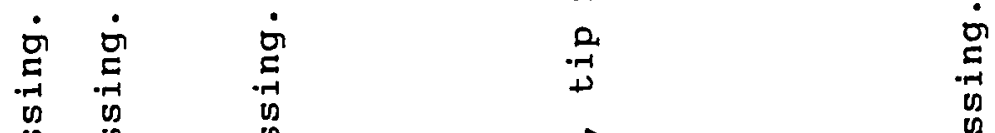

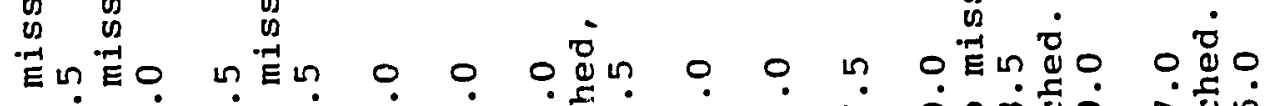

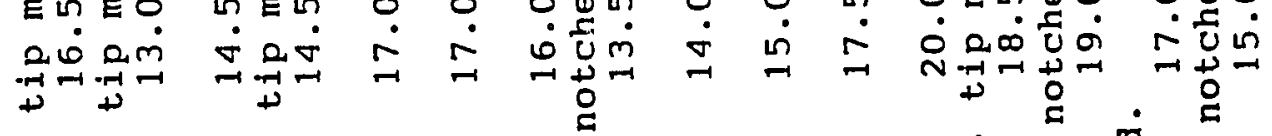

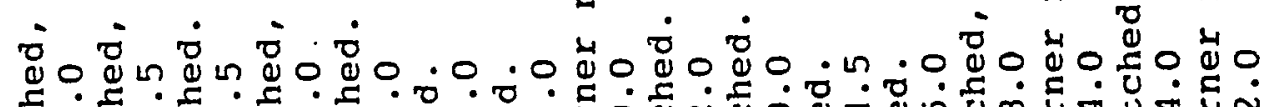
U一

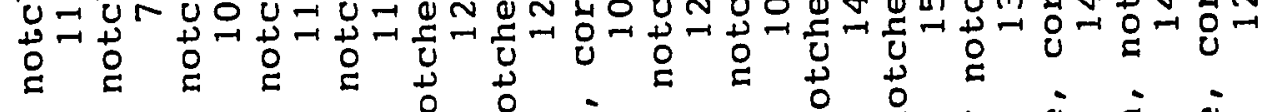

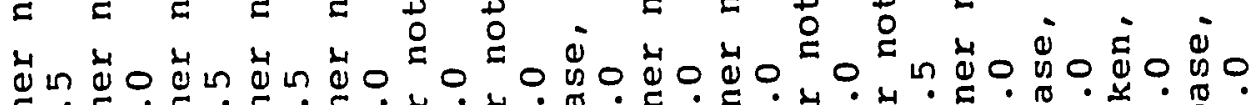
ت

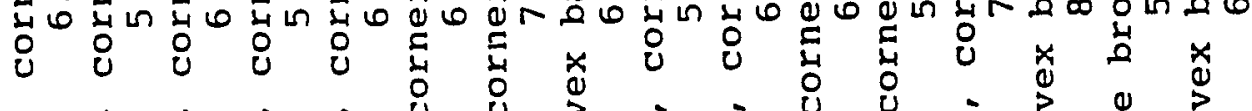

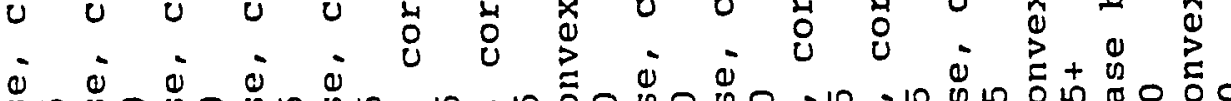
Un

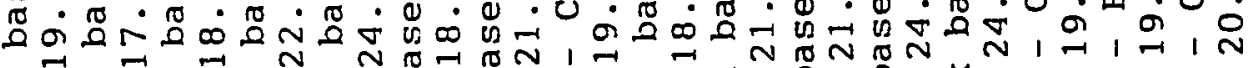

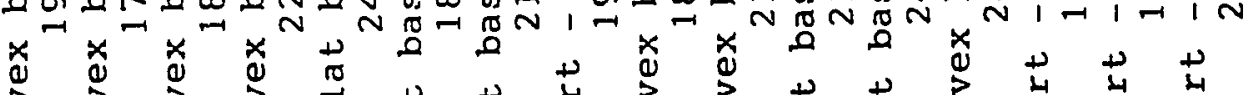

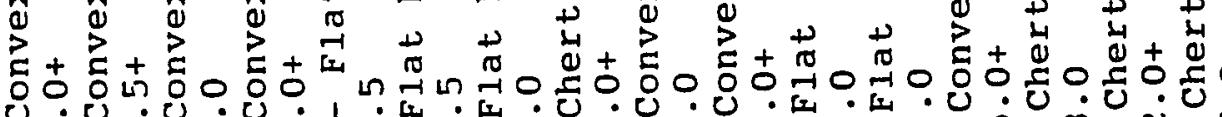
U U 0 ن 0

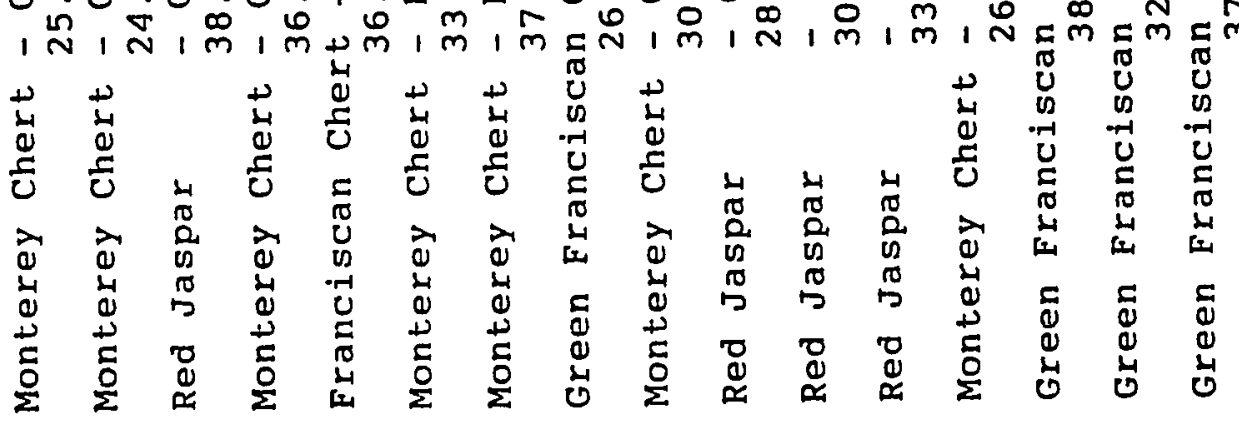

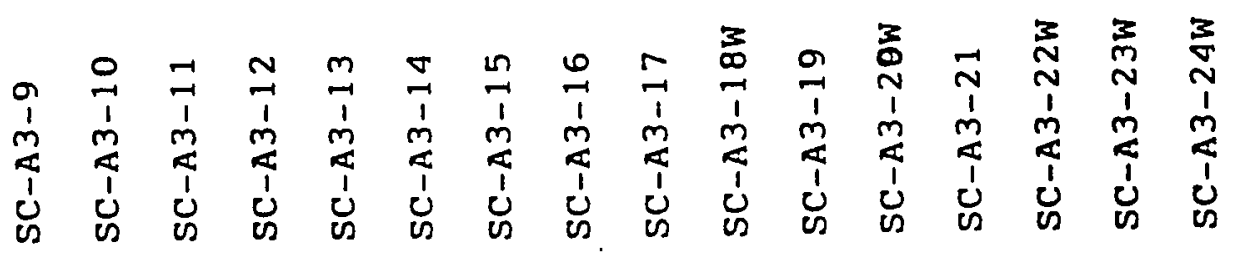




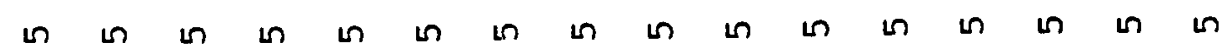

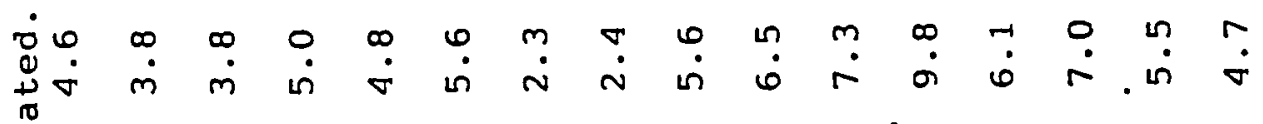

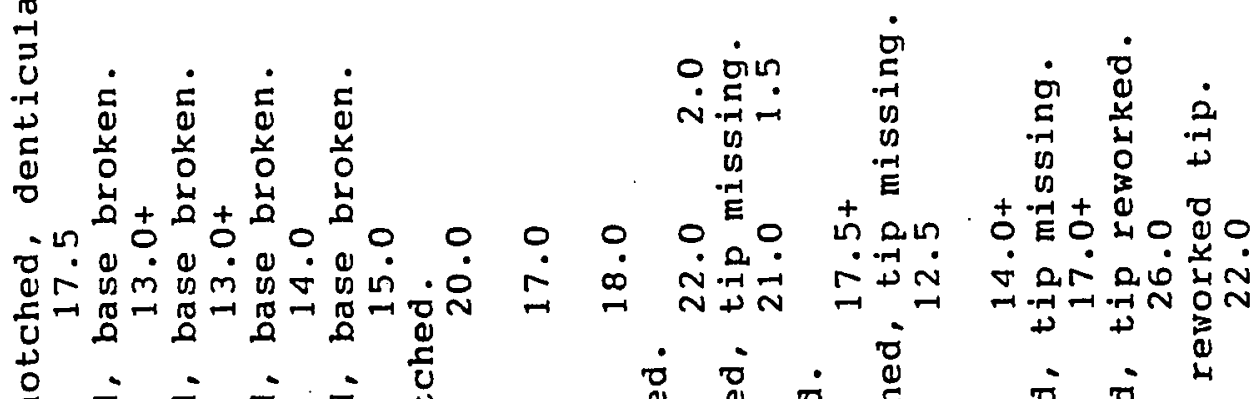

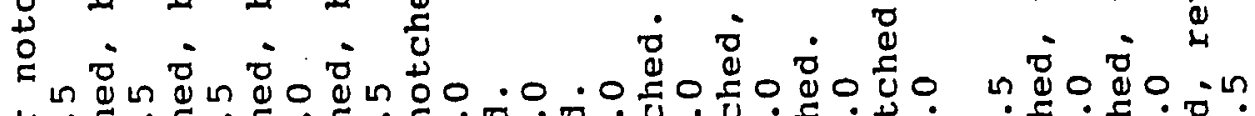

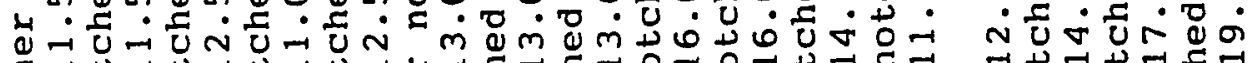

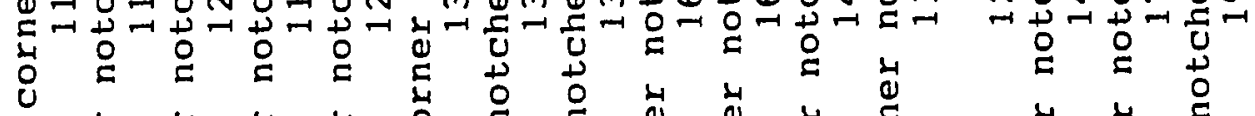

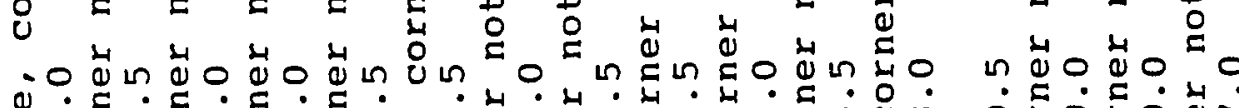

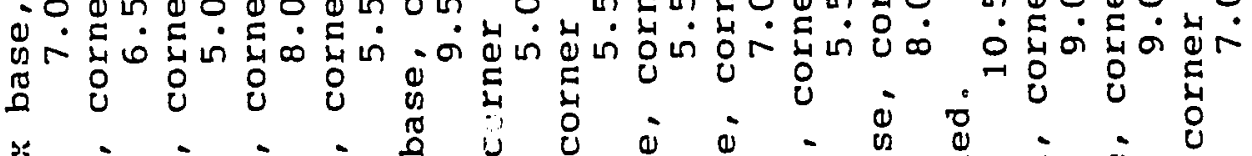

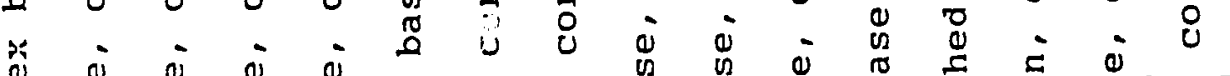

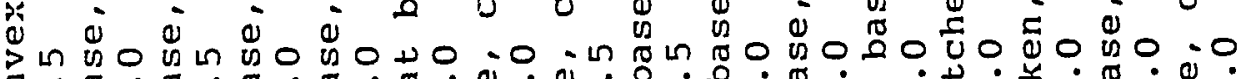

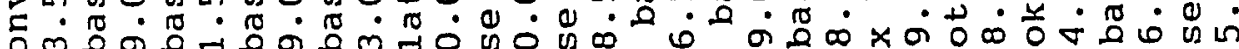

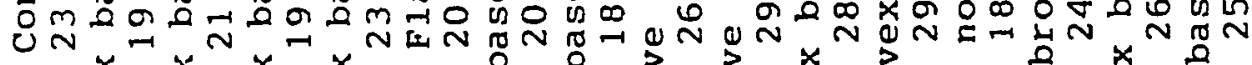

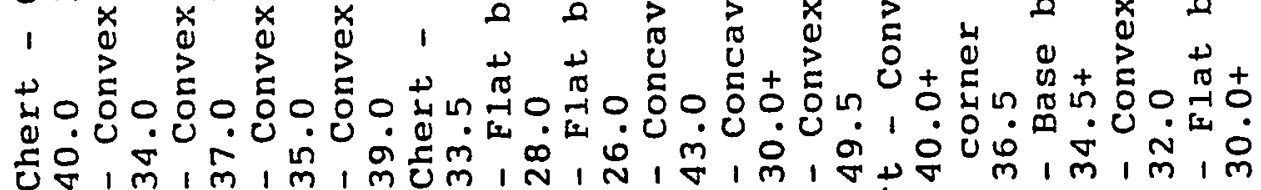

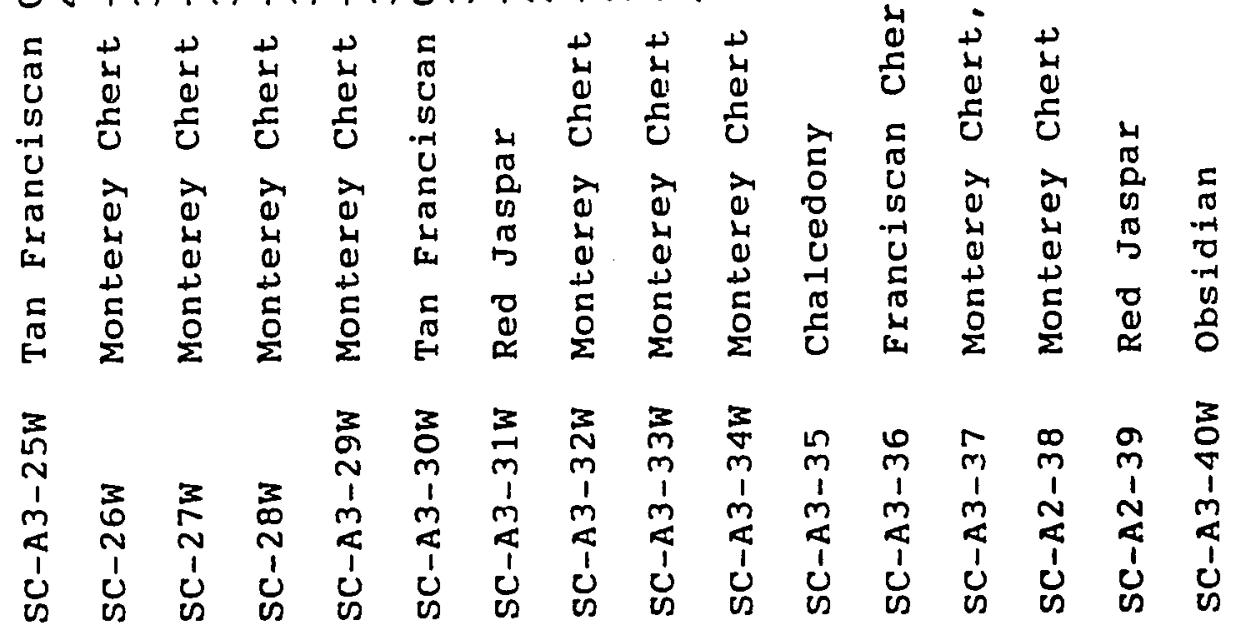




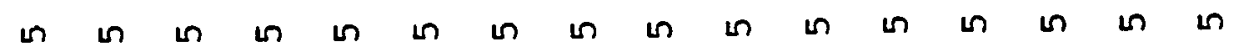

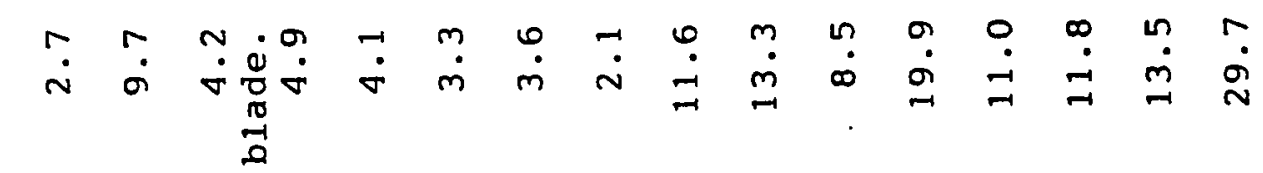

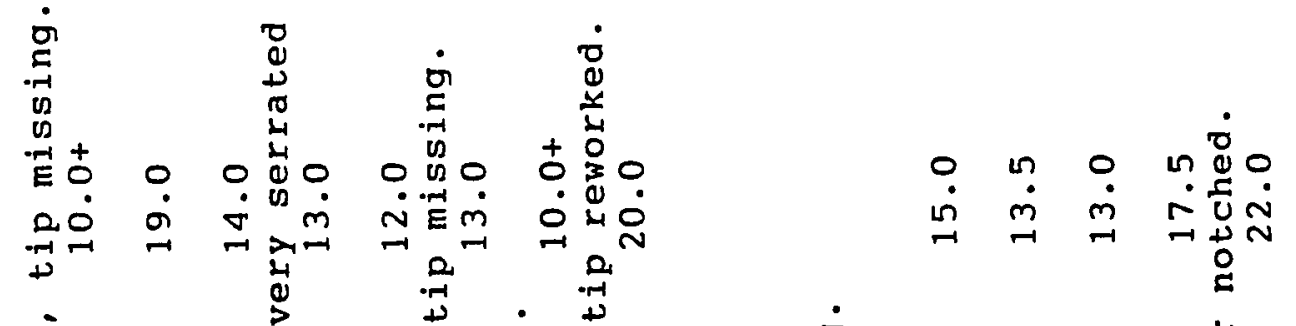

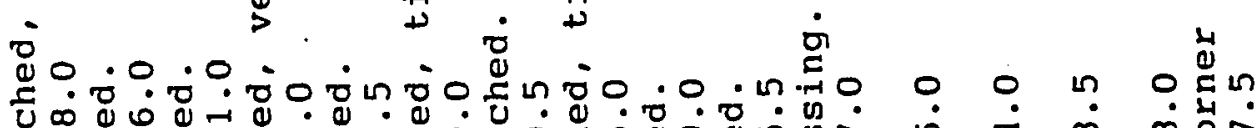

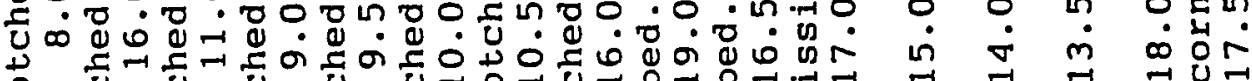

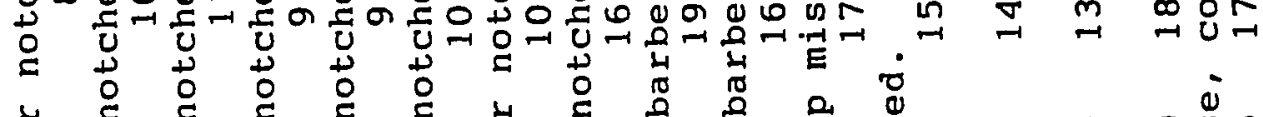
山。

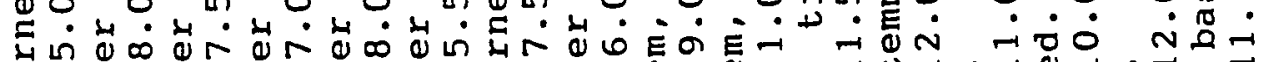

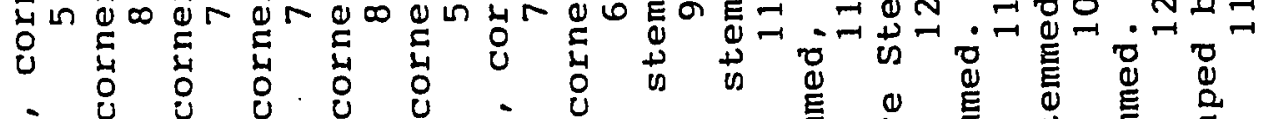

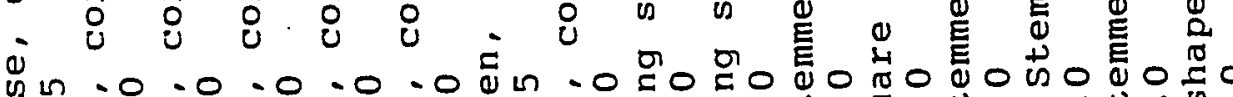

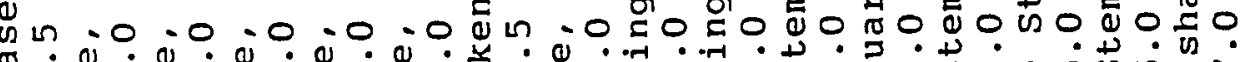

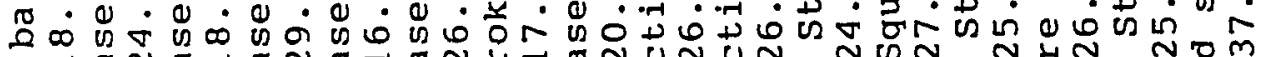

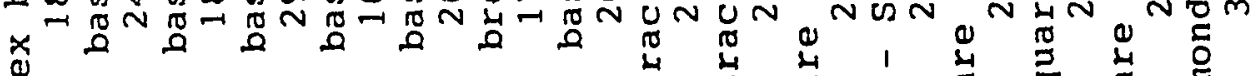

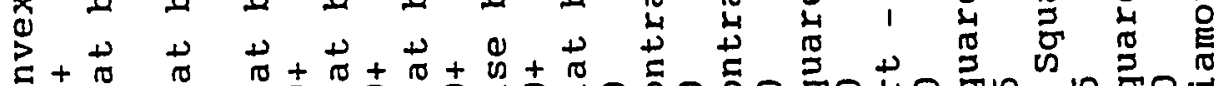

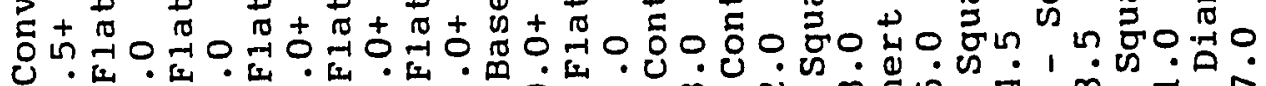

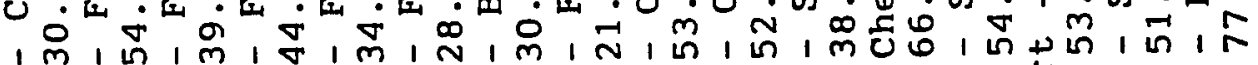

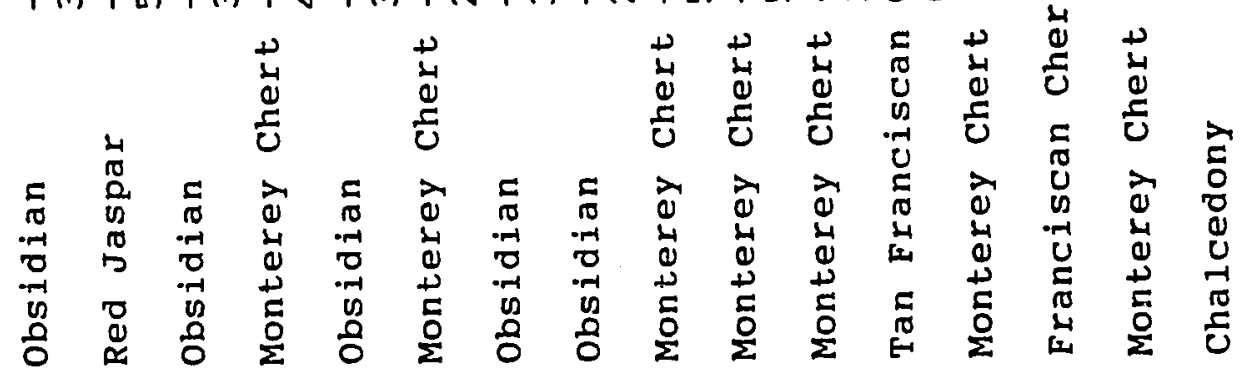

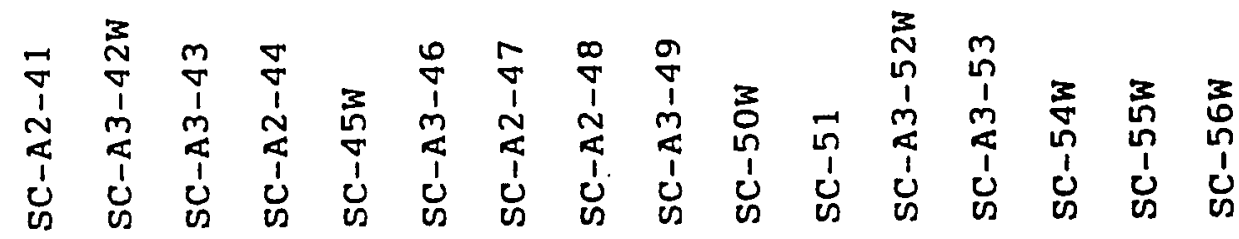




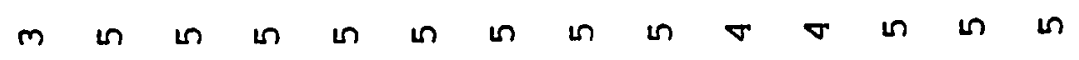

$\underset{\substack{10 \\ 0}}{3}$

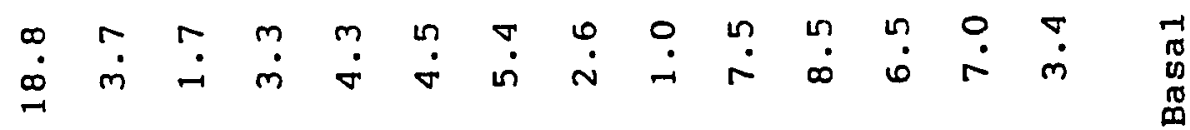

$\stackrel{0}{\dot{N}} \quad \sum^{\prime \prime}$

$\stackrel{0}{0} \quad \stackrel{0}{0}$

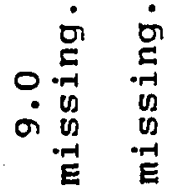

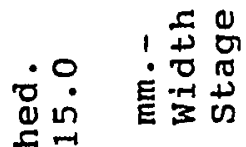

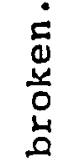

ק்

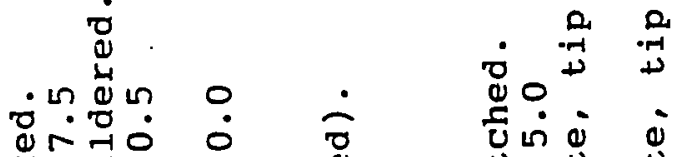

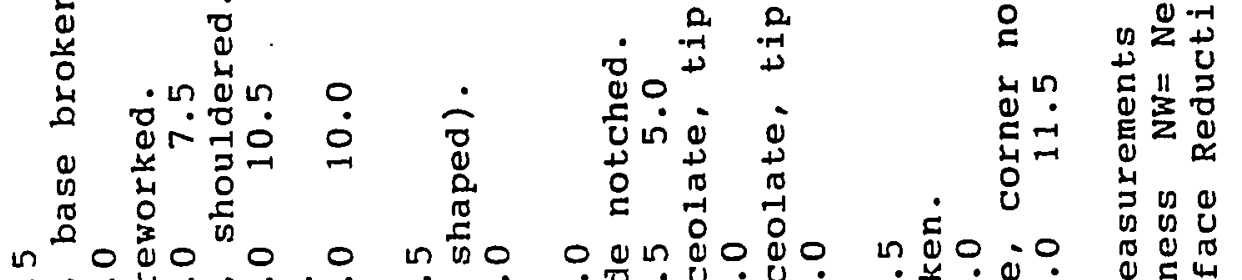

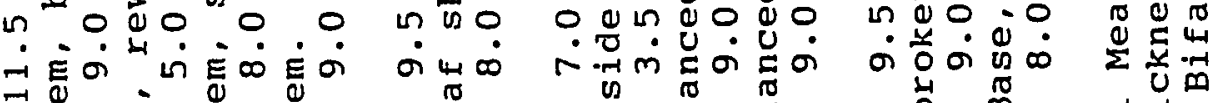

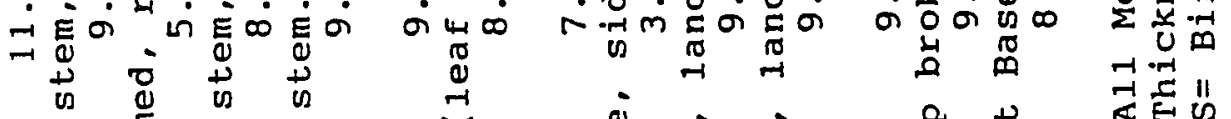

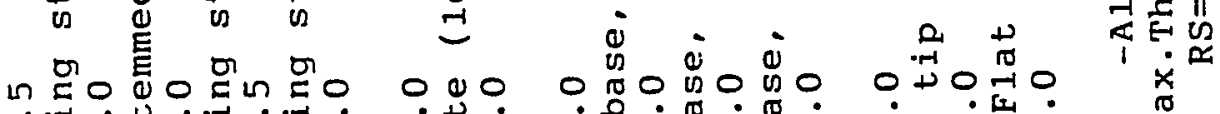

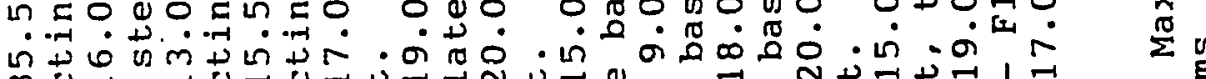

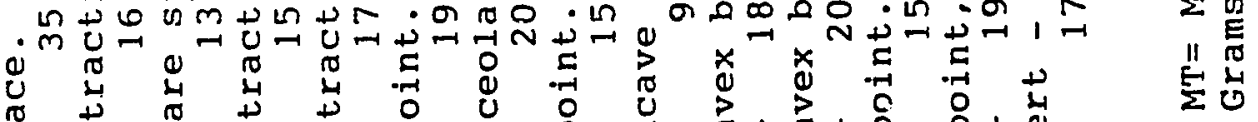

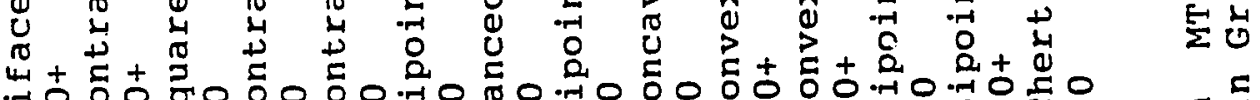

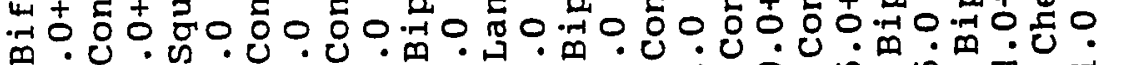

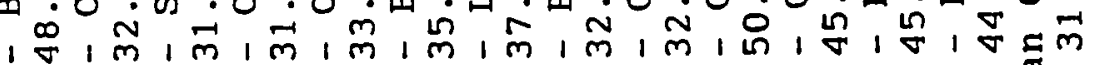

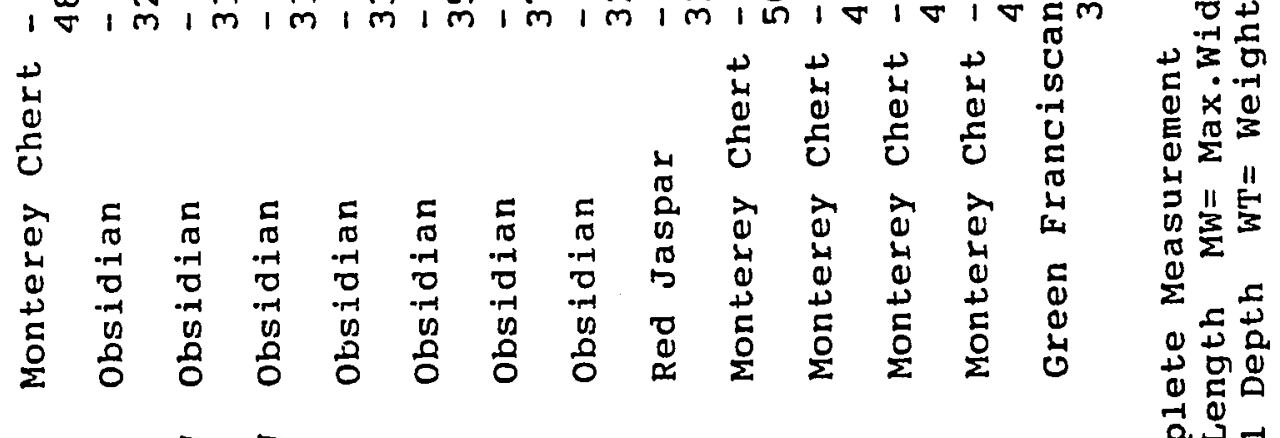

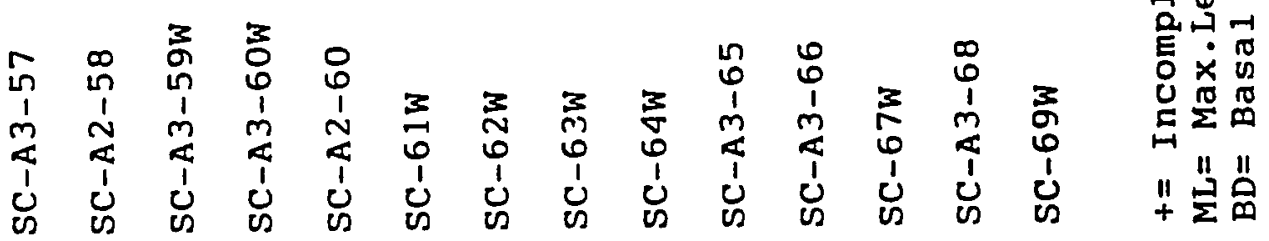




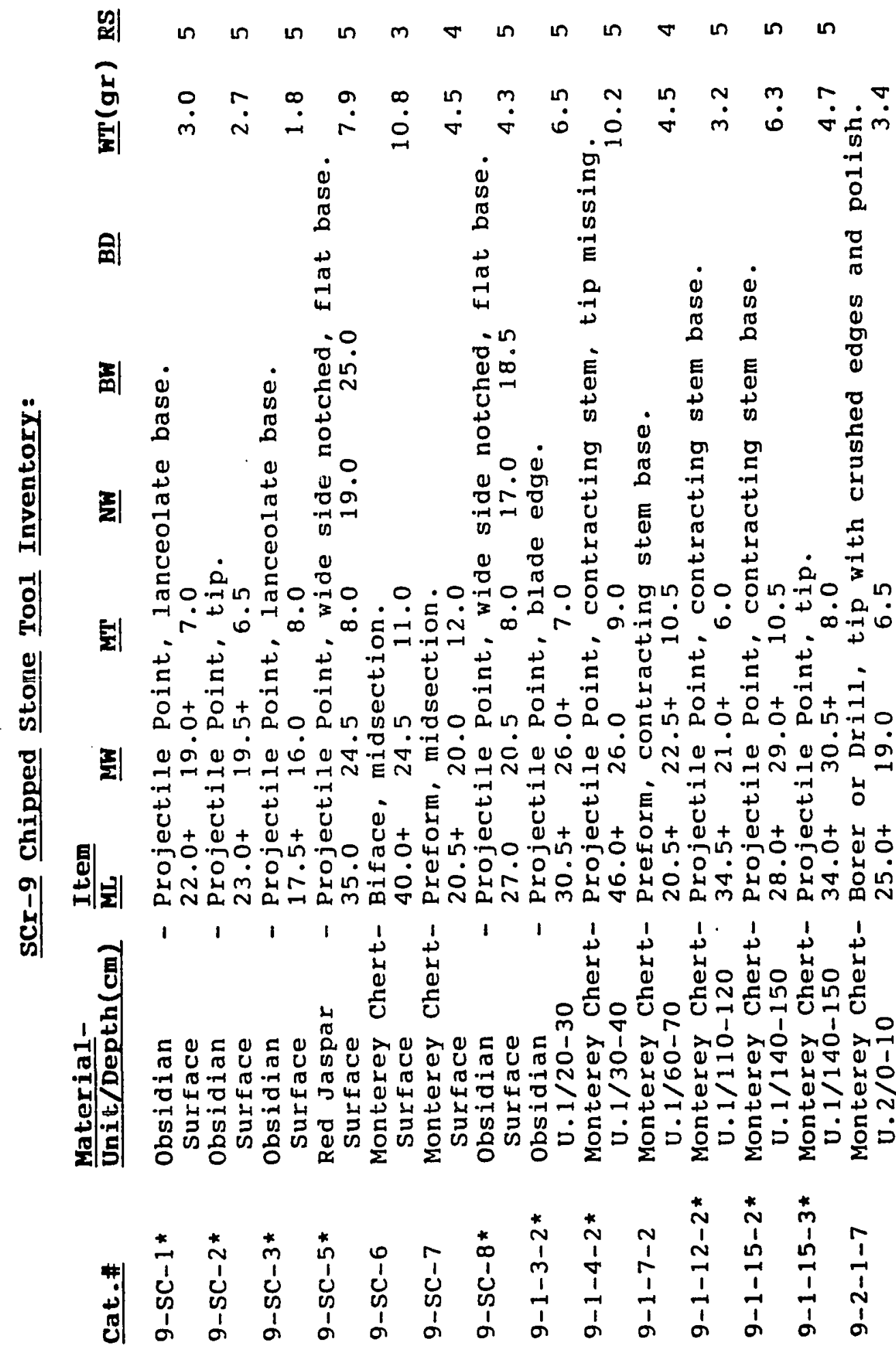




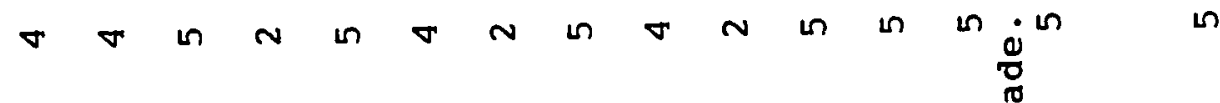

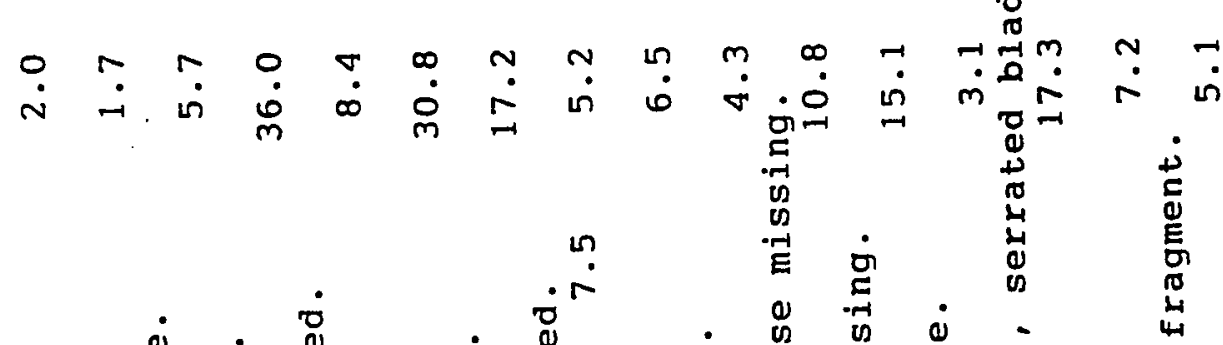

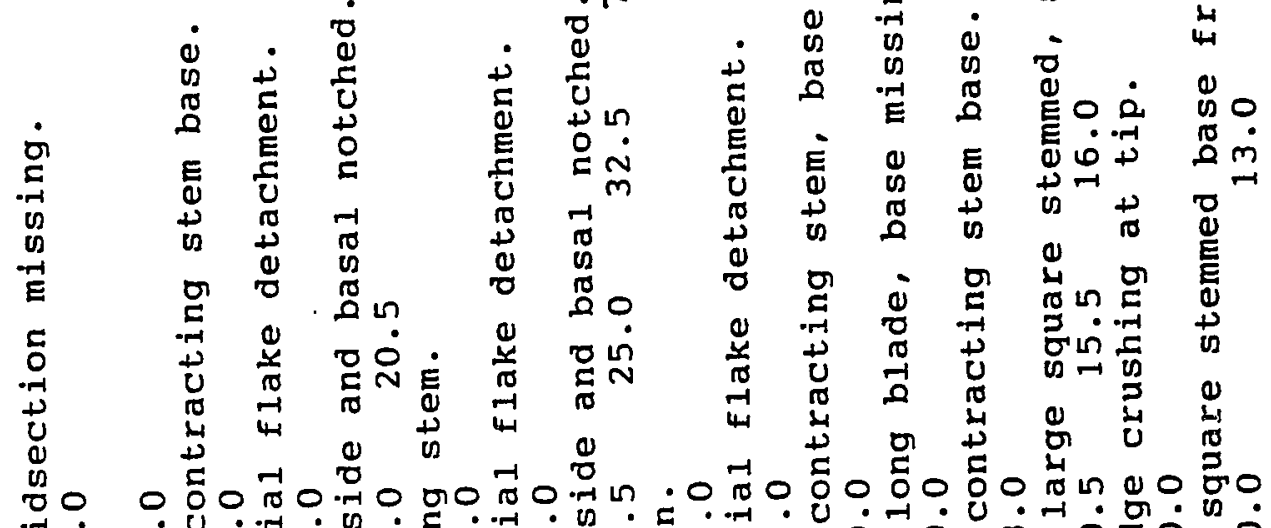

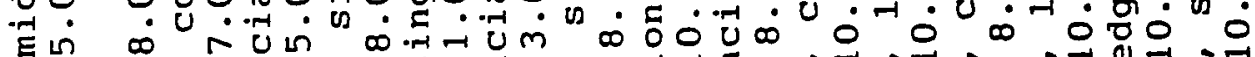

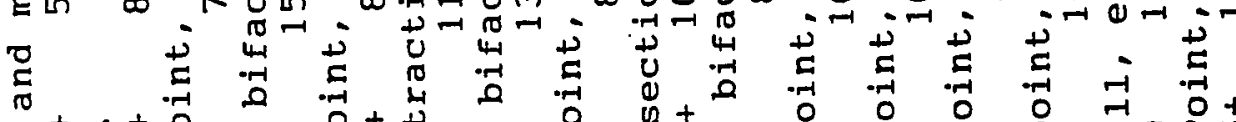

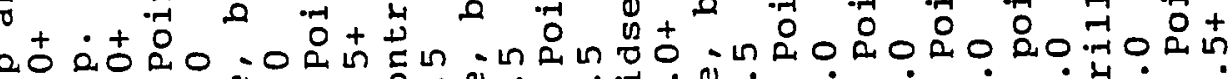
ب-1

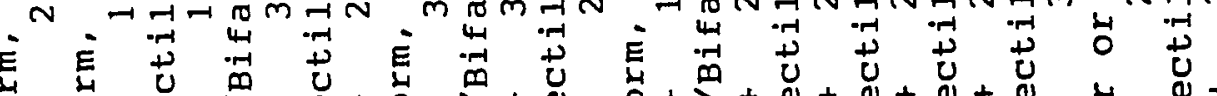

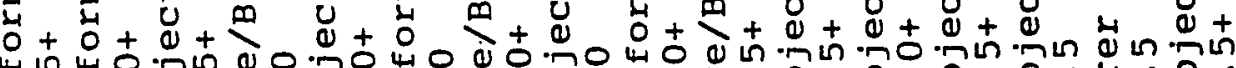
4 4 แ

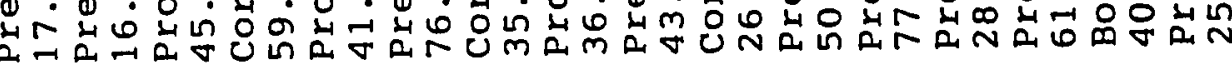

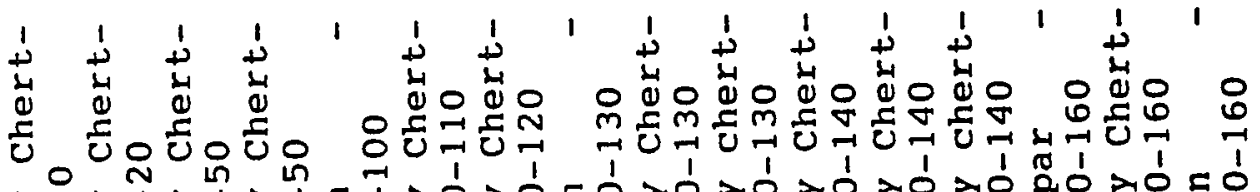
국 궁

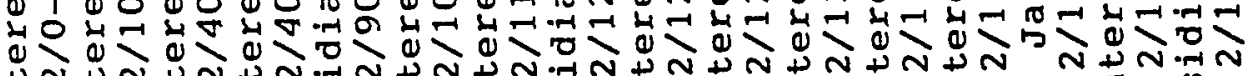
7N

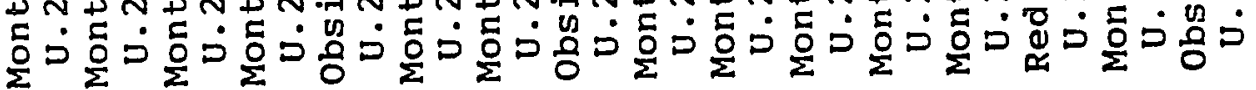

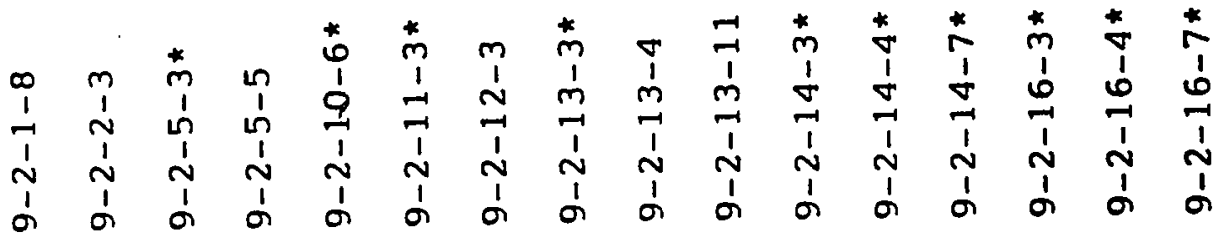




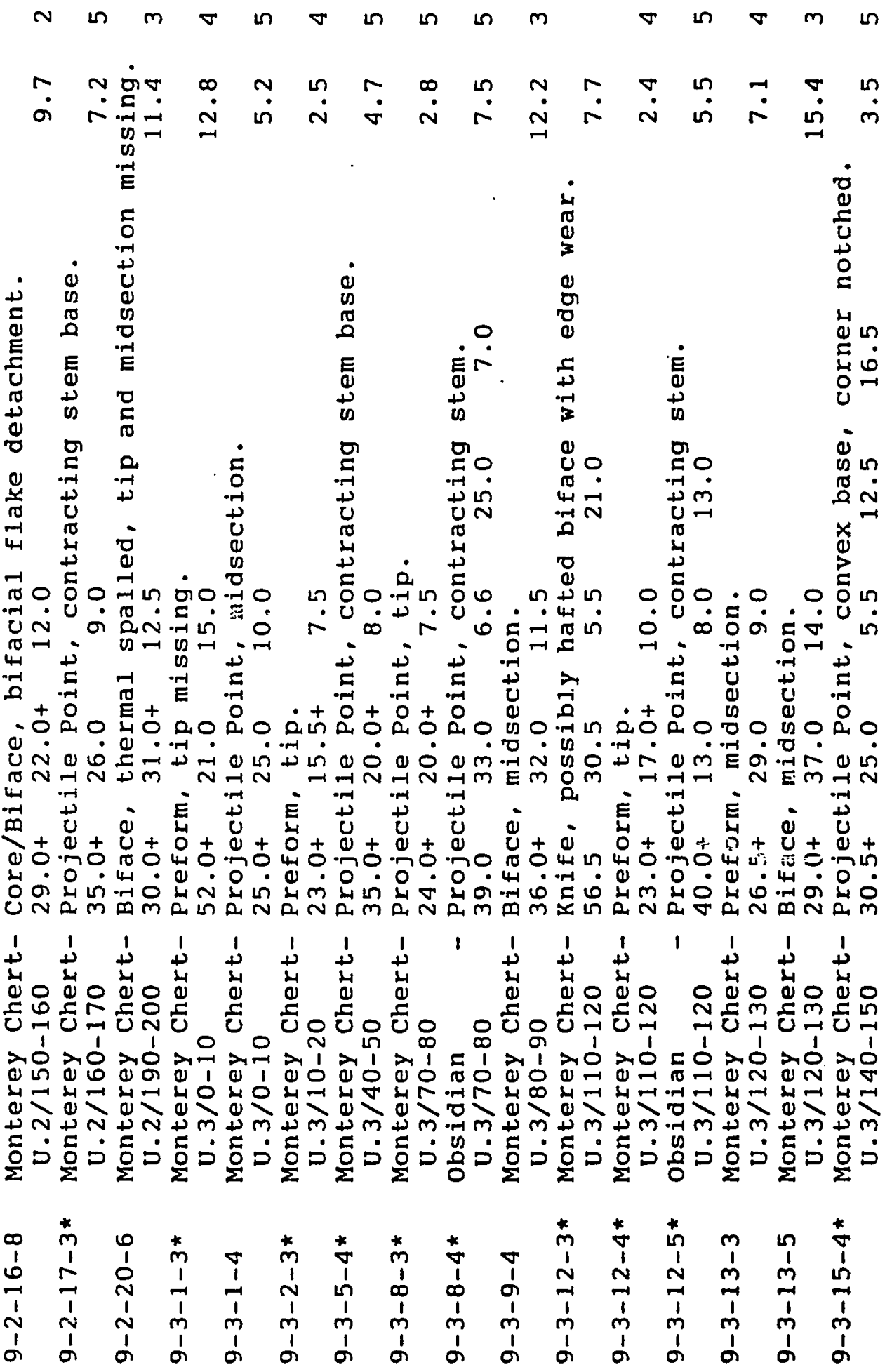




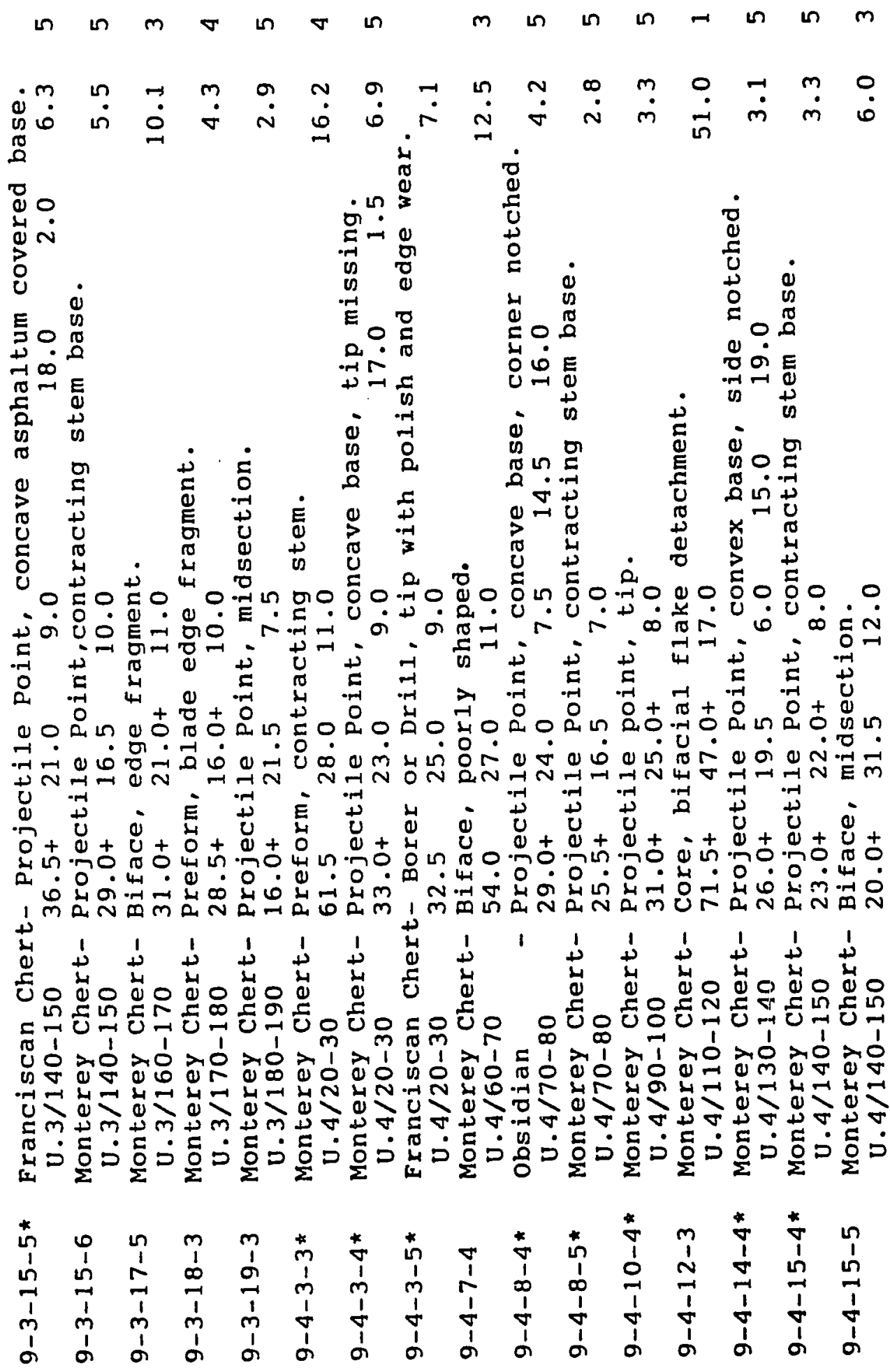




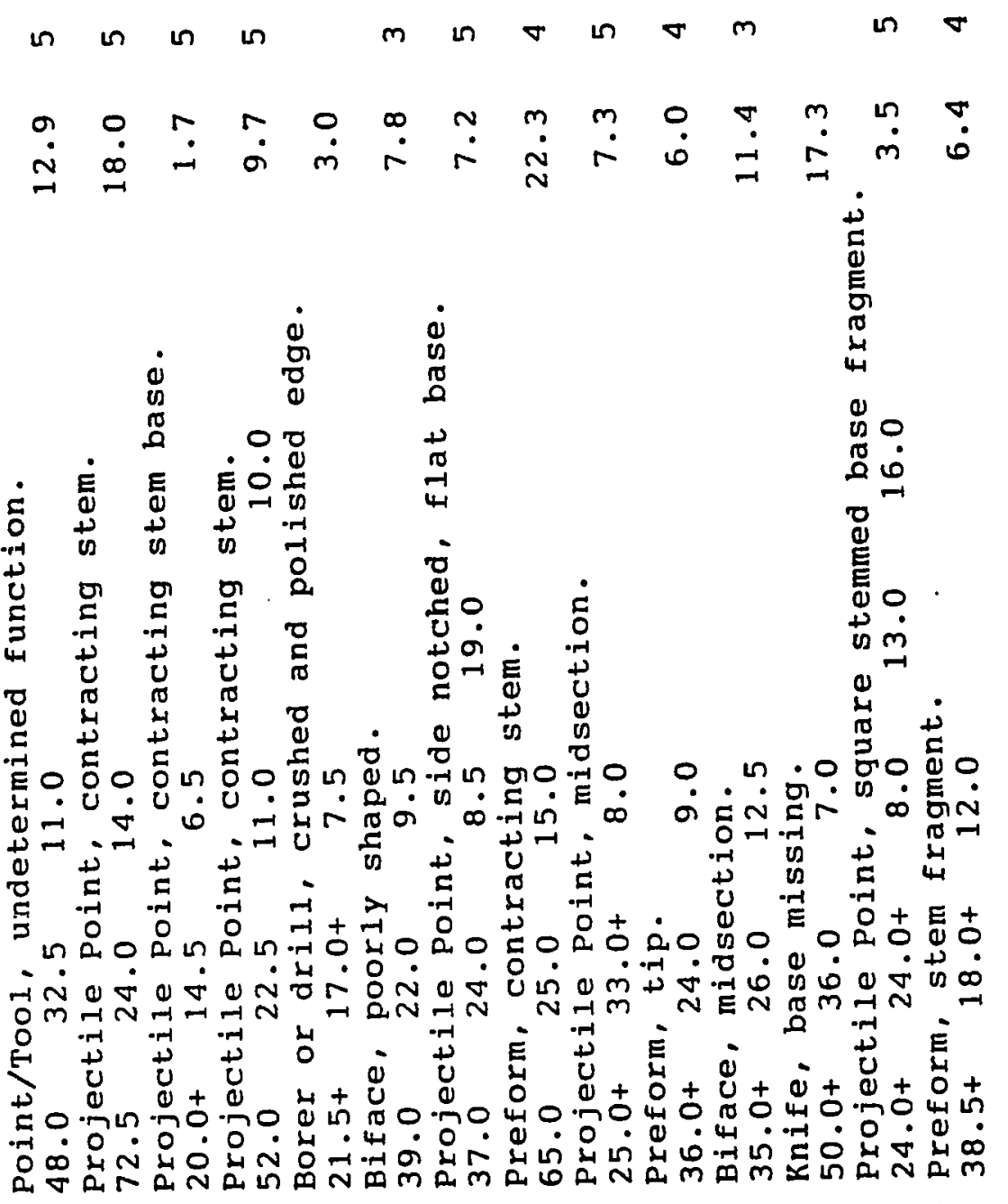

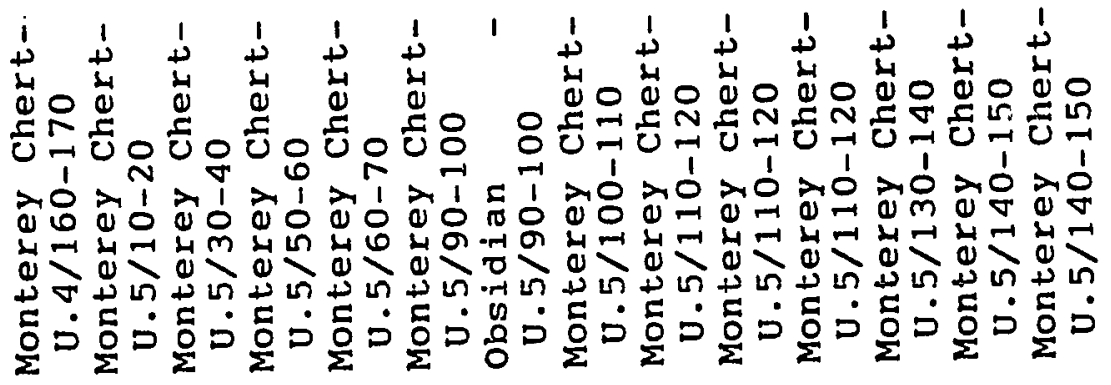

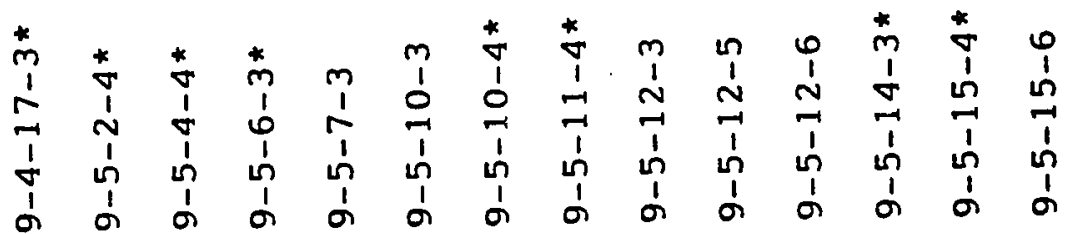




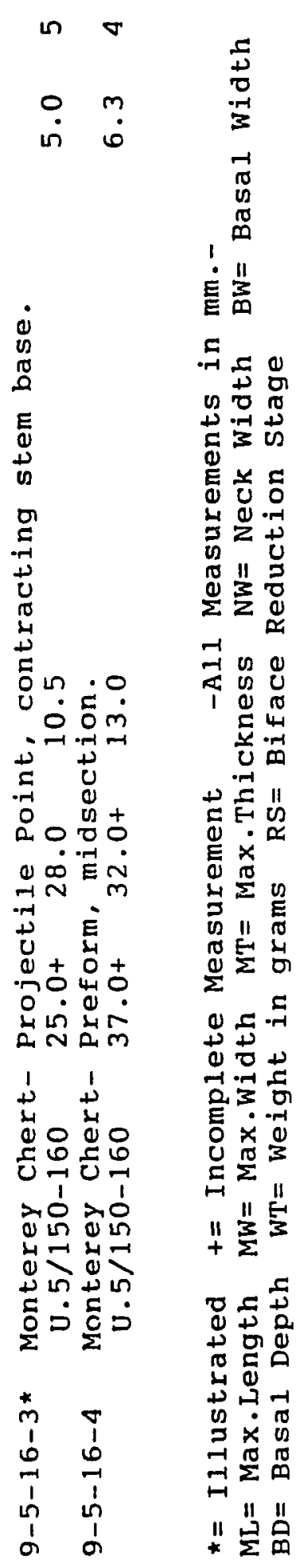




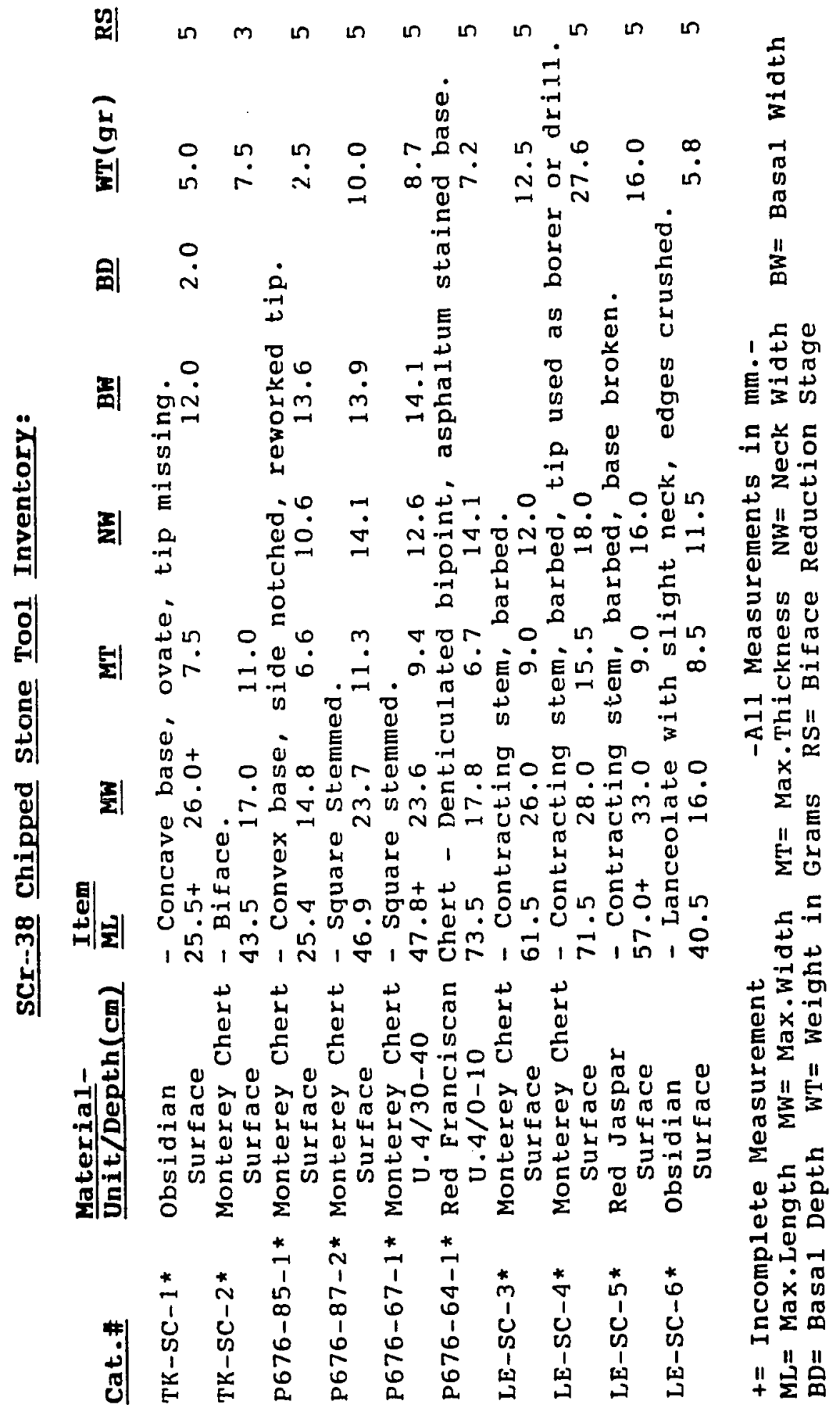




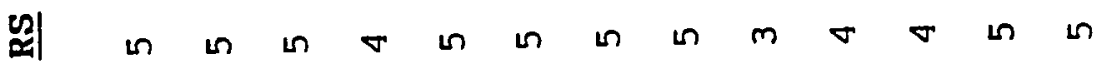

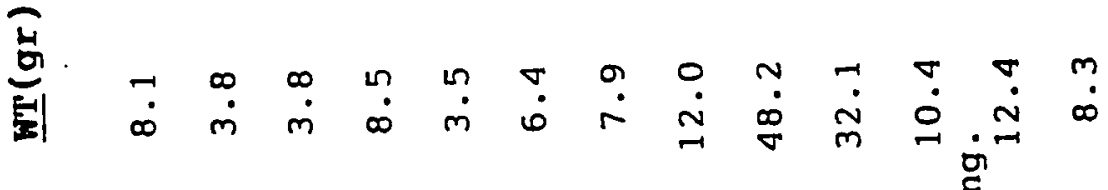

옘

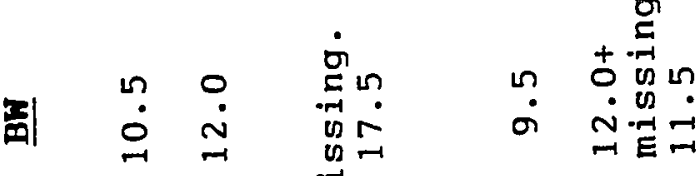

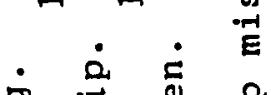

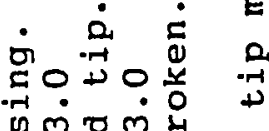

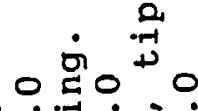

2

טन

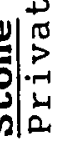

이임음

E

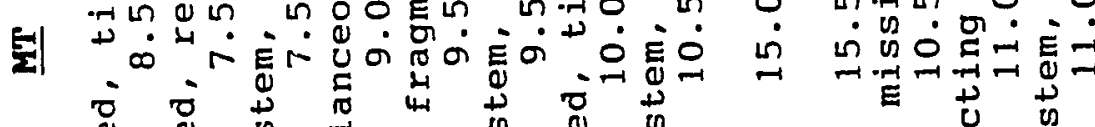

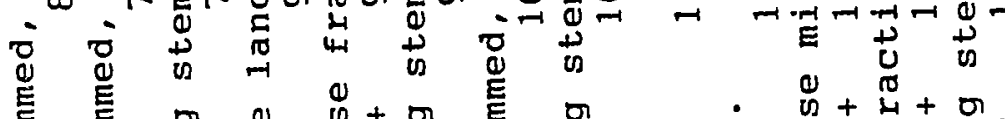

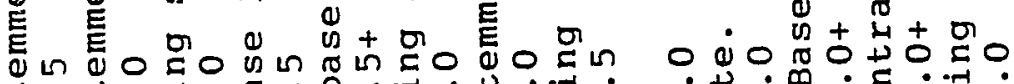

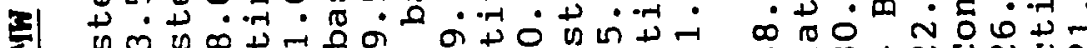

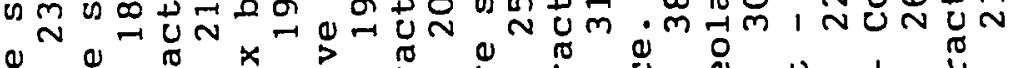

Q

1.

或望

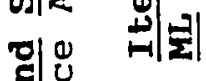

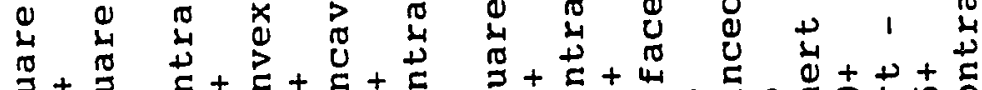

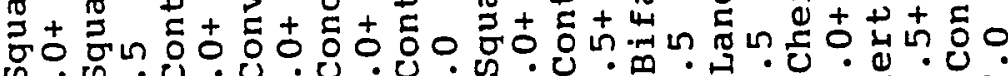

車

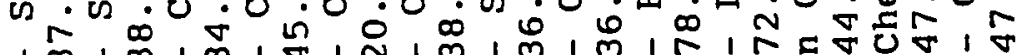

9.)

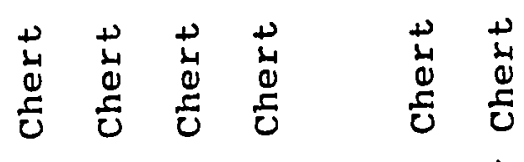

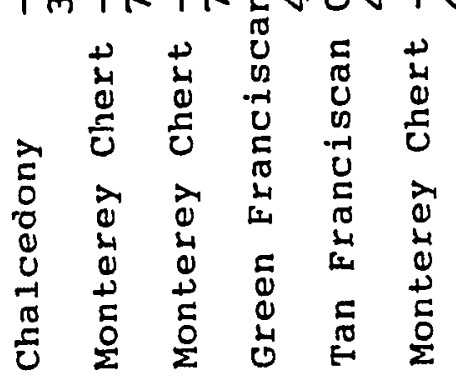

âd

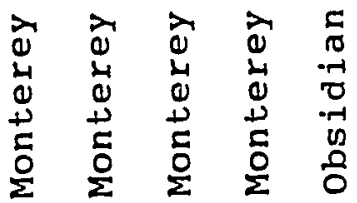

究

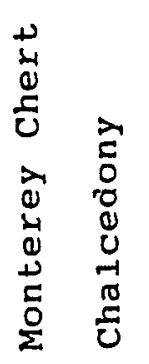

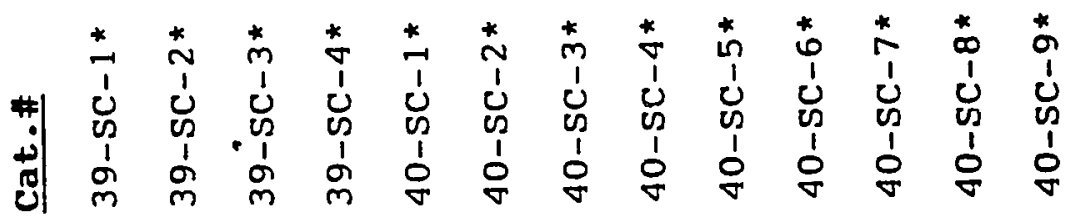




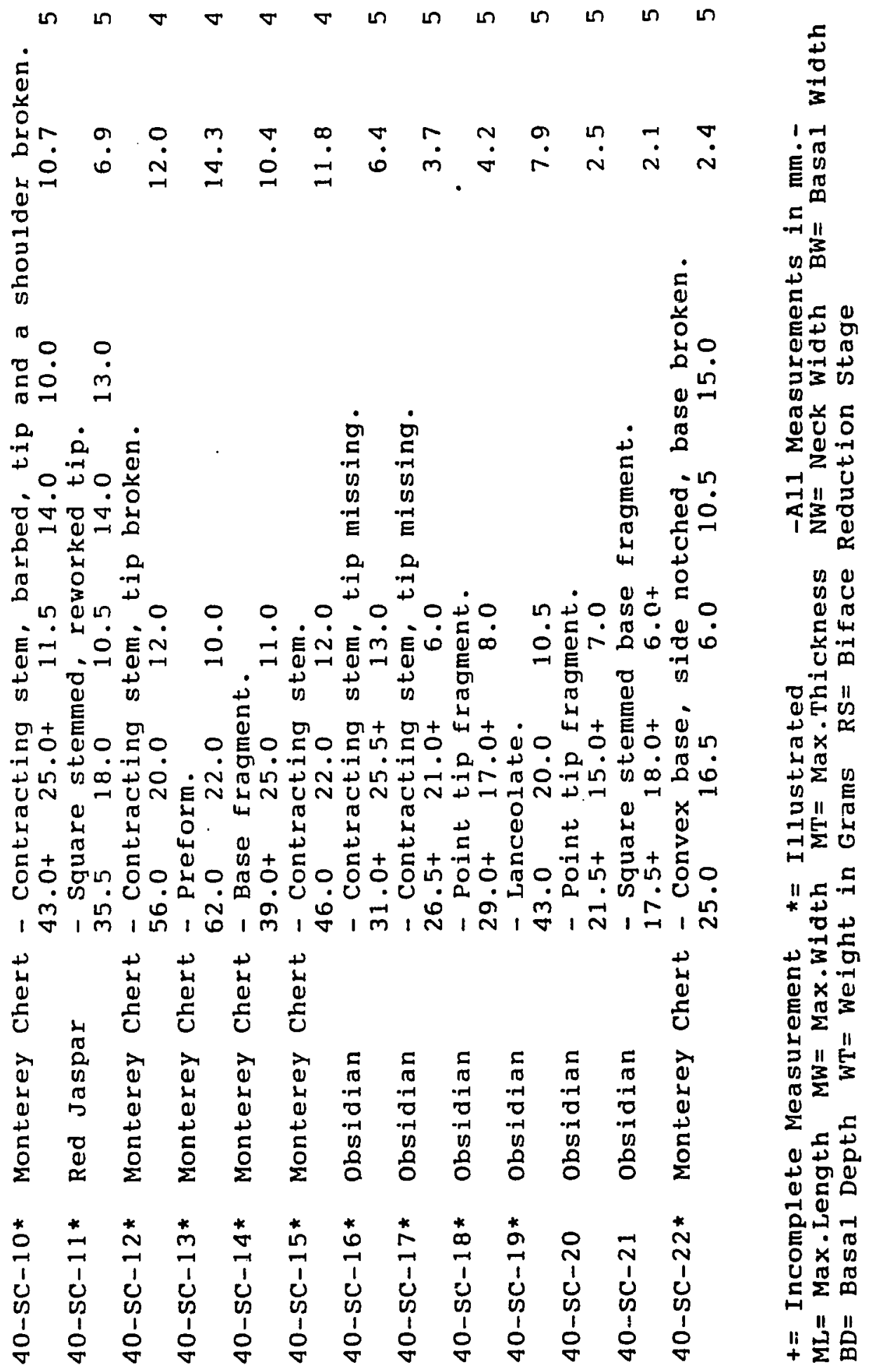




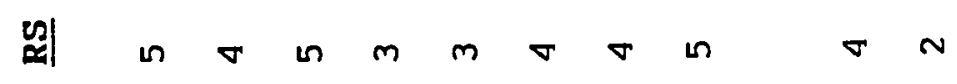

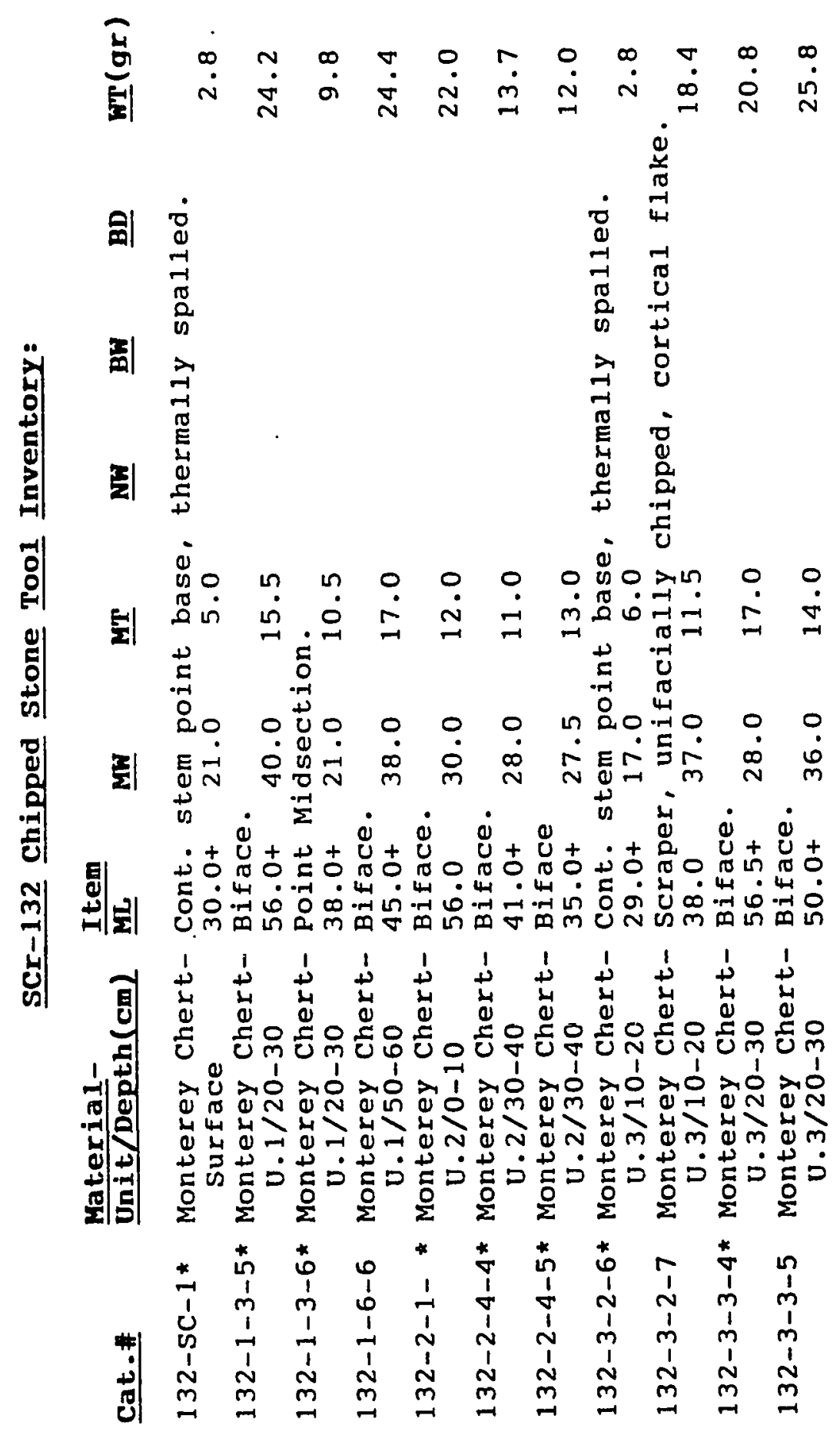


$\nabla$ in $m$

$\begin{array}{lll}n & \infty & m \\ \infty & \infty & \sim \\ -1 & \sim & N\end{array}$

5
1
0
01
3
7
0
0
0
0

盗

i்

$\underset{10}{ \pm}$

un

(2)

E 1

$\sum_{i \rightarrow \infty}^{0} 0$

0 i0 0

$\dot{\sigma} \dot{\sim} \dot{m} \dot{0}$

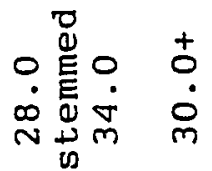

$\dot{u}+\ddot{u}+\dot{u}+$

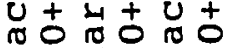

4.

ติ

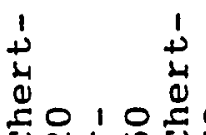

ธํำ

$>0$ 每 1 >

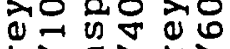

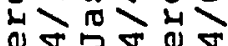

صं

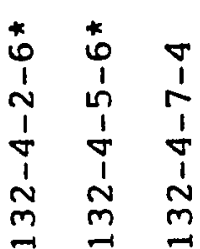

$\frac{11}{3}$ is

$z$

u.

in

닌

完

丩U

다매

$\stackrel{Q}{E} 0$

Q

मx

is $\sum^{\pi} \cdot-$

10 11 m

过

$\Sigma \Sigma \prod_{0}$

虫

$+\frac{1}{+0}$

당

E 30

$0 \cdot \cdot r$

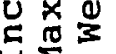

II $\frac{11}{3} \frac{11}{3}$

오 동

0 व

\&

4 a

स $\mathrm{N}$

的少

$\Rightarrow \dot{x}$

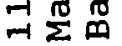

* 当亘 


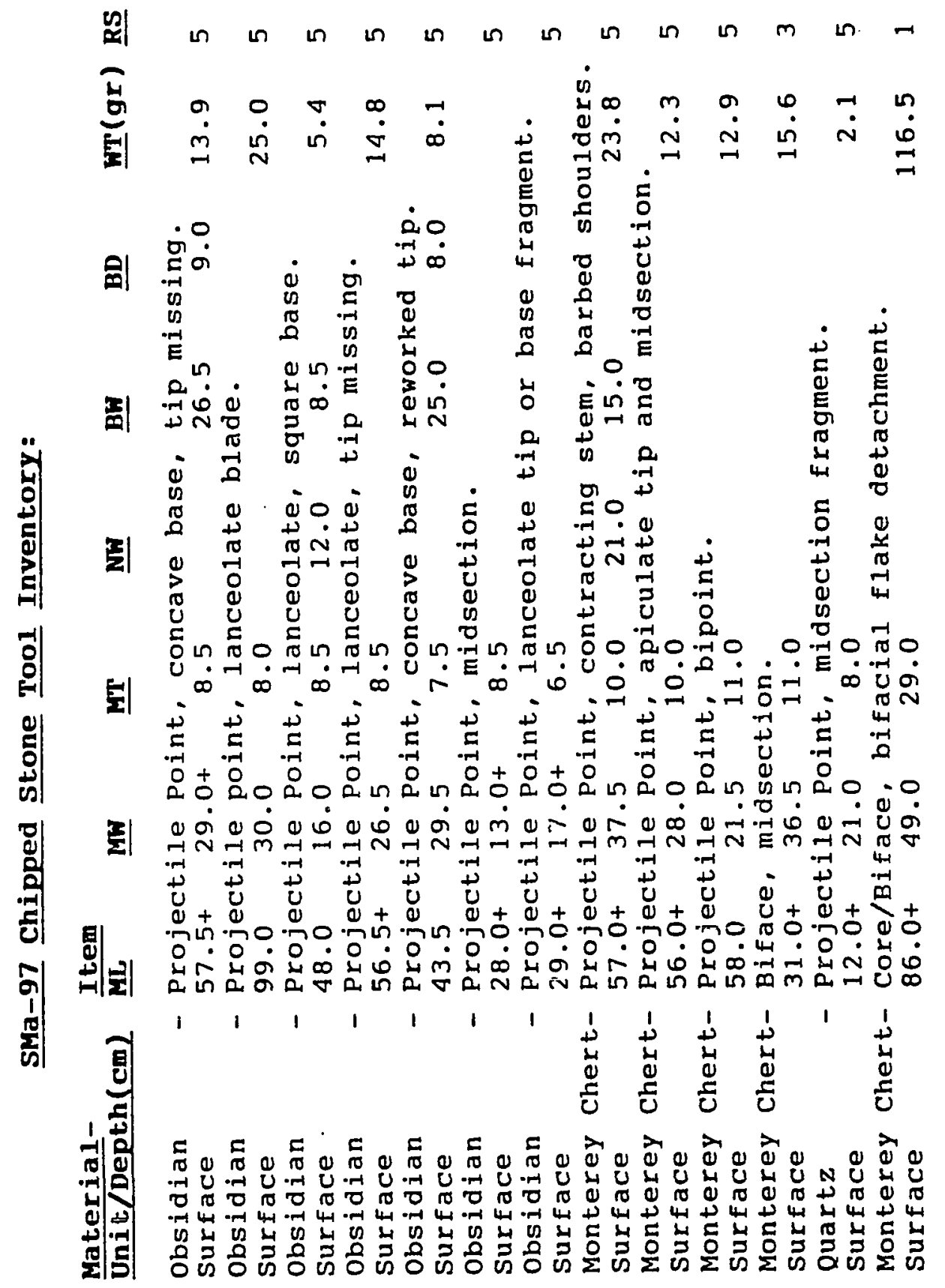

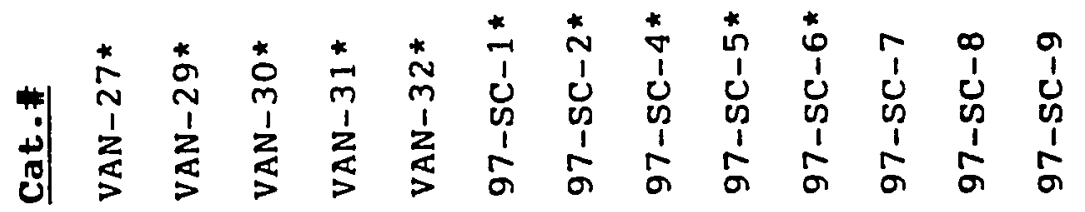




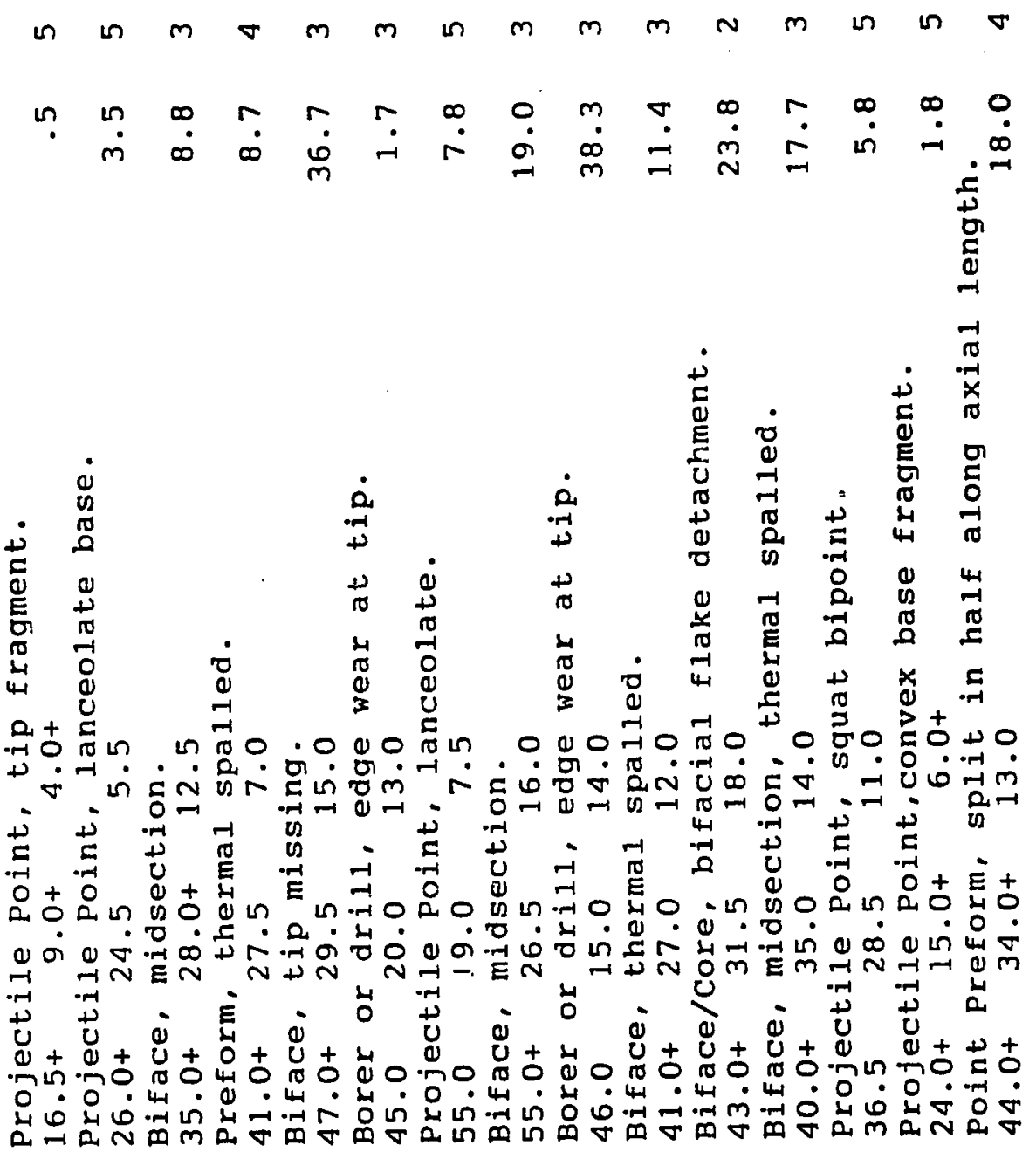

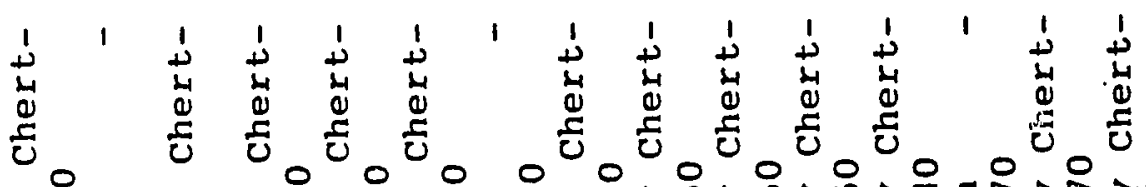

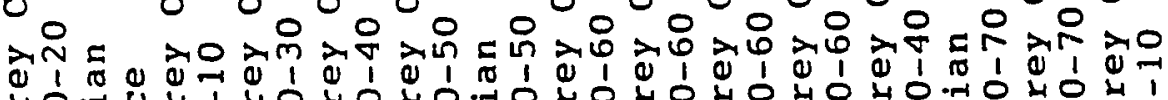
눈 d

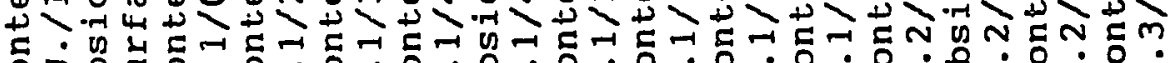

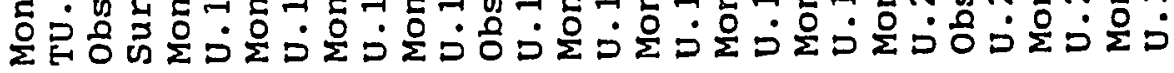

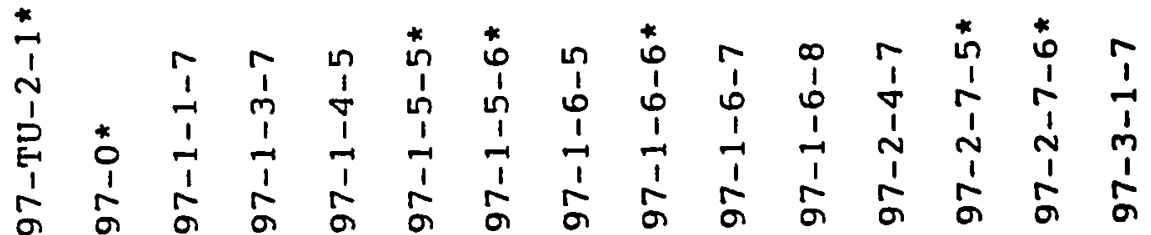




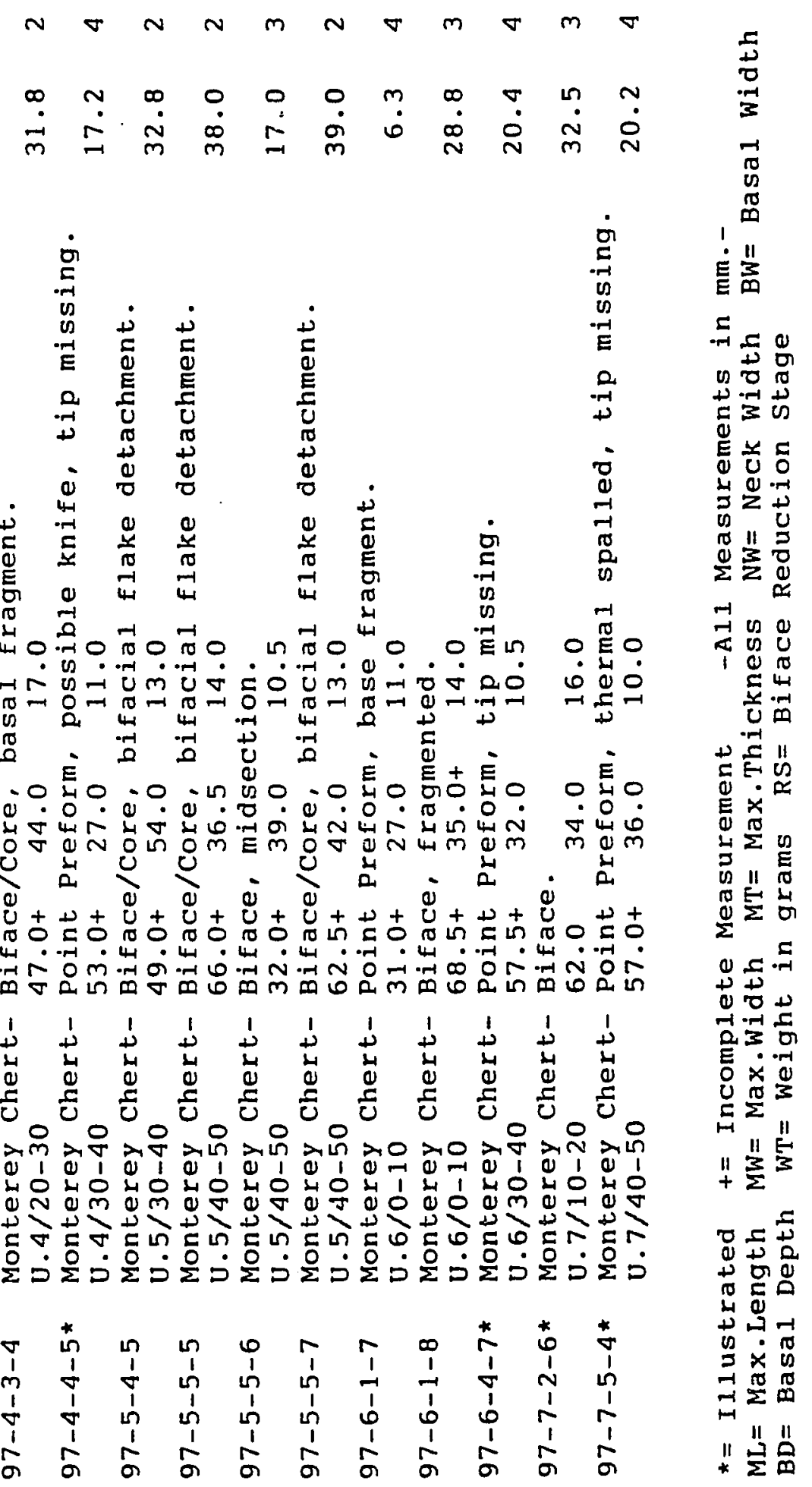


政

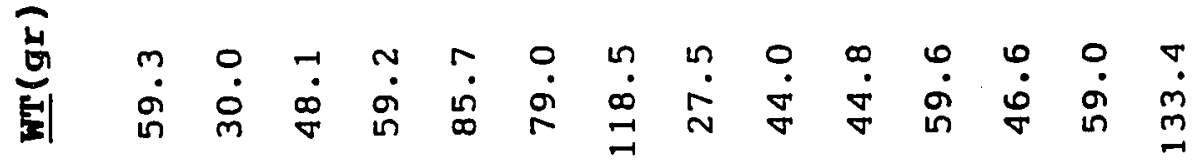

囸

思

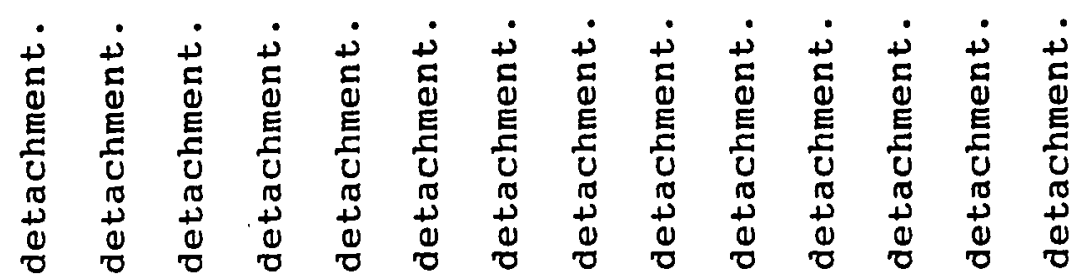

8

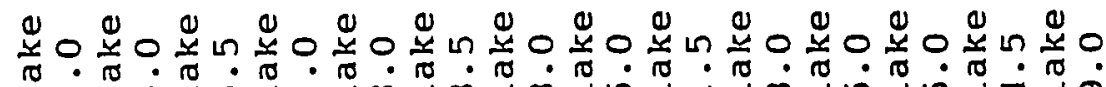

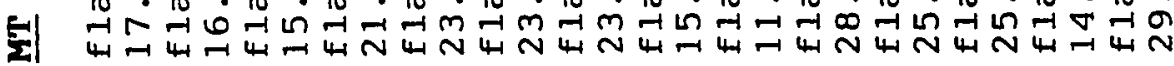

E.

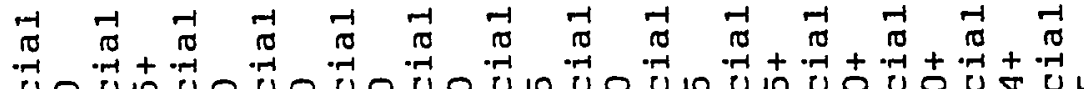

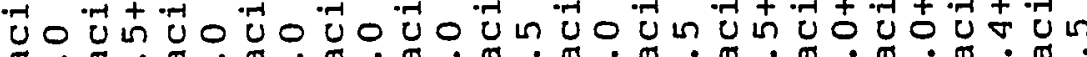

임.

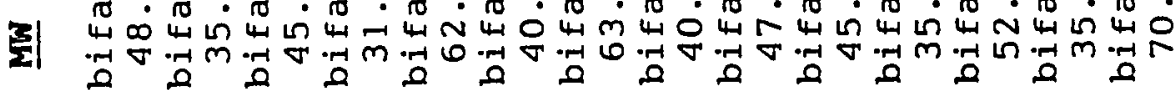

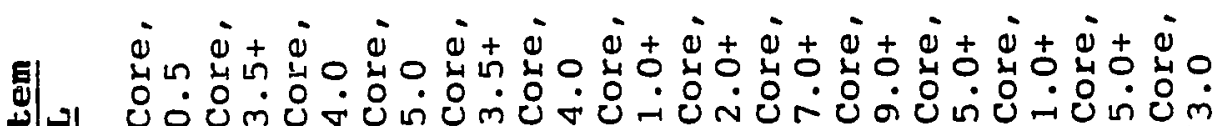

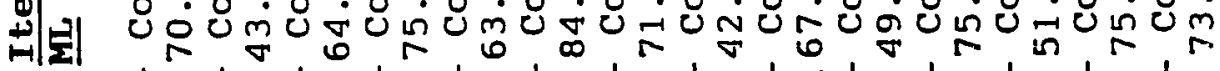

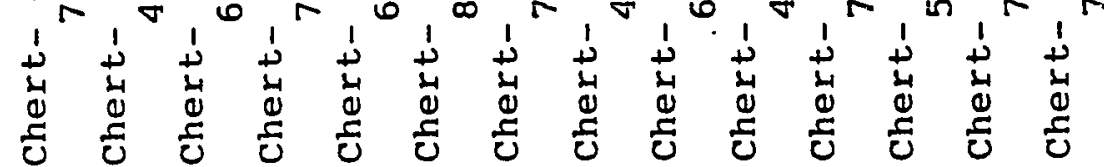

1 خे

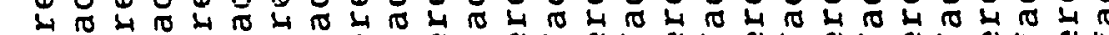
a 4 a 4 a 40 क प

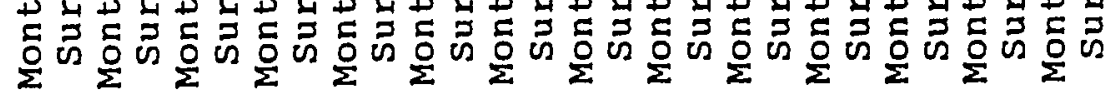

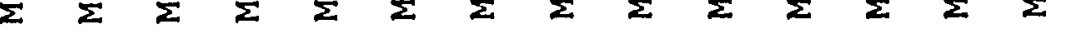

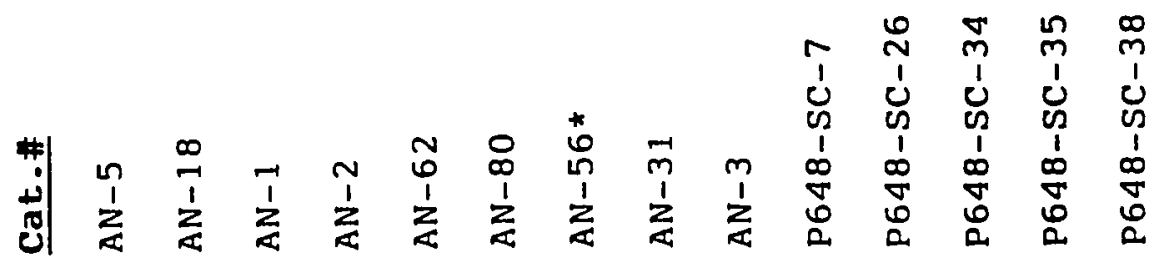




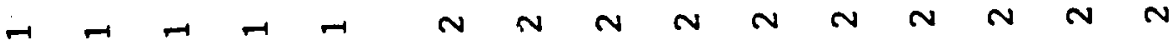

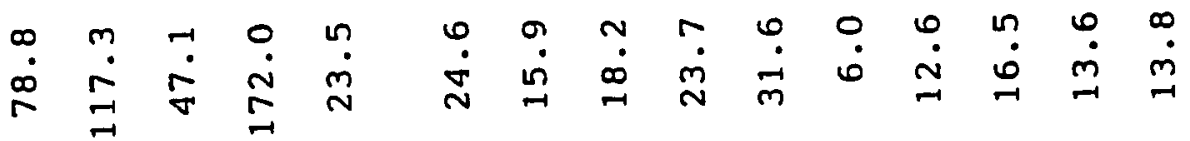

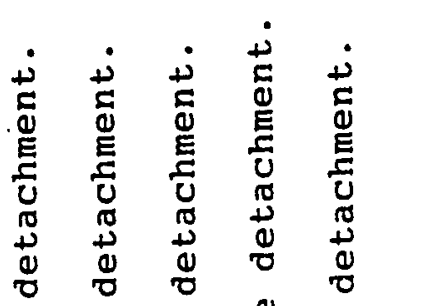

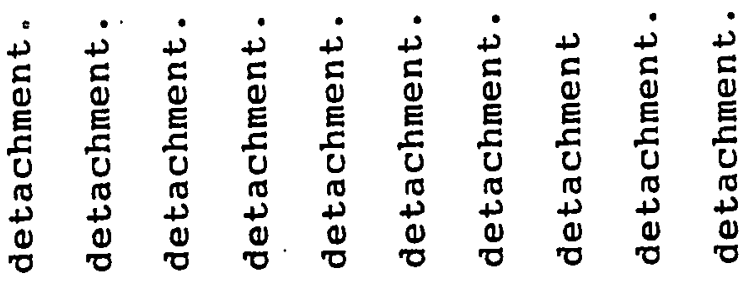

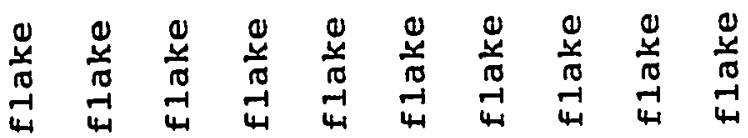

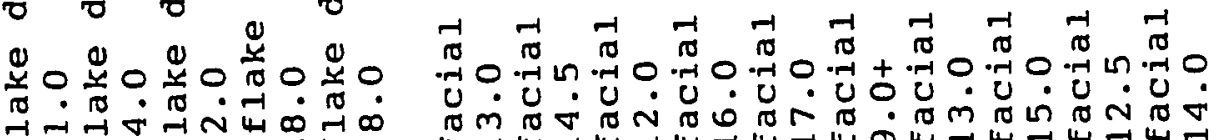
แm

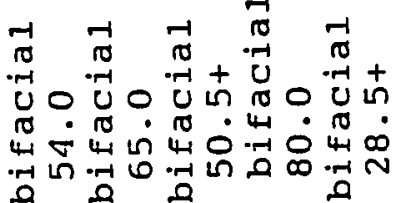
i) $\dot{\omega}+\vec{\omega}+\vec{\omega}+\dot{\omega}+$

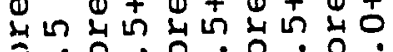
U

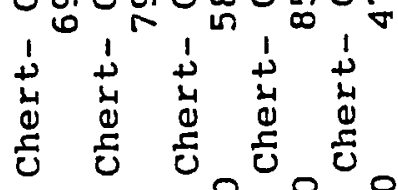

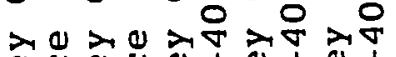

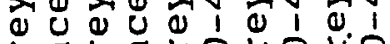
4

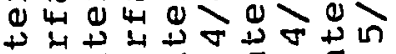

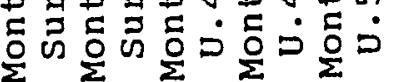

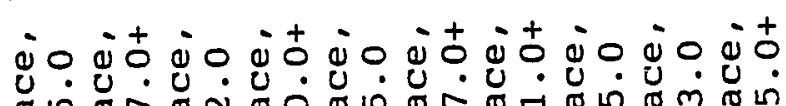

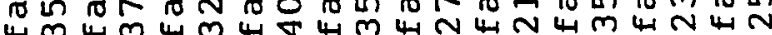
落

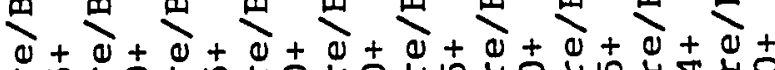

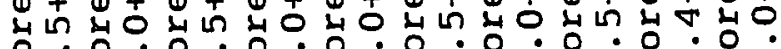

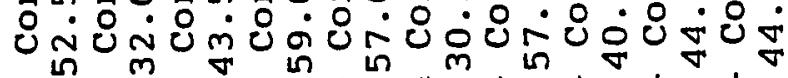

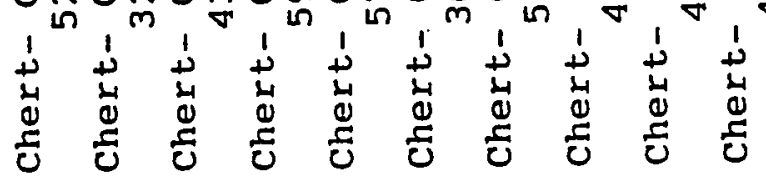
$>0>0>0>0>0>0>0>0>0$

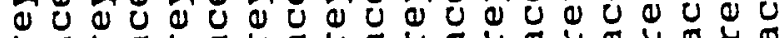
म 0 (1)

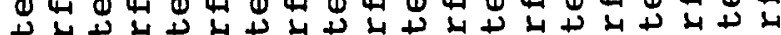

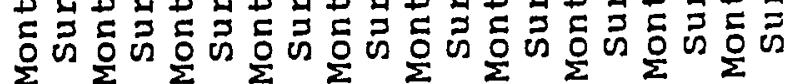

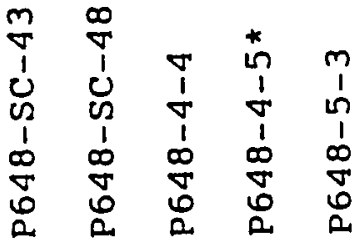

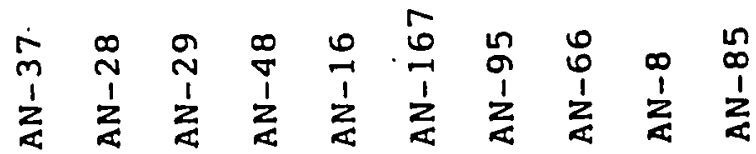




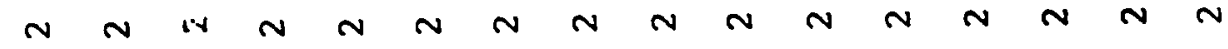

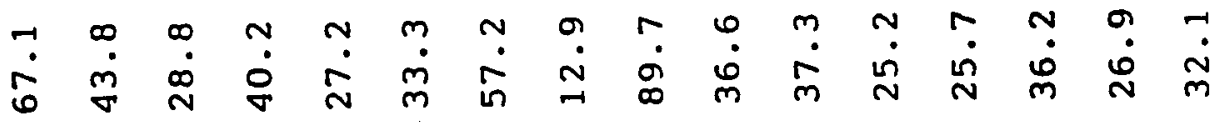

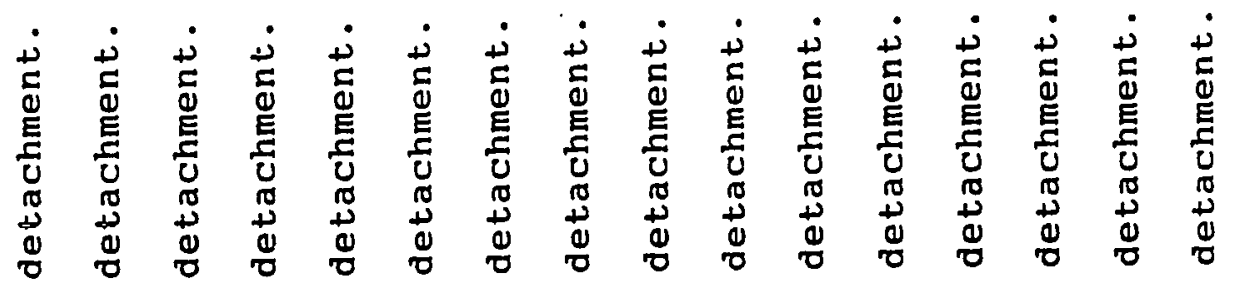

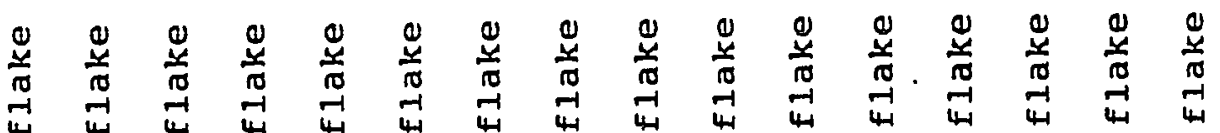

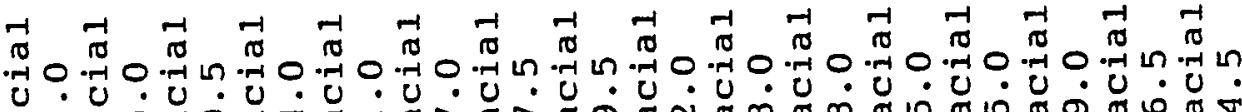

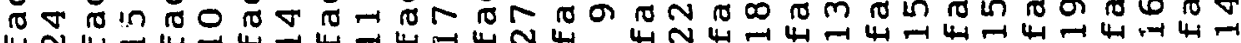

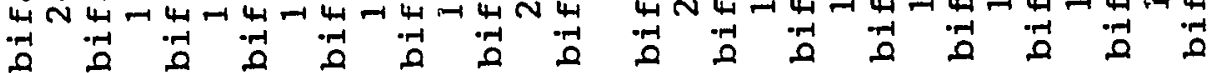

ju

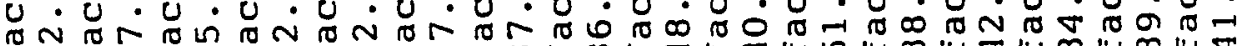

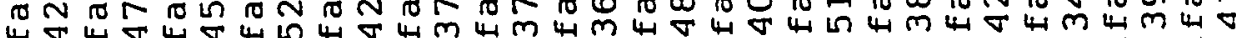

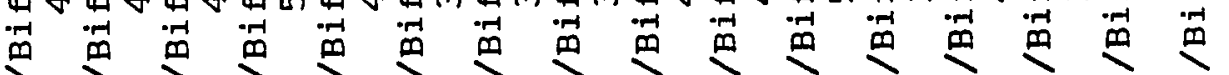

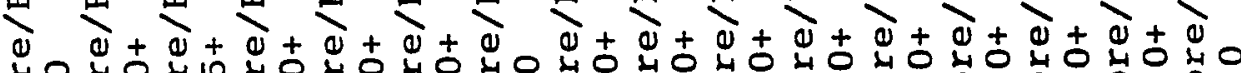

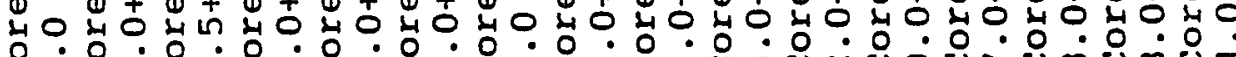
U

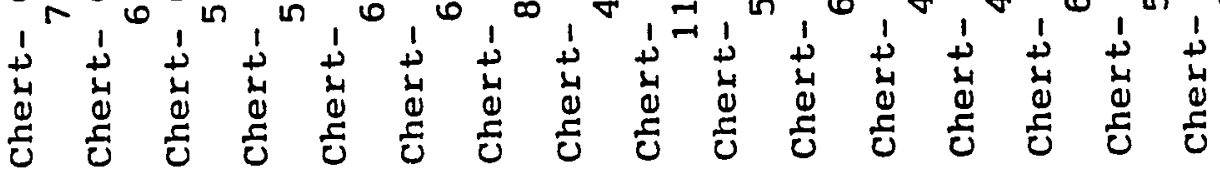

خ बU ब 山同 Q

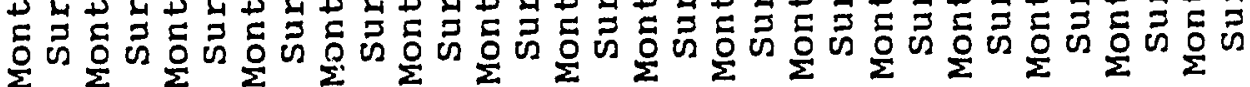

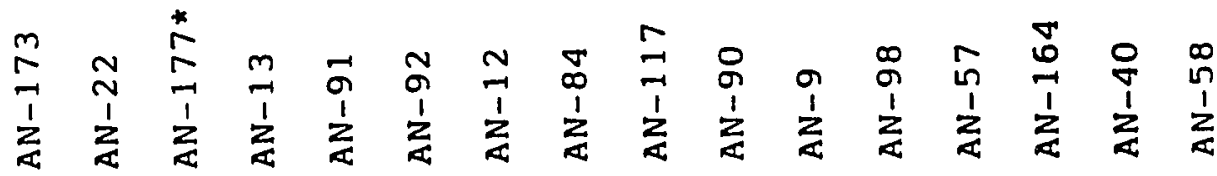




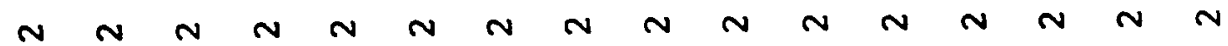

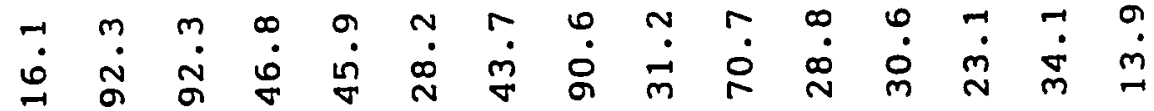

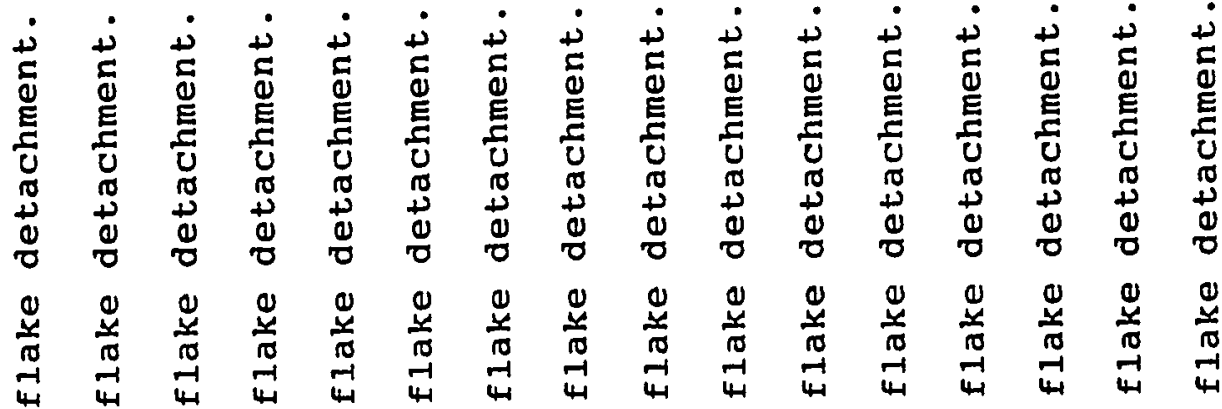

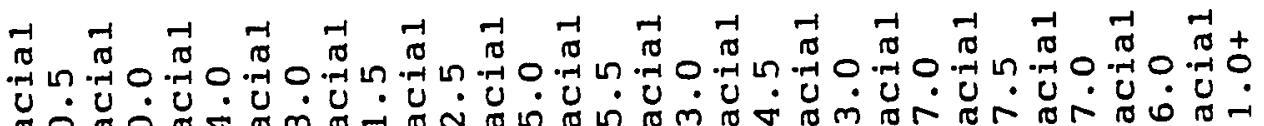

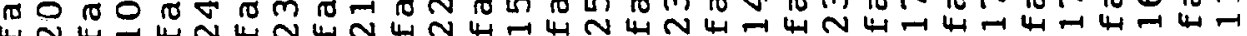
م

jo

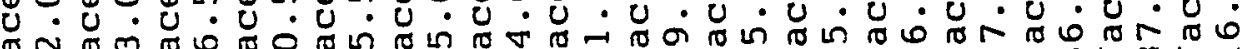

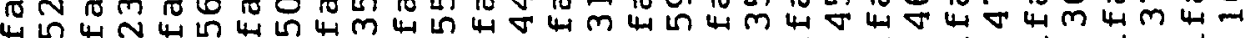

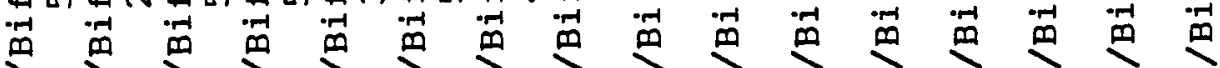
ओ 낸 Uمن

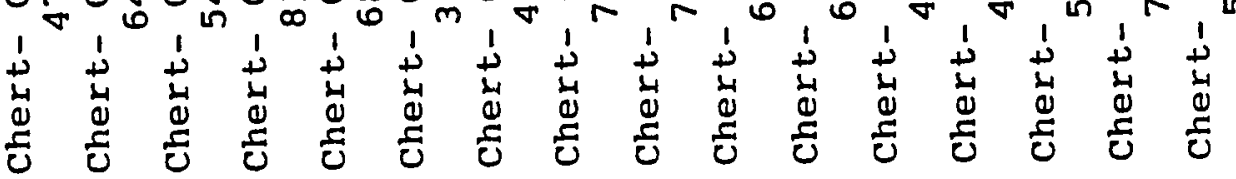

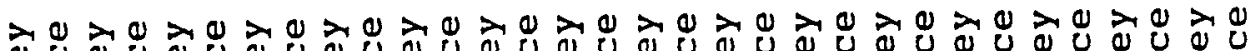

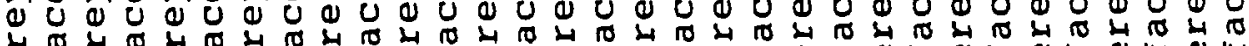
ब لي

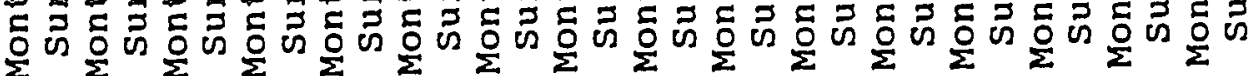

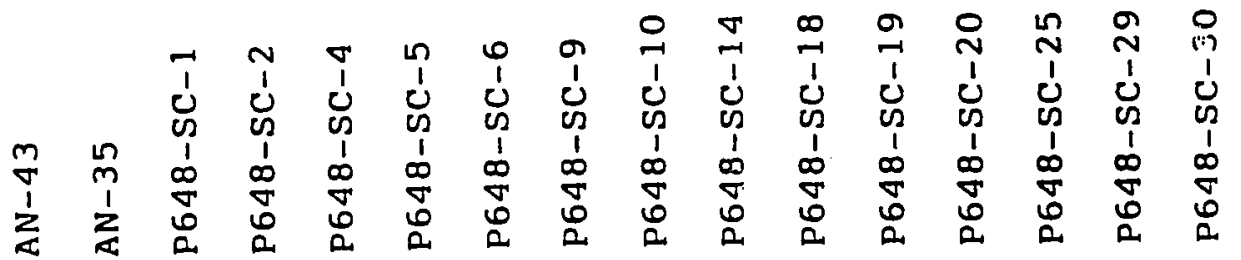




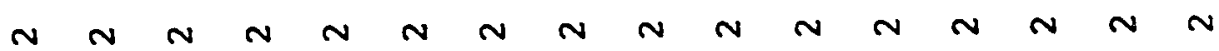

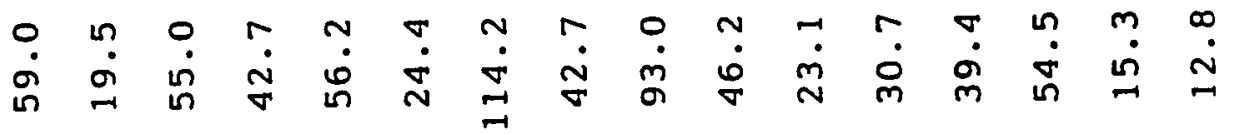

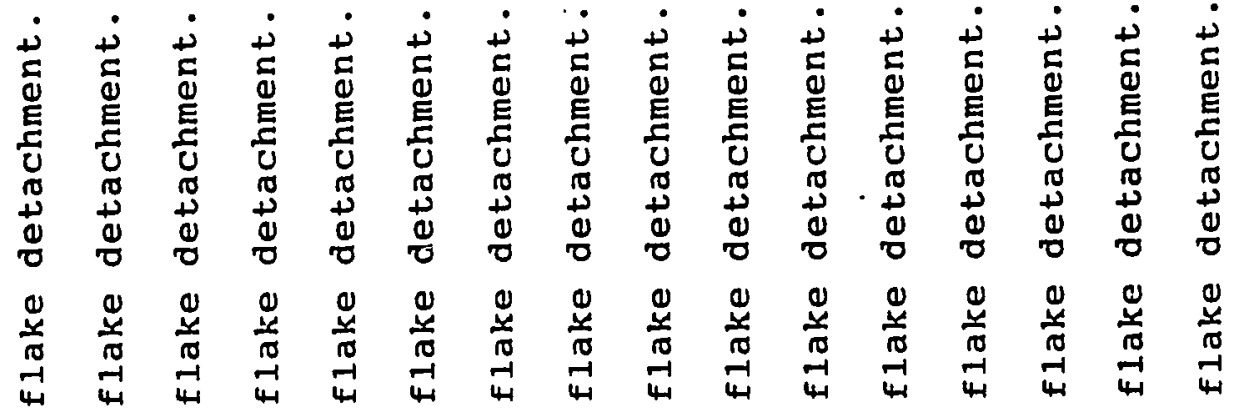

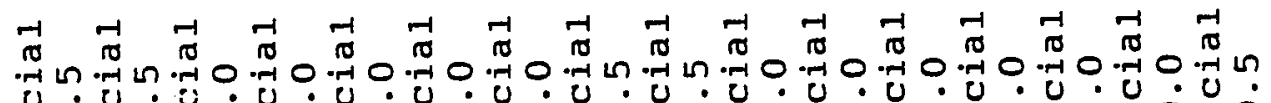

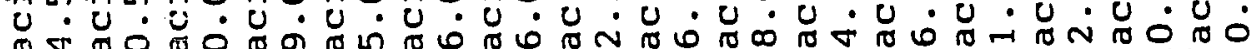

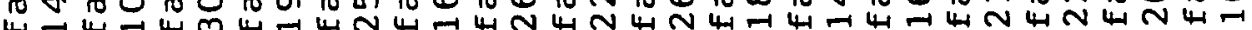

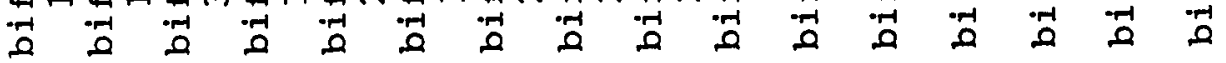

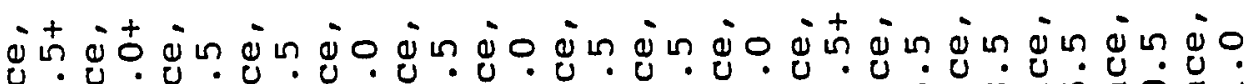
U

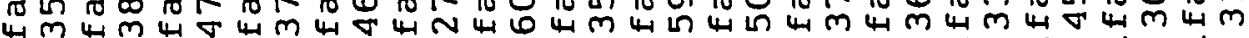

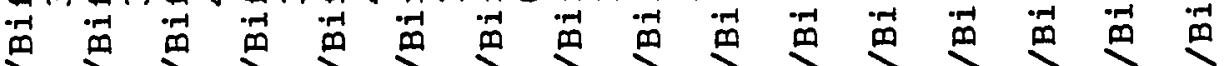

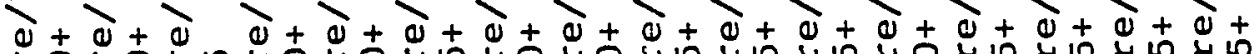

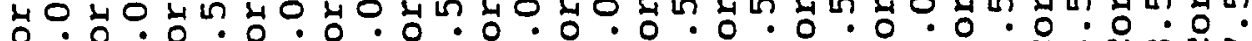
Uñ نु

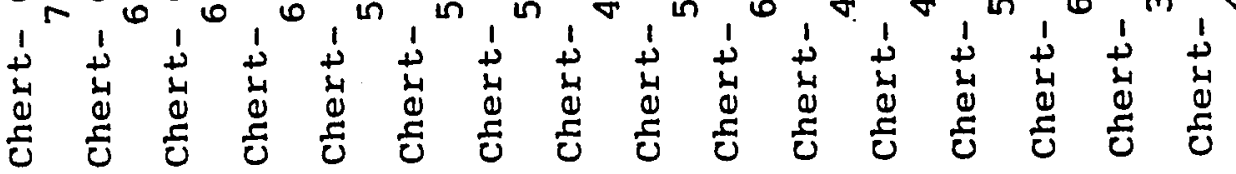

入 Q

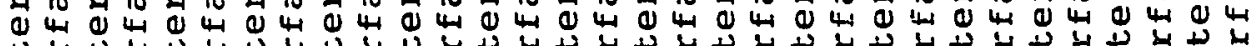

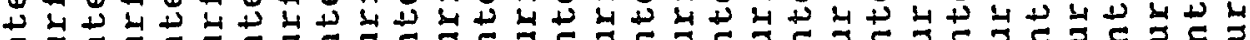

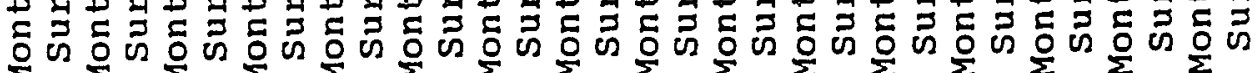

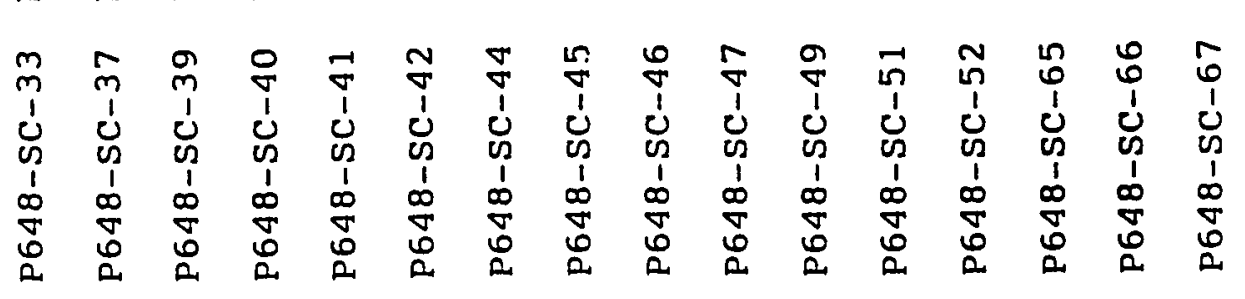




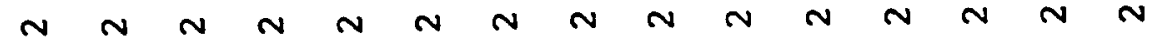

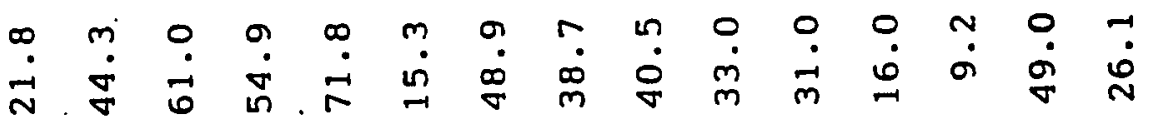

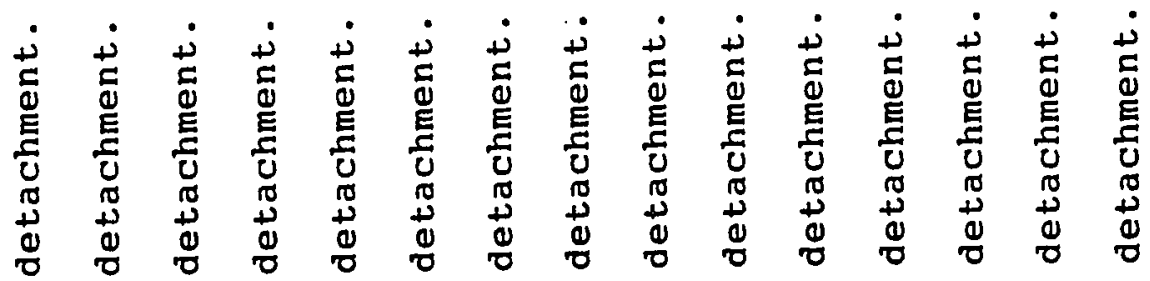

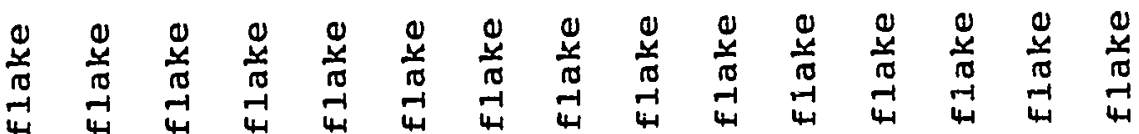

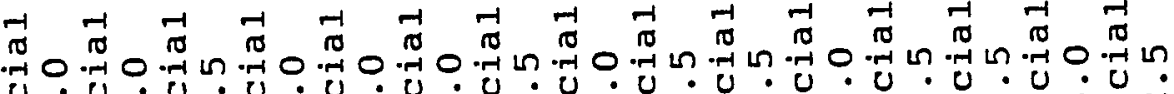

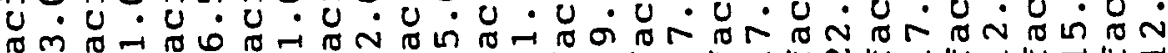

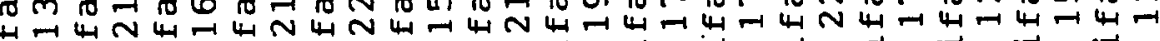
قُ

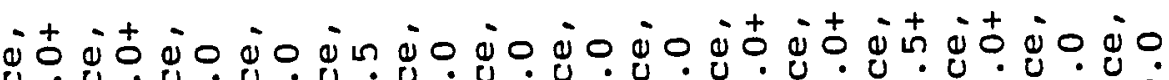

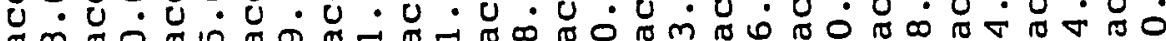

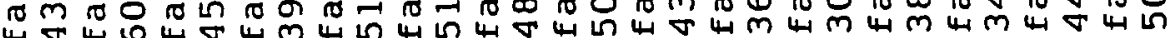

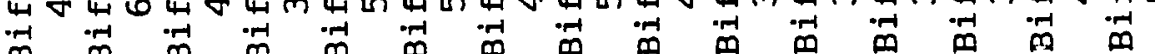

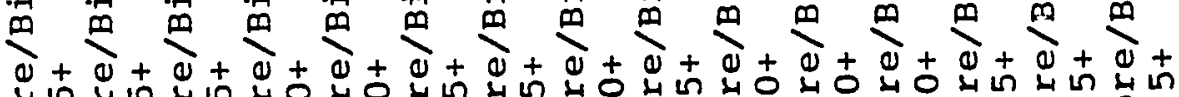
는

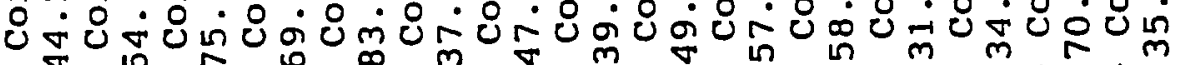

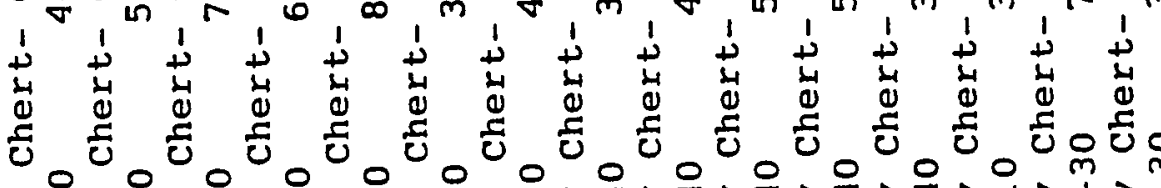

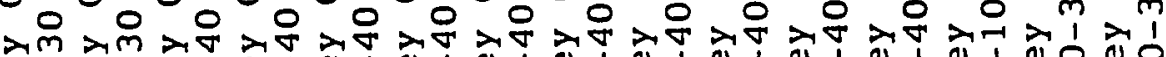

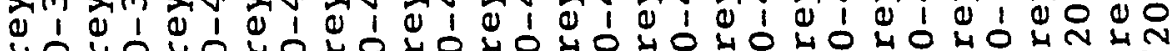

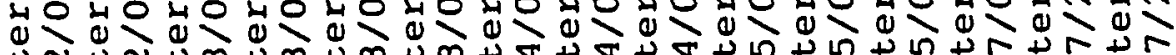

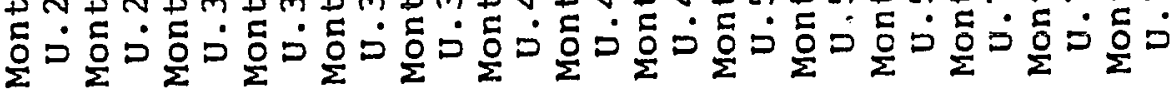

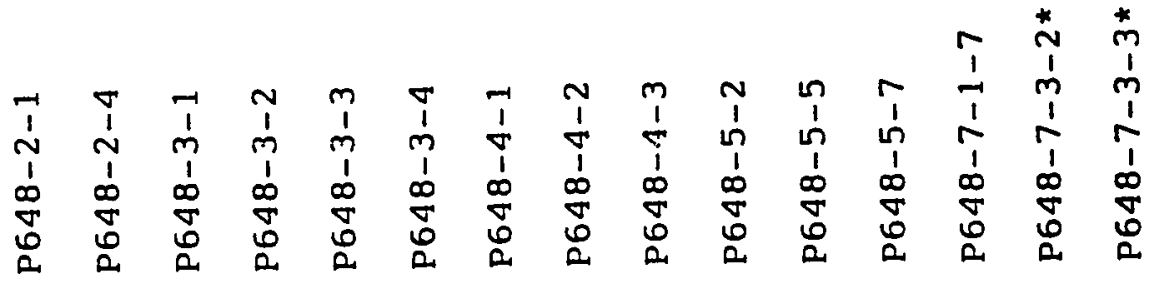




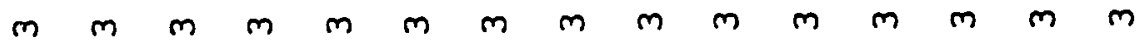

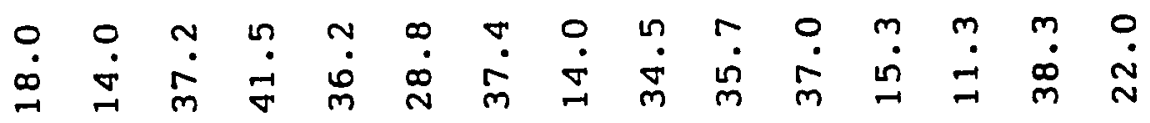

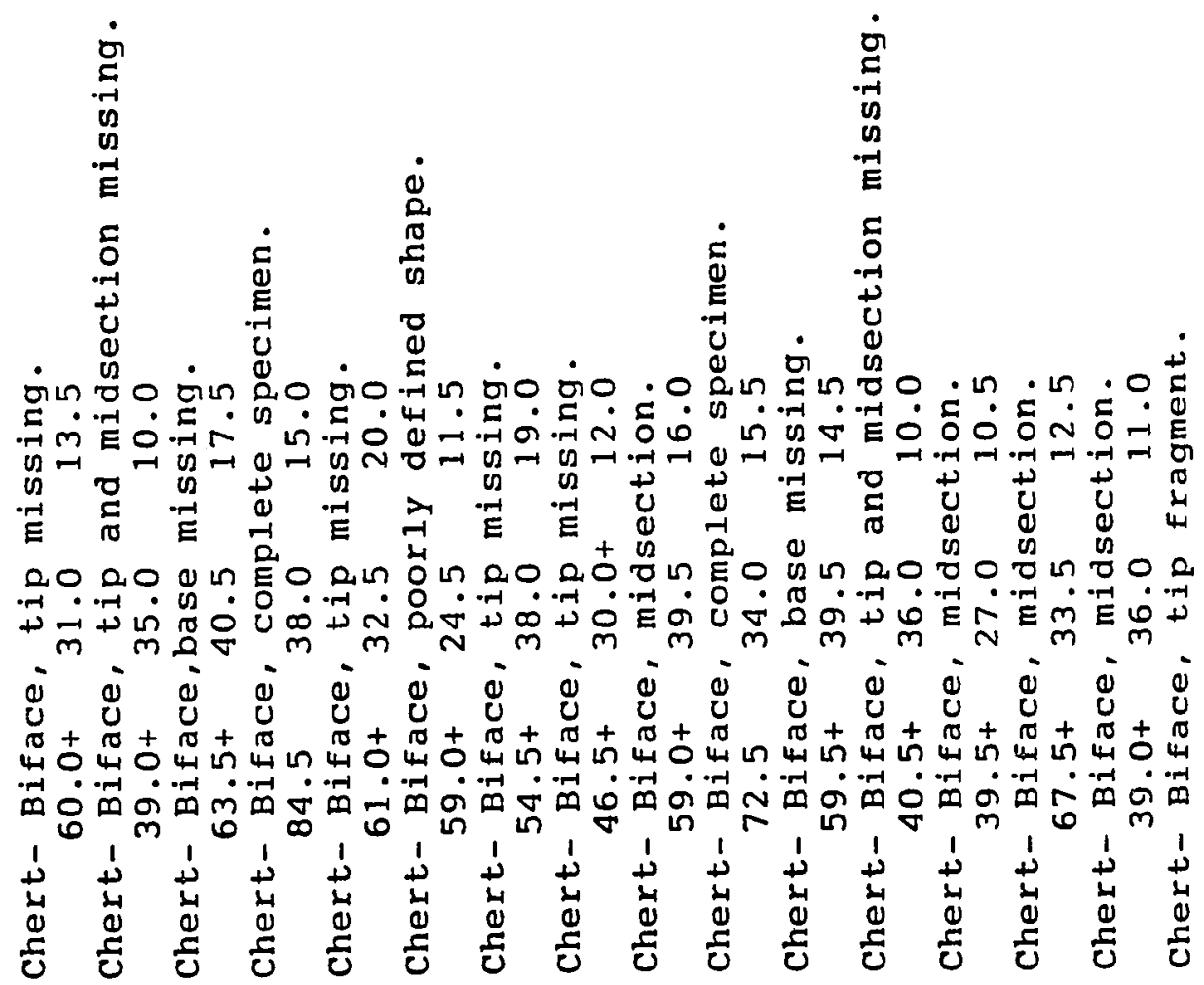

خ ब

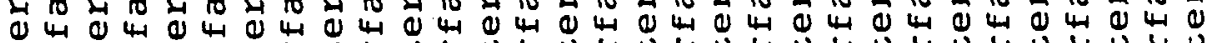

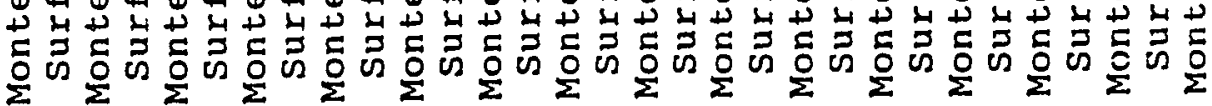

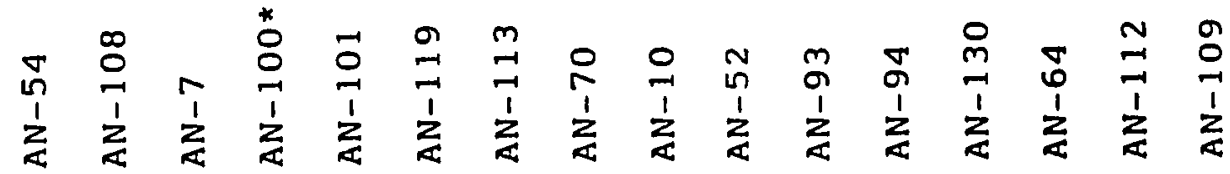




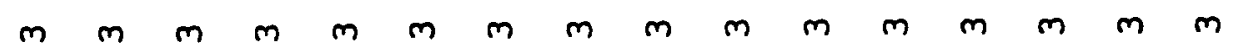

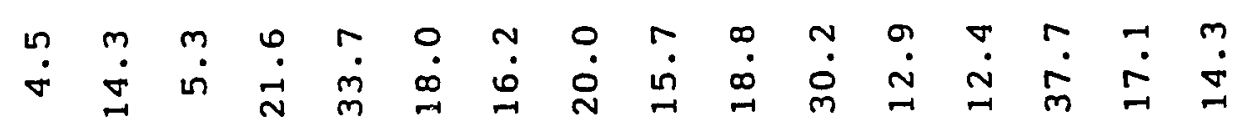

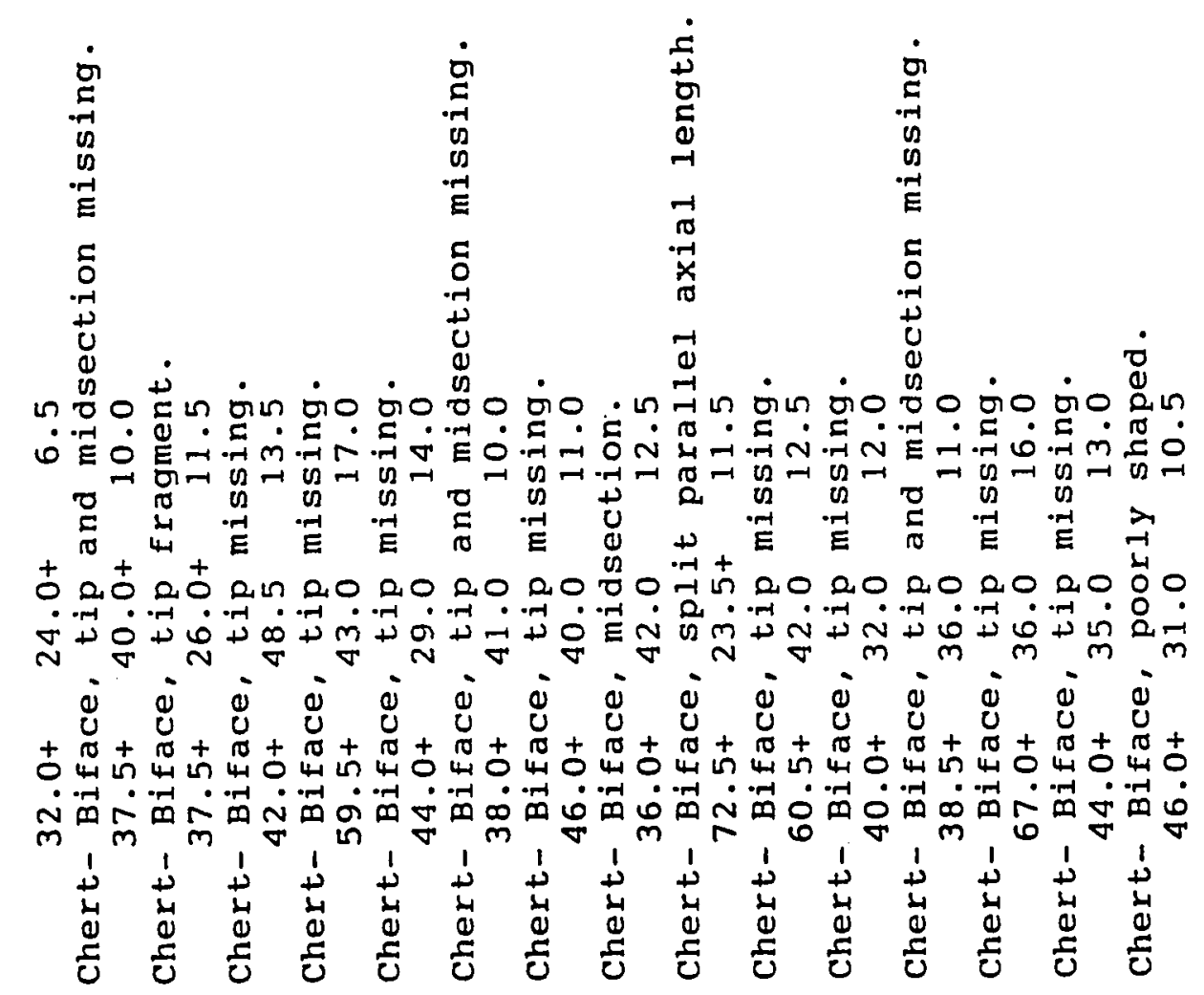

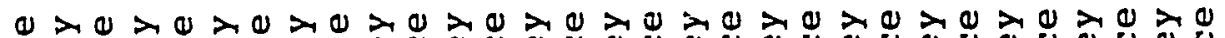

U ब 0 ब

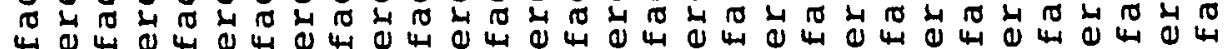

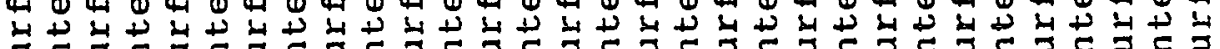

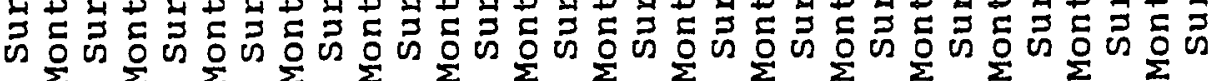

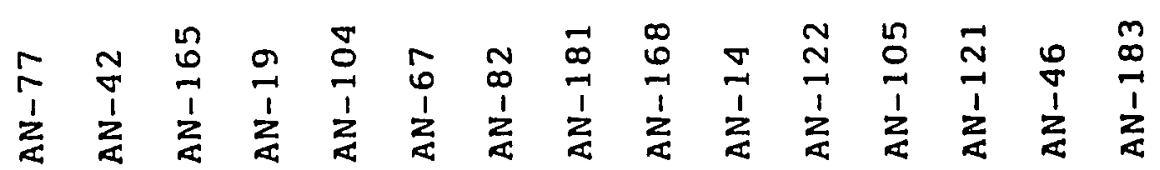



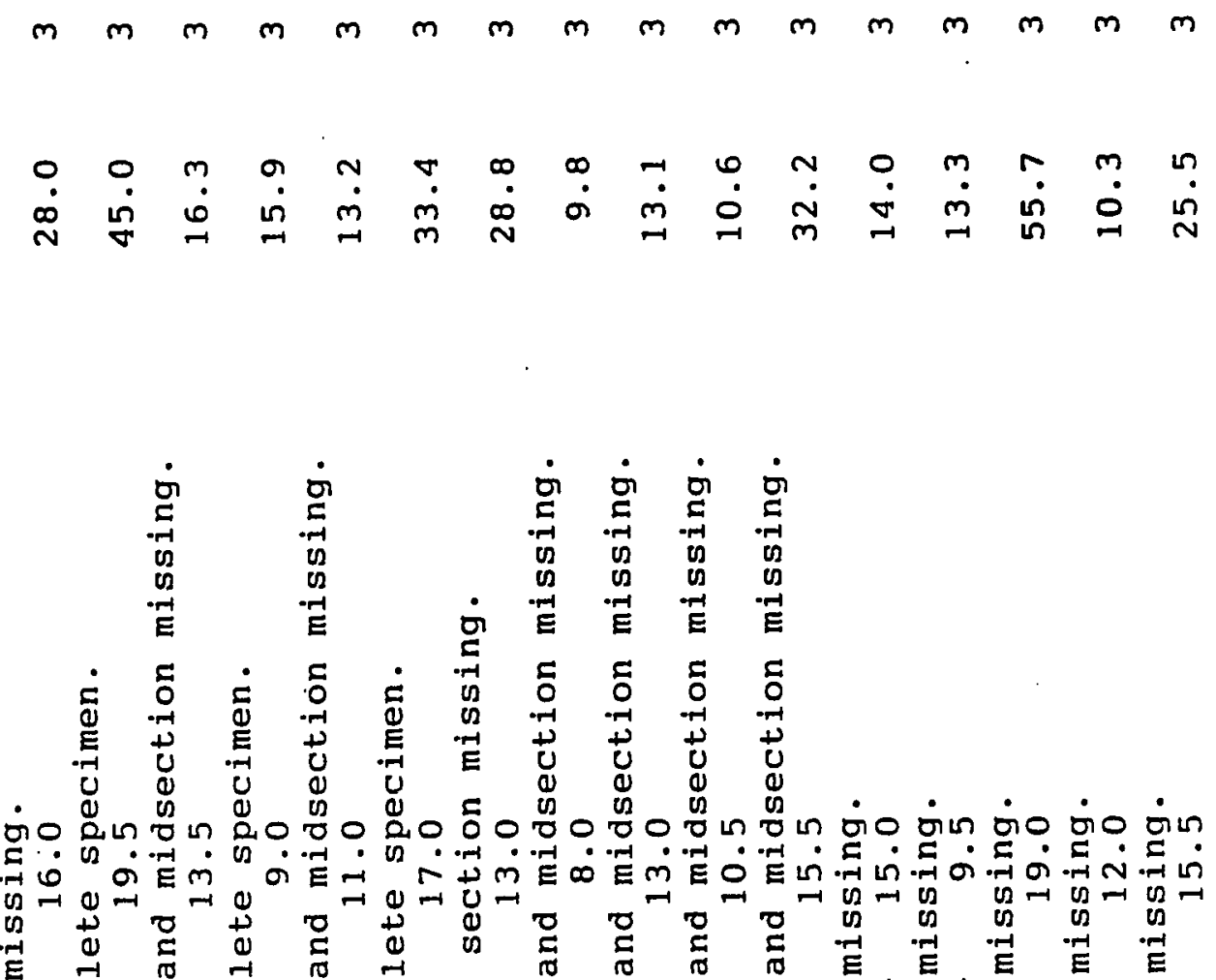

Q

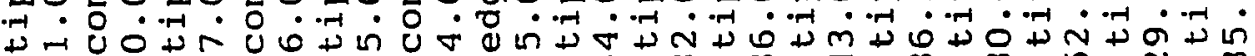

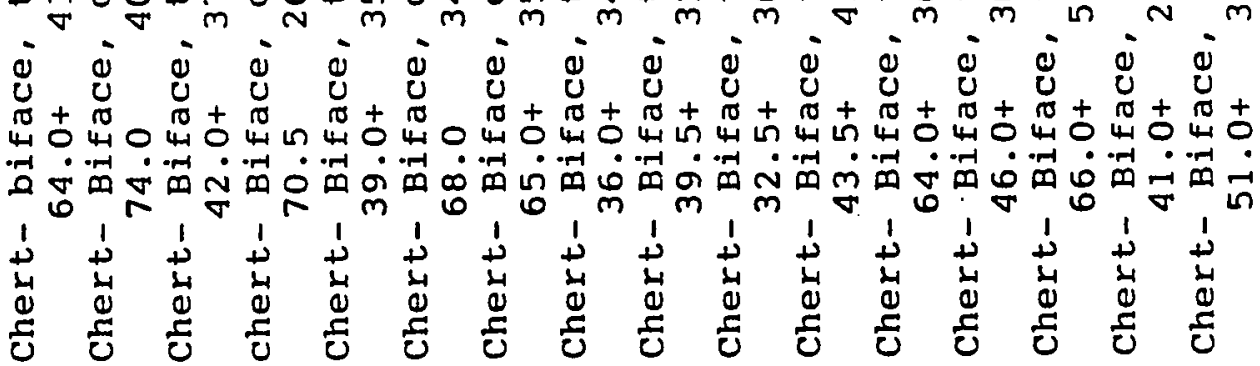

$>\theta>\theta>\theta>\theta>0>\theta>\theta>0>\theta>0>0>0>\theta>0>0>0$

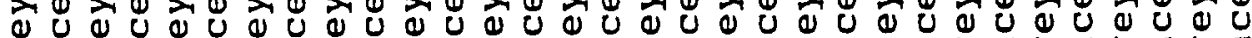
幽 ब出

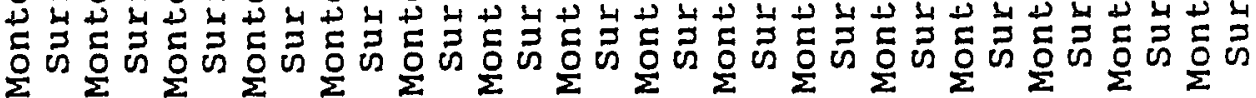

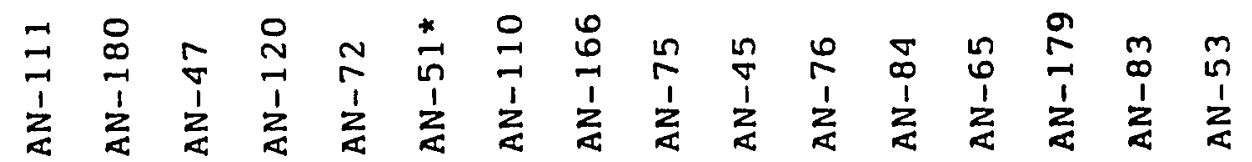




$$
\begin{aligned}
& m m m m m m m m m m m m
\end{aligned}
$$

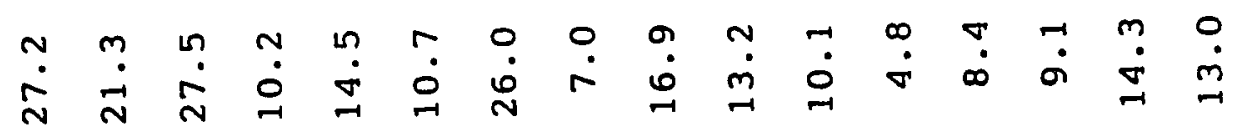

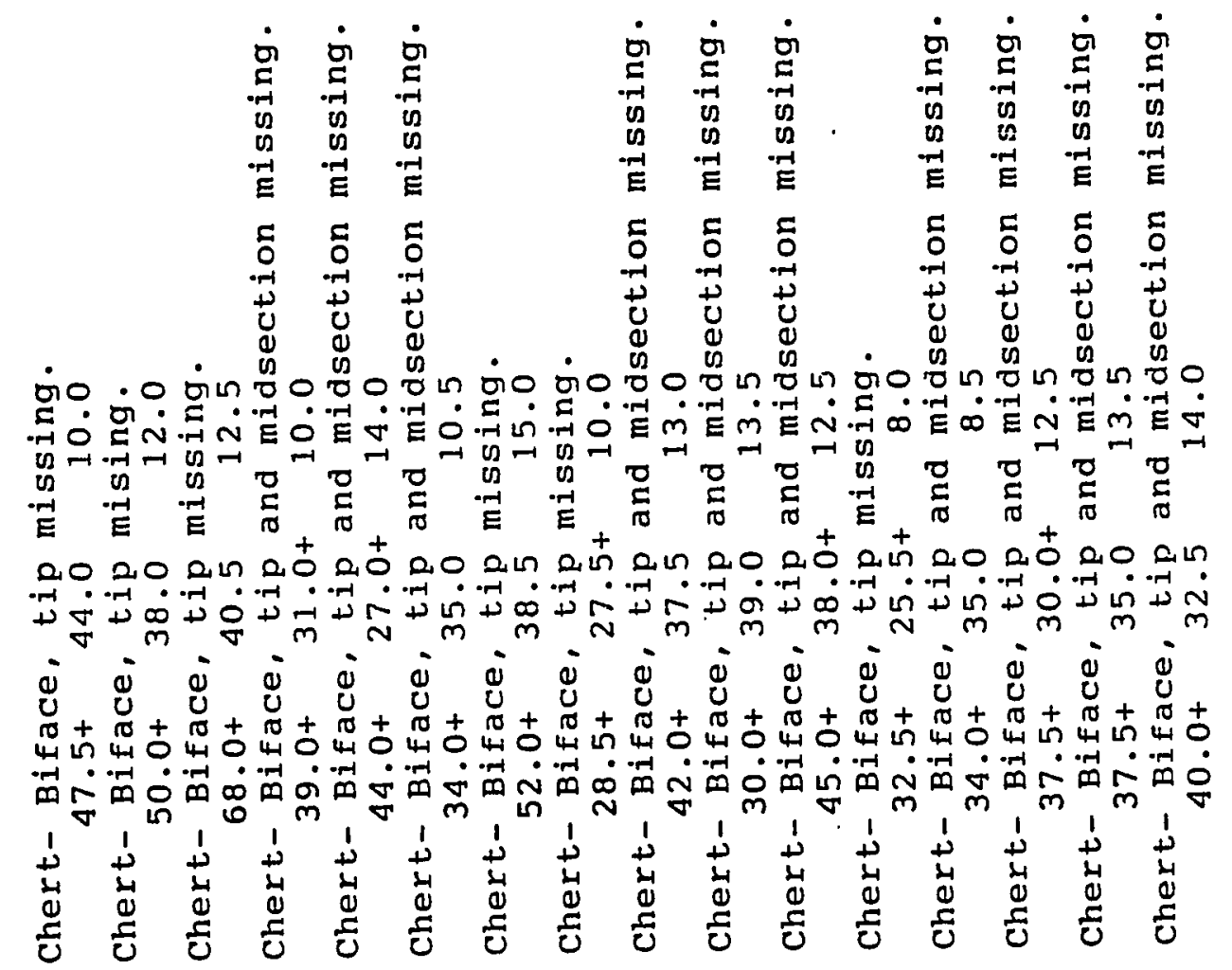

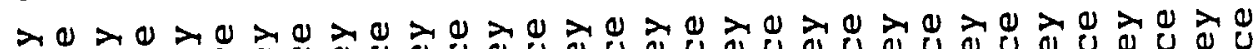
बU ब म لـ

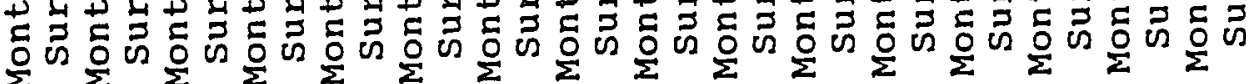

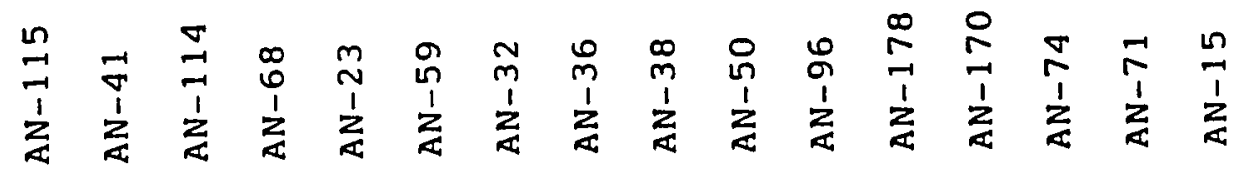




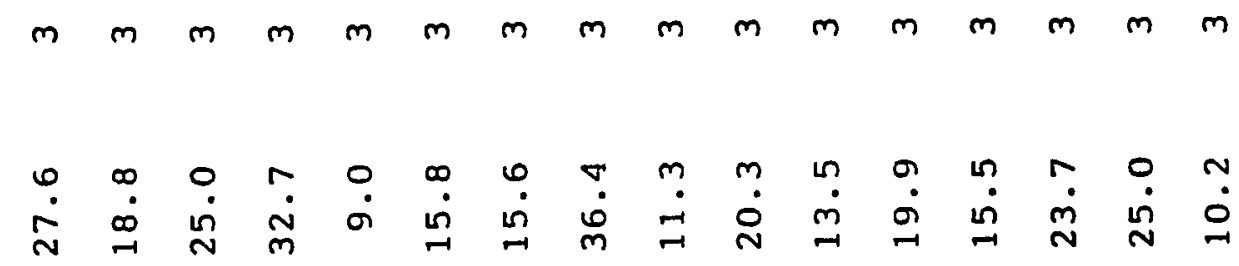

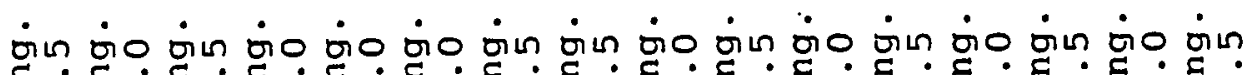

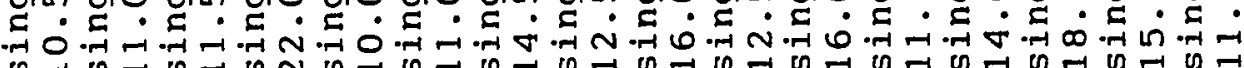

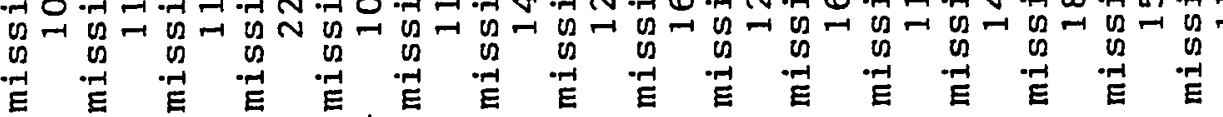

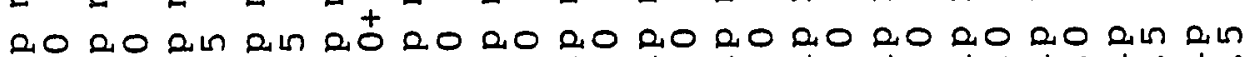

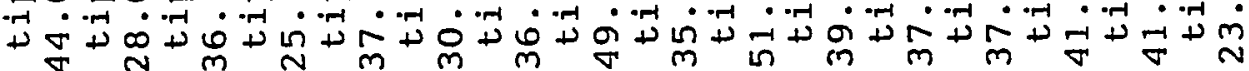

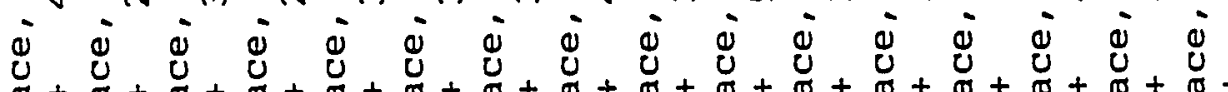

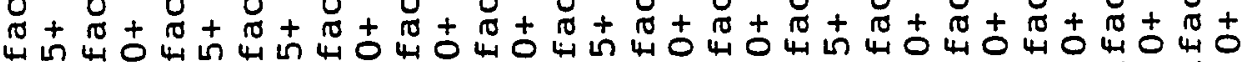

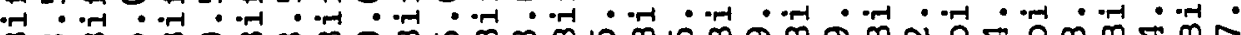
m

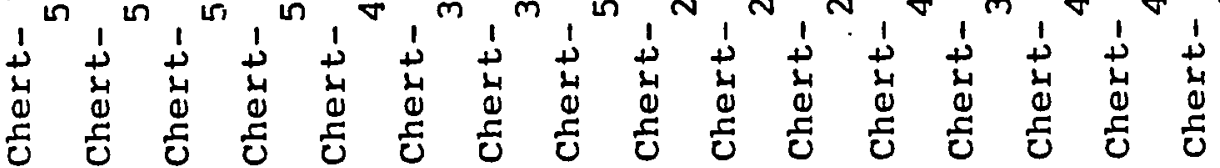

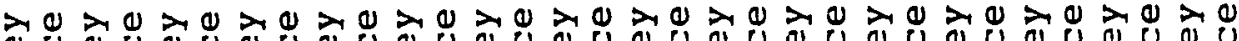

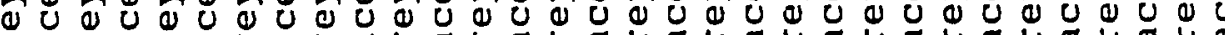
4)

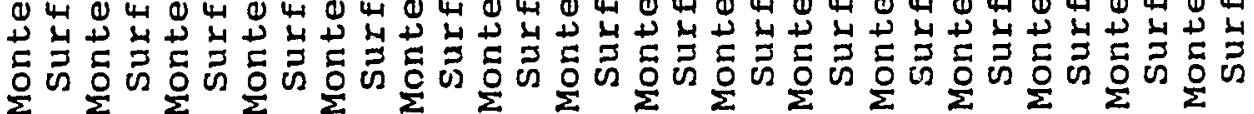

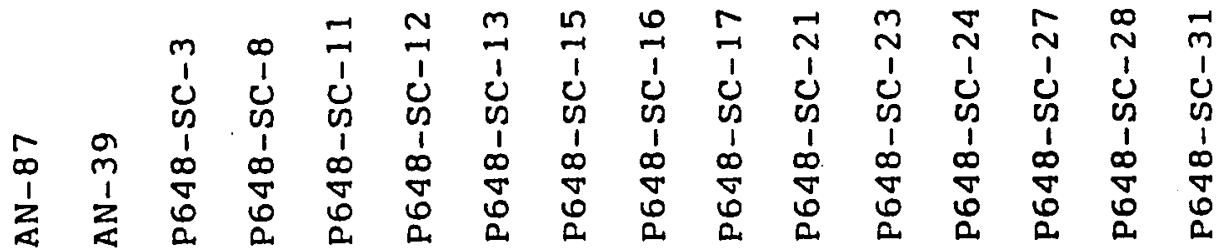




$$
\begin{aligned}
& m m m m m m m m m m m m m m m m m m m m m m m m m m m m m
\end{aligned}
$$

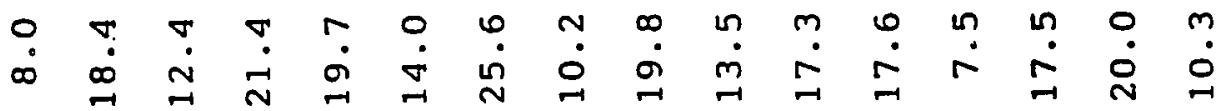

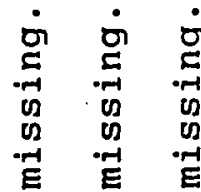

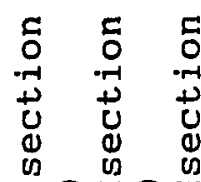

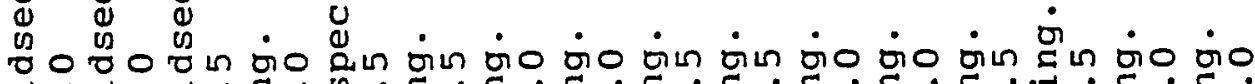

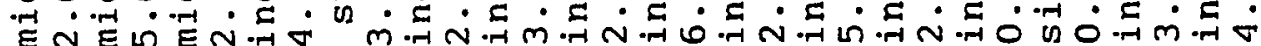
荡

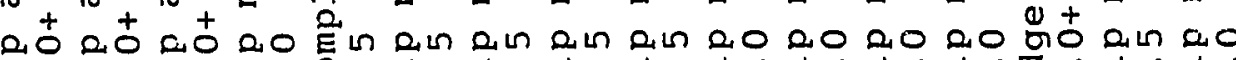

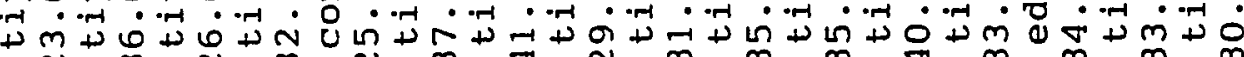

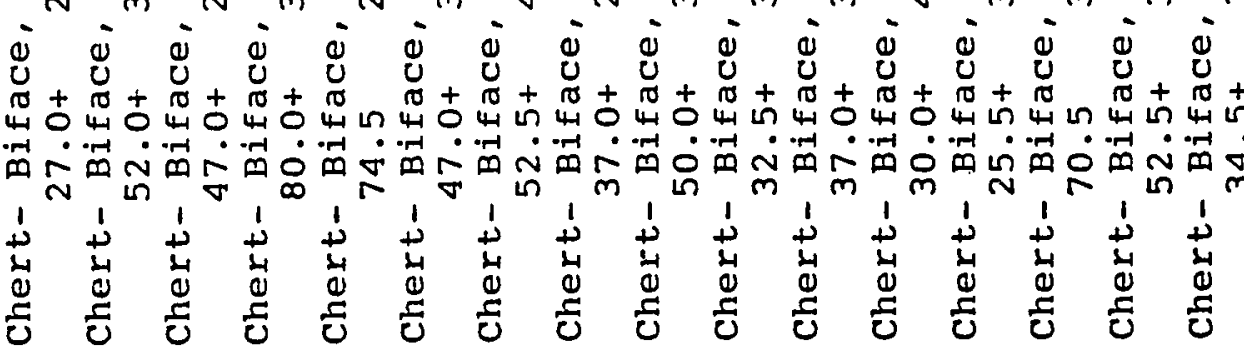

入े 4 (1)

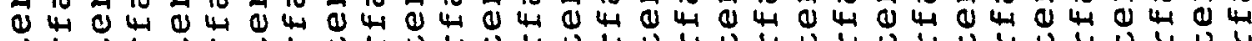

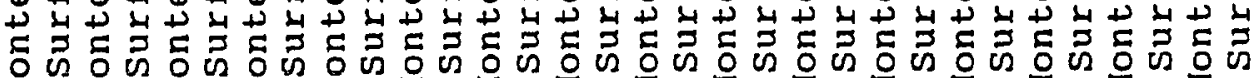

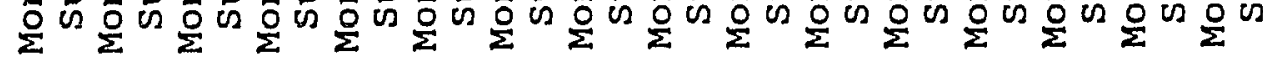

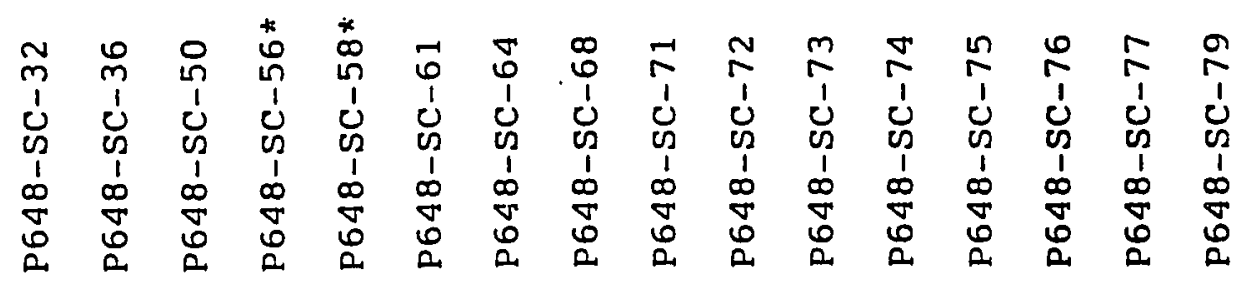




$$
\begin{aligned}
& m m m m m m m m m m m m m m m m m m m m m m m m m m m m m m
\end{aligned}
$$

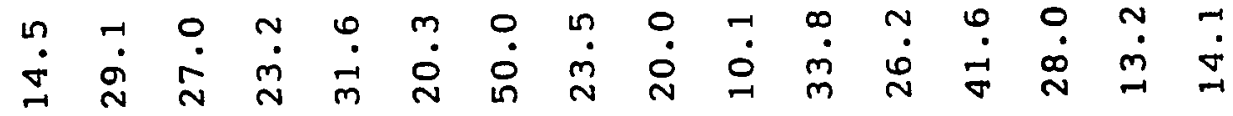

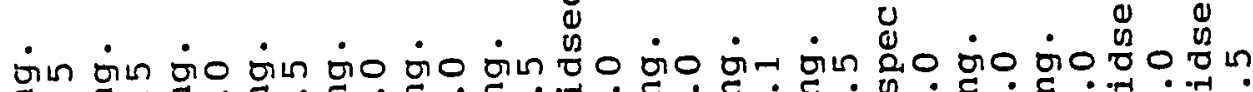

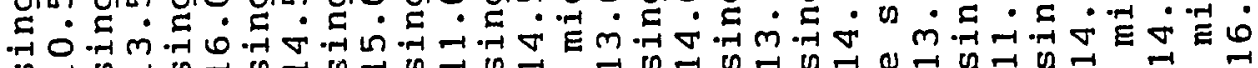

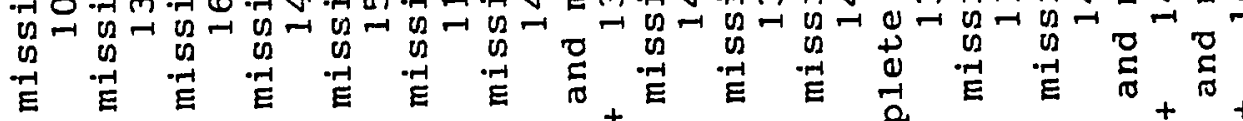

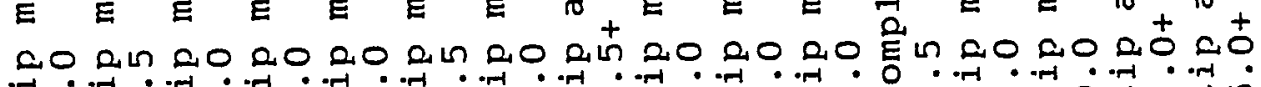

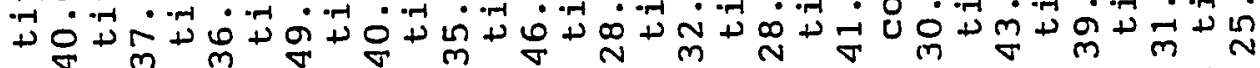

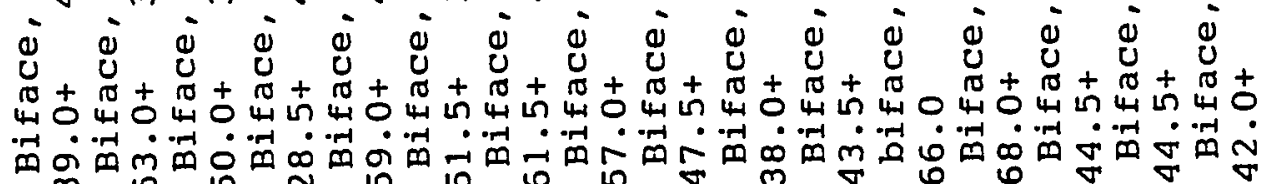

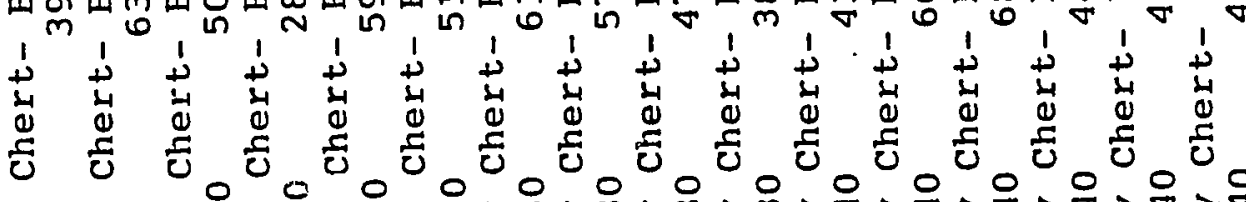

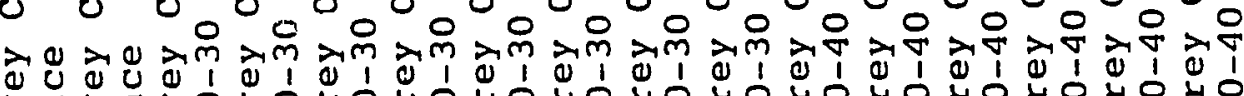
눈

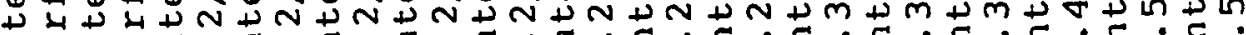

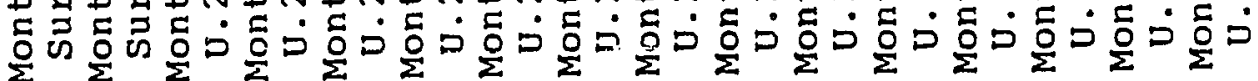

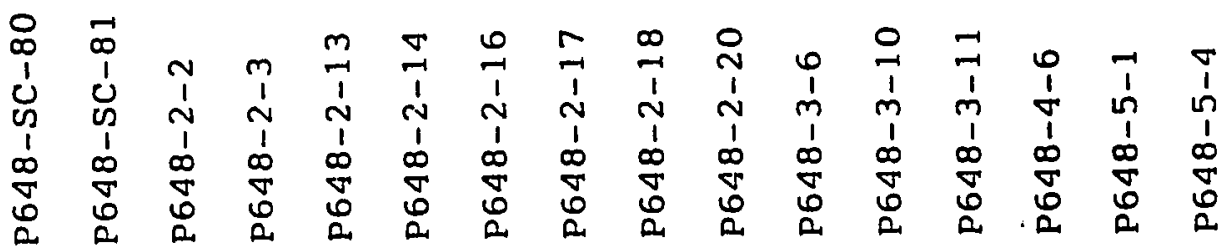




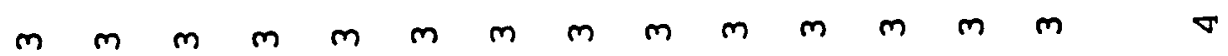

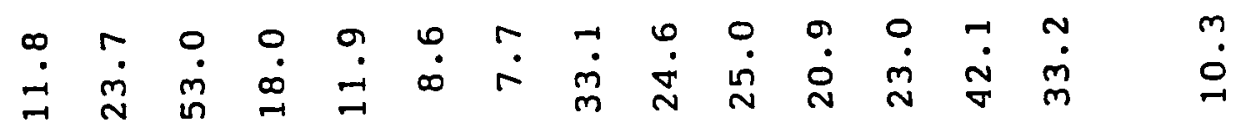

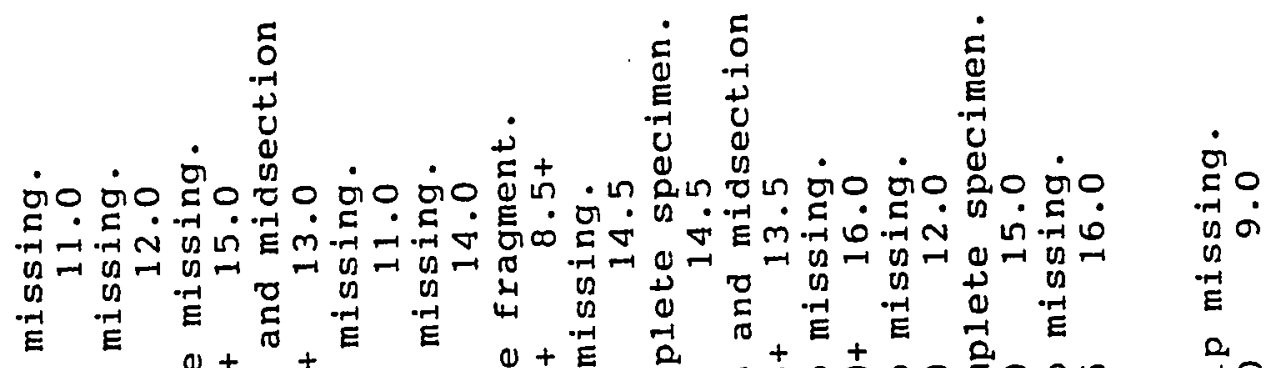

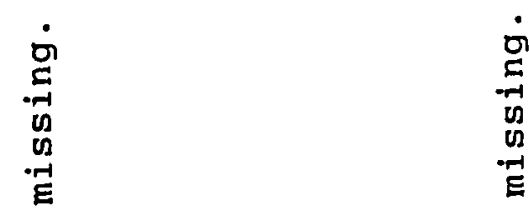

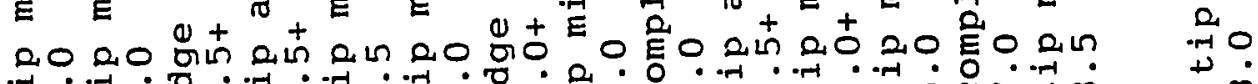

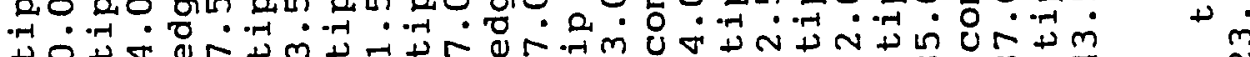

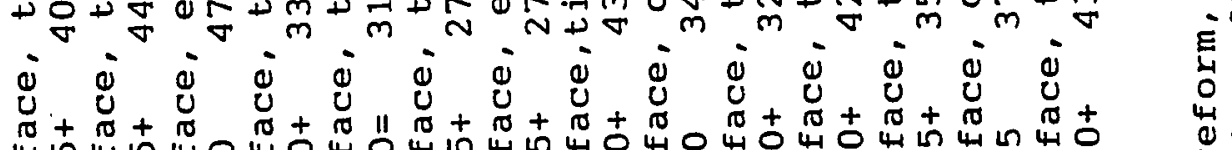

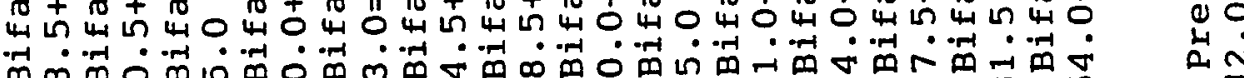

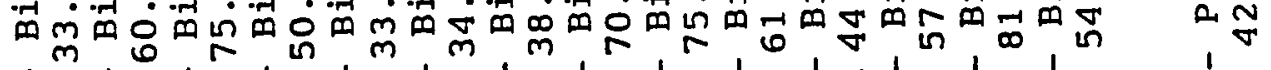

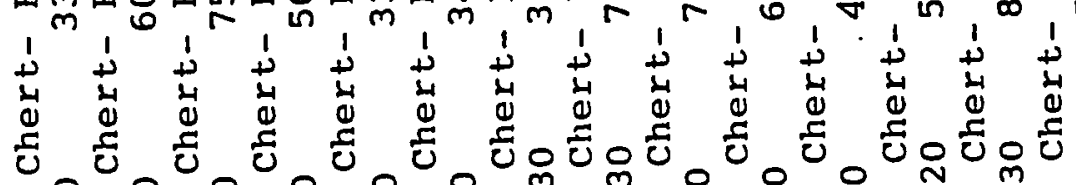

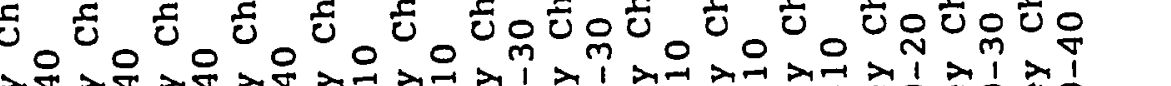

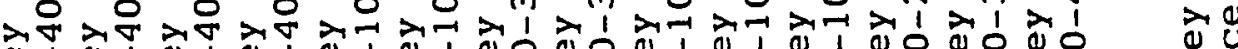

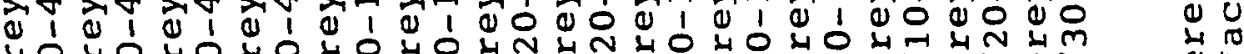

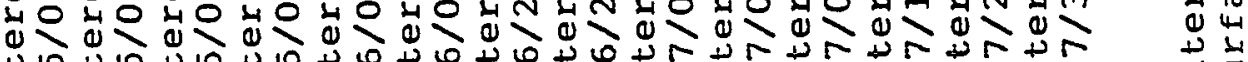

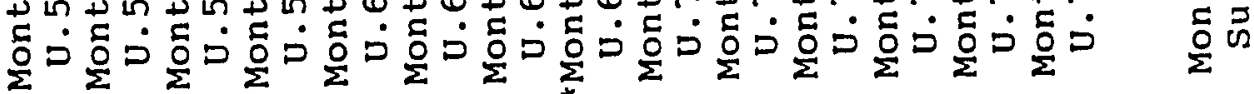

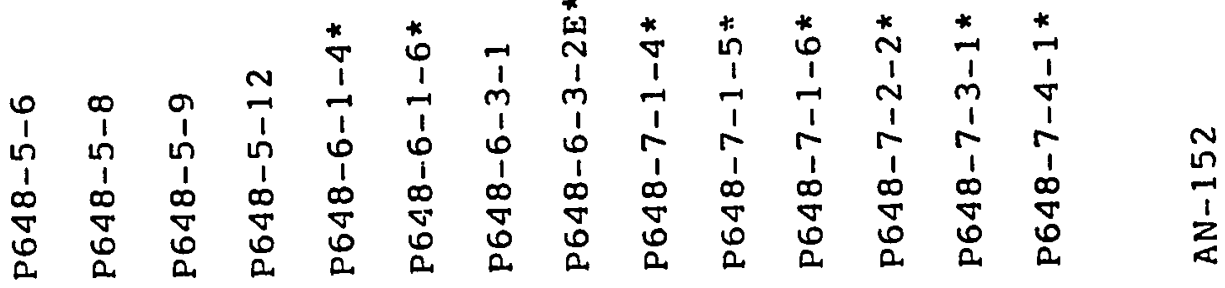




$$
\begin{aligned}
& \begin{array}{llllllllllllllll}
\nabla & \nabla & \nabla & \nabla & \nabla & \nabla & \nabla & \nabla & \nabla & \nabla & \nabla & \nabla & \nabla & \nabla & \nabla & \nabla
\end{array}
\end{aligned}
$$

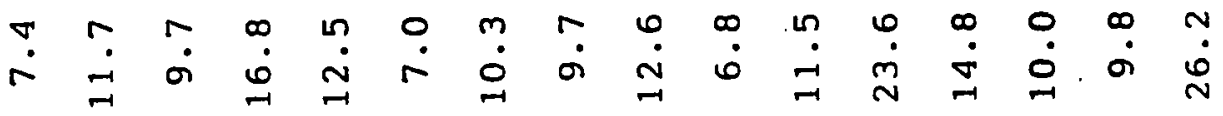

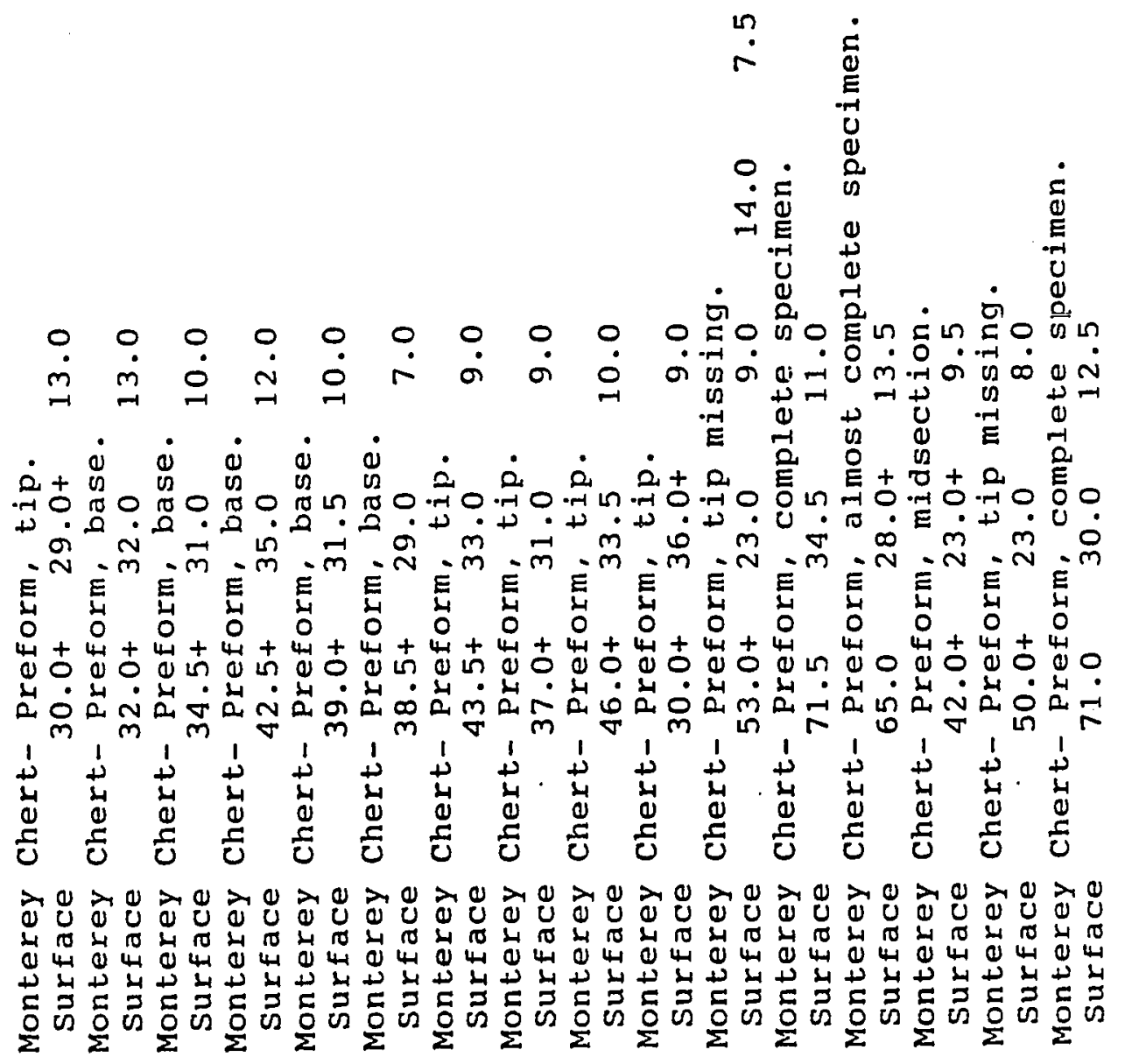

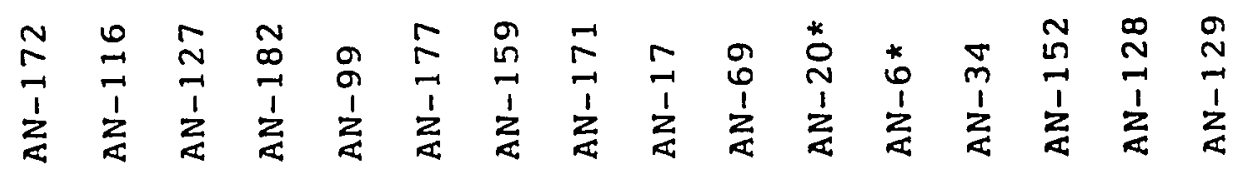




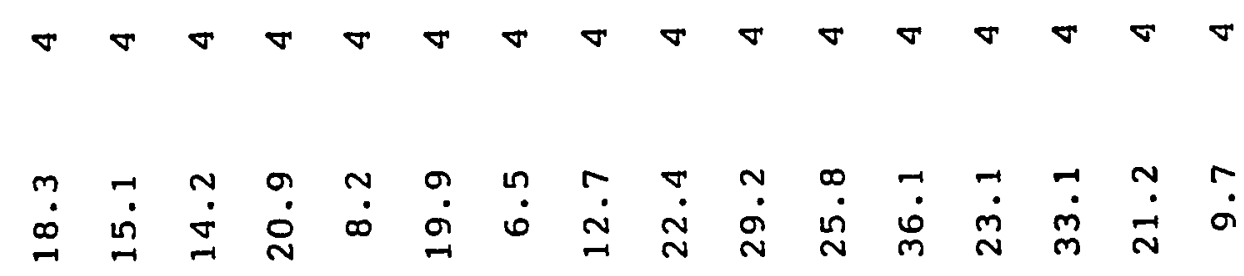

$\stackrel{\dot{\Xi}}{\dot{\Xi}}$

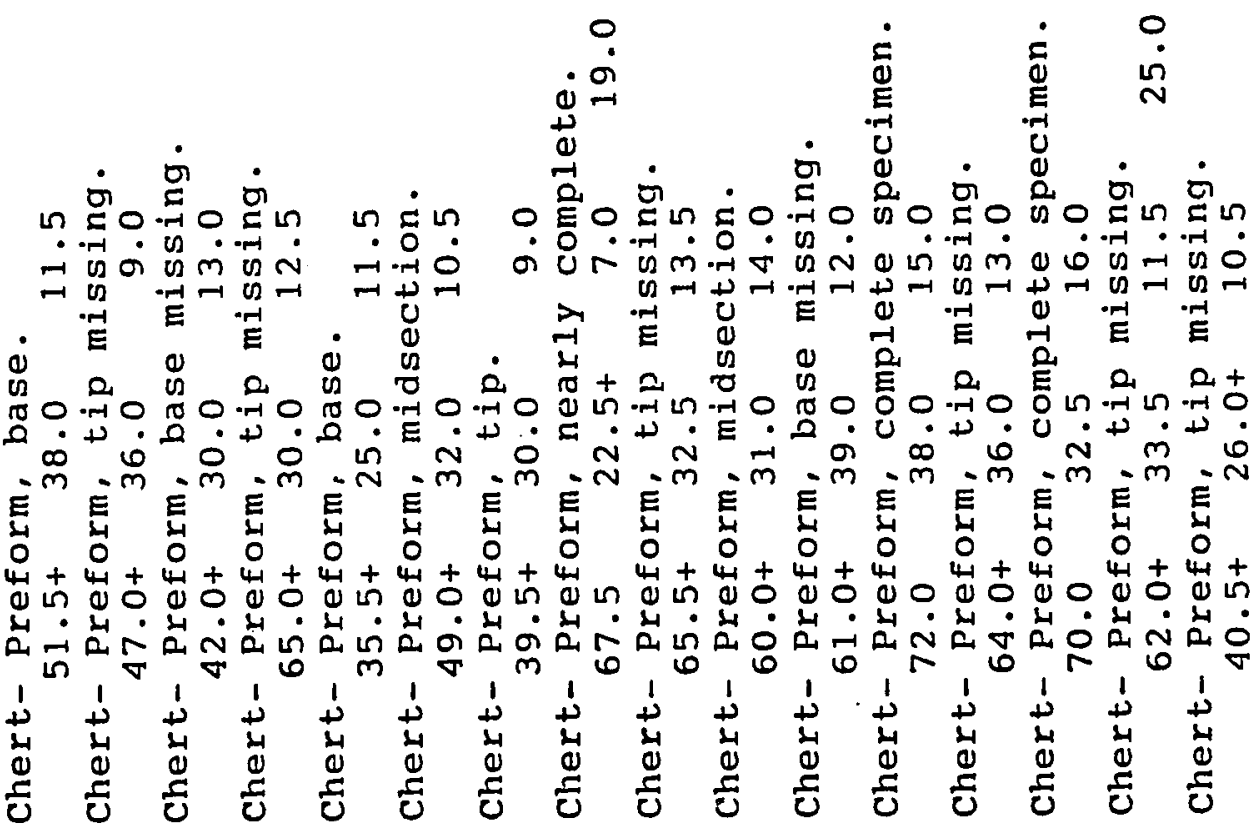

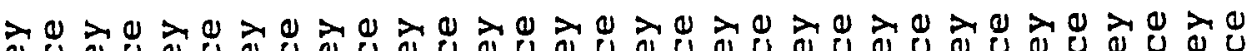

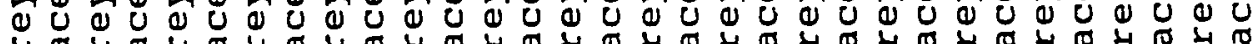

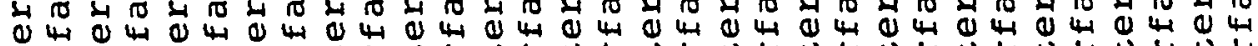

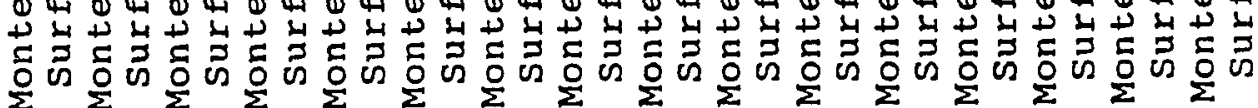

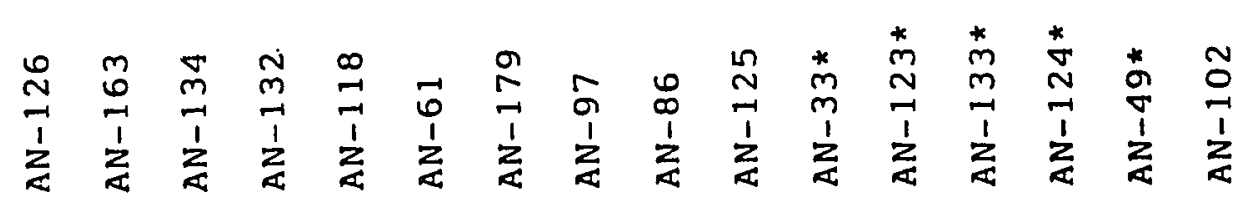




$$
\begin{aligned}
& \begin{array}{llllllllllllllll}
\nabla & \nabla & \sigma & \nabla & \nabla & \nabla & \nabla & \nabla & \nabla & \nabla & \nabla & \nabla & \nabla & \nabla & \nabla & \nabla
\end{array}
\end{aligned}
$$

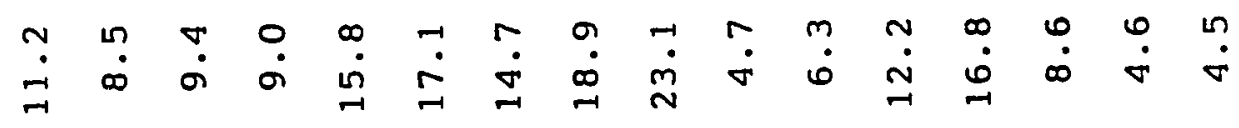<smiles>[Mg]O[Hg]</smiles>

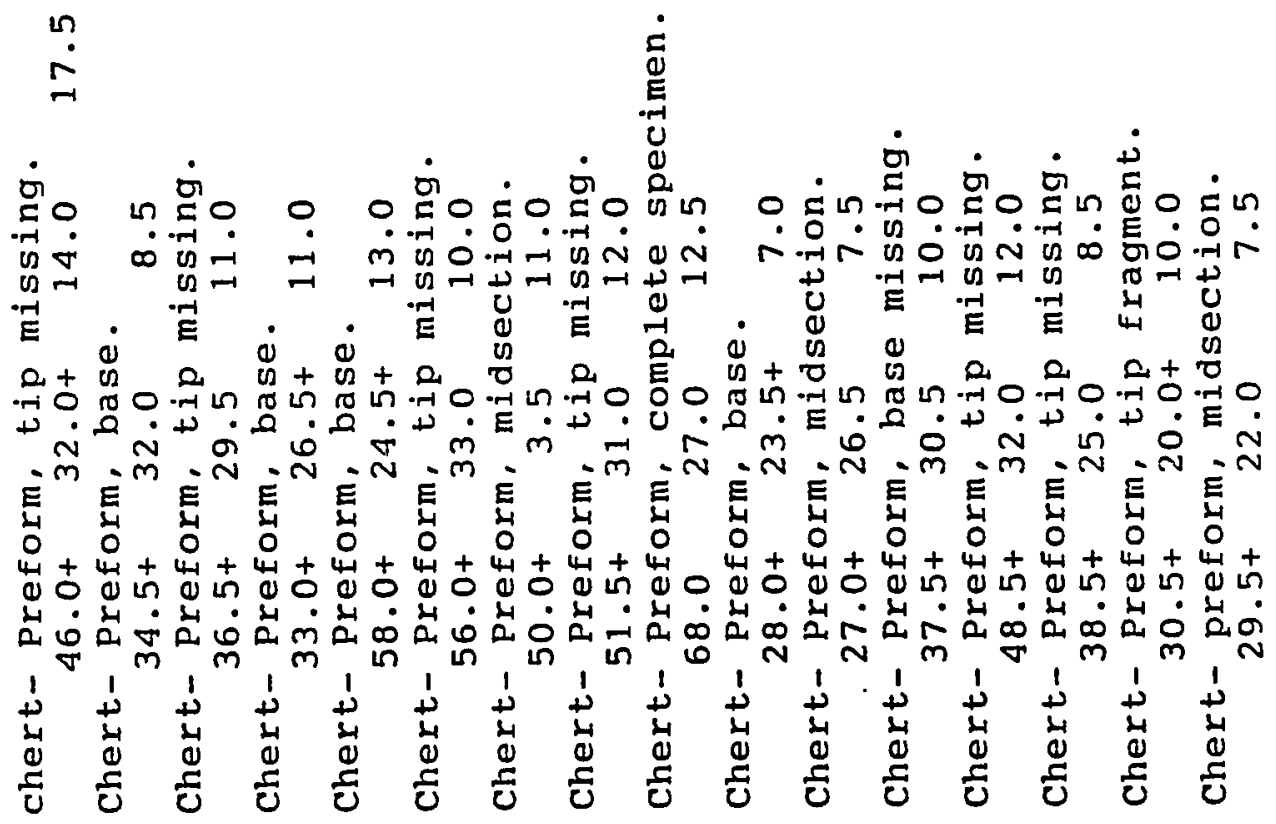

خ্

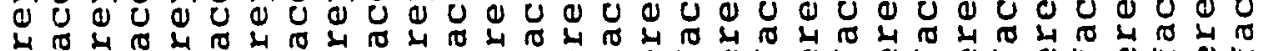
0 出

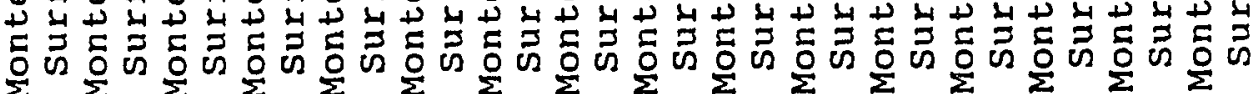

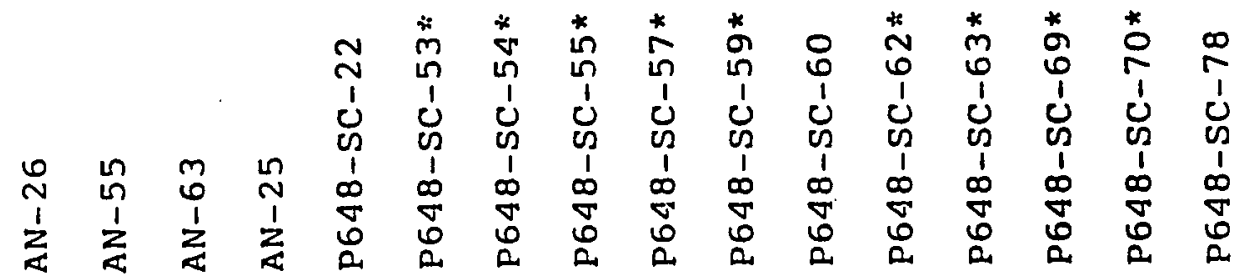




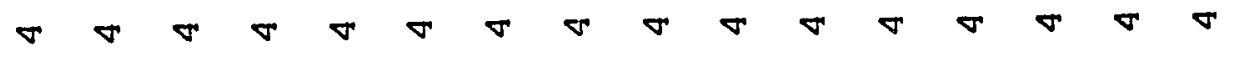

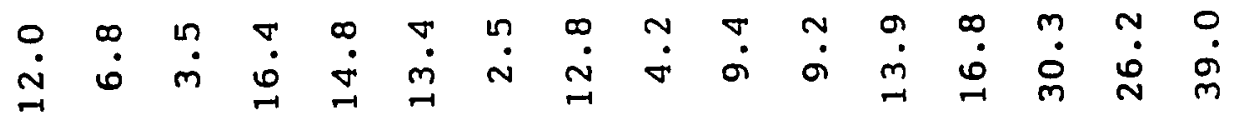

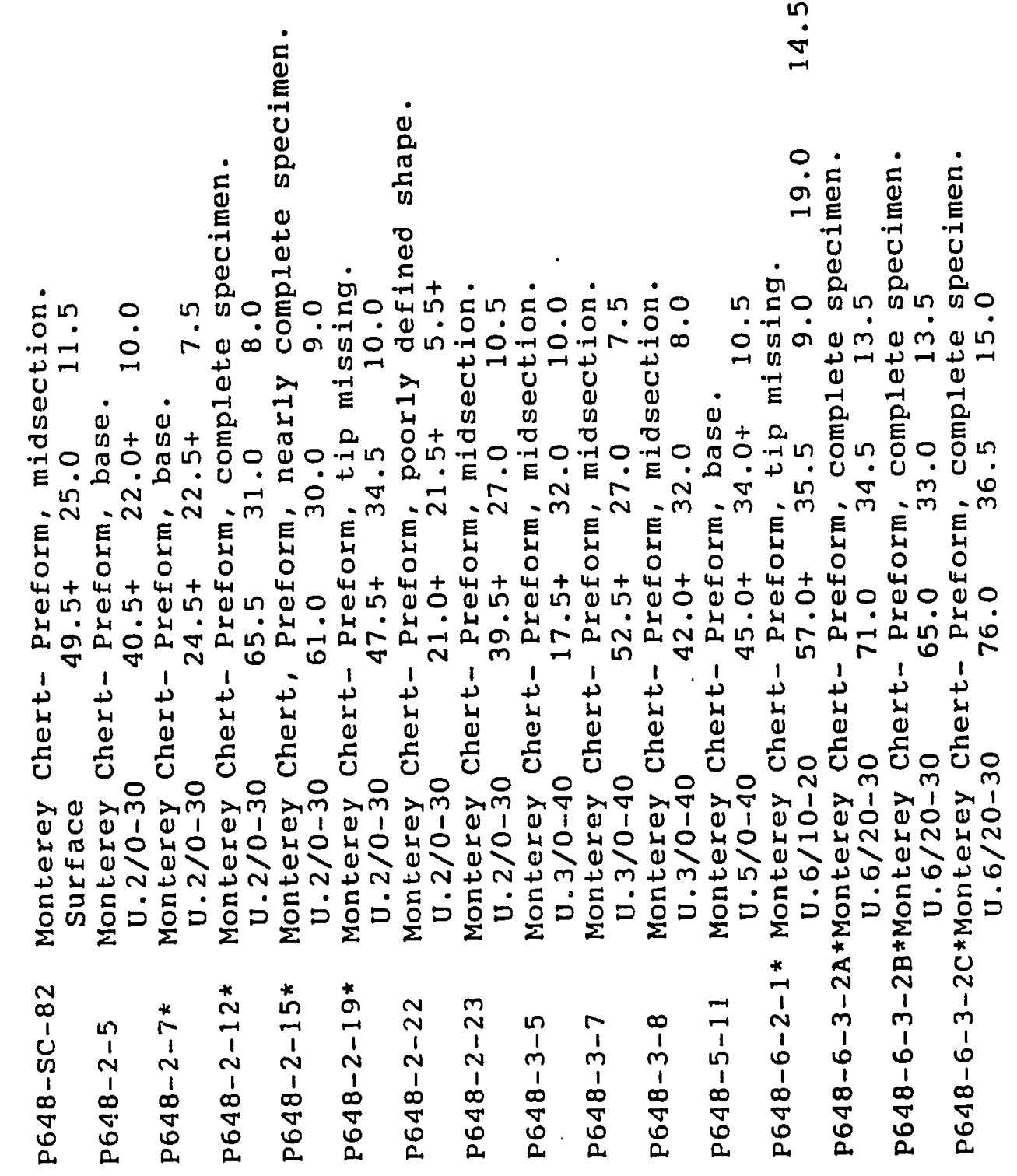




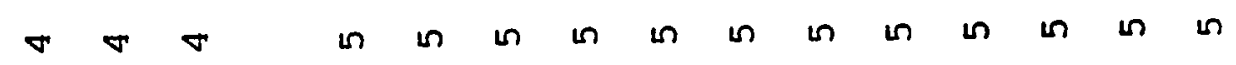

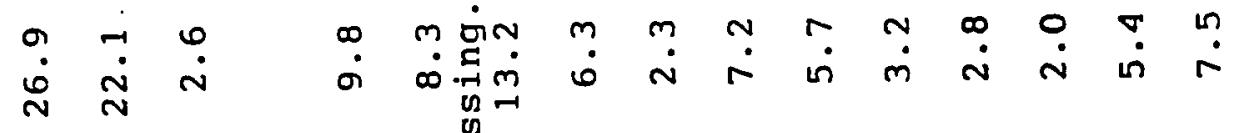

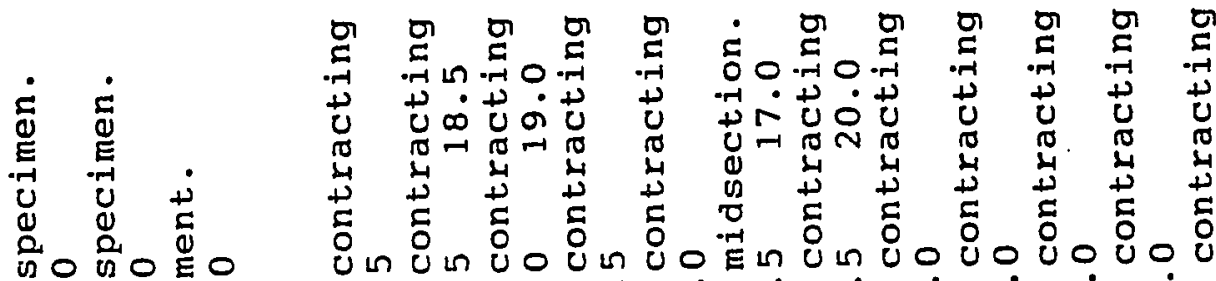

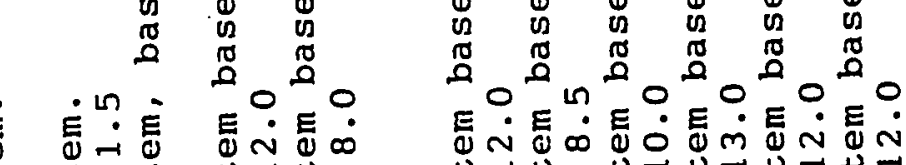

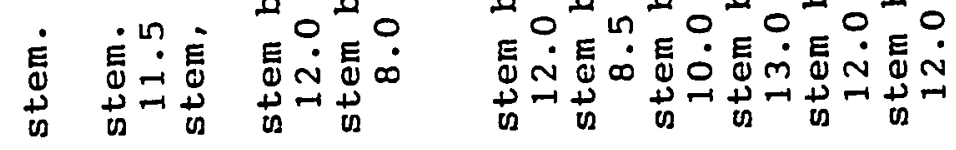

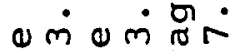

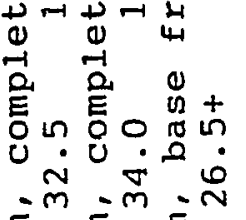

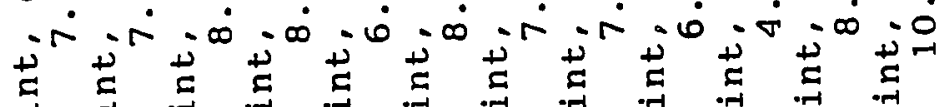

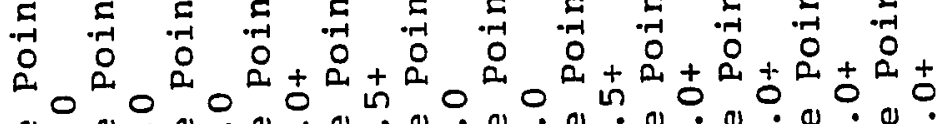

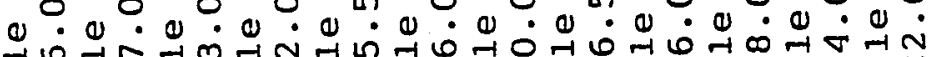

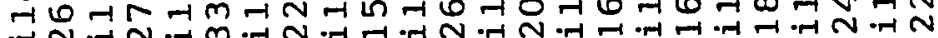

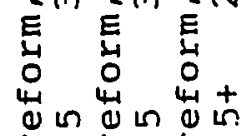

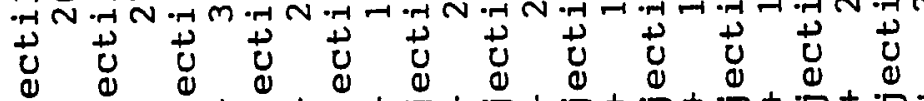

L

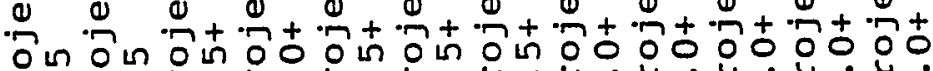

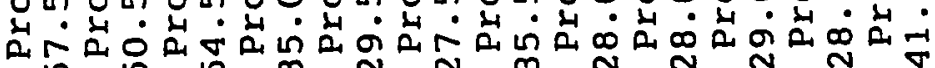

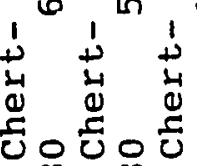

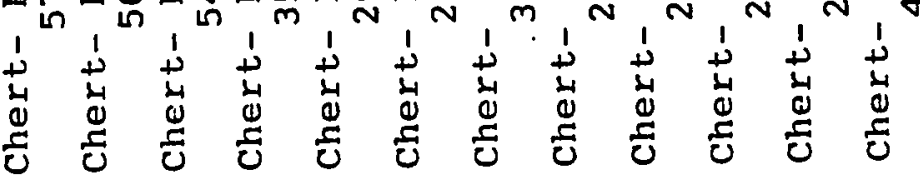

$m>m>1$

入 $\theta$ 入入

จิ

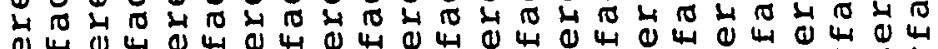
0404 出

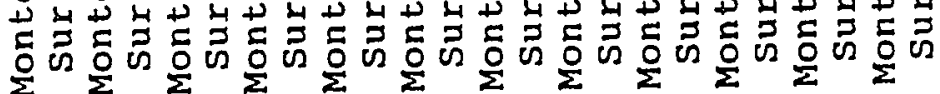
a)

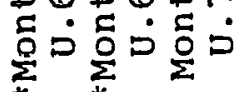

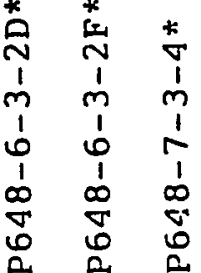

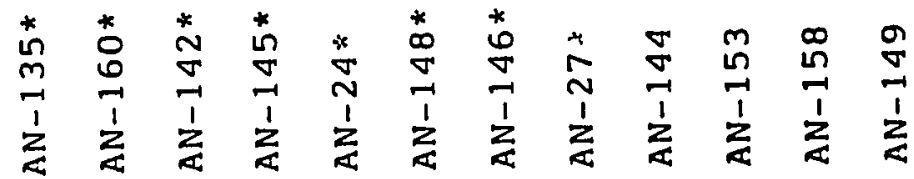


in in in in in $n$ in $n$ in $\ln$ in $\ln$ in $\ln$ in $\ln$ in

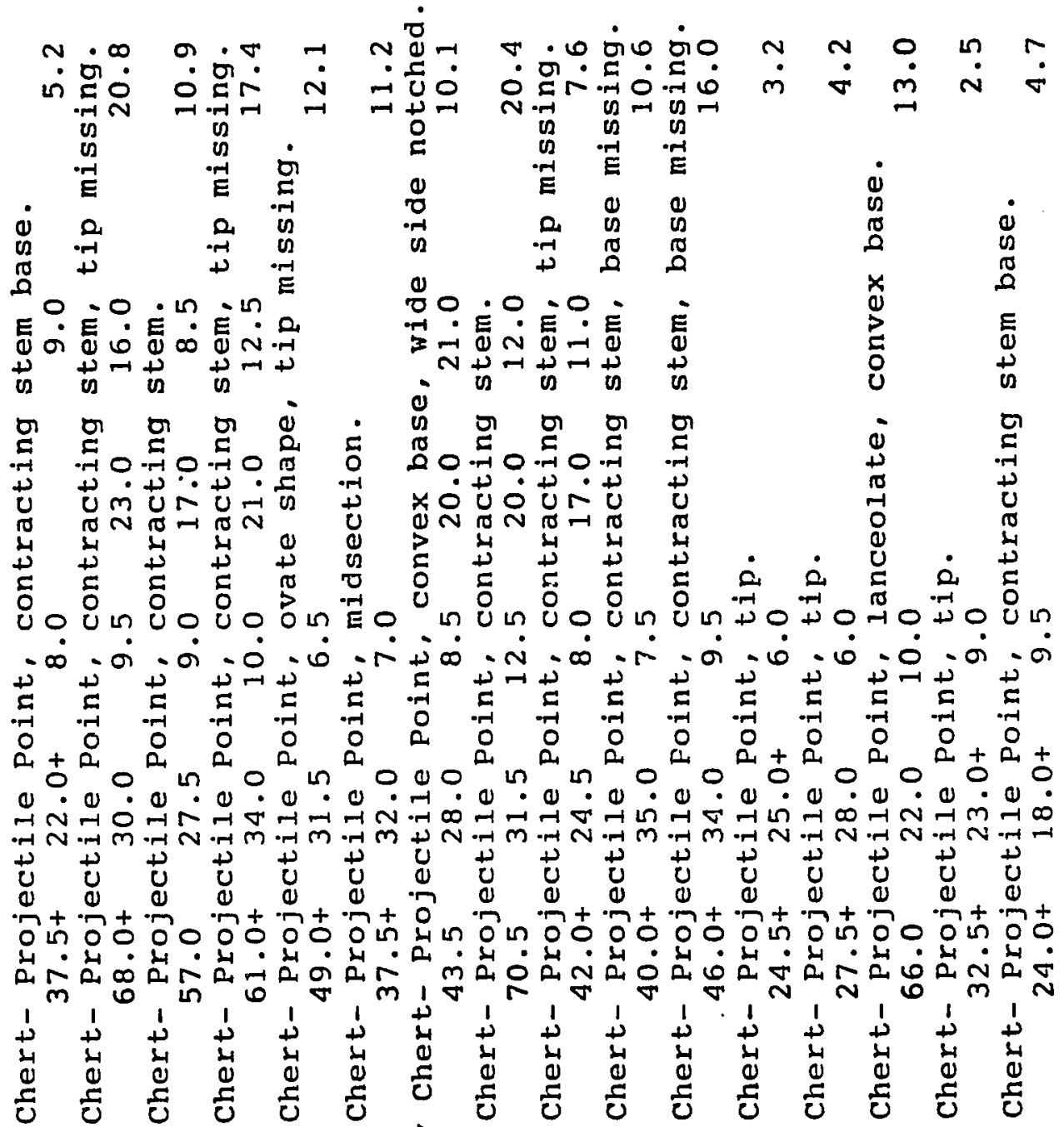

خ

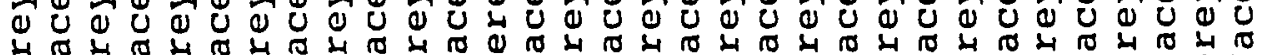

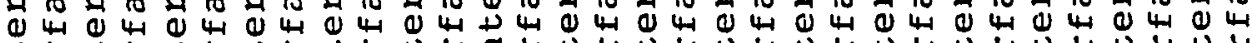
ل

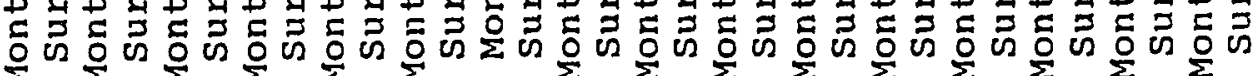

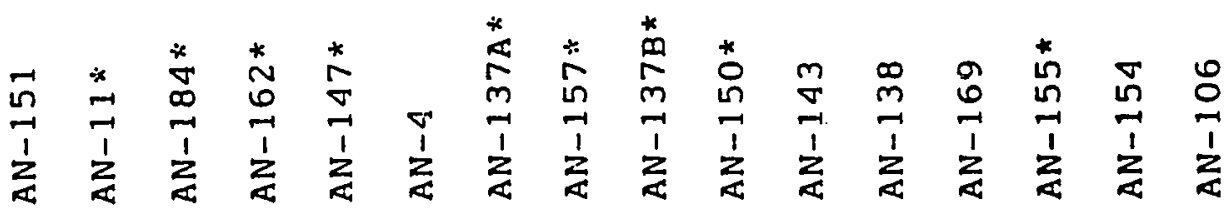




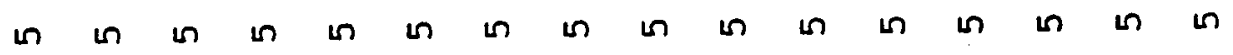

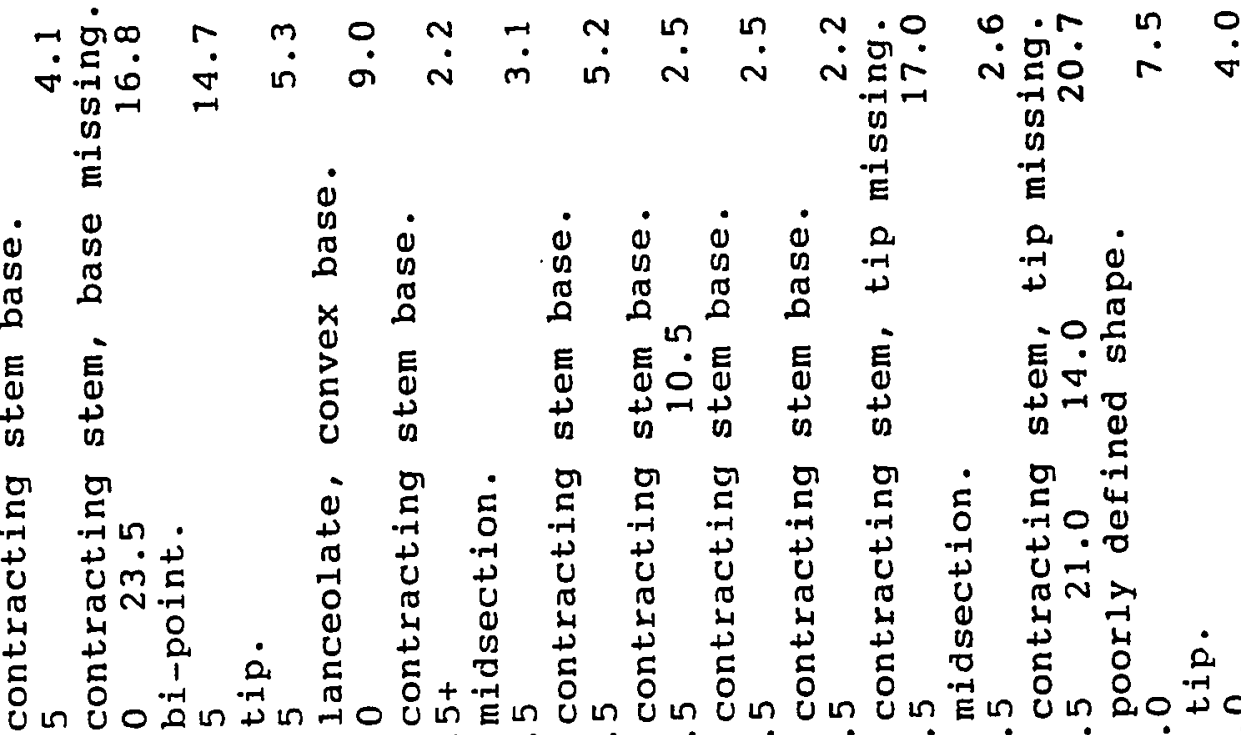

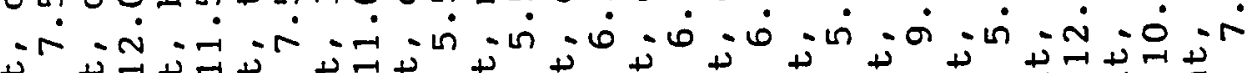

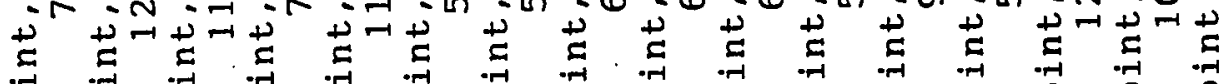

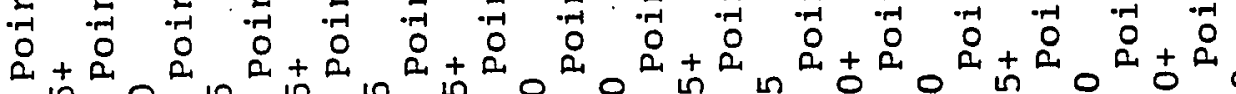

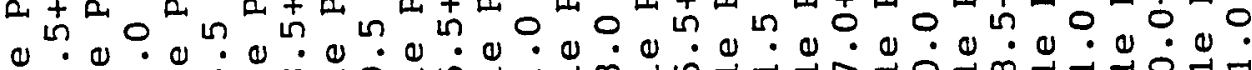

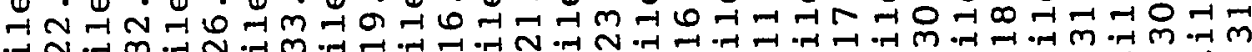
范

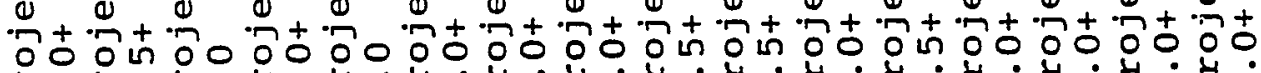

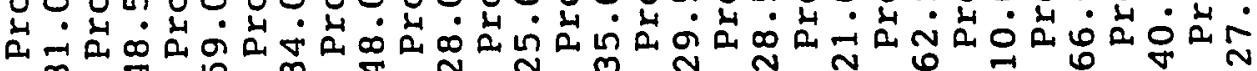

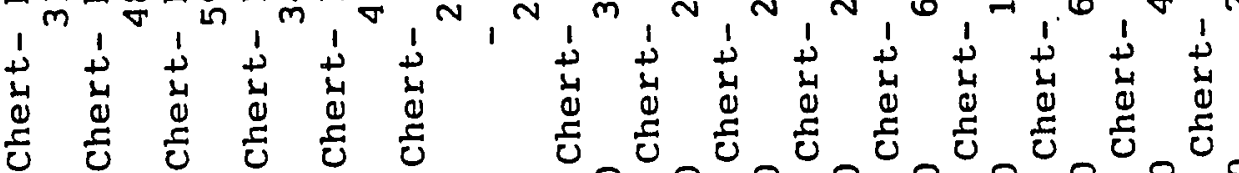

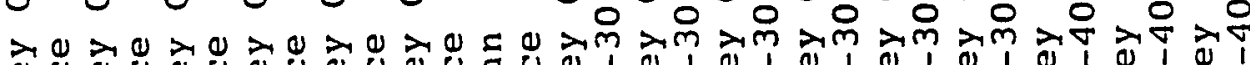
ไิ 山 4.

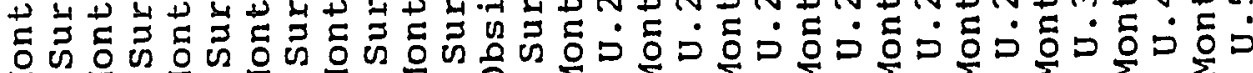

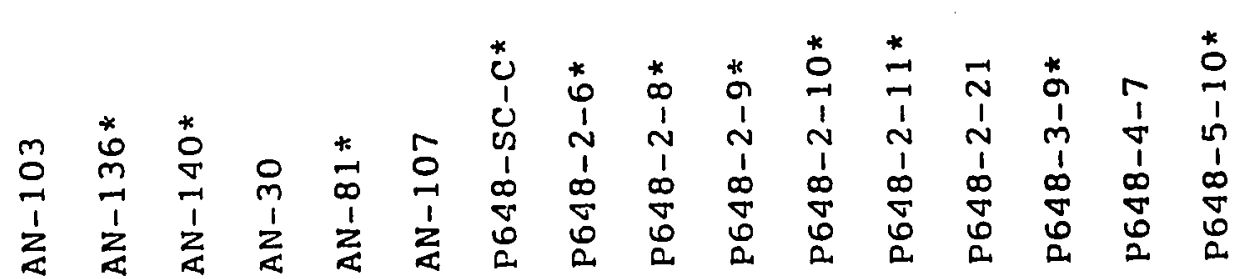


$n$ n in $\ln$ in $\ln$ in $\ln$ in $\ln$

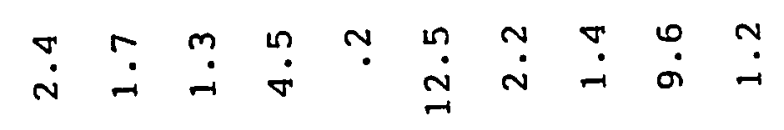

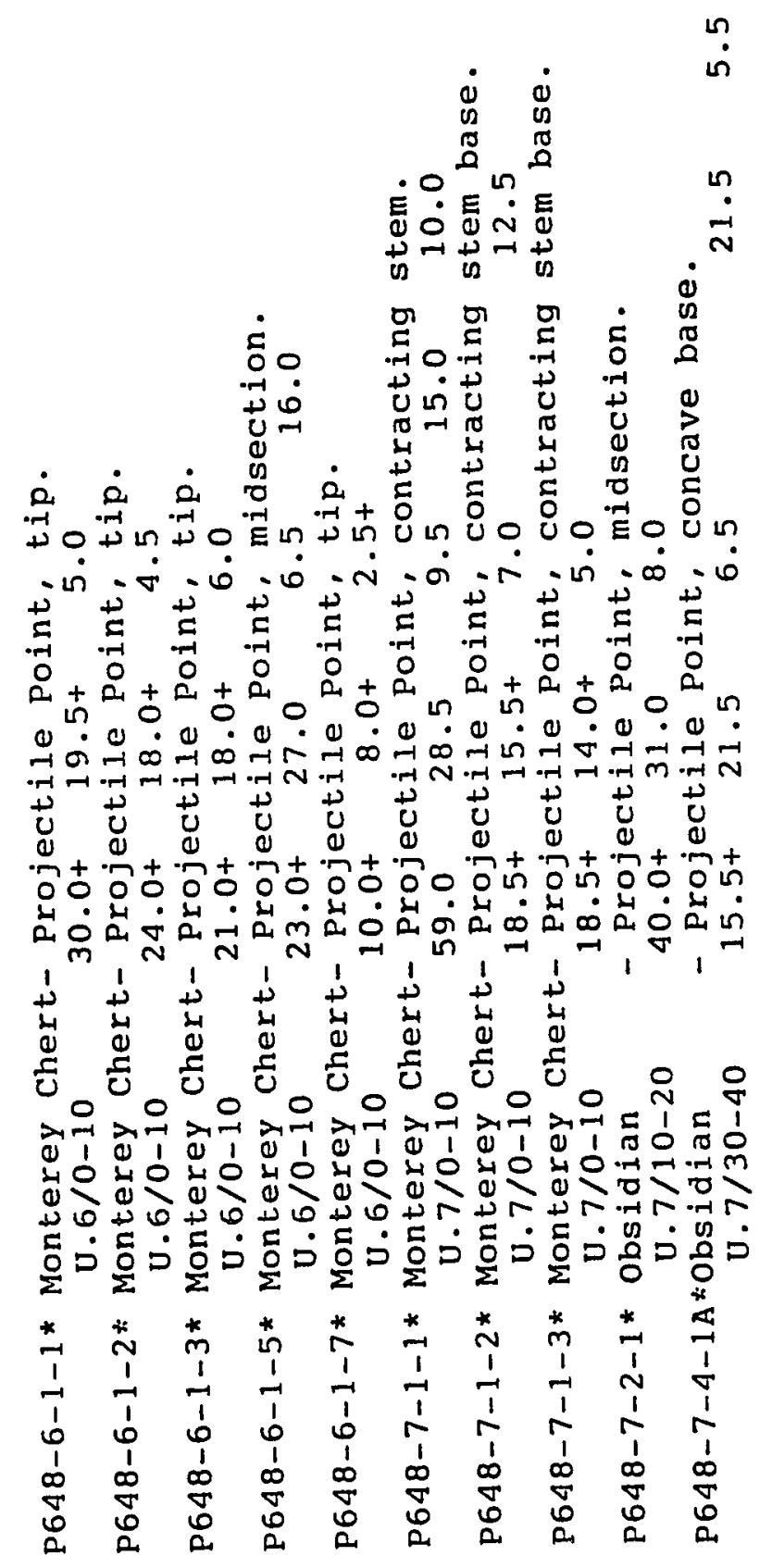




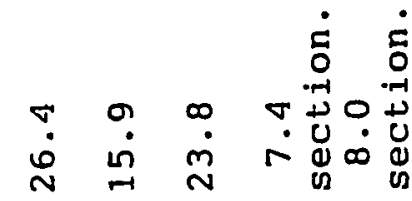

$\frac{1}{1}$

-1
$\pi$
02
0
0
1
1

E

$i_{-1}$

ด 苛

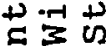

(․․

选

$\stackrel{4}{4} \cdot-1$

z

(II

$\sum \frac{0}{2}$

$\rightarrow$

-

40

E $\mathbb{H}_{-\rightarrow}^{-1}$

的

NE II

$E$

$\ddot{\dot{x}} \dot{x}^{2}$

Q

$4 \sum$ on

in 11

它岂

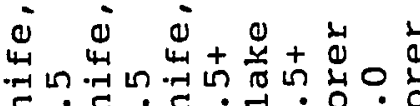

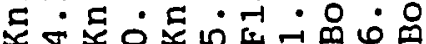

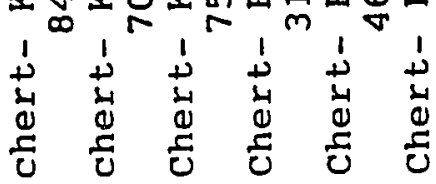

خ ญ

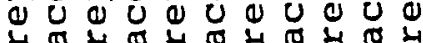

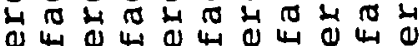

14

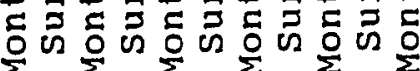

$\Sigma$

0.

(돈

${ }_{-1}^{0}$

$0 \%$

Eับ

$\sum^{0} 3$

E

II $\sum^{11}$

$+\Sigma$

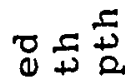

+ 守

\%

可

o

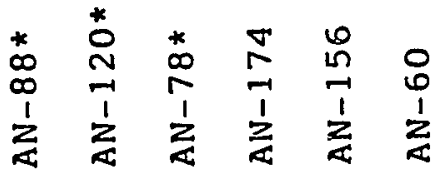

-

$\rightarrow$

*荌哭 


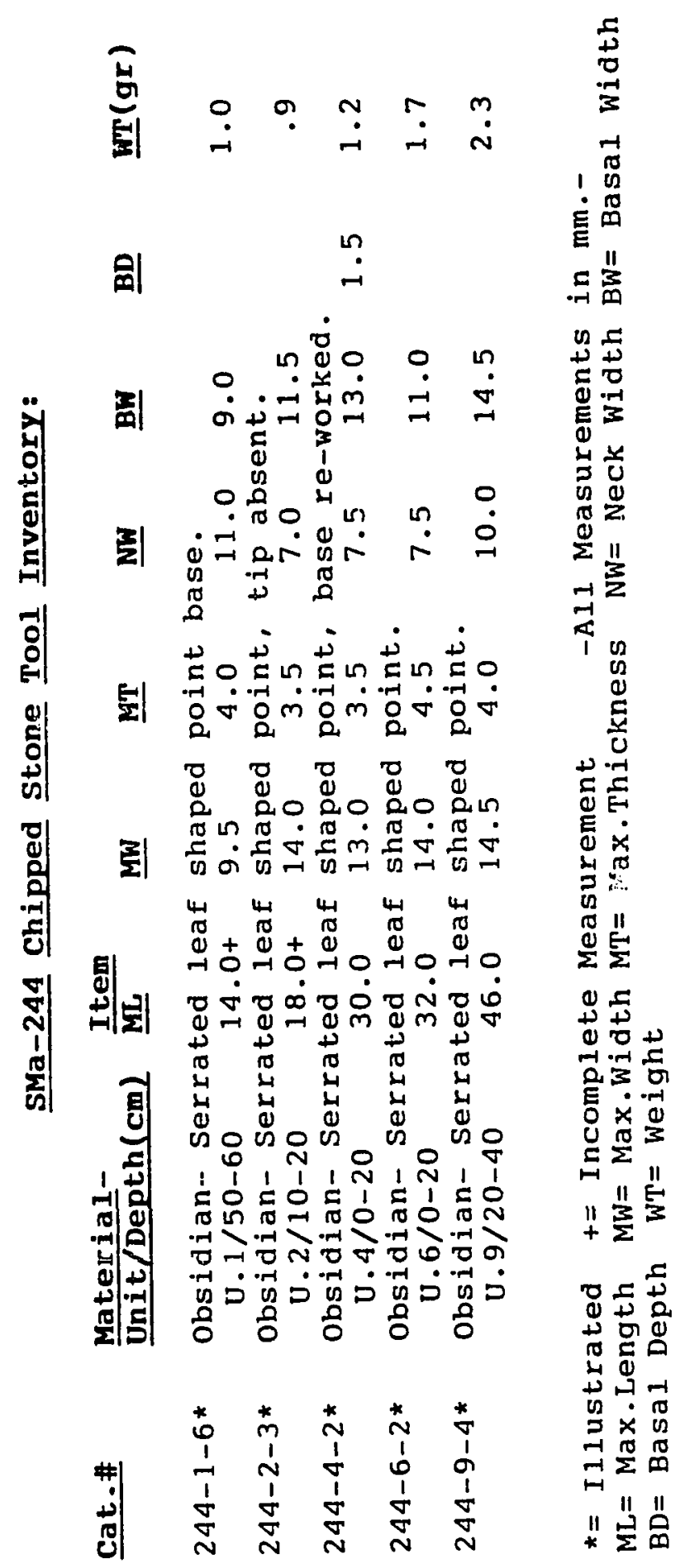


APPENDIX E

Cobble artifact inventories for sites scr-7, scr-9, scr-132, SMa-97, SMa-218, SMa-238, and SMa-244. 


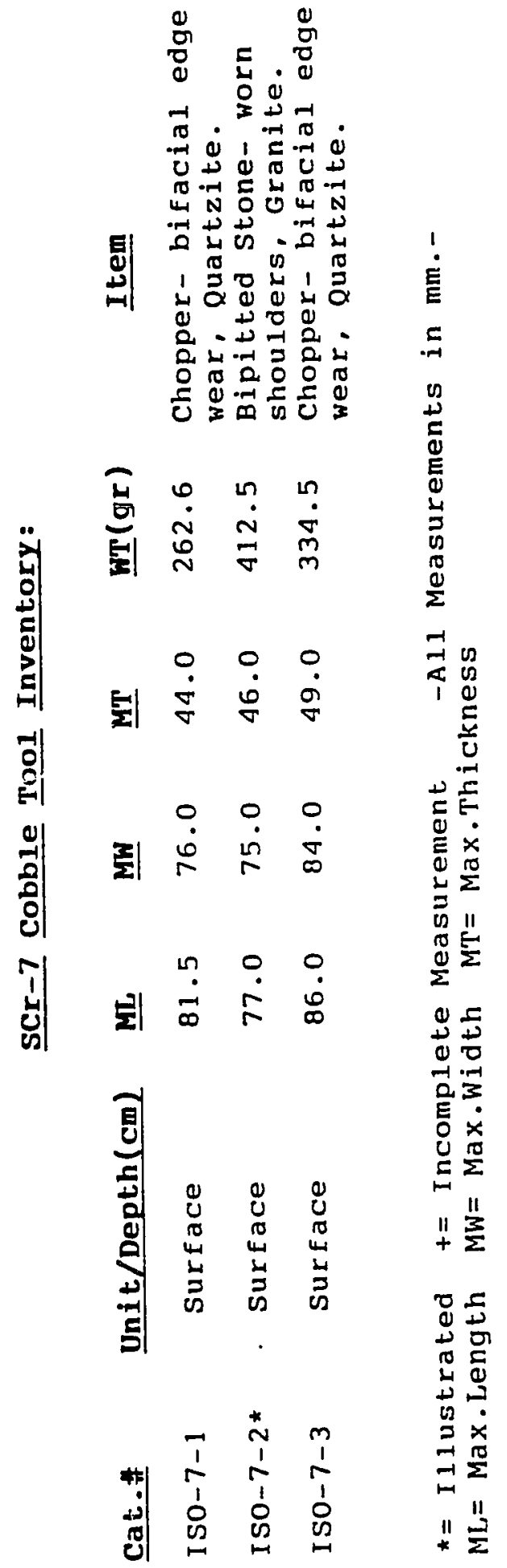




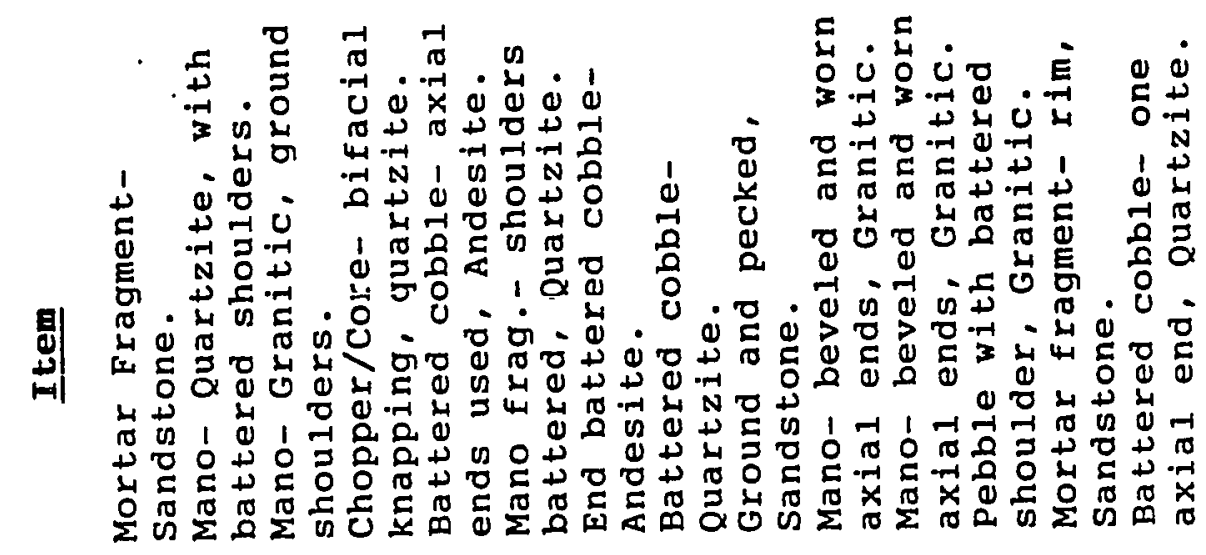

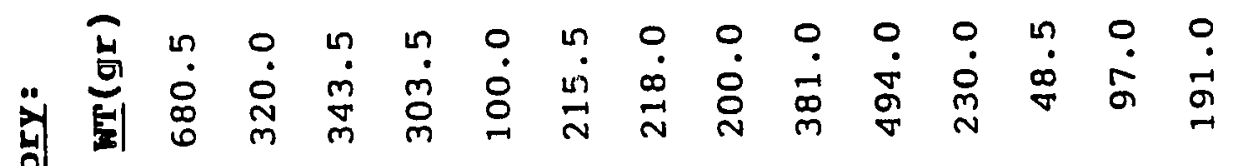

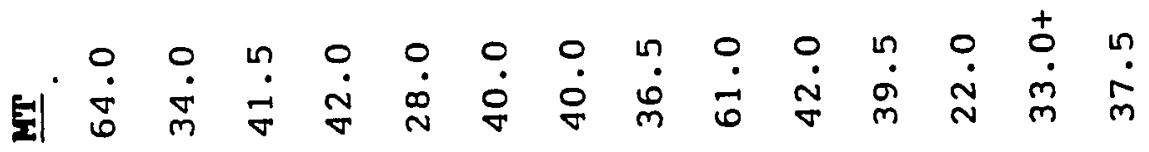

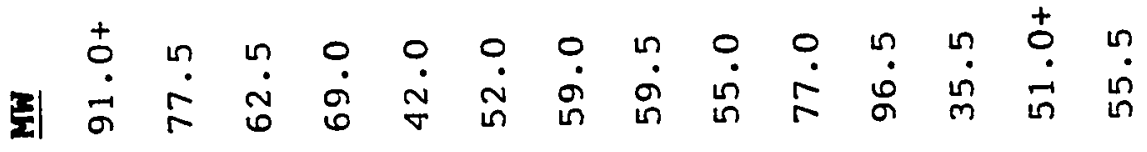

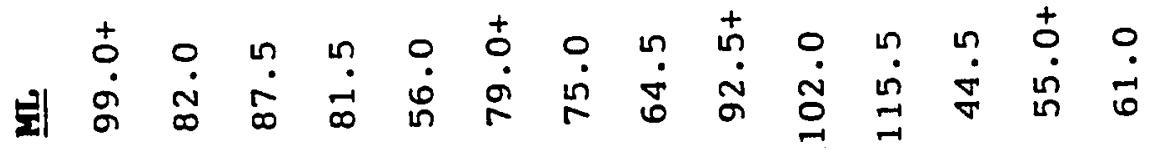

염

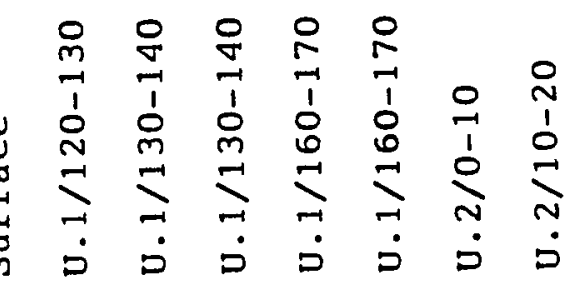

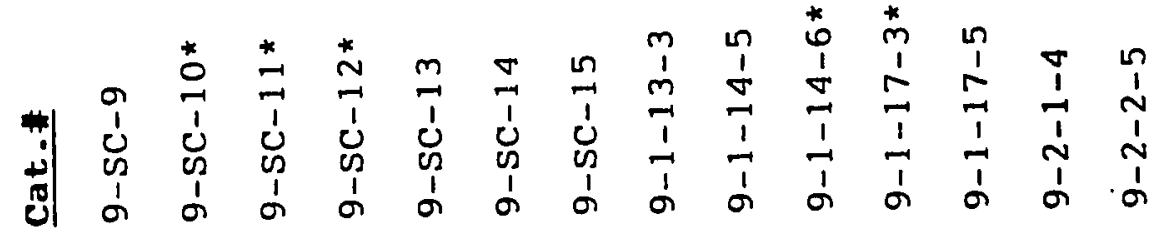




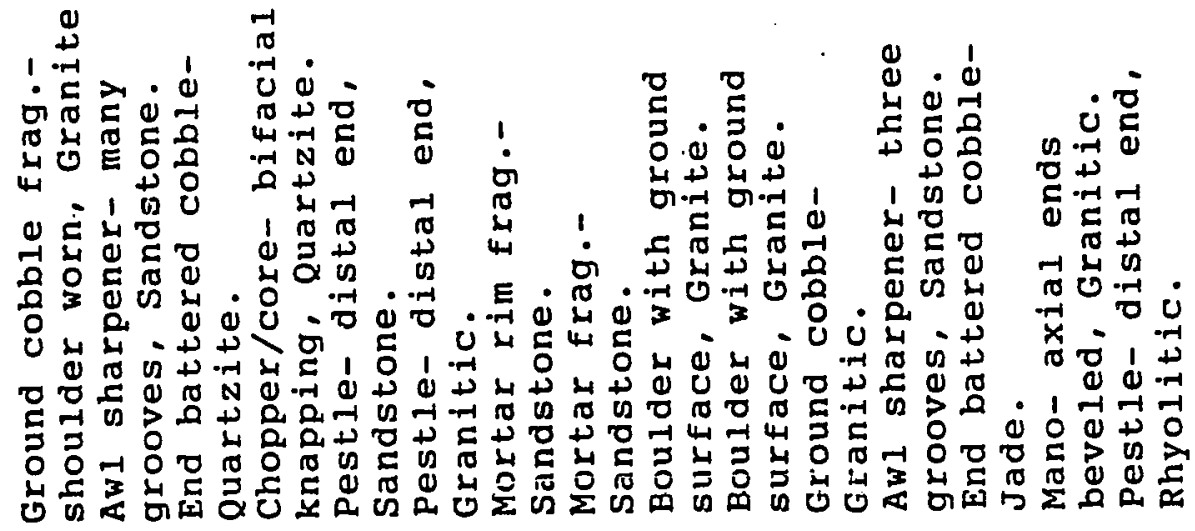

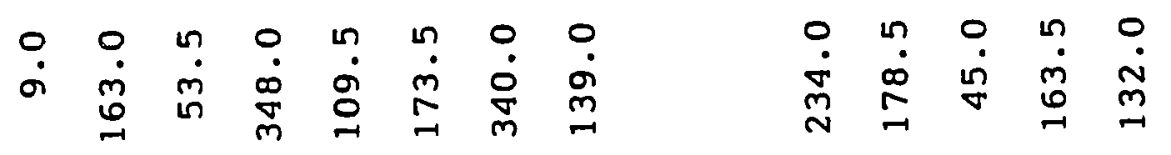

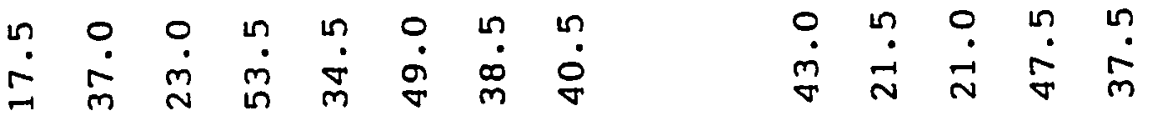

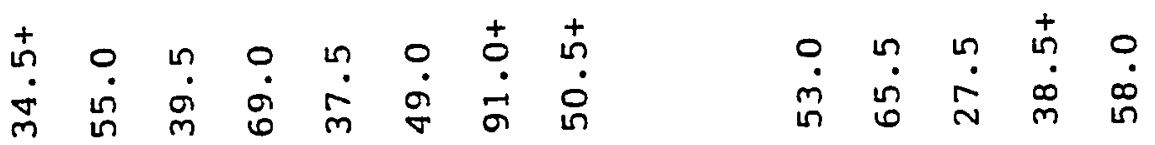

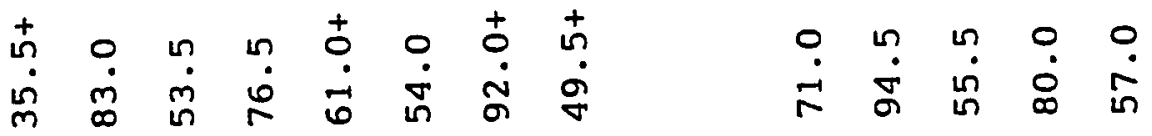

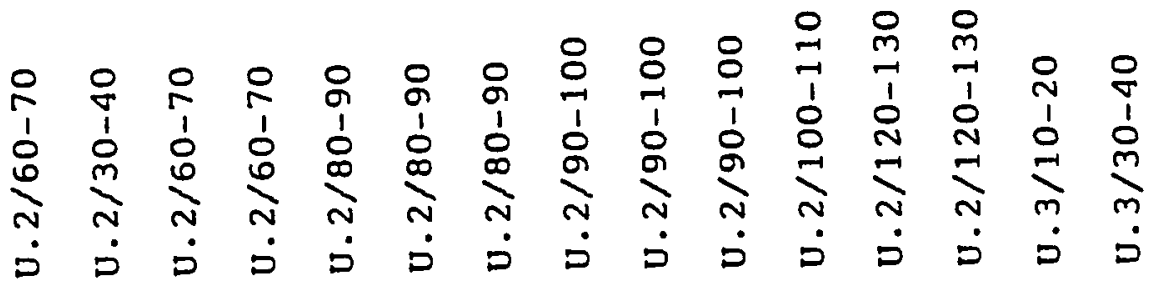

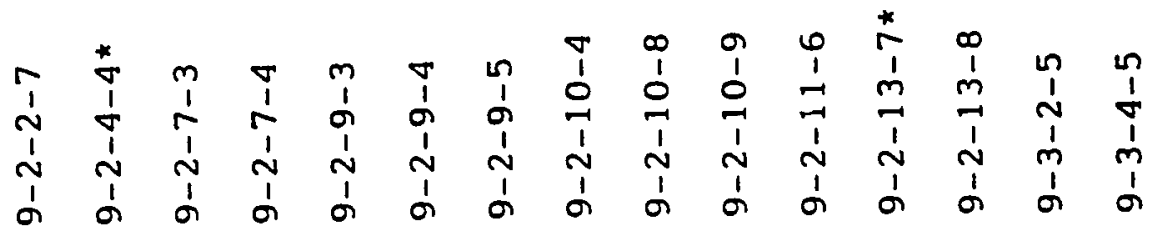




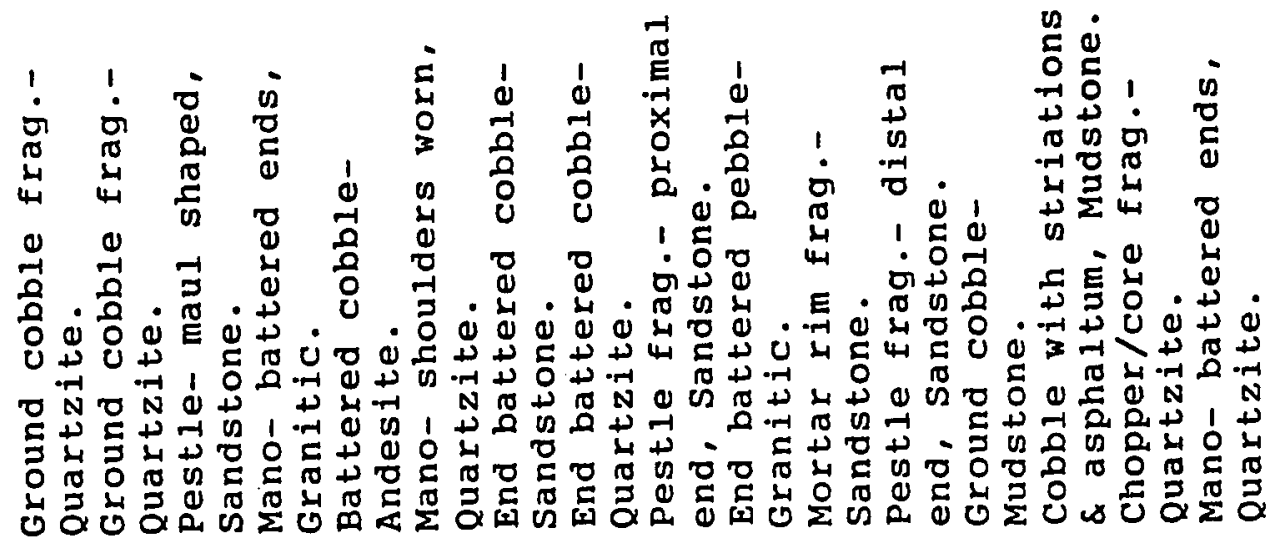

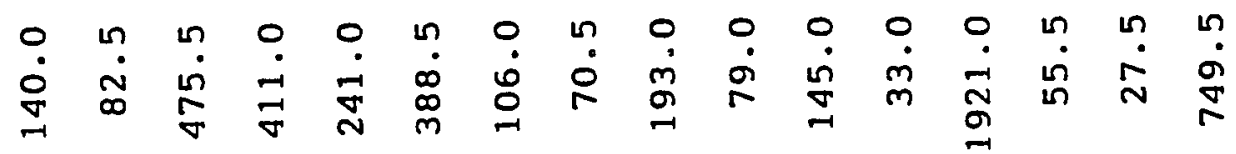

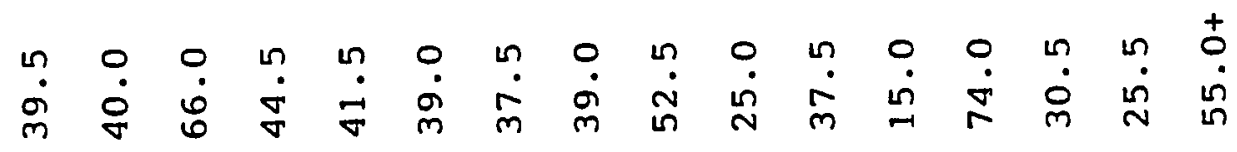

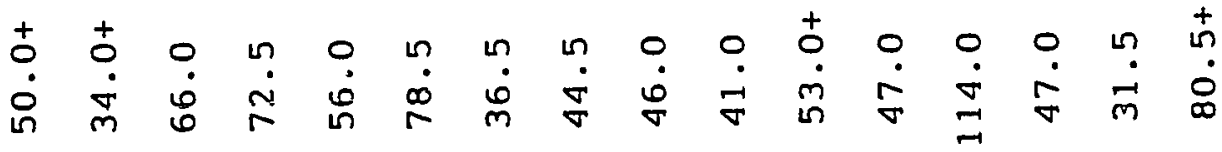

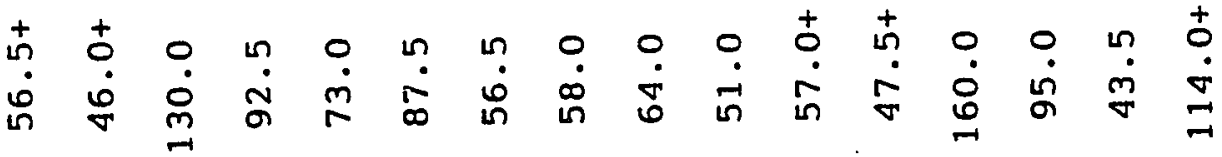

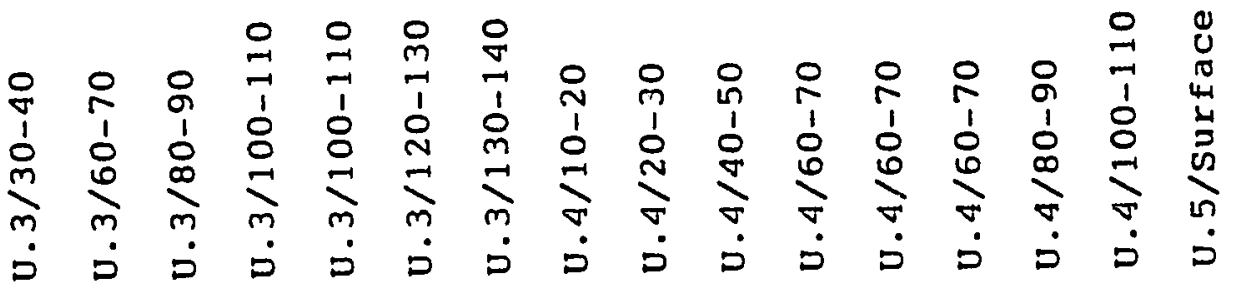

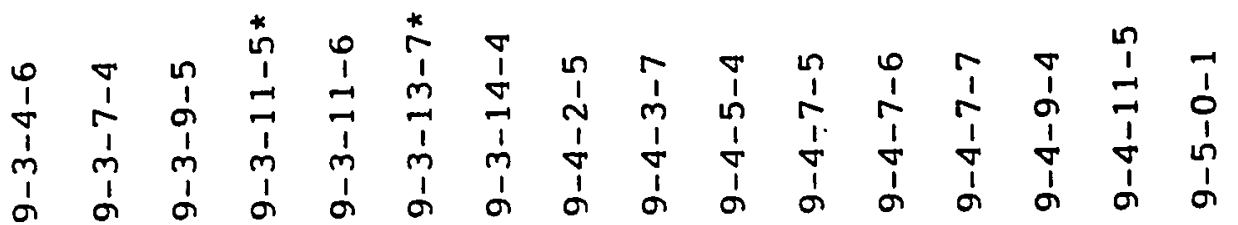




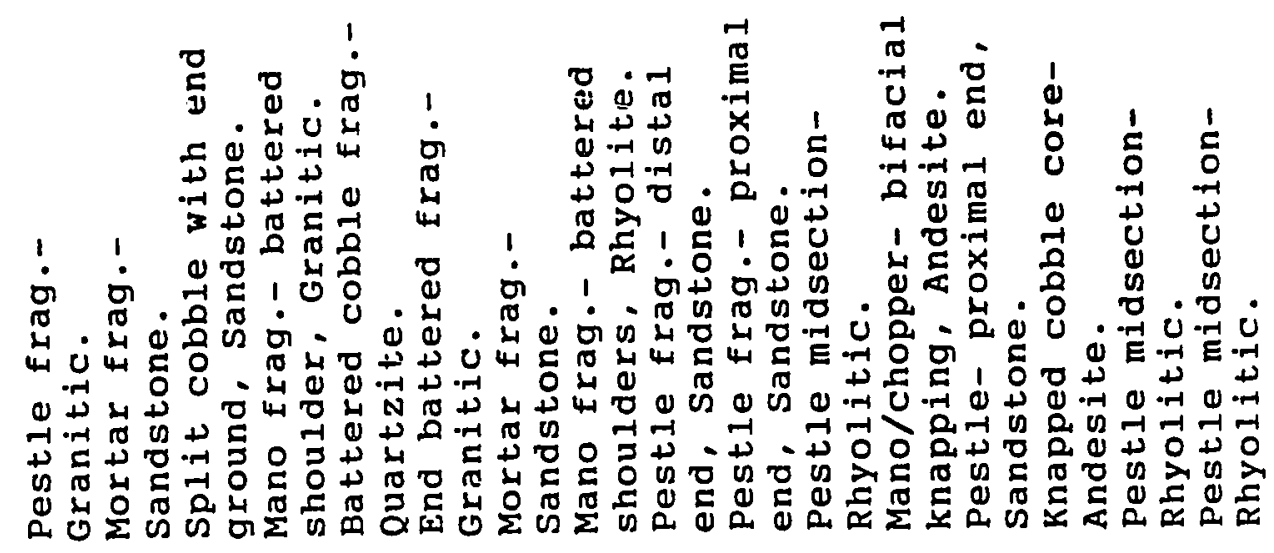

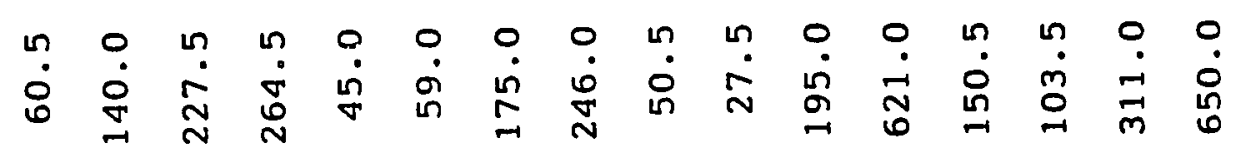

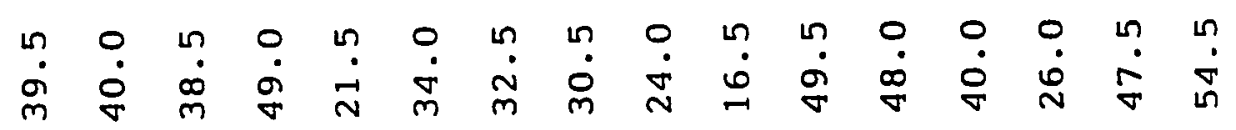

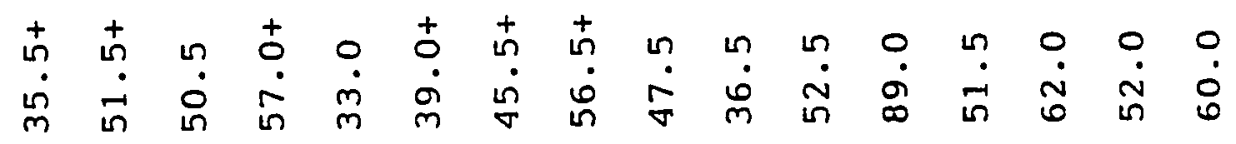

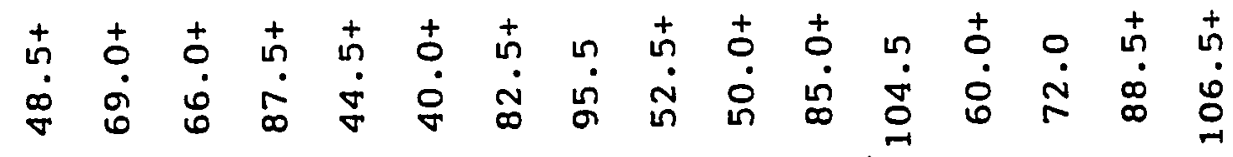

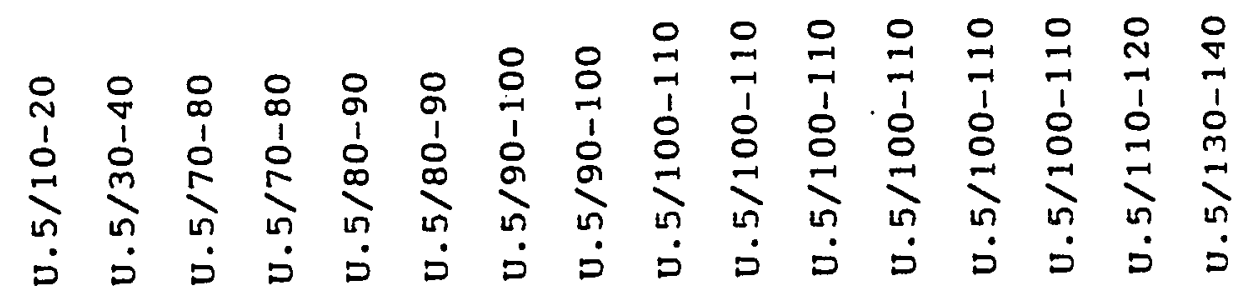

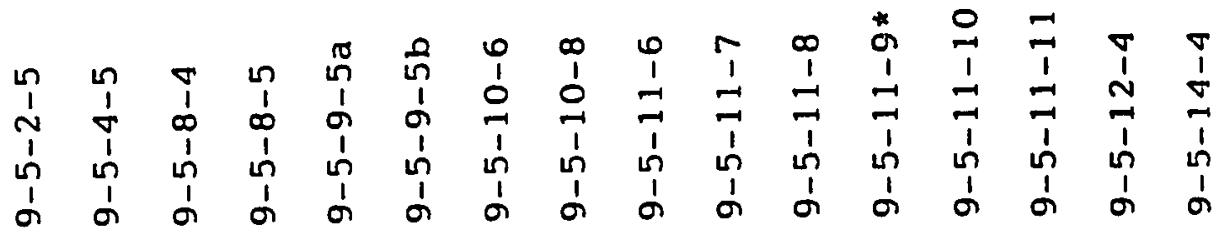




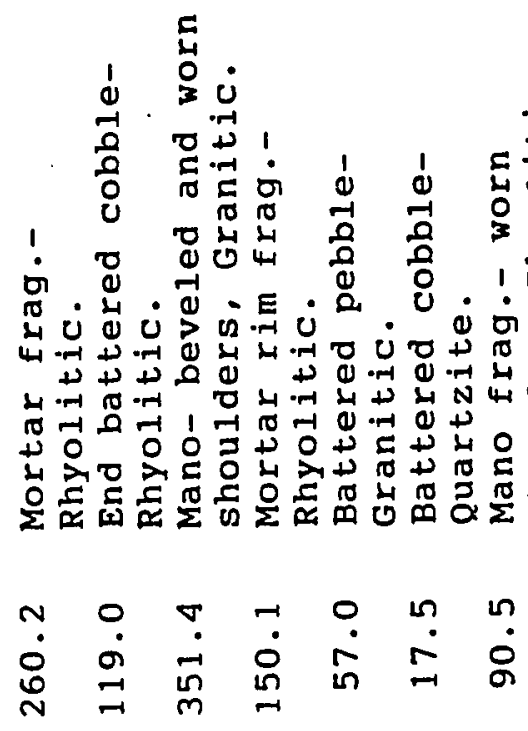

皇

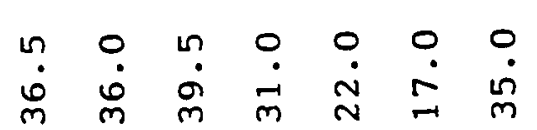

$\begin{array}{lllllll}n & + & 0 & t & 0 & n & 0 \\ i & \dot{m} & \dot{\sigma} & \dot{\sigma} & \dot{0} & \dot{m} & n\end{array}$

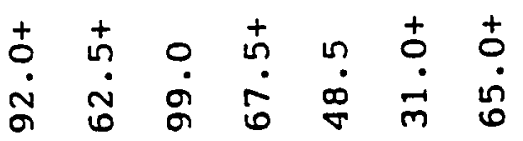

年的

\{

要

هي

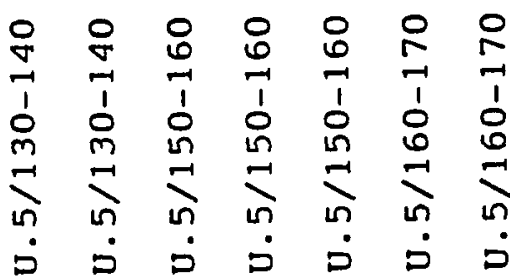

을

บ

$+\frac{11}{3}$

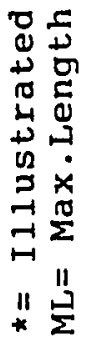




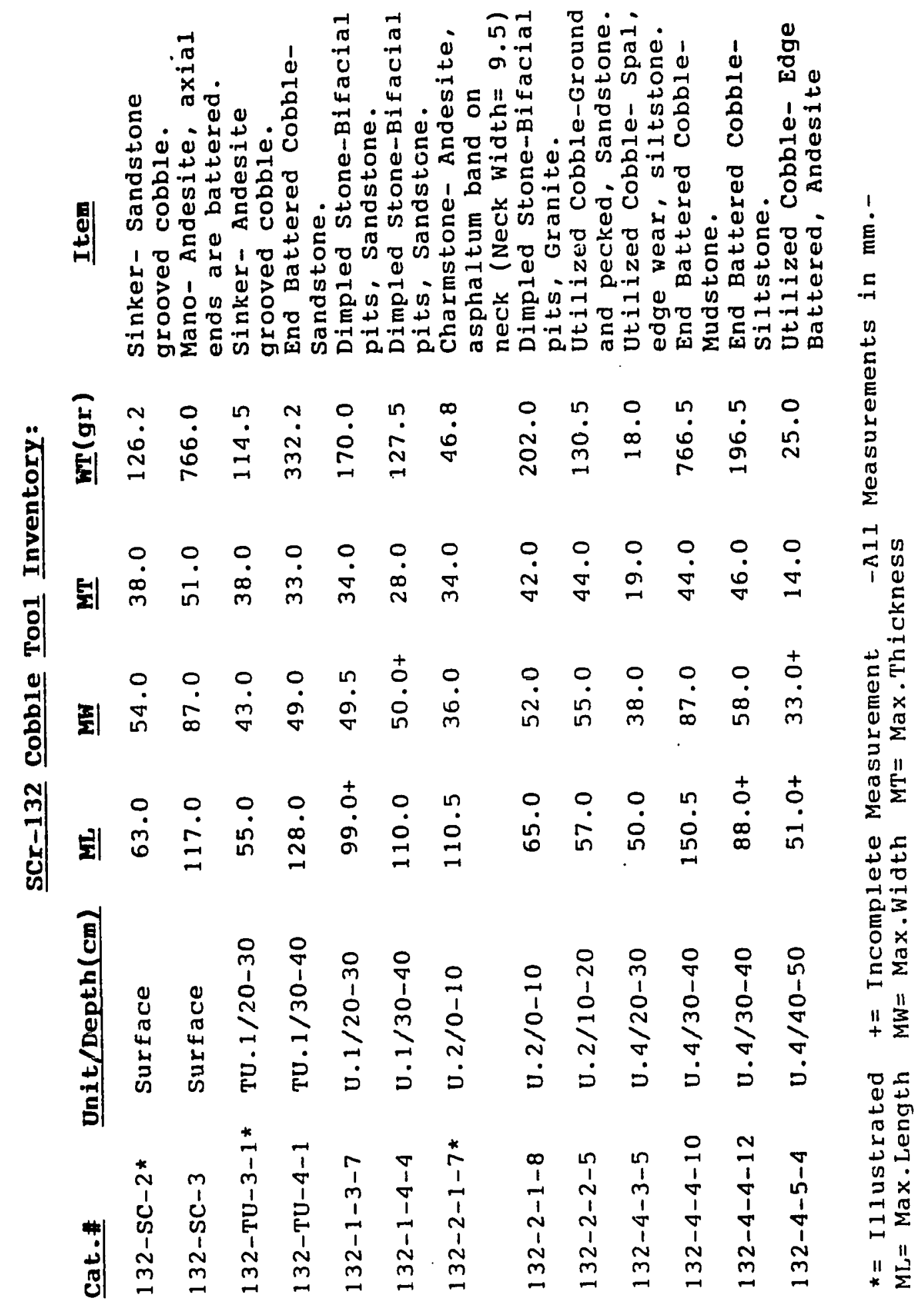




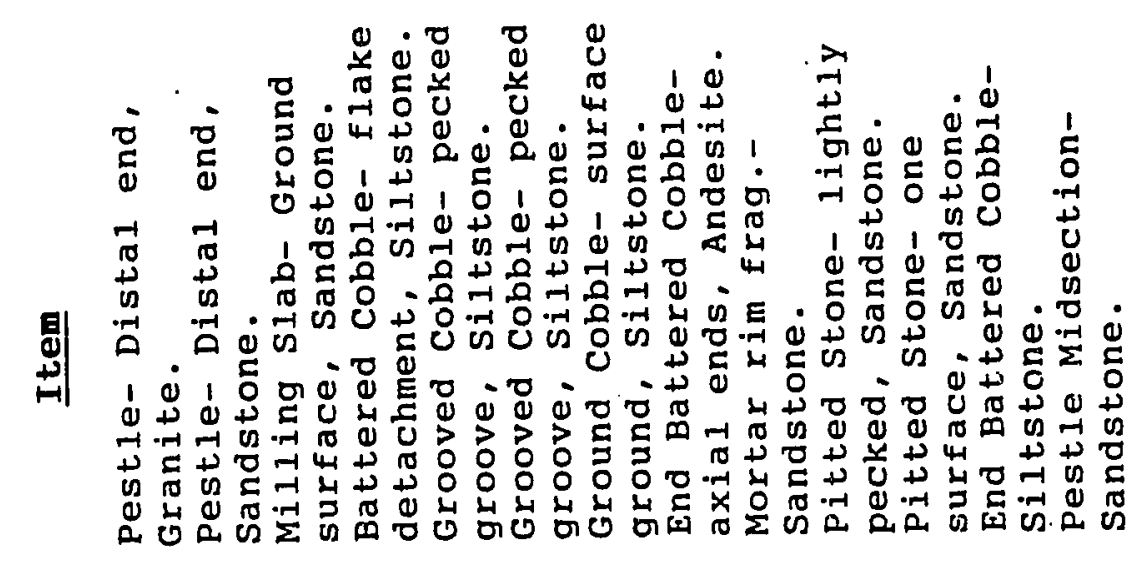

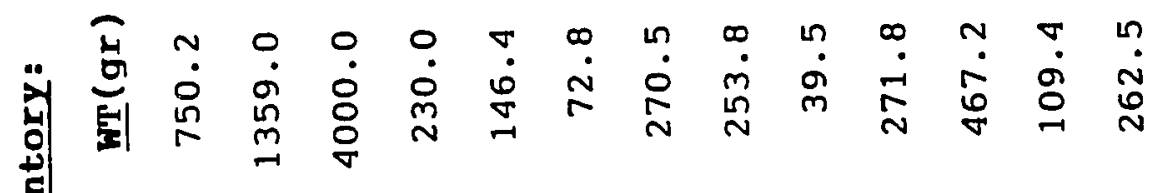

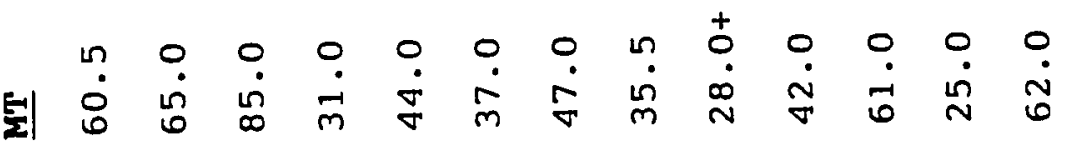

:

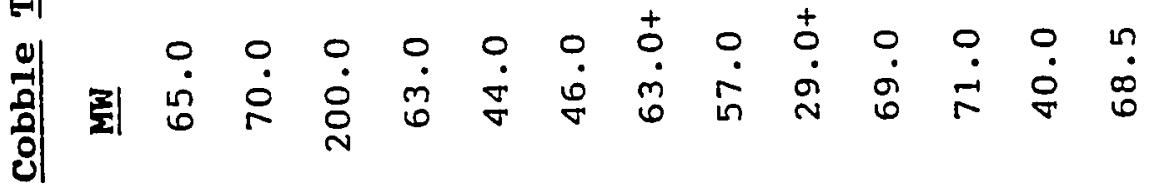

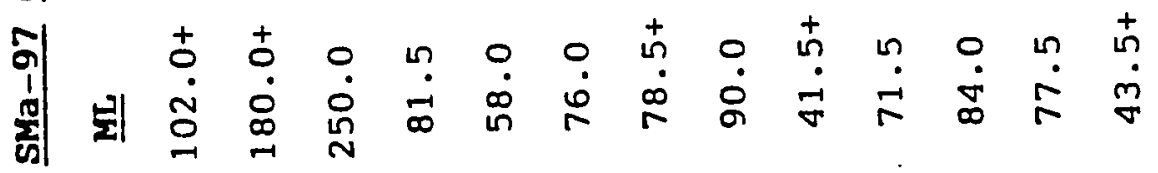

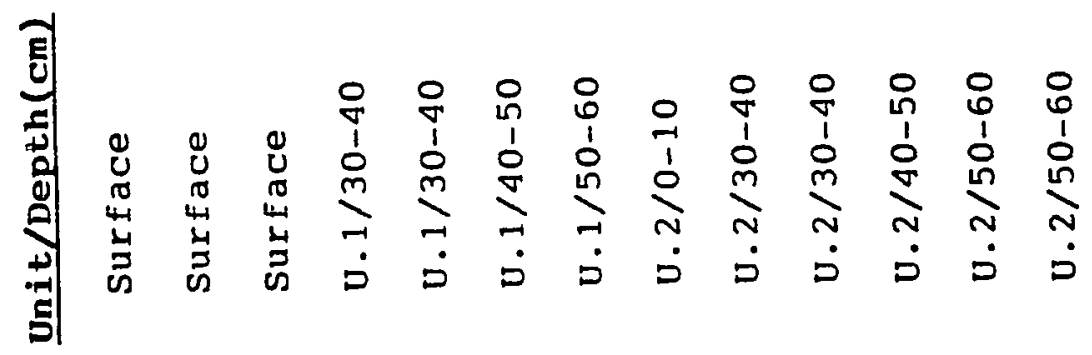

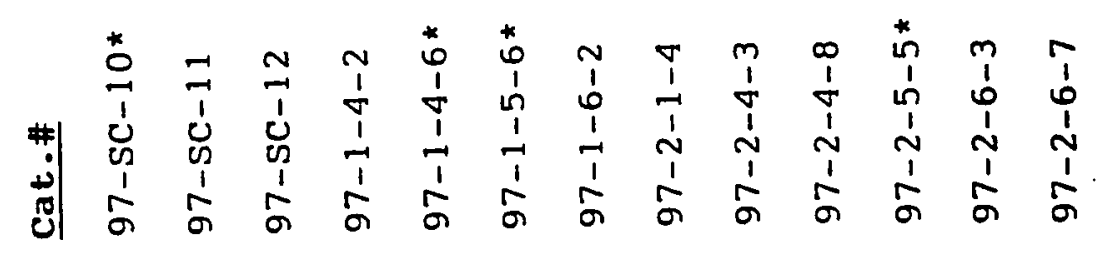




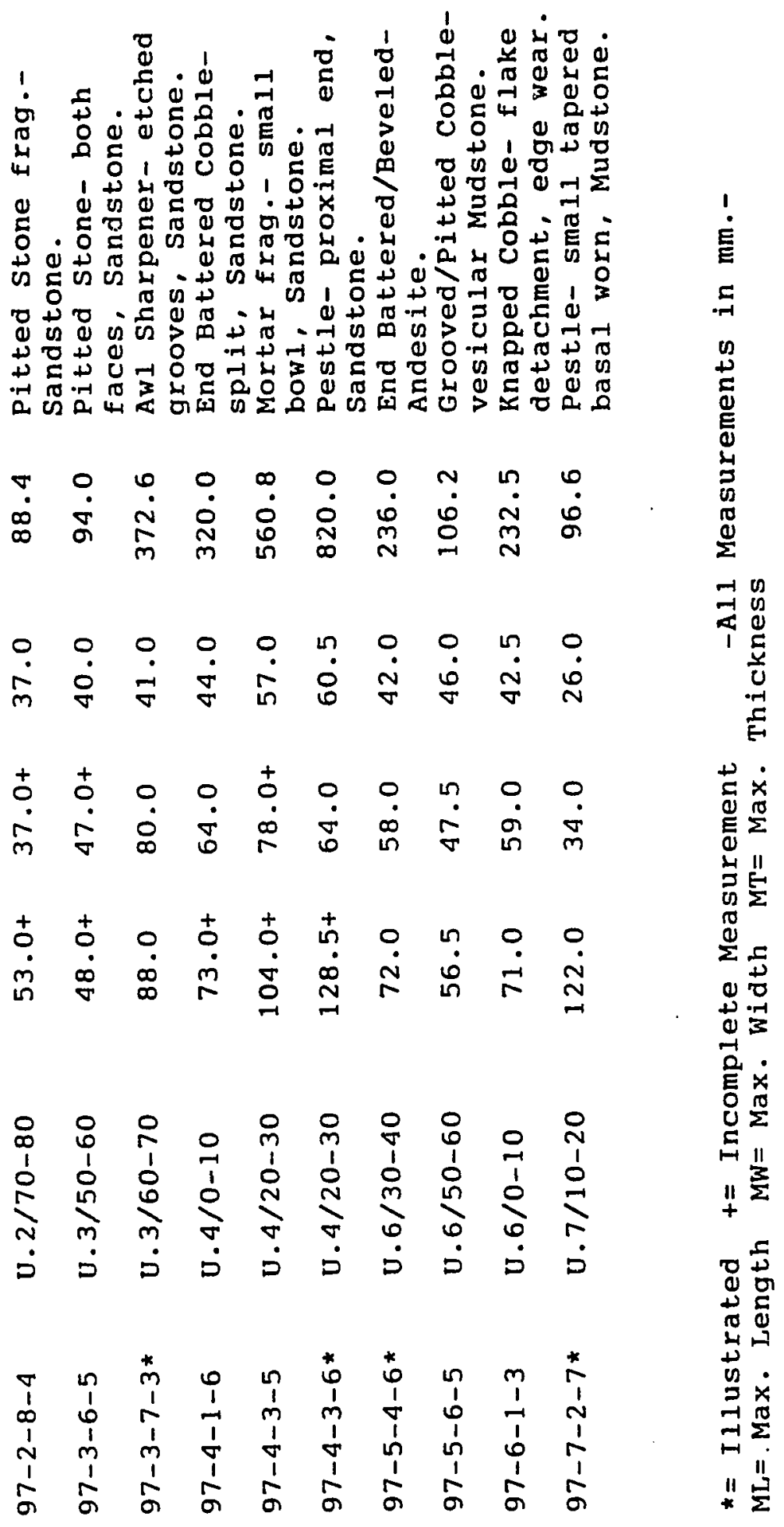




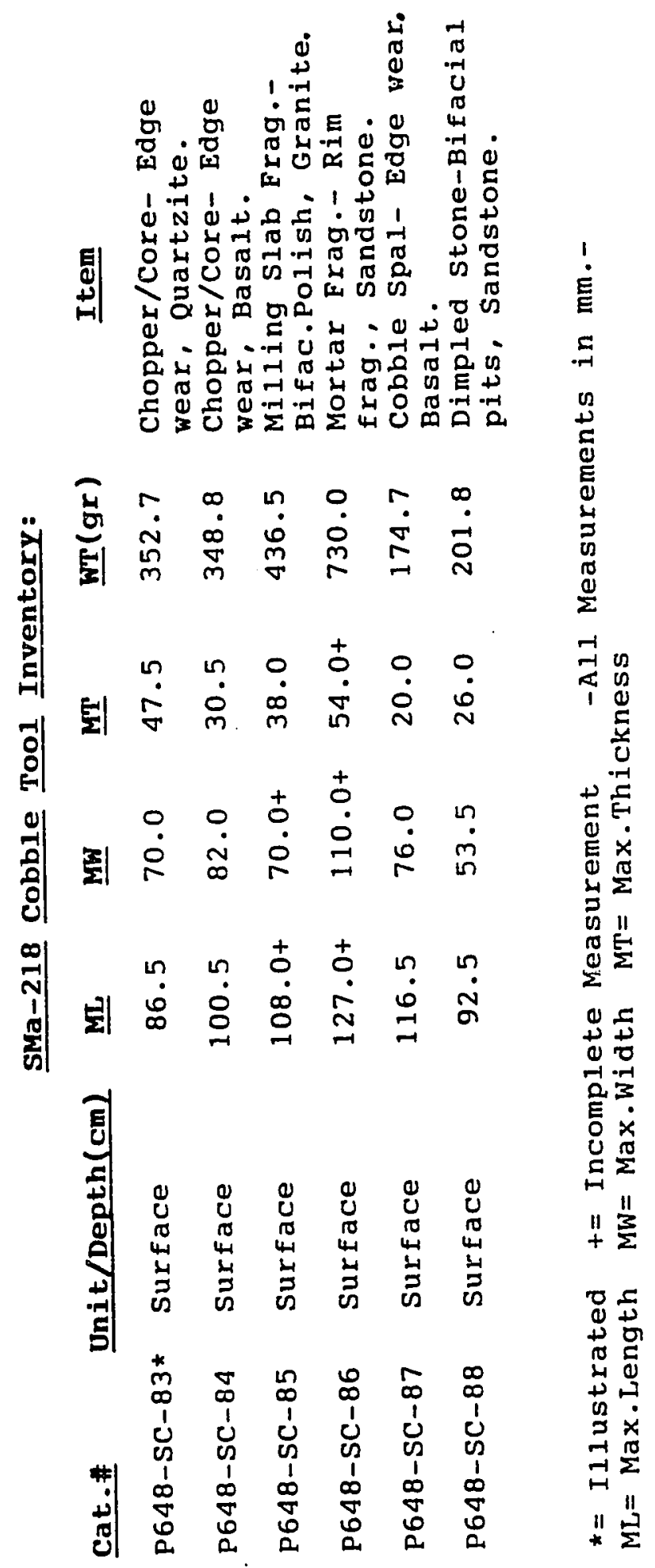



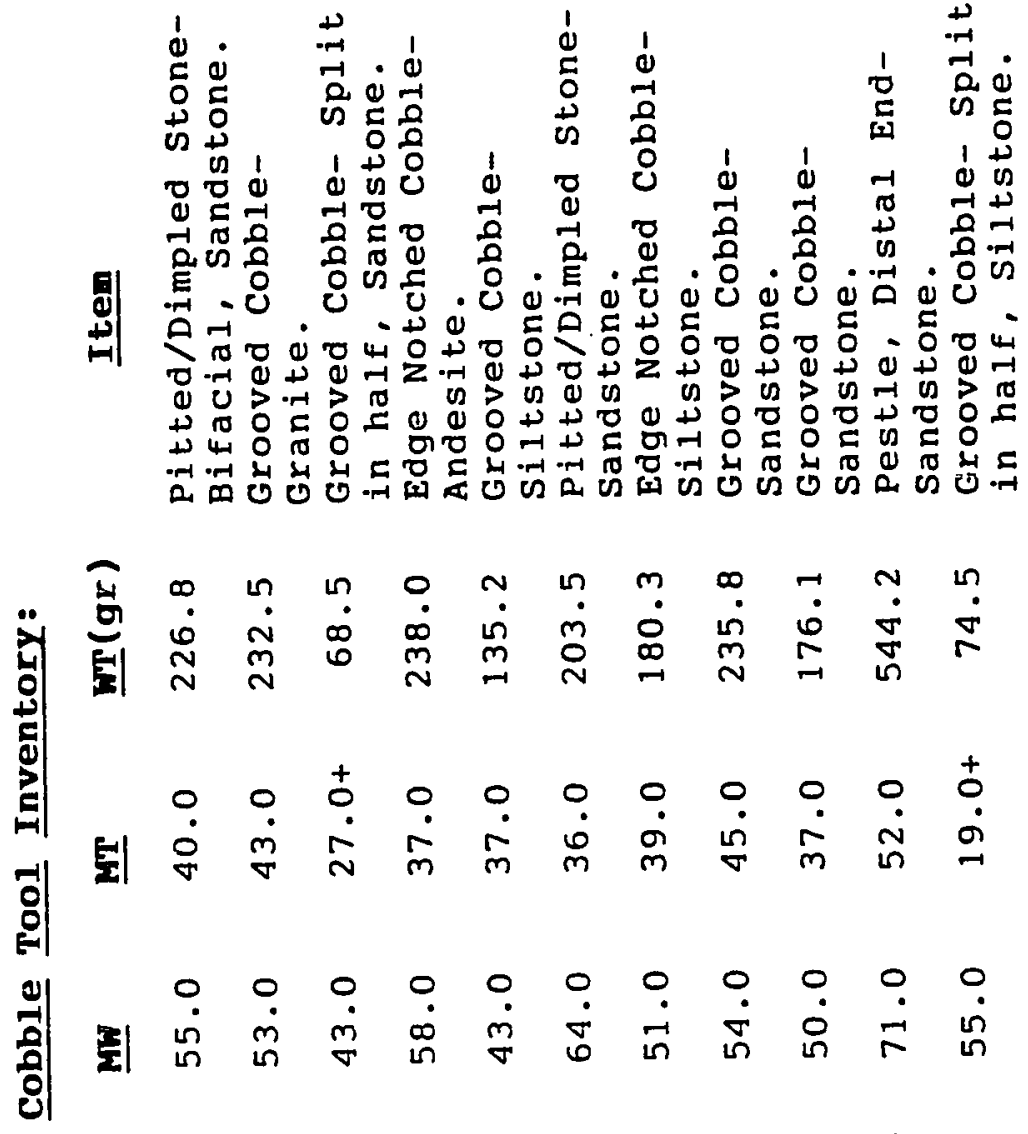

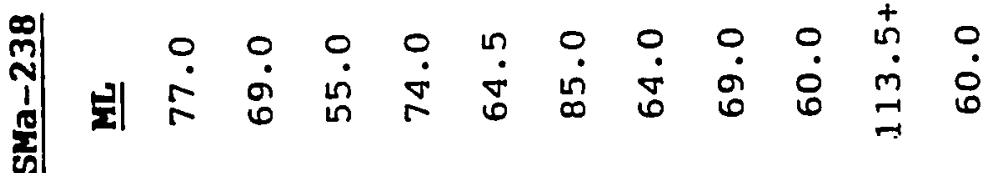

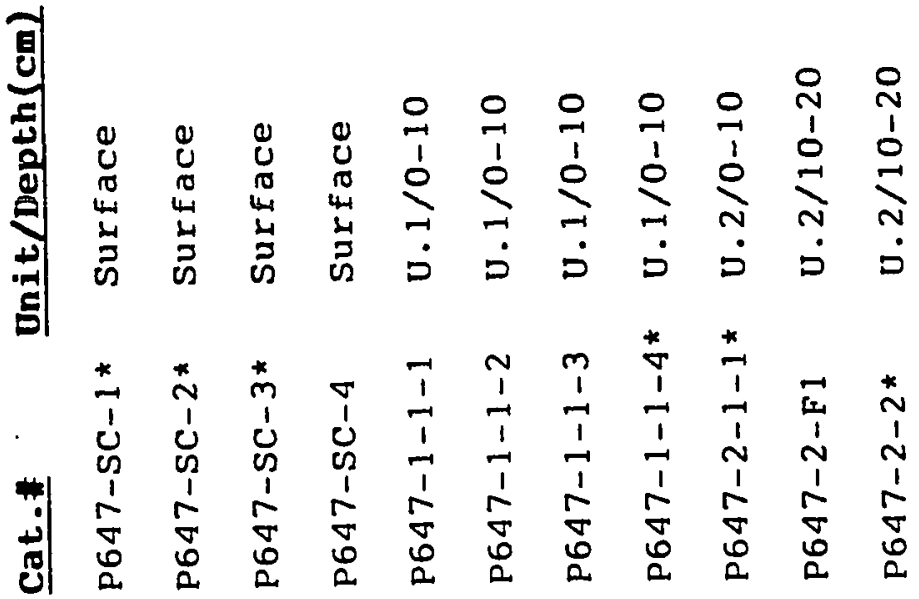



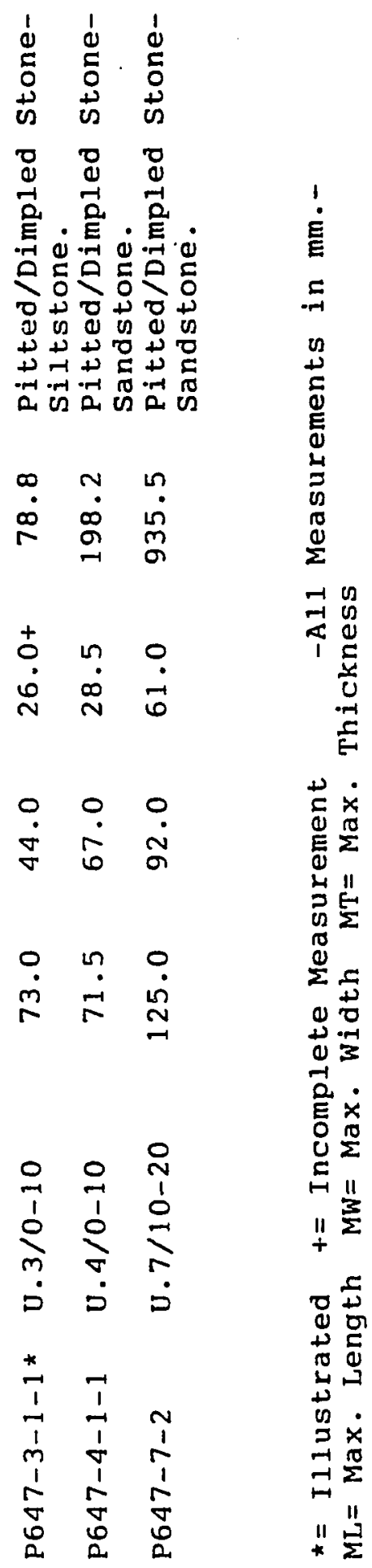


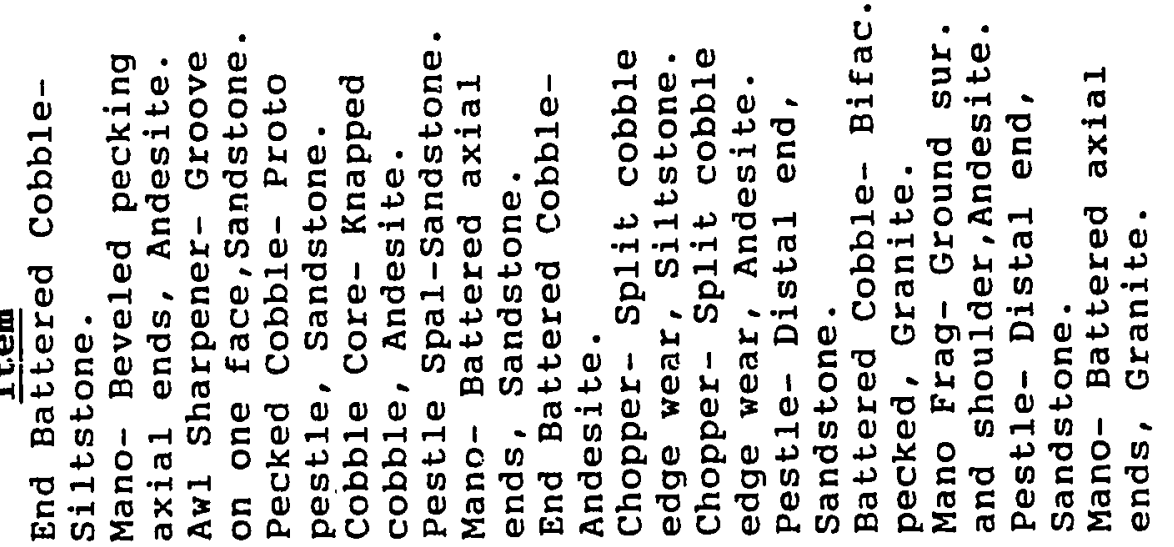

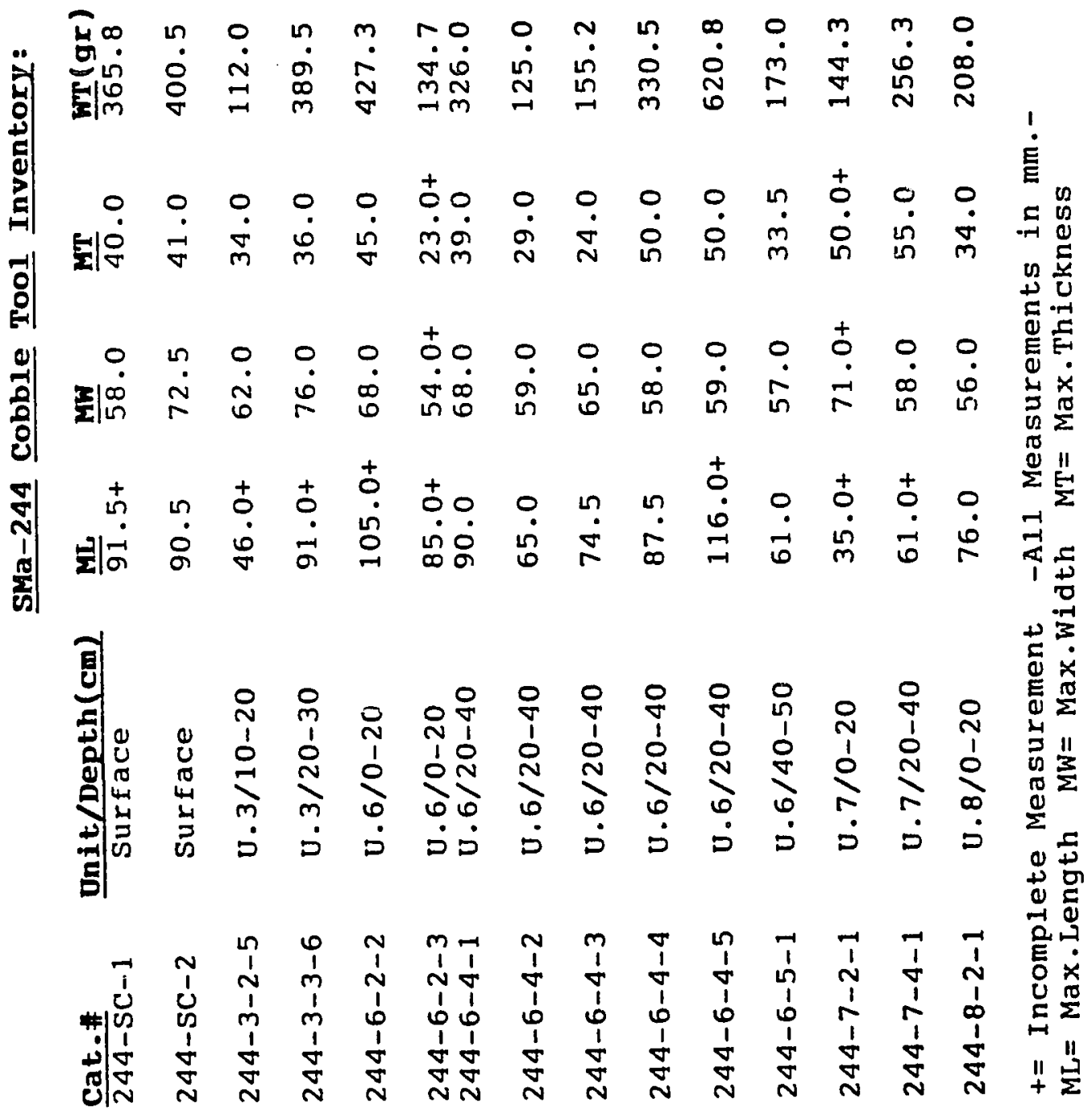

